OAK RIDGE NATIONAL LABORATORY

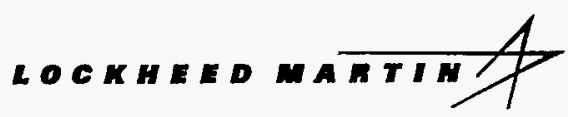

\section{RECEIVED}

\author{
AUG 301996 \\ OSTI
}

Propulsion System Materials Program

Semiannual Progress Report for

October 1995 Through March 1996

Prepared for

U.S. Department of Energy

Assistant Secretary for

Energy Efficiency and Renewable Energy

Office of Transportation Technologies
MANAGED AND OPERATED BY

LOCKHEED MARTIN ENERGY RESEARCH CORPORATION FOR THE UNTED STATES

DEPARTLENT OF ENERGY

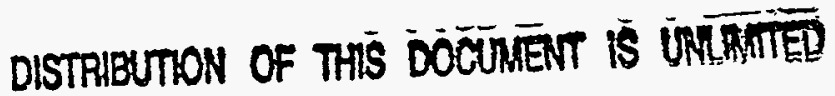

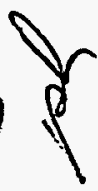


This report has been reproduced directly from the best available copy.

Avallable to DOE and DOE contractors from the Office of Scientific and Technical Information, P.O. Box 62, Oak Ridge, TN 37831; prices available from (423) 576-8401, FTS 626-8401.

Available to the public from the National Technical Information Service, U.S. Department of Commerce, 5285 Port Royal Rd., Springfield, VA 22161.

This report was prepared as an account of work sponsored by an agency of the United States Government. Neither the United States Government nor any agency thereof, nor any of their employees, makes any warranty, express or implied, or assumes any legal liability or responsibility for the accuracy, compteteness, or usefulness of any information, apparatus, product, or process disclosed, or represents that its use would not infringe privately owned rights. Reference herein to any specific commercial product, process, or service by trade name, trademark, manufacturer, or otherwise, does not necessarily constitute or imply its endorsement, recommendation, or favoring by the United States Government or any agency thereof. The views and opinions of authors expressed herein do not necessarily state or reflect those of the United States Government or any agency thereof. 


\section{DISCLAIMER}

Portions of this document may be illegible in electronic image products. Images are produced from the best available original document. 
, 
Metals and Ceramics Division

\title{
PROPULSION SYSTEM MATERIALS PROGRAM \\ SEMIANNUAL PROGRESS REPORT FOR \\ OCTOBER 1995 THROUGH MARCH 1996
}

\author{
D. R. Johnson \\ Program Manager
}

Date Published: July 1996

NOTICE: $\quad$ This document contains information of a preliminary nature. It is subject to revision or correction and therefore does not represent a final report.

\author{
Prepared for \\ U.S. Department of Energy \\ Assistant Secretary for Energy Efficiency and Renewable Energy \\ Office of Transportation Technologies \\ EE 5105000 \\ Prepared by the \\ OAK RIDGE NATIONAL LABORATORY \\ Oak Ridge, Tennessee 37831-6285 \\ managed by \\ LOCKHEED MARTIN ENERGY RESEARCH CORP. \\ for the \\ U.S. DEPARTMENT OF ENERGY \\ under Contract DE-AC05-96OR22464
}




\section{REPORTS PREVIOUSLY ISSUED}

ORNLTM-9325

ORNLTM-9466

ORNLTM-9497

ORNLTM-9673

ORNL/M-9947

ORNLTM-10079

ORNLTM-10308

ORNL/TM-10469

ORNL/TM-10705

ORNL/TM-10838

ORNL/TM-11116

ORNLTM-11239

ORNL/TM-11489

ORNLTM-11586

ORNL/TM-11719

ORNL/TM-11859

ORNL/TM-11984

ORNLTTM-12133

ORNL/TM-12363

ORNL/TM-12428

ORNL/TM-12674

ORNL/TM-12778

ORNL/TM-12924

ORNL/TM-13046

ORNL/TM-13219
Period March 1983-September 1983

Period October 1983-March 1984

Period April 1984-September 1984

Period October 1984-March 1985

Period April 1985-September 1985

Period October 1985-March 1986

Period April 1986-September 1986

Period October 1986-March 1987

Period April 1987-September 1987

Period October 1987-March 1988

Period April 1988-September 1988

Period October 1988-March 1989

Period April 1989-September 1989

Period October 1989-March 1990

Period April 1990-September 1990

Period October 1990-March 1991

Period April 1991-September 1991

Period October 1991-March 1992

Period April 1992-September 1992

Period October 1992-March 1993

Period April 1993-September 1993

Period October 1993-March 1994

Period April 1994-September 1994

Period October 1994-March 1995

Period April 1995-September 1995

Research sponsored by the U.S. Department of Energy, Assistant Secretary for Energy Efficiency and Renewable Energy, Office of Transportation Technologies, as part of the Propulsion System Materials Program, under contract DE-AC05-960R22464 with Lockheed Martin Energy Research Corp. 


\section{CONTENTS}

SUMMARY

0.0 PROJECT MANAGEMENT AND COORDINATION .................................... 3

1.0 MATERIALS AND PROCESSING .............................................................. 5

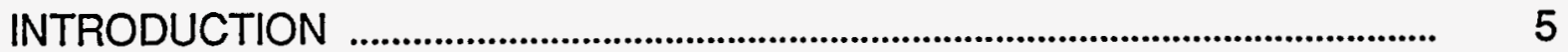

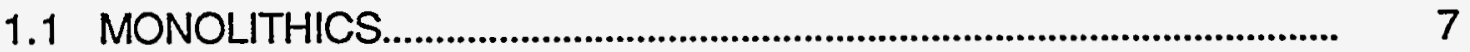

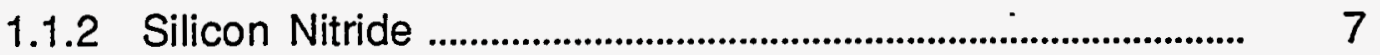

Cost Effective Sintered Reaction Bonded Silicon Nitride and Microwave Anealing of Silicon Nitride (ORNL) .............. 7

Cost Effective Sintering of Silicon Nitride Ceramics (SIU-C)

1.1.4 Processing of Monolithics ........................................................ 34

Improved Processing (ORNL) .................................................... 34

1.2 CERAMIC COMPOSITES ................................................................. 41

1.2.2 Silicon Nitride Matrix ..................................................................... 41

Optimization of Silicon Nitride Ceramics

(University of Michigan)

Microstructure Optimization of SRBSN

(University of Michigan).

Development of Silicon Nitride Ceramic Materials with Elongated Grain Microstructures Exhibiting High Fracture Toughness, Phase III (AlliedSignal Inc.)

1.2.3 Oxide Matrix

Dispersion-Toughened Ceramic Composite (ORNL)........... 
1.2.4 Low Expansion Materials

Characterization and Testing of Low-Expansion

Ceramic Materials (ORNL)

Development of NZP Ceramic-Based "Cast-in-Place"

Diesel Engine Port Liners (LoTEC, Inc.)

Development of Low Cost NZP Powder Synthesis and Processing Technology (LOTEC, Inc.)

1.3 THERMAL AND WEAR COATINGS

Fabrication and Testing of Corrosion-Resistant Coatings (ORNL)

1.4 JOINING.

1.4.1 Ceramic-Metal Joints

Joining of Ceramics for Heat Engine Applications (ORNL)

Cost-Effective Ceramic Machining (ORNL).

Innovative Grinding Wheel Design for

Cost-Effective Machining of Advanced Ceramics,

Phase II (Norton Company)

High-Speed, Low-Damage Grinding of Advanced

Ceramics (Eaton Manufacturing Technologies

Center)

Chemically Assisted Machining of Ceramics

(NIST)

Laser Scatter Methods for Detecting Subsurface

Machining Damage in Ceramics

(Argonne National Laboratory)

Cost Modeling Analysis of Fabrication Approaches - for Silicon Nitride Components (AlliedSignal, Inc.). 
1.5.2 Advanced Ceramic Manufacturing Technology

Advanced Manufacturing Technology for

Ceramic Heavy Duty Diesel Turborotors

(Kyocera Industrial Ceramics Corp.).

Development of Advanced Ceramic Manufacturing

Technology (Norton)

2.0 MATERIALS DESIGN METHODOLOGY 209

INTRODUCTION 209

2.2 CONTACT INTERFACES. 211

2.2.2 Dynamic Interfaces.

Development of Standard Test Methods for

Evaluating the Wear Performance of Ceramics

(ORNL)

3.0 DATA BASE AND LIFE PREDICTION.

3.1 STRUCTURAL QUALIFICATION

215

Mechanical Properties and Microstructural

Characterization of $\mathrm{Si}_{3} \mathrm{~N}_{4}$ Ceramics (ORNL). 215

Project Data Base (ORNL) 222

3.2 TIME-DEPENDENT BEHAVIOR 224

Fracture Behavior of Toughened Ceramics (ORNL) 224

Cyclic Fatigue of Toughened Ceramics (ORNL). 229

Life Prediction Verification (ORNL) 257

Toughened Ceramics Life Prediction (NASA Lewis Research Center)

Life Prediction Methodology (AlliedSignal Engines) 


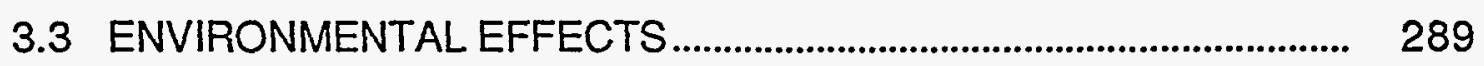

Environmental Effects in Toughened Ceramics

(University of Dayton).

3.4 FRACTURE MECHANICS

Testing and Evaluation of Advanced Ceramics at High Temperature

(North Carolina A\&T State University)

3.5 NONDESTRUCTIVE EVALUATION DEVELOPMENT

Nondestructive Characterization (ORNL)

NDE Standards for Advanced Ceramics (ORNL)

340

$X$-ray Computed Tomographic Imaging (ANL)

342

Nuclear Magnetic Resonance Imaging (ANL).

4.0 TECHNOLOGY TRANSFER

4.1 TECHNOLOGY TRANSFER

4.1.1 Technology Transfer

Technology Transfer (ORNL)

IEA ANNEX I/ Management (ORNL)

Characterization of Ceramic Powders (NIST)

Ceramic Mechanical Property Test Method

Development (NIST) 


\section{PROPULSION SYSTEM MATERIALS PROGRAM \\ SEMIANNUAL PROGRESS REPORT \\ FOR OCTOBER 1995 THRQUGH MARCH 1996}

\section{SUMMARY}

The Propulsion System Materials Program was originally developed by the Department of Energy's Office of Transportation Systems (OTS) in Energy Efficiency and Renewable Energy. This program, part of the OTS's Materials Development Program, was developed to meet the ceramic technology requirements of the OTS's automotive technology programs.

Significant accomplishments in fabricating ceramic components for the Department of Energy (DOE), National Aeronautics and Space Administration (NASA), and Department of Defense (DoD) advanced heat engine programs have provided evidence that the operation of ceramic parts in high-temperature engine environments is feasible. However, these programs have also demonstrated that additional research is needed in materials and processing development, design methodology, and data base and life prediction before industry will have a sufficient technology base from which to produce reliable cost-effective ceramic engine components commercially.

An assessment of needs was completed, and a five-year program plan was developed with extensive input from private industry. In July 1990, the original plan was updated through the estimated completion of development in 1993. The original objective of the program was to develop the industrial technology base required for reliable ceramics for application in advanced automotive heat engines.

During the course of the Propulsion System Materials Program, remarkable progress has been made in the development of reliable structural ceramics. However, further work is needed to reduce the cost of ceramics to facilitate their commercial introduction, especially in the highly cost-sensitive automotive market. To this end, the direction of the Propulsion System Materials Program is now shifting toward reducing the cost of ceramics to facilitate commercial introduction of ceramic components for near-term engine applications. In response to extensive input from industry, the plan is to extend the engine types which were previously supported (advanced gas turbine and low-heat-rejection diesel engines) to include near-term (5-10 years) applications in conventional automobile and diesel truck engines. To facilitate the rapid transfer of this technology to U.S. industry, the major portion of the work is being done in the ceramic industry, with technological support from government laboratories, other industrial laboratories, and universities.

A systematic approach to reducing the cost of components is envisioned. The work elements are as follows: economic cost modeling, ceramic machining, powder synthesis, alternative forming and densification processes, yield improvement, system design studies, standards development, low-expansion ceramics, and testing and data base development. 
This program is managed by ORNL for the Office of Transportation Technologies and is closely coordinated with complementary ceramics tasks funded by other DOE offices, NASA, DOD, and industry. A joint DOE and NASA technical plan has been established, with DOE focus on automotive applications and NASA focus on aerospace applications. A common work breakdown structure (WBS) was developed to facilitate coordination. The work described in this report is organized according to the following WBS project elements:

0.0 Program Management and Coordination

1.0 Materials and Processing

1.1 Monolithics

1.2 Ceramic Composites

1.3 Thermal and Wear Coatings

1.4 Joining

1.5 Ceramic Machining

2.0 Materials Design Methodology

2.1 Modeling

2.2 Contact Interfaces

2.3 New Concepts

3.0 Data Base and Life Prediction

3.1 Structural Qualification

3.2 Time-Dependent Behavior

3.3 Environmental Effects

3.4 Fracture Mechanics

3.5 Nondestructive Evaluation Development

\subsection{Technology Transfer}

\subsection{Technology Transfer}

This report includes contributions from all currently active program participants. The contributions are arranged according to the work breakdown structure outline. 


\title{
O.0 PROGRAM MANAGEMENT AND COORDINATION
}

\author{
D. R. Johnson
}

Oak Ridge National Laboratory

Objective/scope

This task includes the technical management of the program in accordance with the program plans and management plan approved by the Department of Energy (DOE) Oak Ridge Operations Office, and the Office of Transportation Technologies. This task includes preparation of annual field work proposals, initiation and management of subcontracts and interagency agreements, and management of ORNL technical tasks. Monthly management reports and bimonthly reports are provided to DOE; highlights and semiannual technical reports are provided to DOE and program participants. In addition, the program is coordinated with interfacing programs sponsored by other DOE offices and federal agencies, including the National Aeronautics and Space Administration (NASA) and the Department of Defense (DoD). This coordination is accomplished by participation in DOE and NASA joint management meetings, annual interagency heat engine ceramics coordination meetings, DOE contractor coordination meetings, and DOE Energy Materials Coordinating Committee (EMaCC) meetings, as well as special coordination meetings. 



\subsection{MATERIALS AND PROCESSING}

\section{INTRODUCTION}

This portion of the program is identified as program element 1.0 within the work breakdown structure (WBS). It contains five subelements:

(1) Monolithics, (2) Ceramic Composites, (3) Thermal and Wear Coatings, (4) Joining, and (5) Ceramic Machining. Ceramic research conducted within the Monolithics subelement currently includes work activities on low cost $\mathrm{Si}_{3} \mathrm{~N}_{4}$ powder, green state ceramic fabrication, characterization, and densification, and on structural, mechanical, and physical properties of these ceramics. Research conducted within the Ceramic Composites subelement currently includes silicon nitride and oxide-based composites, and low expansion materials. Research conducted in the Thermal and Wear Coatings subelement is currently limited to oxide-based coatings and involves coating synthesis, characterization, and determination of the mechanical and physical properties of the coatings. Research conducted in the Joining subelement currently includes studies of processes to produce strong, stable joints between zirconia ceramics and iron-base alloys. As part of an expanded effort to reduce the cost of ceramic components, a new initiative in cost effective machining has been started.

A major objective of the research in the Materials and Processing program element is to systematically advance the understanding of the relationships between ceramic raw materials such as powders and reactant gases, the processing variables involved in producing the ceramic materials, and the resultant microstructures and physical and mechanical properties of the ceramic materials. Success in meeting this objective will provide U.S. companies with new or improved ways for producing economical, highly reliable ceramic components for advanced heat engines. 


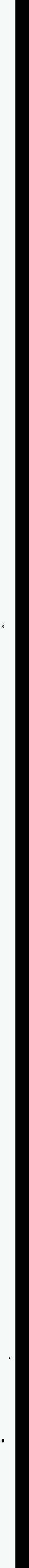


1.1.2 Silicon Nitride

\author{
W.B.S. ELEMENT 1.1.2.4 \\ COST-EFFECTIVE SINTERED REACTION-BONDED SILICON NITRIDE AND \\ MICROWAVE ANNEALING OF SILICON NITRIDE \\ J. O. Kiggans, T. N. Tiegs, H. T. Lin, F. C. Montgomery, D. L. Barker, \\ J. M. Snodgrass, D. W. Coffey, and C. C. Davisson \\ Oak Ridge National Laboratory \\ Oak Ridge, TN 37831
}

\title{
Objective / Scope
}

There are two major objectives of this research element: the first objective is the development of new sintered reaction-bonded silicon nitride materials that will serve as cost-effective materials for use in suitable applications; the second objective of this element is the investigation of properties of dense silicon nitride materials annealed in the microwave furnace. Primary investigations have shown that microwave annealing of dense silicon nitride materials results in improved high temperature creep properties in these materials. This study seeks to find the reason(s) for these improved properties.

\section{Technical Highlights}

\section{Scale Up Nitridation - Sintering Studies}

This is the final report discussing the development of scale-up techniques for the nitridation and sintering of silicon preforms using microwave heating to fabricate SRBSN. As reported in last month's bimonthly report, two large nitridation and sintering experiments were performed in the $4000 \mathrm{~L}$ Y-12 microwave furnace. Statistical results describing the results were presented in the previous bi-monthly report, however photos of the experimental set-up and the final parts were not available during the previous reporting period. These photos are presented in this report. Figure 1 shows the gelcast rectangular silicon bars and the silicon bucket tappets, as both samples were packaged for microwave processing. Figures 2 is photos of the final SRBSN parts, respectively, after they were fabricated in these experiments. The photos and statistical data in Table 1 clearly show the capability of scale-up using microwave processing.

Up to this point in the microwave scale-up initiative, only statistical data, which includes the average sintered densities and the statistical deviation of the sintered densities, concerning SRBSN materials produced by microwave heating has been reported. An experiment was performed during this reporting period to provide statistical data related to scale-up of the fabrication of SRBSN using conventional heating. For this experiment, 35, $7 \mathrm{~cm}$ diameter by $1.27 \mathrm{~cm}$ thick, die-pressed silicon preforms (purchased from Golden Technologies, Inc.) were sliced into a total of $210,3.2 \mathrm{~cm}$ tall by 1.27 thick rectangular bars. Binder burnout of the parts was then performed by heating the samples to a final temperature of $400^{\circ} \mathrm{C}$ for $1 \mathrm{~h}$ in air. Samples were then weighed and placed on hot-pressed BN setter plates inside two $11.5 \mathrm{~cm}$ wide by $11.5 \mathrm{~cm}$ deep by $45 \mathrm{~cm}$ long graphite crucibles for nitridation in nitrogen with $4 \mathrm{vol}$. \% hydrogen, to a final condition of $1450^{\circ} \mathrm{C}$ for $1 \mathrm{~h}$. The nitrided samples were then weighed, placed on the BN setters in the same crucibles, packed in $\mathrm{Si}_{3} \mathrm{~N}_{4}-15 \mathrm{wt} \% \mathrm{BN}-4 \mathrm{wt} \% \mathrm{Y}_{2} \mathrm{O}_{3}-1 \mathrm{wt} \% \mathrm{SiO}_{2}$, and sintered in flowing nitrogen to a final condition of $1780^{\circ} \mathrm{C}$ for $4 \mathrm{~h}$. Densities of every fourth sample was measured using the alcohol immersion density technique, and the average density and the standard deviation were calculated using these densities. 
Table 1 gives the average density and the standard deviation of densities for this 210 sample run along with data for other conventional and microwave experiments. These data indicate that the statistical deviation of densities for groups of samples processed by both conventional and by microwave heating increased as the sample number increased. In fact, it indicates that for the standard deviation of the densities for the conventional processing experiment involving 210 samples was higher that the microwave experiment which included 230 samples. These results reinforce previous statements that the microwave heating may be viable for certain scale-up processes.

\section{Golden Technologies CRADA}

Several final experiments were performed to determine the optimum SiC content in the crucibles which were used for nitridation of silicon clevis pins (provided by Golden Technologies, Inc.). Three crucible types were made from gelcast plates containing 40, 60 , and $80 \mathrm{wt} \% \mathrm{SiC}, 4.2 \mathrm{wt} \% \mathrm{Y}_{2} \mathrm{O}_{3}, 0.8 \mathrm{wt} \% \mathrm{SiO}_{2}$, and with a remaining balance $\mathrm{Si}_{3} \mathrm{~N}_{4}$ (crucible construction described in the 1995, April-May bimonthly report). The final density of the crucibles was approximately $1.9 \mathrm{~g} / \mathrm{cm}^{3}$, with the final nominal wt \% compositions of the crucibles approximately the same as the gelcast plates. 81 clevis pins were weighed and then placed into each crucible at a spacing of $0.5 \mathrm{~cm}$, edge to edge (Fig. 3). The samples were then heated in the ORNL $6 \mathrm{~kW}$ microwave furnace in nitrogen with 4 vol. \% hydrogen to a final condition of $1300^{\circ} \mathrm{C}$ for $1 \mathrm{~h}$. The total heating cycle of each run, excluding cool down, was $11.7 \mathrm{~h}$. Samples were then weighed and weight gains were calculated.

Figure 4 shows the standard deviations of the weight gains of the total group of samples, the samples placed adjacent to the inside wall of the SiC crucible walls edge (outside samples), and the samples placed interior to the outside samples (inside samples). These data show that lowest standard deviations and the smallest deviations between the "outside" and "inside" samples were obtained with the "80 wt \% crucible." The reason for this is that the microwave absorption and heat generated by of the "80 wt \% crucible" resembled most closely the sample pieces, and this results in a more uniform temperature profile within the crucible. Figure 5 shows a photo of 90 clevis pins processed by microwave heating in a confirmation run using the "80 wt \% crucible."

The final scale-up experiment performed for the Golden CRADA was a test to determine if the clevis pin samples could be processed in a horizontal layout and in multiple layers during both binder burnout and microwave nitridation on flat grooved setter trays. This processing method allows minimal handling of the samples and resembles the sample handling at Golden Technologies. Figure 6 is a drawing of the sample positioning on the "80 wt \% SiC" setter plates. The samples and plates were heated to $400^{\circ} \mathrm{C}$ in air for binder removal, and then placed in an alumina fiber box in the microwave furnace where nitridation was performed according to the procedures used for previous crucible tests.

The results of this last experiment were successful, with good weight gain measurements for all processed samples. The results indicate that this type of "easy" sample handling can be used in microwave scale-up processing.

\section{SRBSN Composition Study Part 1}

Silicon nitride materials are the leading ceramics for structural applications at elevated temperatures because of their excellent combination of properties. However, cost is the major impediment for the use of silicon nitride in commercial applications. ${ }^{1}$ Sintered reaction-bonded silicon nitride (SRBSN) is an attractive alternative to the more 
conventional approaches that begin with $\mathrm{Si}_{3} \mathrm{~N}_{4}$ powders. ${ }^{2-6}$ Because of the low silicon powder cost, the process is cost-effective compared to the expensive high-purity powders. ${ }^{7}$

A significant amount of work on SRBSN has been done since the 1970's and a large database of information is available., ${ }^{2,3}$ However, within the last 10 years the level of research has been minor. In that same time period, a considerable amount of understanding on silicon nitride processing, microstructure development and property relationships has been established. The purpose of the present study was to examine the current state of SRBSN materials and determine the effect of different silicon precursor powders and different sintering additives on the processing and final mechanical properties.

The silicon powders are important because they determine to a large extent the overall purity of the system and the $\alpha-\mathrm{Si}_{3} \mathrm{~N}_{4}$ phase content developed during nitridation of the silicon. $^{8}$ Much of the previous work reported in the literature used rather coarse $\mathrm{Si}$ powders $(>10 \mu \mathrm{m})$ and relatively low purity $(>0.5 \mathrm{wt}$. \% $\mathrm{Fe}){ }^{2-5}$ Considerably finer particle sizes and higher purity are presently available. The sintering additives also influence the $\alpha-\mathrm{Si}_{3} \mathrm{~N}_{4}$ phase content and, in addition, affect the microstructural development during densification. ${ }^{9}$ Most previous work on SRBSN employed $\mathrm{Y}_{2} \mathrm{O}_{3}$ and $\mathrm{Al}_{2} \mathrm{O}_{3}$ as the sintering additives. ${ }^{4-6}$ It is also well known that alternative sintering aids have been found to result in very different final material properties. ${ }^{9}$ Consequently, several alternative additives were studied to see if they provided any advantage over the $\mathrm{Y}_{2} \mathrm{O}_{3}-\mathrm{Al}_{2} \mathrm{O}_{3}$ system in terms of densification, microstructural development or final properties.

\section{Experimental Procedures}

The starting materials consisted of appropriate amounts of silicon, $\alpha-\mathrm{Si}_{3} \mathrm{~N}_{4}, \mathrm{Al}_{2} \mathrm{O}_{3}, \mathrm{MgO}$, $\mathrm{MgAl}_{2} \mathrm{O}_{4}$ and $\mathrm{Y}_{2} \mathrm{O}_{3}$ to give final compositions after nitriding as shown in Table 2. The silicon powders were chosen so that they represented a large variation in impurity content. The $\mathrm{Y}_{2} \mathrm{O}_{3}-\mathrm{Al}_{2} \mathrm{O}_{3}$ additive system was used as a base material because of the large database already established and it was used to test the different silicon powders. SRBSN without the $\alpha$-seed additive was tested because elimination of the seed is desirable since it represents a significant portion of the raw materials cost. ${ }^{7}$ The $\mathrm{MgO}-\mathrm{Y}_{2} \mathrm{O}_{3}$ additives were studied because they were reported to produce materials with very high fracture toughnesses." High toughness has also been reported for the $\mathrm{MgO}-\mathrm{Al}_{2} \mathrm{O}_{3}-\mathrm{Y}_{2} \mathrm{O}_{3}$ additive system. ${ }^{12}$ Previous work on the $\mathrm{Y}_{2} \mathrm{O}_{3}-\mathrm{SiO}_{2}$ system showed that it resulted in materials that had good high temperature strength retention. ${ }^{13}$

The powders were turbomilled in isopropanol with $0.7 \mathrm{wt} . \%$ PVP $\mathrm{K}-15^{\mathrm{b}}$ and 1 wt.\% Darvan $821 \mathrm{~A}^{\mathrm{c}}$ added as dispersants. The mixtures were dried, screened to -200 mesh and isopressed at $207 \mathrm{MPa}$ into discs approximately $7 \mathrm{~cm}$ in diameter and $2 \mathrm{~cm}$ thick. Binder burnout consisted of a heat-treatment to $550^{\circ} \mathrm{C}$ in air prior to sintering. The nitridation was carried out in either a tungsten-mesh or a graphite-resistance furnace with a $\mathrm{N}_{2}-4 \% \mathrm{H}_{2}$ gas flow and controlled heating to $1450^{\circ} \mathrm{C}$. The samples were then sintered in a graphiteelement furnace with $\mathrm{Si}_{3} \mathrm{~N}_{4}$ packing powder under one atmosphere $\mathrm{N}_{2}$ to $1780-1800^{\circ} \mathrm{C}$ for 2 hours.

Densities were determined by the Archimedes' method. Samples of high density were machined into bend bar specimens with nominal dimensions of $3 \mathrm{~mm} \times 4 \mathrm{~mm} \times 50 \mathrm{~mm}$. Flexural strength testing was done in four point bending with inner and outer spans of 20 $\mathrm{mm}$ and $40 \mathrm{~mm}$, respectively. Fracture toughness was determined by an indentation and fracture method. Three batches of samples were fabricated and because the values were

\footnotetext{
${ }^{\circ}$ GAF Chemicals, Wayne, NJ: Polyvinylpyrrolidone $\mathrm{K}-15$
}

${ }^{c}$ R. T. Vanderbilt, Norwalk, CT 
similar between batches, the results were averaged together to provide a more reliable set of data.

\section{Results and Discussion}

After nitridation the $\alpha-\mathrm{Si}_{3} \mathrm{~N}_{4}$ phase contents were determined by $\mathrm{x}$-ray diffraction and the results are summarized in Fig. 7. As shown, for the different Si powders, the $\alpha$-content can be well correlated with the starting powder Fe content. This is similar to previous studies. ${ }^{8,9}$ The $\alpha$-content developed with alternate sintering aids shows significant differences with the higher $\alpha$-contents associated with the $\mathrm{MgO}-\mathrm{Y}_{2} \mathrm{O}_{3}$ and $\mathrm{Y}_{2} \mathrm{O}_{3}-\mathrm{SiO}_{2}$ systems. The presence of the $\alpha-\mathrm{Si}_{3} \mathrm{~N}_{4}$ was found to enhance the formation of $\alpha$-phase during nitridation of the silicon.

As shown in Fig. 8, high densities were achieved for nearly all of the samples with the exception of the $\mathrm{Y}_{2} \mathrm{O}_{3}-\mathrm{SiO}_{2}$ system. The sintering conditions had been selected to obtain high densities, however, the one set that did not sinter well was also the most refractory of the grain boundary phases therefore densification was marginal. All of the other materials had high enough densities to obtain mechanical property measurements.

The results on the room temperature flexural strength and fracture toughness for the various Si powder types are shown in Fig. 9. For the strength, a decrease was observed as the Fe content was also decreased. X-ray diffraction indicated that some unreacted Si was present in the samples from the highest purity Si powder. This unreacted Si may explain the lower strength and indeed, optical examination showed the fracture origins to be black spots that were most likely regions of unreacted $\mathrm{Si}$. The fracture toughness did not show any significant differences for the samples from the various Si types. Microstructurally, the higher Fe content silicon powders resulted in a slightly finer overall grain size as shown in Fig. 10 ( $a$ and $b$ ). The finer grain size is probably due to the higher starting $\alpha$-phase content after nitridation.

The results on the room temperature flexural strength and fracture toughness for the alternate sintering additives are shown in Fig. 11. High strengths and toughness were observed for the $\mathrm{Y}_{2} \mathrm{O}_{3}-\mathrm{Al}_{2} \mathrm{O}_{3}$ and $\mathrm{MgO}-\mathrm{Al}_{2} \mathrm{O}_{3}-\mathrm{Y}_{2} \mathrm{O}_{3}$ based materials. The low strength and high toughness exhibited by the $\mathrm{MgO}-\mathrm{Y}_{2} \mathrm{O}_{3}$ samples is related to its lower sintered density. The mechanical properties correlated well with the starting $\alpha-\mathrm{Si}_{3} \mathrm{~N}_{4}$ contents as shown in Fig. 12.

The high temperature strength and strength retention are shown in Figs. 13 and 14. As shown previously, the room temperature strength for the different $\mathrm{Si}$ - powders increased with increasing $\mathrm{Fe}$ content. However, the high temperature strength decreased more rapidly with the higher $\mathrm{Fe}$ content so that the samples made from higher purity Si had better strength retention.

Results on the weight gain during oxidation at $1000^{\circ} \mathrm{C}$ for 100 hours is shown in Fig. 15 . Only the samples with $\mathrm{MgO}-\mathrm{Al}_{2} \mathrm{O}_{3}-\mathrm{Y}_{2} \mathrm{O}_{3}$ additives showed any significant oxidation weight gain and that is most likely related to the low sintered densities of those materials. Flexural strength (measured at room temperature) after oxidation showed some decrease from the initial values for all samples except the one containing no added $\alpha-\mathrm{Si}_{3} \mathrm{~N}_{4}$ seed (Fig. 16). The $\alpha-\mathrm{Si}_{3} \mathrm{~N}_{4}$ seed in the present study was nitrided material that was generally of higher purity than the silicon powders used so impurity effects are negligible. It is a common practice to give these types of powders a hydrofluoric acid treatment to reduce the oxygen content and this may have contributed to the strength reduction due to oxidation. However, the results need to be confirmed to support such an explanation. 


\section{Conclusions}

The type of silicon powder and sintering additive type were found to influence the processing and final mechanical properties of sintered reaction bonded silicon nitride. High purity silicon powders produced low $\alpha-\mathrm{Si}_{3} \mathrm{~N}_{4}$ content during nitridation. The Si powder type had no apparent effect on densification. More complete nitridation and higher room temperature mechanical properties were observed for the Si powders with higher $\mathrm{Fe}$ contents. However, the higher $\mathrm{Fe}$ contents resulted in greater high temperature strength degradation and so there was better high temperature strength retention with the higher purity Si.

High $\alpha-\mathrm{Si}_{3} \mathrm{~N}_{4}$ contents were found after nitridation with $\alpha-\mathrm{Si}_{3} \mathrm{~N}_{4}$ seeded materials and with $\mathrm{MgO}-\mathrm{Y}_{2} \mathrm{O}_{3}$ as the sintering additive. Densification was inhibited by refractory additives, such as $\mathrm{Y}_{2} \mathrm{O}_{3}-\mathrm{SiO}_{2}$. The highest room temperature strength and fracture toughness values correlated to high nitrided $\alpha-\mathrm{Si}_{3} \mathrm{~N}_{4}$ contents. The high temperature strength behavior was similar for all additive types.

\section{SRBSN Composition Study Part 2}

The purpose of the present study was to further examine the current state of SRBSN materials and determine the effect of different silicon precursor powders, different sintering additives, and different $\mathrm{Si}_{3} \mathrm{~N}_{4}$ seed materials on the processing and final mechanical properties.

\section{Experimental Procedures}

The starting materials for the SRBSN materials used in this study consisted of appropriate amounts of $\mathrm{Si}, \alpha-\mathrm{Si}_{3} \mathrm{~N}_{4}, \beta-\mathrm{Si}_{3} \mathrm{~N}_{4}, \mathrm{Al}_{2} \mathrm{O}_{3}, \mathrm{SiO}_{2}, \mathrm{Y}_{2} \mathrm{O}_{3} \mathrm{CaO}, \mathrm{SiC}$, and $\mathrm{Cr}_{2} \mathrm{O}_{3}$ to give final compositions after nitriding as shown in Table 3 . Two new silicon powders, Elkem metallurgical Si powder (lot \# 49485), and Globe metallurgical Si powder were used. Also, seven different $\mathrm{Si}_{3} \mathrm{~N}_{4}$ seed materials; several new sintering aid combinations; and several additives, which have been noted in the literature to affect nitridation of $\mathrm{Si}$, were used.

The powders were attritor milled in isopropanol with $0.7 \mathrm{wt}$. \% PVP K-15* as a dispersant. The mixtures were dried, screened to -200 mesh and isopressed at $207 \mathrm{MPa}$ into discs approximately $7 \mathrm{~cm}$ in diameter and $2 \mathrm{~cm}$ thick. Binder burnout consisted of a heat-treatment to $550^{\circ} \mathrm{C}$ in air prior to sintering. The nitridation was carried out in a graphite-resistance furnace with a $\mathrm{N}_{2}-4 \% \mathrm{H}_{2}$ gas flow and controlled heating to $1450^{\circ} \mathrm{C}$. The samples were then sintered in a graphite-element furnace with $\mathrm{Si}_{3} \mathrm{~N}_{4}$ packing powder under one atmosphere $\mathrm{N}_{2}$ to $1780-1800^{\circ} \mathrm{C}$ for 2 hours.

Densities were determined by the Archimedes' method. Samples of high density were machined into bend bar specimens with nominal dimensions of $3 \mathrm{~mm} \times 4 \mathrm{~mm} \times 50 \mathrm{~mm}$. Flexural strength testing was done in four point bending with inner and outer spans of 20 $\mathrm{mm}$ and $40 \mathrm{~mm}$, respectively. Fracture toughness values were determined by an indentation and fracture method.

Results and Discussion

Table 4 is a summary of the densities, strengths, and toughness values for sample compositions. Data from Table 4 are represented in Figures 17, 18, and 19.

*GAF Chemicals, Wayne, NJ: Polyvinlylpyrrolidone K15 
As expected, Figure 17 shows that the $\mathrm{Si}_{3} \mathrm{~N}_{4}$ seed type affected sinterability of the samples, with the highest density obtained for the $\mathrm{LC} 10 \alpha-\mathrm{Si}_{3} \mathrm{~N}_{4}+\beta$-seed combination. Of particular interest was the fact the material containing 20 wt $\% \mathrm{LC} 10 \alpha-\mathrm{Si}_{3} \mathrm{~N}_{4}$ seed did not sinter as well as material containing the standard $10 \mathrm{wt} \% \mathrm{LC10} \alpha-\mathrm{Si}_{3} \mathrm{~N}_{4}$ seed. Figures 18 and 19 show that the sintered densities of the samples did not correlate completely with the strength and toughness values. Samples containing the E10, S1, and $\mathrm{M} 11 \alpha-\mathrm{Si}_{3} \mathrm{~N}_{4}$ seeds exhibited the highest strength and toughness, but had lower densites than the $\mathrm{LC} 10 \alpha-\mathrm{Si}_{3} \mathrm{~N}_{4}+\beta$-seed material

Figures 20,21, and 22 shows data from Table 4 for the densities, strengths, and fracture toughness values, respectively, for samples prepared using various nitridation and sintering aids. The most promising result from this study was the combination of chromium nitrate with the 9Y3A sintering aids. This material had the best densification and strength of all the samples in this group. It was interesting that the addition of chromium acetate had a very negative effect on the strength of this material. The difference in the effect of the two chrome derivatives may lay in the fact that chromium nitrate is soluble in alcohol (used for Si dispersion), however chromium acetate has a low solubility in alcohol. The solubility of these materials may affect their coating of the silicon materials on which they react. Two other materials, the 8Y4A material and the 9Y3A-Globe material, showed promising strength values. Only small differences were seen in the toughness values between samples in this group.

Further tests are underway to determine if longer sintering times will improve the densification behavior and increase the mechanical properties of selected samples from this study. All samples are being polished and etched to study the effects of the various compositions on the microstructures of the dense materials.

\section{REFERENCES}

1. L. M. Sheppard, "Cost-Effective Manufacturing of Advanced Ceramics," Am. Ceram. Soc. Bull., 70 [4] 692-707 (1991).

2. A. J. Moulson, "Reaction-Bonded Silicon Nitride: Its Formation and Properties," J. Mater. Sci., Vol. 14, pp. 1017-1051 (1979)

3. F. L. Riley, "Nitridation and Reaction Bonding," pp. 265-288 in Nitrogen Ceramics, F. L. Riley (ed.), Noordhoff, Netherlands (1977)

4. J. A. Mangels and G. J. Tennenhouse, "Densification of Reaction-Bonded Silicon Nitride," Am. Ceram. Soc. Bull., 59 [12] 1216-1222 (1980).

5. J. A. Mangels, "Sintered Reaction-Bonded Silicon Nitride," Ceram. Eng. Sci. Proc., 2[7-8] 589-603 (1981).

6. L. K. L. Falk, R. Pompe, G. L. Dunlop, "Development of Microstructure During the Fabrication of $\mathrm{Si}_{3} \mathrm{~N}_{4}$ by Nitridation and Pressureless Sintering of $\mathrm{Si}_{2} \mathrm{Si}_{3} \mathrm{~N}_{4}$ Compacts," J. Mater. Sci., 20, 3545-3556 (1985).

7. T. N. Tiegs, J. O. Kiggans, and K. L. Ploetz, "Cost-Effective Sintered ReactionBonded Silicon Nitride for Structural Ceramics," Ceram. Eng. Sci. Proc., 14 [1-2] 378388 (1993).

8. R. Pompe and L. Hermansson, "Characterization of Silicon Powders for the Production of $\mathrm{Si}_{3} \mathrm{~N}_{4}$," Mater. Sci. Eng., 71, 355-362 (1985).

9. P. L. Antona, A. Giachello, and P. C. Martinengo, "Nitridation of Silicon in the Presence of Oxides," pp. 753-766 in Ceramic Powders (ed. P. Vincenzini), Elsevier Sci. Pub., Amsterdam (1983).

10. A. J. Pyzik, D. F. Carroll and C. J. Hwang, "The Effect of Glass Chemistry on the Microstructure and Properties of Self Reinforced Silicon Nitride, "pp. 411-416 in Silicon 
Nitride Ceramics, Edited by I-W. Chen, P. F. Becher, M. Mitomo, G. Petzow and T. S. Yen, Materials Research Society, Pittsburgh, PA (1993).

11. A. J. Pyzik and D. R. Beamen, "Microstructure and Properties of Self- Reinforced Silicon Nitride, " J. Am. Ceram. Soc., 76 [11] 2737-2744 (1993).

12. V. Tikare and S. R. Choi, "Influence of the Microstructure on Its R-Curve and Fatigue Behavior," Ceram. Eng. Sci. Proc., 12 [7-8] 1437-1447 (1991).

13. I. P Tuersley, G. Leng-Ward, and M. H. Lewis, "High-Temperature $\mathrm{Si}_{3} \mathrm{~N}_{4}$-Based Ceramics," Brit. Ceram. Proc.,46. 231-246 (1990)

Status of Milestones

On Schedule

Problems Encountered

None

Publications

T. N. Tiegs, J. O. Kiggans, F. C. Montgomery, H. T. Lin, J. D. Snodgrass, E. S. Sabolsky and D. W. Coffey, "Effect of Composition On The Processing and Properties of Sintered Reaction-Bonded Silicon Nitride," to be published in the proceedings of the 1996 Conference on Composites, Advanced Ceramics, Materials and Structures, CoCoa Beach, Fl. Jan. 7-11, 1996.

\section{Communications/Visits/Travel}

Presentation of paper entitled, "Effect of Composition On The Processing and Properties of Sintered Reaction-Bonded Silicon Nitride," by T. N. Tiegs at the 1996 Conference on Composites, Advanced Ceramics, Materials and Structures, CoCoa Beach, Fl., Jan.11, 1996. 
Table 1. Summary Data for SRBSN Fabrication

$\begin{array}{lcccc}\text { Furnace Type } & \text { Location } & \text { \# Samples } & \begin{array}{c}\text { Avg. Density } \\ \text { g/cm }\end{array} & \begin{array}{c}\text { St. Dev. Densities } \\ \mathrm{g} / \mathrm{cm}^{3}\end{array} \\ \text { Graphite } & \text { ORNL } & 9 \mathrm{a} & 3.26 & 0.003 \\ \text { Graphite } & \text { ORNL } & 210^{\mathrm{d}} & 3.22^{*} & 0.052 \\ \text { Microwave } & \mathrm{ORNL} & 8^{\mathrm{a}} & 3.27 & 0.005 \\ \text { Microwave } & \mathrm{ORNL} & 21^{\mathrm{a}} & 3.23 & 0.002 \\ \text { Microwave } & \mathrm{ORNL} & 72^{\mathrm{b}} & 3.30 & 0.018 \\ \text { Microwave } & \mathrm{ORNL} & 108^{\mathrm{c}} & 3.25 & 0.008 \\ \text { Microwave } & \mathrm{Y}-12 & 90^{\mathrm{a}} & 3.18 & 0.020 \\ \text { Microwave } & \mathrm{Y}-12 & 230^{\mathrm{c}} & 3.19^{*} & 0.019 \\ \text { a bucket tappets } & & & \\ \text { b } \mathrm{Si}_{3} \mathrm{~N}_{4}-9 \% \mathrm{La}_{2} \mathrm{O}_{3}-3 \% \mathrm{Al}_{2} \mathrm{O}_{3} & & & \\ \text { c } \mathrm{Si}_{3} \mathrm{~N}_{4}-9 \% \mathrm{Y}_{2} \mathrm{O}_{3}-3 \% \mathrm{Al}_{2} \mathrm{O}_{3} & & \\ \text { d Coors proprietary composition } & & \\ \text { * Average density value based on measurement of the density of every fourth sample. }\end{array}$

Table 2 . Summary of compositions used for SRBSN study.

\begin{tabular}{|c|c|c|c|}
\hline Sample ID & Final Composition ${ }^{2,6}$ & $\begin{array}{l}\alpha-\mathrm{Si}_{3} \mathrm{~N}_{4} \\
\text { Content } \\
\text { (wt. \%) }\end{array}$ & $\begin{array}{c}\text { Si Powder } \\
\text { Fe Content } \\
\text { (wt. \%) }\end{array}$ \\
\hline $\begin{array}{l}\text { Elkem or A-Y } \\
\text { K.N. 4C } \\
\text { K.N. 5C } \\
\text { Albemarle }\end{array}$ & $\begin{array}{l}\mathrm{Si}_{3} \mathrm{~N}_{4}-9 \% \mathrm{Y}_{2} \mathrm{O}_{3}-3 \% \mathrm{Al}_{2} \mathrm{O}_{3} \\
\mathrm{Si}_{3} \mathrm{~N}_{4}-9 \% \mathrm{Y}_{2} \mathrm{O}_{3}-3 \% \mathrm{Al}_{2} \mathrm{O}_{3} \\
\mathrm{Si}_{3} \mathrm{~N}_{4}-9 \% \mathrm{Y}_{2} \mathrm{O}_{3}-3 \% \mathrm{Al}_{2} \mathrm{O}_{3} \\
\mathrm{Si}_{3} \mathrm{~N}_{4}-9 \% \mathrm{Y}_{2} \mathrm{O}_{3}-3 \% \mathrm{Al}_{2} \mathrm{O}_{3}\end{array}$ & $\begin{array}{l}10 \\
10 \\
10 \\
10\end{array}$ & $\begin{array}{c}0.29^{\mathrm{d}} \\
0.1^{\mathrm{e}} \\
0.018^{\mathrm{f}} \\
0.001^{\mathrm{g}}\end{array}$ \\
\hline $\begin{array}{l}\text { A-Y* } \\
M-Y \\
M-A-Y \\
Y-S\end{array}$ & $\begin{array}{l}\mathrm{Si}_{3} \mathrm{~N}_{4}-9 \% \mathrm{Y}_{2} \mathrm{O}_{3}-3 \% \mathrm{Al}_{2} \mathrm{O}_{3} \\
\mathrm{Si}_{3} \mathrm{~N}_{4}-6.4 \% \mathrm{Y}_{2} \mathrm{O}_{3}-3.2 \% \mathrm{MgO}^{\mathrm{h}} \\
\mathrm{Si}_{3} \mathrm{~N}_{4}-5 \% \mathrm{Y}_{2} \mathrm{O}_{3}-5 \% \mathrm{MgAl}_{2} \mathrm{O}_{4} \\
\mathrm{Si}_{3} \mathrm{~N}_{4}-7.6 \% \mathrm{Y}_{2} \mathrm{O}_{3}-6.5 \% \mathrm{SiO}_{2}\end{array}$ & $\begin{array}{l}0 \\
10 \\
10 \\
10\end{array}$ & $\begin{array}{l}0.29^{d} \\
0.29^{d} \\
0.29^{d} \\
0.29^{d}\end{array}$ \\
\hline
\end{tabular}

aAll compositions contained approximately $1.7 \mathrm{wt} . \% \mathrm{SiO}_{2}$ to simulate typical $\mathrm{Si}_{3} \mathrm{~N}_{4}$ powder.

${ }^{6} \mathrm{Y}_{2} \mathrm{O}_{3}$-Molycorp, White Plains, NY; Grade 5600, >99.99\% ; $\mathrm{Al}_{2} \mathrm{O}_{3}$-Reynolds, Malakoff, TX; Grade RC-HP DBM, $\mathrm{MgAl}_{2} \mathrm{O}_{4}$, Ceralox, Tucson, AZ; MgO, Mallinckrodt, St. Louis, MO; Reagent Grade; $\mathrm{SiO}_{2}$, U. S. Silica, $5 \mu \mathrm{m}$.

'Starck, Berlin, Germany; Grade LC-10N. The $10 \%$ is based on $\mathrm{Si}_{3} \mathrm{~N}_{4}$ content after nitridation.

${ }^{d}$ Elkem Metals Co., Buffalo, NY; Grade Metallurgical Si; $3.4 \mu \mathrm{m}$ mean particle size.

${ }^{\circ}$ KemaNord, Stockholm, Sweden, Grade 4C; $6.4 \mu \mathrm{m}$ mean particle size.

${ }^{f}$ KemaNord, Stockholm, Sweden, Grade 5C; $6.2 \mu \mathrm{m}$ mean particle size.

${ }^{8}$ Albemarle Corp., Baton Rouge, LA; $0.35 \mu \mathrm{m}$ mean particle size.

hample also contained $0.2 \% \mathrm{CaO}$ added as $\mathrm{CaCO}_{3}$. 
Table 3. Summary of compositions used for SRBSN study

\begin{tabular}{|c|c|c|c|}
\hline Sample ID & Final Composition ${ }^{a}$ & $\begin{array}{c}\mathrm{Si}_{3} \mathrm{~N}_{4} \\
\text { Seed Type }\end{array}$ & $\begin{array}{c}\mathrm{Si}_{3} \mathrm{~N}_{4} \\
\text { Seed (wt \%) }\end{array}$ \\
\hline $\begin{array}{l}\text { Elkem }^{b} \text { SRB 1b } \\
\text { Elkem }^{\mathrm{b}} \text { SRB } 10 \\
\text { Elkem }^{\mathrm{b}} \text { SRB } 11 \\
\text { Elkem }^{\mathrm{b}} \text { SRB } 12 \\
\text { Elkem }^{\mathrm{b}} \text { SRB } 13 \\
\text { Elkem }^{\mathrm{b}} \text { SRB } 14 \\
\text { Elkem } \\
\text { Elkem } \text { SRB } 15 \\
\text { Elkem }{ }^{\mathrm{b}} \text { SRB } 16 \\
\text { Elkem } 17 \\
\text { Elkem }{ }^{\mathrm{b}} \text { SRB } 18 \\
\text { Elkem } 19 \\
\text { Elkem }{ }^{\mathrm{b}} \text { SRB } 20 \\
\text { Elkem }^{\mathrm{b}} \text { SRB } 21 \\
\text { Globe }^{\mathrm{c}} \text { SRB } 25 \\
\text { Elkem }^{\mathrm{d}} \text { SRB } 154\end{array}$ & $\begin{array}{l}\mathrm{Si}_{3} \mathrm{~N}_{4}-9 \% \mathrm{Y}_{2} \mathrm{O}_{3}^{\mathrm{e}}-3 \% \mathrm{Al}_{2} \mathrm{O}_{3} \\
\mathrm{Si}_{3} \mathrm{~N}_{4}-9 \% \mathrm{Y}_{2} \mathrm{O}_{3}^{\mathrm{f}}-3 \% \mathrm{Al}_{2} \mathrm{O}_{3} \\
\mathrm{Si}_{3} \mathrm{~N}_{4}-9 \% \mathrm{Y}_{2} \mathrm{O}_{3}^{\mathrm{f}}-3 \% \mathrm{Al}_{2} \mathrm{O}_{3} \\
\mathrm{Si}_{3} \mathrm{~N}_{4}-9 \% \mathrm{Y}_{2} \mathrm{O}_{3}^{\mathrm{f}}-3 \% \mathrm{Al}_{2} \mathrm{O}_{3} \\
\mathrm{Si}_{3} \mathrm{~N}_{4}-9 \% \mathrm{Y}_{2} \mathrm{O}_{3}^{\mathrm{f}}-3 \% \mathrm{Al}_{2} \mathrm{O}_{3} \\
\mathrm{Si}_{3} \mathrm{~N}_{4}-9 \% \mathrm{Y}_{2} \mathrm{O}_{3}^{\mathrm{f}}-3 \% \mathrm{Al}_{2} \mathrm{O}_{3} \\
\mathrm{Si}_{3} \mathrm{~N}_{4}-9 \% \mathrm{Y}_{2} \mathrm{O}_{3}^{\mathrm{f}}-3 \% \mathrm{Al}_{2} \mathrm{O}_{3} \\
\mathrm{Si}_{3} \mathrm{~N}_{4}-9 \% \mathrm{Y}_{2} \mathrm{O}_{3}^{\mathrm{f}}-3 \% \mathrm{Al}_{2} \mathrm{O}_{3} \\
\mathrm{Si}_{3} \mathrm{~N}_{4}-9 \% \mathrm{Y}_{2} \mathrm{O}_{3}^{\mathrm{f}}-3 \% \mathrm{Al}_{2} \mathrm{O}_{3}-0.2 \% \mathrm{Cr}_{2} \mathrm{O}_{3}^{\mathrm{g}} \\
\mathrm{Si}_{3} \mathrm{~N}_{4}-9 \% \mathrm{Y}_{2} \mathrm{O}_{3}^{\mathrm{f}}-3 \% \mathrm{Al}_{2} \mathrm{O}_{3}-0.2 \% \mathrm{CaO}^{\mathrm{f}} \mathrm{C}^{\mathrm{f}} \\
\mathrm{Si}_{3} \mathrm{~N}_{4}-9 \% \mathrm{Y}_{2} \mathrm{O}_{3}^{\mathrm{f}}-3 \% \mathrm{Al}_{2} \mathrm{O}_{3}-0.2 \% \mathrm{SiC}^{\mathrm{f}} \\
\mathrm{Si}_{3} \mathrm{~N}_{4}-8 \% \mathrm{Y}_{2} \mathrm{O}_{3}^{\mathrm{f}}-3 \% \mathrm{Al}_{2} \mathrm{O}_{3}-2.5 \% \mathrm{SiO}_{2} \\
\mathrm{Si}_{3} \mathrm{~N}_{4}-8 \% \mathrm{Y}_{2} \mathrm{O}_{3}^{\mathrm{f}}-4 \% \mathrm{Al}_{2} \mathrm{O}_{3} \\
\mathrm{Si}_{3} \mathrm{~N}_{4}-6 \% \mathrm{Y}_{2} \mathrm{O}_{3}^{\mathrm{f}}-6 \% \mathrm{Al}_{2} \mathrm{O}_{3} \\
\mathrm{Si}_{3} \mathrm{~N}_{4}-9 \% \mathrm{Y}_{2} \mathrm{O}_{3}^{\mathrm{f}}-3 \% \mathrm{Al}_{2} \mathrm{O}_{3} \\
\mathrm{Si}_{2} \mathrm{~N}_{4}-9 \% \mathrm{Y}_{2} \mathrm{O}_{3}^{\mathrm{e}}-3 \% \mathrm{Al}_{2} \mathrm{O}_{3}-0.4 \% \mathrm{Cr}_{2} \mathrm{O}_{3}{ }^{\mathrm{e}}\end{array}$ & $\begin{array}{l}\text { LC } 10-N^{\mathrm{k}} \\
\mathrm{E}-03^{\mathrm{l}} \\
\mathrm{E}-10^{\mathrm{m}} \\
\mathrm{S} 1^{\mathrm{n}} \\
\mathrm{M} 11^{\mathrm{p}} \\
\mathrm{LC} 10^{\mathrm{p}} \\
\mathrm{LC} 10^{\mathrm{p}} \\
\text { LC } 10^{\mathrm{p}}, \mathrm{B}-\mathrm{Si}_{3} \mathrm{~N}_{4}^{\mathrm{q}} \\
\mathrm{LC} 10^{\mathrm{p}} \\
\mathrm{LC} 10^{\mathrm{p}} \\
\mathrm{LC} 10^{\mathrm{p}} \\
\mathrm{LC} 10^{\mathrm{p}} \\
\mathrm{LC} 10^{\mathrm{p}} \\
\mathrm{LC} 10^{\mathrm{p}} \\
\mathrm{LC} 10^{\mathrm{p}} \\
\text { LC } 10-\mathrm{N}^{\mathrm{k}}\end{array}$ & $\begin{array}{c}10 \\
10 \\
10 \\
10 \\
10 \\
10 \\
20 \\
5,5 \\
10 \\
10 \\
10 \\
10 \\
10 \\
10 \\
10 \\
10\end{array}$ \\
\hline
\end{tabular}

${ }^{a}$ Unless indicated, all compositions contained approximately $1.5 \mathrm{wt}$. \% $\mathrm{SiO}_{2}, \mathrm{U}$. S. Silica, Berkeley Springs, WV, $5 \mu \mathrm{m}$ particle size; and indicated amounts of $\mathrm{Al}_{2} \mathrm{O}_{3}$ - Reynolds, Malakoff, TX; Grade RC-HP DBM.

bilicon, Elkem Metals Co., Buffalo, NY; Metallurgical Grade, (lot 49485), < $10 \mu \mathrm{m}$ particle size.

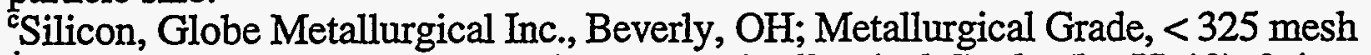

'Silicon, Elkem Metals Co., Buffalo, NY; Metallurgical Grade, (lot JS-19), $3.4 \mu \mathrm{m}$ particle size.

${ }^{e} \mathrm{Y}_{2} \mathrm{O}_{3}$ - Molycorp, White Plains, NY; Grade 5600, >99.99\%

${ }^{f} \mathrm{Y}_{2} \mathrm{O}_{3}$ - Starck, Berlin, Germany; Grade Fine, $>99.99 \%$

${ }^{8} \mathrm{Cr}_{2} \mathrm{O}_{3}$ added as chrome acetate $\left(\mathrm{C}_{6} \mathrm{H}_{9} \mathrm{CrO}_{6}\right)$, Atomergic Chemetals, Plainview, $\mathrm{NY}$.

${ }^{h} \mathrm{CaO}$ added as $\mathrm{CaCO}_{3}$, Mallinckrodt, St. Louis, $\mathrm{MO}$; Analytical Grade.

iSiC, Starck, Berlin, Germany; Grade A-10.

${ }^{\mathrm{j}} \mathrm{Cr}_{2} \mathrm{O}_{3}$ as chrome nitrate $\left(\mathrm{CrN}_{3} \mathrm{O}_{9}\right)$, Aldrich, Milwaukee, WI; $99 \%$ pure.

${ }^{\mathrm{k}} \mathrm{Si}_{3} \mathrm{~N}_{4}$, Starck Gmbh \& Co., Berlin, Germany; Grade LC 10-N, 0.5 mean particle size.

${ }^{1} \mathrm{Si}_{3} \mathrm{~N}_{4}$, UBE Industries, LTD, Japan; Grade E-03, $1.0 \mu \mathrm{m}$ mean particle size.

${ }^{\mathrm{m}} \mathrm{Si}_{3} \mathrm{~N}_{4}$, UBE Industries, LTD, Japan; Grade E-10, $0.2 \mu \mathrm{m}$ mean particle size.)

${ }^{n} \mathrm{Si}_{3} \mathrm{~N}_{4}$, Starck Gmbh \& Co., Berlin, Germany; Grade $\mathrm{S1}, 0.7$ mean particle size.

${ }^{\circ} \mathrm{Si}_{3} \mathrm{~N}_{4}$, Starck Gmbh \& Co., Berlin, Germany; Grade M11, 0.5 mean particle size.

${ }^{\mathrm{P}} \mathrm{Si}_{3} \mathrm{~N}_{4}$, Starck Gmbh \& Co., Berlin, Germany; Grade LC 10, 0.7 mean particle size.

${ }^{a} \mathrm{\beta}_{-} \mathrm{Si}_{3} \mathrm{~N}_{4}$, Shin Etsu, Japan; Lot \# KSN-80SP 
Table 4. Cumulative data for die-pressed pellets from new SRBSN materials.

\begin{tabular}{|c|c|c|c|c|c|}
\hline Sample ID (Description) & $\begin{array}{l}\text { Density } \\
\left(\mathrm{g} / \mathrm{cm}^{3}\right)\end{array}$ & $\begin{array}{l}\text { Strength } \\
(\mathrm{MPa})\end{array}$ & $\begin{array}{l}\text { Std Dev } \\
\text { (Mpa) }\end{array}$ & $\begin{array}{l}\text { Toughness } \\
(\mathrm{MPa} \sqrt{\mathrm{m}})\end{array}$ & $\begin{array}{l}\text { St Dev } \\
(\mathrm{MPa} / \mathrm{m})\end{array}$ \\
\hline Elkem SRB 1b (9Y3A LC10N) & 96.2 & $\overline{575}$ & 95 & 6.4 & 0.1 \\
\hline ElkemSRB 10 (9Y3A E03) & 92.9 & 534 & 11 & 5.8 & 0.1 \\
\hline Elkem SRB 11 (9Y3A E10) & 94.8 & 628 & 23 & 6.0 & 0.1 \\
\hline Elkem SRB 12 (9Y3A S1) & 94.4 & 595 & 23 & 6.2 & 0.4 \\
\hline Elkem SRB 13 (9Y3A M11) & 95.4 & 602 & 9 & 6.0 & 0.3 \\
\hline Elkem SRB 14 (9Y3A LC10) & 96.2 & 526 & 25 & 6.3 & 0.0 \\
\hline Elkem SRB 15 (9Y3A LC10, 20\%) & 95.4 & 475 & 21 & 6.5 & 0.3 \\
\hline Elkem SRB $16\left(9 \mathrm{Y} 3 \mathrm{~A} \mathrm{LC} 10, \beta_{\mathrm{Si}} \mathrm{N}_{4}\right)$ & 97.7 & 458 & 3 & 5.2 & 0.1 \\
\hline Elkem SRB $17\left(9 \mathrm{Y}^{2} \mathrm{~A} \mathrm{Cr}_{2} \mathrm{O}_{3} \mathrm{LC} 10\right)$ & 96.3 & 145 & 29 & 4.9 & 0.2 \\
\hline ElkemSRB 18 (9Y3A CaÖ LC10) & 96.3 & 592 & 43 & 5.7 & 0.3 \\
\hline Elkem SRB 19 9Y3A SiC LC10) & 96.6 & 558 & 81 & 6.3 & 0.1 \\
\hline Elkem SRB $20\left(8 \mathrm{Y}_{3} \mathrm{~A}_{2.5 \mathrm{SiO}_{2}} \mathrm{LC} 10\right)$ & 94.7 & 479 & 51 & 6.0 & 0.1 \\
\hline Elkem SRB 21 (8Y4ALC10) & 97.1 & 647 & 16 & 5.6 & 0.5 \\
\hline Elkem SRB 22 (6Y6A LC10) & 96.6 & 542 & 77 & 6.1 & 0.3 \\
\hline Globe SRB 25 (9Y3A LC10) & 94.5 & 639 & 17 & 5.8 & 0.2 \\
\hline Elkem SRB $154\left(9 \mathrm{Y}^{2} \mathrm{~A} \mathrm{Cr}_{2} \mathrm{O}_{3} \mathrm{LC} 10\right)$ & 97.8 & 676 & 25 & 6.2 & 0.1 \\
\hline
\end{tabular}




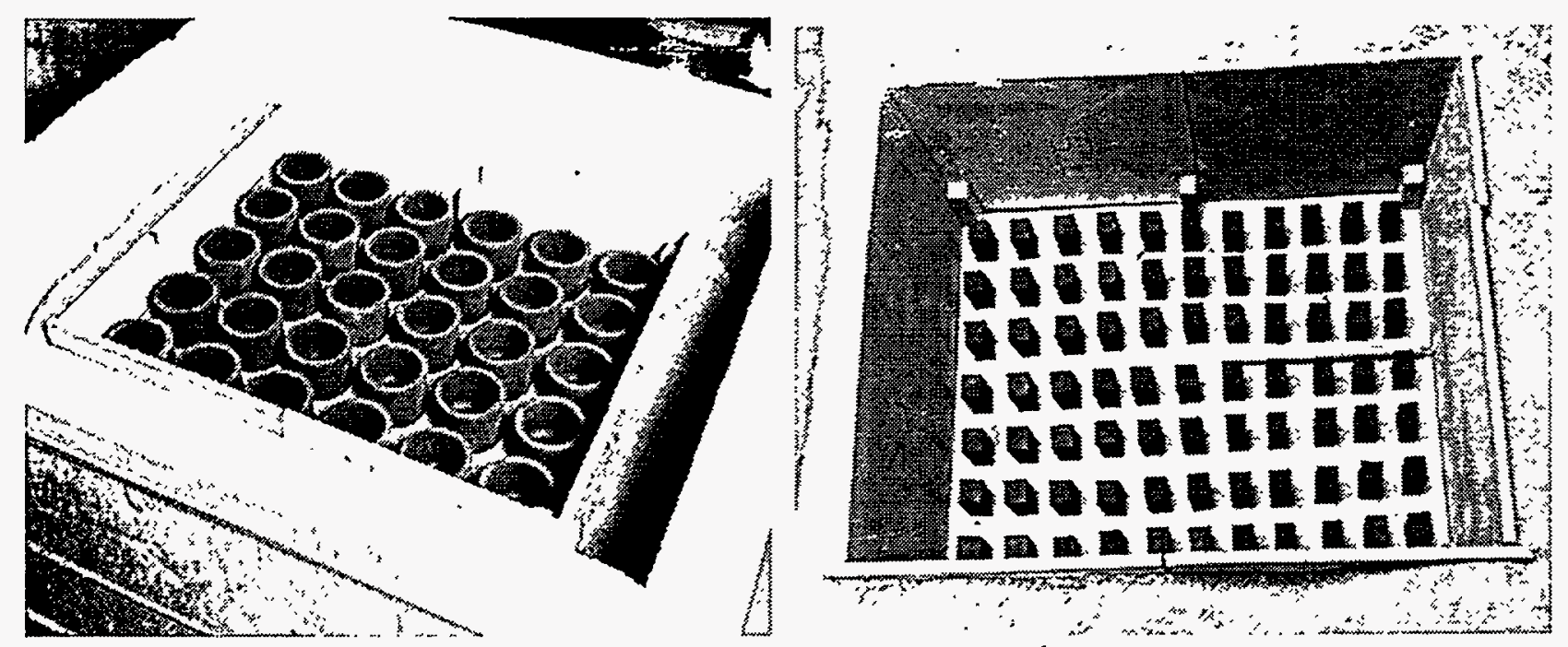

Fig. 1. Microwave insualtion packages with silicon preforms loaded prior to microwave processing in the $4000 \mathrm{l}$ microwave furnace.
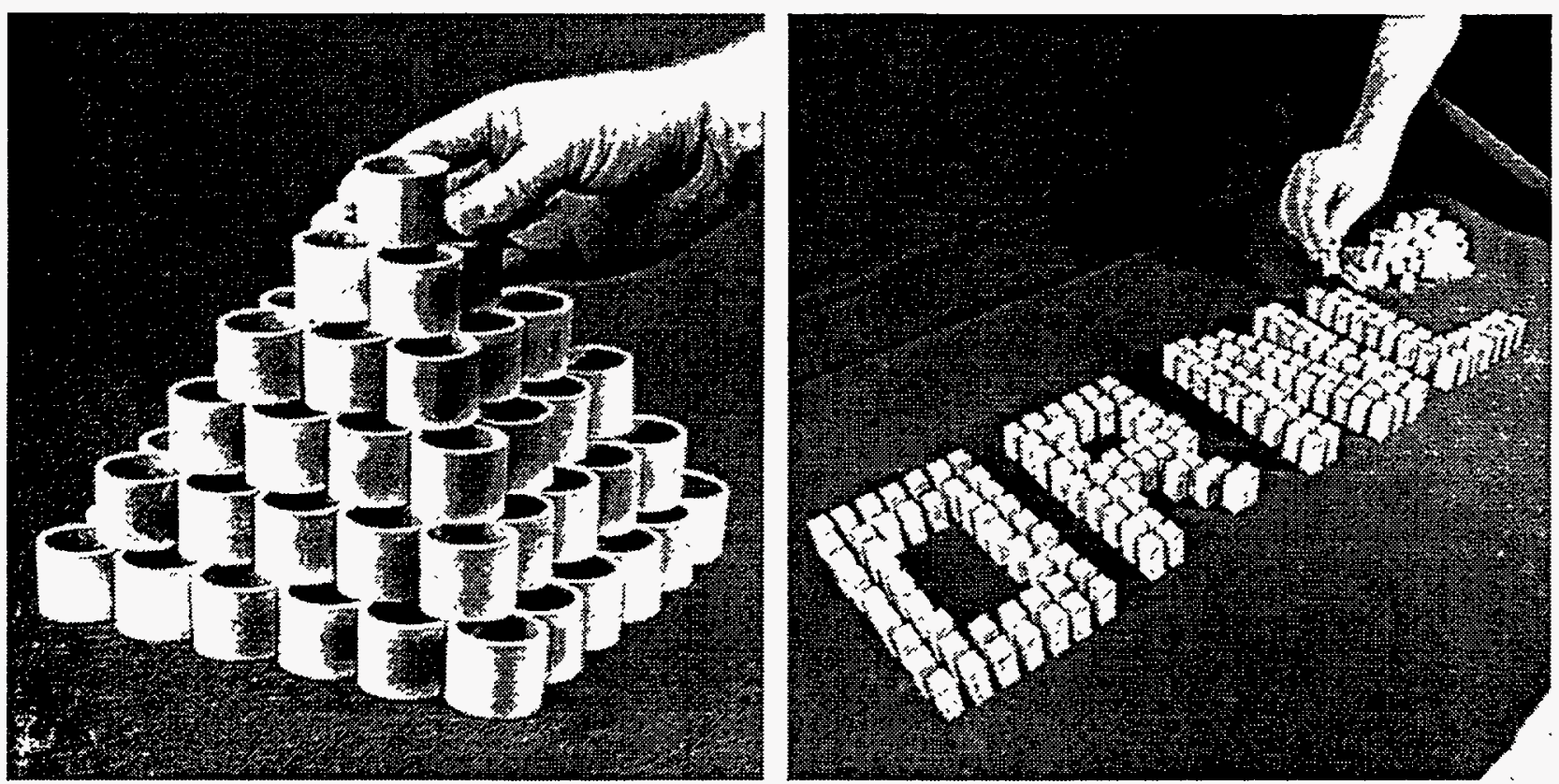

Fig. 2. SRBSN parts fabricated using microwave heating in the $4000 \mathrm{~L}$ microwave furnace. 


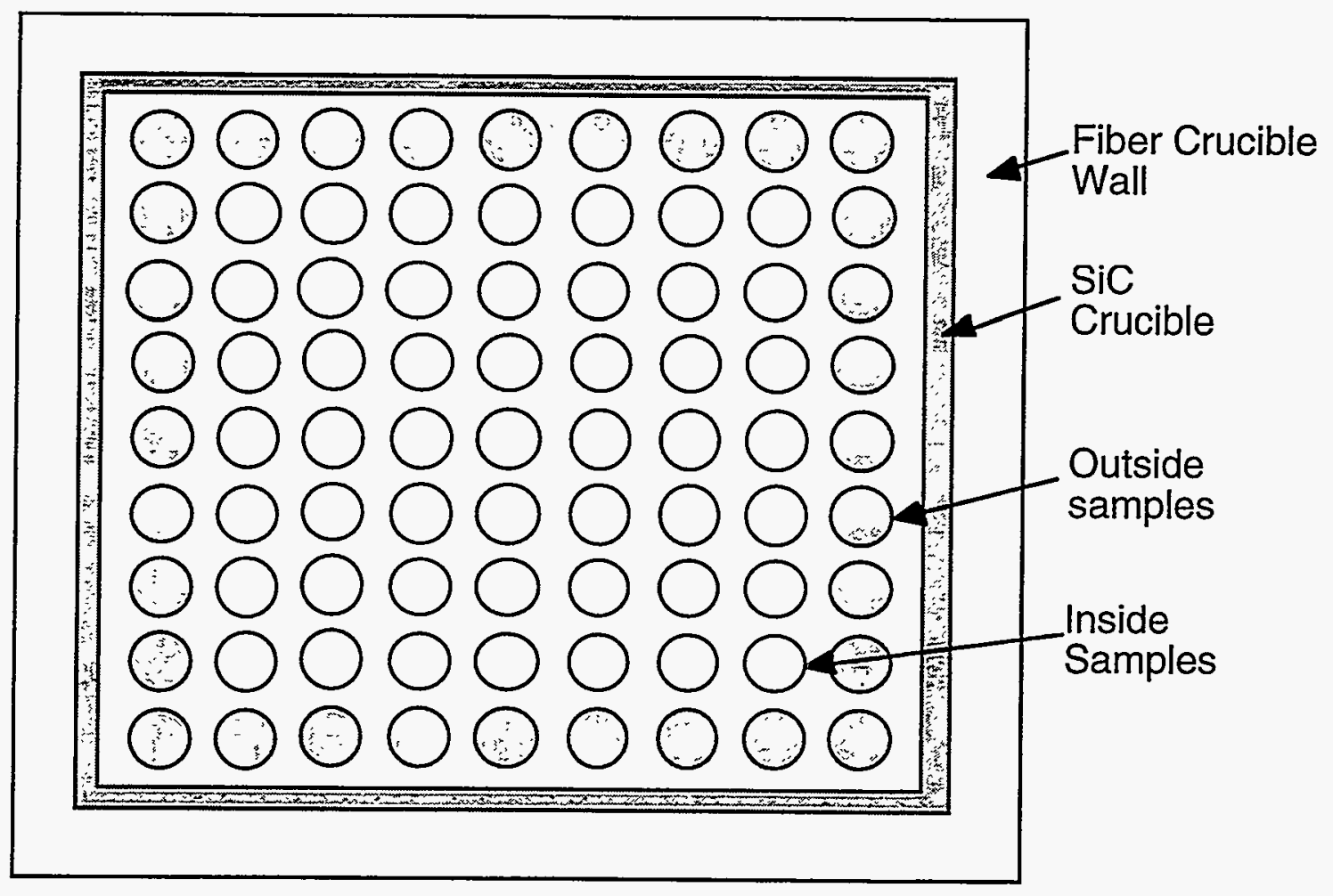

Fig. 3. Drawing of microwave package for clevis pin - crucible tests.

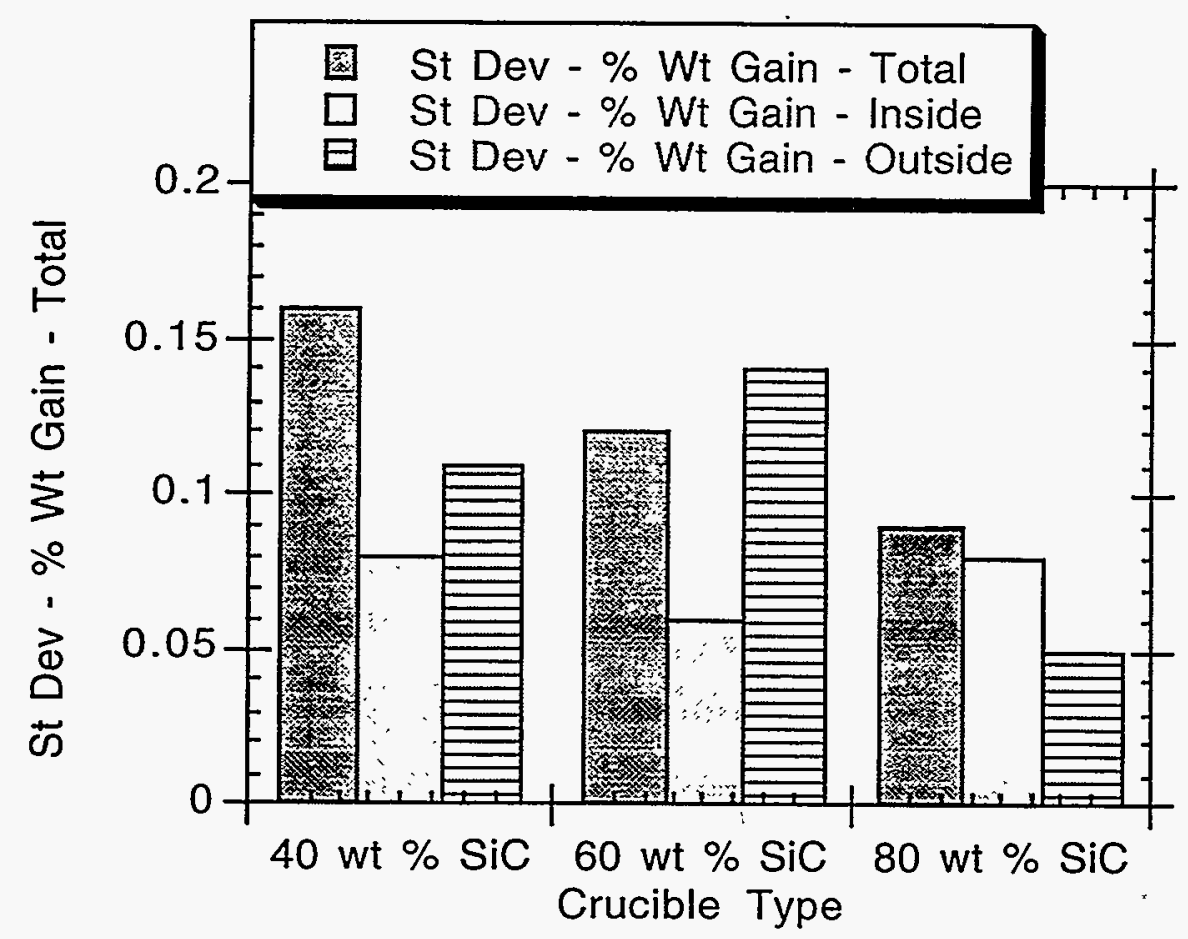

Fig. 4. Standard deviations of weight gains of the clevis pins in tests with three microwave crucibles. 


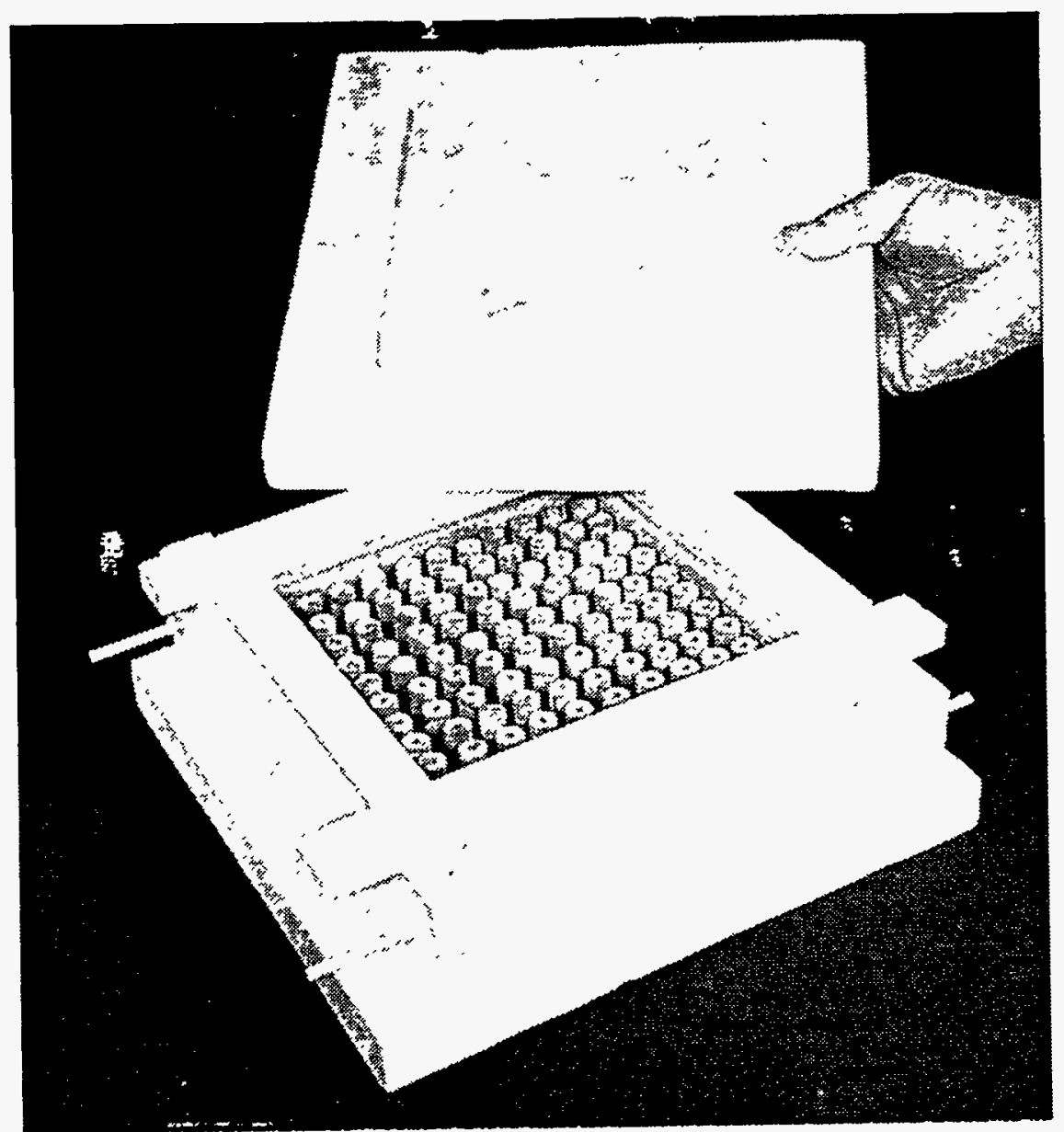

Fig. 5. Photo of 90 clevis pins nitrided using microwave heating in a $80 \mathrm{wt}$. \% SiC crucible.

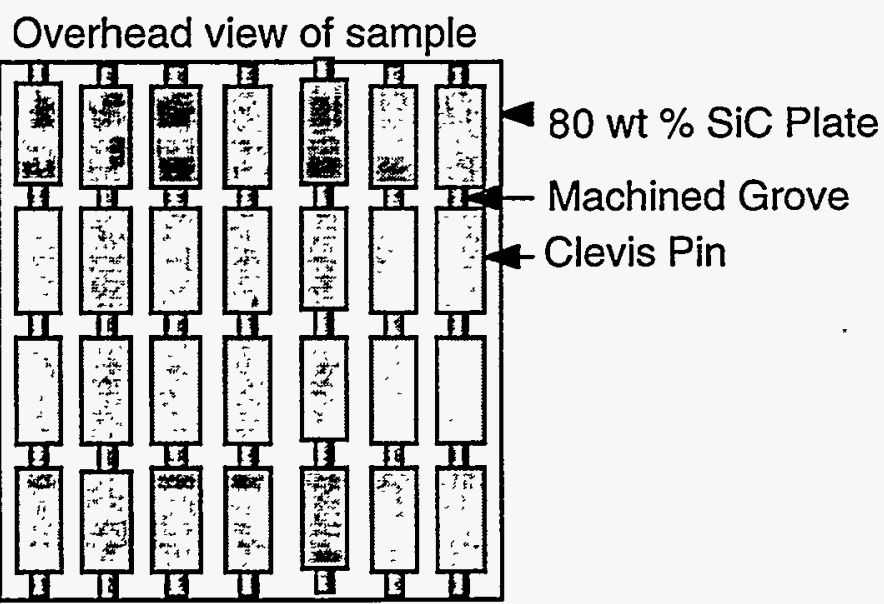

Cross section view of samples and setters

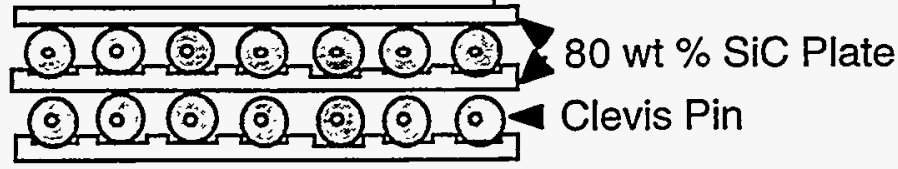

Fig. 6. Microwave crucible used for convenient sample handling during binder burnout and microwave nitridation of clevis pins 

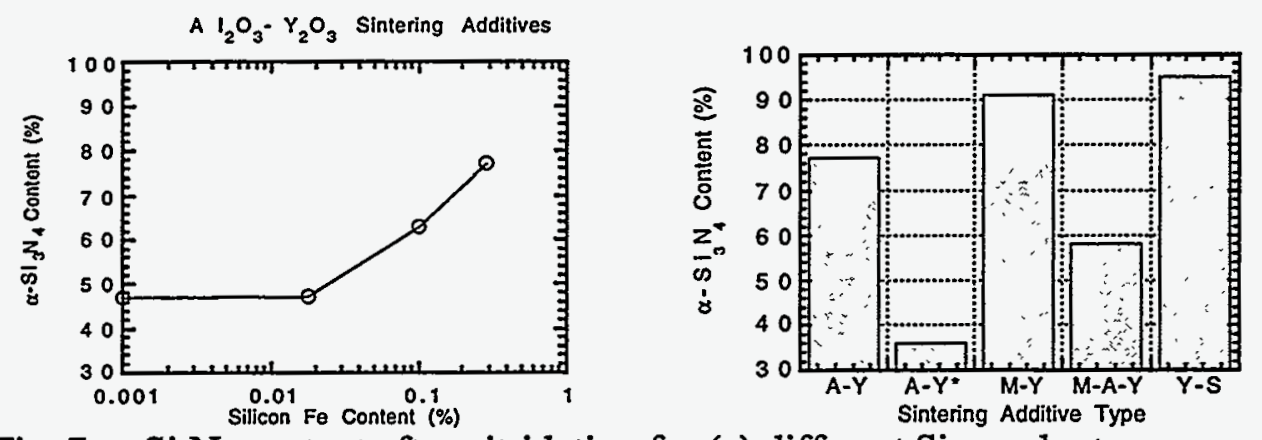

Fig. 7. $\alpha-\mathrm{Si}_{3} \mathrm{~N}_{4}$ content after nitridation for (a) different Si powder types correlated with starting Fe content, and (b) alternate sintering additives. Sample designations listed in Table 2.
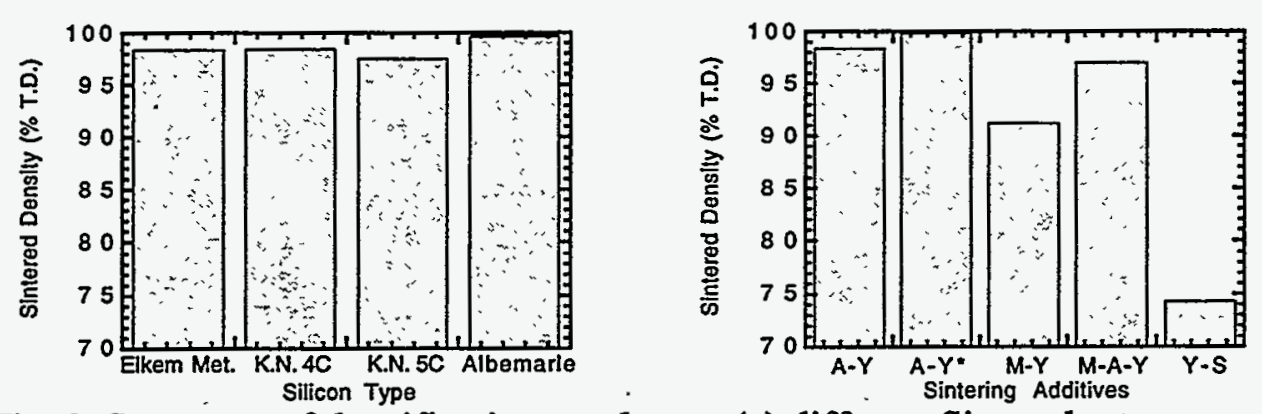

Fig. 8. Summary of densification results on (a) different Si powder types, and (b) alternate sintering additives. Sample designations listed in Table 2.
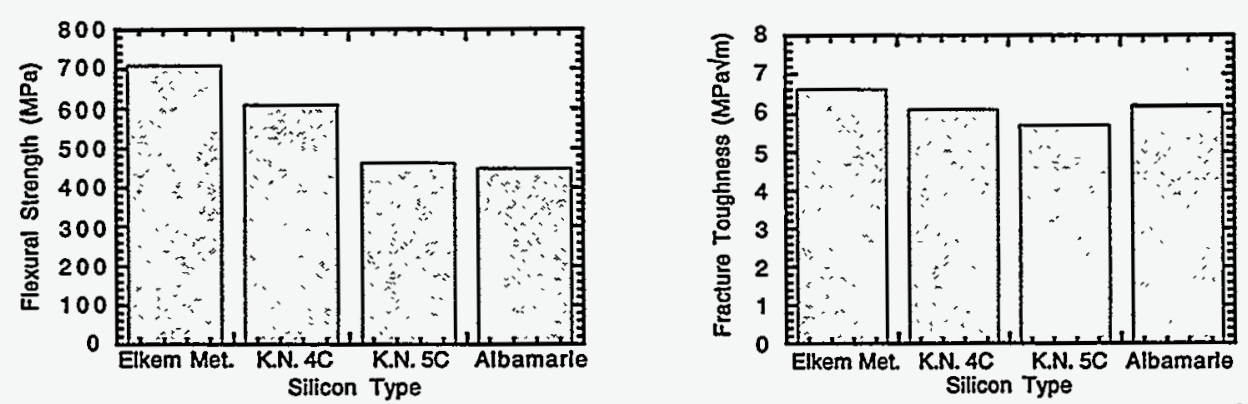

Fig. 9. Room temperature flexural strength (a) and fracture toughness (b) of SRBSN from different $\mathrm{Si}$ powder types. Additive composition was $\mathrm{Si}_{3} \mathrm{~N}_{4}-9 \% \mathrm{Y}_{2} \mathrm{O}_{3}-3 \% \mathrm{Al}_{2} \mathrm{O}_{3}$. Sample designations listed in Table 2. 

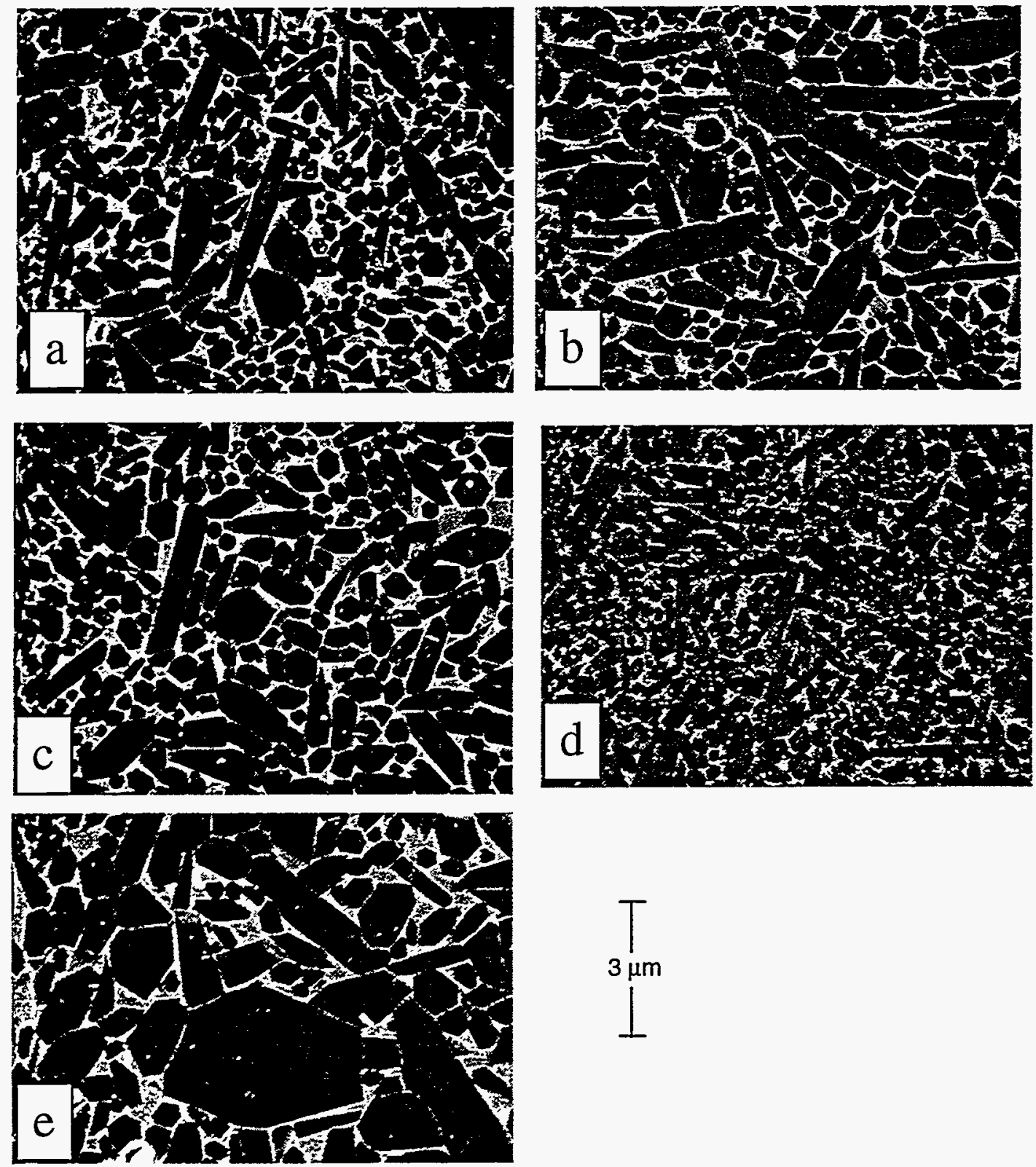

Fig. 10. Microstructures of SRBSN, (a) composition $\mathrm{Si}_{3} \mathrm{~N}_{4}-9 \% \quad \mathrm{Y}_{2} \mathrm{O}_{3}-3 \% \mathrm{Al}_{2} \mathrm{O}_{3}$ with Elkem $\mathrm{Si}$ (Elkem or AY); (b) composition $\mathrm{Si}_{3} \mathrm{~N}_{4}-9 \% \mathrm{Y}_{2} \mathrm{O}_{3}-3 \% \mathrm{Al}_{2} \mathrm{O}_{3}$ with KemaNord 4C Si (K.N. 4C); (c) composition $\mathrm{Si}_{3} \mathrm{~N}_{4}-9 \% \mathrm{Y}_{2} \mathrm{O}_{3}-3 \% \mathrm{Al}_{2} \mathrm{O}_{3}$ with Elkem $\mathrm{Si}$ and no $\alpha$-seed $\left(\mathrm{AY}^{*}\right)$; (d) composition $\mathrm{Si}_{3} \mathrm{~N}_{4}-5 \% \mathrm{Y}_{2} \mathrm{O}_{3}-5 \% \mathrm{MgAl}_{2} \mathrm{O}_{4}$ with Elkem Si (MAY); (e) composition $\mathrm{Sị}_{3} \mathrm{~N}_{4}-6.4 \% \mathrm{Y}_{2} \mathrm{O}_{3}-3.2 \%$ $\mathrm{MgO}$ with Elkem Si (MY). 

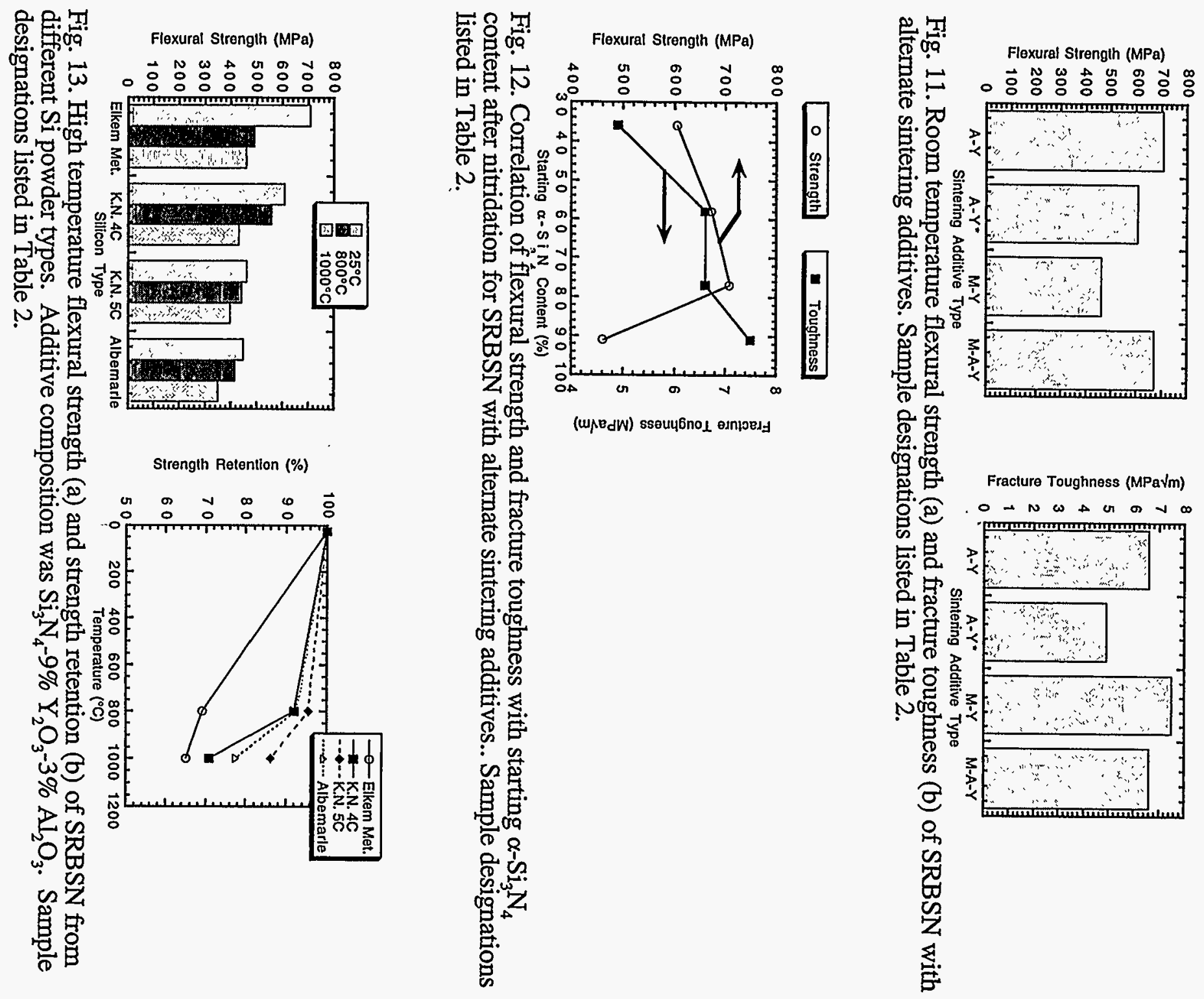

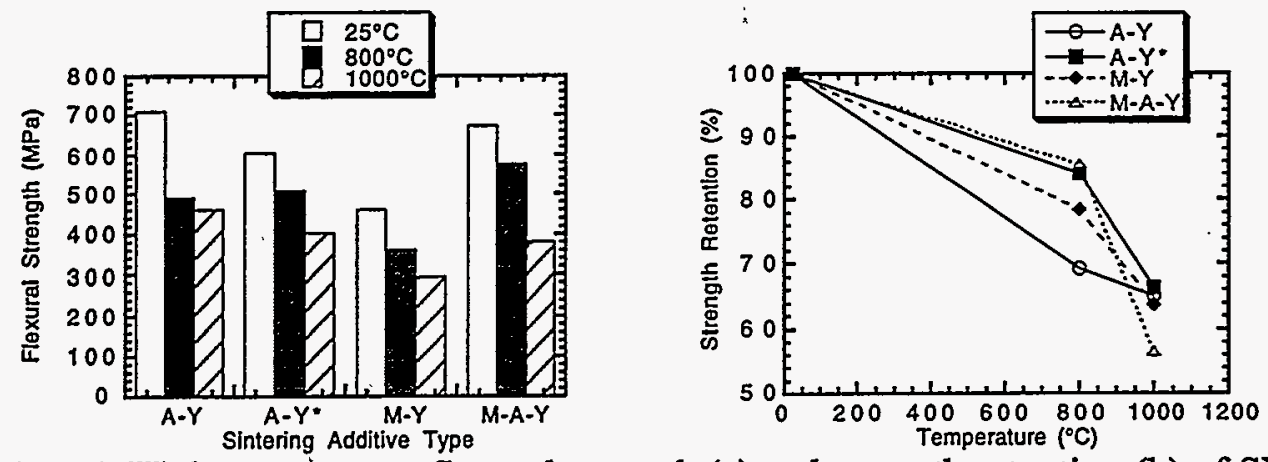

Fig. 14. High temperature flexural strength (a) and strength retention (b) of SRBSN with alternate sintering additives. Sample designations listed in Table 2.
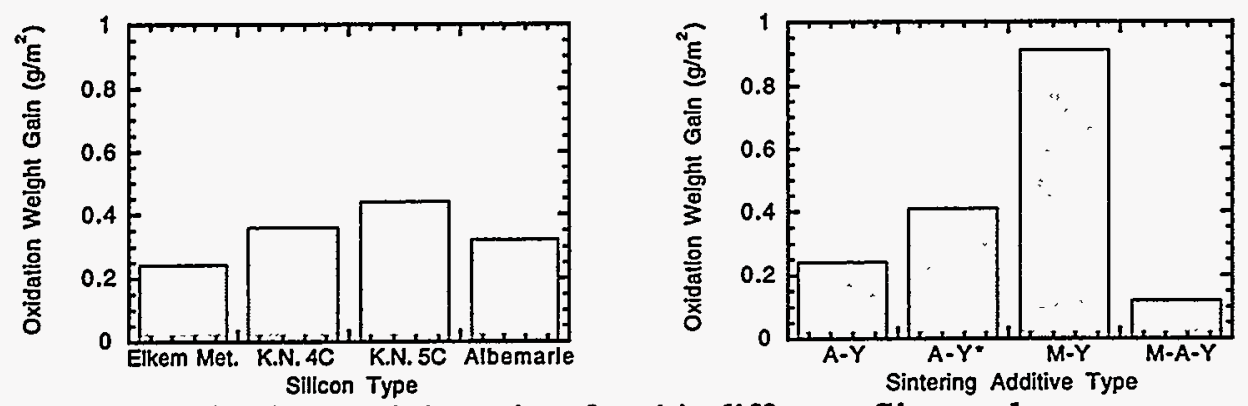

Fig. 15. Oxidation weight gains for (a) different $\mathrm{Si}$ powder types, and (b) alternate sintering additives. Oxidation at $1000^{\circ} \mathrm{C}$ for 100 hours in air. Sample designations listed in Table 2.
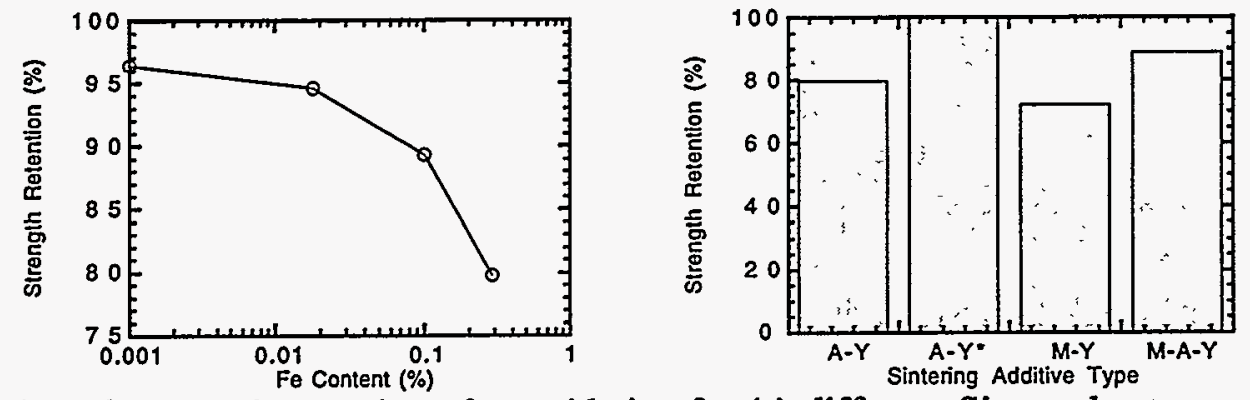

Fig. 16. Strength retention after oxidation for (a) different Si powder types correlated with starting $\mathrm{Fe}$ content, and (b) alternate sintering additives. Oxidation at $1000^{\circ} \mathrm{C}$ for 100 hours in air. Sample designations listed in Table 2. 


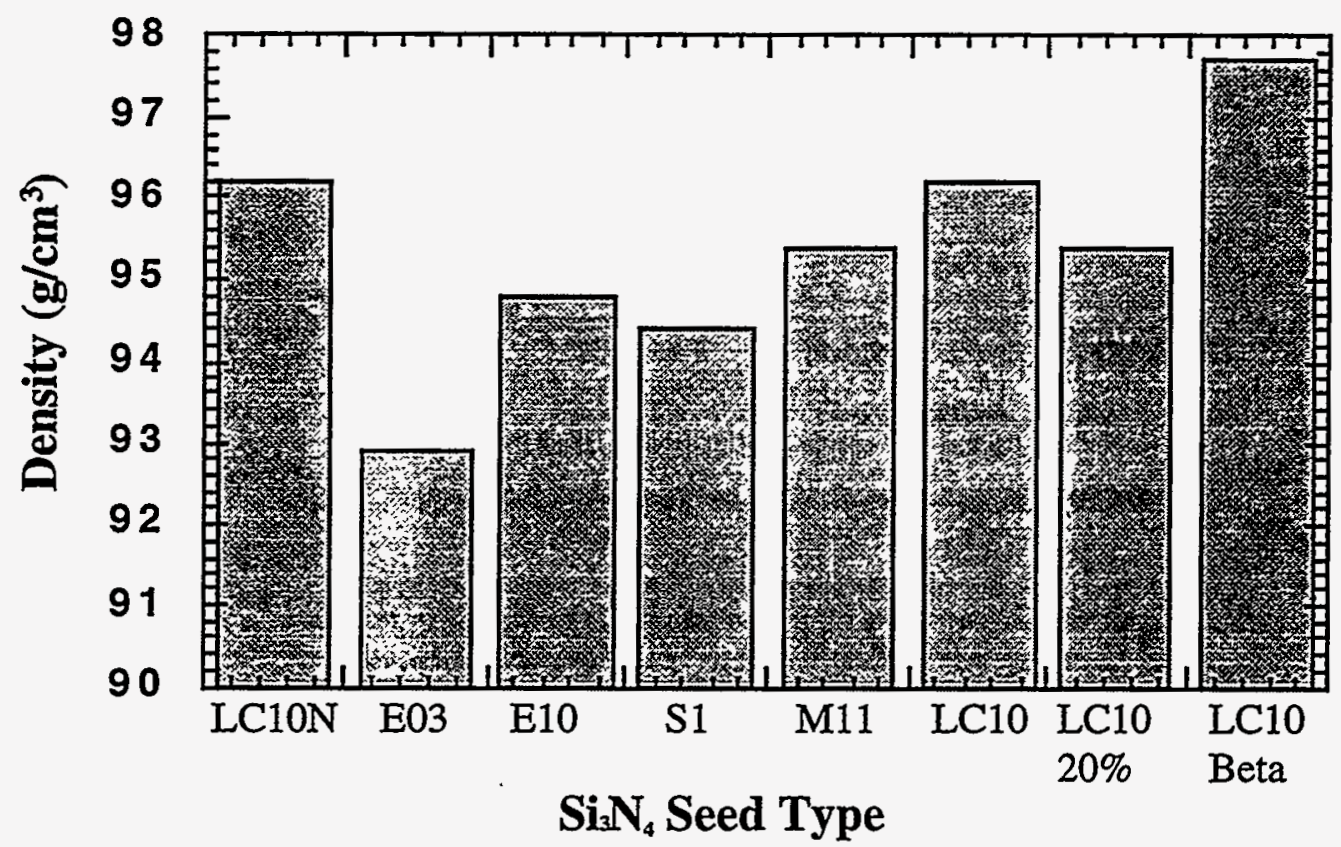

Figure 17. Density of $\mathrm{SRBSN}$ samples as related to $\mathrm{Si}_{3} \mathrm{~N}_{4}$ seed type

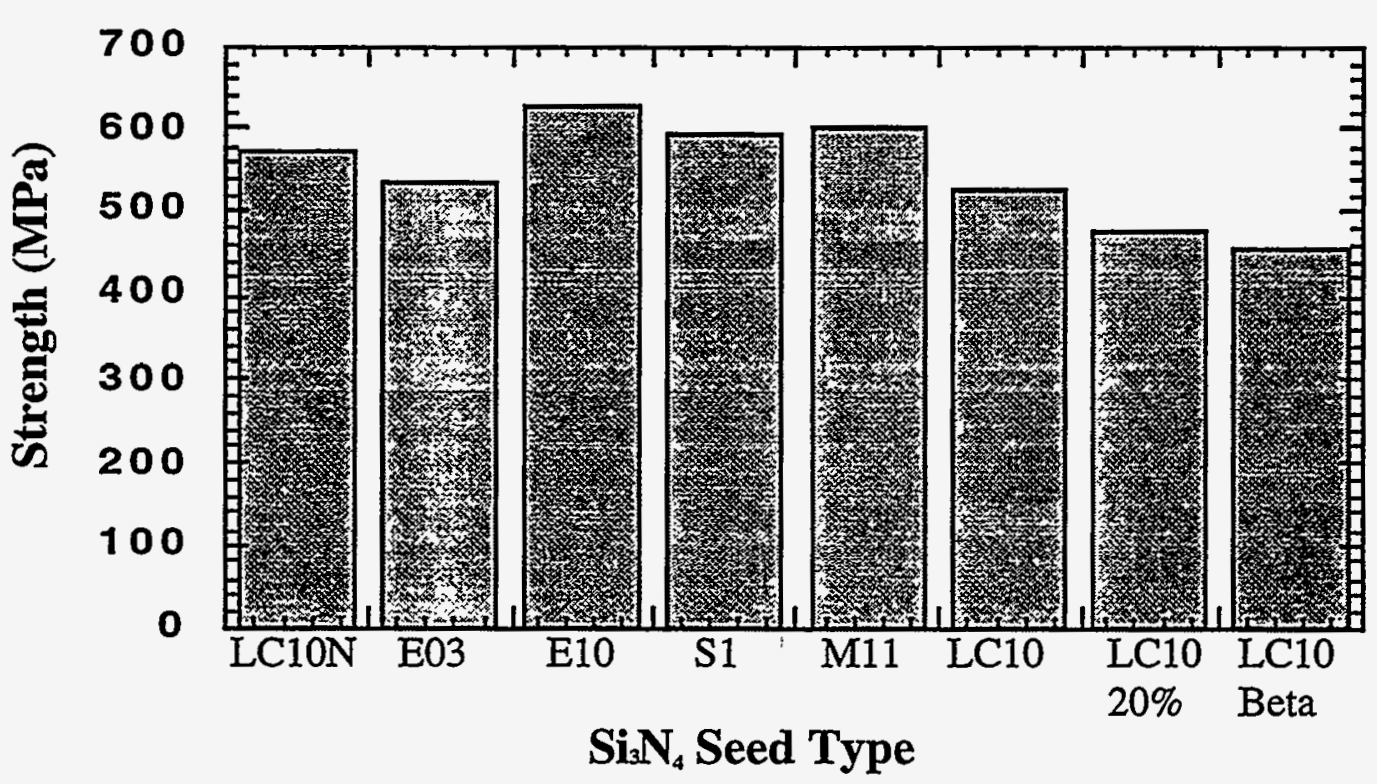

Figure 18. Strength of $\mathrm{SRBSN}$ samples as related to $\mathrm{SizN}_{4}$ seed type 


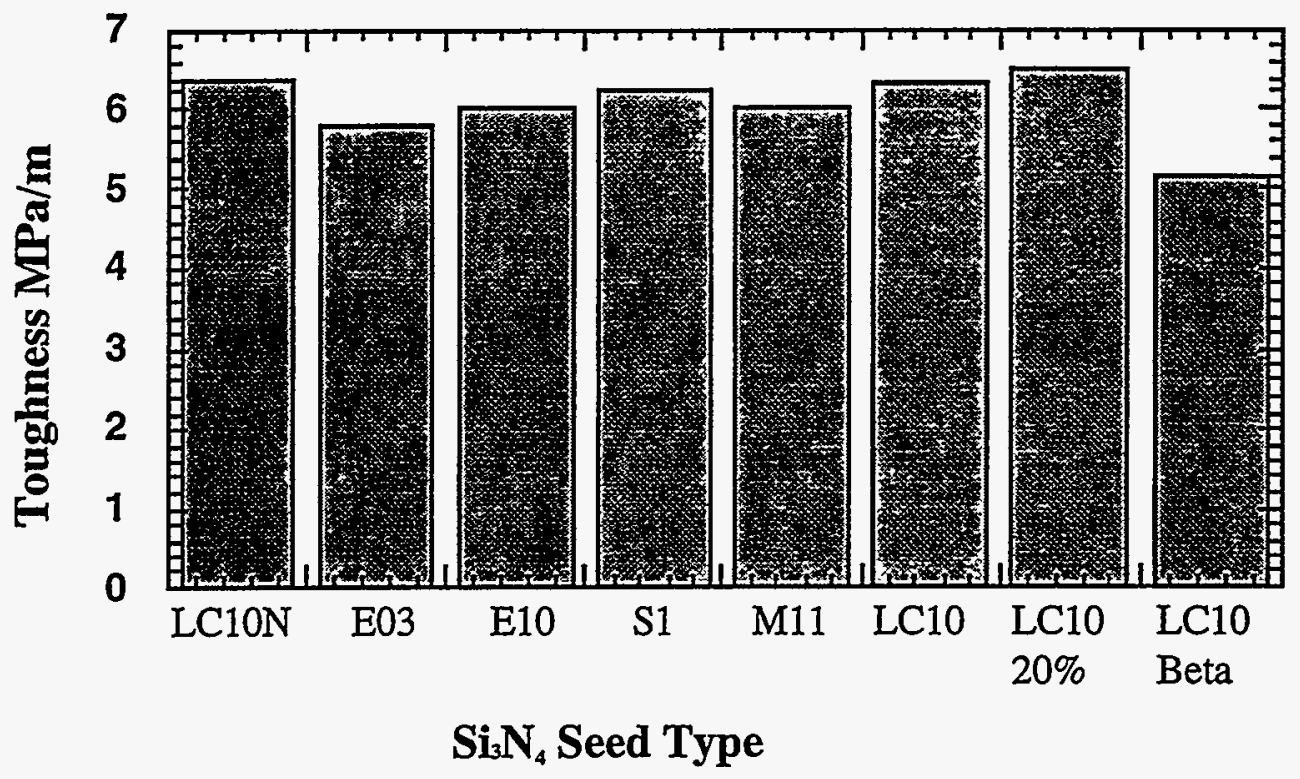

Figure 19. Toughness values for $\mathrm{SRBSN}$ materials having different $\mathrm{Si}_{3} \mathrm{~N}_{4}$ seed types.

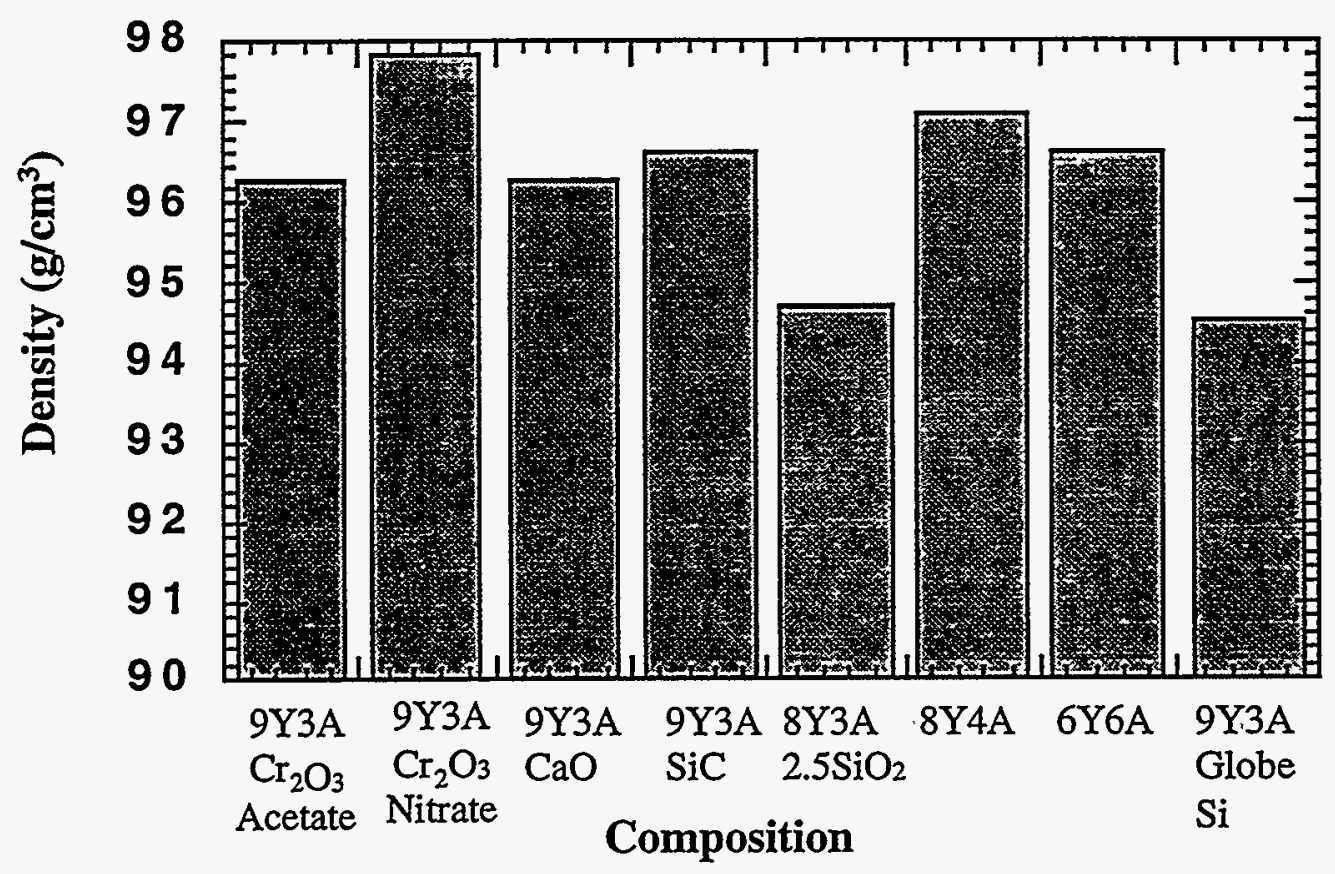

Figure 20. Density values for SRBSN materials made using different sintering aids. 


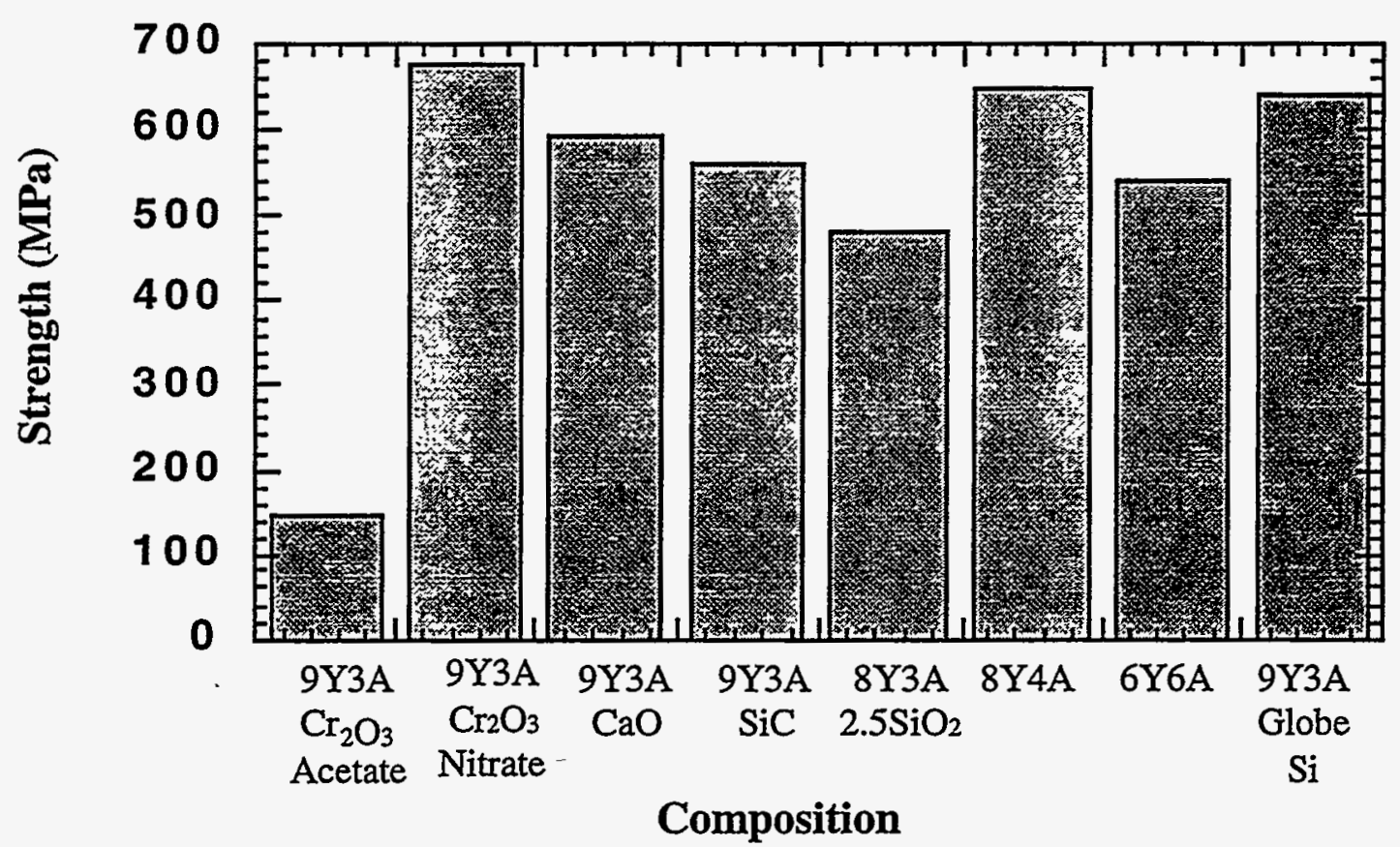

Figure 21. Strength values for SRBSN materials made using different sintering aids.

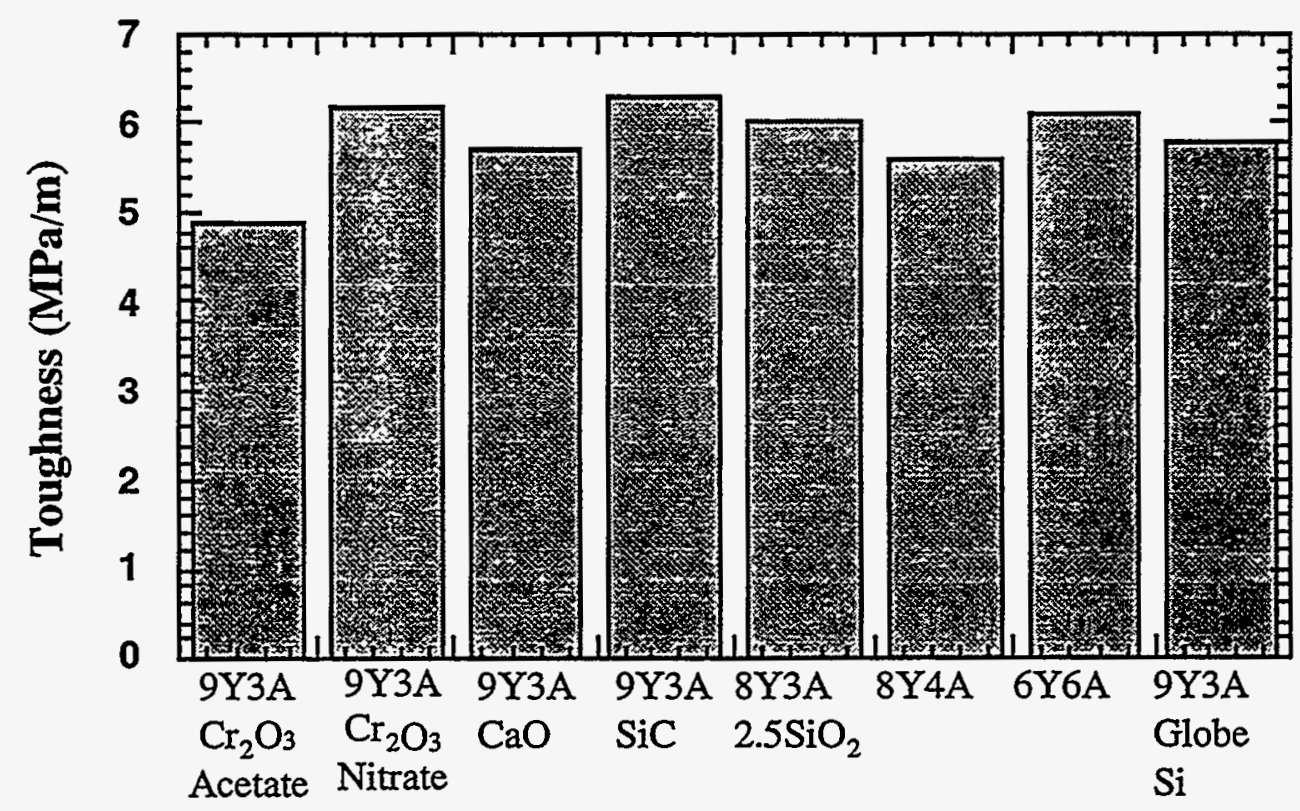

Composition

Figure 22. Toughness values for different SRBSN compositions. 
Cost Effective Sintering of Silicon Nitride Ceramics (SIU-C)-

D. E. Wittmer, Southern Illinois University, Carbondale, IL 62901

\section{Objective/Scope}

The purpose of this work is to investigate the potential of cost effective sintering of $\mathrm{Si}_{3} \mathrm{~N}_{4}$ through the development of continuous sintering techniques and the use of lower cost $\mathrm{Si}_{3} \mathrm{~N}_{4}$ powders and sintering aids.

\section{Technical Highlights}

\section{Task 1. Refine Economic Model and Design for Chosen Furnace Configuration}

This task was completed as reported in a previous semiannual report.

\section{Task 2. Continue evaluation of sintering parameters on properties of selected $\mathrm{Si}_{3} \mathrm{~N}_{4}$ compositions}

\section{Processing/Property Evaluations}

During this reporting period, four lots of the A4Y6 formulation using H. C. Starck M-11 powder (a gratis sample provided by $\mathrm{H}$. C. Starck) were continuously sintered in the Model 44-BF belt furnace. Sintering times were varied between 30 and $120 \mathrm{~min}$. at sintering temperatures of $1725^{\circ}$ to $1800^{\circ} \mathrm{C}$. Variables for these lots were milling media type (silicon nitride or YTZ) and dispersion technique (pH control or dispersant with $\mathrm{pH}$ control). The dispersant utilized was Rohm and Haas-Duramax D-3007 which is an acrylic copolymer with low sodium content.

The use of D-3007 appeared to marginally increase the green density from $63.5 \%$ to $65.0 \%$ of theoretical density. It is believed that this difference in green density did not appear to have a significant effect on the sintered density.

The sintered density for the A4Y 6 formulation, using the M-11 powder, was slightly lower than the $99 \%$ (and above) of theoretical density measured for the same formulation processed from Ube E-10 or Shin-Etsu powders. The sintering results along with the processing conditions are given in Table I. The major effect of processing appears to be the milling media type. Higher density was achieved using the YTZ media than for the silicon nitride (SN) media. The difference is not directly related to media weight loss during milling as both media do not wear significantly during the 2 hours of turbomilling. From these results the use of a combined $\mathrm{NH}_{4} \mathrm{OH} / \mathrm{D}-3007$ dispersant does not appear to improve the sintered density. However, the effect on the final microstructure has yet to be determined. Additional M-11 powder from another powder 
lot was requested and received from Starck to repeat some of these experiments. Additional materials were also received from Shin-Etsu for further evaluations.

\section{Industrial Collaboration/Affiliation}

\section{Eaton Corporation}

During this reporting period, Eaton Corporation and SIU-C signed a memorandum of understanding (MOU) to initiate a study of continuous sintering of their SRBSN. Continuous sintering of SRBSN was previously conducted in a MOU with Golden Technologies, Inc., which has since ceased their SRBSN operation in Golden, Co.

Under the MOU with Eaton Corporation, they will provide the SRBSN raw material and will nitride test specimens. About 8,000 to 10,000 test pieces (in the form of oversized MOR bars) will be continuously sintered at SIU-C, as part of a M.S. thesis by Steven Etherton. During this reporting period, Steven Etherton (graduate student at SIU) visited Eaton Corporation and pressed approximately 7,500 SRBSN test bars. About half of these bars have been nitrided by Eaton and delivered to SIU-C for continuous sintering.

Eleven continuous sintering runs, each containing 84 test bars, were made under the conditions outlined in Table II. These results show that the highest density $(3.34 \mathrm{~g} / \mathrm{cc}$ or $100 \%$ of the target density) was achieved at 1750 for $4 \mathrm{~h}$. The corresponding weight loss was 3.8\% and the 4-point flexural strength, in the as-sintered form, was $432+/-19$ $\mathrm{MPa}$ (for 10 test bars for each sintering condition). Ten bars from each sintering run have also been sent out for machining into type-B test bars for 4-point flexural strength and fracture toughness measurements. 42 test bars from each sintering trial have been returned to Eaton Corporation for their analyses.

Once the previous sintering runs have been fully characterized, additional sintering runs are planned which will determine the effect of furnace load on sinterability and properties. Approximately 6,000 test bars will be continuously sintered under "optimized" conditions and the data used to determine "efficiency" as a function of load. This task will most likely be completed during the summer and early fall.

There is also a possibility that microwave nitridation of the Eaton SRBSN will take place at ORNL by Terry Tiegs. It is anticipated that bars of the same Eaton SRBSN will be nitride by microwave and then sintered, both conventionally and continuously. This will allow for a comparison of both nitridation and sintering techniques.

\section{Norton Advanced Ceramics}

During this reporting period, several billets and valves were received from NAC as part of the Norton Advanced Ceramics ACMT contract. These materials were continuously sintered and returned to NAC. The results are reported by NAC as part of the ACMT contract. 


\section{Golden Technologies, Inc.}

During this reporting period, 12 continuous sintering runs were completed on Golden Technologies Company SRBSN before word was received that they were no longer going to pursue the ACMT contract for producing SRBSN clevice pins. Many of the specimens of SRBSN from GTC were sintered to full density under a range of continuous sintering conditions. Discussions with Jim Edler at Eaton Corporation encouraged collaboration with them to initiate continuous sintering of SRBSN made by Eaton Corporation, as previously discussed.

\section{Allied Signal, Inc.}

No additional samples have been received from Allied Signal, Inc. (ASI) for continuous sintering, during this reporting period. Information from ASI indicated that densities for previously continuous sintered GS-44 (large) billets were slightly lower than their target density. ASI indicated that they would be providing more samples of smaller dimensions for additional work.

\section{Task 3. Continue Evaluation of Low Cost $\mathrm{Si}_{3} \mathrm{~N}_{4}$ Powder}

As mentioned in Task 2, additional M-11 and Shin-Etsu powders from other powder lots have been received. These powders will be processed during the next reporting period. The evaluation of milling media type and milling time will continue for the A4Y6 and A2Y8 formulations.

Some of the Dow Chemical Co. powder is being analyzed to try to determine a plausible explanation for why the billets of A2Y6 and A4Y6 formulations show decreased density with increased sintering time and/or temperature, while the A2Y8 formulation appears now to be sintering "normally". Two batches of the Dow powder were heat treated in flowing $\mathrm{N}_{2}$ at $1775^{\circ} \mathrm{C}$ for $2 \mathrm{~h}$ and $1825^{\circ} \mathrm{C}$ for $2 \mathrm{~h}$ in an attempt to nucleate some $\beta$ phase in the original powder. This was done in order to try to control growth of the $\beta$ phase during sintering of the various formulations being investigated. $\mathrm{XRD}$ confirmed that there did not appear to be any change in the phases after heat treatment at $1775^{\circ} \mathrm{C}$. However, heat treatment at $1825^{\circ} \mathrm{C}$ did produce some $\beta$ phase and significant decomposition of the powder. During processing of the A4Y6 composition from this powder, the free $\mathrm{Si}$ in the heat treated powder caused problems during casting. Additional heat treatment is planned for lower temperature and longer time to eliminate the decomposition and formation of free $\mathrm{Si}$.

In addition, some preformed $\beta$ seed (Ube Industries) was added to the as-received Dow powder to attempt to provide a source of $\beta$ at the onset of sintering. Following our standard turbomilling/forming procedures, disks were continuously sintered in a comparative time/temperature matrix with a control composition processed with Ube powder. Seeding with this type of $\beta$ seed did not appear to have any measurable effect on 
the sintering behavior. It is believed that the seed was too fine and was dissolved in the liquid phase during the initial stage of sintering; therefore, it was not an effective nucleating agent. Larger $\beta$ seed will be formed in our laboratory and evaluated for its effectiveness as a nucleator.

Also during this reporting period, a small sample of Latvian plasma derived powder was received and sintered in the form of $2.5 \mathrm{~cm}$ diameter disks. This powder is manufactured with the sintering aids included during the plasma spraying process. The sinterability was excellent as judged by limited continuous sintering. Additional disks will be sintered in a large enough size to measure strength and fracture toughness. The powder cost is predicted to be about the same as $U$ Ube $\mathrm{Si}_{3} \mathrm{~N}_{4}$ without the sintering aids added. This could provide considerable cost advantage, since the cost of processing to disperse the sintering aids would be eliminated. The actual cost and availability are presently being determined. A larger lot of this material will be ordered for additional evaluation when the information is provided by the supplier.

\section{Task 4. Design and Construct Prototype Belt Furnace}

This task has been completed. Additional funding has been requested to continue evaluation of the belt furnace through sintering evaluations, using materials provided by industrial partners/collaborators. This work is now being performed in Task 2 , but will be the basis for Task 5 if additional funding is approved.

\section{Status of Prototype Belt Furnace}

The Model 44-BF belt furnace (with the tungsten hot zone installed) has been in operation for over 380 hours of high-temperature operation (66 sintering runs) without any major problems with the furnace.

\section{Status of Milestones}

1. Refine Economic Model and Design for Chosen

Completed

Furnace Configuration

2. Continue Evaluation of Sintering Parameters

On Schedule

on Properties of Selected $\mathrm{Si}_{3} \mathrm{~N}_{4}$ Compositions

Continuing

3. Continue Evaluation of Low Cost $\mathrm{Si}_{3} \mathrm{~N}_{4}$ Powders

On Schedule

Continuing

4. Design and construct prototype belt furnace

Completed 


\section{Communications/Visits/Travel}

D. E. Wittmer received approved of Memorandum of Understanding from GTC.

Jim Stephan from GTC visited SIU to observe continuous sintering of SRBSN.

D. E. Wittmer received FAX and phone call from Jim Stephan at GTC to inform me that GTC was no longer going to pursue Ceramic Technology at the Golden, CO facility.

D. E. Wittmer and S. Etherton traveled to Cocoa Beach, FL to present paper.

D. E. Wittmer and J. Edler, Eaton Corp. drafted and received approved of Memorandum of Understanding to continue SRBSN work using Eaton SRBSN.

D. E. Wittmer and S. Etherton traveled to Eaton Corp. to meet with J. Edler.

\section{Problems Encountered}

\section{$\underline{\text { Publications }}$}

D. E. Wittmer, B. E. Rodely, V. A. Knapp, S. P. Etherton, and C.W. Miller, Jr., "Comparison of Properties for Formulations Prepared From Two Silicon Nitride Powders," Ceramic Engineering and Science Proceedings, (To be published in 1996.)

\section{Presentations}

D. E. Wittmer", B. E. Rodely, V. A. Knapp, and S. P. Etherton, Southern Illinois University, Carbondale, $\mathbb{I L}$ and C. W. Miller, Jr., Centorr/Vacuum Industries, Inc., Nashua, NH, "Comparison of Properties for Formulations Prepared From Two Silicon Nitride Powders," Presented at the 1996 Conference on Composites and Advanced Materials, Cocoa Beach, FL, January 7-11, 1996. 
Table I. Results for A4Y6 formulation using Starck M-11 Silicon Nitride Powder

\begin{tabular}{|c|c|c|c|c|c|c|c|c|c|}
\hline \multicolumn{2}{|c|}{$\begin{array}{c}\text { Sintering } \\
\text { Conditions }\end{array}$} & \multicolumn{3}{c|}{ M1 } & \multicolumn{2}{c|}{ M2 } & \multicolumn{2}{c|}{ M3 } \\
\hline $\begin{array}{c}\text { Temp. } \\
\left({ }^{\circ} \mathrm{C}\right)\end{array}$ & $\begin{array}{c}\text { Time } \\
(\mathrm{min})\end{array}$ & $\begin{array}{c}\text { \% of } \\
\text { TD }\end{array}$ & $\begin{array}{c}\text { \% Wt. } \\
\text { Loss }\end{array}$ & $\begin{array}{c}\text { \% of } \\
\text { TD }\end{array}$ & $\begin{array}{c}\text { \% Wt. } \\
\text { Loss }\end{array}$ & $\begin{array}{c}\text { \% of } \\
\text { TD }\end{array}$ & $\begin{array}{c}\text { \% Wt. } \\
\text { Loss }\end{array}$ & $\begin{array}{c}\text { \% of } \\
\text { TD }\end{array}$ & $\begin{array}{c}\% \text { Wt. } \\
\text { Loss }\end{array}$ \\
\hline \multirow{3}{*}{1725} & 60 & 95.3 & 0.95 & 92.5 & 1.01 & 96.0 & 1.25 & 95.7 & 1.14 \\
\cline { 2 - 11 } & 90 & 96.4 & 1.16 & 92.2 & 1.67 & 96.7 & 1.25 & 96.6 & 1.17 \\
\cline { 2 - 11 } & 120 & 96.9 & 1.11 & 94.0 & 1.22 & 97.3 & 1.42 & 97.1 & 1.29 \\
\hline \multirow{3}{*}{1750} & 60 & 98.2 & 0.99 & 95.8 & 1.05 & 98.4 & 1.83 & 98.0 & 1.13 \\
\cline { 2 - 11 } & 90 & 98.0 & 1.17 & 95.0 & 1.14 & 98.1 & 1.51 & 98.1 & 1.35 \\
\cline { 2 - 11 } & 120 & 97.8 & 1.29 & 95.0 & 1.48 & 98.1 & 1.49 & 97.9 & 1.25 \\
\hline \multirow{3}{*}{1775} & 30 & 95.1 & 0.74 & 91.8 & 0.69 & 95.8 & 1.17 & 95.6 & 0.99 \\
\cline { 2 - 10 } & 60 & 97.0 & 1.15 & 93.8 & 1.24 & 97.1 & 1.53 & 97.2 & 1.18 \\
\cline { 2 - 10 } & 120 & 98.8 & 1.50 & 96.4 & 1.01 & 98.8 & 1.88 & 98.7 & 1.56 \\
\hline 1800 & 30 & 95.4 & 0.84 & 92.2 & 0.83 & -- & -- & -- & - \\
\hline
\end{tabular}

M1 - 2 h turbomilling, $\mathrm{YTZ}$ media, $\mathrm{NH}_{4} \mathrm{OH}$ dispersant $\mathrm{M} 2$ - $2 \mathrm{~h}$ turbomilling, $\mathrm{SN}$ media, $\mathrm{NH}_{4} \mathrm{OH}$ dispersant

M3 - $2 \mathrm{~h}$ turbomilling, YTZ media, $\mathrm{NH}_{4} \mathrm{OH}$ and $\mathrm{D}-3007$ dispersant

M4 - $2 \mathrm{~h}$ turbomilling, YTZ media, $\mathrm{NH}_{4} \mathrm{OH}$ and D-3007 dispersant (repeat of $\mathrm{M} 3$ for control) 
Table II. Continuous Sintering Results for Initial Time/Temperature Matrix for Eaton Corporation SRBSN

\begin{tabular}{|c|c|c|c|c|c|c|c|c|c|c|c|c|}
\hline \multirow{3}{*}{$\begin{array}{l}\text { Time } \\
\text { (min) }\end{array}$} & \multicolumn{12}{|c|}{ Sintering Temperature } \\
\hline & \multicolumn{3}{|c|}{$1725^{\circ} \mathrm{C}$} & \multicolumn{3}{|c|}{$1750^{\circ} \mathrm{C}$} & \multicolumn{3}{|c|}{$1775^{\circ} \mathrm{C}$} & \multicolumn{3}{|c|}{$1800^{\circ} \mathrm{C}$} \\
\hline & $\begin{array}{c}\text { Bulk } \\
\rho \\
(\mathrm{g} / \mathrm{cc})\end{array}$ & $\begin{array}{l}\text { Wt. } \\
\text { Loss } \\
(\%)\end{array}$ & $\begin{array}{c}\text { 4-Pt. } \\
\text { Flex,* } \\
(\mathrm{MPa})\end{array}$ & $\begin{array}{c}\text { Bulk } \\
\rho \\
(\mathrm{g} / \mathrm{cc})\end{array}$ & $\begin{array}{l}\text { Wt. } \\
\text { Loss } \\
(\%)\end{array}$ & $\begin{array}{c}\text { 4-Pt. } \\
\text { Flex.* } \\
(\mathrm{MPa})\end{array}$ & $\begin{array}{c}\text { Bulk } \\
\rho \\
(\mathrm{g} / \mathrm{cc})\end{array}$ & $\begin{array}{l}\text { Wt. } \\
\text { Loss } \\
(\%)\end{array}$ & $\begin{array}{l}\text { 4-Pt. } \\
\text { Flex.* } \\
(\mathrm{MPa})\end{array}$ & $\begin{array}{c}\text { Bulk } \\
\rho \\
(\mathrm{g} / \mathrm{cc})\end{array}$ & $\begin{array}{l}\text { Wt. } \\
\text { Loss } \\
(\%)\end{array}$ & $\begin{array}{c}\text { 4-Pt. } \\
\text { Flex.* } \\
(\mathrm{MPa})\end{array}$ \\
\hline 60 & $-\cdots$ & --- & $-\cdots$ & 3.11 & 2.16 & $\begin{array}{c}424+1- \\
47\end{array}$ & 3.19 & 3.36 & $\begin{array}{c}420+/- \\
53\end{array}$ & 3.26 & 5.25 & $\begin{array}{c}380+/- \\
44\end{array}$ \\
\hline 90 & 3.03 & 1.77 & $\begin{array}{c}392+/- \\
54\end{array}$ & 3.22 & 2.5 & $\begin{array}{c}456+/- \\
34\end{array}$ & 3.29 & 3.84 & $\begin{array}{c}485+/- \\
40\end{array}$ & $\cdots$ & --- & --- \\
\hline 120 & 3.18 & 2.35 & $\begin{array}{c}380+1- \\
29\end{array}$ & 3.25 & 2.67 & $\begin{array}{c}450+/- \\
28\end{array}$ & 3.30 & 4.01 & $\begin{array}{c}435+/- \\
56\end{array}$ & $-\cdots$ & -- & --- \\
\hline 240 & 3.29 & 2.97 & $\begin{array}{c}440+1- \\
24\end{array}$ & 3.34 & 3.83 & $\begin{array}{c}432+/- \\
19\end{array}$ & --- & $-\cdots$ & --- & $\cdots$ & -- & $\cdots$ \\
\hline
\end{tabular}

* 4-point flexural strengths are for the as-sintered bars 


\title{
1.1.4 Processing of Monolithics
}

W.B.S. ELEMENT 1.1.4.2

IMPROVED PROCESSING

\author{
S. D. Nunn, O. O. Omatete, and C. A. Walls \\ Oak Ridge National Laboratory
}

\section{Objective/Scope}

To develop gelcasting as an advanced near-net-shape ceramic forming process. This program will address the technical aspects of the gelcasting process, evaluation of the applicability of gelcasting to a wide range of commercially available ceramic powders, and identification and assessment of manufacturing concerns and issues as they relate to commercialization of gelcasting. The emphasis of the program will be on gelcasting of silicon nitride ceramics and developing industry acceptance of the process. Issues of practicality and ES\&H will be addressed in the development of the program. The technical feasibility of inprocess and NDE testing methods for improving quality and reliability of gelcast ceramics will also be addressed.

\section{Technical Highlights}

I. Defect-free Gelcasting of Ceramic Components (S. D. Nunn)

A new task has been initiated to demonstrate the ability to gelcast a quantity of components which are essentially free of defects. The parts will be fabricated using a silicon nitride composition. The configuration of the component is yet to be determined, but must allow non-destructive evaluation (NDE) of the parts in both the green state and after firing.

Tests to determine the best silicon nitride composition have been completed. A composition has been found that will gelcast readily and still allow parts to sinter to full density. Initial tests are now undenway to determine the repeatability of the process.

II. Drying of Gelcast Green Bodies (O. O. Omatete)

Thirteen alumina plates which were dried under three different drying have been processed through sintering. Table 1 shows the results. All $1 / 2^{\prime \prime}$ thick plates survived binder burnout whereas all 1" plates cracked into several pieces. There was also a 2" plate not shown in the tables that cracked during binder burnout. This indicated that plates thicker than 1" cannot be dried successfully using any of the three drying schedules.

Only one of the six $1 / 2$ " plates did not survive sintering, probably because condensate dropped on it as it dried. It cracked into two pieces only. The sintered parts attained fairly high densities ( 97.7 to $99.7 \%$ of theoretical). After sintering, a large flaw that looked like water drop showed up on plate \#1. Plates \#1, \#9, and \#11 were polished and sent for non-destructive evaluation (NDE), after which their strengths will be measured by fourpoint bending.

The complete results of the NDE of the three 1/2" plates were received. The NDE was done by ultrasonic testing in three modes: flaw test, back-surface test, and surface-wave test. The flaw test in which the ultrasonic waves penetrated the samples indicated that the range of flaws in the good samples, \#9 and \#11 was $100-200 \mu \mathrm{m}$. The flaw test also showed the large flaw from water drop that condensed on sample \#1. In addition, the flaw test shows that the flaws were fairly uniformly distributed over the samples even for the sample \#1 with its large water drop flaw. Some of the results from NDE are shown in Table 
2. The Young's and shear moduli, and the Poisson's ratio are similar to values reported in the literature. These surface tests show the polish lines and the water drop mark on the surface of the plates. These results indicate that the NDE is useful for both qualitative and quantitative evaluation of the gelcast samples.

\section{Table 1: Detailed Data on Dried Alumina Plates}

\begin{tabular}{|c|c|c|c|c|c|c|c|}
\hline $\begin{array}{l}\text { Run } \\
\#\end{array}$ & $\begin{array}{l}\text { Drying } \\
\text { Sched. }\end{array}$ & Size of plate & Premix & $\begin{array}{l}\% \text { of } \mathrm{H} 20 \\
\text { Lost }\end{array}$ & $\begin{array}{l}\text { Survived } \\
\text { Burnout }\end{array}$ & $\begin{array}{l}\text { Survived } \\
\text { Firing }\end{array}$ & $\begin{array}{l}\% \mathrm{~T} . \\
\text { Density }\end{array}$ \\
\hline 1 & 1 & $.5^{\prime \prime} \times 4^{\prime \prime} \times 4^{\prime \prime}$ & MAM/MBAM & 98.0 & $Y$ & Y & 97.7 \\
\hline 3 & $\mathbf{1}$ & $.5^{\prime \prime} \times 4^{\prime \prime} \times 4^{\prime \prime}$ & MAM/MBAM & 97.3 & $Y$ & $Y$ & 97.8 \\
\hline 5 & 1 & $.5^{\prime \prime} \times 4^{\prime \prime} \times 4^{\prime \prime}$ & MAM/PEG & 94.1 & $Y$ & $Y$ & 97.7 \\
\hline 6 & I & $.5^{\prime \prime} \times 4^{\prime \prime} \times 4^{\prime \prime}$ & MAM/PEG & 82.5-cond. & $Y$ & $N$ & 99.7 \\
\hline 7 & $\mathbf{I}$ & $.5^{\prime \prime} \times 4^{\prime \prime} \times 4^{\prime \prime}$ & MAM/MBAM & 99.0 & $Y$ & $Y$ & 98.4 \\
\hline 9 & |II & $.5^{\prime \prime} \times 4^{\prime \prime} \times 4^{\prime \prime}$ & MAM/PEG & 91.4 & $Y$ & $Y$ & 99.7 \\
\hline 11 & |II & $.5^{\prime \prime} \times 4^{\prime \prime} \times 4^{\prime \prime}$ & MAM/MBAM & 98.8 & $Y$ & $Y$ & 99.6 \\
\hline 2 & 1 & $1^{\prime \prime} \times 4^{\prime \prime} \times 4^{\prime \prime}$ & MAM/MBAM & 101.4 & N & - & - \\
\hline 8 & $\mathbf{I}$ & $1^{\prime \prime} \times 4^{\prime \prime} \times 4^{\prime \prime}$ & MAM/MBAM & 98.2 & $N$ & - & - \\
\hline 10 & $i$ & $1^{\prime \prime} \times 4^{\prime \prime} \times 4^{\prime \prime}$ & MAM/PEG & 71.3 & $N$ & - & - \\
\hline 12 & III & $1^{\prime \prime} \times 4^{\prime \prime} \times 4^{\prime \prime}$ & MAM/MBAM & 84.9 & $N$ & - & - \\
\hline 13 & 1 & $1^{\prime \prime} \times 4^{\prime \prime} \times 4^{\prime \prime}$ & MAM/PEG & 74.8-crack & $N$ & - & - \\
\hline
\end{tabular}

Table 2: NDE Measurements on Alumina Plates

\begin{tabular}{|l|l|l|l|}
\hline $\begin{array}{l}\text { Plate } \\
\text { Number }\end{array}$ & $\begin{array}{l}\text { (E) Young's } \\
\text { Modulus, GPa }\end{array}$ & $\begin{array}{l}\text { (G) Shear } \\
\text { Modulus, GPa }\end{array}$ & $\begin{array}{l}(n) \text { Poisson's } \\
\text { Ratio }\end{array}$ \\
\hline 1 & 380 & 154 & 0.232 \\
9 & 403 & 163 & 0.236 \\
11 & 401 & 162 & 0.238 \\
\hline
\end{tabular}

Because no 1" plate has survived binder burn-out, several 1" plates were gelcast and dried under various conditions as outlined in the first experimental design $L_{8}\left(2^{7}\right)$ below. Again, during binder burn-out, they all cracked or-shattered. Two new 1" plates were dried in the humidity chamber and at ambient, respectively. These were left in an oven set at $50^{\circ} \mathrm{C}$ for about three weeks to ensure that all the moisture was driven off. These plates were debindered and both still cracked into several pieces. Thus, the cracking during binder burnout was not due to the moisture left in the plates after drying.

Two new sets of drying experiments have been designed. The first is an $L_{8}\left(2^{7}\right)$ in which there are six variables at two levels. All the samples are $1^{n}$ thick and the variables are: monomer system, monomer ratio, ceramic powder, solids loading, gelling temperature, and plasticizer content. The three drying conditions: ambient, room temperature with controlled humidity, and high temperature with controlled humidity in the chamber, serve as noise in this design. The other design is an $L_{9}\left(3^{4}\right)$ which looks at three levels each of thickness $\left(0.5^{\prime \prime}, 1^{n}\right.$ 
and $\left.2^{\prime \prime}\right)$, temperature $\left(25,35\right.$ and $\left.45^{\circ} \mathrm{C}\right)$, and $\%$ relative humidity $(75,85$, and 95$)$. Drying test will be performed based on both designs.

\section{Green Machining of Gelcast Ceramics (S. D. Nunn, C. A. Walls)}

Green machining of gelcast ceramics is being investigated as a simple method for rapid prototyping of ceramic components for testing and evaluation. A computer controlled, 3-axis milling machine was acquired for use in this study. A CAD system on the computer is used to define the component geometry and the file is converted to machine control code to drive the milling machine and produce the part which is then fired to form the finished component. New geicasting chemical systems are being examined to identify the system having the best machining characteristics.

Examination of a variety of monomer/crosslinker formulations commonly used for near-netshape fabrication with alumina were studied as our first iteration using 10 different slurry formulations. The methacrylamide monomer system and an alternate low toxicity monomer were evaluated against several molecular weights of polyethylene glycol(X)dimethacrylate. Slurry formulations processed with $\mathrm{N}, \mathrm{N}^{\prime}$-methylenebisacrylamide in earlier work led us to concentrate on the polyethylene glycol(X)dimethacrylate as the crosslinker of choice for this part of the study due to superior machining performance in alumina ceramics.

The study was expanded to include chemical additives in cast 11 through 14 formulations. These additives were evaluated to determine their effect on machining characteristics of earlier formulations. Silicon nitride trails began in response to early successes in alumina gelcast ceramics. These early successes were due to improved machining performance with the introduction of chemical additives to the gelcasting formulations. All three of the chemical additives show promise and none has been eliminated from study. Trials 15 through 16 and 18 were run to evaluate silicon nitride formulations With trial 17 run to evaluate alumina. Trial 16 produced a 4" $X 4$ " $\times 1$ " silicon nitride plate that was successfully machined and sintered.

At present we are developing procedures to measure the effects of the varied chemistries on the machining formulations and Taguchi studies including formulations $1,3,19$ and 20 are planned to help isolate factors of greatest significance to machining performance. We plan to expand the materials studies to include silicon carbide, ferrites, steels, and super alloys. Machining additives will have to be tailored to each material composition in the same way that monomer/crosslinker systems have been developed for each material.

A full chart of the formulations examined to date is shown in Table 3. The silicon nitride formulations have been composed of UBE-SN-E03 or E05 powder with yttrium oxide and aluminum oxide as the sintering aides.

Mounting hardware has been received for assembling the horizontal spindle on the 3-axis milling machine to machine axially symmetric components in a manner similar to turning a part on a lathe. A new horizontal spindle has been assessed and will require more mounting hardware to achieve precise dimensions. Preliminary efforts have focused on making parts for molds. The ability to machine gelcast material in this manner has also been demonstrated. Future work will include determining appropriate tools and cutting procedures for machining ceramics with the horizontal spindle.

Evaluation of file conversion software for use on the 3-axis milling machine indicates that preparing machine control code from files which were originally prepared using other CAD software or from scanned engineering drawings is easily accomplished. The ornl logo has been scanned and implemented in a demonstration piece. Other demonstrations are now being implemented. 
Table 3. Gelcassting formulations for machining trials.

\begin{tabular}{|c|c|c|c|c|c|c|}
\hline & Formu & ions for $M$ & Tachining Trials & & & \\
\hline Cast \# & $\%$ sol. & Monomer & Crosslinker & Ratio M/C & $\begin{array}{l}\% \text { Machining } \\
\text { Additive }\end{array}$ & Ceramic \\
\hline 1 & 15 & MAM & PEG(1000)DMA & 3 to 1 & no & Alumina \\
\hline 2 & 15 & MAM & PEG(1000)DMA & 2 to 1 & no & Alumina \\
\hline 3 & 20 & \#2 & PEG(1000)DMA & 3 to 1 & no & Alumina \\
\hline 4 & 20 & $\# 2$ & PEG(1000)DMA & 2 to 1 & no & Alumina \\
\hline 5 & 15 & MAM & PEG (400)DMA & 3 to 1 & no & Alumina \\
\hline 6 & 15 & MAM & PEG (600)DMA & 3 to 1 & no & Alumina \\
\hline 7 & 20 & $\# 2$ & PEG(400)DMA & 3 to 1 & no & Alumina \\
\hline 8 & 20 & $\# 2$ & PEG(600)DMA & 2 to 1 & no & Alumina \\
\hline 9 & 15 & MAM/NVP & PEG(1000)DMA & 1.5 to 1.5 to 1 & no & Alumina \\
\hline 10 & 15 & MAM/NVP & PEG(1000)DMA & 1.5 to 1.5 to 1 & no & Alumina \\
\hline 11 & 15 & MAM & PEG(1000)DMA & 3 to 1 & $10 \%$ of \#1 & Alumina \\
\hline 12 & 15 & MAM & PEG(1000)DMA & 3 to 1 & $20 \%$ of $\# 1$ & Alumina \\
\hline 13 & 15 & MAM & PEG(1000)DMA & 3 to 1 & $20 \%$ of \#2 & Alumina \\
\hline 14 & 15 & MAM & PEG(1000)DMA & 3 to 1 & $20 \%$ of \#3 & Alumina \\
\hline 15 & 15 & MAM & PEG(1000)DMA & 3 to 1 & $20 \%$ of $\# 3$ & UBE E03 \\
\hline 16 & 15 & MAM & PEG(1000)DMA & 3 to 1 & $20 \%$ of $\# 3$ & UBE E05 \\
\hline 16-TiC & 15 & MAM & PEG(1000)DMA & 3 to 1 & $20 \%$ of $\# 3$ & UBE E05 \\
\hline 16-FE & 15 & MAM & PEG(1000)DMA & 3 to 1 & $20 \%$ of $\# 3$ & UBE E05 \\
\hline 17 & 15 & MAM & PEG(1000)DMA & 3 to 1 & $15 \%$ of $\# 3$ & Alumina \\
\hline 18 & 20 & $\# 2$ & PEG(1000)DMA & 3 to 1 & $17.5 \%$ of \#3 & UBE E05 \\
\hline 19 & 20 & MAM & PEG(1000)DMA & 3 to 1 & no & Alumina \\
\hline 20 & 15 & \#2 & PEG(1000)DMA & 3 to 1 & no & Alumina \\
\hline
\end{tabular}

Dispersants: Alumina $=0.5 \%$ Darvan $821-A$, Silicon Nitride $=0.5 \%$ Dolapix PC-33 
IV. Mold Surface and Gelcasting Slurry Chemical Interactions (O. O. Omatete and F. C. Montgomery)

A new task has been initiated to examine chemical interactions between some mold surfaces and gelcasting slurries which can result in incomplete gelation of the slurry near the mold wall. Understanding these interactions may provide an expanded range of usable mold materials and substantially improve the control of the surface quality of gelcast components.

Gelation is being studied in two types of molds: (1) glass and (2) RTV silicone. Glass is good mold material for ceramic gelcasting since methacrylamide gels formed in glass molds are fully expanded and completely fill the interior of the mold. RTV silicone, on the other hand, is a poor mold material because the gels cast against RTV are significantly smaller in diameter than the mold and the cast part has a thin fluid of ceramic on its surface. For these initial studies, the weight of material rinsed from the gel surface is being used as an measure of the extent of polymerization.

Table 4 compares the weights of residue in the rinses obtained after a 40 min polymerization at 60 ${ }^{\circ} \mathrm{C}$ in the different molds. In Table 4, the weight of material which was rinsed from the gel surface has been divided by the initial combined weight of MAM and MBAM in the polymerizing solution and then converted to percent. The amount of material which was soluble in the rinses ranged from 2 to $10 \%$ of the initial weight of the monomers. Furthermore, in all tests, the final dry weight was significantly less than the weight obtained after about $230 \mathrm{~min}$ of drying. This bchavior is similar to that obtained by drying MAM solutions and suggests that MAM may still be present when the polymerization stopped.

Table 4. Comparison of the Amount of Material Obtained by Rinsing the Surface of MAM/MBAM Cross-linked Gels.

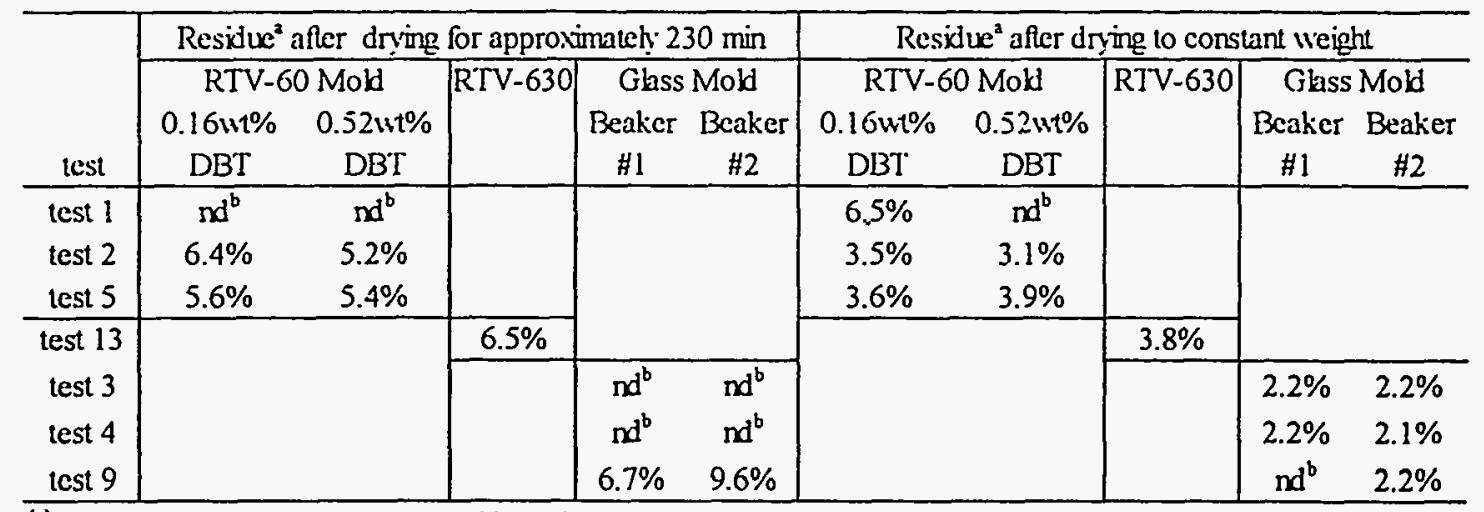

(a) weight of residue divided by the initial weight of MAM and MBAM in gel casting solution

(i) not determmed

Three different RTV molds were used to hold the polymerizing solution. Neither the type of RTV nor the amount of agent used to cure the mold had any affect on the amount of water soluble residue on the surface of the MAM/MBAM gel. However, comparing the amount of dried residue obtained from gels cast against glass in $250 \mathrm{ml}$ beakers with the residue from gcls cast against RTV shows that there is less residue when glass is used as the mold material.

Since inadequatc polymerization time would result in unreacted monomer dissolicd in the medium, gels were prepared by polymerization at $60 \pm 1^{\circ} \mathrm{C}$ for times ranging from 25 to 90 minutes. The amount of liquid remaining in the mold (Table 5) was greater when RTV was used as the mold 
Table 5. Volume of Liquid Remaining in Mold After Polymerizing MAM/MBAM

\begin{tabular}{c|ccc|lll}
\hline Gclation $^{\mathrm{a}}$ & \multicolumn{3}{|c|}{ RTV-60 Molds } & \multicolumn{3}{|c}{ Glass Molds } \\
Time (nin) & Test I.D. & $0.16 w \%$ DBT & 0.52 wt\% DBT & Test I.D. & \#1 & \#2 \\
\hline 25 & test 8 & 2.3 & 2.2 & test 10 & 1.6 & 1.3 \\
40 & & nd $^{\mathrm{b}}$ & nd & test 9 & 1.8 & 1.7 \\
60 & test 6 & 2.1 & 2.3 & & nd $^{\mathrm{b}}$ & nd $^{\mathrm{b}}$ \\
90 & test 7 & 3.3 & 3.0 & test 11 & 2.5 & 2.4 \\
\hline
\end{tabular}

(a) polymerization at $60^{\circ} \mathrm{C}$

(b) not determined

material than when the polymerization was conducted against glass. Interestingly, the amount of liquid left in both types of molds is larger for the longest polymerization time. This may be related to changes in the hydrophilic nature of the resulting polyacrylamide gel caused by the longer polymerization time.

The weight of dried residue rinsed from the gel surface (Table 6) is also larger for the gels polymerized in RTV- 60 molds than for the gels polymerized in glass beaker molds for equivalent reaction times. Furthermore, the amount of residue was largest for the 25 min reaction time suggesting that the polymerization ceased when the mold cooled as it was removed from the oven. In contrast to the amount of liquid left in the mold, the weight of dried residue was constant for polymerization times from 40 to $90 \mathrm{~min}$. This implies that the polymerization reaction has ceased. Thus, with our reaction conditions, reaction times of at least $40 \mathrm{~min}$ do not limit the extent of conversion. Quite probably, interactions between the APS initiator and the mold material have resulted in depletion of the APS thereby limiting the extent of polymerization. We will test this hypothesis by studying the effect that the concentration of APS and TMEDA have on the polymerization.

Table 6. Weight of Residue in Gel Surface Rinses as a Function of the Polymerization Time.

\begin{tabular}{|c|c|c|c|c|c|c|c|c|c|c|}
\hline \multirow{3}{*}{$\begin{array}{l}\text { Gel Time } \\
\text { (min) }\end{array}$} & \multicolumn{5}{|c|}{ RTV-60 Mold } & \multicolumn{5}{|c|}{ Glass Beaker Molds } \\
\hline & \multirow[b]{2}{*}{ test } & \multicolumn{2}{|c|}{$\begin{array}{c}\text { Residue }^{2} \text { after } \\
\text { drying for } \sim 230 \mathrm{~min}\end{array}$} & \multicolumn{2}{|c|}{$\begin{array}{l}\text { Residue' after drying } \\
\text { to constant weight }\end{array}$} & \multirow[b]{2}{*}{ test } & \multicolumn{2}{|c|}{$\begin{array}{c}\text { Residuc after } \\
\text { dring for }-230 \mathrm{~min}\end{array}$} & \multicolumn{2}{|c|}{$\begin{array}{l}\text { Residue after drying } \\
\text { to constant weight }\end{array}$} \\
\hline & & $\begin{array}{c}0.16 w t \% \\
\text { DBT }\end{array}$ & $\begin{array}{c}0.52 w t \% \\
\text { DBT }\end{array}$ & $\begin{array}{c}0.16 w t \% \\
\text { DBT }\end{array}$ & $\begin{array}{c}0.52 u t \% \\
\text { DBT }\end{array}$ & & $\begin{array}{c}\text { Beaker } \\
\# 1\end{array}$ & $\begin{array}{c}\text { Beaker } \\
\# 2\end{array}$ & $\begin{array}{c}\text { Beaker } \\
H 1\end{array}$ & $\begin{array}{c}\text { Beaker } \\
\# 2 \\
\end{array}$ \\
\hline 25 & test 8 & $13.3 \%$ & $10.6 \%$ & $n d^{b}$ & $9.3 \%$ & test 10 & $18.2 \%$ & $7.4 \%$ & $5.6 \%$ & $3.9 \%$ \\
\hline 40 & test $2 \& 5$ & $6.0 \%$ & $5.3 \%$ & $3.5 \%$ & $3.5 \%$ & test 9 & $6.7 \%$ & $9.6 \%$ & $\mathrm{nd}^{\mathrm{b}}$ & $2.2 \%$ \\
\hline 60 & test 6 & $5.1 \%$ & $4.3 \%$ & $4.3 \%$ & $4.0 \%$ & & $\mathbf{n d}^{\mathrm{b}}$ & $n^{b}$ & $\mathrm{nd}^{\mathrm{b}}$ & $n^{d^{b}}$ \\
\hline 90 & $\operatorname{test} 7$ & $5.0 \%$ & $5.1 \%$ & $3.7 \%$ & $3.8 \%$ & test 11 & $4.0 \%$ & $3.6 \%$ & $2.2 \%$ & $2.1 \%$ \\
\hline
\end{tabular}


Status of Milestones

On schedule.

Milestone 114213 - Demonstrate the ability to green machine gelcast ceramic materials using computer-controlled milling machine was completed on schedule on Mar -31-1996.

Communications $/$ isits $/$ Travel

None.

Problems encountered

None.

Publications and Presentations

S. D. Nunn presented a paper entitled "Green Machining of Gelcast Ceramic Materials" at the 1996 Conference on Composites, Advanced Ceramics, Materials and Structures in Cocoa Beach, FL. 


\title{
1.2 CERAMIC COMPOSITES
}

\subsubsection{Silicon Nitride Matrix}

\section{Optimization of Silicon Nitride Ceramics}

\author{
K.J. Lee and T.Y. Tien \\ Materials Science and Engineering \\ The University of Michigan
}

\section{Objective/Scope}

The objective of this investigation is to develop silicon nitride ceramics with high flexural strength, high fracture toughness at room temperatures, and superior creep resistance at elevated temperatures. It has been demonstrated that these properties depend on morphology of the $\mathrm{B}_{-} \mathrm{Si}_{3} \mathrm{~N}_{4}$ grains and the nature of the grain boundary phase. The fiber-like structure of $B-\mathrm{Si}_{3} \mathrm{~N}_{4}$ grains can be obtained by sintering the silicon nitride ceramics at high temperature under nitrogen over pressure. The mechanical properties can be improved by controlling the size and aspect ratio of $B-\mathrm{Si}_{3} \mathrm{~N}_{4}$ grains and the composition and nature of the grain boundary phase. The composition of the sintering additives will affect the microstructural development, grain boundary characteristics, and hence, the mechanical properties. It is believed that with thorough understanding of these relationships, ceramics with optimum mechanical properties can be obtained. The effect of the nature of the grain boundary phases on the properties of silicon nitride ceramics have been studied. The results have been understood in terms of differential of the thermal expansion coefficients of grain boundary phases and the silicon nitride grains. Also, the relationship between grain size as well as aspect ratios of $\mathrm{B}-\mathrm{Si}_{3} \mathrm{~N}_{4}$ grains and mechanical properties have also been established. The goal of this project is to gather the results obtained and use experiment design to synthesize silicon nitride with optimum properties.

\section{Technical Highlights}

In previous studies, it was found that the higher the thermal expansion coefficient of the grain boundary phases than the silicon nitride grains, the higher the fracture toughness. For the first iteration, two sets of additive compositions and three sets of heating schedules were used to synthesize the silicon nitride ceramics. (See Table I)

The batches were mixed by attrition milling with isopropyl alcohol. Approximately 2 $\mathrm{g}$ of mixed powders were cold pressed into pellets of $12.5 \mathrm{~mm}$ in diameter and then cold isostatically pressed under $160 \mathrm{MPa}$. The pellets were placed in a BN crucible and sintered under 10 ATM of $\mathrm{N}_{2}$ pressure in a high pressure furnace. Toughness of the samples was determined using indentation method. The toughness of these samples was calculated using the equation suggested by Anstis et al.[1]

The density, hardness, and fracture toughness of the samples were measured and the results are shown in Table II. For composition A, the hardness obtained from heating schedule I is higher than that obtained from heating schedule III, but their density and fracture toughness remain almost the same. For composition $B$, the density can reach $98.02 \%$ (theoretical density is $3.286 \mathrm{~g} / \mathrm{cm}^{3}$ ) when using heating schedule III, but the density obtained from heating schedule II only reached $93.97 \%$.

\section{Status of Milestones}

On schedule 
Communications/Visits/Travel

None

Problems Encountered

None

Publications

None

\section{References}

1. G.R. Anstis, P. Chantikul, B.R. Lawn, and D.B. Marshall, "A Critical Evaluation of Indentation Techniques for Measuring Fracture Toughness: I. Direct Crack Measurements," J. Amer. Cer. Soc., 4 [9] 533-38 (1981). 


\section{TABLE I}

\begin{tabular}{|c|c|c|c|}
\hline Run No. & Additive Compositions & & eating Schedule. \\
\hline 1 & A: Ba-aluminosilicate & \multicolumn{2}{|c|}{ I: 1-step sintering + annealing } \\
\hline 2 & B: YAG & \multicolumn{2}{|c|}{ II: 2-step sintering + annealing } \\
\hline 3 & A: Ba-aluminosilicate & \multicolumn{2}{|c|}{ III: 3 -step sintering + annealing } \\
\hline 4 & B: YAG & \multicolumn{2}{|c|}{ III: 3 -step sintering + annealing } \\
\hline \multicolumn{4}{|c|}{ Composition A: 90 vol\% $\mathrm{Si}_{3} \mathrm{~N}_{4}+10$ vol\% $2 \mathrm{BaO}: 2 \mathrm{Al}_{2} \mathrm{O}_{3}: 5 \mathrm{SiO}_{2}$} \\
\hline \multicolumn{4}{|c|}{ Composition B: $90 \mathrm{wt} \% \mathrm{Si}_{3} \mathrm{~N}_{4}+10 \mathrm{wt} \%$ YAG (93 vol\% $\left.\mathrm{Si}_{3} \mathrm{~N}_{4}+7 \mathrm{vol} \% \mathrm{YAG}\right)$} \\
\hline \multicolumn{4}{|c|}{ Heating Schedule I: $1900^{\circ} \mathrm{C} / 1 \mathrm{hr}+$ annealing } \\
\hline \multirow{3}{*}{\multicolumn{4}{|c|}{$\begin{array}{l}\text { Heating Schedule II: } 1640^{\circ} \mathrm{C} / 3 \mathrm{hr}+1840^{\circ} \mathrm{C} / 3 \mathrm{hr}+1640^{\circ} \mathrm{C} / 2 \mathrm{hr}+\text { annealing } \\
\text { Heating Schedule III: } 1640^{\circ} \mathrm{C} / 3 \mathrm{hr}+1900^{\circ} \mathrm{C} / 1 \mathrm{hr}+1640^{\circ} \mathrm{C} / 2 \mathrm{hr}+\text { annealing } \\
\text { Annealing: } 1350^{\circ} \mathrm{C} / 15 \mathrm{hr}\end{array}$}} \\
\hline & & & \\
\hline & & & \\
\hline \multicolumn{4}{|c|}{ TABLE II } \\
\hline Run No. & $\begin{array}{l}\text { Density } \\
\left(\mathrm{g} / \mathrm{cm}^{\wedge} \mathbf{3}\right)\end{array}$ & $\begin{array}{l}\text { Hardness } \\
\quad(\text { GPa })\end{array}$ & $\begin{array}{c}\text { Fracture Toughness } \\
\left(\text { MPaM^0.5) }^{\circ}\right.\end{array}$ \\
\hline 1 & $3.189(99 \%)$ & 16.27 & 6.4 \\
\hline 2 & $3.088(93.97 \%)$ & 13.88 & 6.56 \\
\hline 3 & $3.162(98.18 \%)$ & 15.26 & 6.59 \\
\hline 4 & $3.221(98.02 \%)$ & 16.56 & 5.45 \\
\hline
\end{tabular}




\title{
Microstructure Optimization of SRBSN
}

\author{
L.H. Qi and T.Y. Tien \\ Materials Science and Engineering \\ The University of Michigan
}

\section{Objective/Scope}

Sintered reaction bonded silicon nitride is one of the most cost effective methods for producing silicon nitride ceramics in large quantities. It involves the nitridation of the starting metallic silicon particle compacts and post nitridation sintering. The purpose of this project is to develop a process to produce SRBSN with minimum defects. This investigation seeks to obtain green compacts with uniform pore distribution. The nitridation process will be optimized to produce uniform microstructure. Post nitridation sintering will be studied to develop desirable morphology of the B-Si3N4 grains.

\section{Technical Highlights}

In order to obtain the SRBSN with uniform microstructure and good properties, metallic silicon powder compacts with narrow pore size distribution are necessary. The pore size distribution of green compacts will be affected by the forming methods and silicon particle size distribution. Three silicon powders with different particle size distribution (Powders A, B and C) were used as starting materials. The effect of different organic solvents on pressure casting process and the pore size distribution in green compacts were studied. Methods which produce optimum green compacts were used for further studies.

The silicon powder has been used as received and it did not contain $\mathrm{Fe}$ as impurity. Fe was added by infiltration of iron nitrate solution into the silicon green compacts. Infiltration volume was controlled to $0.3 \mathrm{~mL} / 1 \mathrm{~g} \mathrm{Si}$ so that the silicon green compacts kept their shapes. After infiltration, the compacts was placed into a vacuum oven at $80^{\circ} \mathrm{C}$ for 24 hours. The amount of Fe element added in silicon compacts was about $0.5 \mathrm{wt} \%$. All silicon green compacts prepared were sent to Ceradyne Inc. for nitridation. Details for nitridation conditions will be reported later. As shown in Table I, nitridation was not complete for compacts that did not contain iron. However, the percent of nitridation cannot be estimated because the green compacts before nitridation contained binders.

Pore size distribution of the nitridated compacts were determined and the results are given in Fig. 2. Pore size distribution of the green compacts also shows the change before and after nitridation. A sintering additive will be added in solution form and these samples will then be sintered. Mechanical properties of these SRBSN will then be determined.

\section{Status of Milestones}

On schedule

\section{Communications/Visits/Travel}

None 
Problems Encountered

None

Publication

None 
Differential Volume Per Gram \%

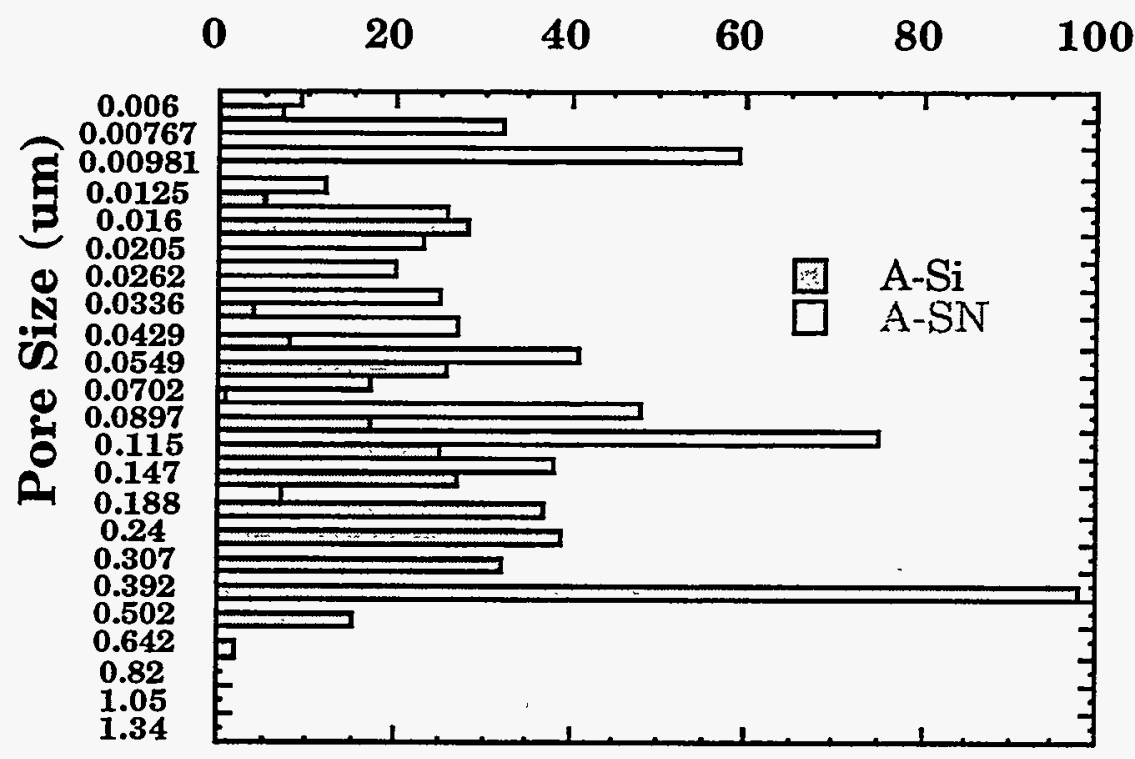

(A)

Differential Volume Per Gram \%

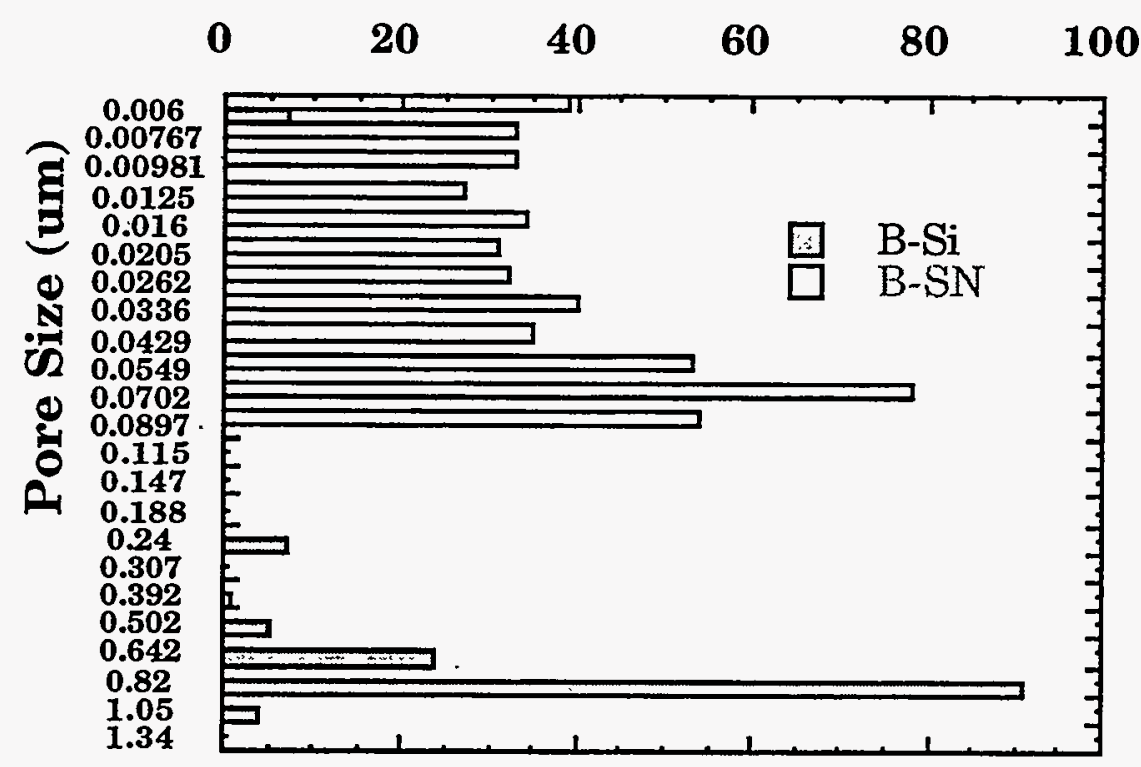

(B) 
Differential Volume Per Gram \%

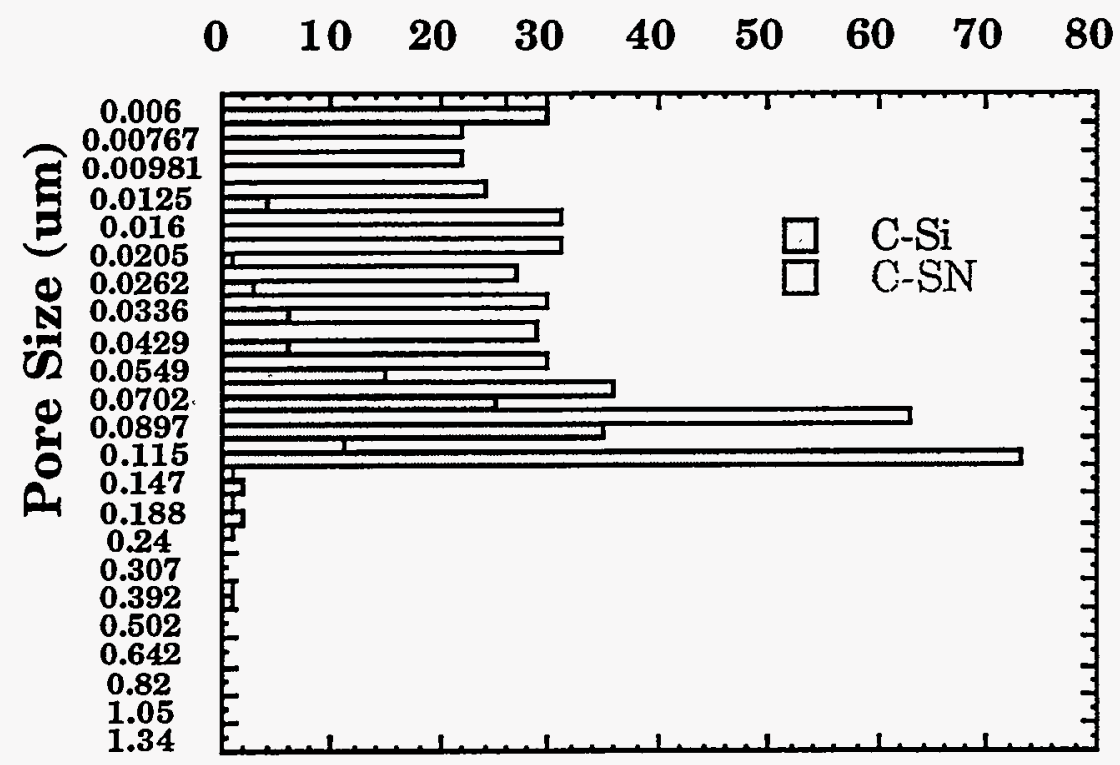

(C)

Fig.1. The Pore Size Distribution of the nitriding cake (A) made from silicon powder' $A^{\prime} \quad$ (B) made from silicon powder ' $B$ " $\quad$ (C) made from silicon powder ' $C$ "

Table.1 The weight gain of compact after nitridation

\begin{tabular}{llllcl}
\hline Sample & Powder & Fe\% & $\begin{array}{c}\text { Initial weight } \\
(\mathrm{g})\end{array}$ & $\begin{array}{c}\text { Nitride weight } \\
(\mathrm{g})\end{array}$ & $\begin{array}{c}\text { weight gain } \\
\text { per unit (\%) }\end{array}$ \\
\hline 1\# & A & 0.05 & 8.531 & 12.504 & 46.57 \\
2\# & A & 0 & 6.921 & 10.043 & 45.11 \\
3\# & B & 0.05 & 9.692 & 15.18 & 56.6 \\
4\# & B & 0 & 9.457 & 13.876 & 46.7 \\
5\# & C & 0.05 & 9.195 & 14.317 & 55.7 \\
6\# & C & 0 & 4.162 & 6.312 & 51.6 \\
\hline
\end{tabular}


Development of Silicon Nitride Ceramic Materials with Elongated Grain Microstructures Exhibiting High Fracture Toughness, Phase III

H. Yeh, J. Wimmer, C-W. Li, and J. Goldaker (AlliedSignal, Inc.)

\section{Objective/Scope}

Under Phase I, an in situ reinforced silicon nitride material (AS800, Composition 2) with elongated grain microstructure and high toughness has been developed. It was accomplished through composition and processing optimization using a laboratory scale process. Built upon Phase I results, Phase II was initiated. Under Phase II, an in-depth characterization was conducted on the Phase I material (Composition 2) fabricated by a prototype scale process. In addition, the as-processed surface properties of the laboratory scale material have been improved, and a lower cost larger scale process has been demonstrated, which included the demonstration of fabricating a net shape component. Under both Phases I and II, the conventional pressure slip casting process was utilized as the green forming process.

AS800 material properties have generated a high level of interest from end users. In order to accelerate the adoption of AS800 in engines, an extensive property database is needed for the material produced by the current production process, which includes a larger scale green forming process and an intermediate temperature thermal treatment. (The material characterized under Phase II was not fabricated by the production process.) In anticipation of future advanced engine requirements, a material with further improved high temperature properties is also needed. Furthermore, to meet the cost and property requirements for thin wall parts for hybrid electric vehicles, an advanced fabrication process needs to be developed. To meet the above needs and to facilitate timely commercialization of AS800, this program (Phase III) was initiated, which consists of three technical tasks to be conducted over a thirty (30)-month period: Task 1 - Material Database for Production Process, Task 2 - AS800 High Temperature Property Improvement, and Task 3 - Gelcasting of Thin Walled Shapes of AS800 Silicon Nitride. The technical effort was initiated in October 1995.

\section{Technical Highlights}

\section{Task 1 - Material Database for Production Process}

The specifications covering the manufacture of heat engine components require the development and use of a fixed process to ensure reproducibility of component performance. The material property database used in the component design must also be representative of the fixed process. During Phase II, the process used to manufacture AS 800 had evolved from laboratory scale to prototype and then to a scaled-up production process. The objective of this task is to generate a material property database representative of the production process. 
The test matrix shown in Table 1 is based on heat engine company inputs and focuses on tensile properties and cyclic oxidation durability. These characteristics are critical to component design and yet are the most difficult to generate. The elastic and thermal properties determined in Phase II are still representative of AS800 and will not be re-measured. Similarly, additional flexural data is not required since sufficient flexural data will be generated during normal lot qualification testing of production material.

Table 1 - Test Matrix

(No. of Specimens)

\begin{tabular}{|l|c|c|c|c|c|c|c|c|}
\hline \multicolumn{1}{|c|}{ TEST } & RT & $\begin{array}{c}760^{\circ} \mathrm{C} \\
\left(1400^{\circ} \mathrm{F}\right)\end{array}$ & $\begin{array}{c}982^{\circ} \mathrm{C} \\
\left(1800^{\circ} \mathrm{F}\right)\end{array}$ & $\begin{array}{c}1093^{\circ} \mathrm{C} \\
\left(2000^{\circ} \mathrm{F}\right)\end{array}$ & $\begin{array}{c}1204^{\circ} \mathrm{C} \\
\left(2200^{\circ} \mathrm{F}\right)\end{array}$ & $\begin{array}{c}1260^{\circ} \mathrm{C} \\
\left(2300^{\circ} \mathrm{F}\right)\end{array}$ & $\begin{array}{c}1315^{\circ} \mathrm{C} \\
\left(2400^{\circ} \mathrm{F}\right)\end{array}$ & $\begin{array}{c}1370^{\circ} \mathrm{C} \\
\left(2500^{\circ} \mathrm{F}\right)\end{array}$ \\
\hline Tensile Fast Fracture & 10 & 10 & 30 & 10 & 10 & 10 & 10 & 10 \\
\hline Tensile Rupture $(100 \mathrm{~h})$ & & & 15 & 15 & 15 & & 15 & 10 \\
\hline Tensile Creep & & & 5 & 5 & 5 & & 5 & \\
\hline $\begin{array}{l}\text { Cyclic Oxidation } \\
\text { Durability }\end{array}$ & & & & & & & 36 & \\
\hline
\end{tabular}

The production process for AS800 was further improved during the first half of this reporting period, primarily to improve the high temperature time-dependent properties of AS800. This improved process has been selected as the fixed process for fabricating all the test specimens listed in Table 1. During the second half of this reporting period, the focus was on fabricating the buttonhead tensile specimens, which consisted of fabricating 5 " $\times 9$ " $\times 1$ " plates and then machine the plates into tensile specimens. A total of one hundred and ninety tensile specimens are required. Forty (40) specimens have been completely machined and delivered to ORNL for testing. The remaining specimens will be fabricated during the next reporting period.

\section{Task 2 - AS800 High Temperature Property Improvement}

The objective of this task is to further improve the current AS800 material properties to meet future advanced engine requirements. To achieve this goal, composition and process refinements are required. An alternate composition (Composition 5) was identified under Phase I, which, in the laboratory scale, exhibited superior high temperature properties to the current AS800 (Composition 2).

The initial results obtained under Phase I indicated that Composition 5 was not as robust as current AS800 in processing, especially in a larger scale. The property goals for this task is to be met by materials fabricated by a large scale production process; however the earlier property data were mainly generated by the laboratory scale material. In order to have an earlier identification of scale up issues, the initiate effort in this task is to compare the properties between laboratory process material and production process material. This comparison includes green processing as well as thermal processing. During this reporting period, all the test specimens were fabricated and mechanical property characterization has been initiated and is still in-progress. The characterization 
test matrix includes room temperature and $2500^{\circ} \mathrm{F}$ fast flexural strengths, $2400^{\circ} \mathrm{F}$ stress rupture, and dynamic fatigue.

Task 3 - Gelcasting of Thin Walled Shapes of AS800 Silicon Nitride

To be initiated in the next reporting period

Communications/Visits/Travel

None

Problems Encountered

None

Publications

None 


\subsubsection{Oxide Matrix}

W.B.S. ELEMENT 1.2.3.1

DISPERSION TOUGHENED CERAMIC COMPOSITE

T. N. Tiegs, F. C. Montgomery, P. A. Menchhofer, D. L. Barker and D. W. Coffey

Oak Ridge National Laboratory

Oak Ridge, TN 37831

\section{Objective/Scope}

Significant improvement in the reliability of structural ceramics for advanced engine applications could be attained if the critical fracture toughness $\left(\mathrm{K}_{\mathrm{tc}}\right)$ were increased without strength degradation. Early results from ORNL research showed that significant increases in fracture toughness could be achieved by manipulating the microstructure to promote toughening mechanisms such as crack bridging. Excellent properties were obtained in this manner for the alumina and mullite matrix systems reinforced with $\mathrm{SiC}$ whiskers. In silicon nitride, acicular or elongated grains can be generated by in-situ growth and these can provide significant toughening on the same order as the whisker reinforced materials. Microstructural development to promote this type of growth in silicon nitride is the current emphasis of the project.

\section{Technical Highlights}

\section{In-Situ Toughening of Silicon Nitride by Microstructure Development}

Characterization and Modification of As-Fabricated Surfaces Formed During Gas Pressure Sintering (GPS) - In the previous years, studies were done to reduce surface reactions layers during densification and to optimize the GPS process for silicon nitride. These processing techniques developed were used to fabricate silicon nitride materials to maximize the mechanical properties of the as-sintered surfaces. The studies included control of the sintering parameters to maximize bulk properties and minimizing the surface reaction layer. To further reduce the need for machining, investigations of the relationships between green machining, bisque machining and final machining on the mechanical properties were performed. In addition, the effects of post-sintering surface treatments, such as oxidation, inert gas heat-treatment and abrasive cleaning (blasting, vibratory agitation and rotary tumbling) were studied. For each of the conditions, two compositions of silicon nitride with different intergranular phases were tested. These compositions are $\mathrm{Si}_{3} \mathrm{~N}_{4}-6 \% \mathrm{Y}_{2} \mathrm{O}_{3}-2 \% \mathrm{Al}_{2} \mathrm{O}_{3}$, and $\mathrm{Si}_{3} \mathrm{~N}_{4}-\mathrm{Sr}_{2} \mathrm{La}_{4} \mathrm{Yb}_{4}\left(\mathrm{SiO}_{4}\right)_{6} \mathrm{O}_{2}$ (at 8 equivalent \% oxygen).

Because a number variables were to be studied, a Taguchi experimental array was formulated to assess the impact of each of the surface processing variables on the final properties after gas-pressure sintering. The experimental array with the variables is shown in Table 1. The samples were densified by gas-pressure sintering and the test surfaces were characterized by measuring surface roughness parameters using a laser profilometer. In general, the sintering process increased the surface roughness of the samples except for the rough cast samples which were not machined before sintering.

Results on the mechanical properties for the various surface treatments along with the experimental conditions for the two compositons of samples are shown in Tables 2 and 3. The effect of the green surface condition on the final average flexural strength at room temperature is shown in Fig. 1. As expected, the smooth cast surface condition exhibited the high strengths with both of the compositons tested. The fine machined green surface had conflicting results between the two compositons, however, it is believed that the unusually low strengths for the $\mathrm{Si}_{3} \mathrm{~N}_{4}-6 \% \quad \mathrm{Y}_{2} \mathrm{O}_{3}-2 \% \quad \mathrm{Al}_{2} \mathrm{O}_{3}$ composition is an anomoly. 
Some additional tests will be done to confirm this. In all cases, the rough as-cast surfaces showed the lowest average strengths which was anticipated.

The strength results indicated there was no significant effects either good or bad from bisque machining of the materials. Thus, the only advantage such a procedure may have is in dimensional control of the final part. Also, no obvious differences in properties were noted for sintering in contact with either $\mathrm{BN}$ or $\mathrm{SiC}$ setters, although the $\mathrm{BN}$ appeared to give slightly better strengths.

As expected, the most significant treatment that effects the strength is the final grinding operation as shown in Fig. 2. The effect was most apparent in the $\mathrm{Si}_{3} \mathrm{~N}_{4}-6 \% \quad \mathrm{Y}_{2} \mathrm{O}_{3}-2 \%$ $\mathrm{Al}_{2} \mathrm{O}_{3}$ composition samples. Interestingly, the $\mathrm{Si}_{3} \mathrm{~N}_{4}-\mathrm{Sr}_{2} \mathrm{La}_{4} \mathrm{Yb}_{4}\left(\mathrm{SiO}_{4}\right)_{6} \mathrm{O}_{2}$ composition samples exhibited only slightly lower as-sintered surface strengths as compared to the machined surface samples. This is also evident in a comparison of the samples from experiments 1 and 15 for the TRSN-52 samples. Grit tumbling and sand blasting on the as-sintered surfaces did not result in improved strengths. It had been speculated that the grit tumbling or blasting of the surfaces to remove the immediate surface reaction layers would have improved the strength at least somewhat. However, that was not observed.

The various post sintering thermal treatments indicated that either no treatment or a thermal shock exposure had the highest strengths for both compositions (Fig. 3). Oxidation and high temperature annealing resulted in lower strengths. Oxidation reduction of strength was most pronounced for the $\mathrm{Si}_{3} \mathrm{~N}_{4}-\mathrm{Sr}_{2} \mathrm{La}_{4} \mathrm{Yb}_{4}\left(\mathrm{SiO}_{4}\right)_{6} \mathrm{O}_{2}$ composition samples and maybe a result of stability problems with the composition in the exposed surface area. The thermal annealing procedure results in a crystallization of the intergranualar phases and typically decreased strengths are observed.

$\mathrm{B}_{-} \mathrm{Si}_{3} \mathrm{~N}_{4}$ Nucleation and Initial Stage Microstructure Development - It is just being recognized how important the $B$-phase nucleation and initial growth stage of microstructure development is to the final properties of the silicon nitride, especially with all of the recent work involved in $\beta$-seeding of the starting materials. ${ }^{1-7}$ In fact, the $\beta$-phase nucleation and initial growth is a key step to producing materials with high fracture toughness. This microstructure development is directly related to the kinetics and morphology changes that occur during $ß$-phase nucleation and initial growth. Understanding of the process variables in the initial stage of sintering and their control is essential for obtaining materials with high reliability and superior mechanical properties. Thus, a study was initiated to determine the inter-relationships between the raw silicon nitride powders, the sintering additives as the liquid phase forms, $\beta$-phase nucleation and the kinetics of the $\alpha$-to- $\beta$ transformation. This is an area where there is a large body of fragmented data and observations, however, there is no systematic examination of the system. The present work plans to examine the effects of the silicon nitride powders, the type of sintering additive and the effect of $B-\mathrm{Si}_{3} \mathrm{~N}_{4}$ seeds on the initial microstructure development.

Numerous studies have shown that the silicon nitride powder used in fabrication is an extremely important variable in the microstructural development and final properties of the materials. Most of the early studies of silicon nitride powders were concerned only with either the densification behavior, the final mechanical properties or the high temperature properties produced by the various grades of powders available. None of the studies have done a comparative assessment of the effects of the raw materials on the microstructural development from a fundamental $B$-nucleation standpoint. Generally, the previous work found that high starting $\alpha-\mathrm{Si}_{3} \mathrm{~N}_{4}$ contents in the powders are preferable for densification and final material mechanical properties. However, B-phase starting powders have also been used to produce materials with good mechanical properties. ${ }^{8}$ 
Several powders will be examined in this research study that comprise a wide variety of characteristics, such as surface area, particle size, purity, and oxygen content (Table 4). All are high in $\alpha$-phase content.

Table 4 - Characteristics of silicon nitride powders. Manufacturers' reported values.

\begin{tabular}{|c|c|c|c|c|c|c|c|c|}
\hline $\begin{array}{l}\text { Manu- } \\
\text { facturer }\end{array}$ & Grade & $\begin{array}{l}\text { Fabrication } \\
\text { Route }\end{array}$ & $\begin{array}{l}\text { Approx } \\
\text { Rel. } \\
\text { Cost* }\end{array}$ & $\begin{array}{l}\text { Mean } \\
\text { Particle } \\
\text { Size } \\
(\mu \mathrm{m})\end{array}$ & $\begin{array}{l}\text { Surface } \\
\text { Area } \\
\left(\mathrm{m}^{2} / \mathrm{g}\right)\end{array}$ & $\begin{array}{l}\alpha \text {-Phase } \\
\text { Content } \\
(\%)\end{array}$ & $\begin{array}{l}\text { Oxygen } \\
\text { Content } \\
\text { (wt. \%) }\end{array}$ & $\begin{array}{l}\text { Total } \\
\text { Impurity } \\
\text { Content } \\
\text { (ppm) }\end{array}$ \\
\hline Ube & $E-10$ & Diimide & 1.7 & $-\infty$ & 11.7 & $>95$ & 1.40 & $<200$ \\
\hline Starck & M 11 & Si Nit.a & 1.3 & 0.55 & 13.5 & 94 & 1.78 & $<300$ \\
\hline Starck & GP & Gas Phase & 1.4 & 0.55 & 10.9 & 95 & 1.12 & $<200$ \\
\hline Dow & EXP & Carbo. Red. ${ }^{\mathrm{c}}$ & N. A. & 0.84 & 9.3 & $>92$ & 1.7 & $<600$ \\
\hline Ube & E-03 & Diimide & 1 & -- & 3.3 & $>95$ & 0.82 & $<200$ \\
\hline
\end{tabular}

${ }^{*}$ Based on purchases of $10 \mathrm{~kg}$. aSilicon nitridation. bValues in wt. \% .

${ }^{c}$ Carbothermal reduction.

Examination of the role of powders in the microstructure development is not only an academic exercise, but is of considerable engineering importance. Several studies have shown that the diimide-derived powders generally result in materials with the best mechanical properties. However, these powders are also the most expensive. Thus, there is a desire to use less expensive powders to fabricate materials with good properties.

To test the effect of raw materials on the initial stage microstructure development, the various powders will be mixed with several different sintering additives that give a wide range of liquid properties. The intergranular phases chosen are shown in Table 5. The $\mathrm{Y}_{2} \mathrm{O}_{3}-\mathrm{Al}_{2} \mathrm{O}_{3}$ system (compositions 1 and 2 ) is one that has been studied extensively and has been used for most of the basic studies on grain growth and densification behavior. It is included here as a defacto standard for comparison with other studies. The choice of two different contents with provide some data on the effect of diffusion in the initial stage sintering process. The $\mathrm{Y}_{2} \mathrm{O}_{3}-\mathrm{MgO}$ system has also been studied previously and has been used to fabricate materials with high fracture toughness. It also represents a system with a lower eutectic temperature that the others. The $\mathrm{Y}_{2} \mathrm{Si}_{2} \mathrm{O}_{7}$ (at 5 equivalent \% oxygen) composition represents a very refractory grain boundary phase that will have a high liquid phase viscosity.

Table 5. Sintering additive compositions and approximate eutectic temperatures with silicon nitride and silica.

Composition

1) $6 \mathrm{w} / \mathrm{o} \mathrm{Y}_{2} \mathrm{O}_{3}-2 \mathrm{w} / \mathrm{o} \mathrm{Al}_{2} \mathrm{O}_{3}$

2) $9 \mathrm{w} / \mathrm{o} \mathrm{Y}_{2} \mathrm{O}_{3}^{3}-3 \mathrm{w} / \mathrm{O} \mathrm{Al} \mathrm{O}_{3}$

3) $6 \mathrm{w} / \mathrm{o} \mathrm{Y}_{2} \mathrm{O}_{3}-1 \mathrm{w} / \mathrm{o} \mathrm{MgO}$

4) $\mathrm{Y}_{2} \mathrm{Si}_{2} \mathrm{O}_{7}$ (at 5 equivalent \% oxygen)

5) $\mathrm{Sr}_{2} \mathrm{La}_{4} \mathrm{Yb}_{4}\left(\mathrm{SiO}_{4}\right)_{6} \mathrm{O}_{2}$ (at 8 equivalent $\%$ oxygen)
Approx. Eutectic Temperature $\left({ }^{\circ} \mathrm{C}\right)$

1280

1280

1200

1500

1400

The mixtures will then be heated to numerous intermediate temperatures for short to long periods of time. This will result in partial densification and $\alpha$-to- $\beta$ transformation. Measurement of the densification kinetics will allow determination of the activation energies involved in particle rearrangement and during solution-reprecipitation accompanying the $\alpha$-to- $\beta$ transformation. The samples will then be subjected by $x$-ray 
diffraction and the morphology examined by SEM. Initial results on the B-phase transformation rate as a function of the heating temperature and time are shown in Fig. 4. The rate of transformation will be correlated with the microstructure changes and differentiations made between the different types of $\mathrm{Si}_{3} \mathrm{~N}_{4}$ powders. It is anticipated that the transformation rate kinetics will be similar for the same sintering additives, but the preexponential rate constant will be a function of the $\mathrm{Si}_{3} \mathrm{~N}_{4}$ particle size.

\section{Cooperative Research and Development Agreement (Materials and Electrochemical Research Corp.) -}

The Cooperative Research and Development Agreement (CRADA) with Materials and Electrochemmical Research Corp. (MER) was completed. Materials were made with different starting $\alpha / \mathrm{B}_{-} \mathrm{Si}_{3} \mathrm{~N}_{4}$ ratios and with the addition of sintering aids as coatings instead of powders. The test matrix is shown in Tables 6 and 7.

The samples that achieved densities $>90 \%$ were machined into test bars for mechanical property testing as summarized in Table 8. As shown, a wide range of strengths and fracture toughness were obtained.

The effect of the type of $\mathrm{B}-\mathrm{Si}_{3} \mathrm{~N}_{4}$ seed on flexural strength and fracture toughness are illustrated in Fig. 5. The seeds fabricated by the reaction of either yttrium nitrate or $\mathrm{Y}_{2} \mathrm{O}_{3}$ powder and Ube E-10 $\mathrm{Si}_{3} \mathrm{~N}_{4}$ developed materials with the highest flexural strength. However, the fracture toughness of these materials (at the $25 \%$ addition level) showed no improvement over the baseline composition having no $\beta$-seed addition. High observed fracture toughness are usually associated with bimodal microstructures of high aspect ratio grains. The $\beta$-seeds made with Ube $\mathrm{E} 10 \mathrm{Si}_{3} \mathrm{~N}_{4}$ were similar in size to the $\alpha$-phase powder and during the initial stage liquid formation these seeds may have had dissolution rates similar or higher than the $\alpha$-phase powder. In that case, the $\beta$-seeds would have a minor contribution to the $\beta$-nucleation and result in the development of a uniform grain size. This may explain the improved strengths with no increase in toughness, but microstructure analysis will be done to confirm this.

In contrast, the $\beta$-seeds made with the Ube E03 or Starck $\mathrm{S}_{1} \mathrm{Si}_{3} \mathrm{~N}_{4}$ (and $\mathrm{Y}_{2} \mathrm{O}_{3}$ powder) were generally larger than the starting $\alpha$-phase powder. This resulted in materials with similar or slightly lower strengths, but significantly higher fracture toughness as shown in Fig. 5. The microstructures are believed to be more bimodal in grain size which would result in the increased fracture toughness. In the case of the samples made with the $\beta$-seed from Shin-Etsu, the low strengths are attributable to the poor densification exhibited by these materials. The higher toughness is probably due to a combination of some large $B$ $\mathrm{Si}_{3} \mathrm{~N}_{4}$ particles in the powder and the low density.

The effects of the $\beta$-seed content on flexural strength and fracture toughness are summarized in Fig. 6. As indicated, improvements in strength were observed with the addition of $25 \%$ ß-seed. At the other two additive levels (5 and $50 \%$ ) generally lower strengths were obtained, however, the results were mixed. The fracture toughness also showed no definite trend. Higher toughnesses were observed with $50 \%$ ß-seed additions, while the other additive levels showed no consistent improvements. Microstructural analysis will be used to explain the results.

\section{Status of Milestones}

Milestone 123116, Development of high toughness silicon nitride with optimized assintered surface properties was completed. The results have been reported in the bimonthly progress reports and are summarized in the current report. 


\section{Communications/Visits/Travel}

Travel by T. N. Tiegs on October 1, 1995 to the AlliedSignal Ceramic Components Company in Torrance, CA to review their program on toughened silicon nitride.

\section{Problems Encountered}

Problems with the temperature control and pressure regulation valve on the gas pressure sintering furnace has caused some delay in fabrication of the samples for CRADA with MER Corp.

\section{Publications}

None.

\section{References}

1. G. Wötting, H. Feuer and E. Gugel, "The Influence of Powders and Processing Methods on Microstructure and Properties of Dense Silicon Nitride," pp. 133-46 in Silicon Nitride Ceramics, Edited by I-W. Chen, P. F. Becher, M. Mitomo, G. Petzow and T. S. Yen, Materials Research Society, Pittsburgh, PA (1993).

2. M. J. Hoffmann, "Analysis of Microstructural Development and Mechanical Properties of $\mathrm{Si}_{3} \mathrm{~N}_{4}$ Ceramics," pp. 59-72 in Tailoring of Mechanical Properties of $\mathrm{Si}_{3} \mathrm{~N}_{4}$ Ceramics, M. J. Hoffmann and G. Petzow (ed.), Kluwer Acad. Pub., Netherlands (1994). ,

3. K. Hirao, T. Nagaoka, M. Yasuoka, M. E. Brito and S. Kanzaki, "Microstructure Control of Silicon Nitride by Seeding Rod-like $\mathrm{B}_{-} \mathrm{Si}_{3} \mathrm{~N}_{4}$ Particles," pp. 867-870 in Advanced Materials '93, J/A: Ceramics, Powders, Corrosion and Advanced Processing, N. Mizutani et al (ed.) Trans. Mat. Res. Soc. Jpn, Vol. 14A, Elsevier Sci. (1994).

4. M. Herrmann, S. Kessler and C. Schubert, "Microstructural Design of Dense $\mathrm{Si}_{3} \mathrm{~N}_{4}$," pp. 847-851 in Euro-Ceramics II, Vol. 2, Deutsche Keramische Gesellschaft, Koln, Germany (1993).

5. D. E. Wittmer, D. Doshi and T. E. Paulson, "Development of $B-\mathrm{Si}_{3} \mathrm{~N}_{4}$ for Self Reinforced Compoistes," pp. 594-602 in Proc. 4th Internat. Symp. on Ceramic Materials and Components for Engines, Elsevier Applied Sci., New York, NY(1992).

6. K. Hirao, T. Nagaoka, M. E. Brito and S. Kanzaki, "Microstructure Control of Silicon Nitride by Seeding Rodlike B-Si3 $\mathrm{N}_{4}$ Particles," J. Am. Ceram. Soc., 77[7]1857-62(1994).

7. N. Hirosaki and Y. Akimune, "Microstructure Characterization of Gas-PressureSintered B-Silicon Nitride Containing Large B-Silicon Nitride Seeds," J. Am. Ceram. Soc., 77[4] 1093-97(1994).

8. M. Mitomo, H. Hirotsuru, H. Suematsu and T. Nisimura, "Fine-Grained Silicon Ntride Ceramics Prepared from ß-Powder," J. Am. Ceram. Soc., 78[1]211-14(1995). 
Table 1. Experimental array to identify important surface property variables affecting the final properties of the sintered silicon nitride materials. The design is a $\mathrm{L}_{16}\left(4^{5}\right)$ with machine after bisque firing and surface sintering condition dummy-loaded to two variables..

Surface Processing Variables

\begin{tabular}{|c|c|c|c|c|c|}
\hline $\begin{array}{l}\text { Test } \\
\text { No. }\end{array}$ & $\begin{array}{l}\text { Green Surface } \\
\text { Condition }\end{array}$ & $\begin{array}{l}\text { Machine After } \\
\text { Bisque Firing }\end{array}$ & $\begin{array}{l}\text { Surface Sintering } \\
\text { Condition }\end{array}$ & $\begin{array}{l}\text { Post-Sinter } \\
\text { Surface Treatment }\end{array}$ & $\begin{array}{l}\text { Post-Sinter } \\
\text { Thermal } \\
\text { Treatment } \\
\end{array}$ \\
\hline 1 & As-Cast (Smooth) & No & $\begin{array}{l}\text { Exposed } \\
\text { Atmosphere }\end{array}$ & None & None \\
\hline 2 & As-Cast (Smooth) & No & $\begin{array}{l}\text { Exposed } \\
\text { Atmosphere }\end{array}$ & Grit Tumble & Oxidize \\
\hline 3 & As-Cast (Smooth) & Yes & $\begin{array}{l}\text { Adjacent to } \mathrm{SiC} \\
\text { Setter }\end{array}$ & Sandblast & Thermal Shock \\
\hline 4 & As-Cast (Smooth) & Yes & $\begin{array}{l}\text { Adjacent to } \mathrm{SiC} \\
\text { Setter }\end{array}$ & Machine & $\begin{array}{l}\text { Inert Gas Heat- } \\
\text { treat }\end{array}$ \\
\hline 5 & As-Cast (Rough) & No & $\begin{array}{l}\text { Exposed } \\
\text { Atmosphere }\end{array}$ & Sandblast & $\begin{array}{l}\text { Inert Gas Heat- } \\
\text { treat }\end{array}$ \\
\hline 6 & As-Cast (Rough) & No & $\begin{array}{ll}\text { Exposed } & \text { to } \\
\text { Atmosphere } & \end{array}$ & Machine & Thermal Shock \\
\hline 7 & As-Cast (Rough) & Yes & $\begin{array}{l}\text { Adjacent to SiC } \\
\text { Setter }\end{array}$ & None & Oxidize \\
\hline 8 & As-Cast (Rough) & Yes & $\begin{array}{l}\text { Adjacent to } \mathrm{SiC} \\
\text { Setter }\end{array}$ & Grit Tumble & None \\
\hline 9 & $\begin{array}{l}\text { Machined (Coarse } \\
\text { Grit) }\end{array}$ & No & $\begin{array}{l}\text { Adjacent to SiC } \\
\text { Setter }\end{array}$ & Machine & Oxidize \\
\hline 10 & $\begin{array}{l}\text { Machined (Coarse } \\
\text { Grit) }\end{array}$ & No & $\begin{array}{l}\text { Adjacent to } \mathrm{SiC} \\
\text { Setter }\end{array}$ & Sandblast & None \\
\hline 11 & $\begin{array}{l}\text { Machined (Coarse } \\
\text { Grit) }\end{array}$ & Yes & $\begin{array}{l}\text { Exposed } \\
\text { Almosphere }\end{array}$ & Grit Tumble & $\begin{array}{l}\text { Incrt Gas Heat- } \\
\text { treat }\end{array}$ \\
\hline 12 & $\begin{array}{l}\text { Machined (Coarse } \\
\text { Grit) }\end{array}$ & Yes & $\begin{array}{l}\text { Exposed } \\
\text { Atmosphere }\end{array}$ & None & Thermal Shock \\
\hline 13 & $\begin{array}{l}\text { Machined (Finc } \\
\text { Grit) }\end{array}$ & No & $\begin{array}{l}\text { Adjacent to SiC } \\
\text { Setter }\end{array}$ & Grit Tumble & Thermal Shock \\
\hline 14 & $\begin{array}{l}\text { Machined (Fine } \\
\text { Grit) }\end{array}$ & No & $\begin{array}{l}\text { Adjacent to } \mathrm{SiC} \\
\text { Setter }\end{array}$ & None & $\begin{array}{l}\text { Inert Gas Heat- } \\
\text { trealt }\end{array}$ \\
\hline 15 & $\begin{array}{l}\text { Machined (Fine } \\
\text { Grit) }\end{array}$ & Ycs & $\begin{array}{l}\text { Exposed } \\
\text { Aimosphere }\end{array}$ & Machine & None \\
\hline 16 & $\begin{array}{l}\text { Machined (Fine } \\
\text { Grit) }\end{array}$ & Yes & $\begin{array}{l}\text { Exposed } \\
\text { Atmosphere }\end{array}$ & Sandblast & Oxidize \\
\hline
\end{tabular}


Table 2. Results from Taguchi experimental array to identify important surface property variables affecting the final properties of the sintered silicon nitride materials. Samples of gas pressure sintered $\mathrm{Si}_{3} \mathrm{~N}_{4}-6 \% \mathrm{Y}_{2} \mathrm{O}_{3}-2 \% \mathrm{Al}_{2} \mathrm{O}_{3}$ composition.

Surface Processing Variables

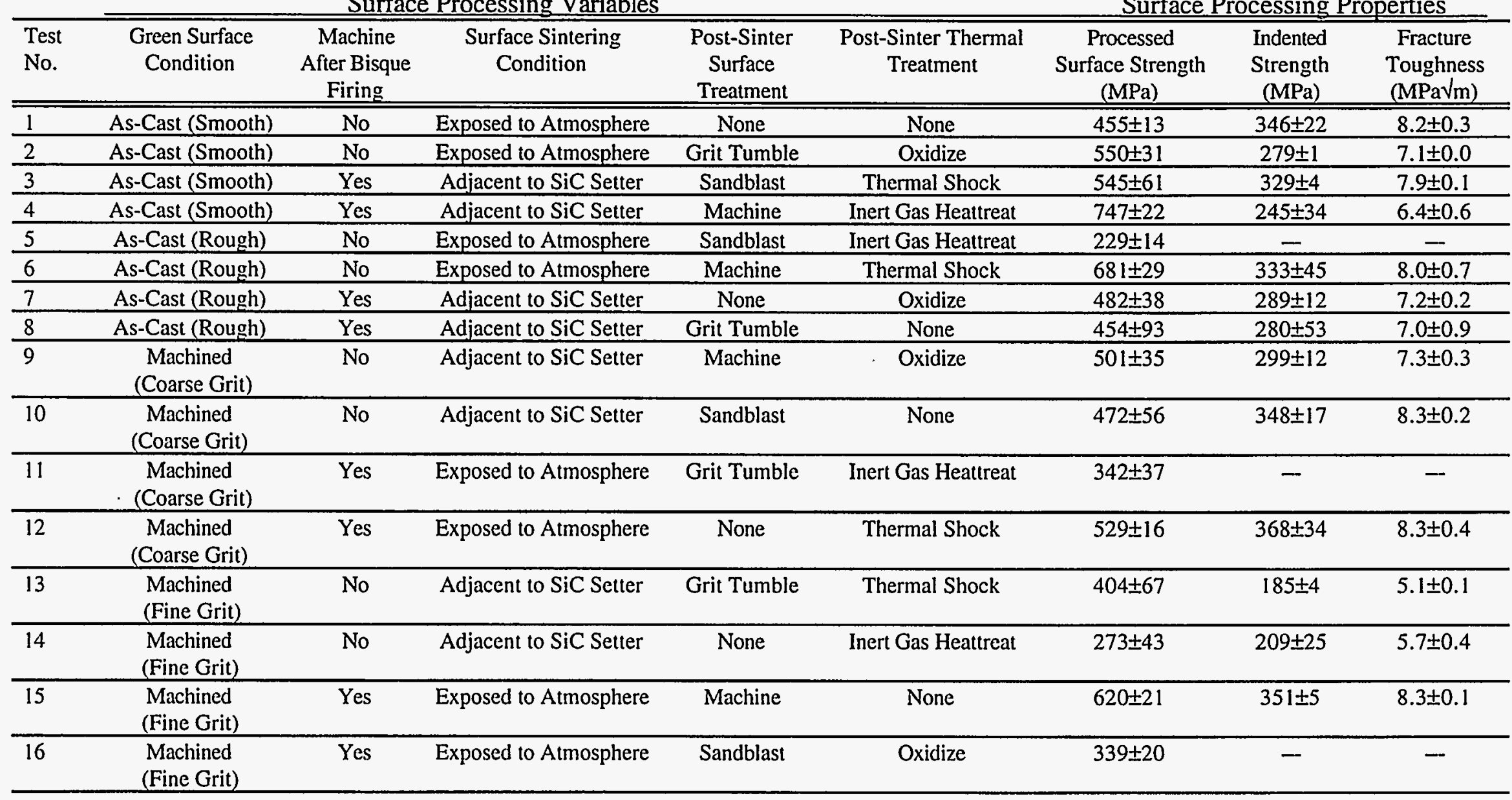


Table 3. Results from Taguchi experimental array to identify important surface property variables affecting the final properties of the sintered silicon nitride materials. Samples of gas pressure sintered $\mathrm{Si}_{3} \mathrm{~N}_{4}-\mathrm{Sr}_{2} \mathrm{La}_{4} \mathrm{Yb}_{4}\left(\mathrm{SiO}_{4}\right)_{6} \mathrm{O}_{2}$ composition.

\begin{tabular}{|c|c|c|c|c|c|c|c|c|}
\hline \multicolumn{6}{|c|}{ Surface Processing Variables } & \multicolumn{3}{|c|}{ Surface Processing Properties } \\
\hline $\begin{array}{l}\text { Test } \\
\text { No. }\end{array}$ & $\begin{array}{c}\text { Green Surface } \\
\text { Condition } \\
.\end{array}$ & $\begin{array}{c}\text { Machine } \\
\text { After Bisque } \\
\text { Firing } \\
\end{array}$ & $\begin{array}{c}\text { Surface Sintering } \\
\text { Condition }\end{array}$ & $\begin{array}{c}\text { Post-Sinter } \\
\text { Surface } \\
\text { Treatment } \\
\end{array}$ & $\begin{array}{c}\text { Post-Sinter Thermal } \\
\text { Treatment }\end{array}$ & $\begin{array}{c}\text { Processed } \\
\text { Surface Strength } \\
(\mathrm{MPa}) \\
\end{array}$ & $\begin{array}{c}\text { Indented } \\
\text { Strength } \\
(\mathrm{MPa}) \\
\end{array}$ & $\begin{array}{c}\text { Fracture } \\
\text { Toughness } \\
(\mathrm{MPa} / \mathrm{m}) \\
\end{array}$ \\
\hline 1 & As-Cast (Smooth) & No & Exposed to Atmosphere & None & None & $801 \pm 83$ & $408 \pm 2$ & $9.5 \pm 0.1$ \\
\hline 2 & As-Cast (Smooth) & No & Exposed to Atmosphere & Grit Tumble & Oxidize & $464 \pm 35$ & $309 \pm 55$ & $7.9 \pm 1.2$ \\
\hline 3 & As-Cast (Smooth) & Yes & Adjacent to SiC Setter & Sandblast & Thermal Shock & $571 \pm 84$ & $412 \pm 61$ & $9.8 \pm 1.5$ \\
\hline 4 & As-Cast (Smooth) & Yes & Adjacent to SiC Setter & Machine & Inert Gas Heattreat & $566 \pm 29$ & $113 \pm 12$ & $3.6 \pm 0.4$ \\
\hline 5 & As-Cast (Rough) & No & Exposed to Atmosphere & Sandblast & Inert Gas Heattreat & $183 \pm 31$ & - & - \\
\hline 6 & As-Cast (Rough) & No & Exposed to Atmosphere & Machine & Thermal Shock & $819 \pm 56$ & $338 \pm 21$ & $8.1 \pm 0.4$ \\
\hline 7 & As-Cast (Rough) & Yes & Adjacent to SiC Setter & None & Oxidize & $396 \pm 187$ & $354 \pm 9$ & $8.8 \pm 0.4$ \\
\hline 8 & As-Cast (Rough) & Yes & Adjacent to SiC Setter & Grit Tumble & None & $548 \pm 96$ & $429 \pm 47$ & $10.2 \pm 1.2$ \\
\hline 9 & $\begin{array}{c}\text { Machined } \\
\text { (Coarse Grit) }\end{array}$ & No & Adjacent to SiC Setter & Machine & Oxidize & $574 \pm 128$ & $111 \pm 8$ & $3.6 \pm 0.2$ \\
\hline 10 & $\begin{array}{c}\text { Machined } \\
\text { (Coarse Grit) }\end{array}$ & No & Adjacent to SiC Setter & Sandblast & None & - & - & - \\
\hline 11 & $\begin{array}{c}\text { Machined } \\
\text { (Coarse Grit) }\end{array}$ & Yes & Exposed to Atmosphere & Grit Tumble & Inert Gas Heattreat & $482 \pm 111$ & $258 \pm 37$ & $6.6 \pm 0.7$ \\
\hline 12 & $\begin{array}{c}\text { Machined } \\
\text { (Coarse Grit) }\end{array}$ & Yes & Exposed to Atmosphere & None & Thermal Shock & $676 \pm 32$ & $368 \pm 9$ & $8.7 \pm 0.3$ \\
\hline 13 & $\begin{array}{l}\text { Machined } \\
\text { (Fine Grit) }\end{array}$ & No & Adjacent to SiC Setter & Grit Tumble & Thermal Shock & $560 \pm 64$ & $514 \pm 149$ & $11.6 \pm 2.6$ \\
\hline 14 & $\begin{array}{l}\text { Machined } \\
\text { (Fine Grit) }\end{array}$ & No & Adjacent to SiC Setter & None & Inert Gas Heattreat & - & - & - \\
\hline 15 & $\begin{array}{l}\text { Machined } \\
\text { (Fine Grit) }\end{array}$ & Yes & Exposed to Atmosphere & Machine & None & $833 \pm 85$ & $387 \pm 6$ & $8.9 \pm 0.1$ \\
\hline 16 & $\begin{array}{c}\text { Machined } \\
\text { (Fine Grit) }\end{array}$ & Yes & Exposed to Atmosphere & Sandblast & Oxidize & $535 \pm 44$ & $222 \pm 17$ & $6.0 \pm 0.4$ \\
\hline
\end{tabular}


Table 6. Test matrix to determine effects of $\mathrm{B}_{-} \mathrm{Si}_{3} \mathrm{~N}_{4}$ Content and type for samples fabricated at ORNL.

\begin{tabular}{|c|c|c|c|c|}
\hline $\begin{array}{l}\text { Test } \\
\text { No. }\end{array}$ & Grain Boundary Phase Composition & $\begin{array}{l}\text { Rare Earth } \\
\text { Addition }\end{array}$ & $\begin{array}{c}{\mathrm{B}-\mathrm{Si}_{3} \mathrm{~N}_{4}} \\
\text { Content }(\%)\end{array}$ & $\begin{array}{c}\mathrm{B}-\mathrm{Si}_{3} \mathrm{~N}_{4} \\
\text { Seed Source }\end{array}$ \\
\hline$\overline{\overline{\mathrm{MR}}-1}$ & $\mathrm{Sr}_{2} \mathrm{La}_{4} \mathrm{Yb}_{4}\left(\mathrm{SiO}_{4}\right)_{6} \mathrm{O}_{2}(8 \mathrm{eq} \%$ ox $)$ & Powder & 0 & -- \\
\hline MR-2 & $\mathrm{Sr}_{2} \mathrm{La}_{4} \mathrm{Yb}_{4}\left(\mathrm{SiO}_{4}\right)_{6} \mathrm{O}_{2}(8 \mathrm{eq} \%$ ox $)$ & Powder & 25 & ORNL \#1 \\
\hline MR-3 & $\mathrm{Sr}_{2} \mathrm{La}_{4} \mathrm{Yb}_{4}\left(\mathrm{SiO}_{4}\right)_{6} \mathrm{O}_{2}(8 \mathrm{eq} \%$ ox $)$ & Powder & 25 & ORNL \#2 \\
\hline MR-4 & $\mathrm{Sr}_{2} \mathrm{La}_{4} \mathrm{Yb}_{4}\left(\mathrm{SiO}_{4}\right)_{6} \mathrm{O}_{2}(8 \mathrm{eq} \%$ ox $)$ & Powder & 25 & ORNL \#3 \\
\hline MR-5 & $\mathrm{Sr}_{2} \mathrm{La}_{4} \mathrm{Yb}_{4}\left(\mathrm{SiO}_{4}\right)_{6} \mathrm{O}_{2}(8 \mathrm{eq} \%$ ox $)$ & Powder & 25 & ORNL \#4 \\
\hline MR-6 & $\mathrm{Sr}_{2} \mathrm{La}_{4} \mathrm{Yb}_{4}\left(\mathrm{SiO}_{4}\right)_{6} \mathrm{O}_{2}(8 \mathrm{eq} \%$ ox $)$ & Powder & 25 & Shin-Etsu \\
\hline MR-7 & $\mathrm{Sr}_{2} \mathrm{La}_{4} \mathrm{Yb}_{4}\left(\mathrm{SiO}_{4}\right)_{6} \mathrm{O}_{2}(8 \mathrm{eq} \%$ ox $)$ & Powder & 50 & ORNL \#1 \\
\hline MR-8 & $\mathrm{Sr}_{2} \mathrm{La}_{4} \mathrm{Yb}_{4}\left(\mathrm{SiO}_{4}\right)_{6} \mathrm{O}_{2}(8 \mathrm{eq} \%$ ox $)$ & Powder & 5 & ORNL \#1 \\
\hline MR-9 & $\mathrm{Y}_{2} \mathrm{Si}_{2} \mathrm{O}_{7}$ (5 eq. $\%$ ox.) & Powder & 0 & -- \\
\hline MR-10 & $\mathrm{Y}_{2} \mathrm{Si}_{2} \mathrm{O}_{7}$ (5 eq. $\%$ ox.) & Powder & 25 & ORNL \#1 \\
\hline MR-11 & $\mathrm{Sr}_{2} \mathrm{La}_{4} \mathrm{Yb}_{4}\left(\mathrm{SiO}_{4}\right)_{6} \mathrm{O}_{2}(8 \mathrm{eq} \%$ ox $)$ & Powder & 50 & ORNL \#2 \\
\hline MR-12 & $\mathrm{Sr}_{2} \mathrm{La}_{4} \mathrm{Yb}_{4}\left(\mathrm{SiO}_{4}\right)_{6} \mathrm{O}_{2}$ (8 eq \% ox) & Powder & 5 & ORNL \#2 \\
\hline
\end{tabular}

Table 7. Test matrix to determine effects of $\mathrm{B}-\mathrm{Si}_{3} \mathrm{~N}_{4}$ content and rare addition method for samples fabricated at MER.

\begin{tabular}{lllcc}
\hline $\begin{array}{l}\text { Test } \\
\text { No. }\end{array}$ & Composition & $\begin{array}{l}\text { Rare Earth } \\
\text { Addition }\end{array}$ & $\begin{array}{c}\mathrm{B}_{-} \mathrm{Si}_{3} \mathrm{~N}_{4} \\
\text { Content (\%) }\end{array}$ & $\begin{array}{c}\beta-\mathrm{Si}_{3} \mathrm{~N}_{4} \\
\text { Seed Source }\end{array}$ \\
\hline \hline $\mathrm{MC}-1$ & $4 \% \mathrm{Nd}_{2} \mathrm{O}_{3}-1 \% \mathrm{Al}_{2} \mathrm{O}_{3}$ & Powder & 0 & -- \\
$\mathrm{MC}-2$ & $4 \% \mathrm{Nd}_{2} \mathrm{O}_{3}-1 \% \mathrm{Al}_{2} \mathrm{O}_{3}$ & Coating & 0 & - \\
$\mathrm{MC}-3$ & $4 \% \mathrm{Nd}_{2} \mathrm{O}_{3}-1 \% \mathrm{Al}_{2} \mathrm{O}_{3}$ & Coating & 25 & Shin-Etsu \\
$\mathrm{MC}-4$ & $4 \% \mathrm{Nd}_{2} \mathrm{O}_{3}-1 \% \mathrm{Al}_{2} \mathrm{O}_{3}$ & Coating & 50 & Shin-Etsu \\
$\mathrm{MC}-5$ & $4 \% \mathrm{Nd}_{2} \mathrm{O}_{3}-1 \% \mathrm{Al}_{2} \mathrm{O}_{3}$ & Coating & 5 & Shin-Etsu \\
$\mathrm{MC}-6$ & $4 \% \mathrm{Y}_{2} \mathrm{O}_{3}-1 \% \mathrm{Al}_{2} \mathrm{O}_{3}$ & Powder & 0 & - \\
$\mathrm{MC}-7$ & $4 \% \mathrm{Y}_{2} \mathrm{O}_{3}-1 \% \mathrm{Al}_{2} \mathrm{O}_{3}$ & Coating & 0 & - \\
$\mathrm{MC}-8$ & $\mathrm{Y}_{2} \mathrm{Si}_{2} \mathrm{O}_{7}(5$ eq. $\%$ ox.) & Powder & 0 & - \\
$\mathrm{MC}-9$ & $\mathrm{Y}_{2} \mathrm{Si}_{2} \mathrm{O}_{7}(5$ eq. \% ox.) & Coating & 0 & - \\
$\mathrm{MC}-10$ & $\mathrm{Y}_{2} \mathrm{Si}_{2} \mathrm{O}_{7}(5$ eq. $\%$ ox.) & Coating & 25 & Shin-Etsu \\
\hline
\end{tabular}


Table 8. Summary of results on densification of samples from CRADA with MER Corp. gas pressure sintered at $1900^{\circ} \mathrm{C} / 1950^{\circ} \mathrm{C}$.

\begin{tabular}{lcccc}
\hline Sample No. & $\begin{array}{c}\text { Density } \\
\left(\mathrm{g} / \mathrm{cm}^{3}\right)\end{array}$ & $\begin{array}{c}\text { Density } \\
\text { (\% T. D.) }\end{array}$ & $\begin{array}{c}\text { Flexural } \\
\text { Strength (MPa) }\end{array}$ & $\begin{array}{c}\text { Fracture } \\
\text { Toughness, } \\
(\mathrm{MPa} \text { m })\end{array}$ \\
\hline \hline MR-1 & 3.50 & 99.5 & 646 & 6.6 \\
MR-2 & 3.53 & 100.3 & 721 & 6.4 \\
MR-3 & 3.54 & 100.5 & 704 & 6.3 \\
MR-4 & 3.53 & 100.4 & 665 & 8.2 \\
MR-5 & 3.54 & 100.5 & 498 & 7.9 \\
MR-6 & 3.31 & 94.0 & 359 & 7.7 \\
MR-7 & 3.52 & 99.9 & 425 & 7.7 \\
MR-8 & 3.51 & 99.6 & 514 & 8.7 \\
MR-9 & 3.22 & 96.1 & 550 & 6.9 \\
MR-10 & 3.11 & 92.9 & 464 & 9.0 \\
MR-11 & 3.52 & 100.0 & 682 & 8.1 \\
MR-12 & 3.50 & 99.4 & 616 & 5.6 \\
MC-1 & 3.22 & 98.1 & 627 & 8.5 \\
MC-2 & 3.22 & 98.3 & 529 & 5.5 \\
MC-3 & 2.81 & 85.7 & -- & - \\
MC-4 & 2.66 & 81.2 & -- & - \\
MC-5 & 3.18 & 97.0 & 669 & 6.1 \\
MC-6 & 3.18 & 97.9 & 651 & 5.9 \\
MC-7 & 3.15 & 97.0 & 348 & 6.2 \\
MC-8 & 3.23 & 96.4 & 562 & 6.4 \\
MC-9 & 3.05 & 91.0 & 508 & 6.3 \\
MC-10 & 3.16 & 94.4 & 540 & 5.7 \\
\hline
\end{tabular}




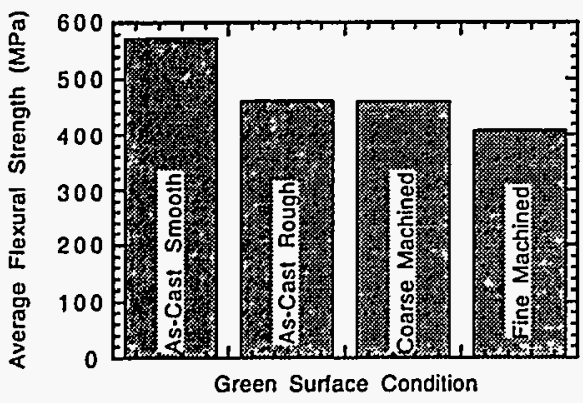

(a)

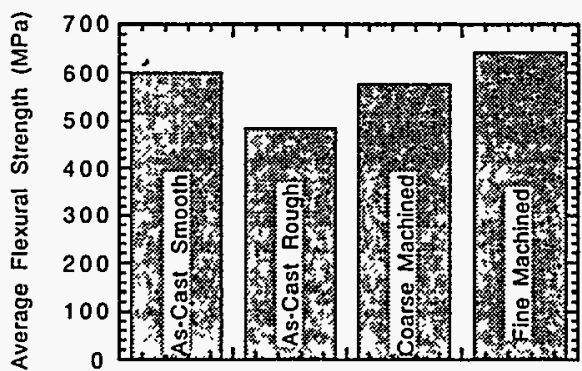

(b)

Green Surface Condition

Fig. 1. Average flexural strength for gas-pressure sintered samples with various green surface conditions. (a) $\mathrm{Si}_{3} \mathrm{~N}_{4}-6 \% \quad \mathrm{Y}_{2} \mathrm{O}_{3}-2 \% \quad \mathrm{Al}_{2} \mathrm{O}_{3}$ and (b) $\mathrm{Si}_{3} \mathrm{~N}_{4}-\mathrm{Sr}_{2} \mathrm{La}_{4} \mathrm{Yb}_{4}\left(\mathrm{SiO}_{4}\right)_{6} \mathrm{O}_{2}$ compositions samples.

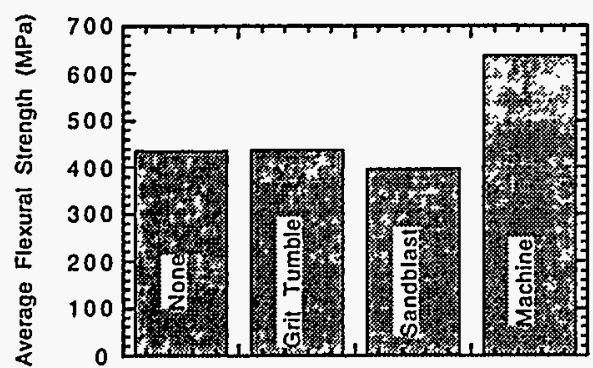

(a)
Post Sinter Surface Treatment

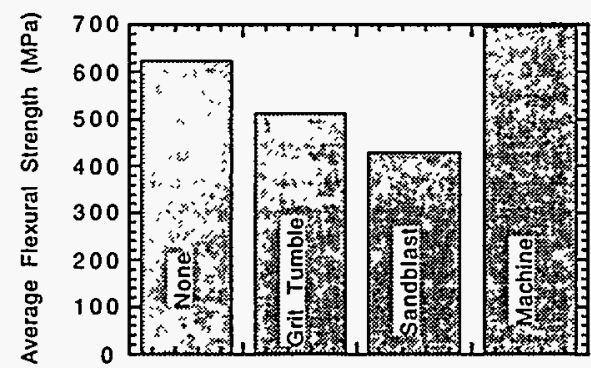

(b)

Post Sinter Surface Treatment

Fig. 2. Average flexural strength for gas-pressure sintered samples with various post sintering surface treatments. (a) $\mathrm{Si}_{3} \mathrm{~N}_{4}-6 \% \quad \mathrm{Y}_{2} \mathrm{O}_{3}-2 \% \quad \mathrm{Al}_{2} \mathrm{O}_{3}$ and (b) $\mathrm{Si}_{3} \mathrm{~N}_{4}-$ $\mathrm{Sr}_{2} \mathrm{La}_{4} \mathrm{Yb}_{4}\left(\mathrm{SiO}_{4}\right)_{6} \mathrm{O}_{2}$ compositions samples.

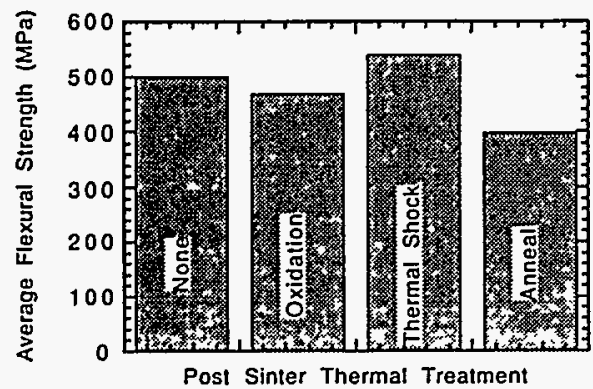

(a)

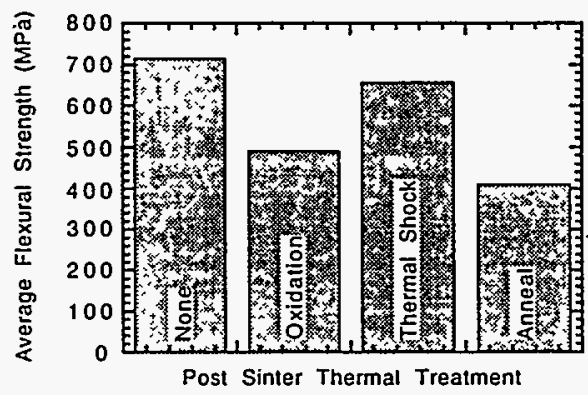

(b)

Fig. 3. Average flexural strength for gas-pressure sintered samples with various post sintering thermal treatments. (a) $\mathrm{Si}_{3} \mathrm{~N}_{4}-6 \% \quad \mathrm{Y}_{2} \mathrm{O}_{3}-2 \% \quad \mathrm{Al}_{2} \mathrm{O}_{3}$ and (b) $\mathrm{Si}_{3} \mathrm{~N}_{4}-$ $\mathrm{Sr}_{2} \mathrm{La}_{4} \mathrm{Yb}_{4}\left(\mathrm{SiO}_{4}\right)_{6} \mathrm{O}_{2}$ compositions sam-les. 


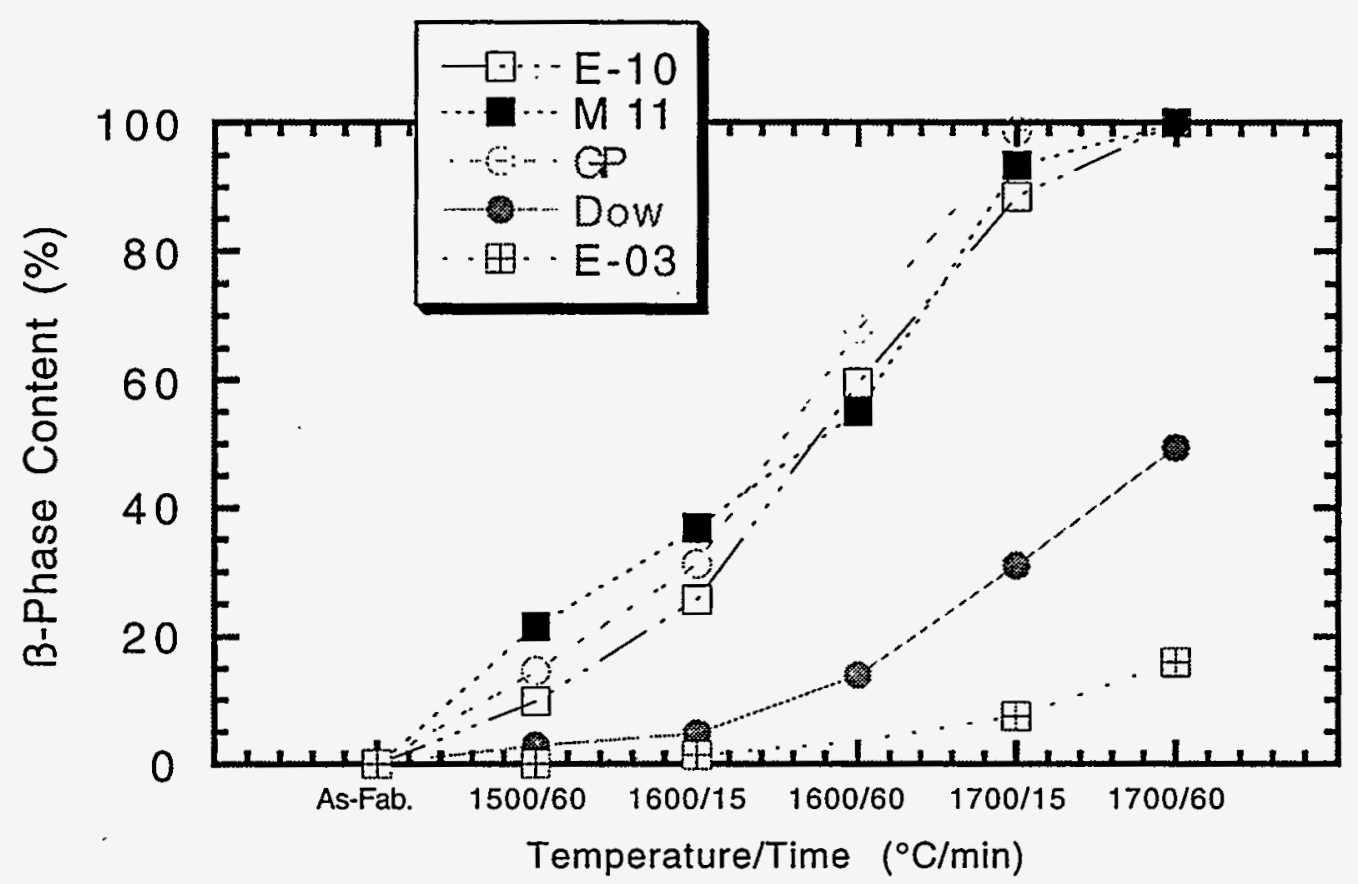

Figure 4. B-Phase content for various silicon nitride powder types heated at selected temperatures and times. Sintering additives for all samples were $6 \% \mathrm{Y}_{2} \mathrm{O}_{3}$ and $2 \% \mathrm{Al}_{2} \mathrm{O}_{3}$. 


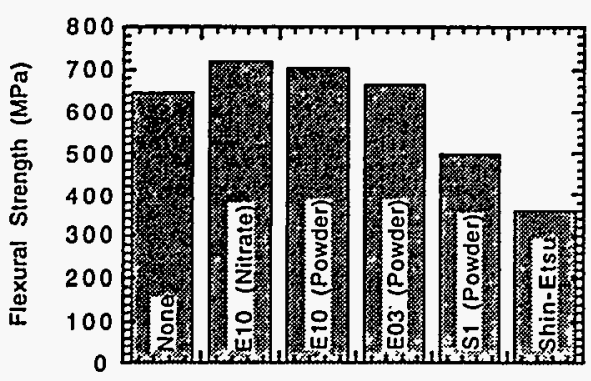

(a)

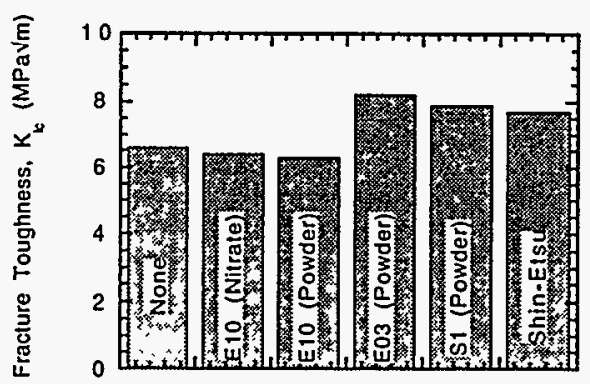

(b)

Fig. 5. Effect of $\beta$-seed type on the (a) flexural strength and (b) fracture toughness for gaspressure sintered silicon nitride with $\mathrm{Si}_{3} \mathrm{~N}_{4}-\mathrm{Sr}_{2} \mathrm{La}_{4} \mathrm{Yb}_{4}\left(\mathrm{SiO}_{4}\right)_{6} \mathrm{O}_{2}$ composition.

(a)

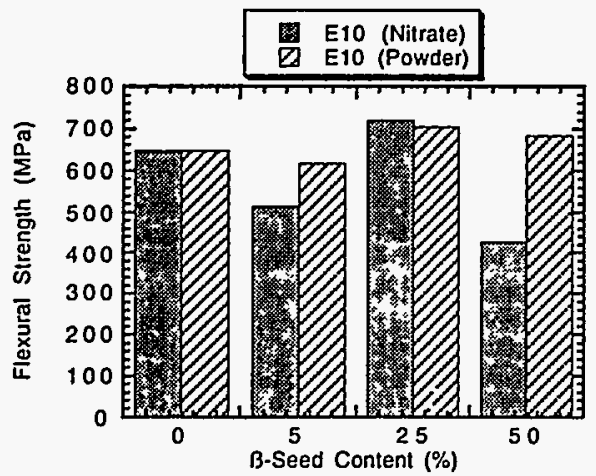

Fig. 6. Effect of $B$-seed content on the (a) flexural strength and (b) fracture toughness for gas-pressure sintered silicon nitride with $\mathrm{Si}_{3} \mathrm{~N}_{4}-\mathrm{Sr}_{2} \mathrm{La}_{4} \mathrm{Yb}_{4}\left(\mathrm{SiO}_{4}\right)_{6} \mathrm{O}_{2}$ composition. 


\title{
1.2.4 Low Expansion Materials
}

\section{W. B. S. Element 1.2.4.3 \\ CHARACTERIZATION AND TESTING OF \\ LOW EXPANSION CERAMIC MATERIALS}

\author{
S. Shanmugham and D. P. Stinton
}

\section{Objective/Scope}

Insulated exhaust portliners are needed in advanced diesel engines to increase engine fuel efficiency by increasing the combustion temperatures and reducing the combustion heat that is lost through the head and into the water cooling system. Low expansion materials have potential for this application due to their very low thermal conductivity, extraordinary thermal shock resistance, and reduction of attachment stresses. Thermal shock resistance is critical because the shape of the portliners requires that they be cast into the metallic cylinder head. Functioning exhaust portliners are inaccessible after they are cast into cylinder heads and hence, must not require maintenance for the life of the head $(\sim 1$ million miles). Contracts have been placed with Golden Technologies, Inc., formerly Coors Ceramic Co., and LoTEC., Inc., to develop cost effective processes for the fabrication of portliners. Coors is investigating $\mathrm{Al}_{2} \mathrm{TiO}_{5}$ and $\mathrm{Ca}_{1-x} \mathrm{Mg}_{\mathrm{x}} \mathrm{Zr}_{4} \mathrm{P}_{6} \mathrm{O}_{24}$, while LoTEC is investigating $\mathrm{Ba}_{1+\mathrm{x}} \mathrm{Zr}_{4} \mathrm{P}_{6-2 x} \mathrm{Si}_{2 x} \mathrm{O}_{24}(\mathrm{BaZPS})$ and $\mathrm{Ca}_{1-\mathrm{x}} \mathrm{Sr}_{\mathrm{x}} \mathrm{Zr}_{4} \mathrm{P}_{6} \mathrm{O}_{24}$ (CSZP). ORNL is assisting Golden Technologies and LoTEC with the characterization and evaluation of their compositions.

\section{Technical Highlights}

A systematic investigation of the mechanical and thermal properties of BaZPS ceramics as a function of composition ( $\mathrm{Si}$ at\%) and grain size has been initiated. Five compositions $(x=0,0.175,0.25$, 0.375 , and 0.500 ) were synthesized from stoichiometric proportions of the reagent grade oxides using a solid-state reaction method and were sintered at $1600^{\circ} \mathrm{C}$ for 3000 minutes. To determine the influence of the grain size, three compositions ( $x=0,0.175$ and 0.500$)$ were additionally sintered for 30 and 300 minutes to result in smaller grain sized samples. In addition, a systematic investigation of the mechanical properties of the CSZP with $\mathrm{x}=0.5$ (CS50) ceramic has been initiated. In this semi-annual report, the hardness results for BaZPS with $\mathrm{x}=0$ and 0.5 as a function of grain size along with the high temperature flexure strength results for CS50 are presented. 
The grain sizes were determined from the optical micrographs of the etched specimens and the results reported are an average obtained from five micrographs. The grain sizes of the BaZPS composition with $\mathrm{x}=0$ sintered for 30,300 , and $3000 \mathrm{~min}$ were $1.83 \mu \mathrm{m}, 2.70 \mu \mathrm{m}$ and $5.08 \mu \mathrm{m}$, respectively. The grain sizes of the BaZPS composition with $\mathrm{x}=0$ sintered for 30,300 , and $3000 \mathrm{~min}$ were $1.36 \mu \mathrm{m}, 1.91 \mu \mathrm{m}$ and $2.67 \mu \mathrm{m}$, respectively.

The hardness testing was conducted on a Tukon Series 200 hardness tester (Wilson Instruments, Inc.) and the BaZPS samples used were $12 \times 4 \times 3 \mathrm{~mm}$. The samples were mounted with the $12 \times$ $4 \mathrm{~mm}$ side facing the die and epoxy was poured over it and allowed to set for $16 \mathrm{~h}$. The specimens were then removed from the die and an identification mark was engraved. The samples were ground parallel using a 200 grit, resinoid bonded diamond grinding wheel on a surface grinder. The samples were rough polished using a $6 \mu \mathrm{m}$ diamond paste on a wire mesh cloth followed by rough polishing utilizing a $6 \mu \mathrm{m}$ diamond paste on a perforated cloth. Final polishing was carried out in two steps. First the samples were polished using a $3 \mu \mathrm{m}$ diamond paste on a texmet cloth. Then, the sample was polished using a $0.5 \mu \mathrm{m}$ diamond paste on a nylon cloth to obtain an optical surface finish.

The hardness indentations were made using a Knoop indenter with loads of 50-300 gms at a constant loading time of $10 \mathrm{sec}$. The diagonal of the indentations were measured' using a VIA-110 video hardness measurement system, which is attached to the hardness tester. The Knoop's hardness was then calculated using the standard formula.

CS50 was synthesized from stoichiometric proportions of the reagent grade oxides using a solid-state reaction method. A ceramic slip of CS50 was prepared with water as the carrier medium with an appropriate binder and a dispersant. The slip was vibratory milled for $8 \mathrm{~h}$ and cast into tiles of $63.5 \times 63.5 \times 9.5 \mathrm{~mm}$. The solidified tiles were bisque fired at an appropriate temperature to remove the binder and the dispersant. The tiles were then sintered at $1550^{\circ} \mathrm{C}$ in air for $4 \mathrm{~h}$. The tiles were then surface ground and cut into test specimens of $3 \times 4 \times 50 \mathrm{~mm}$. The test samples had a density of $2.75 \mathrm{~g} / \mathrm{cm}^{3}$.

LoTec., Inc has reported the properties of CS50 as summarized in Table 1. 
Table 1. Material Properties of CS50

\begin{tabular}{|l|l|}
\hline Property & Value \\
\hline Theoretical Density & $3.3 \mathrm{~g} / \mathrm{cm}^{3}$ \\
Flexural strength at $25^{\circ} \mathrm{C}$ & $75 \pm 5 \mathrm{MPa}$ \\
Coefficient of thermal expansion & $3.0 \times 10^{-6} /{ }^{\circ} \mathrm{C}$ \\
Modulus & $65 \mathrm{GPa}$ \\
\hline
\end{tabular}

The flexural strength of CS50 was determined using a specially designed flexure test system capable of separately testing up to three test specimens in series. The testing was conducted using a four-point bend fixture with $40 \mathrm{~mm}$ and $20 \mathrm{~mm}$ outer and inner spans, respectively. Three specimens were each tested at $1000^{\circ} \mathrm{C}$ and $1200^{\circ} \mathrm{C}$ after soaking for 15 minutes.

The hardness test results for the BaZPS with $\mathrm{x}=0$ sintered for different time periods are summarized in Table 2 . It was observed that the hardness values for BaZPS with $\mathrm{x}=0$ increased with increasing sintering time. Also, the hardness values decreased with increase in indentation loads for BaZPS with $\mathrm{x}=0$.

Table 2. Hardness results for BaZPS with $\mathrm{x}=0$ as a function of sintering time

\begin{tabular}{|l|c|c|c|c|}
\hline Time (min) & \multicolumn{4}{|c|}{ Hardness (GPa) } \\
\cline { 2 - 5 } Load (g) $\rightarrow>$ & 50 & 100 & 200 & 300 \\
\hline 30 & $4.08 \pm 0.09$ & $3.10 \pm 0.06$ & $2.75 \pm 0.05$ & $2.71 \pm 0.03$ \\
\hline 300 & $4.25 \pm 0.14$ & $3.49 \pm 0.04$ & $3.03 \pm 0.04$ & $3.05 \pm 0.05$ \\
\hline 3000 & $4.42 \pm 0.10$ & $4.12 \pm 0.04$ & $3.45 \pm 0.08$ & $3.29 \pm 0.10$ \\
\hline
\end{tabular}

The hardness test results for the BaZPS with $\mathrm{x}=0.5$ sintered for different time periods are summarized in Table 3. It was observed that the hardness values for BaZPS with $\mathrm{x}=0.5$ increased with increasing sintering time. Also, the hardness values decreased with increase in indentation loads for BaZPS with $\mathrm{x}=0.5$. 
Table 3. Hardness results for BaZPS with $\mathrm{x}=0.5$ as a function of sintering time

\begin{tabular}{|l|c|c|c|c|}
\hline Time (min) & \multicolumn{4}{|c|}{ Hardness (GPa) } \\
\cline { 2 - 5 } Load (g) $>$ & 50 & 100 & 200 & 300 \\
\hline 30 & $1.22 \pm 0.03$ & $1.23 \pm 0.03$ & $1.12 \pm 0.01$ & $1.12 \pm 0.01$ \\
\hline 300 & $1.56 \pm 0.08$ & $1.34 \pm 0.04$ & $1.29 \pm 0.05$ & $1.29 \pm 0.03$ \\
\hline 3000 & $3.18 \pm 0.19$ & $2.72 \pm 0.04$ & $2.46 \pm 0.04$ & $2.41 \pm 0.06$ \\
\hline
\end{tabular}

Flexure strength results for CS50 are summarized in Table 4. It was observed that there was no variation in flexural strength of CS50 with temperature.

Table 4. Flexure strength results for CS50

\begin{tabular}{|c|c|}
\hline Temperature $\left({ }^{\circ} \mathrm{C}\right)$ & Flexure Strength (MPa) \\
\hline $\begin{array}{c}25 \text { (LoTec Result) } \\
1000 \\
1200\end{array}$ & $\begin{array}{l}75 \pm 5 \\
77 \pm 5 \\
82 \pm 4\end{array}$ \\
\hline
\end{tabular}

\section{Reference}

None

\section{Milestones}

On Schedule

\section{Communications/Visits/Travel}

D. P. Stinton traveled to Chicago on September 21, 1995 to conduct a Kick-Off Meeting for the Low-Cost Manufacturing of NZP Powders contact. In attendance at the meeting were representatives of DOE, LoTEC, Particle Technology, Inc., Nextech Materials, Ltd., Catalytica, and Magnesium Elektron, Inc.

D. P. Stinton attended the Annual Contractors Coordination Meeting during October 24-26, 1995 in Dearborn, Michigan

D. P. Stinton traveled to Salt Lake City December 6, 199.5 to meet Debbie Haught from DOE, Randy Stafford from Cummins, and 
the people from LoTEC about the fabrication of NZP portliners for casting trials at Cummins.

D. P. Stinton visited Nextech Materials, Ltd. in Cleveland, Ohio and Particle Technology, Inc. in Hanover, MD on January 30 and 31, 1996 to discuss the fabrication of low-cost NZP powders.

D. P. Stinton traveled to Washington, D.C. January 31, 1996 and made a presentation to Bob Schulz and John Fairbanks that reviewed the progress on Low-Expansion Ceramics and Low-Cost NZP Powders Programs.

Problems Encountered

None 


\section{Development of NZP Ceramic Based "Cast-in-Place" Diesel Engine Port Liners}

Rama Nageswaran, Jack Zheng, and Santosh Y. Limaye (LoTEC, Inc.).

\section{Objective/Scope}

The overall objective of this research is to develop sodium-zirconium-phosphate (NZP) ceramic based "cast-in-place" diesel engine port liners. Specific objectives are: (1) Development and optimization of the overall insulation system, (2) Refinement of compliant layer formation process around the ceramic insulation system, (3) Development and adaptation of cost-effective powder and material fabrication processes, and (4) Creation of database of high temperature properties (stability in diesel exhaust environment, thermal cycling, thermal shock etc.).

\section{Technical Progress}

The following summarizes work completed or begun during the last six-month period, October 1995 and ending March 1996, in Phase II of this program. Detailed description of the progress in each area has also been provided.

(I) Penn State completed investigative studies involving (a) Acoustic Emission as a tool for analyzing microcracking behavior in NZP ceramics and (b) Low Cost Combustion Synthesis of NZP (BS-25 and CS-50) powders;

(II) Characterization of properties of various compositions in the CSS' $\left(\mathrm{Ca}_{(1+\mathrm{x}) / 2} \mathrm{Sr}_{(1+\mathrm{x}) / 2} \mathrm{Zr}_{4} \mathrm{P}_{6}\right.$. ${ }_{2 x} \mathrm{Si}_{2 \mathrm{x}} \mathrm{O}_{24}$ ) series, mainly room temperature and high temperature $\mathrm{X}$-ray analysis;

(III) Metal casting trials with (a) straight tubes of low modulus and strain tolerant BS-25 and CS-50 ceramics and (b) L-shaped liners of regular BS-25 and CS-50 ceramics;

(IV) (a) Characterization of thermal diffusivity of CS-50 and (b) Heat transfer modeling of metal casting around CS-50 was initiated but could not be completed because of problems at the computer facility and restricted CPU time;

(V) Diesel-engine exposure tests on cast-in-place straight tube exhaust ports having BS-25 and CS50 liners (underway) at Cummins Engine Company, Columbus, IN;

(VI) Demonstration of feasibility of slip casting complicated port liner shapes (S-shaped intake and Y-shaped exhaust) and metal casting around these shapes for making diesel engine ports.

\section{I.(a) Acoustic Emission Based Study of Microcracking in NZP Ceramics :}

Acoustic Emission based microcracking studies were conducted on $\mathrm{BS}\left(\mathrm{Ba}_{1+\mathrm{x}} \mathrm{Zr}_{4} \mathrm{P}_{6}\right.$. $\left.{ }_{2 x} \mathrm{Si}_{2 \mathrm{x}} \mathrm{O}_{24}\right)$ and $\mathrm{CS}^{\prime}\left(\mathrm{Ca}_{1-\mathrm{x}} \mathrm{Sr}_{\mathrm{x}} \mathrm{Zr}_{4} \mathrm{P}_{6} \mathrm{O}_{24}\right)$ series compositions for two different geometry of 
samples - bar and cylinder shaped. AE activity of all samples were studied during cooling from $1000^{\circ} \mathrm{C}$ to $\sim 55^{\circ} \mathrm{C}$. The effect of grain size, grain growth, differences in axial expansion coefficients etc. were correlated with the microcracking phenomena or AE activity. Results and analysis of the acoustic emission data compiled during these studies led to the following broadbased conclusions (more details can be found in the appendage to this report.):

1. Microcracking in a hexagonal polycrystalline material during cooling is a function of axial thermal expansion coefficients, $\alpha_{\mathrm{a}}$ and $\alpha_{\mathrm{c}}$. This dependency is different in the two cases: $\mathrm{i}$ ) $\alpha_{a}<\alpha_{c}$ and ii) $\alpha_{a}>\alpha_{c}$.

2. Both modulus of elasticity and AE activity, during cooling in BS-25, exhibit a moderate linear increase with increasing density due to a decrease in induced porosity.

3. Both modulus of elasticity and AE activity, during cooling in BS-25, exhibit a large linear increase with increasing density due to increase in sintering temperature.

4. The surface area and volume of the specimens determine the degree of microcracking during cooling from $1000^{\circ} \mathrm{C}$. A large surface-to-volume ratio reduces the microcracking.

5. In the uncycled specimens of the BS and CS' series, a significant amount of microcracking takes place during cooling from $1000^{\circ} \mathrm{C}$ to $110^{\circ} \mathrm{C}$. An additional $\sim 12 \%$ microcracking occurs between $110^{\circ} \mathrm{C}$ and $55^{\circ} \mathrm{C}$.

6. Below $55^{\circ} \mathrm{C}$, very little or no $\mathrm{AE}$ activity takes place.

7. An increase in thermal expansion below $55^{\circ} \mathrm{C}$ cannot be explained by the microcracking phenomenon.

8. Thermal cycling of anisotropic CS' and BS specimens leads to decreased microcracking and thermal expansion during cooling below $500^{\circ} \mathrm{C}$; increased bulk CTE, grain growth, decreased E-modulus, and increased flexural strength. The reduction in AE counts in these compositions can be attributed to $\sim 20 \%$ growth in the average grain size and as a result $\sim 20 \%$ reduction in grain boundary volume.

9. Thermal cycling of the near-isotropic BS-25 and CS-50 leads to an increase in microcracking and total thermal expansion during cooling below $500^{\circ} \mathrm{C}$, an increased bulk CTE. However, there is hardly any grain growth. At present, there is not any plausible explanation for this behavior.

10. The CS-37 composition exhibits AE behavior and mechanical properties intermediate to those of all the isotropic and anisotropic compositions. 


\section{(b) Low Cost Synthesis of NZP Materials (SCD) :}

The synthesis of BS- 25 and CS-50 by the combustion method using urea $\left(\mathrm{NH}_{2}-\mathrm{CO}-\mathrm{NH}_{2}\right)$ and metal complexes of different salts was successfully completed. The optimum amount of urea and ammonium nitrate to be used for making amorphous NZPs (BS-25 and CS-50) after combustion reaction were first determined.

Generally, the processing consisted of thorough mixing of the precursors in a large mortar with a few drops of water, whereupon the mix is transferred to a wide necked pyrex beaker, the volume of which is large enough to allow expansion of the powder mix $\sim 50$ to 100 times. The beaker is then inserted in an oven which is already heated to $500^{\circ} \mathrm{C}$. The mixture stays in the furnace for 5 minutes; during this period the temperature rises and there is intense foaming and flaming. The reacted powders are taken out (designated "as-reacted") and some of these powders heated to different temperatures for calcination $\left(800^{\circ} \mathrm{C}\right.$ to $\left.1300^{\circ} \mathrm{C}\right)$.

As mentioned in earlier reports, issues that were critical to overall success of the combustion synthesis process are: (i) reaction temperatures and their control, (ii) crystallinity, and (iii) total costs. The optimum temperature for initiation of the decomposition reactions involving urea and metal nitrates was found to be $<500^{\circ} \mathrm{C}$. After initiation of the combustion reaction, its sustenance was controlled by the amounts of urea and nitrates present. The urea : ammonium nitrate ratio also determined the yield of NZP phase and its crystallinity. The assynthesized BS-25 and CS-50 powders were mostly amorphous. Subsequent heat treatment of the amorphous powders at temperatures of up to $1300^{\circ} \mathrm{C}$ resulted in greatly enhanced crystallinity of the NZP phase.

After determining the optimum amounts of urea and ammonium nitrate, the following methods and precursors were used in attempts to synthesize BS-25 and CS-50. (Results from these reactions are discussed below.)

(i) $\mathrm{Ba} / \mathrm{Ca} / \mathrm{Sr} / \mathrm{Zr}$ nitrates $+\mathrm{NH}_{4} \mathrm{H}_{2} \mathrm{PO}_{4}(\mathrm{ADP})+\mathrm{Urea}+\mathrm{NH}_{4} \mathrm{NO}_{3}$.

(ii) $\mathrm{Ba} / \mathrm{Ca} / \mathrm{Sr}$ nitrates $+\mathrm{ZrO}_{2}+\mathrm{NH}_{4} \mathrm{H}_{2} \mathrm{PO}_{4}(\mathrm{ADP})+\mathrm{Urea}+\mathrm{NH}_{4} \mathrm{NO}_{3}$.

(iii) $\mathrm{Ba} / \mathrm{Ca} / \mathrm{Sr}$ nitrates $+\mathrm{ZrO}_{2}+\mathrm{ZrP}_{2} \mathrm{O}_{7}+\mathrm{NH}_{4} \mathrm{H}_{2} \mathrm{PO}_{4}(\mathrm{ADP})+\mathrm{Urea}+\mathrm{NH}_{4} \mathrm{NO}_{3}$.

(iv) $\mathrm{Ba} / \mathrm{Ca} / \mathrm{Sr}$ zirconates $+\mathrm{ZrP}_{2} \mathrm{O}_{7}+\mathrm{Urea}+\mathrm{NH}_{4} \mathrm{NO}_{3}$

(v) $\mathrm{Ba} / \mathrm{Ca} / \mathrm{Sr}$ zirconates $+\mathrm{ZrO}_{2}+\mathrm{NH}_{4} \mathrm{H}_{2} \mathrm{PO}_{4}(\mathrm{ADP})+\mathrm{Urea}+\mathrm{NH}_{4} \mathrm{NO}_{3}$.

Reaction routes (i), (ii), and (iii) : The as-reacted powders prepared from the nitrate precursors were nearly X-ray amorphous although containing NZP compositions only. This was evidenced by the $\mathrm{X}$-ray patterns of the $800^{\circ} \mathrm{C}$ and $1000^{\circ} \mathrm{C}$ heat-treated materials, which show 
nearly single phase $\mathrm{BS} 25$ and $\mathrm{CS} 50$. Very minor amounts of $\mathrm{ZrP}_{2} \mathrm{O}_{7}$ existed that disappeared after further heat treatments such as during bisquing and sintering.

The surface areas of the combustion synthesized powders seemed to be much higher than the calcined and milled powders made from the oxide reaction synthesis process, which have surface areas in the range of 2 to $12 \mathrm{~m}^{2} / \mathrm{g}$. The morphology of the particles as examined by SEM revealed irregular and flaky grains. This likely is responsible for the high surface area of the (SCD) combustion-synthesized powders.

Reaction routes (iv) and (v) : Because of the expensive nature of the metal nitrates, especially $\mathrm{Zr}$ nitrate, as an alternative source, unstabilized $\mathrm{ZrO}_{2}$ from Z-TECH Corp. with average particle size of $1.5 \mu \mathrm{m}$ was used for some of the experiments. Calcined $\mathrm{ZrP}_{2} \mathrm{O}_{7}$ from MEI Inc. was also employed either by itself or in a mixture with $\mathrm{ZrO}_{2}$. After reaction synthesis, some of the powders were heat-treated at $800^{\circ} \mathrm{C}$ and $1000^{\circ} \mathrm{C}$. All the powders were analyzed using X-ray diffraction. Table 1 provides the phase compositions (of reactions that involved ZTech $\mathrm{ZrO}_{2}$ ) of as-synthesized and the powders subsequently heated to 800 and $1000^{\circ} \mathrm{C}$.

It is clear from Table 1 , that the precursor routes involving $\mathrm{Z}$-Tech's $\mathrm{ZrO}_{2}$ did not produce any combustion reaction and result in the formation of any NZP phase. This is primarily attributed to the fact that $\mathrm{ZrO}_{2}$ and $\mathrm{ZrP}_{2} \mathrm{O}_{7}$ are mostly unreactive and remain so even at the highest reaction temperatures. The coarse particle sizes of the $\mathrm{ZrO}_{2}$ precursor may also have contributed to its inertness. New trials with a finer grade $\mathrm{DK}-1 \mathrm{ZrO}_{2}$ powder from a different vendor (Zirconia Sales, America) were then attempted. Whereas the use of coarse grained $\mathrm{ZrO}_{2}$ yielded very small amounts of crystalline NZP (BS-25 or CS-50) phase, fine grained $\mathrm{ZrO}_{2}$ yielded significant amounts of NZP. These yields increased with increasing temperature. Nearly single phase and fully crystalline NZP was obtained by heat treating at $1200^{\circ} \mathrm{C}$. Reaction routes (iv) and (v) that involved the fine-grained $\mathrm{DK}-1 \mathrm{ZrO}_{2}$ seem to be the most successful of all.

Economics : Approximate retail costs for each precursor and total cost for making $1 \mathrm{~kg}$. of BS-25 and CS-50 powder using these precursors and different reaction routes are shown in Table 2. From Table 2, it can be seen that the costs for producing BS-25 and CS-50 are $\sim \$ 50$ per $\mathrm{kg}$ when zirconates are used in place of nitrates as starting precursors. This represents a dramatic improvement in costs compared to the $\$ 250$ per $\mathrm{kg}$. costs when metal nitrates were being used. Further reduction in costs is easily attainable with the use of larger quantities of powders bought at wholesale prices. 
Powder \& Bulk Properties : Table 3 compares surface areas of powders obtained from the combustion synthesis (SCD) reaction methods with those from conventional oxide mixing method. From data in the table, it can be inferred that surface areas of the as-is SCD powders are comparable to those of conventionally processed ones except when nitrate precursors are used. It is interesting to note that the soluble precursors nitrates and phosphates take part in the foaming process to form a powder with an extremely large surface area. When the participants in the combustion process are a mixture of soluble phases and insoluble powders (zirconates) the surface area is much smaller. However, surface areas of all as-is powders are expected to decrease with heat treatment to form crystalline, single phase NZP powders.

BS-25 and CS-50 powders obtained from combustion synthesis process were ball milled for 8 hours followed by drying and screening. Test specimens in the form of pellets were then pressed $(210 \mathrm{MPa})$ and sintered at various temperatures. Measurements of sintered density and grain sizes were made. Table 4 summarizes sintering conditions, density data, and grain sizes as determined from SEM micrographs. Next, bars $5 \mathrm{~cm}$ long were pressed in molds (110MPa) and sintered at $1400^{\circ} \mathrm{C} / 10 \mathrm{hrs}$. These bars pressed to lower densities than pellets because of the geometry involved. Modulus of elasticity was measured on these bars and these data seemed to compare well with elastic modulii of bars of the same density obtained from powders processed using conventional oxide mixing and reaction process (see Table 5 and Figs. 1 and 2).

Summary : The following set of conclusions were reached from the studies on low cost combustion synthesis of NZP powders:

1. The combustion method using $\mathrm{Ca} / \mathrm{Sr} / \mathrm{Ba} / \mathrm{Zr}$ nitrates together with $\mathrm{ADP}, \mathrm{SiO}_{2}$ (microsilica), Urea, and $\mathrm{NH}_{4} \mathrm{NO}_{3}$ can be used for the synthesis of BS-25 and CS-50. The optimum amount of urea and $\mathrm{NH}_{4} \mathrm{NO}_{3}$ is $\sim 30$ and 20 mole/mole of NZP, respectively for BS-25 and CS-50. However, these powders need heat treatment to temperatures $\geq 1000^{\circ} \mathrm{C}$ to obtain nearly single phase and crystalline NZP powders.

2. Because of the high costs of the nitrate precursors, especially $\mathrm{Zr}$ nitrate, alternative starting materials were needed. Replacing the $\mathrm{Ca} / \mathrm{Sr} / \mathrm{Ba} / \mathrm{Zr}$ nitrates and the $\mathrm{ADP}$ with $\mathrm{Ca} / \mathrm{Sr} / \mathrm{Ba}$ zirconate and $\mathrm{ZrP}_{2} \mathrm{O}_{7}$ had a negative effect as the NZP phase was absent. Extra amounts of urea and $\mathrm{NH}_{4} \mathrm{NO}_{3}$ did not improve the synthesis of NZP phase.

3. One viable combustion synthesis route involving inexpensive precursors was successfully attained. This employs : (i) $\mathrm{Ca} / \mathrm{Sr}$ zirconates $+\mathrm{ADP}+\mathrm{ZrO}_{2}$ together with urea and $\mathrm{NH}_{4} \mathrm{NO}_{3}$ for $\mathrm{CS}-50$, and $\mathrm{Ba}$ zirconate $+\mathrm{ADP}+\mathrm{SiO}_{2}+\mathrm{ZrO}_{2}$. together with urea and $\mathrm{NH}_{4} \mathrm{NO}_{3}$ for BS25. Using fine grained $\mathrm{ZrO}_{2}$ dramatically improved the synthesis of the NZP phase. 
However, surface areas of as-is powders are significantly lowered when soluble nitrates are substituted by insoluble zirconates.

4. Cost per kg. for synthesis of BS-25 and CS-50 powders using combustion reactions can be brought down to about $\$ 50$ from $\$ 200$ by using zirconate precursors instead of nitrates. These costs are still higher than projected costs that would make the process commercially viable.

II. Characterization of NZP Ceramics - CS'S Series $\left(\mathrm{Ca}_{(1+x) / 2} \mathrm{Sr}_{(1+x) / 2} \mathrm{Zr}_{4} \mathrm{P}_{6-2 x} \mathrm{Si}_{2 x} \mathrm{O}_{24}\right)$ :

Previously synthesized CS'S10, CS'S25, and CS'S37 were subjected to high temperature $\mathrm{X}$-ray diffraction measurements. Figure 3 is a plot of the lattice parameters and lattice volume as a function of temperature. Figure 4 shows the axial thermal expansion data, together with the bulk thermal expansion data. Figure 5 provides the bulk thermal expansion and AE data of members of the CS'S series. The bulk thermal expansion decreases with increasing $\mathrm{x}$, and as expected, the $\mathrm{AE}$ counts of the same material are dependent on the sintering conditions and decrease with increasing $x$ in the material.

\section{Metal Casting Trials :}

(a) Low Modulus BS-25 and CS-50 : One trial each for low modulus BS-25 and CS-50 straight tubes involving casting of the metal around the ceramic was conducted to verify results of FEA. It can be recalled that because of the higher compliance of the low modulus materials as compared to the regular ones, FEA predicted thinner compliant layers for the former case $(2 \mathrm{~mm}$ vs. $3 \mathrm{~mm}$ for BS- 25 and $1.5 \mathrm{~mm}$ vs. $2 \mathrm{~mm}$ for CS-50) to obtain crack free cast-in-place ports. Casting trials corroborated these predictions, except for the appearance of a somewhat benign compression crack in the BS-25 low modulus tube. More trials are needed to verify the closeness of FEA predictions to actual. Such trials are underway. (Successfully cast ports will be sent to Cummins for diesel engine exhaust exposure tests .)

(b) L-shaped BS-25 and CS-50 Port Liners : Two trials each for BS-25 and CS-50 Lshaped tubes involving casting of the metal around the ceramic was conducted to test predictions of FEA obtained for straight tube port liners. Casting trials indicated that as with the straight tube port liners $2 \mathrm{~mm}$ and $3 \mathrm{~mm}$ thick compliant layers were adequate to result in successful ports of CS-50 and BS-25, respectively. In the upcoming reports, photographs of these L-shaped ports will be provided. Actual FEA of the L-shaped port-liners is still needed to assess if stresses 
in L-shaped liners are comparable to those in straight tube liners in spite of the bend. Such FEA is underway and is expected to be completed in the course of the project.

\section{IV. (a) Thermal diffusivity of CS-50 :}

Sintered cylindrical specimens of CS-50 were used (at Penn State) to measure thermal diffusivity. All surfaces of the test specimen were coated with a heat resistant black paint. The goal was to measure thermal diffusivity. Instead of the laser flash technique, a simpler method was used; which involved placing specimens on a substrate of platinum foil heated to constant temperatures of up to $900^{\circ} \mathrm{C}$. The thermal diffusivity, $h$, in a non-steady state thermal flow is given by the following relationship(1):

$$
\partial \mathrm{T} / \partial \mathrm{t}=\mathrm{h} \cdot \mathrm{d}^{2} \mathrm{~T} / \mathrm{d} \mathrm{x}^{2}
$$

where $t$ is the time, $T$ is the temperature, and $x=$ distance into the specimen from the substrate.

The disk shaped CS-50 specimen, with a surface area of $\sim 71.6 \mathrm{~mm}^{2}$ and a constant thickness $(1.99 \mathrm{~mm})$, was coated on each side with a heat resistant mix of carbon and platinum. It was then placed on the preheated platinum foil and the surface temperatures of the specimen was recorded as a function of time. The density of the CS-50 was $2.74 \mathrm{~g} / \mathrm{cm}^{3}$, which corresponds to a theoretical density of $83.3 \%$. In order to eliminate errors from heat resistances caused by the interfaces between platinum/specimen and specimen/thermocouple, a reference (BS-25) having nearly the same dimensions and geometry and a known thermal diffusivity was also measured.

Surface temperatures measured as a function of time revealed that they became constant after 3 to 5 minutes (see Fig.6). In order to calculate the thermal diffusivity, the following assumptions were made: 1) the temperature distribution in the specimen is nearly linear after one minute, 2) any possible errors incurred by assuming this is the same for the two measured specimens, and 3) the heat transfer resistivities at the platinum/specimen and specimen/thermocouple interfaces are the same for the two specimens. Solution of equation (i) for this situation using all the above assumptions allows for the thermal diffusivities to be determined from specimen temperatures calculated as the average of substrate temperature and surface temperature. The calculated thermal diffusivities are given in Table 6 below.

\section{(b) Heat Transfer Modeling of Metal Casting with CS-50 :}

Thermal gradient stresses arising from metal casting around CS-50 was sought to be modeled using heat transfer modeling involving a numerical technique. The goal of modeling was to predict any failure of CS-50 port liner due to thermal gradient stresses. This modeling is has stalled because of restricted access to the outside computing facility. 


\section{Diesel Engine Testing Of Port Liners :}

Diesel-engine exposure tests on cast-in-place straight tube exhaust ports having BS-25 and CS-50 liners are currently underway at Cummins Engine Company, Columbus, IN. Up to 1000 hours of exposure has been planned. If the tubes survive the exposure, then samples will be cut out of the exposed ceramic and tested for various properties such as phase content, residual mechanical strength, thermal expansion etc.

\section{Fabrication of and Metal Casting With Complex Shaped Port Liners ::}

Attempts have been made to test the concept of metal casting around simple shaped NZP port liners to real shapes such as the $\mathrm{Y}$-shaped exhaust port liner and S-shaped intake port liner. A few Y-shaped and S-shaped BS-25 and CS-50 port liners have been successfully slip cast. As a next step, iron metal will be cast around the liners having a compliant layer in shoe box molds.

\section{Future Work}

Diesel engine testing of straight tube BS-25 and CS-50 port liners is underway at Cummins Engine Company. FEA and more metal casting trials involving L-shaped port liners is underway. Also, finite-difference based heat transfer modeling is continuing and slated for completion soon as access to facility is obtained. Limited work on Y-shaped exhaust port liner will be continued to demonstrate the feasibility of metal casting around complicated shapes. Penn State is in the process of measuring flexural strengths of specimens made from BS-25 and CS-50 powders synthesized using their low cost combustion synthesis (SCD) process. These results are expected shortly.

Status of milestones: Program is getting back on schedule.

\section{Communications/Visits/Travel :}

1) S. Y. Limaye traveled to Dearborn, Michigan to attend Annual Automotive Technology Development Contractors Coordination Meeting in October 1995.

2) S.Y.Limaye and R. Nageswaran traveled to Indianapolis, IN to attend the 98th Annual Meeting of American Ceramic Society and to Columbus, IN to visit the Cummins Diesel Engine Co. and Technical Center.

Problems Encountered : Moving to the new facility had resulted in delays. 
Publications :

1) R. Nageswaran, J. Zheng, and S. Y. Limaye, "Finite Element Based Optimization of MetalNZP Ceramic Composite Diesel Engine Port Liners," Presented at 47th Pacific Coast Regional Meeting of the American Ceramic Society held at Seattle, Washington, November 1-3, 1995.

2) E. Breval, D.K. Agrawal, R.Nageswaran, and S.Y. Limaye, "Influence of thermal cycling on thermal expansion and microcracking of NZP materials", presented at the 98th Annual Meeting of the American Ceramic Society held at Indianapolis, IN in April 1996.

\section{References :}

1) V. Vlack, Materials Science for Engineers, Addison-Wesley, London, 1971, pp 165-176. 
Table 1. Characterization of BS-25 and CS-50 synthesized using the combustion method.

\begin{tabular}{|c|c|c|c|c|}
\hline \multirow{2}{*}{$\begin{array}{c}\text { NZP } \\
\text { Material }\end{array}$} & \multirow{2}{*}{$\begin{array}{c}\text { Zirconia } \\
\text { Precursors }\end{array}$} & \multicolumn{3}{|c|}{ Final Phase Composition (XRD) } \\
\hline & & As-Synthesized & $800^{\circ} \mathrm{C} / 8 \mathrm{~h}$ & $1000^{\circ} \mathrm{C} / 14 \mathrm{~h}$ \\
\hline BS-25 & Zir. Nitrate & $\mathrm{BS} 25(\mathrm{w})$ & $\mathrm{BS} 25(\mathrm{~m})$ & $\mathrm{BS} 25(\mathrm{~m})$ \\
\hline CS-50 & Zir. Nitrate & $\begin{array}{l}\text { CS } 50(t) \\
\text { Amorphous }\end{array}$ & $\begin{array}{l}\mathrm{CS} 50(\mathrm{w}) \\
\mathrm{ZrP}_{2} \mathrm{O}_{7}(\mathrm{vvw})\end{array}$ & $\begin{array}{l}\mathrm{CS} 50(\mathrm{~m}) \\
\mathrm{ZrP}_{2} \mathrm{O}_{7}(\mathrm{vvw})\end{array}$ \\
\hline BS-25 & $\mathrm{ZrO}_{2}(\mathrm{Z}-\mathrm{Tech})$ & $\begin{array}{ll}\mathrm{ZrP}_{2} \mathrm{O}_{7} & (\mathrm{w}) \\
\mathrm{ZrO}_{2} & (\mathrm{vw})\end{array}$ & $\begin{array}{ll}\mathrm{ZrP}_{2} \mathrm{O}_{7} & (\mathrm{~m}) \\
\mathrm{ZrO}_{2} & (\mathrm{w})\end{array}$ & - \\
\hline CS -50 & $\mathrm{ZrO}_{2}(\mathrm{Z}-\mathrm{Tech})$ & $\begin{array}{l}\mathrm{ZrP}_{2} \mathrm{O}_{7}(\mathrm{w}) \\
\mathrm{ZrO}_{2} \quad \text { (w) }\end{array}$ & $\begin{array}{ll}\mathrm{ZrP}_{2} \mathrm{O}_{7} & (\mathrm{~m}) \\
\mathrm{ZrO}_{2} & (\mathrm{~m}) \\
\end{array}$ & - \\
\hline BS-25 & $\mathrm{ZrO}_{2}(\mathrm{Z}-\mathrm{Tech})+\mathrm{ZrP}_{2} \mathrm{O}_{7}$ & $\begin{array}{ll}\mathrm{ZrP}_{2} \mathrm{O}_{7} & (\mathrm{w}) \\
\mathrm{ZrO}_{2} & \text { (w) } \\
\end{array}$ & $\begin{array}{ll}\mathrm{ZrP}_{2} \mathrm{O}_{7} & (\mathrm{~m}) \\
\mathrm{ZrO}_{2} & (\mathrm{w}) \\
\end{array}$ & - \\
\hline CS-50 & $\mathrm{ZrO}_{2}(\mathrm{Z}-\mathrm{Tech})+\mathrm{ZrP}_{2} \mathrm{O}_{7}$ & $\begin{array}{ll}\mathrm{ZrP}_{2} \mathrm{O}_{7} & (\mathrm{~m}) \\
\mathrm{ZrO}_{2} & (\mathrm{w})\end{array}$ & $\begin{array}{ll}\mathrm{ZrP}_{2} \mathrm{O}_{7} & \text { (s) } \\
\mathrm{ZrO}_{2} & \text { (w) }\end{array}$ & - \\
\hline
\end{tabular}

Intensity of X-ray Diffraction Peaks
s : strong
$\mathrm{m}$ : medium
vw: very weak
vvw : very very weak
w: weak
$\mathrm{t}:$ trace

Table 2. Summary of raw materials' costs and suppliers, and total cost for production of $1 \mathrm{~kg}$. of BS-25 and CS-50 powders using the combustion synthesis (SCD) route.

\begin{tabular}{|c|c|c|c|}
\hline Materials & Amount (gm) & Price (\$) & Vendor \\
\hline $\mathrm{CaZrO}_{3}$ & 89.6 & 0.98 & $\overline{\text { TAM }}$ \\
\hline $\mathrm{SrZrO}_{3}$ & 113.4 & 1.19 & TAM \\
\hline $\mathrm{ZrO}_{2}(\mathrm{DK}-1)$ & 369.6 & 6.84 & $\widehat{\text { DAIICHI }}$ \\
\hline $\mathrm{NH}_{4} \mathrm{H}_{2} \mathrm{PO}_{4}$ & 690 & 6.74 & Aldrich \\
\hline Urea & 1170 & 4.56 & Aldrich \\
\hline $\mathrm{NH}_{4} \mathrm{NO}_{3}$ & 1920 & 31.02 & Fisher Scientific \\
\hline$\overline{\mathrm{CS}-50}$ & Total $=1000$ & $\overline{51.33}$ & \\
\hline $\mathrm{BaZrO}_{3}$ & 312.76 & 3.42 & Ferro \\
\hline $\mathrm{ZrO}_{2}(\mathrm{DK}-1)$ & 306.61 & 6.19 & DAIICHI \\
\hline $\mathrm{NH}_{4} \mathrm{H}_{2} \mathrm{PO}_{4}$ & 572.40 & 5.58 & Aldrich \\
\hline $\mathrm{SiO}_{2}$ & 27.15 & 0.01 & $\overline{\text { ELKEM }}$ \\
\hline Urea & 1058.82 & 4.13 & Aldrich \\
\hline $\mathrm{NH}_{4} \mathrm{NO}_{3}$ & 1737.56 & 28.07 & Fisher Scientific \\
\hline$\overline{\mathrm{BS}-25}$ & Total =1000 & $\overline{47.40}$ & \\
\hline
\end{tabular}


Table 3. Comparison of surface areas of BS-25 and CS-50 powders synthesized by combustion synthesis and oxide mixing.

\begin{tabular}{|c|c|c|c|}
\hline Composition & Reaction Mixtures & $\begin{array}{l}\text { Powder } \\
\text { Condition }\end{array}$ & $\begin{array}{c}\text { Surface Area } \\
\left(\mathrm{m}^{2} / \mathrm{g}\right)\end{array}$ \\
\hline BS-25 (SCD) & $\mathrm{Ba} / \mathrm{Zr}$ nitrates $+\mathrm{SiO}_{2}+\mathrm{ADP}$ & As-is & 65.99 \\
\hline$\overline{\mathrm{CS}-50 \text { (SCD) }}$ & $\mathrm{Ca} / \mathrm{Sr} / \mathrm{Zr}$ nitrates + ADP & As-is & 185.80 \\
\hline BS-25 (SCD) & $\mathrm{Ba}$ zirconates+ADP+SiO$+\mathrm{ZrO}_{2}$ & As-is & 1.55 \\
\hline$\overline{\mathrm{CS}-50(\mathrm{SCD})}$ & $\mathrm{Ca} / \mathrm{Sr}$ zirconates+ADP $+\mathrm{ZrO}_{2}$ & As-is & 1.37 \\
\hline BS-25 (Oxide Mixing) & $\mathrm{Ba}$ zirconate $+\mathrm{SiO}_{2}+\mathrm{Zirconium}$ Phosphate & As-is & 1.27 \\
\hline CS-50 (Oxide Mixing) & $\mathrm{Ca} / \mathrm{Sr}$ zirconate+ Zirconium Phosphate & As-is & 0.88 \\
\hline
\end{tabular}

Table 4. Sintering results of the combustion synthesized CS-50 and BS-25 powders. Grain sizes were measured using SEM.

\begin{tabular}{|c|c|c|c|c|}
\hline \multirow{2}{*}{ Sintering, ${ }^{\circ} \mathbf{C} / \mathbf{h}$} & \multicolumn{2}{|c|}{ CS-50 } & \multicolumn{2}{|c|}{ BS-25 } \\
\hline & $\rho, g / \mathrm{cm}^{3}$ (\%theo) & Grain size $(\mu \mathrm{m})$ & $\rho, g / \mathrm{cm}^{3}$ (\%theo) & Grain size $(\mu \mathrm{m})$ \\
\hline $1300^{\circ} \mathrm{C} / 4 \mathrm{~h}$ & $2.30(70.3)$ & $1-2$ & $2.13(60.5)$ & $0.5-1$ \\
\hline $1300^{\circ} \mathrm{C} / 8 \mathrm{~h}$ & $2.36(72.3)$ & $2-4$ & $2.17(61.6)$ & $1-3$ \\
\hline $1300^{\circ} \mathrm{C} / 4 \mathrm{~h}$ & $2.37(72.5)$ & $1-2$ & $2.13(60.5)$ & $0.5-2$ \\
\hline $1300^{\circ} \mathrm{C} / 8 \mathrm{~h}$ & $2.49(76.1)$ & $2-5$ & $2.34(63.6)$ & $0.5-3$ \\
\hline
\end{tabular}

Table 5. Modulus of elasticity of bars pressed from combustion synthesized CS-50 and BS-25 powders (average of 6 measurements for each bar).

\begin{tabular}{||c|c|c|c|c|c||}
\hline \multicolumn{3}{|c|}{ CS-50 } & \multicolumn{3}{c|}{ BS-25 } \\
\hline$\rho, \mathrm{g} / \mathrm{cm}^{3}$ & \multicolumn{2}{|c|}{ E(GPa) } & $\rho, \mathrm{g} / \mathrm{cm}^{3}$ & \multicolumn{2}{c|}{ E(GPa) } \\
\hline \hline 2.639 & & $63.0 \pm 1.0$ & 1.964 & 24.47 & $24.5 \pm 0.4$ \\
\hline 1.933 & 17.98 & $18.2 \pm 0.3$ & 1.930 & 22.05 & $20.4 \pm 1.1$ \\
\hline 1.977 & 18.82 & $19.5 \pm 0.7$ & 1.995 & 23.94 & $25.0 \pm 0.8$ \\
\hline
\end{tabular}


Table 6. Thermal diffusivity measurements derived from surface temperatures of a plateshaped specimen ( $-2 \mathrm{~mm}$ thick) placed on a Pt substrate of constant temperature.

\begin{tabular}{|c||c||c|}
\hline $\begin{array}{c}\text { Temperature } \\
{ }^{\circ} \mathbf{C}\end{array}$ & BS-25 & CS-50 \\
\cline { 2 - 3 } & Diffusivity (h), $\mathbf{~ m}^{\mathbf{2}} \mathbf{s}^{\mathbf{- 1}} \mathbf{x} \mathbf{1 0}{ }^{-7}$ & Diffusivity (h), $\mathbf{~ m}^{\mathbf{2}} \mathbf{s}^{-1} \mathbf{x} \mathbf{1 0}{ }^{-7}$ \\
\hline $\mathbf{7 5}$ & 5.70 & 6.20 \\
\hline $\mathbf{1 5 0}$ & 5.40 & 5.90 \\
\hline $\mathbf{2 0 0}$ & 5.35 & 5.90 \\
\hline $\mathbf{2 7 5}$ & 5.20 & 5.70 \\
\hline $\mathbf{3 4 0}$ & 5.10 & 5.80 \\
\hline $\mathbf{4 0 0}$ & 5.00 & 5.90 \\
\hline $\mathbf{4 7 5}$ & 4.90 & 5.80 \\
\hline $\mathbf{5 3 0}$ & 4.85 & 5.70 \\
\hline $\mathbf{6 0 0}$ & 4.80 & 5.70 \\
\hline
\end{tabular}



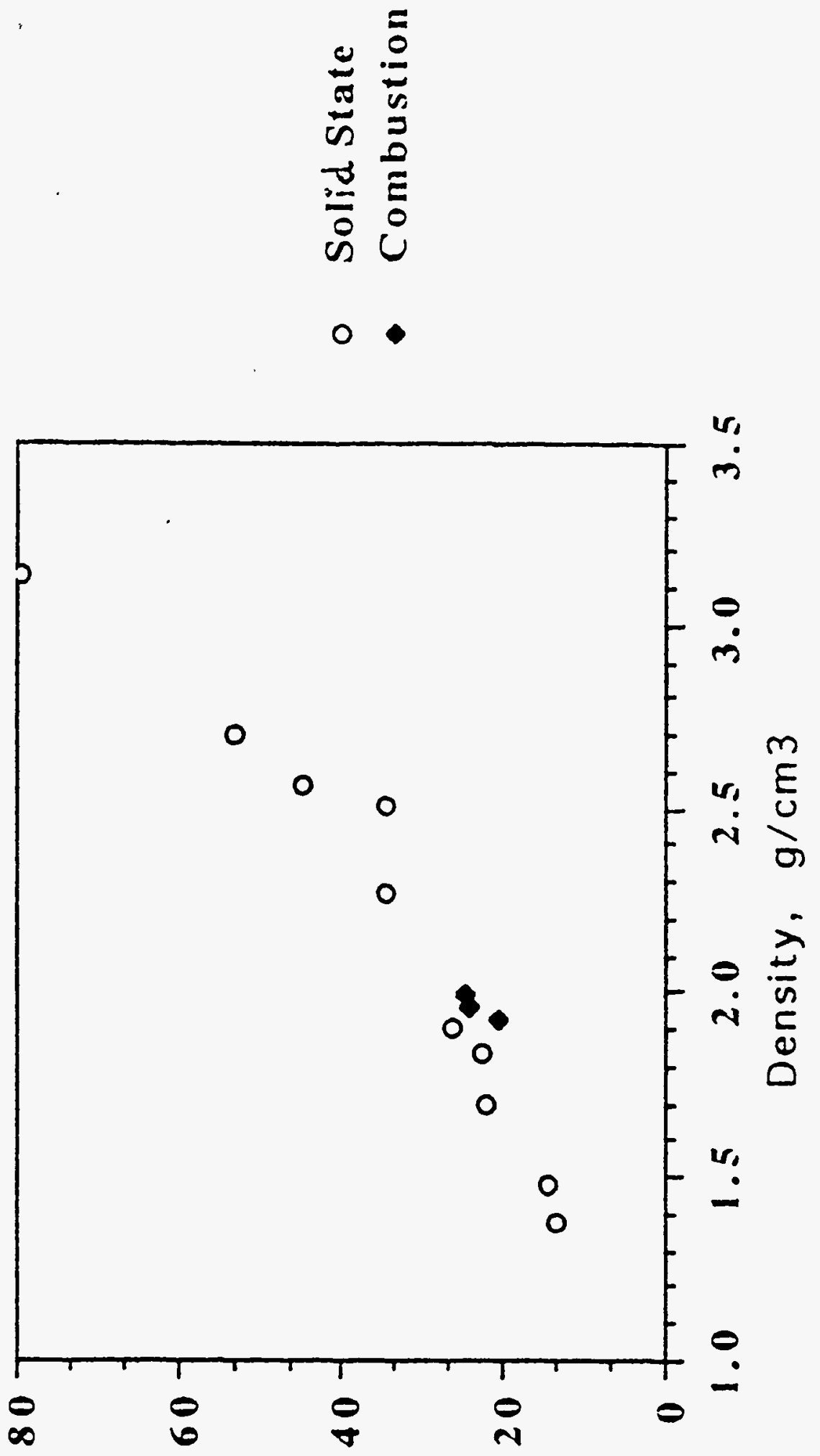

กิ

ed9 'sn[npow -3 

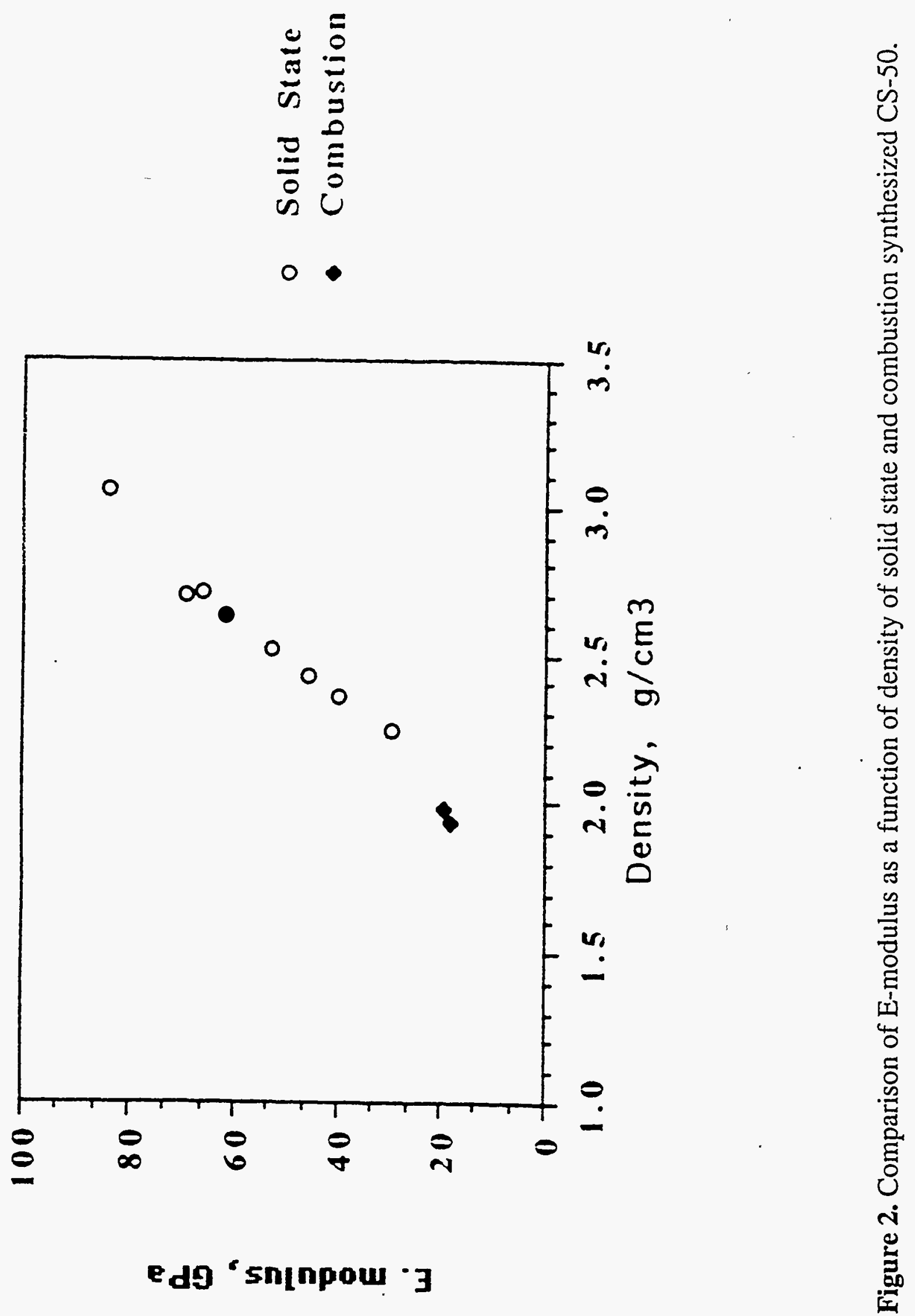

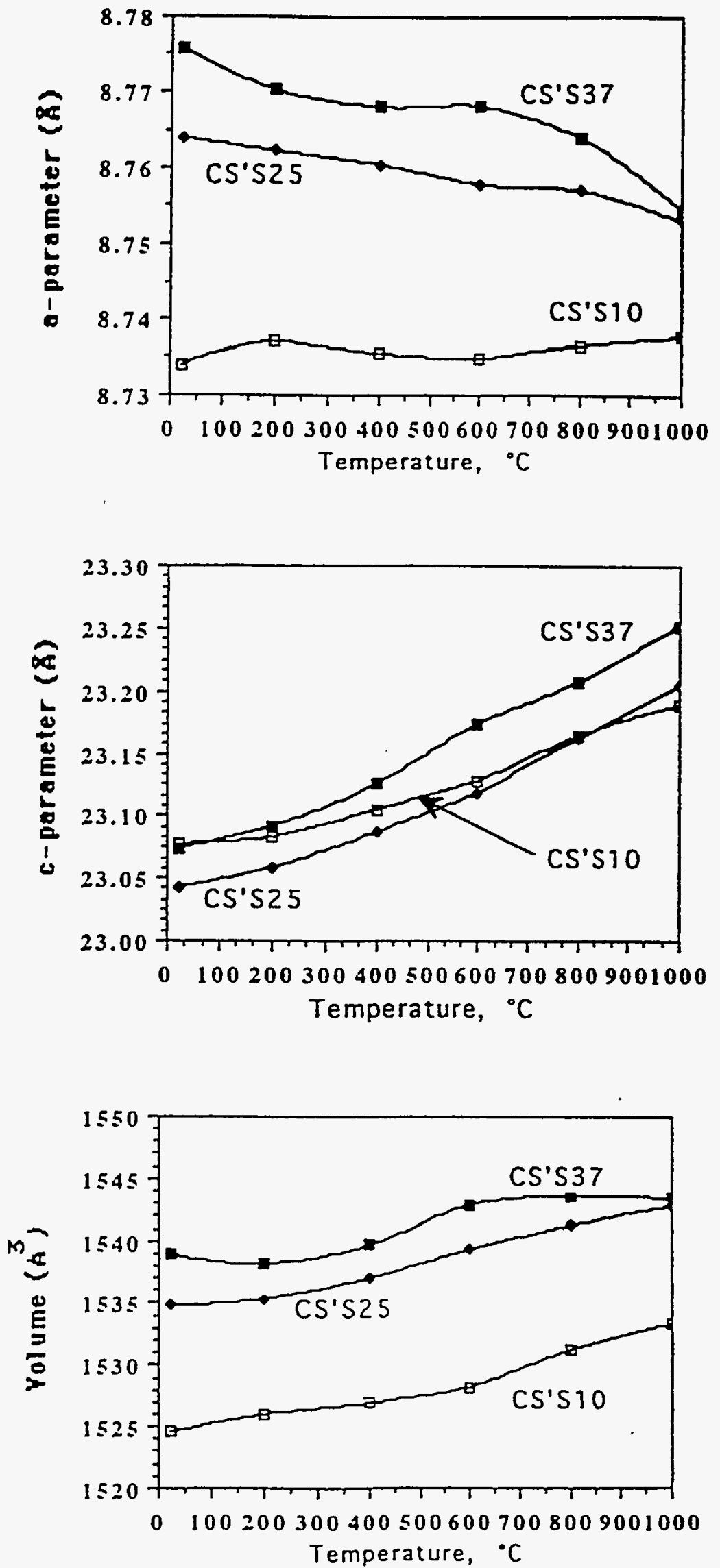

Figure 3. Thermal data for the CS'S series $\left.(\mathrm{Ca}, \mathrm{Sr})_{1+x} \mathrm{Zr}_{4} \mathrm{P}_{6-2 x} \mathrm{Si}_{2 \times} \mathrm{O}_{24}\right)$. Variation of cell parameters and cell volume with temperatures from 25 to $1000^{\circ} \mathrm{C}$. 


\section{CS'S Series}

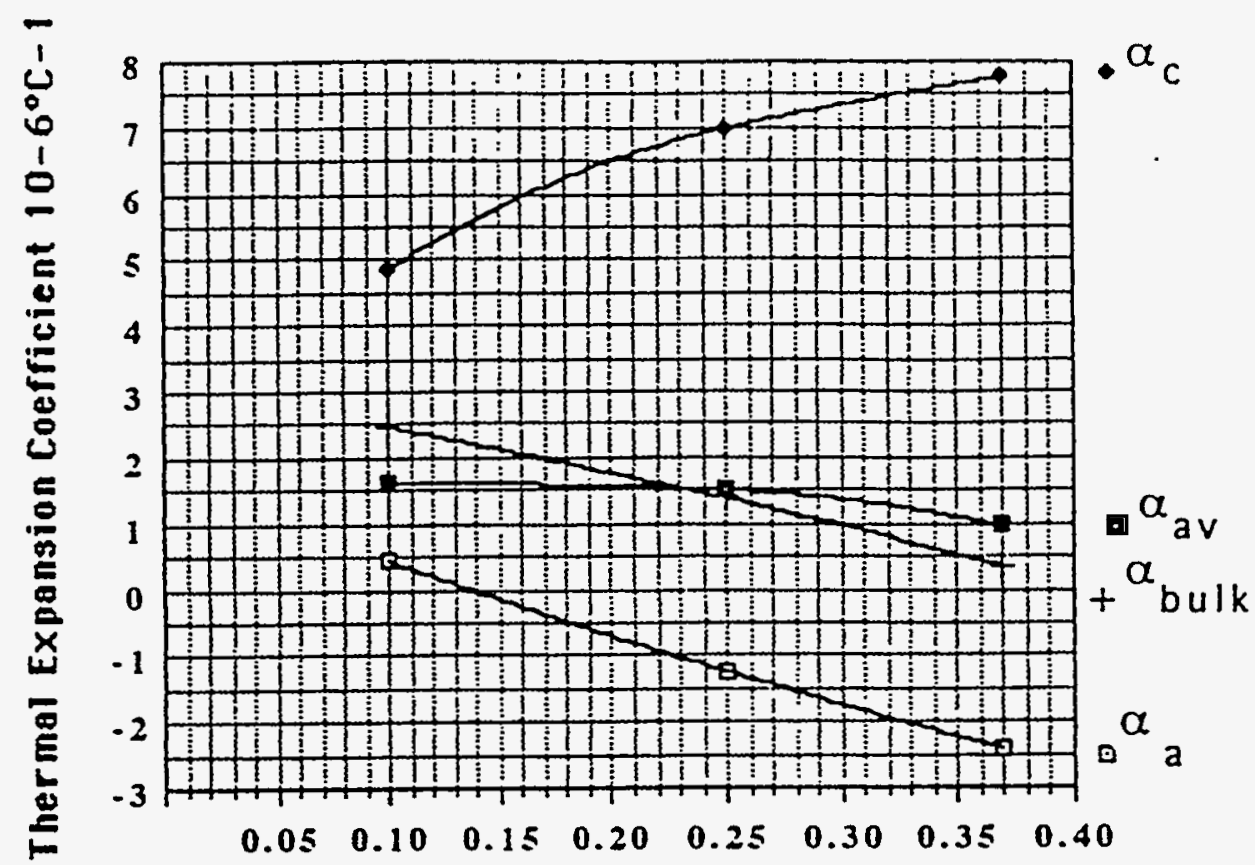

x

Figure 4. Thermal axial expansion data for the CS'S series $\left.(\mathrm{Ca}, \mathrm{Sr})_{1+x} \mathrm{Zr}_{4} \mathrm{P}_{6-2 x} \mathrm{Si}_{2 x} \mathrm{O}_{24}\right)$ shown together with the bulk thermal expansion data. 

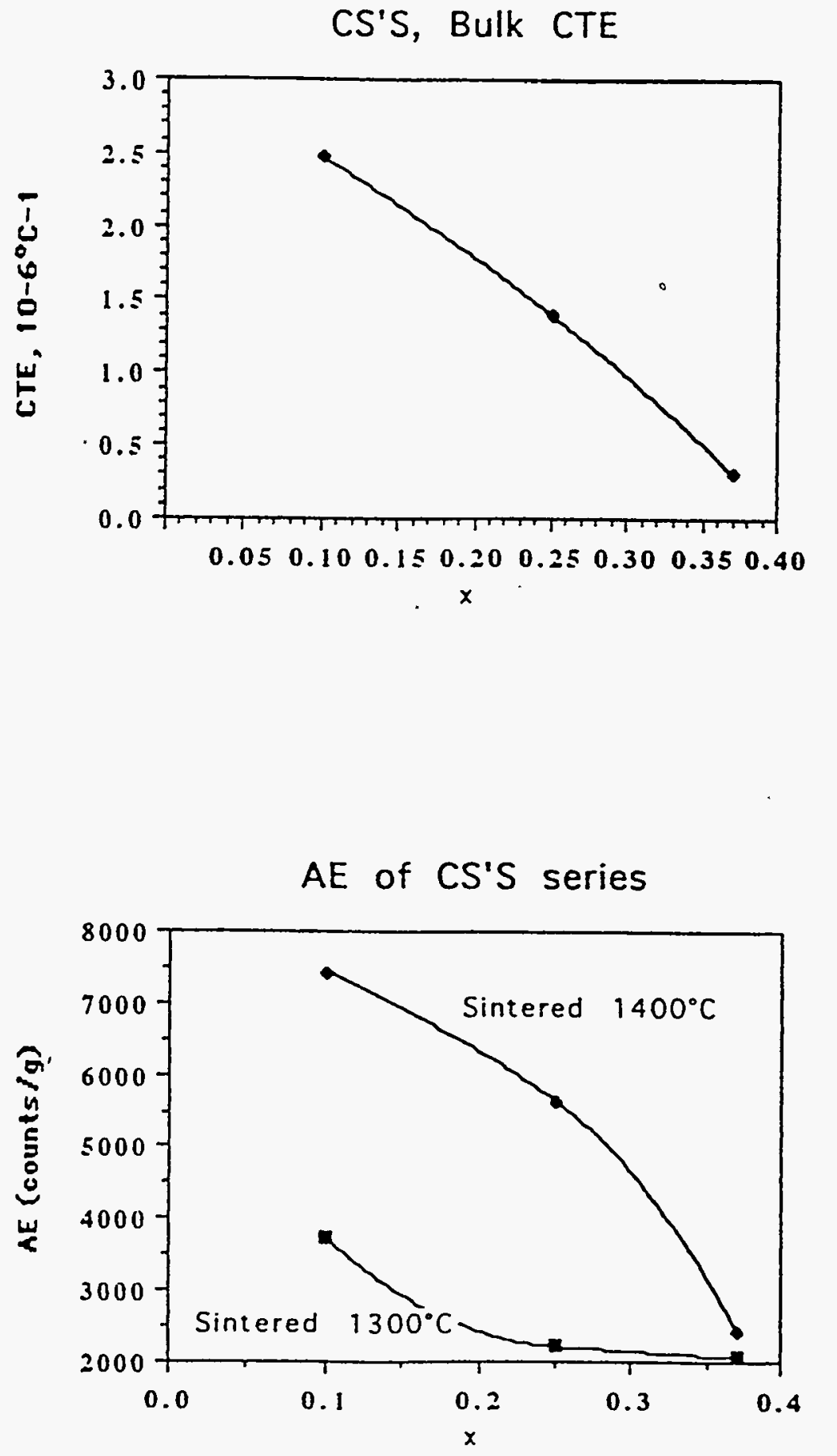

Figure 5. Properties of members of the CS'S series $\left.(\mathrm{Ca}, \mathrm{Sr})_{1+x} \mathrm{Zr}_{4} \mathrm{P}_{6-2 x} \mathrm{Si}_{2 x} \mathrm{O}_{24}\right)$. (a): Bulk CTE. The specimens were sintered at $1300^{\circ} \mathrm{C} / 6 \mathrm{~h}$. (b): Acoustic emission (counts per gram material). The specimens were sintered at $1300^{\circ} \mathrm{C} / 6 \mathrm{~h}$ and $1400^{\circ} \mathrm{C} / 6 \mathrm{~h}$. 
CS'50. Surface Temperatures.

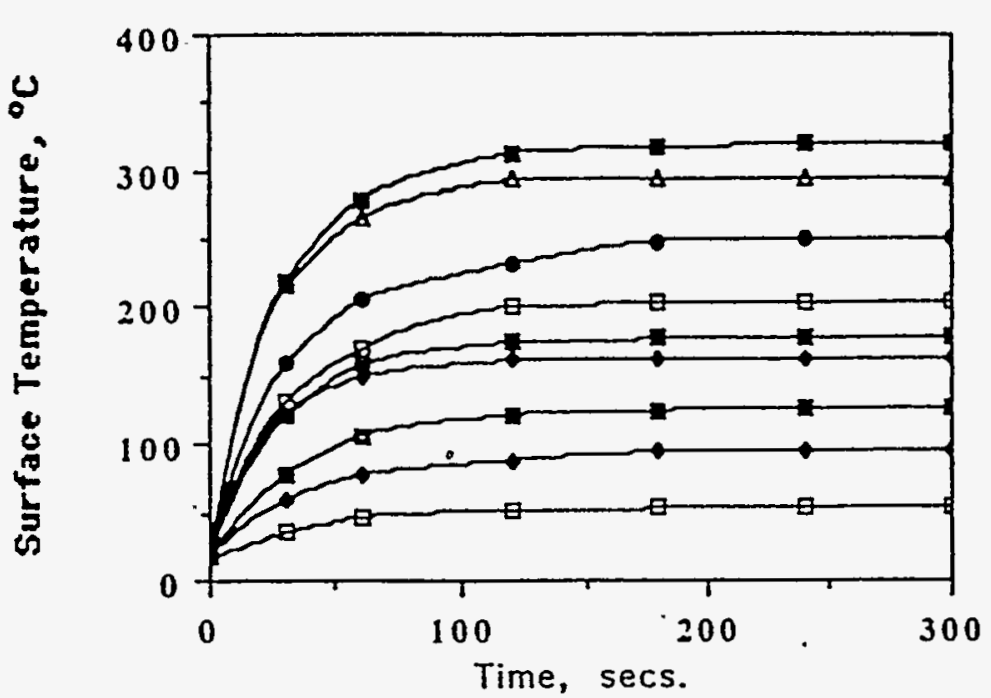

Substrate

Temperature

- $100^{\circ} \mathrm{C}$

- $200^{\circ} \mathrm{C}$

- $300^{\circ} \mathrm{C}$

- $400^{\circ} \mathrm{C}$

- $500^{\circ} \mathrm{C}$

$600^{\circ} \mathrm{C}$

- $700^{\circ} \mathrm{C}$

$\triangle 800^{\circ} \mathrm{C}$

- $900^{\circ} \mathrm{C}$ 


\section{Development of Low Cost NZP Powder Synthesis and Processing Technology}

Jay Curtis, Rama Nageswaran and Santosh Y. Limaye (LoTEC, Inc.)

\section{$\underline{\text { Objective/Scope }}$}

The overall objective of this research is to develop a suitable technology for low cost synthesis and processing of NZP materials. The two NZP materials of primary interset are BS$25\left(\mathrm{Ba}_{1.25} \mathrm{Zr}_{4} \mathrm{Si}_{0.5} \mathrm{P}_{5.5} \mathrm{O}_{24}\right)$ and CS-50 $\left(\mathrm{Ca}_{0.5} \mathrm{Sr}_{0.5} \mathrm{Zr}_{4} \mathrm{P}_{6} \mathrm{O}_{24}\right)$. Specific objectives to be accomplished are: (1) preliminary assessment of powder techniques of specialist vendors for cost-effective NZP powder synthesis, (2) evaluation of NZP powder samples supplied by vendors (3) selection of up to two finalist powder suppliers based on results of initial evaluation, commercial viability of the process, and scale-up costs; (4) advanced evaluation of powders supplied by two companies based on results of material properties testing such as thermal expansion, strength, elastic modulus, etc.; and (5) metal casting trials involving NZP prototype parts and testing of the prototypes for diesel-engine worthiness. A secondary (and minor) objective will be to set up a hydrothermal (or other) low-cost powder synthesis facility at LoTEC as a parallel effort.

\section{Technical Progress}

Specific objectives (1) through (3) above have been accomplished during the last sixmonth time period. Below is a description of the work performed in order to achieve these objectives. In addition, LoTEC is working on optimization of its in-house oxide based process and development of a low temperature chemical process for synthesizing NZP (BS-25 and CS50) powders at low cost. Results of this work will be discussed in upcoming reports.

\section{(1) Preliminary assessment of powder techniques of specialist vendors for cost-effective NZP powder synthesis.}

Project kick off meeting was held on September 21st at Hyatt Regency in Chicago. Representatives from four companies viz. Particle Technology, Inc., NexTech Materials, Ltd., Catalytica, Inc., and Magnesium Elektron, Inc. made presentations to describe their low-cost processing approaches. Phase I contracts (that covers objectives 1 and 2) were initiated with the above four vendors and a 5th vendor, CERAC Inc., who is participating in the program on a purchase order basis.

All vendors who initiated contracts with LoTEC, Inc. periodically submitted confidential reports detailing their progress on the project including a final report for the entire Phase I. 
Powders supplied to LoTEC were from: Catalytica (one BS-25 and one CS-50 powder), Particle Technology (same as Catalytica), and NexTech (three CS-50 powders and one BS-25 powder) which alone have been listed in Table 1. MEI and Cerac did not provide any powders for evaluation. Salient features of each vendor's process are provided in Table 2. During this period, MEI decided to withdraw from the program due to business considerations. Cerac is about to deliver kilogram samples of BS-25 powders on the LoTEC purchase order (P.O.). However, Cerac will not be directly involved any further in the program because they did not meet any of the deadlines in Phase I.

Preliminary characterization of powders began with routine room temperature XRD analysis to assess phase contents. Results of this fast-scan XRD analysis indicated that all calcined powders, except the ones with deliberately-introduced excess phosphate, were phase pure (to the resolution limit of the diffractometer at this scan rate) and showed good crystallinity.

At that stage, facilities of three vendors viz. Catalytica, NexTech, and Particle Technology were visited and important information gathered on the respective synthesis processes, their status's, and future capabilities. This information was critical for performing an overall assessment of the vendors prior to Phase II.

(2) Evaluation of NZP powder samples supplied by vendors for phase and impurity contents, particle size and distributions, surface areas, thermal stability, dispersibility, flowability, sinterability after green forming, and synthesis costs.

A more detailed evaluation of vendors' powders was performed at both LoTEC and at High Temperature Materials Laboratory (HTML) of Oak Ridge National Laboratory (ORNL). Tests and results are discussed here below.

Impurities/Minor Phases:

Actual room temperature $\mathrm{x}$-ray diffraction (XRD) patterns of the various BS-25 and CS50 powders have been mapped with JCPDS standards corresponding to most probable major and minor phases in Figures 1 and 2, respectively. These patterns were obtained using a diffractometer at ORNL and using $\mathrm{CuK} \alpha$ radiation. The scan rate was $0.1 \% \mathrm{~min}$. This gives a resolution limit of approximately $2 \%$ for detecting minor phases.

From these plots, it can be seen that both Catalytica powders appear to be phase pure to the resolution limit of the diffractometer. All Catalytica BS-25 peaks can be seen to result from a $\mathrm{BaZr}\left(\mathrm{PO}_{4}\right)_{6}$ type phase and the Catalytica CS-50 peaks from $\mathrm{CaZr} 4\left(\mathrm{PO}_{4}\right)_{6}$ or $\mathrm{SrZr}_{4}\left(\mathrm{PO}_{4}\right)_{6}$ type phases. These phases are the closest the database had to BS-25 and CS-50, respectively. Both 
NexTech powders seem to have minor phases present. The minor phase in NexTech BS-25 corresponded to $\mathrm{BaZrP}_{2} \mathrm{O}_{8}$ (JCPDS 25-0085), while that in NexTech CS-50 matched with $\mathrm{ZrP}_{2} \mathrm{O}_{7}$ (JCPDS 29-1399).

These plots also suggest that Particle Tech CS-50 is phase pure to the resolution limit. However, sintered density measurements involving samples from Particle Tech's CS-50 indicated the presence of impurities in lower concentrations (discussions follow). Particle Tech BS-25 had the same impurity as NexTech BS-25 $\left(\mathrm{BaZrP}_{2} \mathrm{O}_{8}\right)$. However, the intensity of the impurity peaks suggest that this phase is present in a greater concentration in Particle Tech's BS-25.

Room temperature lattice parameters for all the powders have been provided in Table 3. They were obtained by using curve fitting and Reitveld refining programs on XRD patterns with peaks indexed up to $2 \theta=135^{\circ}$. From the table, it can be seen that a significant difference exists between the parameters of Particle Tech's powders and those of the other suppliers' powders. In the case of BS-25, the 'a' parameter of Particle Tech's powder is much smaller than for either Catalytica or NexTech. Also, Particle Tech. CS-50's 'c' parameter is larger than for the other suppliers'. For BS-25, Catalytica and NexTech lattice parameters agree more closely with previous research ${ }^{1}$, while for CS-50, Particle Tech's powder seems to fall in line with results of previous research ${ }^{2}$. Two possible reasons for discrepancies among these lattice parameters are: 1) impurities may be present in any of the powders in concentrations high enough to cause a distortion in the lattice but not to show up in XRD and;2) the stoichiometry may not be exact in some or all of the powders (we may have CS-49 etc. instead of CS-50).

Scanning electron microscopy with energy dispersive spectroscopy (EDS) was also performed at HTML. Unfortunately, it did not prove helpful in determining impurities, including extraneous elements, beyond those already discovered using XRD.

\section{Lattice Thermal Expansion and Order-Disorder Transformations :}

X-ray diffraction was also used to study lattice thermal expansions of Catalytica powders. The other powders were not examined because most NZP materials are poor diffracters and, therefore, each run took an extremely long time. Catalytica powders were chosen because they were determined to most likely be phase pure, as explained above. Figures 3 and 4 show plots of lattice parameter as a function of temperature for BS-25 and CS-50, respectively. The results.are in agreement with those from previous research, except that CS-50's ' $a$ ' parameter exhibited significant deviation from these results ${ }^{1.2}$. Again, this could be due to the same two factors likely responsible for room temperature lattice parameter deviations. 
All BS-25 powders exhibited a gradual order-disorder transition between 650 and $750^{\circ} \mathrm{C}$. All CS-50 powders underwent a similar transformation between 1050 and $1150^{\circ} \mathrm{C}$. These behaviors are in accordance with previous unpublished results.

\section{Particle Size Distributions and Shapes:}

Particle size and distribution of the powders was studied both in as-supplied to condition and also after being screened through a 170 mesh screen. Photographs of the as-supplied and the screened powders are shown in Figures 5 (Catalytica CS-50) - which typified the appearance of most powders - and 6 (Particle Tech BS-25) - which appeared quite different. The pictures in Figures 5(a) and 6(a) of as-supplied powders, were taken at HTML using a scanning electron microscope (SEM) at magnifications of 2000x. Micrographs in figs. 5(b) through 11(b) were obtained using an optical microscope at magnifications of $100 \mathrm{x}$ and represent as-screened (-170 mesh) powders. These figures clearly indicate the propensity of all powders to aggregate together even after screening. Aggregate formation was fairly obvious in the case of Particle Tech BS-25 powder which seemed to be made up of very fine spherules or equiaxed particles (see Figs.6(a) and (b)).

Figures 7-9 show particle size distributions for the screened powders. They were obtained at LoTEC using a Horiba LA-910 laser scattering particle size analyzer. Three important observations could be made from these distributions: (i) Particle Tech's BS-25 and NexTech's CZP\#2 (amorphous CS-50) were much finer than the others; (ii) Distributions for both Catalytica powders and all NexTech crystalline powders follow a general pattern that is typical of the vendor's process. On the other hand, Particle Tech's BS- 25 and CS-50 show different particle size distributions; and (iii) both Catalytica powders and the Particle Tech CS-50 powder had to be crushed prior to screening through a 170 mesh screen, while the other powders could be screened without crushing. This suggests that after calcination (of all powders), NexTech powders obtained using hydrothermal synthesis only formed soft agglomerates whereas other powders tended to form hard agglomerates.

As far as the shape of the particles in all powders, there was no single shape that the particles could be classified into. All powders, except Particle Tech's BS-25, had a significant fraction of non-spherical and irregularly shaped particles or agglomerates.

\section{Surface Areas:}

Table 4 compares the surface areas of the as-received powders (standard deviations are also included). The testing was done at LoTEC with a Quantachrome Nova 2000 surface area 
analyzer. The data in Table 4 reveals that NexTech's amorphous powder has a very high surface area, as expected due to small particle sizes and irregularly shaped particles. However, Particle Tech's BS-25 did not have as large a surface area as its size distribution would lead one to expect. This is likely to be due to one or all of the following: (i) the spherical nature of particles, (ii) aggregate formation tendencies, (iii) hygroscopic behavior, and (iv) insufficient outgassing of the samples prior to testing.

\section{Dispersability/Flowability:}

Flowability was qualitatively examined during die pressing bar specimens at 8,000 psi. Dispersibility tests were performed by dropping $250 \mathrm{mg}$ of screened (-170 mesh) sample into a water $+0.1 \mathrm{w} \%$ dispersant mixture and observing the behavior for 5 minutes and also by stirring the powder into the same mixture and observing the settling behavior for another 5 minutes. Discounting the role density and particle shape will play in the settling behavior under these conditions, the following can be inferred.

Particle Tech.'s BS-25 powder seemed to disperse and flow the most poorly. Bar specimens could not be pressed without breaking apart or laminating. The powder had a 'wet' or 'sticky' feel, and when dumped into the water+dispersant mixture, it fell as large aggregates (possible hygroscopicity). The other powders settled more quickly, but they dispersed into very fine particles as they fell. No difficulty was had in pressing the other powders. Catalytica powders tended to settle out of the stirred mixture a little faster than any of the others, but most of the powder was still dispersed in the mixture 5 minutes after stirring.

An explanation for the above behavior of Particle Tech's BS-25 can be obtained from the following equation, which correlates rheological behavior with the particle size distribution of a powder sample:

$$
S_{w}=\frac{2.56}{\log \left[\frac{d_{90}}{d_{10}}\right]}
$$

In eqn.(1), $S_{w}$, is the distribution width which should ideally follow the rule : $7<S_{w}<2$ for good flowability and dispersibility of dry powders. From the particle size data in for Particle Tech's BS-25 in Fig. 19, $\mathrm{d}_{10}$ (size below which there are $10 \%$ of the total particles) $=0.845 \mu \mathrm{m}$ and $\mathrm{d}_{90}$ (size below which there are $90 \%$ of the total particles) $=6.381 \mu \mathrm{m}$. Use of these numbers in eqn.1 results in $S_{w}$ of 2.91 , which is between 2 and 7, an undesirable situation for good flowability and dispersibility. 


\section{Sinterability:}

Sinterablity .was studied at LoTEC by: 1) screening powders to $170 \mathrm{mesh}$; 2) die pressing bar specimens at $8,000 \mathrm{psi}$; 3) isopressing specimens at 25,000 psi, and 4) sintering 2 bars of each powder sample at 1450,1500 , and $1550^{\circ} \mathrm{C}$. During pressing, however, Particle Tech's BS25 samples laminated or fell apart because of its poor flowability and propensity to aggregating as predicted by Eqn.1.

Figures 10 and 11 are plots of average density (of two bars from each powder type) versus sintering temperature. Under these conditions, none of the powders yielded very high densities (>95\%) after sintering. Particle Tech.'s CS-50 bars diffused into the sintering plate and, therefore, density could not be evaluated. This situation further confirms that the Particle Tech CS-50 powders contained impurities (in small amounts) which were not detected by x-ray diffraction but which resulted in difference of its lattice parameters compared to other CS-50s.

\section{Thermal Analysis :}

Thermal analysis was performed at HTML using differential scanning calorimetery (DSC) to measure thermal events and simultaneous thermal analysis (STA) to measure mass loss. From DSC analysis, some of the useful results obtained were that : (i) Catalytica powders showed absolutely no thermal events; and (ii) All other powders showed no or only very minor thermal events, except, NexTech's amorphous powder which had the expected crystallization exotherm at $\sim 900^{\circ} \mathrm{C}$ (see Figure 12). The results of STA suggested that there was no significant mass loss for any of the powders except NexTech's (amorphous CS-50) CZP\#2. Taken together, these results suggest that phase stability is not an issue with any of the vendor's powders.

\section{(3) Selection of up to two finalist powder suppliers based on results of initial evaluation, commercial viability of the process, and scale up costs.}

\section{Evaluation Summary:}

The overall ratings of the vendors' powders during Phase I (Tasks 1 and 2) of the program are summarized in Table 5. The table also shows the weightage that has been assigned to each parameter, as well as a score of 1 to 4 that each vendor received for each powder parameter. Ratings and numbers associated with each parameter merely served as guidelines for selection of the vendors as part of Task 3 for Phase II of this program. (These results should not be interpreted as endorsement of any one vendor for purposes outside of this program.) From the final numbers in Table 5, 'Catalytica' and 'NexTech' were downselected for Phase II (Tasks 4 and 5) of the program. 


\section{Future Work}

Phase II involving Tasks 3 and 4 of this program is being initiated. Work Statement / Agenda for Phase II activity between LoTEC, Inc., and Catalytica and NexTech has been prepared and agreed upon. LoTEC's new characterization facility is gearing up for the initial work in Phase II which is now planned to be conducted more interactively. As part of this process, LoTEC is acquiring a pyconometer for particle density measurements and a Grindosonic elastic modulus measurement instrument.

Status of milestones: Program is on schedule.

\section{Communications/Visits/Travel:}

1) S. Y. Limaye and R. Nageswaran traveled to Chicago, Illinois to attend the project kickoff meeting on September 21, 1195.

2) S. Y. Limaye, D. Stinton and D. Richerson visited: DOE in Washington D.C, Particle Technology, Inc. Hanover, $\mathrm{MD}$, and NexTech Materials, Ltd. Worthington, $\mathrm{OH}$ in February 1996.

3) J. Curtis traveled to Oak Ridge National Laboratory to conduct various Powder Characterization Tests from February to March 1996.

4) S. Y. Limaye, R. Nageswaran, D. Stinton, and D. Richerson traveled to Catalytica's facility in Mountainview, CA in March 1996.

Problems Encountered: Few

Publications: None

\section{References:}

1) C. Y. Huang, D. K. Agrawal, H. A. McKinstry, and S. Y. Limaye, J. Mater. Res. 9, 2005 (1994).

2) S. Y. Limaye, D. K. Agrawal, R. Roy, and Y. Mehrotra, J. Mater. Sci. 26, $93-98$ (1991). 
Table 1. NZP powder samples supplied to LoTEC, Inc. by NexTech.

\begin{tabular}{|l||l||l||l|}
\hline Label & Composition & Process & Description \\
\hline \hline CZP\#2 & CS-50 & Hydrothermal & Amorphous \\
\hline CZP\#4 & CS-50 & $\begin{array}{l}\text { Hydrothermal } \\
+ \text { Calcination }\end{array}$ & $\begin{array}{l}\text { Small amount of } \\
\text { excess phosphate }\end{array}$ \\
\hline CZP\#7 & CS-50 & $\begin{array}{l}\text { Hydrothermal } \\
+ \text { Calcination }\end{array}$ & Stoichiometric \\
\hline CZP\#6 & BS-25 & $\begin{array}{l}\text { Hydrothermal } \\
+ \text { Calcination }\end{array}$ & Stoichiometric \\
\hline
\end{tabular}

Table 2. BS-25 and CS-50 Powder Suppliers (Vendors) and their Processes.

\begin{tabular}{|c||c||c||c|}
\hline VENDOR & $\begin{array}{c}\text { Synthesis } \\
\text { Technique }\end{array}$ & $\begin{array}{c}\text { Powders } \\
\text { Synthesized }\end{array}$ & $\begin{array}{c}\text { Powder } \\
\text { Amounts }\end{array}$ \\
\hline \hline Catalytica & $\begin{array}{c}\text { Direct Precipitation } \\
\text { (Microfluidizer) }\end{array}$ & BS-25 \& CS-50 & $\begin{array}{c}250 \text { gm. powder } \\
\text { batch }\end{array}$ \\
\hline $\begin{array}{c}\text { NexTech } \\
\text { Materials, Ltd. }\end{array}$ & $\begin{array}{c}\text { Hydrothermal } \\
\text { Synthesis }\end{array}$ & BS-25 \& CS-50 & $\begin{array}{c}200 \text { gm. powder } \\
\text { batch }\end{array}$ \\
\hline $\begin{array}{c}\text { Particle } \\
\text { Technology, }\end{array}$ & $\begin{array}{c}\text { Spray Pyrolysis } \\
\text { MEI, Inc. }\end{array}$ & BS-25 \& CS-50 & Small amounts \\
\hline Medified Solid State & Synthesis & BS-25 & --- \\
\hline
\end{tabular}


Table.3. Comparison of room temperature lattice parmeters.

\begin{tabular}{||c|c||c||c||c|}
\hline POWDER & a, $\AA$ & dev. a, $\AA$ & c, $\AA$ & dev. c, $\AA$ \\
\hline \hline $\begin{array}{c}\text { CATALYTICA } \\
\text { BS-25 }\end{array}$ & 8.683106 & 0.000561 & 24.001209 & 0.001820 \\
\hline $\begin{array}{c}\text { PART. TECH. } \\
\text { BS-25 }\end{array}$ & 8.656983 & 0.000453 & 23.990072 & 0.005001 \\
\hline $\begin{array}{c}\text { NEXTECH } \\
\text { BS-25 }\end{array}$ & 8.681595 & 0.000225 & 24.015543 & 0.002514 \\
\hline $\begin{array}{c}\text { LITERATURE } \\
\text { BS-25 }\end{array}$ & $\sim 8.68$ & N/A & $\sim 24.01$ & N/A \\
\hline \hline $\begin{array}{c}\text { CATALYTICA } \\
\text { CS-50 }\end{array}$ & 8.736960 & 0.000324 & 23.068306 & 0.003648 \\
\hline \begin{tabular}{c} 
PART. TECH. CS-50 \\
\hline $\begin{array}{c}\text { NEXTECH } \\
\text { CS-50, CZP\#4 }\end{array}$
\end{tabular} & 8.730963 & 0.000381 & 23.185337 & 0.004020 \\
\hline $\begin{array}{c}\text { NEXTECH } \\
\text { CS-50, CZP\#7 }\end{array}$ & 8.727640 & 0.000525 & 23.077066 & 0.005511 \\
\hline $\begin{array}{c}\text { LITERATURE } \\
\text { CS-50 }\end{array}$ & $\sim 8.72$ & N/A & $\sim 23.15$ & N/A \\
\hline
\end{tabular}

Table 4. Comparison of Specific Surface Areas of Powder Samples.

\begin{tabular}{|c||cc|}
\hline \multicolumn{1}{|c||}{ SAMPLE } & \multicolumn{3}{|c|}{ SURFACE AREA, sq. m. / g } \\
\hline \hline NexTech | CS-50 CZP \#7 & $9.102 \quad(\sigma=0.134$, two tests $)$ \\
\hline NexTech I CS-50 CZP \#4 & $13.487 \quad(\sigma=0.143$, two tests $)$ \\
\hline NexTech | CS-50 CZP \#2 & $51.717 \quad(\sigma=0.223$, two tests $)$ \\
\hline Catalytica I CS-50 & $5.916 \quad(\sigma=0.309$, three tests $)$ \\
\hline Particle Tech. I CS-50 & $0.466 \quad(\sigma=0.030$, three tests $)$ \\
\hline NexTech | BS-25 & $12.785 \quad(\sigma=0.239$, three tests $)$ \\
\hline Catalytica | BS-25 & $11.611 \quad(\sigma=0.133$, three tests $)$ \\
\hline Particle Tech. I BS-25 & $4.2693 \quad(\sigma=0.069$, two tests $)$ \\
\hline
\end{tabular}


Table 5. Vendor's ratings and final scores

\begin{tabular}{|c|c|c|c|c|c|c|c|c|}
\hline \multicolumn{2}{|c|}{$\begin{array}{c}\text { Designated Criteria } \\
\text { (Phase I) }\end{array}$} & \multirow[t]{2}{*}{ Specific Parameters } & \multirow[t]{2}{*}{$\begin{array}{l}\text { Weightage } \\
\qquad\left(\mathbf{W}_{\mathrm{i}}\right)\end{array}$} & \multicolumn{5}{|c|}{$\begin{array}{l}\text { Vendors (A to E) Rating }\left(V_{i}\right) \\
\text { [Excellent }(4) \text { to Fair }(1)]\end{array}$} \\
\hline & & & & $\mathbf{A}$ & $\mathbf{B}$ & $\mathbf{C}$ & $\mathbf{D}$ & $\mathbf{E}$ \\
\hline \multirow{11}{*}{ Technical } & \multirow{6}{*}{$\begin{array}{l}\text { Powder } \\
\text { Related }\end{array}$} & Phase Purity 1 & 4 & 4 & 3 & 2 & 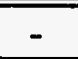 & 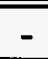 \\
\hline & & Calcination Temp. ${ }^{2}$ & 2 & 2 & 2 & 1 & - & - \\
\hline & & Particle Size \& Surface Area & 4 & 3 & 4 & 2 & - & - \\
\hline & & Thermal (Phase) Stability & 3 & 4 & 4 & 4 & - & - \\
\hline & & Dispersibility \& Flowability & 3 & 3 & 3 & 2 & - & - \\
\hline & & Sinterability & 2 & 3 & 3 & 1 & - & - \\
\hline & \multirow{5}{*}{$\begin{array}{l}\text { Process } \\
\text { Related }\end{array}$} & Scalability ${ }^{3}$ & 5 & 4 & 2 & 1 & 4 & - \\
\hline & & Economics 4 & 4 & 3 & 4 & 4 & - & - \\
\hline & & Production Rates & 4 & 4 & 3 & 1 & - & - \\
\hline & & Environmental Issues & 3 & 3 & 4 & 3 & 4 & - \\
\hline & & Research Work & 2 & 2 & 4 & 1 & - & - \\
\hline \multirow{5}{*}{$\begin{array}{l}\text { Vendor } \\
\text { Related }\end{array}$} & & Analysis \& Reporting & 3 & 3 & 4 & 2 & - & - \\
\hline & & Prior Experience & 2 & 3 & 3 & 1 & 3 & - \\
\hline & & Promptness & 2 & 4 & 3 & 2 & 2 & - \\
\hline & & Integrity & 1 & 4 & 4 & 4 & 4 & - \\
\hline & & Accessibility & 1 & 3 & 3 & 3 & 2 & - \\
\hline \multicolumn{4}{|c|}{ Total Score $\left(\Sigma W_{j} V_{i}\right)=$} & 150 & 148 & 93 & 48 & \\
\hline
\end{tabular}

1 Based on XRD analysis.

2 Lower the calcination temperature required for obtaining phase pure BS and CS powders, the better is the process.

3 Estimated from current status of process equipment and future requirements.

4 Based on vendors' estimates of total operational costs per lb. (excluding capital costs and profits) for production of 10,000 lb./wk. of BS and CS powders. 


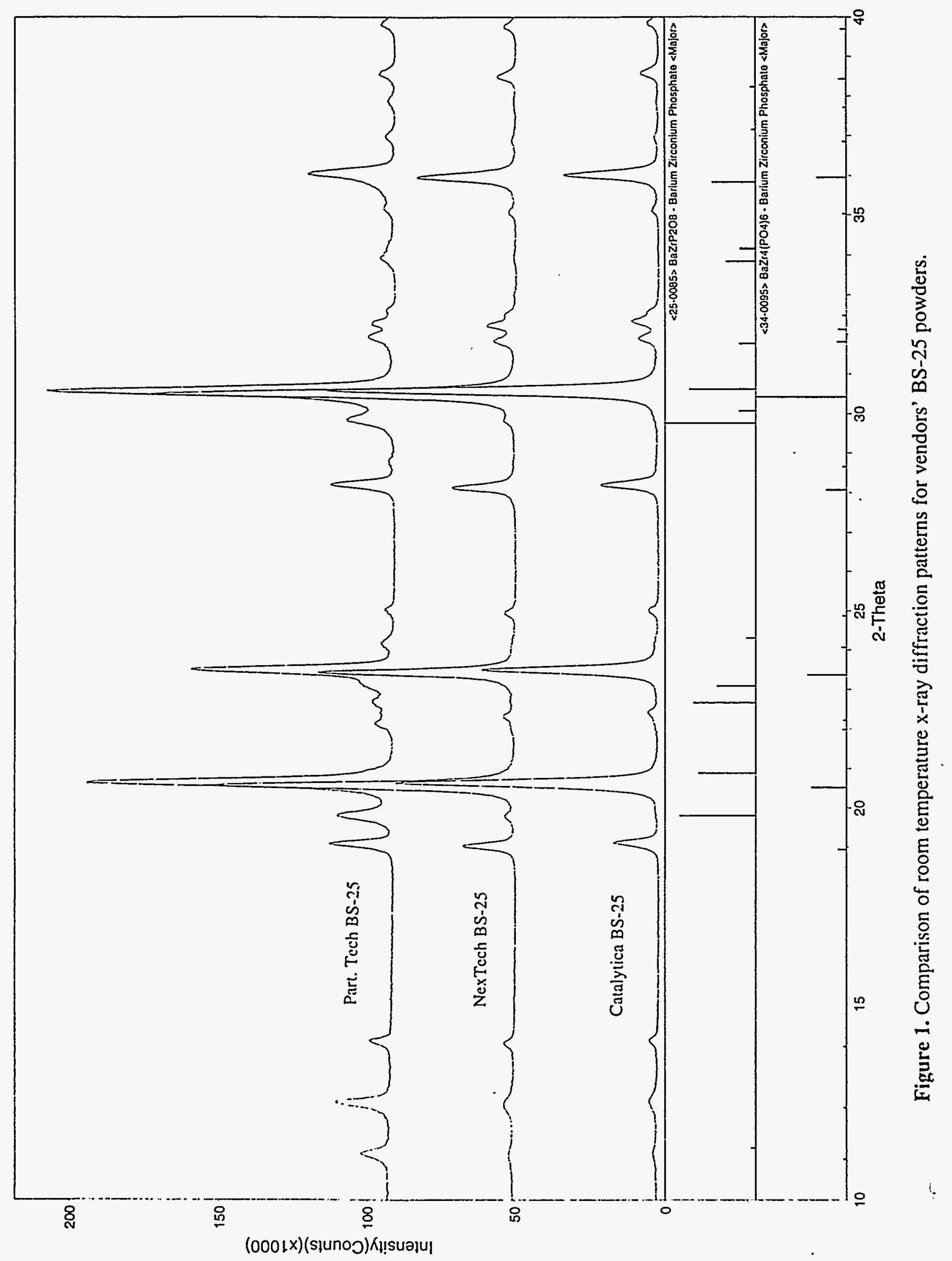




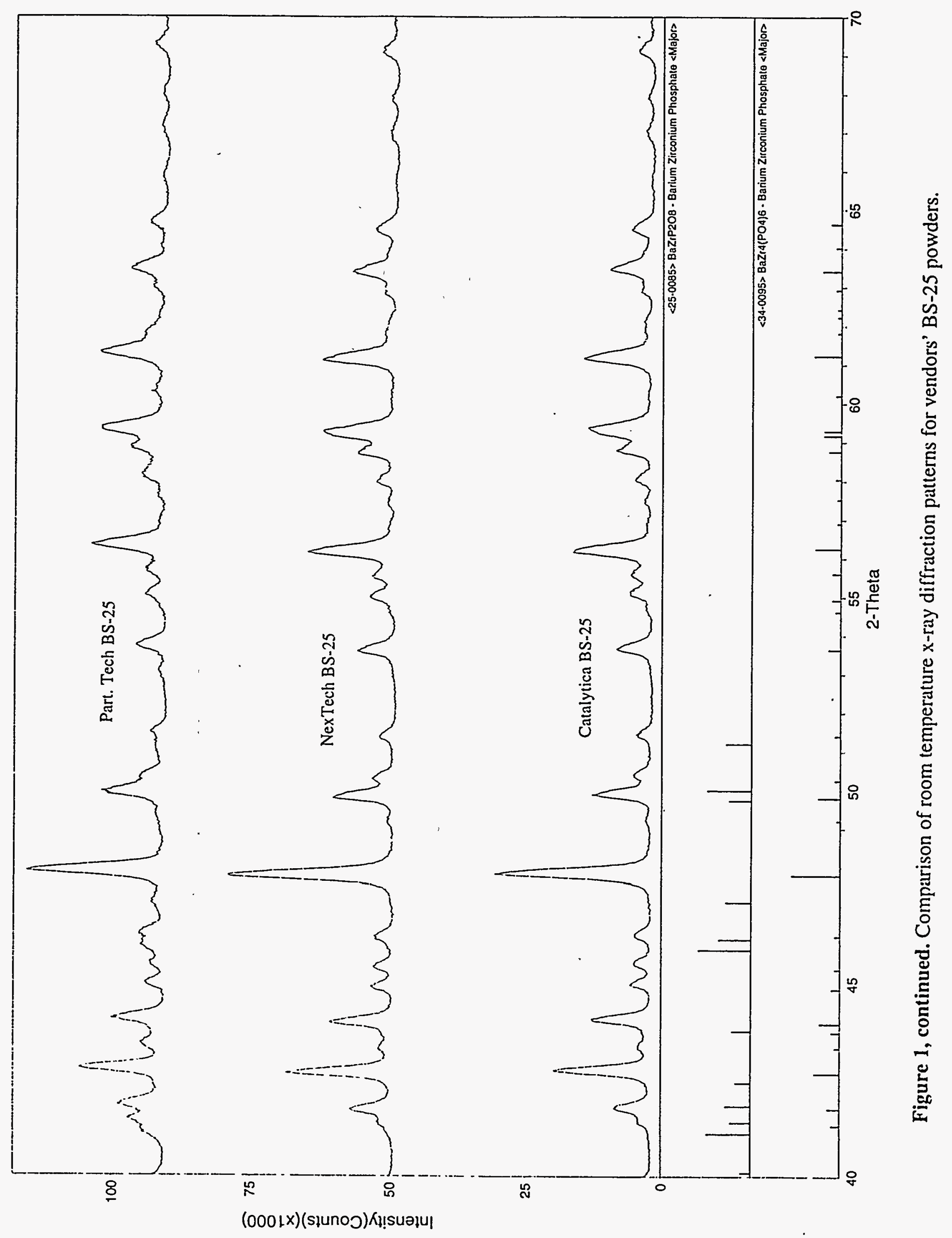




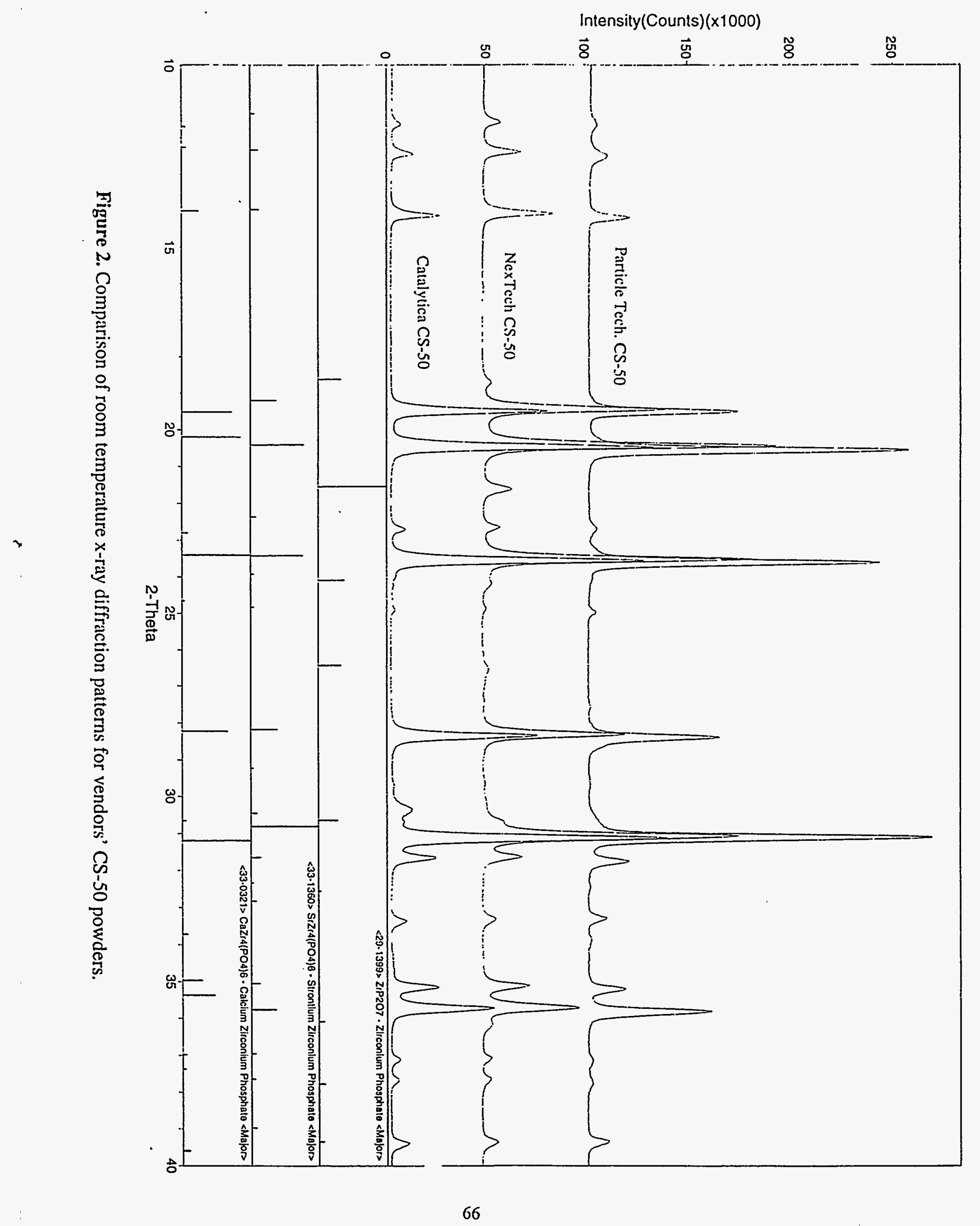




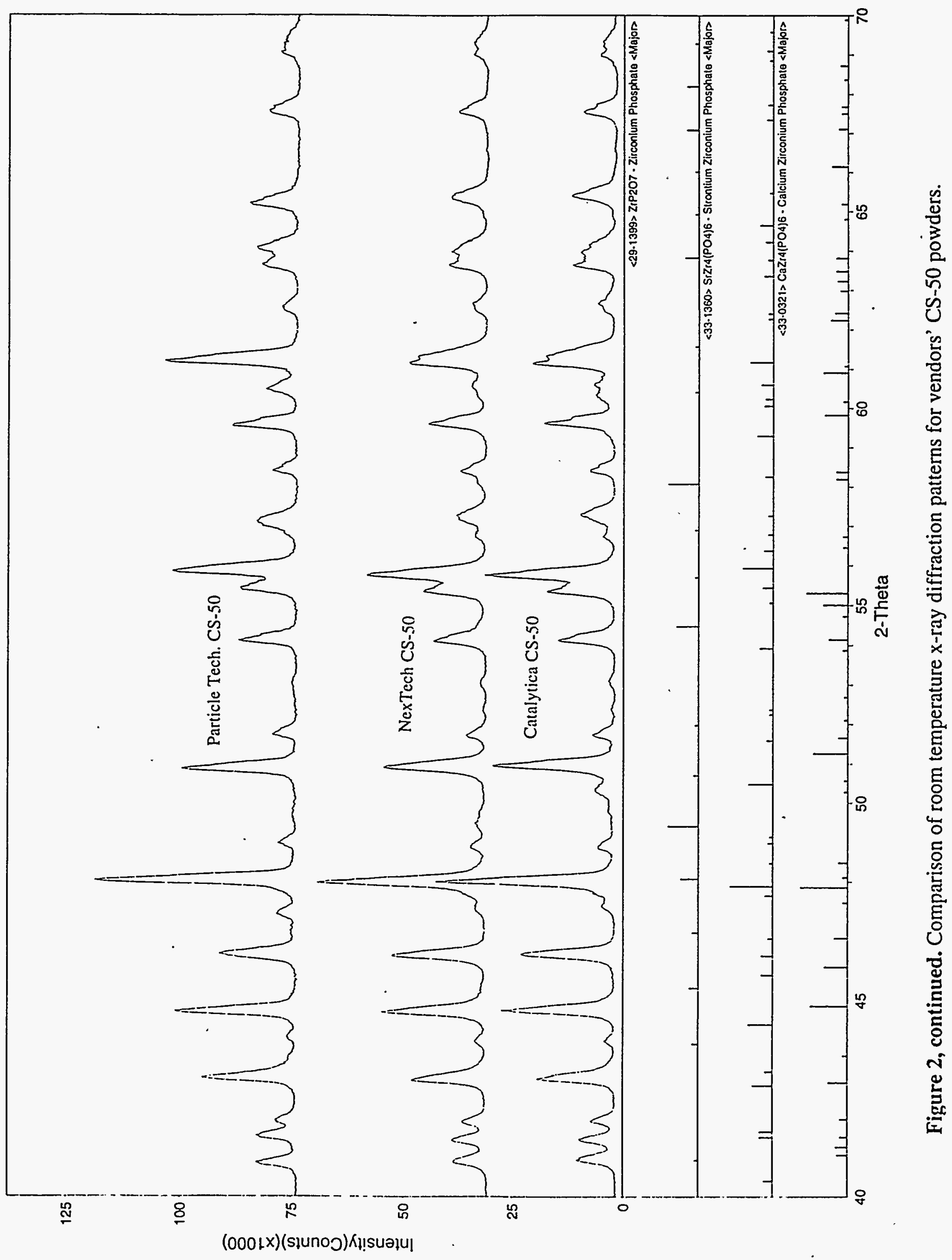




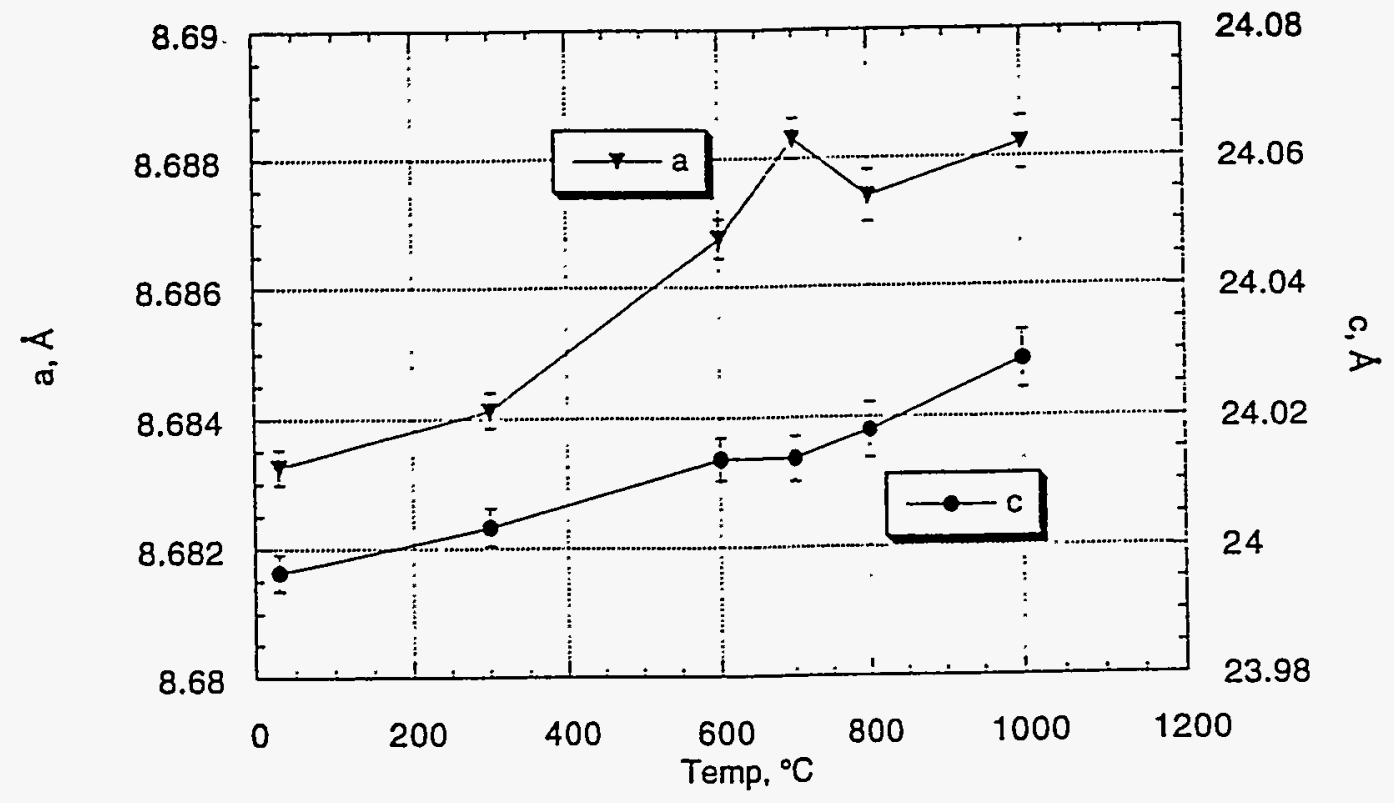

Figure 3. Plots of lattice parameters as a function of temperature for Catalytica BS-25.

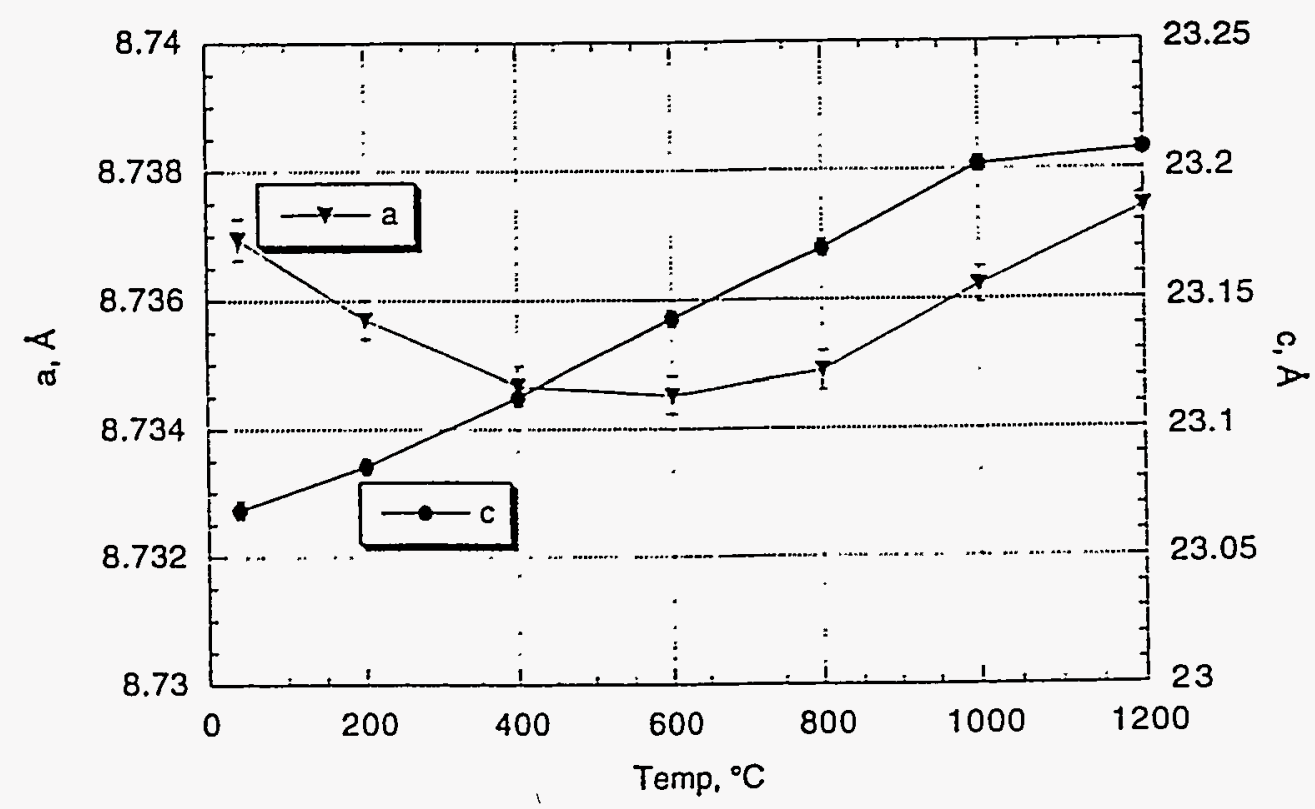

Figure 4. Plots of lattice parameters as a function of temperature for Catalytica CS-50. 

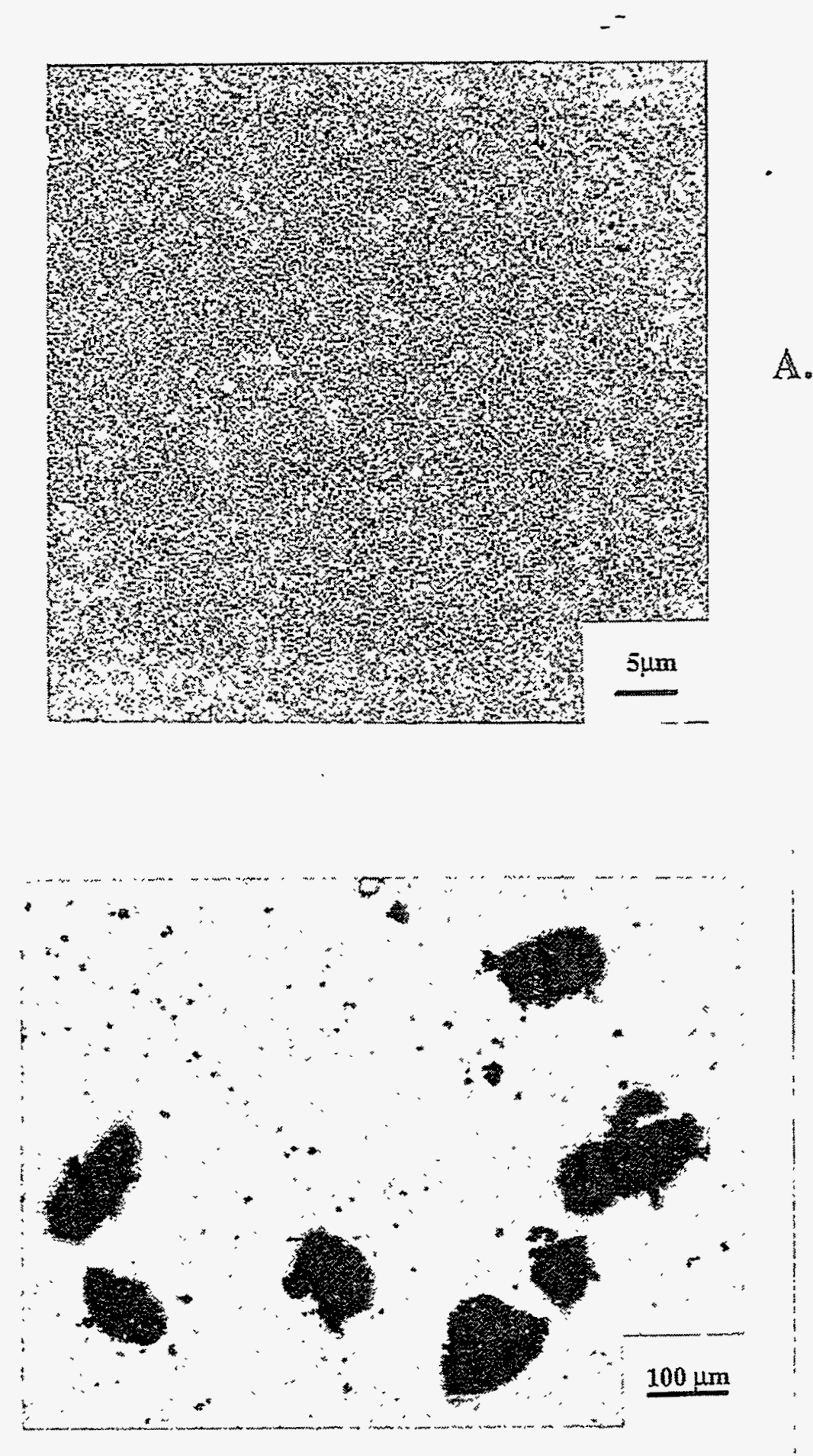

B.

Figure 5. Photomicrograph of Catalytica CS-50 agglomerates taken: A) at high magnification using an SEM; B) at low magnification using an optical microscope. 


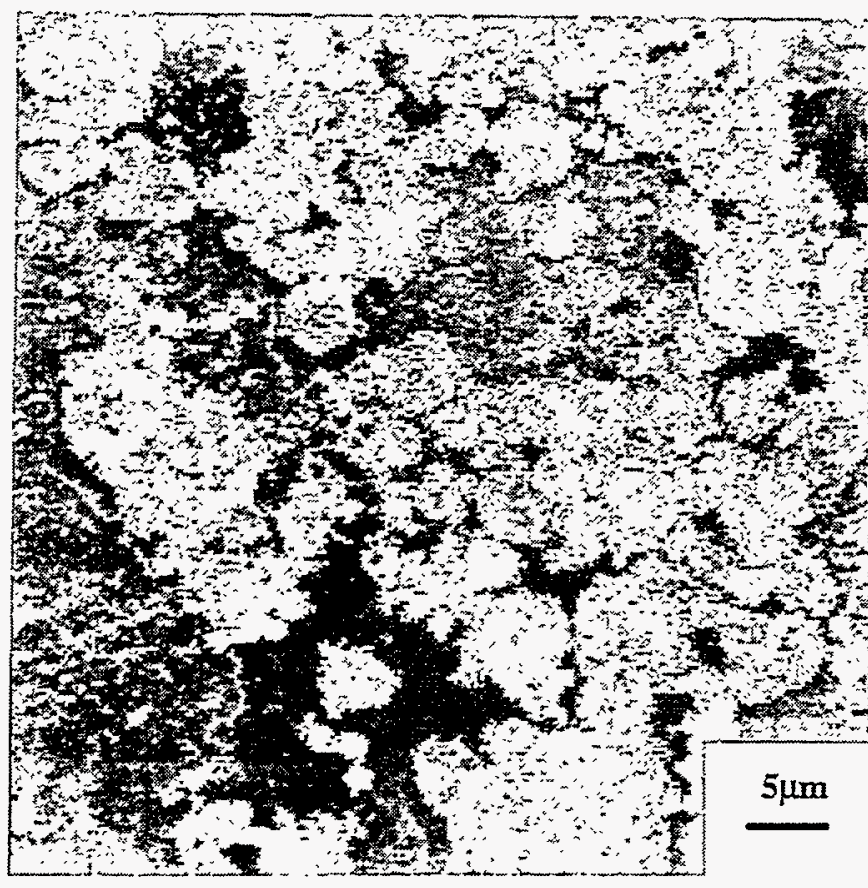

A.

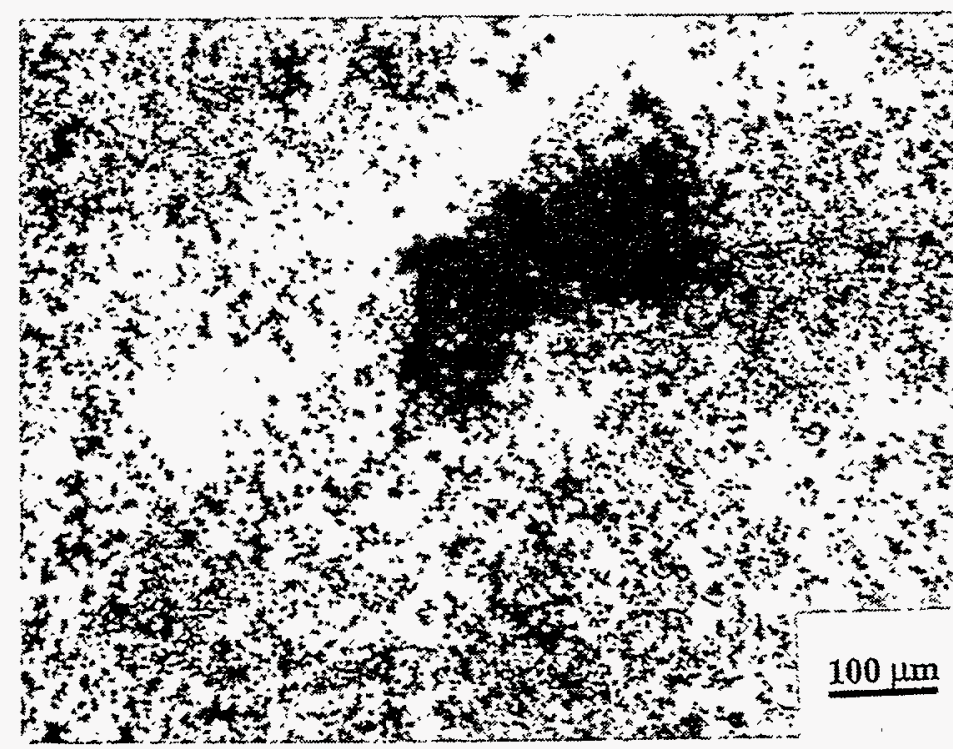

Figure 6. Photomicrograph of Particle Tech BS-25 agglomerates taken: A) at high magnification using an SEM: B) at low magnification using an optical microscope. 


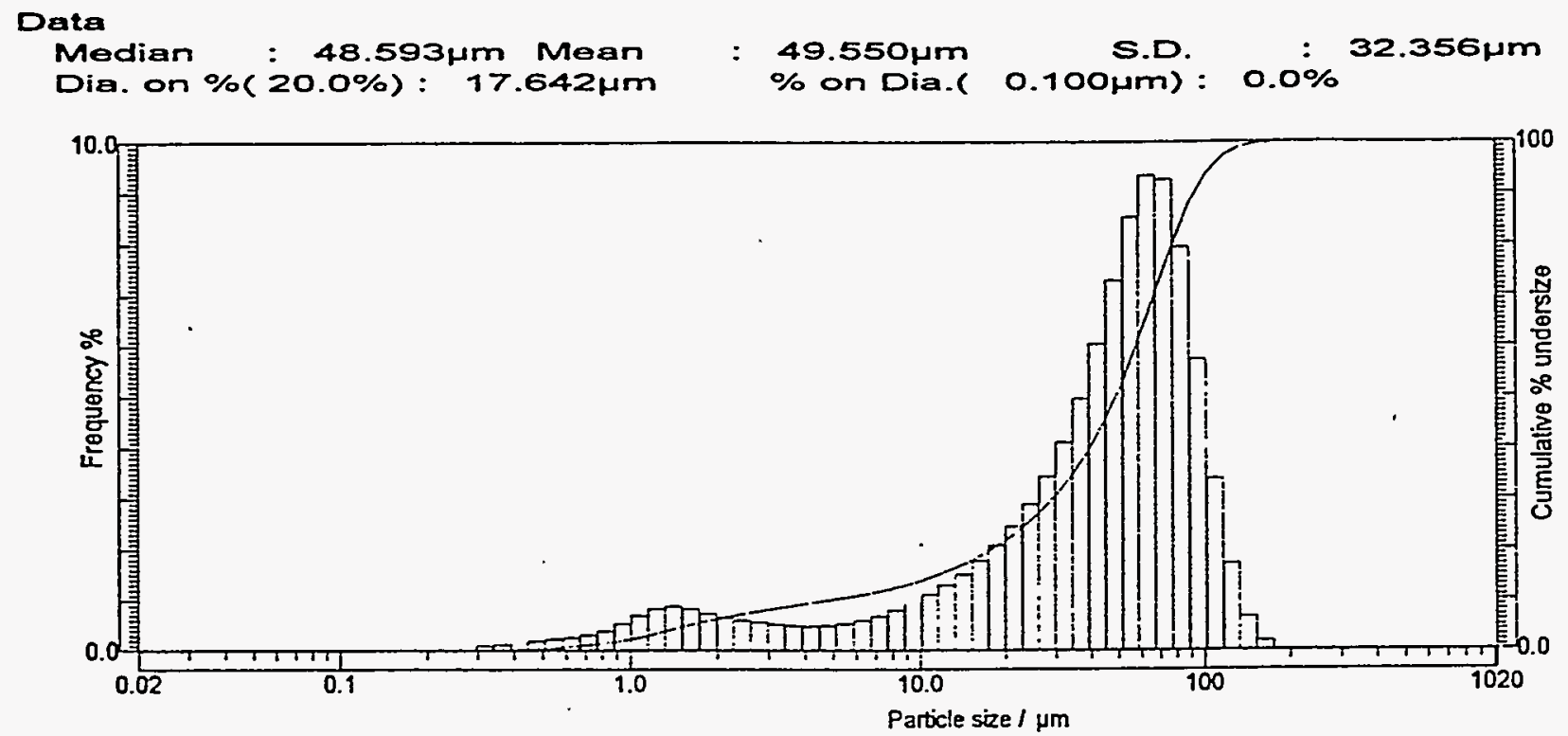

A.
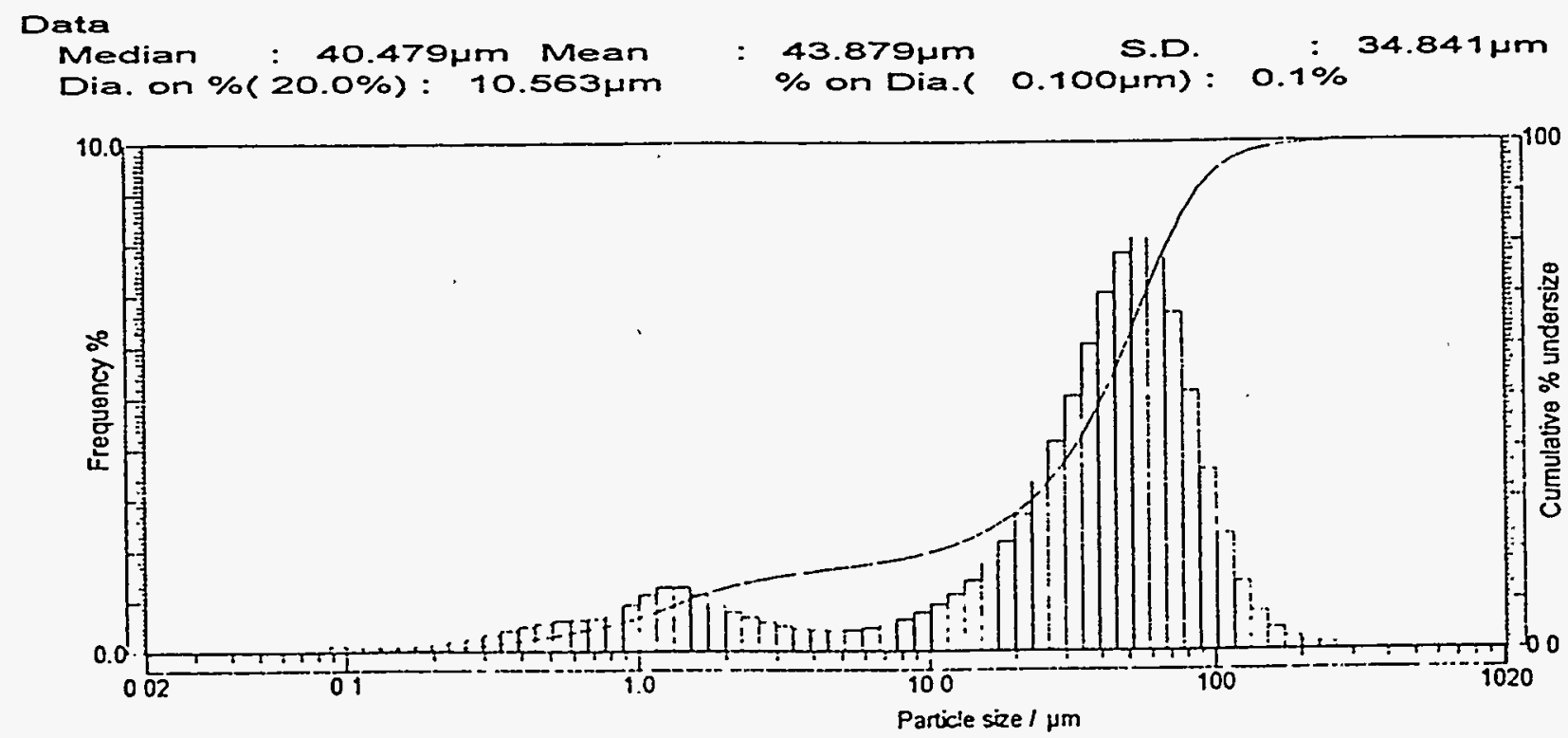

B.

Figure 7. Particle size distributions for: A) Catalytica BS-25; B) Catalytica CS-50. 


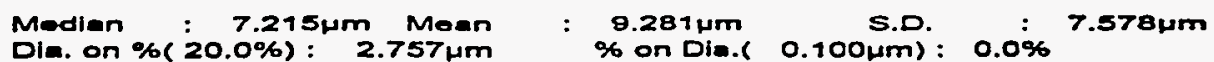

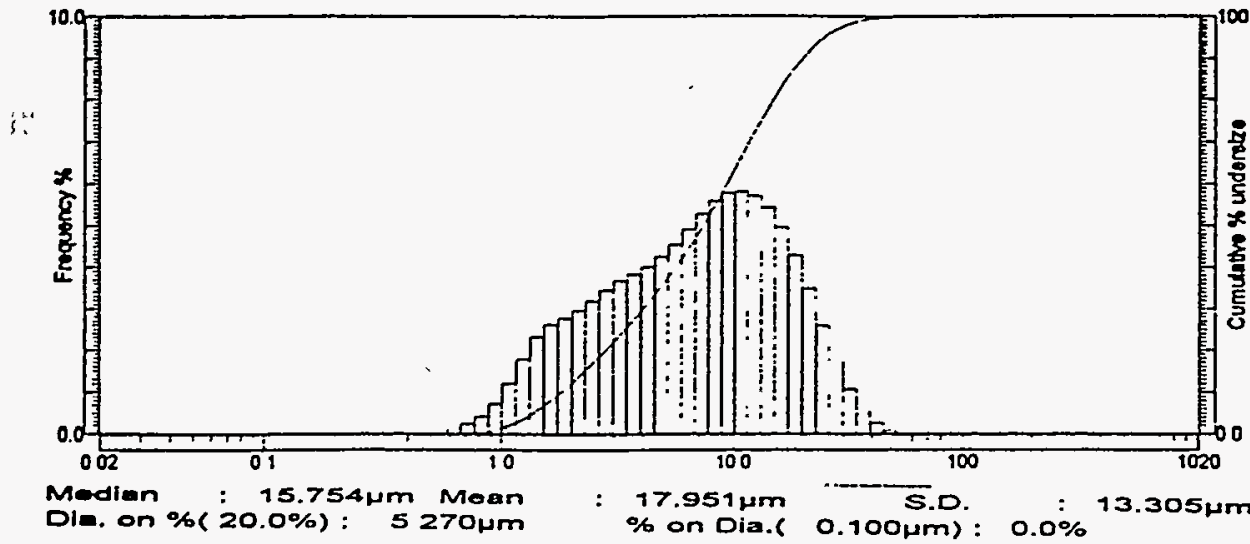

A.

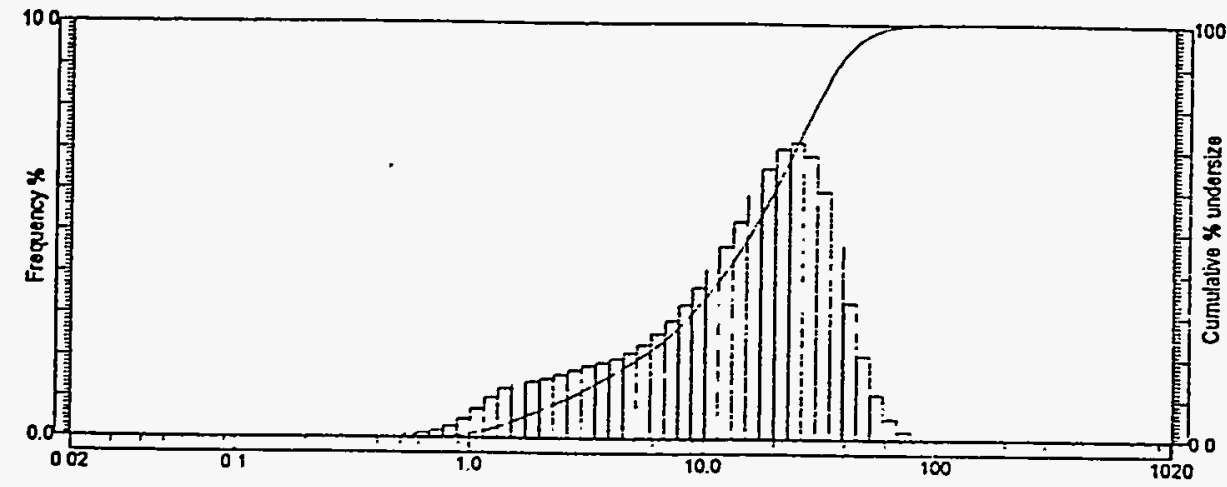

B.
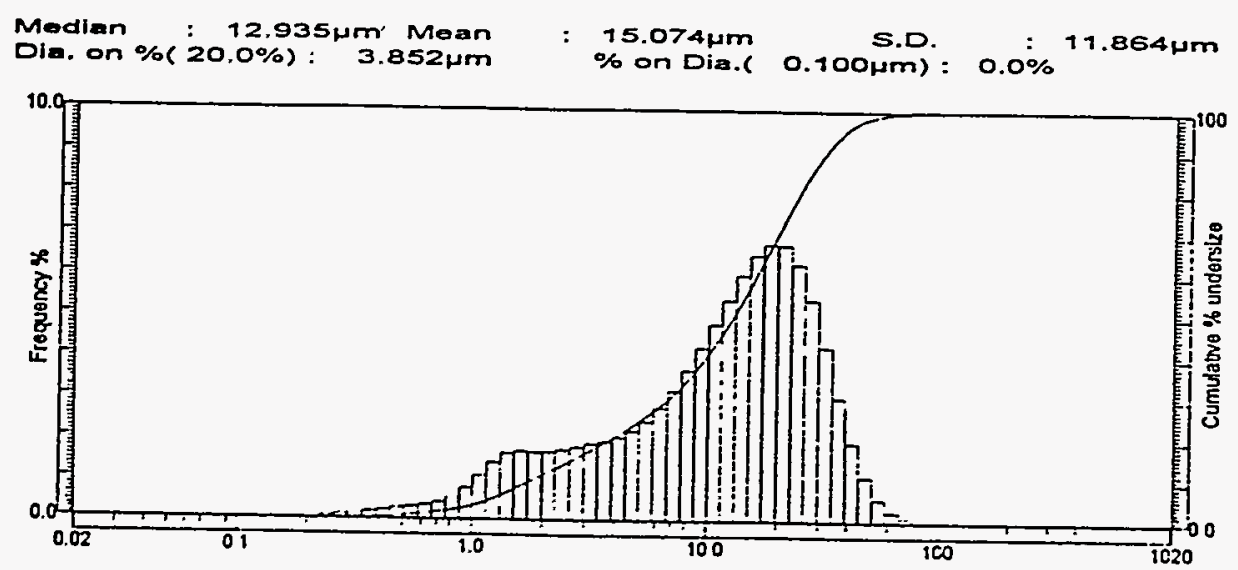

C.
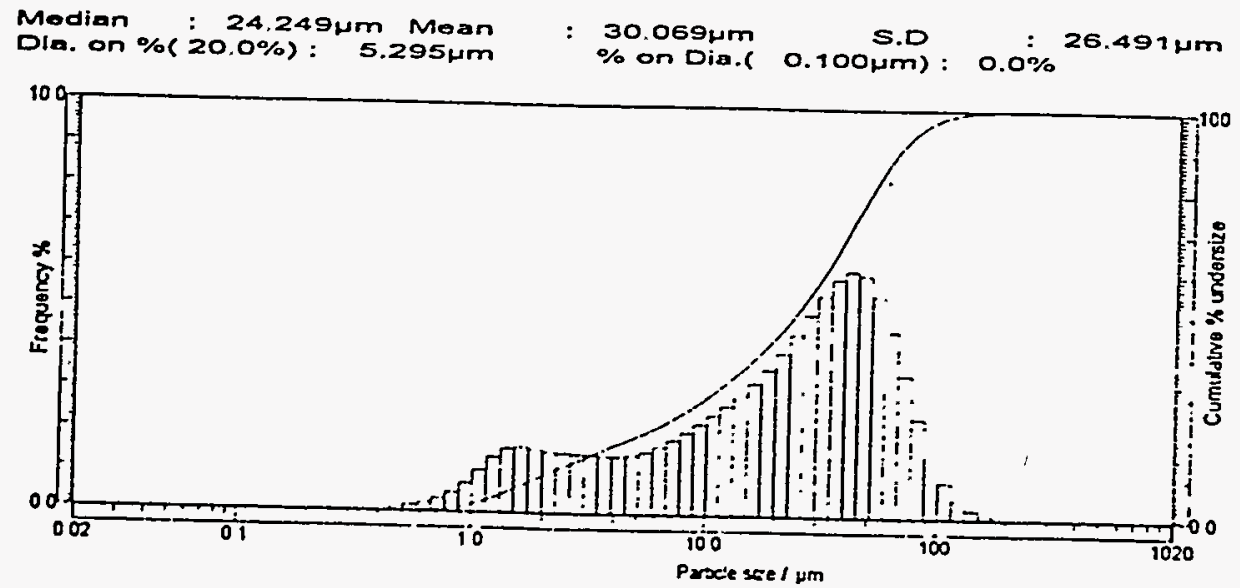

D.

Figure 8. Particle size distributions for NexTech: A) CS-50 CZP\#2 (amorphous): B) CS50 CZP\#4; C) CS-50 CZP\#7; and D) BS-25. 


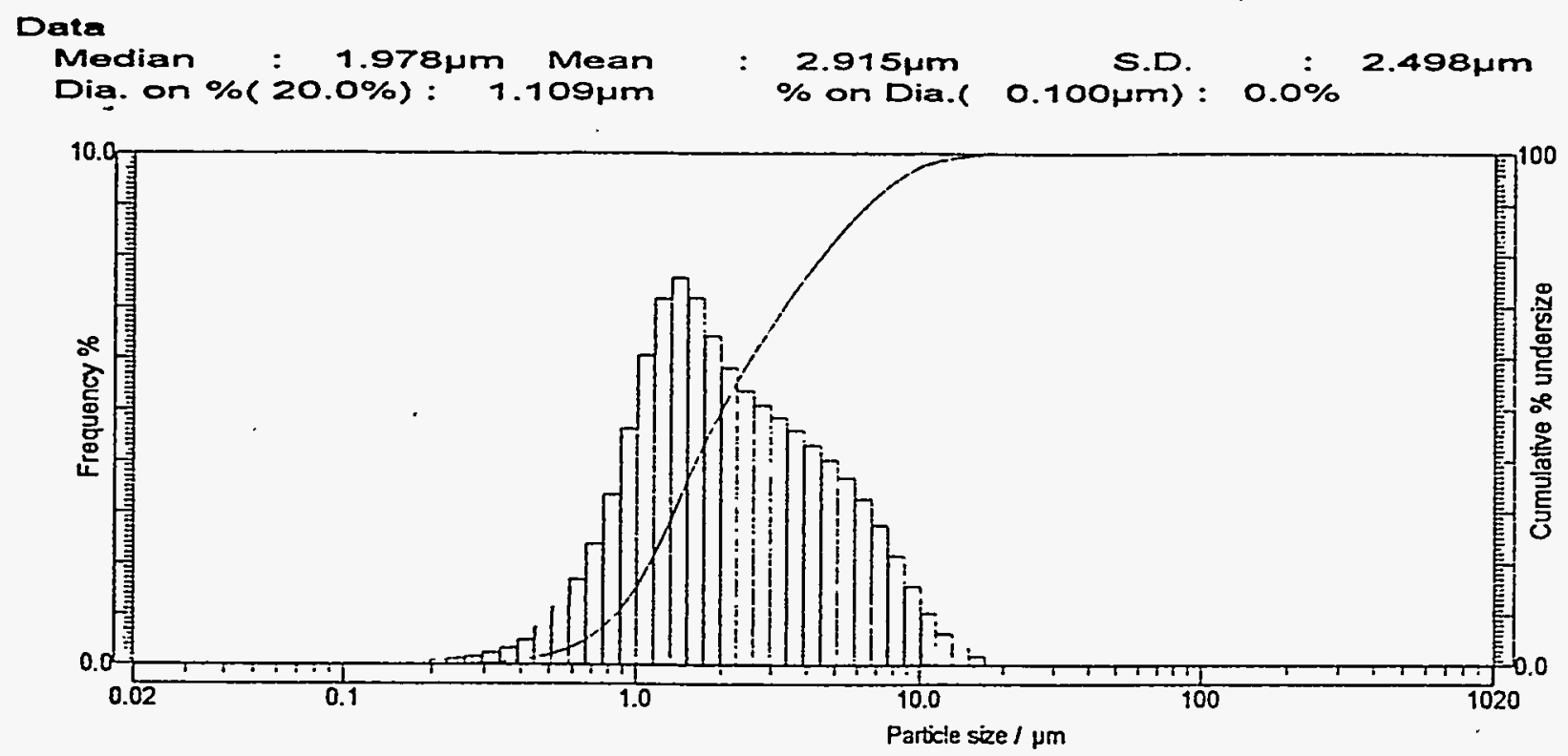

A.

Data

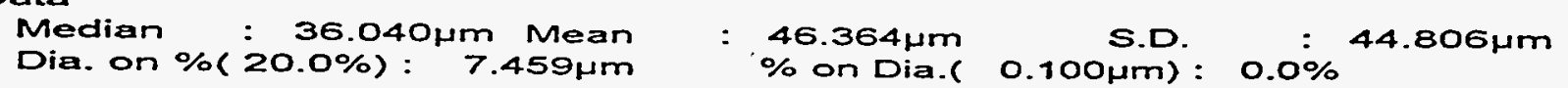

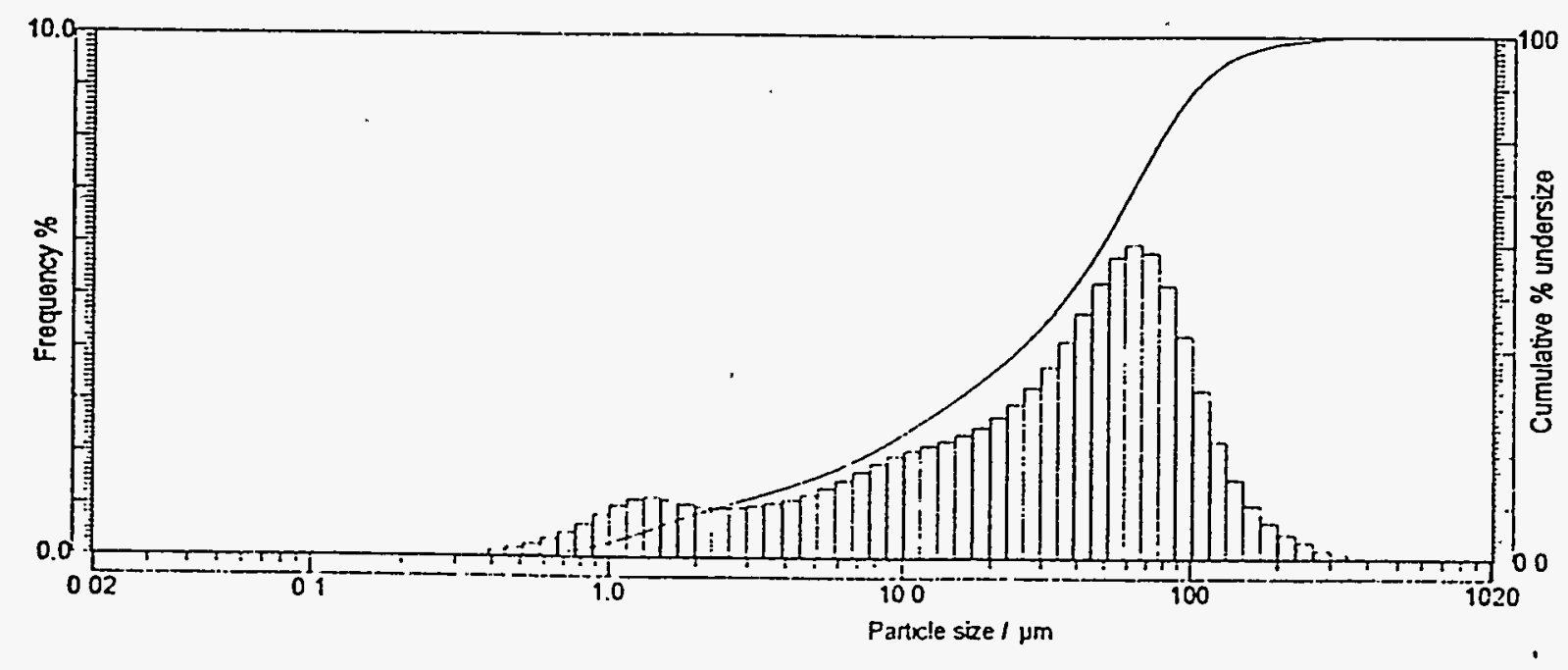

B.

Fïgure 9. Particle size distributions for Particle Technology: A) BS-25: B) CS-50. 


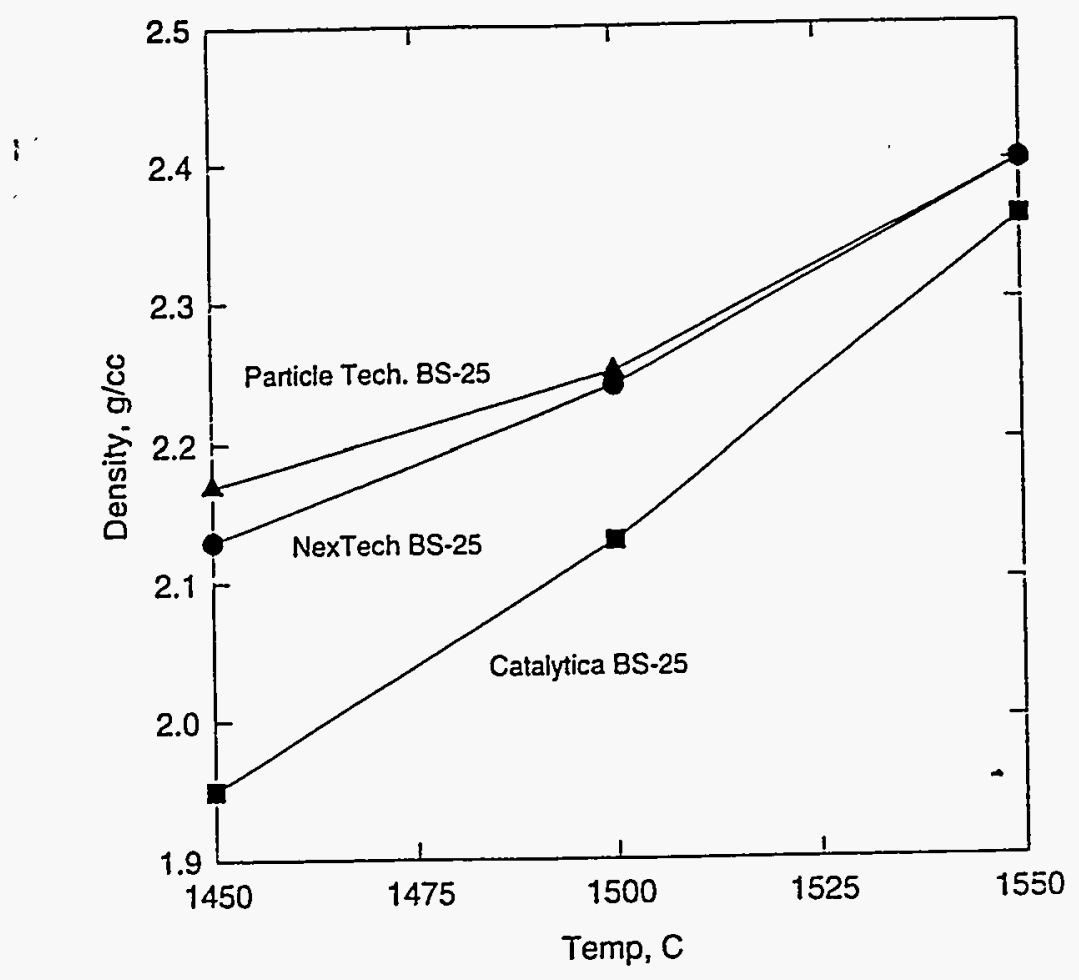

Figure 10. Plot of average density versus sintering temperature for BS-25 powders.

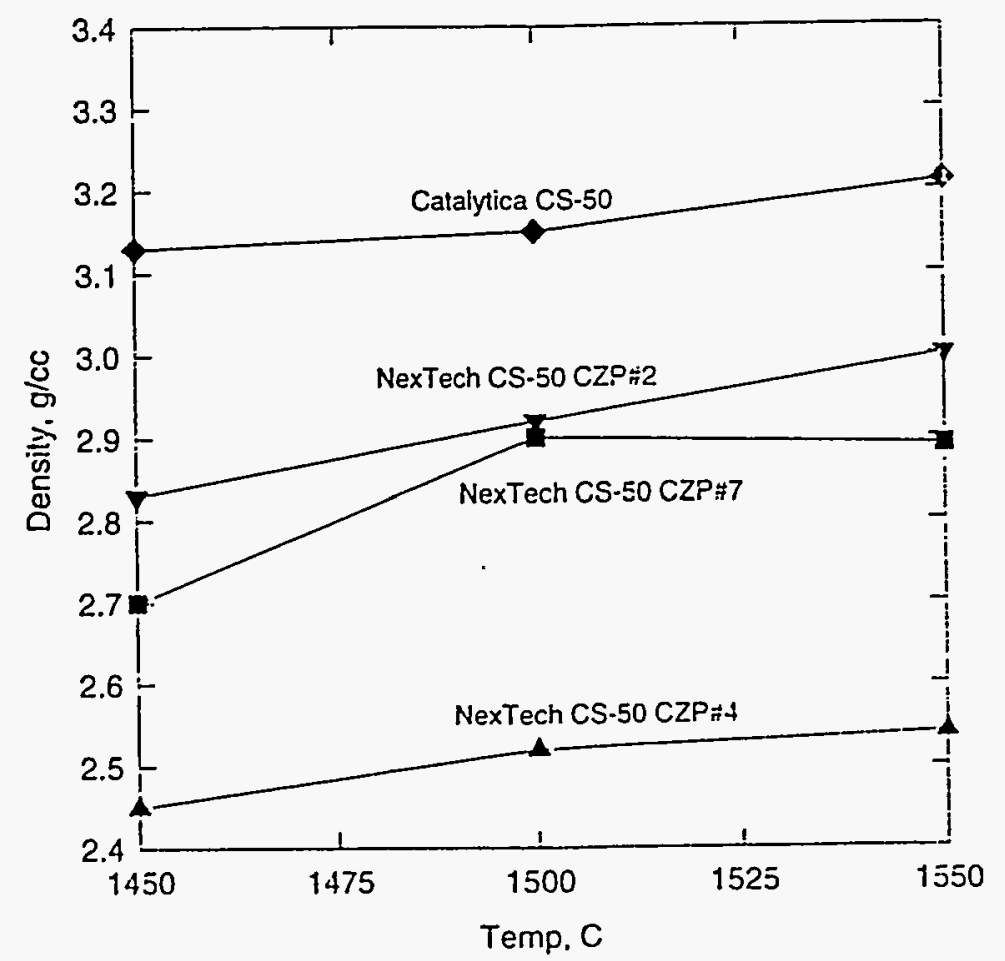

Figure 11. Plot of average density versus sintering temperature for CS-50 powders. 


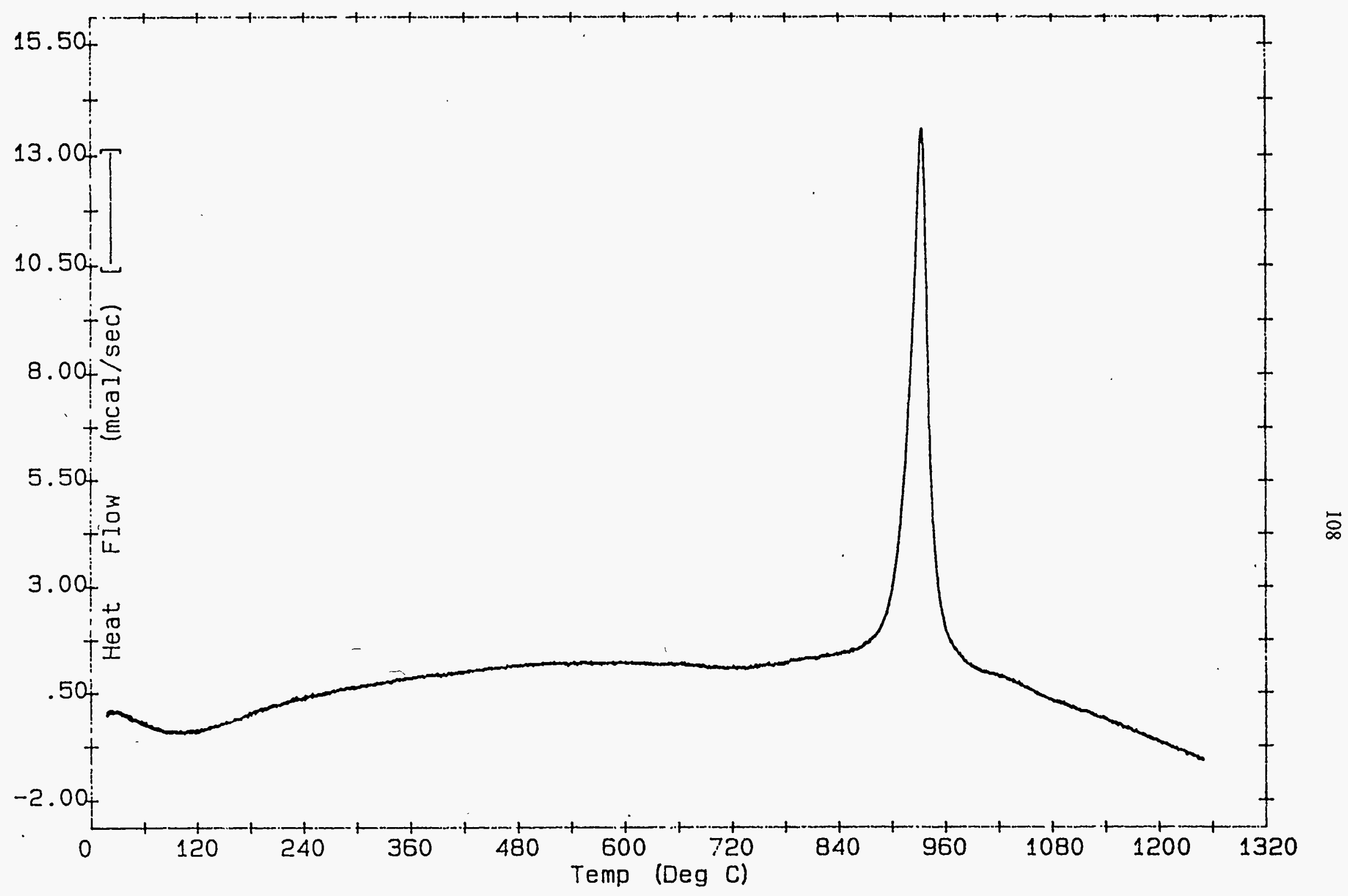

Figure 12. DSC pattern showing a crystallization exotherm for NexTech's non-calcined CS-50 CZP\#2 powder. 


\subsection{THERMAL AND WEAR COATINGS}

\section{FABRICATION AND TESTING OF CORROSION-RESISTANT COATINGS}

W. Y. Lee, K. M. Cooley, Y. Zhang, and D. P. Stinton

Oak Ridge National Laboratory

\section{Objective/Scope}

Hot corrosion of $\mathrm{SiC}$ and $\mathrm{Si}_{3} \mathrm{~N}_{4}$ components in gas turbine engines is potentially a serious problem. The outer surfaces of $\mathrm{SiC}$ and $\mathrm{Si}_{3} \mathrm{~N}_{4}$ parts oxidize at high temperatures to form $\mathrm{SiO}_{2}$ which inhibits further oxidation. However, sodium which is present in high-temperature combustion atmospheres reacts with the $\mathrm{SiO}_{2}$ layer, such that it is no longer protective. The objective of this program is to develop a coating that will protect the underlying $\mathrm{SiC}$ or $\mathrm{Si}_{3} \mathrm{~N}_{4}$ from sodium corrosion and provide simultaneous oxidation protection. To evaluate the behavior of potential materials such as stabilized $\mathrm{ZrO}_{2}$ or $\mathrm{HfO}_{2}, \mathrm{TiO}_{2}, \mathrm{Al}_{2} \mathrm{O}_{3} \cdot \mathrm{TiO}_{2}, 3 \mathrm{Al}_{2} \mathrm{O}_{3} \cdot 2 \mathrm{SiO}_{2}$ (mullite), and $\mathrm{Ta}_{2} \mathrm{O}_{5}$ in sodiumcontaining atmospheres, the corrosion resistance of hot-pressed samples of these materials have been evaluated. A chemical vapor deposition (CVD) process will be developed for the application of the most promising coatings. The effects of the combustion environment upon coating characteristics such as microstructure, strength, adherence, and other properties will also be evaluated.

\section{Technical Progress}

\section{Mullite Coating Preparation}

In this reporting period, the construction of a mullite-CVD reactor system was completed. This CVD process utilizes the $\mathrm{AlCl}_{3}+\mathrm{SiCl}_{4}+\mathrm{CO}_{2}+\mathrm{H}_{2}$ precursor chemistry. It is also designed to use $\mathrm{Ar}$ as a carrier or diluent gas. A liquid vapor feeding system (Tylan General) was set up to control the flow rate of $\mathrm{SiCl}_{4}$, which is a liquid at room temperature. $\mathrm{AlCl}_{3}$ is generated by reacting $\mathrm{Al}$ with $\mathrm{HCl}$ in a $450 \mathrm{~cm}^{3}$ stainless steel chlorinator which is heated to above $250^{\circ} \mathrm{C}$. The flow rate of $\mathrm{AlCl}_{3}$ is controlled by adjusting the $\mathrm{HCl}$ flow rate. $\mathrm{CO}_{2}, \mathrm{H}_{2}$, and $\mathrm{Ar}$ are directly metered using mass flow meters. The reactor system was calibrated for air leaks, temperature uniformity and control, and mass flow control.

A set of initial deposition experiments was performed to test the general operation of the new reactor and to qualitatively assess the effects of processing parameters on coating composition and morphology. The deposition conditions (or ranges) used for the mullite experiments are as follows: temperatures of $950-1100^{\circ} \mathrm{C}$, reactor pressures of $0.67 \mathrm{kPa}$ and $10 \mathrm{kPa}, \mathrm{SiCl}_{4}$ flow rates of $4-13 \mathrm{~cm} / \mathrm{min}$ at STP, and $\mathrm{AlCl}_{3}$ flow rates of $3.3-33 \mathrm{~cm} 3 / \mathrm{min}$. These conditions were basically derived from previous work on depositing pure $\alpha-\mathrm{Al}_{2} \mathrm{O}_{3}$ [Ref. 1] except that, in this work, $\mathrm{SiCl}_{4}$ was added to the reagent stream. For each deposition experiment, $\mathrm{Si}_{3} \mathrm{~N}_{4}$ discs (NCX5102 from Norton, $1.27 \mathrm{~cm}$ diameter $\times 0.32 \mathrm{~cm}$ thickness) and/or Nicalon ${ }^{\mathrm{TM}} / \mathrm{SiC}$ composite. coupons $(1 \mathrm{~cm} \times 1 \mathrm{~cm} \times 0.32 \mathrm{~cm})$ were used as substrates. They were typically placed about $1 \mathrm{~cm}$ apart along the axial direction of the reactor. 
As shown in Figure 1, the growth rate increased exponentially with deposition temperature in the temperature range of 950 to $1100^{\circ} \mathrm{C}$ at a reactor pressure of $10 \mathrm{kPa}$. An apparent activation energy value of $156.3 \mathrm{~kJ} / \mathrm{mole}$ could be estimated from the Arrhenius plot. It was interesting to observe that, when the reactor pressure was decreased to $0.6 \mathrm{kPa}$, the growth rate significantly decreased. Similarly, the deposition kinetics were also sluggish for pure $\mathrm{Al}_{2} \mathrm{O}_{3}$ or $\mathrm{SiO}_{2}$ growth at this low reactor pressure. Therefore, it appears that the growth of mullite (as well as that of pure $\mathrm{Al}_{2} \mathrm{O}_{3}$ and $\mathrm{SiO}_{2}$ ) requires a relatively high reactor pressure $(>0.67 \mathrm{kPa})$.

The characterization results obtained by $x$-ray diffraction (XRD), scanning electron microscopy (SEM), and energy dispersive spectroscopy (EDS) suggest that the coatings deposited in the current work tended to be amorphous. Figure 2 shows the surface morphology of the coating deposited at $1100^{\circ} \mathrm{C}$ and $10 \mathrm{kPa}$ with an $\mathrm{AlCl}_{3} / \mathrm{SiCl}_{4}$ concentration ratio of 2.25. The coating surface was highly uniform, and consisted of smooth nodules which were several micrometers in size. The EDS analysis indicated that most of the coatings prepared in this report did not contain sufficient Al to form the mullite composition $\left(3 \mathrm{Al}_{2} \mathrm{O}_{3} \cdot 2 \mathrm{SiO}_{2}\right)$, even when the $\mathrm{AlCl}_{3} / \mathrm{SiCl}_{4}$ ratio was as high as 8.25. These preliminary observations seem to indicate that the growth of amorphous $\mathrm{SiO}_{2}$ dominates and consequently inhibits the incorporation of $\mathrm{Al}_{2} \mathrm{O}_{3}$. In the next reporting period, the effects of the $\mathrm{AlCl}_{3} / \mathrm{SiCl}_{4}$ concentration ratio and reactor pressure will be systematically studied. Also, the absolute $\mathrm{SiCl}_{4}$ concentration will be lowered to promote the growth of more crystalline deposits.

\section{II. $\mathrm{ZrSiO}_{4}$ as an Alternative Coating Material}

It appears from our investigation to date that mullite is the most promising candidate coating material for protecting $\mathrm{Si}_{3} \mathrm{~N}_{4}$ from $\mathrm{Na}_{2} \mathrm{SO}_{4}$ induced corrosion. However, it is foreseen that there are several major issues associated with the reliable use of the mullite coating for realistic applications. First, the processing of the mullite coating by CVD is expected to be difficult in terms of controlling coating uniformity and stoichiometry in production-scale operation. Also, it has been observed that, while its oxidative stability is excellent, the mullite coating may not be stable in certain reducing environments. Because of these reasons, other coating materials such as $\mathrm{Ca}_{0.5} \mathrm{Sr}_{0.5} \mathrm{Zr}_{4} \mathrm{P}_{6} \mathrm{O}_{24}$ have been considered in this research project. In this reporting period, a study was initiated to assess $\mathrm{ZrSiO}_{4}$ as an alternative coating material.

$\mathrm{ZrSiO}_{4}$, commonly referred to as zircon, has some attractive properties as a coating material for $\mathrm{Si}_{3} \mathrm{~N}_{4}$. For example, its low coefficient of thermal expansion $\left(\sim 4.2 \times 10^{-6} \mathrm{~K}^{-1}\right)$ compares favorably to that of $\mathrm{Si}_{3} \mathrm{~N}_{4}\left(\sim 3 \times 10^{-6} \mathrm{~K}^{-1}\right)$. The elastic modulus of $\mathrm{ZrSiO}_{4}$ is also relatively low $(\sim 160 \mathrm{GPa})$, which is another desirable characteristic of a coating material. $\mathrm{ZrSiO}_{4}$ is a stable compound up to $1700^{\circ} \mathrm{C}$ without any destructive phase transformation. However, it appears that the thermochemical stability of $\mathrm{ZrSiO}_{4}$ with respect to $\mathrm{Na}_{2} \mathrm{SO}_{4}$ is not sufficiently known.

The formation of $\mathrm{ZrSiO}_{4}$ is thermodynamically possible when $\mathrm{ZrCl}_{4}, \mathrm{SiCl}_{4}, \mathrm{CO}_{2}$, and $\mathrm{H}_{2}$ are used as reagents in the temperature range of 800 to $1200^{\circ} \mathrm{C}$. Equilibrium calculations were performed using a computer code, ChemSage, with 120 possible chemical species. According to the calculations, $\mathrm{ZrSiO}_{4}$ is expected to be deposited as 
a single phase coating (without $\mathrm{ZrO}_{2}$ or $\mathrm{SiO}_{2}$ incorporation), as long as the molar ratio between $\mathrm{ZrCl}_{4}$ and $\mathrm{SiCl}_{4}$ is stoichiometric in the presence of excess $\mathrm{CO}_{2}$.

Preliminary deposition experiments were performed as a function of reactor pressure $\left(0.67,5.3\right.$, and $10.0 \mathrm{kPa}$ ) at a constant deposition temperature of $1050^{\circ} \mathrm{C}$ under the following flow rate conditions: $\mathrm{HCl}=25 \mathrm{~cm} 3 / \mathrm{min}$ (used for $\mathrm{Zr}$ chlorination), $\mathrm{SiCl}_{4}=4 \mathrm{~cm} 3 / \mathrm{min}, \mathrm{CO}_{2}=40 \mathrm{~cm}^{3} / \mathrm{min}$, and $\mathrm{H}_{2}=40 \mathrm{~cm} 3 / \mathrm{min}$. The growth rate increased with increasing the reactor pressure. It was found that the coatings contained tetragonal $\mathrm{ZrO}_{2}$ as a crystalline phase by $\mathrm{x}$-ray diffraction. In contrast, when $\mathrm{ZrO}_{2}$ is deposited alone (i.e., without $\mathrm{SiCl}_{4}$ at similar deposition conditions), monoclinic $\mathrm{ZrO}_{2}$ is typically deposited. The coatings are being characterized by microscopy.

\section{Status of Milestones}

On schedule.

\section{Communications/Visits/Travel}

W.Y. Lee presented a paper titled "Characterization of $\mathrm{Si}_{3} \mathrm{~N}_{4}$ Protected with CVD Mullite Coating from $\mathrm{Na}_{2} \mathrm{SO}_{4}$ Induced Corrosion" at the 20th Annual Conference on Composites, Advanced Ceramics, and Materials and Structures, Cocoa Beach, FL, January 7-11, 1996. The presentation was co-authored with Y.W. Bae, D.P. Stinton, and K.L. More.

Brad Beardsley discussed Caterpillar's coating needs with W.Y. Lee and D.P. Stinton during his visit to ORNL on December 12-13, 1995.

D. P. Stinton and Vinod Sarin of Boston University visited Tom Strangman at AlliedSignal Engines, Phoenix, Arizona on March 6, 1996 to discuss corrosion-resistant coating development.

\section{Problems Encountered}

None.

\section{Publication}

W. Y. Lee, D. P. Stinton, D. L. Joslin, "Interaction of Low-Expansion Ceramics with $\mathrm{Na}_{2} \mathrm{SO}_{4}$ at $1000^{\circ} \mathrm{C}$," J. Am. Ceram. Soc., 79, 484 (1996).

W. Y. Lee, K. L. More, D. P. Stinton, and Y. W. Bae, "Characterization of $\mathrm{Si}_{3} \mathrm{~N}_{4}$ Coated with Chemically Vapor Deposited Mullite after $\mathrm{Na}_{2} \mathrm{SO}_{4}$ Induced Corrosion," $\underline{\mathrm{J}}$. Am. Ceram. Soc., accepted.

\section{References}

1. W.Y. Lee, Y.W. Bae, K.M. Cooley, and D.P. Stinton, pp. 21-26 in Ceramic Technology Project Bimonthly Technical Progress Report for April and May 1995. 


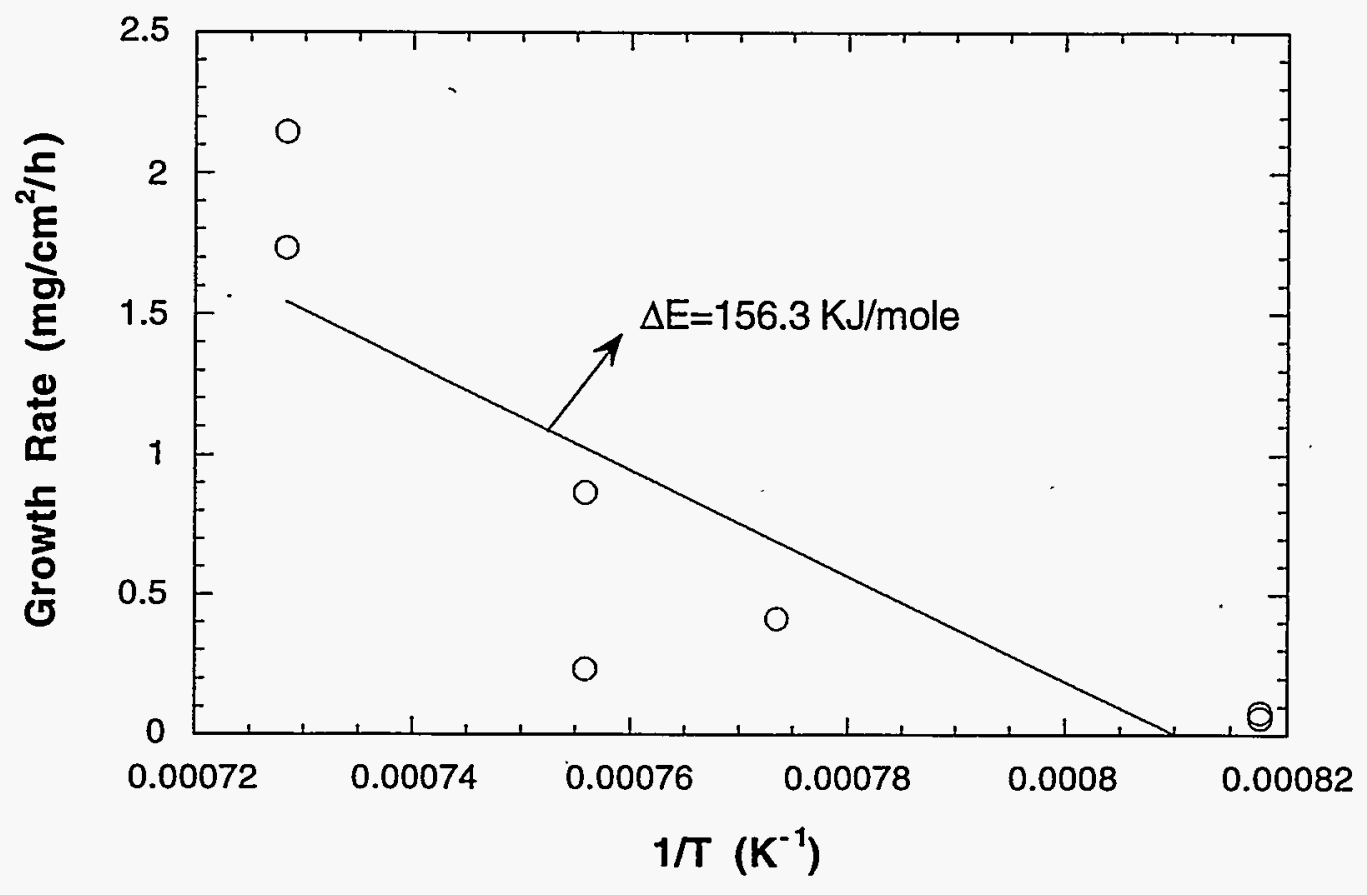

Figure 1. Arrhenius plot between temperature and growth rate. The deposition experiments were performed in the temperature range of 950 to $1100^{\circ} \mathrm{C}$ and at a reactor pressure of $10 \mathrm{kPa}$. 


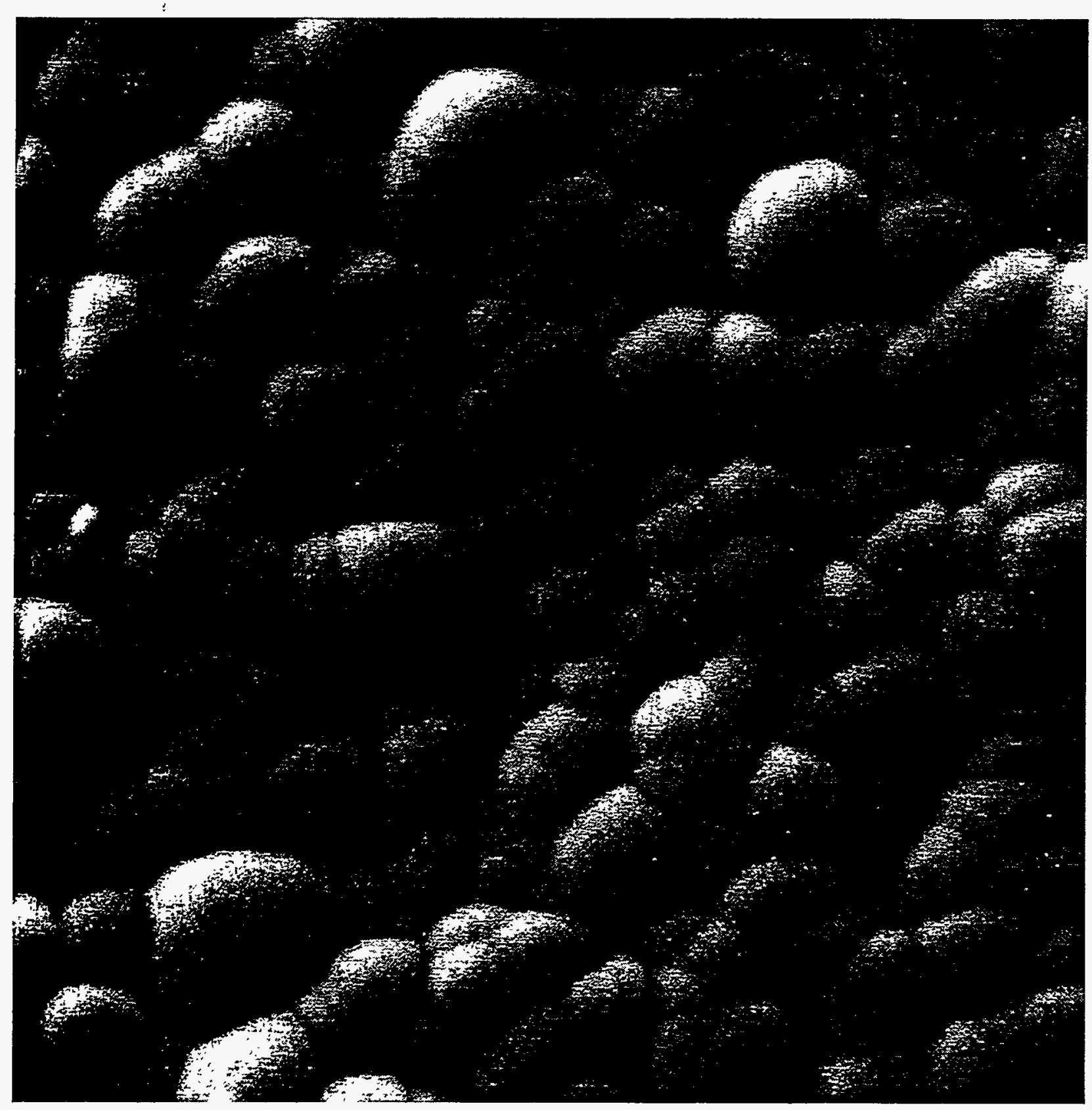

Figure 2. SEM micrograph of the coating deposited at $1100^{\circ} \mathrm{C}$ and $10 \mathrm{kPa}$ with an $\mathrm{AlCl}_{3} / \mathrm{SiCl}_{4}$ concentration ratio of 2.25 (magnification; $2.67 \mathrm{~K}$ ). 


\title{
1.4.1 Ceramic-Metal Joints
}

\author{
WBS Element 1.4.1 \\ JOINING OF CERAMICS FOR HEAT ENGINE APPLICATIONS \\ M. L. Santella
}

\section{Objective/Scope}

The objective of this task is to develop strong reliable joints containing ceramic components for applications in advanced heat engines. The overall emphasis of this task is on studying the brazing characteristics of advanced ceramics such as silicon nitride, silicon carbide and partially stabilized zirconia. The techniques of direct brazing with metallic and nonmetallic filler materials are being used. Vapor coatings are being used where appropriate to circumvent wetting problems associated with braze filler metals. The planned activities during FY 1996 will emphasize the use of structural analysis software to design joints for engine components such as valves and shaft attachments. The objective of this effort with be to identify material combinations and processing that would be feasible for these components, and to produce prototype parts whenever possible.

\section{$\underline{\text { Technical Highlights }}$}

Ceramic-to-metal brazing ( $\mathrm{Ti} / \mathrm{ZrO}_{2}$ ): Machining of two additional $\mathrm{Ti} / \mathrm{ZrO}_{2}$ valve blanks was completed, and $\mathrm{x}$-ray tomography indicated both joints were acceptable. The joints were configured differently on these two valves to examine how well the flow of filler metal could be controlled during brazing. The tomography results showed that control of filler metal flow and location was possible. Both of these additional $\mathrm{Ti} / \mathrm{ZrO}_{2}$ valve blanks were finish machined to the exhaust valve shape. Also, several $\mathrm{Ti} / \mathrm{ZrO}_{2}$ coupons were brazed to provide material for machining into flexure test bars.

Metallographic analysis was done on braze joints made to simulate the materials and processing used to make the $\mathrm{Ti} / \mathrm{ZrO}_{2}$ valves. Previous work showed that a Ti-rich layer formed on the $\mathrm{ZrO}_{2}$ surface during brazing with pure Ag filler metal. Microchemical analysis indicated that the Ti-rich layer was a Ti oxide phase. The solubility of $\mathrm{Ti}$ in $\mathrm{Ag}$ at the brazing temperature of $975^{\circ} \mathrm{C}$ is $2-3 \mathrm{wt} \%$. Consequently, the liquid $\mathrm{Ag}$ became 'active' during brazing. The Ti dissolved in the $\mathrm{Ag}$ then reacted with the $\mathrm{ZrO}_{2}$ to produce wetting and bonding.

The growth of the $\mathrm{TiO}_{\mathrm{x}}$ layer was also being studied. Braze joints were made at temperatures of $960^{\circ} \mathrm{C}$, $1000^{\circ} \mathrm{C}$, and $1050^{\circ} \mathrm{C}$. The $\mathrm{TiO}_{x}$ layer thicknesses corresponding to these brazing temperatures were $42 \mu \mathrm{m}$, $64 \mu \mathrm{m}$, and $104 \mu \mathrm{m}$, respectively. A plot of these data is shown in Fig. 1, where it was assumed that the growth of the $\mathrm{TiO}_{\mathrm{x}}$ films was controlled by diffusion according to

$$
d=\alpha(D t)^{1 / 2}
$$

In this expression, $d$ is the film thickness, $\alpha$ is a constant, $D$ is the diffusion coefficient, and $t$ is time. The slope of this plot corresponds to an activation energy for the rate-controlling diffusion process. The activation energy $\mathrm{Q}=40.6 \mathrm{kcal} / \mathrm{mole}$ is close to that for the diffusion of oxygen in stabilized $\mathrm{ZrO}_{2}, \mathrm{Q}=32$ $\mathrm{kcal} / \mathrm{mole}$. This analysis indicates that oxygen diffusion is controlling the growth of the $\mathrm{TiO}_{\mathrm{x}}$ films in the braze joints.

Ceramic-to-metal brazing ( $\mathrm{Si}_{3} \mathrm{~N}_{4} /$ metal): Input property data files were completed for $\mathrm{Mo}, \mathrm{Nb}$, and $\mathrm{Ta}$, and were made available, along with that of Incoloy 909, for analysis trials. To circumvent the problem of long analysis run time, it was decided to use a simple butt joint geometry to examine material property and process temperature effects on residual stress distributions. The butt joint model was constructed and used to analyze the residual stresses in braze joints of PY6 $\mathrm{Si}_{3} \mathrm{~N}_{4}$ and each of these four metals. A summary of the results is given in Table 1 for a brazing temperature of $870^{\circ} \mathrm{C}$. Peak stress in the $\mathrm{Si}_{3} \mathrm{~N}_{4}$ increased directly with the 
difference in thermal expansion coefficients as expected. Even for Mo, which has the best match of thermal: expansion coefficient, the peak stress experienced by the $\mathrm{Si}_{3} \mathrm{~N}_{4}$ is a significant fraction of its nominal fracture strength of about $700 \mathrm{MPa}$. The stresses experienced by the metals are also quite high, as is the strain in the braze layer. Modifications to the shaft geometry and the processing will be considered in efforts to minimize residual stresses.

Table 1. Peak stress and strain results at $20^{\circ} \mathrm{C}$ for $\mathrm{Si}_{3} \mathrm{~N}_{4}$ brazed to the metals shown.

\begin{tabular}{|c|c|c|c|}
\hline Metal & $\begin{array}{c}\text { Ceramic Major } \\
\text { Principal, MPa }\end{array}$ & $\begin{array}{c}\text { Metal } \\
\text { Von Mises, MPa }\end{array}$ & $\begin{array}{c}\text { Braze Equivalent } \\
\text { Plastic Strain }\end{array}$ \\
\hline Incoloy 909 & 337 & 454 & 1.06 \\
Mo & 294 & 309 & 0.14 \\
Nb & 318 & 378 & 0.24 \\
Ta & 315 & 335 & 0.39 \\
\hline
\end{tabular}

Because of its importance in determining residual stresses in ceramic-to-metal joints, the thermal expansion behavior of $\mathrm{Si}_{3} \mathrm{~N}_{4}$ was considered more carefully as input for finite element analysis. The data file currently in use was obtained through the original producer of the PY6 $\mathrm{Si}_{3} \mathrm{~N}_{4}$ being used as a model material.

However, experimental data were recently obtained which indicate that the thermal expansion coefficient of PY6 is slightly higher at low temperatures than previous data indicated. Data were also obtained for a another sintered $\mathrm{Si}_{3} \mathrm{~N}_{4}$, Kyocera SN252, and these are plotted and compared with data for several metals in Fig. 2. The behavior of both $\mathrm{Si}_{3} \mathrm{~N}_{4}$ 'S are nearly identical from room temperature to $1000^{\circ} \mathrm{C}$ where their thermal expansion coefficients vary from about $2-4 \mathrm{ppm} / \mathrm{C}$. Data are also shown for pure $\mathrm{Mo}, \mathrm{Ni}$, and $\mathrm{W}$, and for the controlled thermal expansion alloy, Incoloy 909.

Even though the thermal expansion mismatches were not highly favorable, component parts of $\mathrm{Si}_{3} \mathrm{~N}_{4}$ and Mo were in anticipation of making $\mathrm{Si}_{3} \mathrm{~N}_{4} / \mathrm{Mo}$ couplings. Efforts to design and analyze the $\mathrm{Si}_{3} \mathrm{~N}_{4} /$ metal joints was redirected to examine the effect of $\mathrm{Si}_{3} \mathrm{~N}_{4}$ chemical composition on its thermal expansion behavior, and how this influences residual stresses in $\mathrm{Si}_{3} \mathrm{~N}_{4} /$ metal joints. Some data on the effect of composition on the thermal expansion of $\mathrm{Si}_{3} \mathrm{~N}_{4}$ was obtained from published literature. In addition, thermal expansion measurements will be made on two sintered $\mathrm{Si}_{3} \mathrm{~N}_{4}$ 's being used in this work, PY6 and GS44. Specimens were prepared to make the measurements.

Lastly, an SEM examination was done on a few of the bend bars used to evaluate the effects of chemical reactions that occur brazing on the strength of $\mathrm{Si}_{3} \mathrm{~N}_{4}$. The data showed that test bars of PY6 $\mathrm{Si}_{3} \mathrm{~N}_{4}$ experienced decreases in both characteristic strength, from $1012 \mathrm{MPa}$ to $440 \mathrm{MPa}$, and Weibull modulus, from 12.9 to 5.8, as a result of brazing. The appearance of the brazed surface on one of the test bars is shown in Fig. 3. The braze filler metal has been dissolved away to reveal the reaction layers produced between the $\mathrm{Si}_{3} \mathrm{~N}_{4}$, the Ti vapor coating, and the filler metal during brazing. Features that appear to be cracks are visible on this surface. This observation, coupled with the bend test results, suggests that chemical reactions during brazing can produce a defect population in addition to that which naturally occurs in the $\mathrm{Si}_{3} \mathrm{~N}_{4}$ which can cause premature failure. Additional analysis of the data and microstructures was planned. 
$\mathrm{TiO}_{\mathrm{x}}$ film growth kinetics

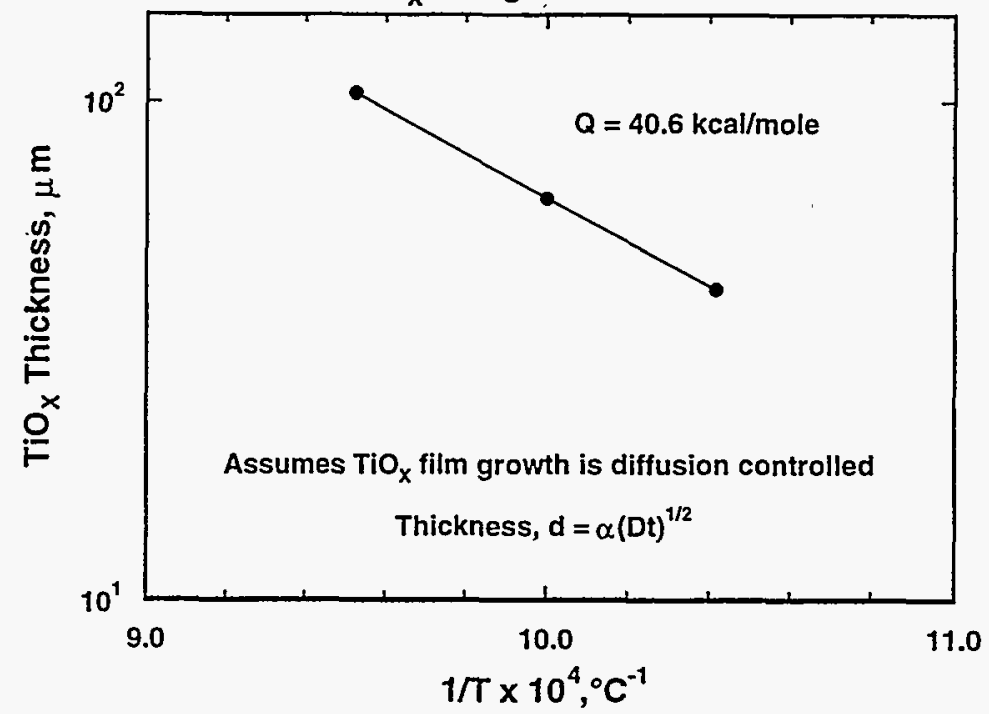

Fig. 1. Arhennius-type plot of $\mathrm{TiO}_{\mathrm{X}}$ film growth in $\mathrm{Ti} / \mathrm{ZrO}_{2}$ braze joints, assuming growth is diffusion controlled. The value of $Q$ agrees well with the activation energy for oxygen diffusion in $\mathrm{ZrO}_{2}(31$ $\mathrm{kcal} / \mathrm{mole})$.

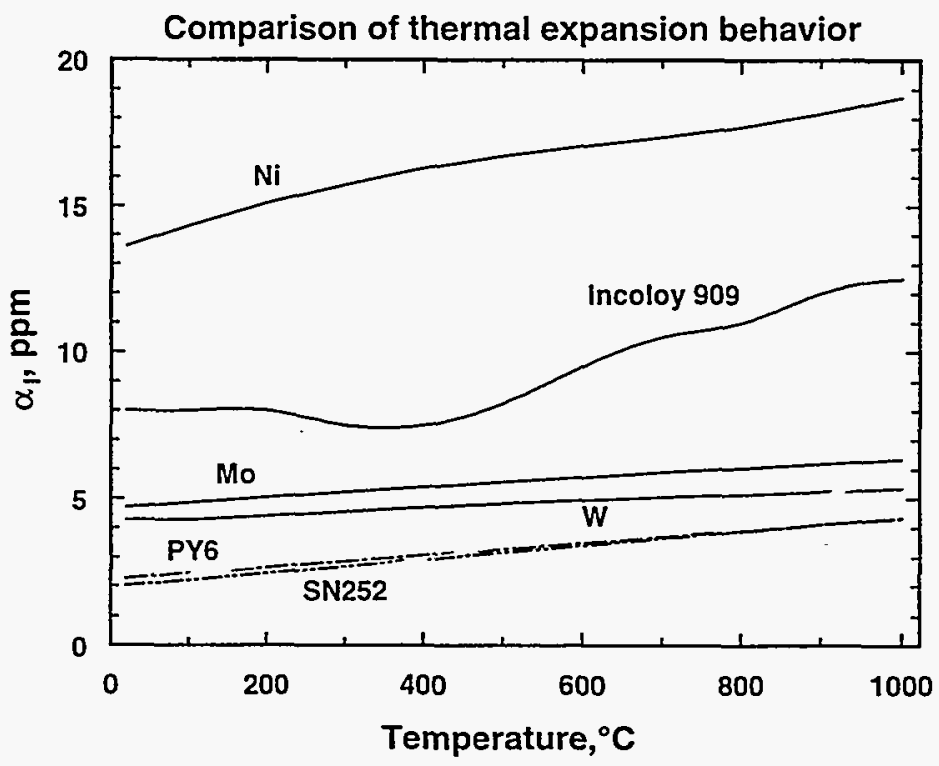

Fig. 2. Variation of thermal expansion coefficient with temperature for PY6 and $S N 252 \mathrm{Si}_{3} \mathrm{~N}_{4}$, and several metals. 


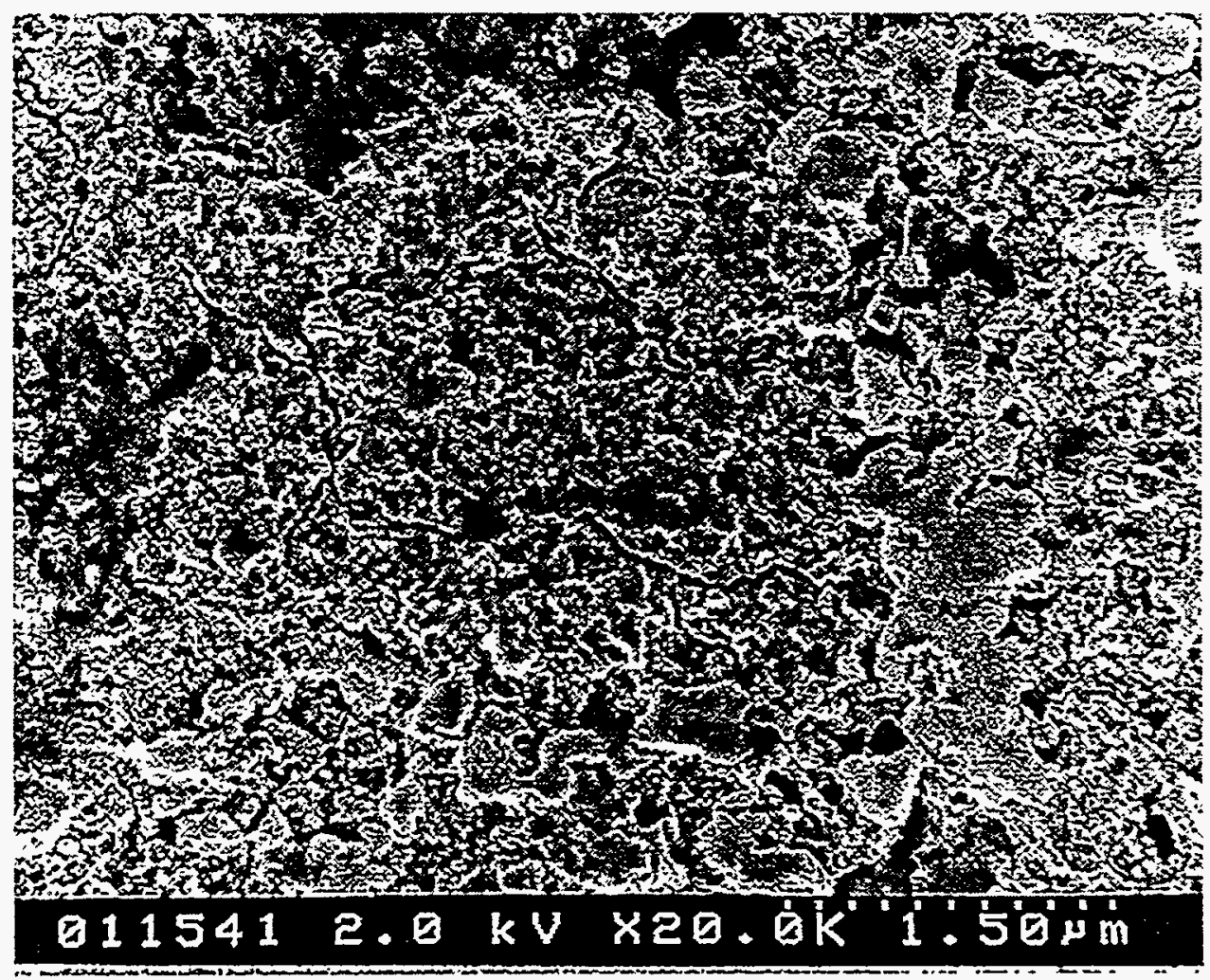

Fig. 3. SEM micrograph showing the microstructure that develops on the surface of a $\mathrm{Si}_{3} \mathrm{~N}_{4}$ bend test bar as a result of brazing. 


\title{
1.5 CERAMIC MACHINING
}

W.B.S. Element 1.5.0.0

\section{Cost-Effective Ceramic Machining}

\author{
P. J. Blau and E. S. Zanoria \\ Oak Ridge National Laboratory
}

\section{Qbjective/Scope}

The objective of this effort is to develop, in conjunction with U. S. industry, advanced technologies and the associated scientific and economic concepts necessary to reduce the costs associated with the machining of structural ceramics; especially, as related to the use of these materials in energy-efficient, low-emissions transportation systems. This effort consists of subcontracts to industry and in-house research at Oak Ridge National Laboratory, Argonne National Laboratory, and the National Institute of Standards and Technology. Progress reports for other than the ORNL in-house research portion of this work may be found elsewhere in this publication. The four subtasks in this effort are:

1. Technology Assessment and Future Needs

2. Advanced Machining Methods Development

3. Ceramic Machinability and Related Performance

4. Structure and Surface Quality of Machined Ceramics

ORNL in-house activities are aimed at two technical areas: (1) investigating the effects of machining practices on the durability of ceramics for valve and valve seat applications and (2) understanding and characterizing the detailed nature of machining-induced surface and sub-surface damage and their evolution in advanced ceramic materials using a range of analytical tools. The latter includes such methods as non-contact surface profiling, atomic force microscopy of ground surfaces, and scanning acoustic microscopy to detect subsurface flaws.

Technical Highlights

a. Machine Installed at HTML, New ASTM Grindability Task Group Established. Work on the subcontract with Chand Kare Technical Ceramics resulted in the design and development of a compact grindability testing system (CGTS). This testing machine exhibited a high degree of repeatability in establishing the grinding rates of several selected ceramic materials. The CGTS was displayed both at the CECM Annual Project Review in Oak Ridge, TN, in September 1995 and the Annual Automotive Contractors Coordinating Meeting in Detroit, MI, in October 1995. The CGTS was delivered and installed in the Machining and Inspection Research User Center at the High Temperature Materials Laboratory (HTML), Oak Ridge, in February 1996. There it will be used to support both the Cost-Effective Ceramic Machining effort and the User Center. Plans are to develop a comprehensive database on grindability numbers for ceramics and other difficult-to-grind materials. In addition, Dr. C. Guo, Chand Kare TC, will begin an HTML fellowship program in summer 1996 involving the correlation of ceramic microstructure to grindability ratings.

During its November 9 meeting in Norfolk, ASTM Subcommittee G02.30 on Abrasive Wear's Chairman Wayne Quantz, Smith International, established a new Task Group (G02.30.09) on "Grindability" and appointed P. Blau to chair it. The purpose of the activity is to develop a standard test method for measuring the grindability of materials, particularly, using Chand Kare's CGTS as the basis. The correlation of the grindability numbers with actual grinding data for the 
same materials on commercial surface and cylindrical grinders by Chand Kare TC and others will be the key to establishing the usefulness of the technique. A draft standard has been prepared for subcommittee consideration at the May 1996 meeting.

b. ORNL In-house Research on Repeated Impact. The effects of tangential slip on the repetitive impact behavior of ground silicon nitride and sialon are being investigated by $P$. Blau who has been joined by a new post-doctoral fellow, Dr. Elmer Zanoria, formerly of the Georgia Institute of Technology. Different specimen fixtures were used to vary the angle of impact from normal incidence to $45^{\circ}$ on the repeated impact testing machine, described in previous reports. The tests were performed at room temperature and ambient humidity conditions which varied from $30 \%$ to $65 \%$. For each impact angle, a set of tests with varying number of impacts were made. The maximum length of a test was 20,000 impacts. The size of the impact crater on the flat sample was measured with a Taylor-Hobson stylus profilometer. Prior to the measurement, the debris in the crater were extracted using a replicating tape to facilitate detection of the true bottom of the crater. Impact craters created with impact angles $\leq 30^{\circ}$ generally exhibited a circular plan view. Whereas, those formed at $45^{\circ}$ show a pronounced elongation along the tangential component of the impact. This is indicates the tendency for slip to occur between the ball and the flat at steeper impact angles.

Figure 1 shows the variation in the crater cross-sectional area with the number of impacts, at different impact angles. The 'area' we report in the figure is parallel to the tangential component of the impact force and passes through the deepest portion of the impact crater. The data in Figure 1 reveals a non-linear increase in the amount of removed material with increasing numbers of impacts. There is no obvious correlation between impact angle and wear for numbers of impacts $\leq$ 2000. In fact, for much lower number of impact $(<500)$, the cross-sectional crater area is nearly independent of the impact angle. Above 2000 impacts, the steepest angle tends to yield larger wear. This trend, contradicts the hypothesis that a decline in the impact angle, favors brittle behavior and increases the wear of ceramics. Shear straining apparently plays a significant role in the evolution of surface damage in ceramics subjected to repetitive glancing impacts.

A later refinement in the ball-on-flat impact-wear testing procedure, described above, was implemented and additional tests were performed. The new procedure further minimized the effects of wear debris on crater evolution by interrupting the test at 500-impact interval and removing the particles from both the ball and flat samples. The debris were extracted by peeling off a cellulose replicating tape glued to the impact site with a drop of acetone. Another aspect of the new procedure is keeping track of the size evolution of a single crater on the flat sample by optical microscopy and surface profilometry, at 1000-impact intervals. The new procedure yields an excellent correlation between the cross-sectional area of the crater and the number of impacts. Applying those techniques, a re-evaluation of the effects of incident angle on the impact wear behavior of flat, polished NT-154 $\mathrm{Si}_{3} \mathrm{~N}_{4}$ was conducted. Results revealed that an optimum angle of $60^{\circ}$ produces the least wear.

c. Surface Profilometry of Ground Ceramics. A comprehensive project was initiated to characterize the surface and subsurface features of the same ceramic specimens using multiple techniques. The material selected for this work is GS-44 silicon nitride produced by Allied Signal Ceramic Components, Torrance CA. It is well-characterized and was used by the International Energy Agency (IEA) as the model material for a multi-national project on ceramic properties. A series of specimens was machined using the Harig CNC II creep-feed grinder in the HTML Machining and Inspection Research User Center. Two conditions were used. The condition categorized as "bad" used a coarse 80 grit $(177 \mu \mathrm{m})$ resin-bonded diamond wheel with an outer diameter of $152.4 \mathrm{~mm}$. The other, regarded as "good," utilized also used a resin-bonded diamond wheel (outer diameter $=203.2 \mathrm{~mm}$ ) which contained finer 320 grit $(44 \mu \mathrm{m})$ abrasives. The linear surface speeds for the bad and good conditions were $35 \mathrm{~m} / \mathrm{s}$ and $47 \mathrm{~m} / \mathrm{s}$, respectively. 
Machining for both good and bad conditions used a table speed of $200 \mathrm{~mm} / \mathrm{min}$, a down feed of $0.018 \mathrm{~mm}$ and a cross-feed of $1.8 \mathrm{~mm}$.

Roughness parameters chosen for this study include kurtosis (Rku), skewness (Rsk), arithmetic roughness $(\mathrm{Ra})$, root-mean-square roughness $(\mathrm{Rq})$, root-mean-square slope $(\mathrm{Dq})$ and maximum peak-to-valley length (Rt). Values based on unfiltered and ASME (ISO) filtered profilometry data were collected. The layout of the profilometry traces on each tile $(5 \mathrm{per}$ machining condition), and the average values for $\mathrm{Ra}, \mathrm{Rq}$, and $\mathrm{Rt}$ for filtered traces across the lay are shown in Fig. 2. Measurement perpendicular to the lay yields profilometry data with less variability on the machined surface and has excellent repeatability. Values measured parallel to the lay tend to be more variable on a given sample. The magnitude and pattern of change in profilometry parameters, comparing bad to good machining conditions, varies with the orientation of stylus travel and the mode of data filtering. Having established the uniformity of the set of 5 square coupons machined in each condition, additional surface characterization will take place in the coming months.

\section{Future Plans}

a. Grindability Research. We will continue to evaluate the characteristics of the Ceramic Grindability Test System at ORNL. Tests will be performed on silicon nitride and on alumina to establish a range of grindability values, investigate the repeatability of the test, study the effects of repeated use of the same belt, and compare data with Chand Kare Technical Ceramic company's previous results. We will work with Dr. Guo during his fellowship program to establish the relationship between microstructure and grindability rating. Finally, we will continue to develop an ASTM standard on abrasive belt testing to determine grindability of ceramics.

b. Repeated Impact Tests. During the coming months, we will obtain additional material and begin a series of repeated impact tests on leading candidate ceramic valve materials in as-machined and post-finishing annealed conditions. This information should prove valuable in investigating the effects of the valve seat bevel angle on the durability of ground silicon nitride materials for that and other applications which involve repeated impacts.

c. Surface Quality Technique Evaluation. Having completed the stylus profilometry evaluation, work will continue on the characterization of the ground GS-44 ceramic tiles. This will include studies using non-contact laser profiling methods at ORNL and Raman spectroscopy, in cooperation with Dr. N. Hecht, University of Dayton Research Institute. Atomic force microscopy of the ground surfaces at ORNL is also planned for the near future.

d. Annual Project Review. Planning will continue for the 1996 review of CostEffective Ceramic Machining Projects in Oak Ridge on September 11-12, 1996. The meeting will be extended to 1-1/2 days in order to facilitate additional discussions and to include several invited presentations related to ceramic machining. Advertisements will be sent out as soon as the program is finalized. Rooms have been set aside at the Garden Plaza and Comfort Inn in Oak Ridge and airline discounts have been set up for meeting attendees.

Status of Milestones

On schedule.

Communications/Visitors/Travel

K. Costello and C. Guo, Chand Kare Technical Ceramics, Worcester, Mass., visited ORNL on February 5-6, 1996 to install the compact grindability testing system and to present an oral review of its use and development. They also presented a copy of the final subcontract report. 
Problems Encountered

None.

Publications/Presentations

1) P. J. Blau, R. L. Martin, and L. Riester (1996) "A Comparison of Several Surface Finish Measurement Methods as Applied to Ground Ceramic and Metal Surfaces," ORNL Technical Report ORNL/M-4924, 28 pp.

2) P. J. Blau and J. Wyrick (1995) "Cost Effective Ceramic Machining Project Review," in Ceramic Technology Newsletter, Fall issue (no. 48), pp. 1-4.

3) ASTM (1996) "New Task Group Formed on Grindability of Structural Ceramic Materials," ASTM Standardization News, February 1996, pp. 15-16.

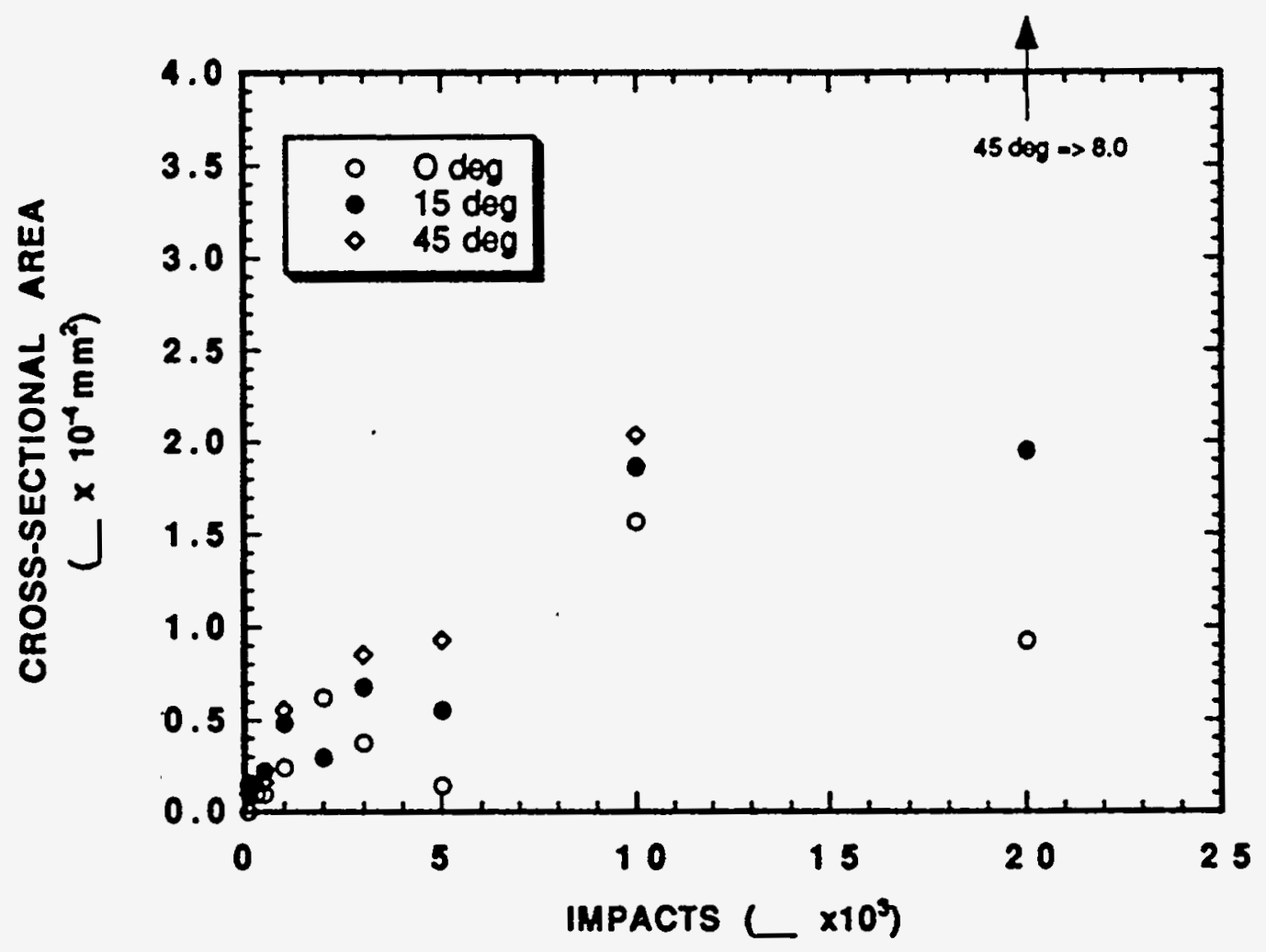

Figure 1. Early data showing the effects of impact angle on the repeated impact damage to NT-154 silicon nitride. Subsequent improvements in test technique produced clearer trends than those shown here. 


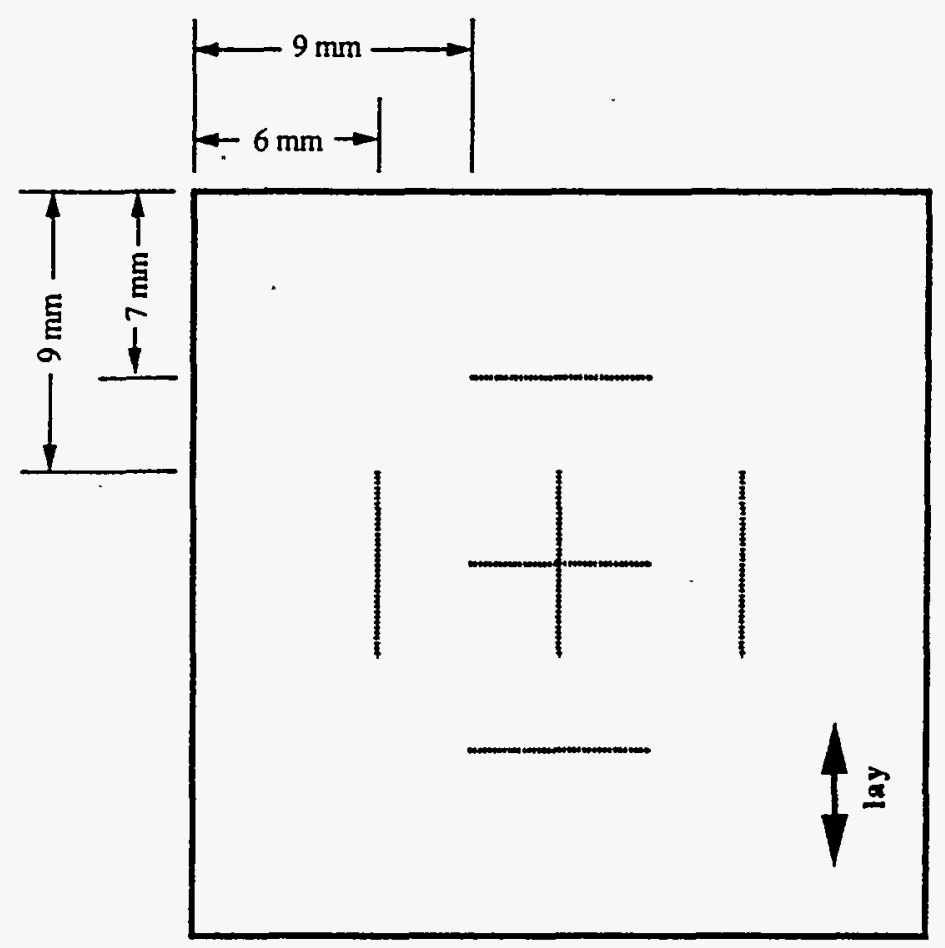

LAYOUT OF TRACES ON THE $25.4 \mathrm{~mm}$ SQUARE TILE

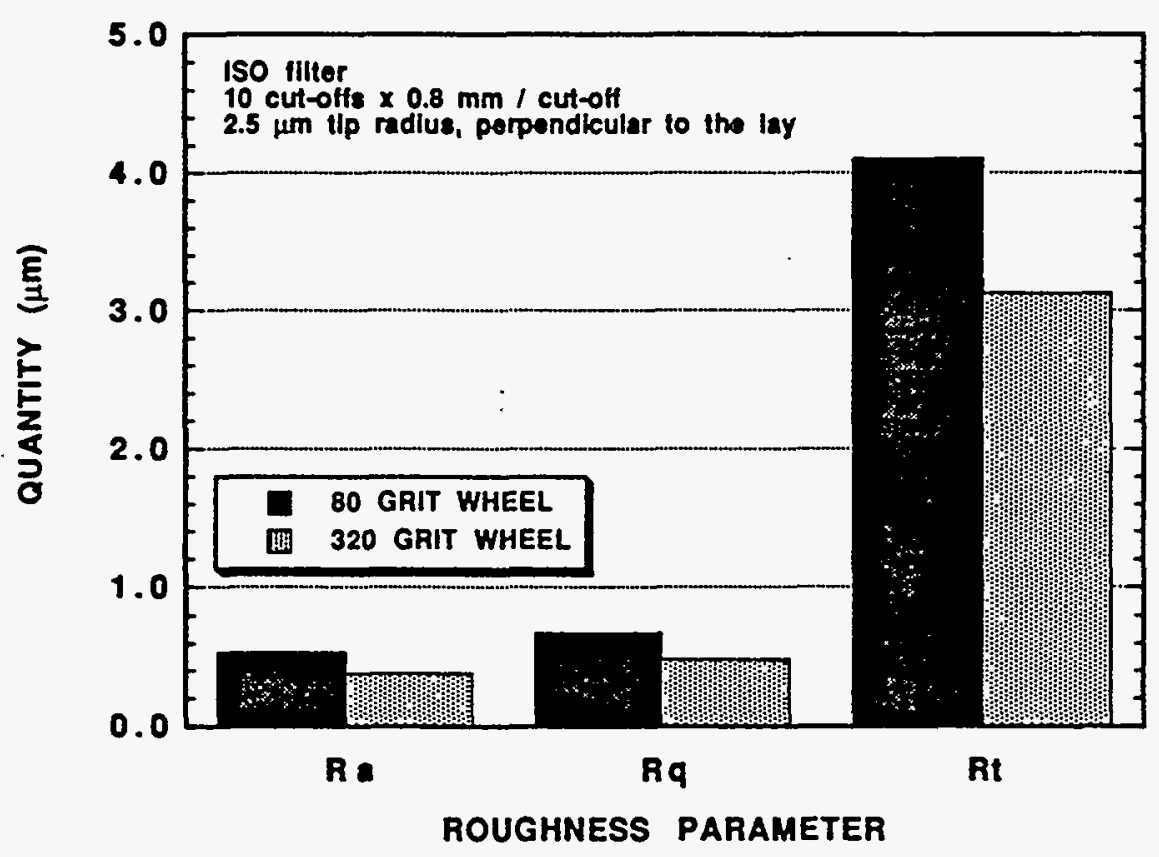

Figure 2. Layout (top) and summary of data (below) for initial characterization of the surface quality of GS-44 tiles ground in two ways. 
Innovative Grinding Wheel Design

for Cost-Effective Machining of Advanced Ceramics, Phase II

R.H. Licht, S. Ramanath, P. Kuo (Norton Company)

\section{Objective/Scope}

The overall objectives of this Phase II program are (1) to scale-up the manufacturing process of the Phase I experimental wheel composition in order to manufacture 356-mm (14 in.) diameter grinding wheels; and (2) to validate the performance of the new wheels in cylindrical grinding of advanced ceramics at independent test sites.

In the completed Phase I, grinding test results of 76-mm (3-in.) and 203-mm (8-in.) diameter wheels indicated that a superior, next-generation grinding wheel for cylindrical grinding of ceramics had been developed ${ }^{(1)}$. Most production grinding of cylindrical ceramic parts is done on machines that use $305-\mathrm{mm}$ (12-in.) to 356-mm (14-in.) diameter wheels. A Phase II program was initiated to scale-up the new Superabrasive wheel specification to these larger diameters. to make further wheel enhancements, and to perform independent validation tests.

Task 1 of Phase II will address wheel processing and wheel variable issues to achieve grinding action for the larger wheels similar to that successfully attained for the smaller Phase I wheels. Also in Task 1, Norton will develop or modify the wheel core for higher speed operation. and will determine the maximum operating speed for the new wheel system.

In Task 2, we plan to fabricate large test wheels, and to perform a cylindrical in-house grinding test at Norton's World Grinding Technology Center (WGTC) prior to independent validation testing. In Task 3, large experimental test wheels will be manufactured for independent validation at ceramic manufacturers. The following organizations are scheduled to perform validation tests: Norton Advanced Ceramics (NAC); AlliedSignal Ceramic Components; Chand Kare Technical Ceramics; and Eaton Manufacturing Technologies Center. Eaton plans to test the new wheel product under high speed grinding conditions. The NAC and WGTC wheel validation activity could complement their valve grinding development efforts currently in process under the DOE Advanced Ceramic Manufacturing Technology Program. Task 4 will include more extensive evaluation of ceramic surface integrity of ground ccramic specimens from the Tasks 2 and 3 grinding tests.

\section{Technical Progress}

The Phase II contract started March 1, 1996 and an internal kick-off meeting was held in early March.

\section{TASK 1: Process Scale-Up}

\section{Task 1.A: Expcrimental Design and Definition}

The basic experimental bond selected in Phase $I$ is used as the starting wheel system for the Phase II program. This baseline wheel specification is AD320-75MXL1993. Work in progress includes: (1) understanding the proposed grinding conditions scheduled to be performed, and selecting the wheel specifications and bond variables consistent with this Phase II 
test plan, (2) reviewing data generated from previous tests for scale-up consideration; and (3) addressing material and manufacturing issues in scaling-up from 203-mm (8 in.) diameter wheels to $356-\mathrm{mm}$ (14 in.) wheels running up to $126 \mathrm{~m} / \mathrm{s}(25,000$ surface $\mathrm{ft} / \mathrm{min}$.). The variables such as diamond type, grit size (particularly the coarser grit), diamond concentration, coating, level of bond porosity, core material, hub design, and wheel manufacturing parameters will be considered in the scale-up experimental design for the new wheel specification(s). These variables will be designed to be consistent with the planned grinding test system conditions, such as wheel-work contact geometry, wheel speed, infeed and grinding force/grain.

\section{Task 1.B: Strength Characterization and High Speed Core Development}

One advantage of using a metal-bond system is the inherent bond strength/high speed capability. Bond strength tests in Phase I demonstrated that a typical metal bond has more than twice the flexural strength of a resin bond used for ceramic grinding. For smaller diameter Phase I wheels, a standard wheel hub composition that was adequate for the required testing parameters was selected. The wheels were speed-tested to approximately $91 \mathrm{~m} / \mathrm{s}(18,000$ surface $\mathrm{ft} / \mathrm{min}$.), and were rated for at least $61 \mathrm{~m} / \mathrm{s}(12,000$ surface $\mathrm{ft} / \mathrm{min}$.) grinding speed. The ultimate wheel speed capability of this abrasive rim-hub combination was not determined in Phase $I$, but will be in Phase II. If higher speeds are required for future wheel testing, a different hub material will be selected to maximize wheel speed capability.

To make wheels strong enough to mect the requirements of the ultra-high speed grinding test plan, the wheel core must be redesigned. Calculations will be performed to establish the minimum strength requirement including proper built-in safety factor. We will analyze the strength and microstructure of the standard wheel core material used for the Phase I 203-mm diameter wheels. Such information will serve as our baseline for designing the new wheel core and its manufacturing process.

TASK 3: Independent Validation Tests

A. Selection of Sites and Wheel Specifications

AlliedSignal Ceramic Components; Chand Kare Technical Ceramics; and Eaton Manufacturing Technologies Center submitted updated independent validation test quotations.

\section{Status of Milestones}

\section{A. Experimental Design and Definition -- In Process, On Schedule}

\section{B. Strength Characterization and High Specd Core Development -- In Process, On Schedulc}

\section{Communications/Visits/Travel}

R. H. Licht attended the Annual Review of Projects in Cost-Effective Ceramic Machining, Pollard Auditorium, Oak Ridge, TN, September 20, 1995. 
R. H. Licht attended the Annual Automotive Technology Development Contractors' Coordination Mecting, Dearborn, MI, October 24-26, 1995.

\section{Publications/Presentations}

R.H. Licht (presenter), S. Ramanath, M. Simpson, E. Lilley, "Development of a NextGeneration Grinding Wheel," Annual Review of Projects in Cost-Effective Ceramic Machining, Ceramic Technology Project, Propulsion System Materials Program, Pollard Auditorium, Oak Ridge, TN, September 20, 1995.

R.H. Licht (presenter), S. Ramanath, M. Simpson, E. Lilley, "Innovative Grinding Wheel Design for Cost-Effective Machining of Dense Ceramics," Annual Automotive Technology Development Contractors' Coordination Meeting, Propulsion System Materials, No. 2. Dearborn. MI, October 25, 1995.

\section{References}

1. R.H. Licht, S. Ramanath, M. Simpson, E. Lilley, Innovative Grinding Wheel Design for Cost-Effective Machining of Advanced Ceramics, Phase I. Final Report, Subcontract No. 87X-SM037V, submitted to ORNL Ceramic Technology Project, U.S. DOE Office of Transportation Technologies, March 31, 1995, in print. 


\section{High-Speed, Low-Damage Grinding of Advanced Ceramics}

Joseph A. Kovach

Eaton Manufacturing Technologies Center

Willoughby Hills, Ohio 44094

Stephen Malkin

University of Massachusetts

Amherst, Mass. 01003

\section{Objective/Scope}

The overall objective of the High Speed Low Damage (HSLD) grinding project is to develop a single step, roughing-finishing process suitable for producing high-quality advanced ceramic components at high material removal rates and at substantially lower cost than traditional, multi-stage grinding processes. Initial implications from Phase I have suggested that HSLD grinding of $\mathrm{Si}_{3} \mathrm{~N}_{4}$ is technically feasible. Accordingly, to achieve the overall program objective, the Phase II effort is focused on:

1.0 Continued expansion of the existing HSLD science base,

2.0 Further development of the enabling HSLD technologies required for successful production implementation. and

3.0 Economic analysis of the HSLD production cost drivers.

\section{Technical Progress}

This semiannual report summarizes technical progress achieved during the period from October 1, 1995 through March 31, 1996. The report describes activities at the University of Massachusetts and the Eaton Manufacturing Technologies Center. A technical overview is presented in the following areas:

1. Ceramic Grinding Mechanism Analysis

2. Temperature Measurements and Energy Partition

3. Centerless Grinding - Simulation \& High Speed Testing

4. Hydrodynamic Forces in Grinding of Ceramics

5. High Speed O.D. Grinding

\subsection{Ceramic Grinding Mechanism Analysis}

The purpose of this work is to investigate the mechanisms of material removal for grinding of ceramics with diamond abrasive wheels and to quantitatively account for the 
energy expended during the material removal process. During this period, much of the effort was focused on developing and testing a scratching energy model, which included measuring forces and energies for grinding over a wide range of conditions. The results were analyzed using the "scratched surface parameter".

Grinding experiments were conducted on three different ceramics: $\mathrm{Sl}_{3} \mathrm{~N}_{4}$ (reaction bonded and hot isostatically pressed) and $\mathrm{Al}_{2} \mathrm{O}_{3}$. Ceramic bars were ground in the down mode using a resin bonded diamond wheel (DN400-N100B-1/4) of $305 \mathrm{~mm}$ diameter. All grinding tests were carried out with a $5 \%$ solution of soluble oil applied at about 300 $\mathrm{cm}^{3} / \mathrm{s}$. Three grinding parameters were varied: depth of cut, workspeed and wheel velocity. These grinding test conditions were selected to cover a wide range of "scratched surface parameter" values within the capability of the grinding machine. The measured grinding power was analyzed using the "scratched surface parameter".

Microscopic observations of ground surfaces show characteristic scratches along the grinding direction generated mainly by ductile flow. A scratching energy model was developed based on the assumption that the associated grinding power depends on the rate of scratched surface area generated. Fig. 1. shows a schematic illustration of the scratched surface area produced by a single abrasive grit. From grinding kinematics, the rate of scratched surface area generated per unit width was derived as:

$$
S_{W}^{\prime}=(6 C / \sin 2 \theta)^{1 / 2}\left(V_{w} V_{S}\right)^{1 / 2}(a)^{3 / 4}\left(d_{e}\right)^{1 / 4}
$$

where $C$ is the cutting point density, $2 \theta$ the included angle between the sides of a cutting point assumed to be triangular, and $V_{W}$ and $V_{S}$ the wheel and workpiece velocities.

Experimental results in Figs. $2-4$ using $\mathrm{C}=100 \mathrm{~mm}^{-2}$ and $\theta=60$ deg show a direct relation between grinding power per unit width and $S_{W}^{\prime}$. However, the results shown in Fig. 2 for RBSN show a different trend (a steeper slope followed by a shallower slope) compared to the results in Figs 3 and 4 for HIPSN and $\mathrm{Al}_{2} \mathrm{O}_{3}$, respectively. It is not clear why this different power response occurs on different ceramics. Assuming that the total grinding energy is associated only with this scratching, the slopes (units $\mathrm{J} / \mathrm{m}^{2}$ ) in each figure would correspond to the average energy per unit area of scratched surface generated, which are listed in Table 1 together with the corresponding fracture surface energy estimated as $G_{C} / 2\left(G_{C}=K_{c} 2 / E\right)$. The slopes are much bigger than the corresponding fracture surface energy for these ceramic materials. In other words, the energy per unit area of scratched surface generated by grinding is much bigger than the energy per area to fracture the surface, which indicates that most of the energy is associated with ductile mode interaction at the scratched surface between the abrasive grains and workpiece materials.

Additional work will be conducted to further investigate the grinding mechanisms for ceramics. Grinding debris and ground surfaces will be examined using SEM for different grinding conditions over various kinds of ceramics. Grinding power and forces will be measured for other ceramics using 120 grit size wheel to see whether the scratching energy model applies more generally. 


\subsection{Temperature Measurements and Energy Partition}

During this reporting period, the latest infrared system was set up and calibrated at Eaton's Manufacturing Technologies Center. Several experiments were conducted to compare the 'new' system with the 'old' system. It was concluded that the new system gave more consistent and reliable results than the 'old' system. Additional experiments were conducted to measure sub-surface temperatures using the new system, which were further used to calculate the energy partition to the workpiece.

The system was calibrated by measuring the radiation from a preheated copper blackbody as it slowly cooled in air. Although the new system has two DC preamplifiers, it is still easier to calibrate the system with an optical chopper, which was required for the calibration of an AC-coupled infrared system. The chopper modulates the radiation from the blackbody, and the chopped signal can be easily analyzed.

In order to compare the "new" system with the "old" system, a grinding test was conducted under the same condition as before. The test was conducted on a Brown \& Sharpe $1236 \mathrm{Hi}-\mathrm{Tech} \mathrm{CNC}$ grinder. Sintered reaction bonded silicon nitride (S/RBSN) from Eaton was ground using a 400 grit resin bonded diamond wheel. The operating conditions were workspeed $V_{W}=127 \mathrm{~mm} / \mathrm{s}$, wheelspeed $V_{S}=30 \mathrm{~m} / \mathrm{s}$, and depth of cut $a=0.0375 \mathrm{~mm}$. It was shown that for an energy partition of $17 \%$, the measured temperatures matched the analytical results very well over the entire depth. The two temperature responses from the MCT and InSb give virtually the same results. The two reponses from the MCT and InSb cells with the "old" system did not give a such good match especially at the trailing edge. It is believed that mismatching at the trailing edge with the "old" system was caused by the particular AC coupled preamplifier. The new system seems to work remarkably well, giving more consistent and reliable results.

After the set up and calibration of the 'new' system, several grinding tests were conducted, using a 400 grit wheel, to measure the sub-surface temperature responses, which were further used to calculate the energy partition to the workpiece. Some results are summarized in Table 2. It is interesting to note that the energy partition ranges from about $9 \%$ to $21 \%$, which is considerably lower than expected. In an attempt to better determine actual grinding zone temperatures, several additional tests were conducted using a 180 grit resin bonded wheel under the conditions given below:

Wheel:

Coolant: Dressing:

Wheel Speeds:

Table Speed:

Depth of Cut:

Removal Rate
Universal Superabrasives D180-100-Ul841-1/4, high temperature polyamide resin bond, $12 \times 1 / 2 \times 5$ Safety Cool 612,10:1 dilution ratio, 30 PSI, 6 GPM Titanium roll dress, $220 \mathrm{Al}_{2} \mathrm{O}_{3}$ stick condition $\left(.25 \mathrm{in}^{3}\right)$ $5000,10000,15000,20000,25000$ SFM

$100 \mathrm{in} / \mathrm{min}$

0.0125 in

$1.25 \mathrm{in}^{3} / \mathrm{min}$-in 
During testing the grinding forces, power, energy, surface finish, and temperature were measured. Figures $5-10$ graphically illustrate the test results summarized below:

\begin{tabular}{|c|c|c|c|c|c|c|}
\hline $\begin{array}{l}\text { Wheel } \\
\text { Speed } \\
\text { (ft/min) }\end{array}$ & $\begin{array}{l}\text { Normal } \\
\text { Force } \\
\text { (lb) }\end{array}$ & $\begin{array}{c}\text { Tangential } \\
\text { Force } \\
\text { (lb) }\end{array}$ & $\begin{array}{l}\text { Power } \\
\text { (hp) }\end{array}$ & $\begin{array}{c}\text { Specific } \\
\text { Energy } \\
\left(\mathrm{in}-\mathrm{lb} / \mathrm{in}^{3} \text { ) }\right.\end{array}$ & $\begin{array}{l}\text { Surface } \\
\text { Finish } \\
\text { (Ra, } \\
\text { minch) }\end{array}$ & $\begin{array}{c}\text { Temperature } \\
\text { Rise } \\
\left({ }^{\circ} \mathrm{F}\right)\end{array}$ \\
\hline 5,000 & 99.1 & 32.3 & 4.5 & $4,506,977$ & 25.7 & 396.8 \\
\hline 10,000 & 71.9 & 16.6 & 4.7 & $4,618,605$ & 22.0 & 245.9 \\
\hline 15,000 & 83.7 & 14.4 & 6.0 & $6,013,953$ & 20.7 & 199.6 \\
\hline 20,000 & 91.5 & 12.6 & 6.7 & $7,004,651$ & 29.0 & 249.2 \\
\hline 25,000 & 105.3 & 12.5 & 7.8 & $8,720,930$ & 40.0 & 265.2 \\
\hline
\end{tabular}

Initially, it was rather surprising to note that the measured temperature rise in all cases was quite low, only ranging from 200 to $400^{\circ} \mathrm{F}$. Moreover, the temperature rise, surface finish, and normal forces, did not consistently decrease as the wheel speed was increased - - - which was anticipated based on previous tests with plated wheels. Consequently, the optical fiber was repolished and the test series repeated. Nevertheless, similar results were observed.

Recall that in previous tests with conventional phenolic resin bonded wheels, the wheel actually caught on fire at $V_{S}=16,000$ SFM. However, with this new high temperature polyamide resin bond there were no signs of bond charring or any orange fire bands during testing. Although the wheel vendor felt that the bond system should be capable of speeds on the order of 20,000 SFM or more, based on the above data it is felt that some degree of bond softening was occurring at speeds above 15,000 SFM. At the conclusion of the 25,000 SFM test the wheel was removed and examined via optical microscopy, which revealed a considerable degree of grit pullout. It appears that as the wheel speed increased, the bond thermally weakened and allowed for the premature release of diamond grit.

To verify the above hypothesis, a video microscope is being mounted inside the machine to allow for complete wheel examination after each test without having to physically remove the wheel. Additional tests are also underway using finer grit wheels $(240,320)$ in an effort to develop higher grinding zone temperatures. Also, to correlate grinding zone temperature with resulting surface fragmentation the workpiece surfaces will be examined at the conclusion of each test. Currently, examination of the existing specimens (ground with the 180 grit wheel) is also underway.

\subsection{Centerless Grinding - Simulation \& High Speed Testing}

Recent efforts in this area have been concentrated on identifying an optimum belowcenter setup angle (e.g. capable of working with widely varying incoming stock lobing conditions) and determining what effects part diameter has on roundness generation. Given the machine setup as follows, 
- Grinding wheel diameter $=16.0$ in

- Regulating wheel diameter $=9.1$ inches

- Workrest blade angle $=-10^{\circ}$

- Workpiece diameter $=0.200^{\prime \prime}+0.010^{\prime \prime}$ stock envelope,

there appeared to be a transition from predominantly poor roundness generation at conditions greater than $20^{\circ}$ + below center to improved roundness at $10-13^{\circ}$ below center. Trends in the data generally indicate that the shallower the below center angle, the better the tendency for roundness correction.

Subsequently, part diameters ranging from $0.100^{\prime \prime}$ to $0.850^{\prime \prime}$ inches were simulated at $16^{\circ}$ below center. Under these conditions, the results tended to indicate that smaller diameter parts $(0.100,0.200$ " inch) round up with a fewer number of revolutions in the grinding zone than did the larger diameter parts. Larger parts $(0.600,0.850 \mathrm{inch})$ were run for up to six times as many revolutions as the smaller parts without any appreciable reduction in lobe height.

\subsection{Hydrodynamic Forces in Grinding of Ceramics}

Measurements of hydrodynamic forces in grinding with diamond wheels ( 120 and 400 grit size) were reported previously. The measurements were conducted for wheel speeds of 16 to $48 \mathrm{~m} / \mathrm{s}$. The theoretically predicted values fit reasonably well with the measured values if the peak-to-valley roughness of the wheel surface is taken as the gap thickness between the wheel and the workpiece. Both the analyses and measurements indicate that the hydrodynamic force can be significant as compared to the grinding force especially for high wheelspeeds. Therefore, it is necessary to separate the hydrodynamic component from the grinding force component. For this purpose, some master plots were made for some typical conditions as seen in Fig.11 which can be used to predict the hydrodynamic force for 120-grit and 400-grit wheels (diameter 12, 14 and 16 inches) up to wheelspeed of $200 \mathrm{~m} / \mathrm{s}$.

\subsection{High Speed O.D. Grinding}

In the HSLD Phase I feasibility effort numerous O.D. grinding tests were conducted with plated diamond wheels. In the present study, a 12"x1" 400 grit phenolic resin bonded wheel was evaluated to determine limiting material removal rates and overall process behavior. Cylindrical S/RBSN test specimens (1.5" diameter, 1" wide) rotating at a workpiece velocity of 300 SFM were ground using Castrol Safety Kool \#612 K (10:1 dilution ratio) applied at $20 \mathrm{PSI}$ and 11 GPM. Again, a maximum wheel speed of 15,000 SFM was selected to avoid potential bond rupture and/or bond ignition. A summary of the test conditions and resulting test data is given in Table 3.

During testing the normal grinding force was closely monitored as both the in-feed rate and wheel speed were progressively incremented. However, in order to obtain the normal grinding forces, the loads due to hydrostatic force had to be determined first. As shown in Figure 12, the normal hydrostatic force reached $11 \mathrm{lb}$. at 15,000 SFM. 
In addition, the resulting normal grinding force as a function of wheel speed is shown in Figure 13 for four different wheel speeds $(4000,6000,10000$, and 15000 SFM). Note that at 4,000 SFM the normal force rapidly exceeded $140 \mathrm{lb}$./in, even while operating at relatively low removal rates $\left(0.36 \mathrm{in}^{3} / \mathrm{min}\right.$-in). Similarly, at conventional wheel speeds (i.e. 6000 SFM) the normal grinding force exceeded $160 \mathrm{lb}$./in under moderate removal rates $(0.72 \mathrm{in} 3 / \mathrm{min}-\mathrm{in})$. However, as the wheel speed was increased the normal forces remained relatively low (under $80 \mathrm{lb} . / \mathrm{in}$ ) and stable over this range of relatively moderate material removal rates.

Subsequently, the material removal rate was increased, while maintaining a constant wheel speed of 15,000 SFM, until either the normal force exceeded $140 \mathrm{lb}$. or the grinding power exceeded the machine limit (approx. $15 \mathrm{HP}$ ). It should be noted that no wheel conditioning or dressing was performed during the testing. The following table summarizes this test series:

$\begin{array}{ccccc}\begin{array}{c}\text { Infeed } \\ \text { Rate } \\ \text { (in/rev) }\end{array} & \begin{array}{c}\text { Material } \\ \text { Removal Rate } \\ \text { (in3/min-in) }\end{array} & \begin{array}{c}\text { Normal } \\ \text { Force } \\ \text { (lb) }\end{array} & \begin{array}{c}\text { Power } \\ \text { (hp) }\end{array} & \begin{array}{c}\text { Specific } \\ \text { Energy } \\ \text { (in-lb/cu in) }\end{array} \\ 0.000220 & 0.792 & 92.0 & 7.3 & 3,673,500 \\ 0.000240 & 0.864 & 92.4 & 8.5 & 3,899,042 \\ 0.000260 & 0.936 & 92.8 & 9.4 & 3,982,423 \\ 0.000280 & 1.008 & 98.6 & 10.0 & 3,928,964 \\ 0.000300 & 1.08 & 100.4 & 10.4 & 3,812,967 \\ 0.000320 & 1.152 & 102.4 & 12.1 & 4,142,875 \\ 0.000340 & 1.224 & 106.0 & 12.5 & 4,043,147 \\ 0.000360 & 1.296 & 117.6 & 14.2 & 4,323,917 \\ 0.000370 & 1.332 & 121.4 & 14.5 & 4,301,595 \\ 0.000380 & 1.368 & 125.0 & 14.7 & 4,252,947 \\ 0.000390 & 1.404 & 124.0 & 14.6 & 4,125,846 \\ 0.000410 & 1.476 & 132.0 & 14.9 & 4,001,317 \\ 0.000420 & 1.512 & 127.6 & 14.4 & 3,781,171 \\ 0.000440 & 1.584 & 127.2 & 16.2 & 4,054,500 \\ 0.000460 & 1.656 & 137.6 & 15.5 & 3,695,761\end{array}$

Although the tests were stopped at $1.656 \mathrm{in} 3 / \mathrm{min}$-in due to machine power limitations, the wheel appeared to be cutting freely and maintained a relatively constant surface roughness at about 90 Ra $\mu$ in throughout the tests. In addition, the part surface finish remained relatively constant at approximately $18 \mathrm{Ra} \mu \mathrm{in}$. Note also that at $15,000 \mathrm{SFM}$, the specific grinding energy did not vary by more than $+/-10 \%$ (see Figures $14 \& 15$ ) over the entire range of material removal rates. Therefore, given additional machine power and workpiece fixture rigidity it is felt that the testing could have easily continued.

Additional tests are being scheduled using a polyamide resin bonded wheel capable of wheel speeds on the order of 25,000 SFM. 


\section{Status of Milestones}

Due to previous problems with the high speed grinding spindle and delays in modification of the Eagle X-Axis slide, the program schedule has slipped. Correspondingly, the program is currently under-spent. As a result, a no-cost project extension has been requested. In an effort to fully satisfy milestone 153206 (described below) extending the contract expiration date to November 30,1996 has been granted. This should allow for successful completion of the following anticipated milestone schedule:

Milestone

153203

153204

153205

153206
Description

Develop a two-color precision pyrometry system to accurately measure ceramic grinding zone temperatures.

Using grinding zone temperature data, determine the thermal balance between the wheel and the workpiece under HSLD grinding conditions.

Develop and report methods for dressing and conditioning of grinding wheels specifically intended for use in the HSLD grinding process.

Conduct economic sensitivity analyses of the HSLD production cost drivers. Assess tradeoffs between cost and resulting quality under a wide range of operating conditions.
Completion Date

Completed

Conventional done; HSLD: Jun 30, 1996

Completed

Sep 15, 1996

\section{Publications}

1) Ganesan, M., Guo, C., Ronen, A., and Malkin, S., Analysis of Hydrodynamic Forces in Grinding, Proceedings of the 26th NAMRC, to appear.

2) Kovach, J., Laurich, M., Ziegler, K., Malkin, S., Sunderland, J., Guo, C., Zhu, B., Ganesan, M., "Developments of High Speed Grinding Technology for Ceramic Components," Annual Automotive CCM proceedings, Vol. 1, Dearborn, Mich., Oct. 2327,1995, .

3) Kovach, J., Laurich, M., Ziegler, K., Zhu, B., Guo, C., Malkin, S., "Developments of High Speed Grinding Technology for Ceramic Components," accepted for 1996 NAMRC.

4) Kovach, J., Laurich, M., Ziegler, K., Malkin, S., Sunderland, J., Guo, C., Zhu, B., Ganesan, M., "Developments of Advanced Grinding Technology for Structural Ceramics," Supergrind Proceedings, Storrs, Conn. Nov. 2, 1995 
Table 1: Comparison between the values of slope and corresponding fracture surface energy

\begin{tabular}{|l||l|l|}
\hline & Slope $\left(\mathrm{J} / \mathrm{m}^{2}\right)$ & Fracture surface energy $\left(\mathrm{J} / \mathrm{m}^{2}\right), \mathrm{G}_{d} / 2$ \\
\hline \hline $\mathrm{SI}_{3} \mathrm{~N}_{4}$ (reaction bonded) & $3000 \sim 7000$ & 40 \\
\hline $\mathrm{SI}_{3} \mathrm{~N}_{4}$ (hot-isostatically pressed)) & $7000 \sim 24000$ & 90 \\
\hline $\mathrm{Al}_{2} \mathrm{O}_{3}$ & $3500 \sim 11000$ & 30 \\
\hline
\end{tabular}

Table 2. Experimental results with Eaton's two-color system with 400 grit size diamond wheel

\begin{tabular}{|l|l|l|l|l|l|l|}
\hline $\begin{array}{l}\text { Test } \\
\text { Number }\end{array}$ & $\begin{array}{l}\text { wheel } \\
\text { speed } \\
\mathrm{v}_{\mathrm{s}}(\mathrm{m} / \mathrm{s})\end{array}$ & $\begin{array}{l}\text { workpiece } \\
\text { speed } \\
\mathrm{v}_{\mathrm{w}}(\mathrm{mm} / \mathrm{s})\end{array}$ & $\begin{array}{l}\text { depth of } \\
\text { cut } \\
\mathrm{a}(\mathrm{mm})\end{array}$ & $\begin{array}{l}\text { specific } \\
\text { energy } \\
\mathrm{u}\left(\mathrm{J} / \mathrm{mm}^{3}\right)\end{array}$ & $\begin{array}{l}\text { heat flux } \\
\mathrm{q}\left(\mathrm{W} / \mathrm{mm}^{2}\right)\end{array}$ & $\begin{array}{l}\text { energy } \\
\text { partition } \\
\varepsilon\end{array}$ \\
\hline 1 & 30 & 127 & 0.038 & 38 & 53 & $17 \%$ \\
\hline 2 & 30 & 63.5 & 0.076 & 39 & 39 & $12 \%$ \\
\hline 3 & 30 & 84.7 & 0.038 & 41 & 39 & $16 \%$ \\
\hline 4 & 19.2 & 84.7 & 0.038 & 28 & 26 & $21 \%$ \\
\hline 5 & 19.2 & 66.7 & 0.025 & 41 & 25 & $18 \%$ \\
\hline 6 & 19.2 & 16.7 & 0.102 & 42 & 12.7 & $9 \pm 3 \%$ \\
\hline
\end{tabular}


400 grit diamond resin bond wheel

Part speed $=$ constant $300 \mathrm{ft} / \mathrm{min}$

Total radial depth of cut $=0.009$ in

\section{HSLD OD Grinding - S/RBSN Cylinders}

Part width $=1.0$ in

Part diameter $=1.470$ in

\begin{tabular}{|c|c|c|c|c|c|c|}
\hline $\begin{array}{l}\text { Wheel } \\
\text { Speed } \\
\text { (ft/min) }\end{array}$ & $\begin{array}{l}\text { Infeed } \\
\text { Rate } \\
\text { (in/rev) }\end{array}$ & $\begin{array}{c}\text { Material } \\
\text { Removal Rate } \\
\left(\mathrm{in}^{2} / \mathrm{min}\right)\end{array}$ & $\begin{array}{l}\text { Normal } \\
\text { Force } \\
\text { (b) }\end{array}$ & $\begin{array}{l}\text { Power } \\
\text { (hp) }\end{array}$ & $\begin{array}{c}\text { Specific } \\
\text { Energy } \\
\text { (in-lb/in?) }\end{array}$ & $\begin{array}{l}\text { Equivalent . } \\
\text { Chip Thickness } \\
\text { (in) }\end{array}$ \\
\hline 4,000 & 0.000080 & 0.288 & 84.0 & 3.3 & $4,591,125$ & 0.000006 \\
\hline 4,000 & 0.000100 & 0.360 & 145.2 & 5.2 & $5,701,300$ & 0.000008 \\
\hline & & & & & & \\
\hline 6,000 & 0.000080 & 0.288 & 72.0 & 2.9 & $4,023,250$ & 0.000004 \\
\hline 6,000 & 0.000100 & 0.360 & 71.2 & 3.4 & $3,743,300$ & 0.000005 \\
\hline 6,000 & 0.000120 & 0.432 & 95.2 & 4.7 & $4,313,833$ & 0.000006 \\
\hline 6,000 & 0.000140 & 0.504 & 90.4 & 4.9 & $3,847,643$ & 0.000007 \\
\hline 6,000 & 0.000160 & 0.576 & 130.4 & 6.0 & $4,153,875$ & 0.000008 \\
\hline 6,000 & 0.000200 & 0.720 & 166.8 & 6.0 & $3,287,900$ & 0.000010 \\
\hline & & & & & & \\
\hline 8,000 & 0.000080 & 0.288 & 56.0 & 2.9 & $4,023,250$ & 0.000003 \\
\hline 8,000 & 0.000100 & 0.360 & 55.4 & 7.0 & $7,695,600$ & 0.000004 \\
\hline 8,000 & 0.000120 & 0.432 & 72.0 & 4.3 & $3,905,917$ & 0.000005 \\
\hline 8,000 & 0.000140 & 0.504 & 71.2 & 4.8 & $3,772,214$ & 0.000005 \\
\hline 8,000 & 0.000160 & 0.576 & 85.6 & 5.4 & $3,716,625$ & 0.000006 \\
\hline 8,000 & 0.000200 & 0.720 & 99.2 & 6.6 & $3,637,700$ & 0.000008 \\
\hline & & & & & & \\
\hline 10,000 & 0.000080 & 0.288 & 52.0 & 3.1 & $4,197,875$ & 0.000002 \\
\hline 10,000 & 0.000100 & 0.360 & 54.8 & 3.5 & $3,847,800$ & 0.000003 \\
\hline 10,000 & 0.000120 & 0.432 & 66.4 & 4.3 & $3,964,583$ & 0.000004 \\
\hline 10,000 & 0.000140 & 0.504 & 65.2 & 4.8 & $3,747,857$ & 0.000004 \\
\hline 10,000 & 0.000160 & 0.576 & 76.4 & 5.7 & $3,891,250$ & 0.000005 \\
\hline 10,000 & 0.000200 & 0.720 & 83.2 & 6.8 & $3,725,150$ & 0.000006 \\
\hline 12,000 & 0.000080 & 0.288 & 50.0 & 3.1 & 4.241875 & 0.000002 \\
\hline 12,000 & 0.000100 & 0.360 & 52.2 & 3.5 & $3,847,800$ & 0.000003 \\
\hline 12,000 & 0.000120 & 0.432 & 63.0 & 4.5 & $4,139,667$ & 0.000003 \\
\hline 12,000 & 0.000140 & 0.504 & 59.6 & 4.8 & $3,747,857$ & 0.000004 \\
\hline 12,000 & 0.000160 & 0.576 & 74.8 & 5.7 & $3,935,250$ & 0.000004 \\
\hline 12,000 & 0.000200 & 0.720 & 80.0 & 6.8 & $3,725,150$ & 0.000005 \\
\hline & & & & & & \\
\hline 14,000 & 0.000080 & 0.288 & 46.0 & 2.7 & $3,716,625$ & 0.000002 \\
\hline 14,000 & 0.000100 & 0.360 & 47.6 & $\overline{3.3}$ & $3,672,900$ & 0.000002 \\
\hline 14,000 & 0.000120 & 0.432 & 58.8 & 4.5 & $4,081,000$ & 0.000003 \\
\hline 14,000 & 0.000140 & 0.504 & 57.2 & 4.7 & $3,697,571$ & 0.000003 \\
\hline 14,000 & 0.000160 & 0.576 & 68.8 & 5.8 & $4,000,563$ & 0.000003 \\
\hline 14,000 & 0.000200 & 0.720 & 72.8 & 9.8 & $5,404,300$ & 0.000004 \\
\hline 15000 & 0000080 & 0000 & 19 & & 3025050 & 000000 \\
\hline$\frac{15,000}{15,000}$ & $\frac{0.000080}{0.000100}$ & $\frac{0.288}{0.360}$ & $\frac{44.4}{53.2}$ & $\frac{2.9}{3.1}$ & $\frac{3,935,250}{3,358,300}$ & $\frac{0.000002}{0.000002}$ \\
\hline 15,000 & 0.000120 & 0.432 & .53 .8 & 4.3 & $3,964,583$ & 0.000002 \\
\hline 15,000 & 0.000140 & 0.504 & 63.2 & 5.0 & $3,897,929$ & 0.000003 \\
\hline 15,000 & 0.000160 & 0.576 & 65.0 & 5.6 & $3,847,938$ & 0.000003 \\
\hline 15,000 & 0.000200 & 0.720 & 74.0 & 7.3 & $4,005,100$ & 0.000004 \\
\hline
\end{tabular}

Table 3: HSLD OD Grinding Data. 


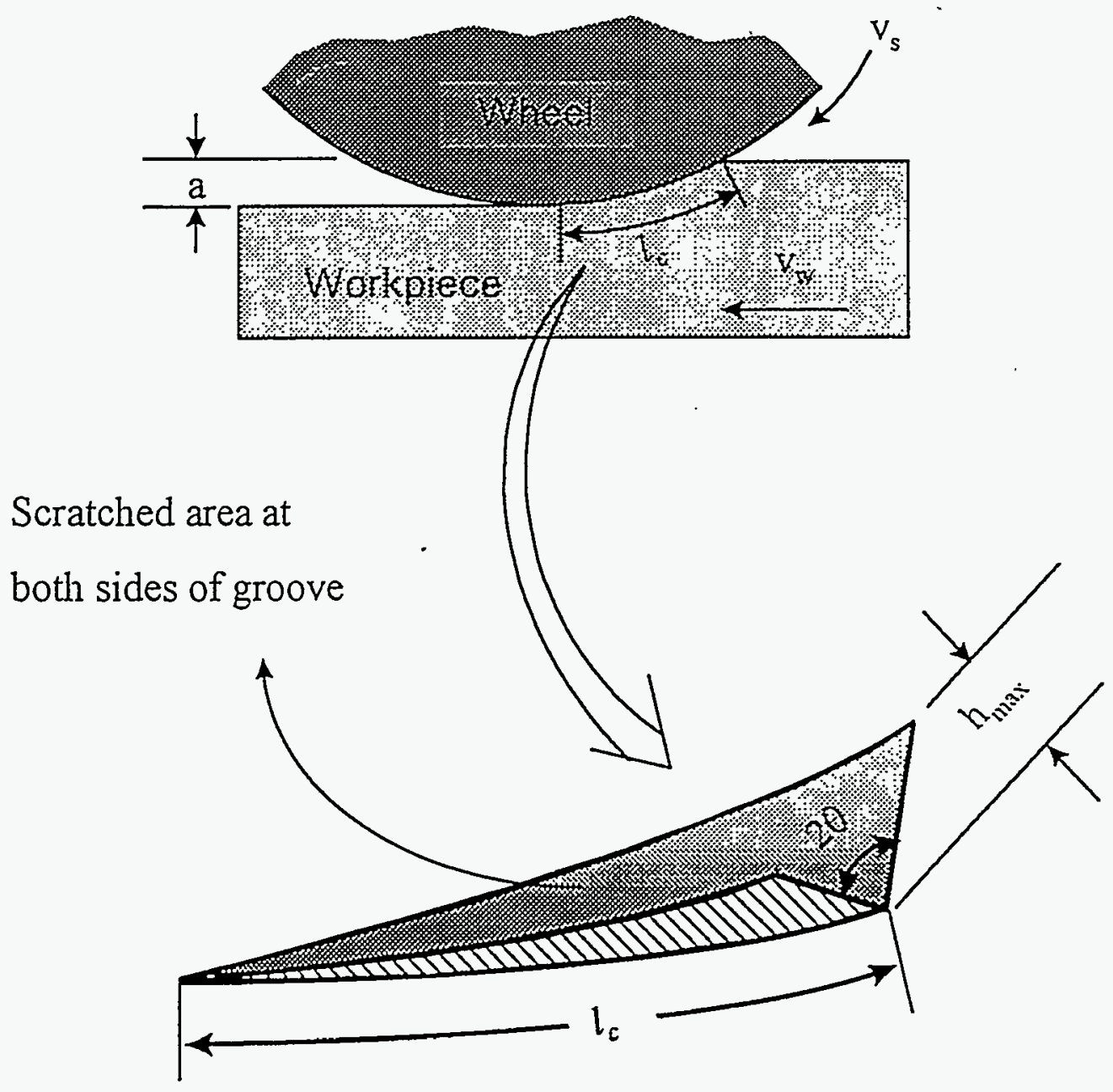

Figure 1. Schematic illustration of scratched surface area. 


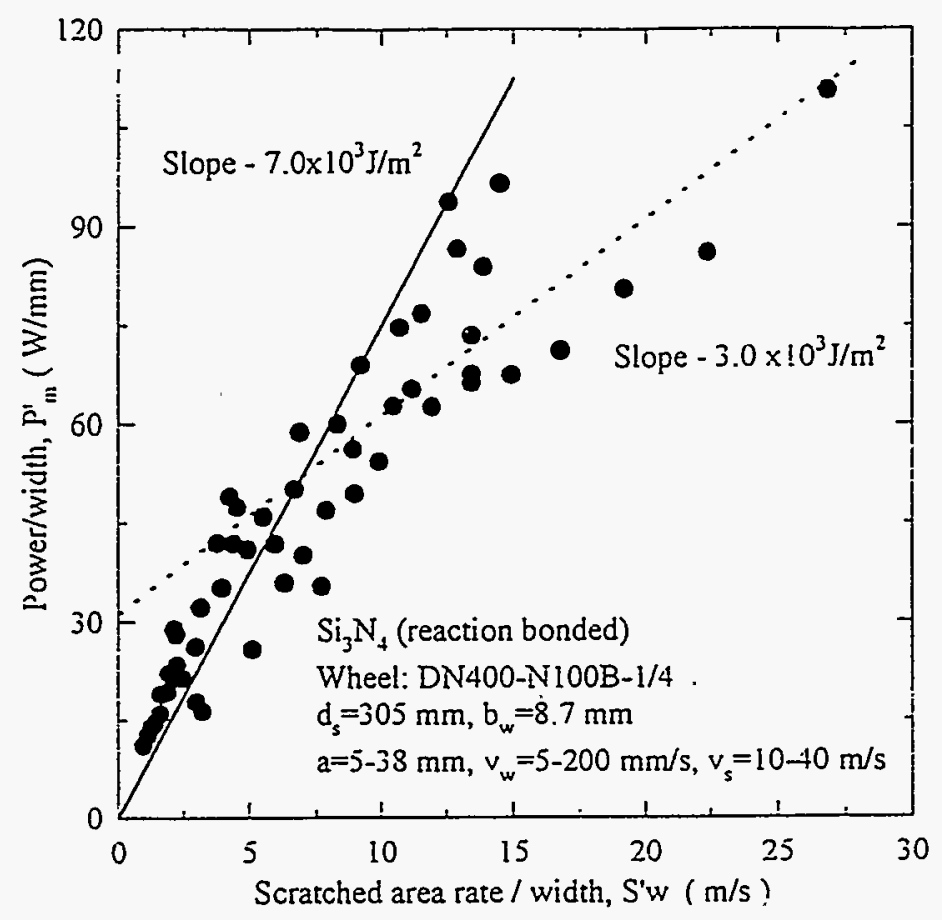

Figure2. Power per unit width versus scratched surface area rate per unit width.

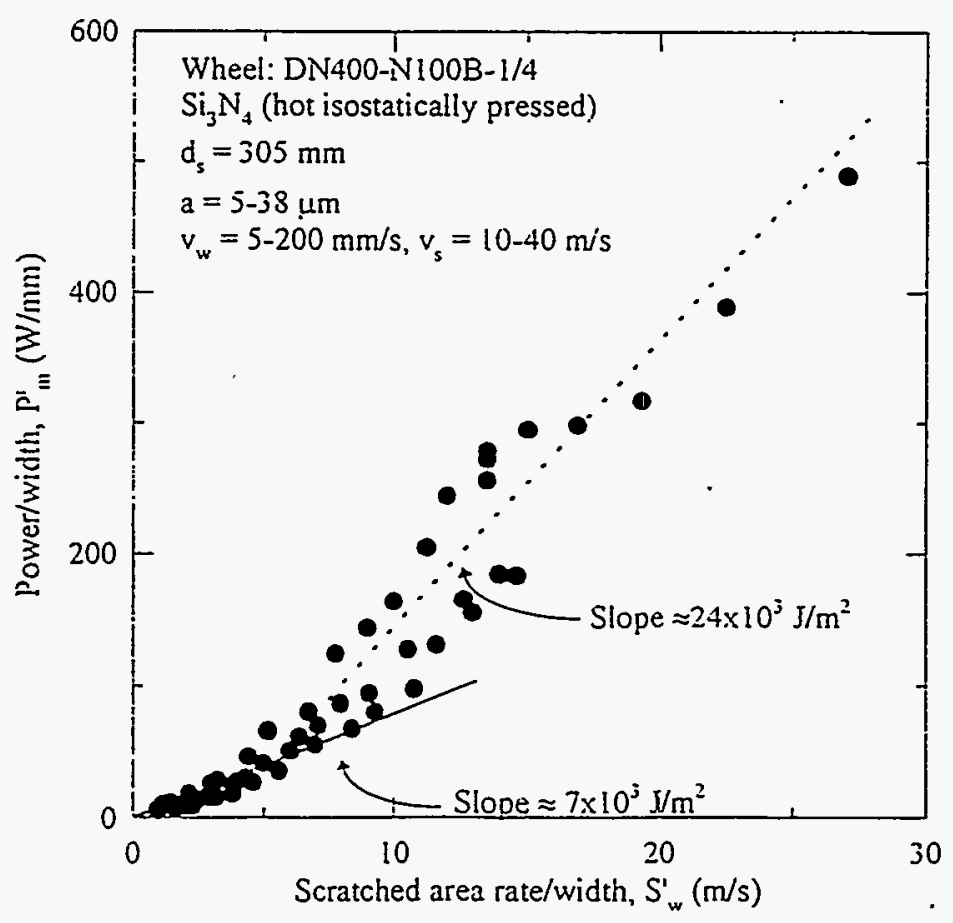

Figure 3. Power per unit width versus scratched surface area rate oer unit width 


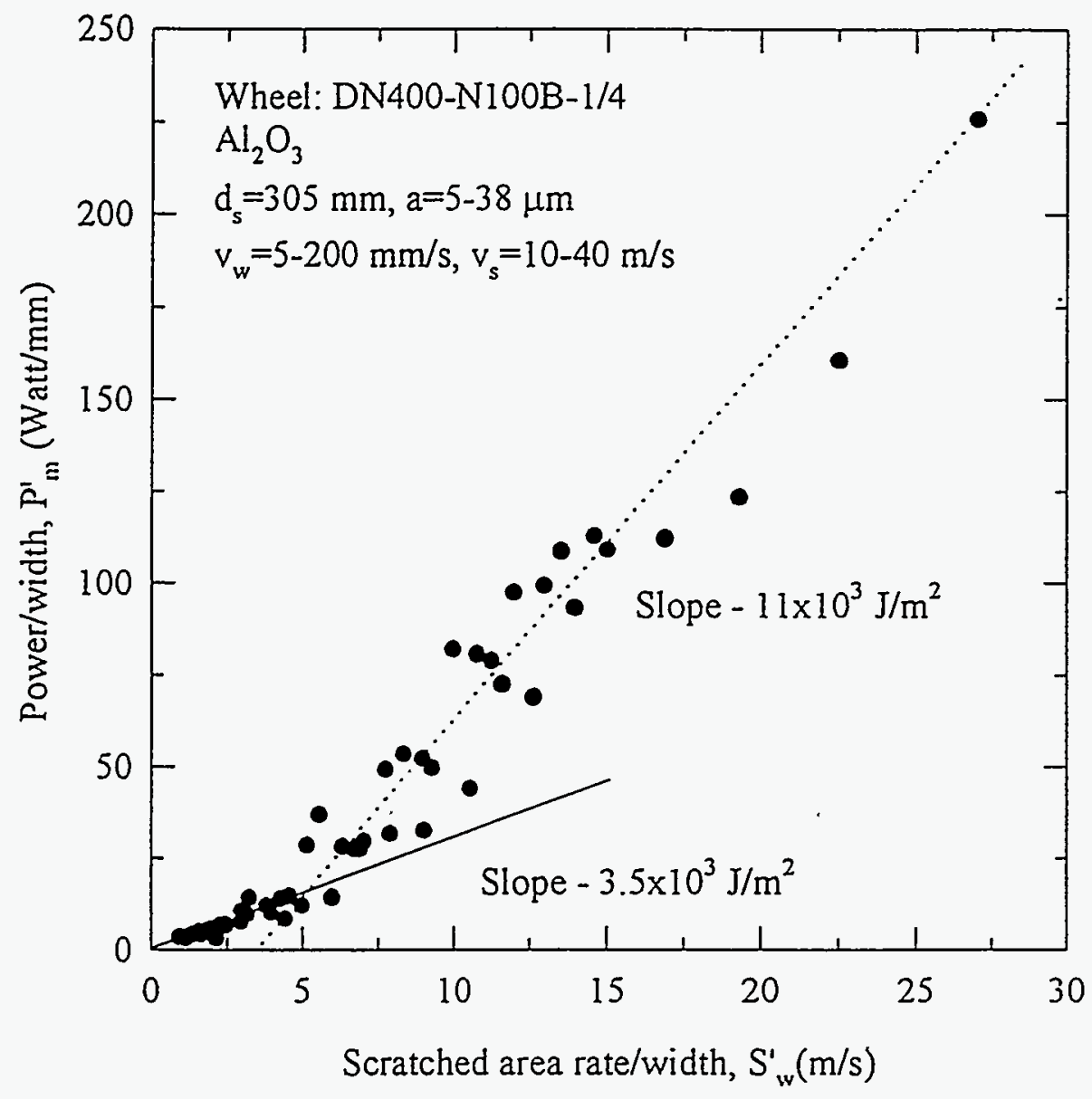

Figure 4. Power per unit width versus scratched surface area rate per unit width 
HSLD SIRBSN Grinding

180 Grit Resin Bond Wheel

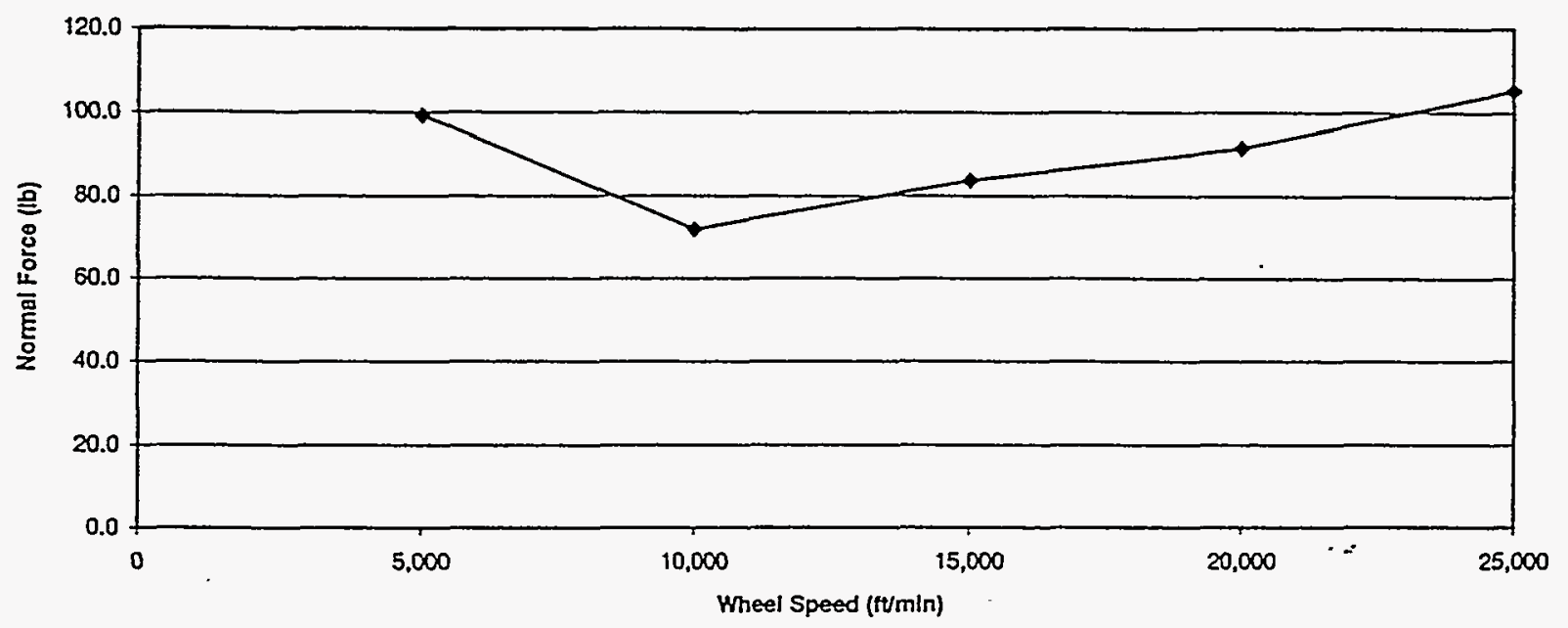

Figure 5. Normal force versus wheel speed.

HSLD S/RBSN Grinding

180 Grit Resin Bond Wheel

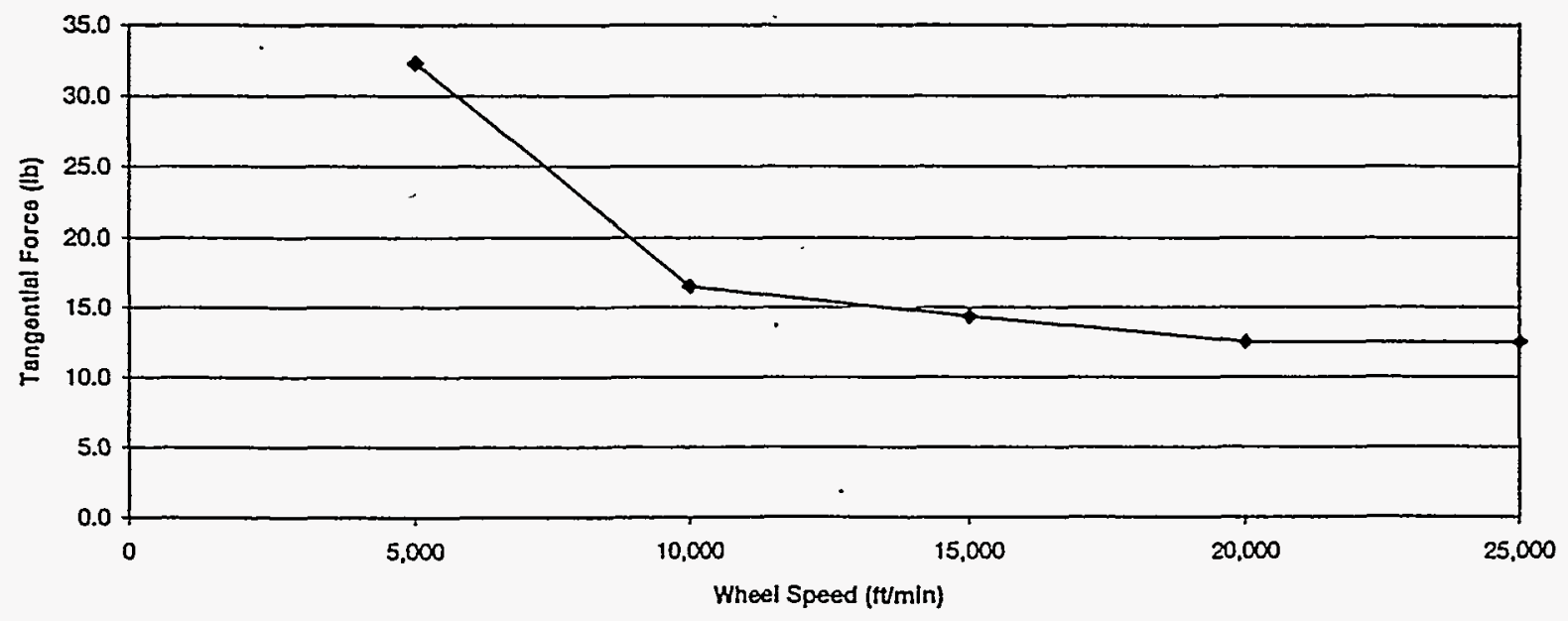

Figure 6. Tangential force versus wheel speed. 
HSLD S/RBSN Grinding

180 Grit Resin Bond Wheel

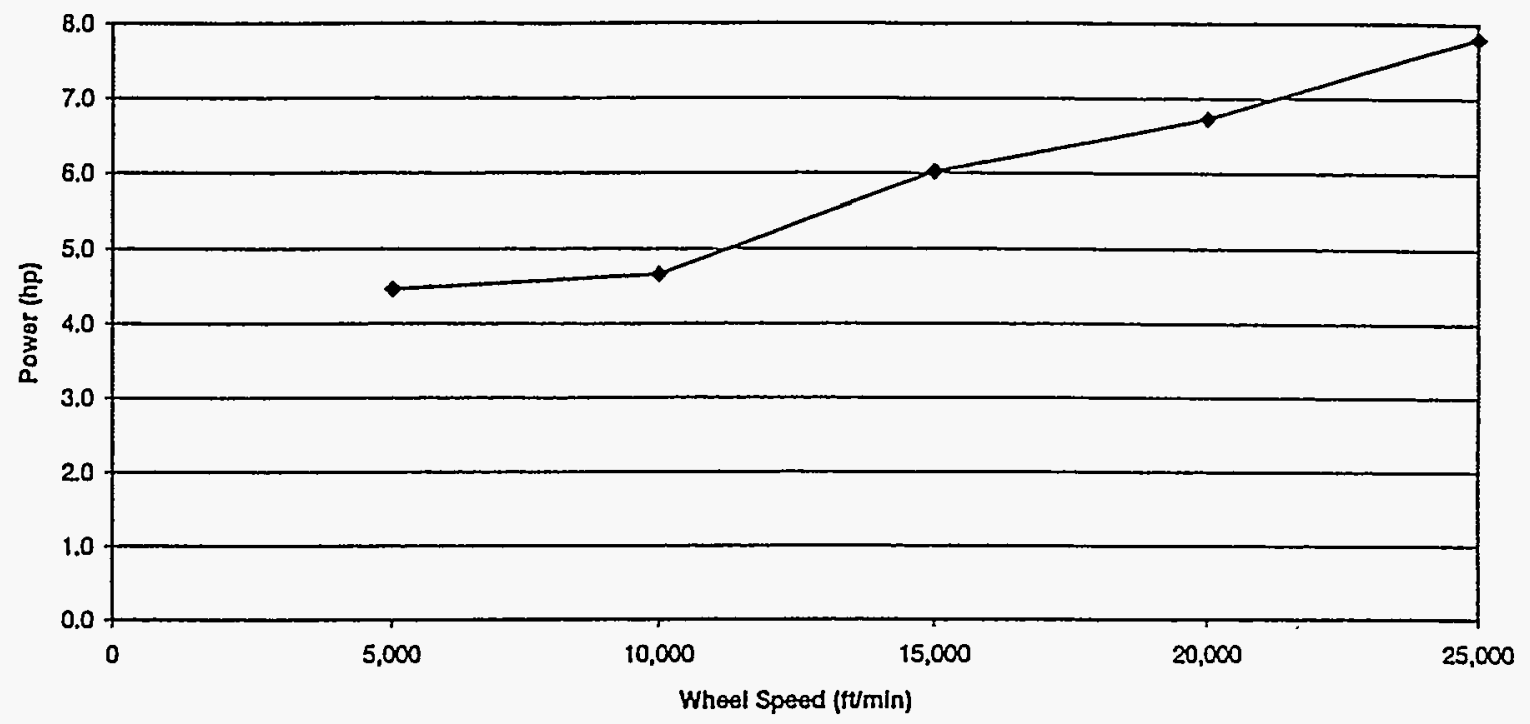

Figure 7. Power versus wheel speed.

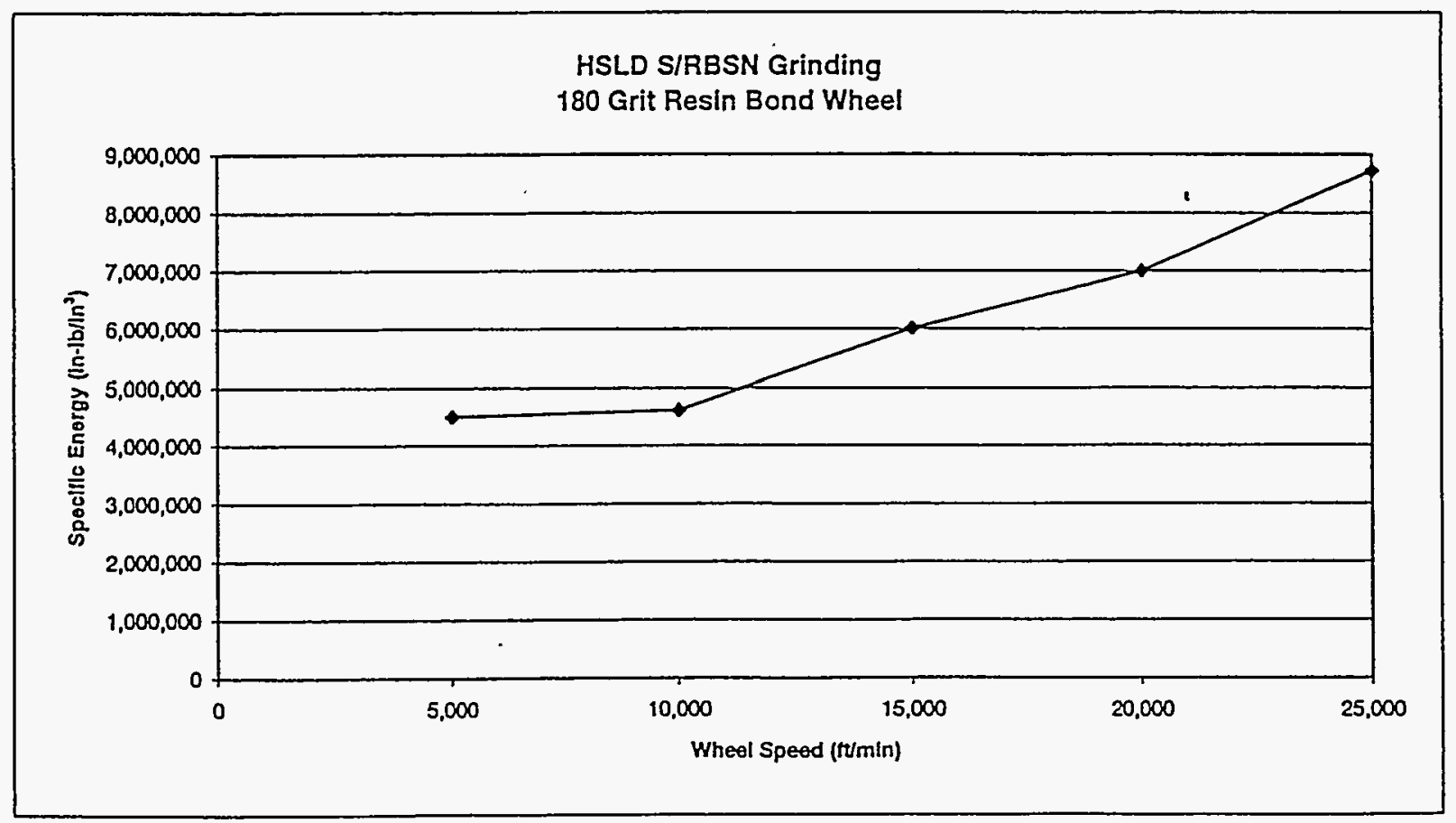

Figure 8. Specific energy versus wheel speed. 
HSLD S/RBSN Grinding

180 Grit Resin Bond Wheel

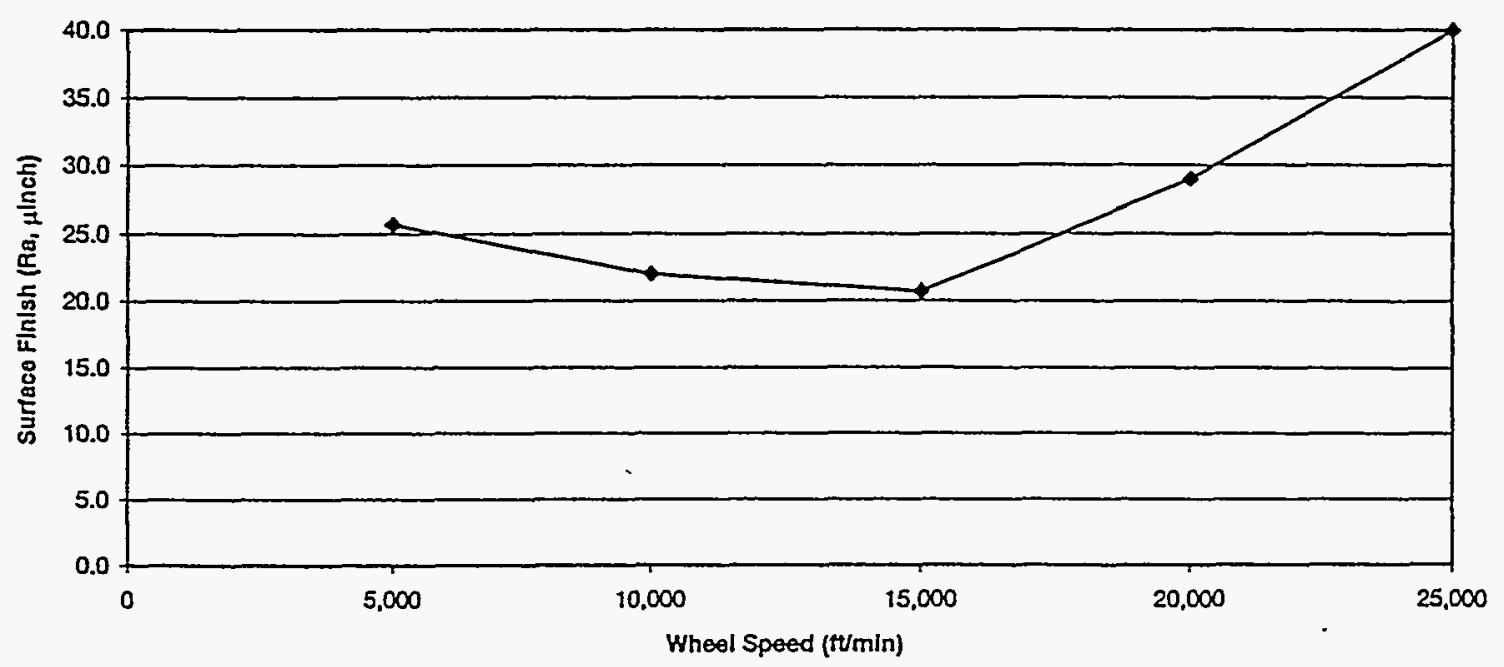

Figure 9. Surface Finish (Ra) versus wheel speed.

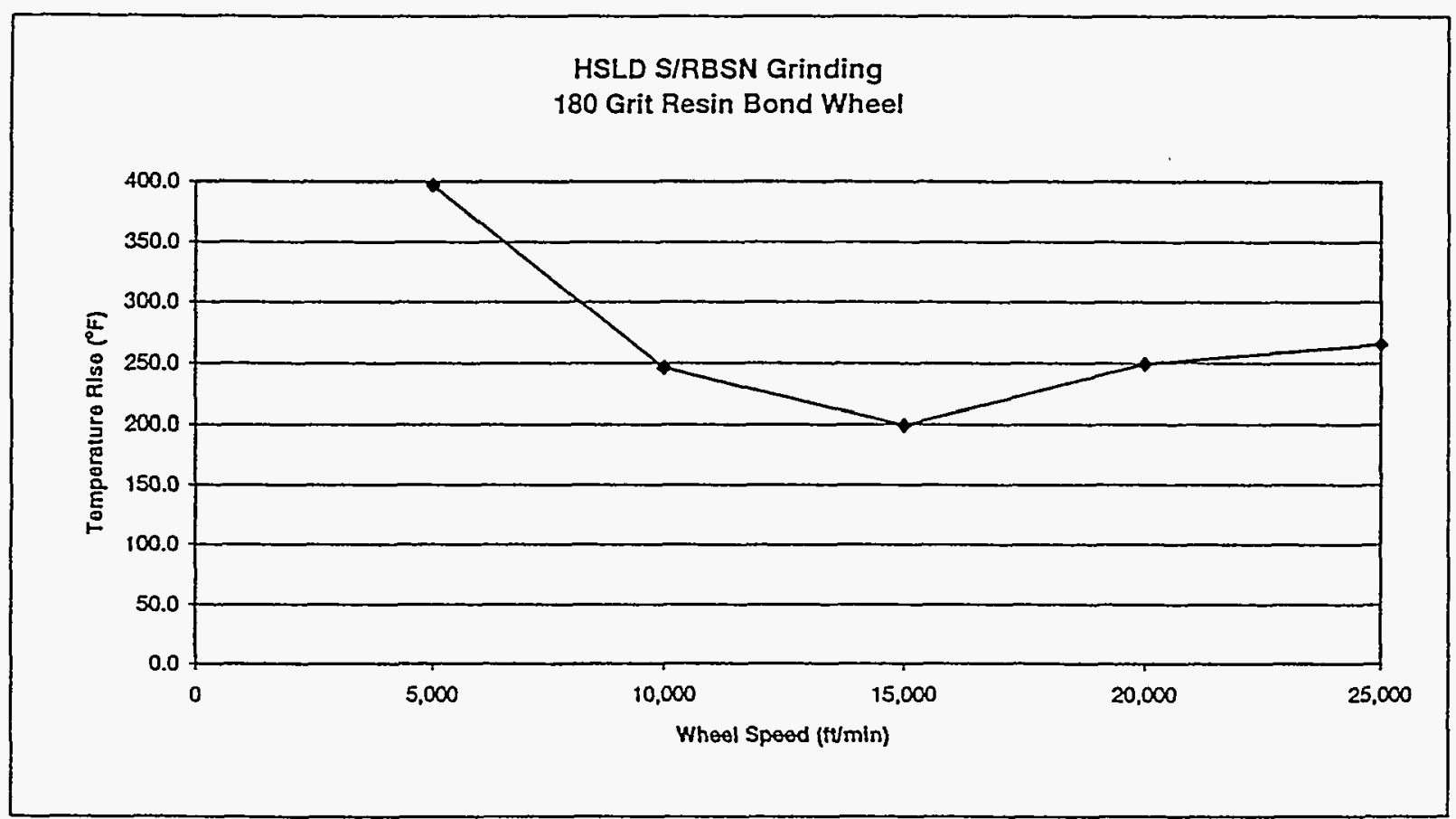

Figure 10. Temperature rise versus wheel speed. 


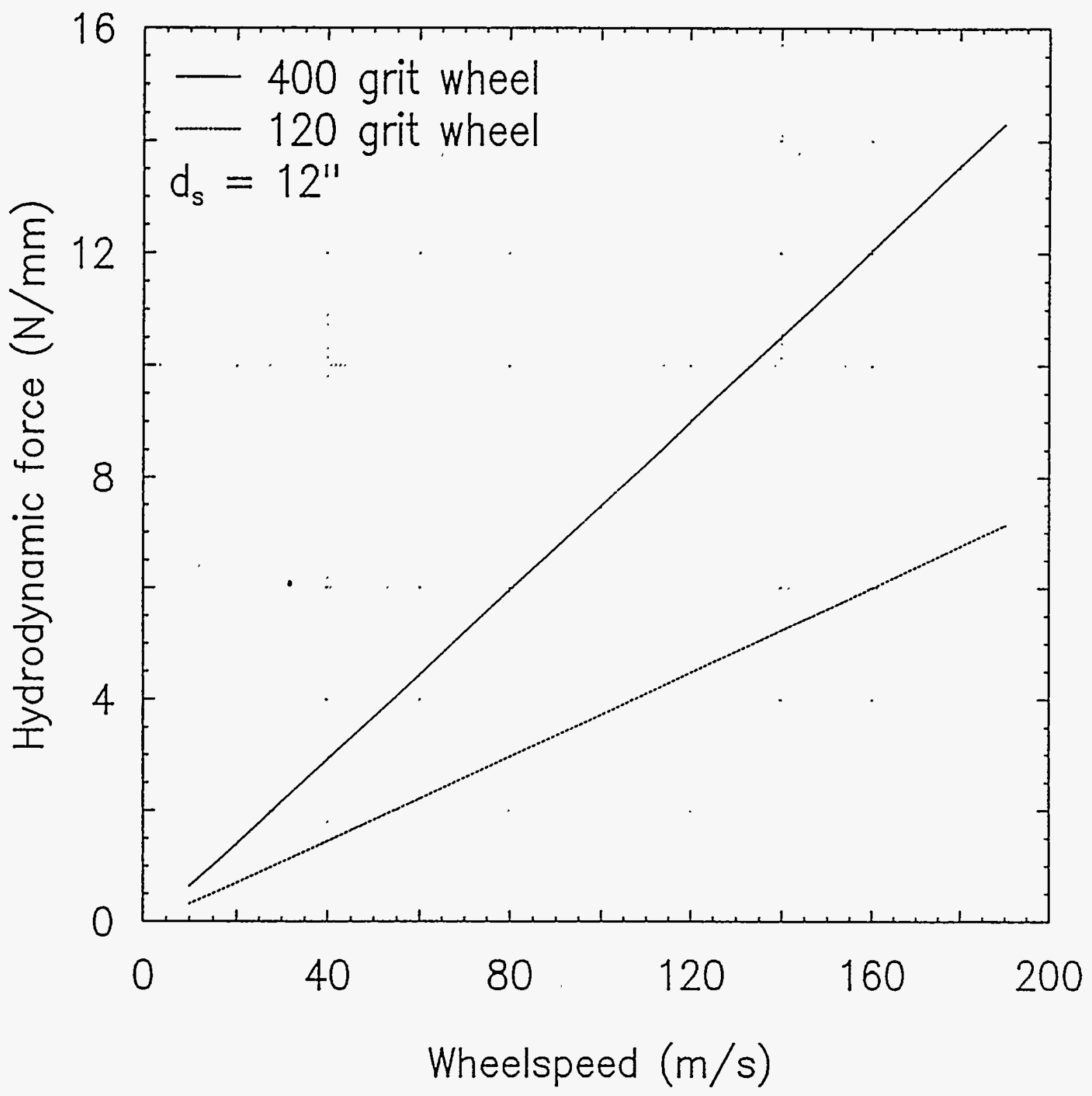

Figure 11. Hydrodynamic force versus wheelspeed for wheel diameter of 12 inches. 
Hydrodynamic Effects

$400 \mathrm{Grit}$ Dlamond Resin Bond Wheel (1.0 Inch wide)

Coolant Flow $=11 \mathrm{GPM}$ at $20 \mathrm{PSI}$

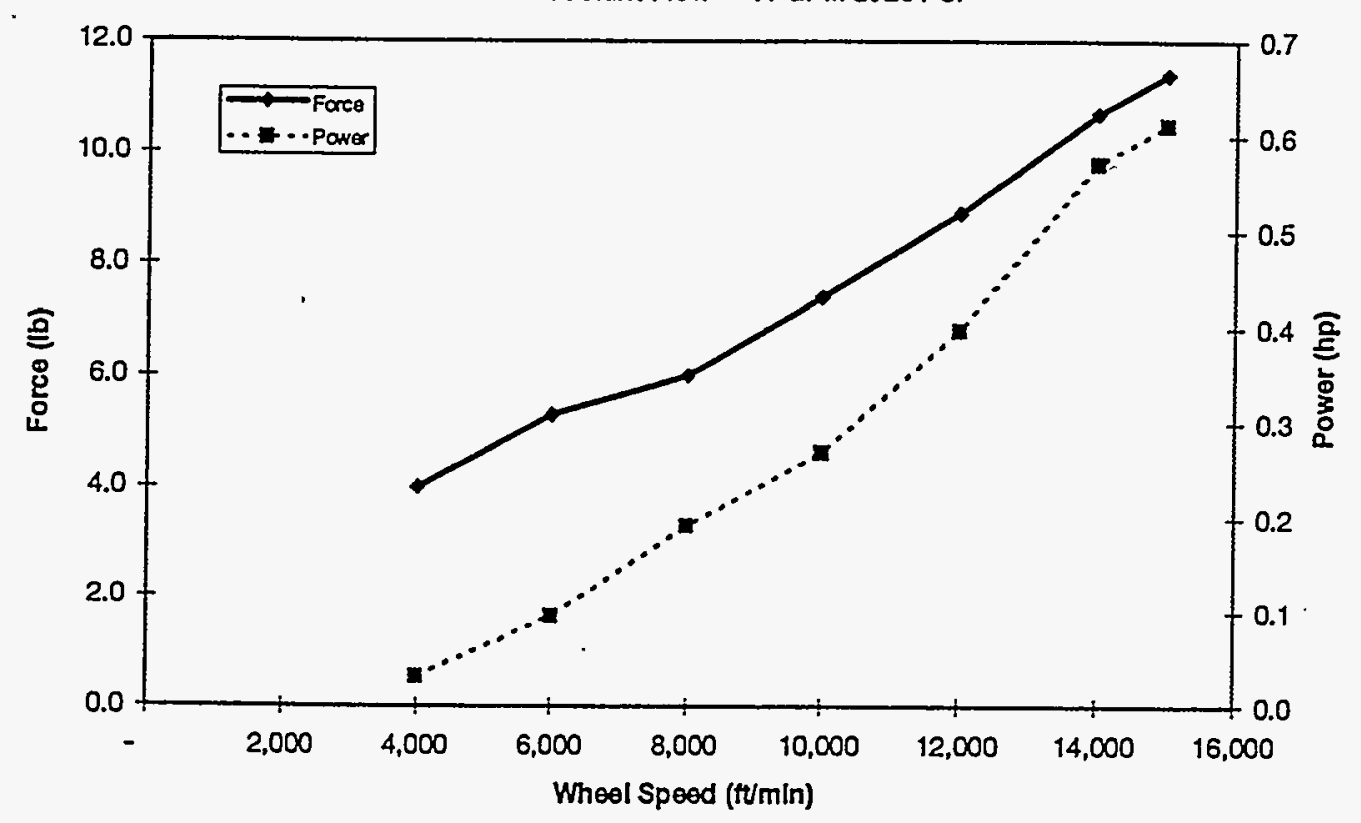

Figure 12

HSLD OD Grinding

400 Grit Diamond Resin Bond Wheel

SIRBSN Cyllnders at $300 \mathrm{rmmin}$

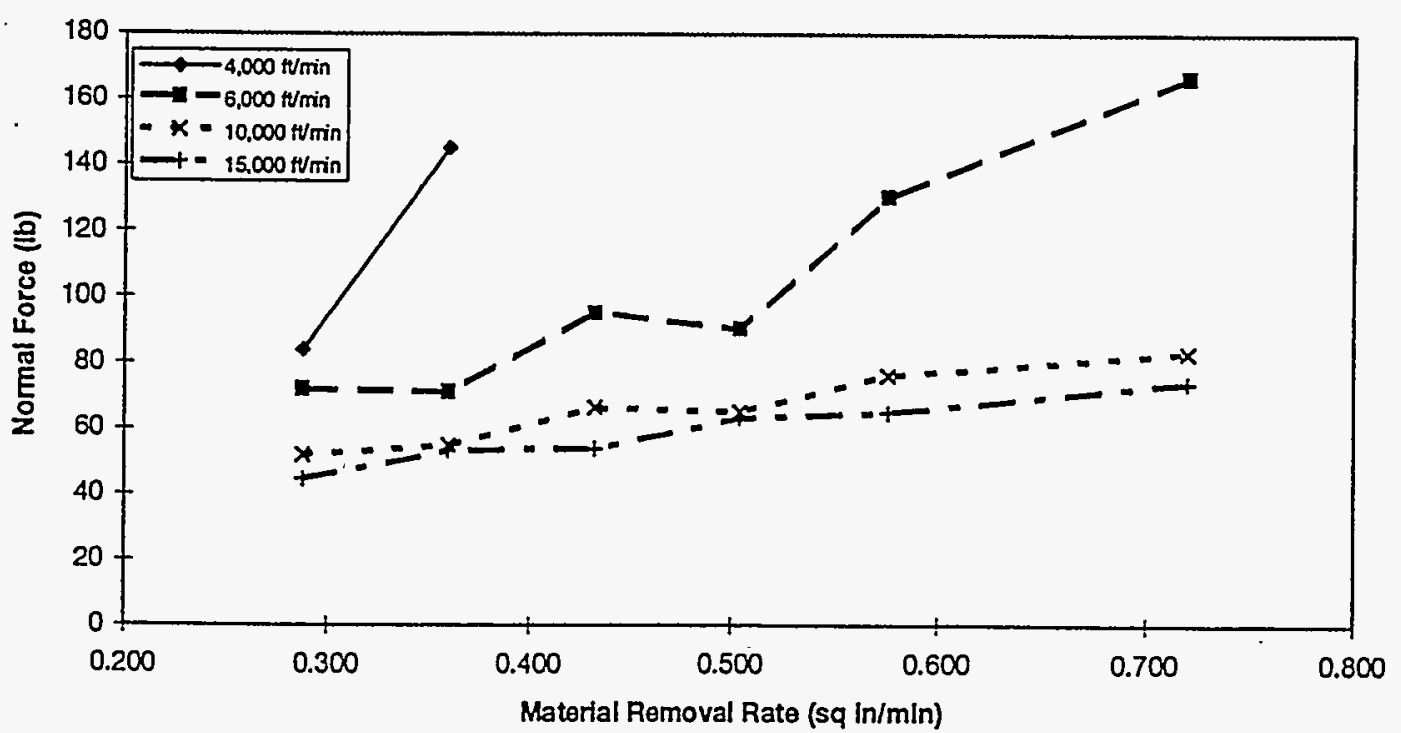

Figure 13 
HSLD OD Grinding

400 Grit Dlamond Resin Bond Wheel

S/RBSN Cylinders at $300 \mathrm{ft} / \mathrm{mln}$

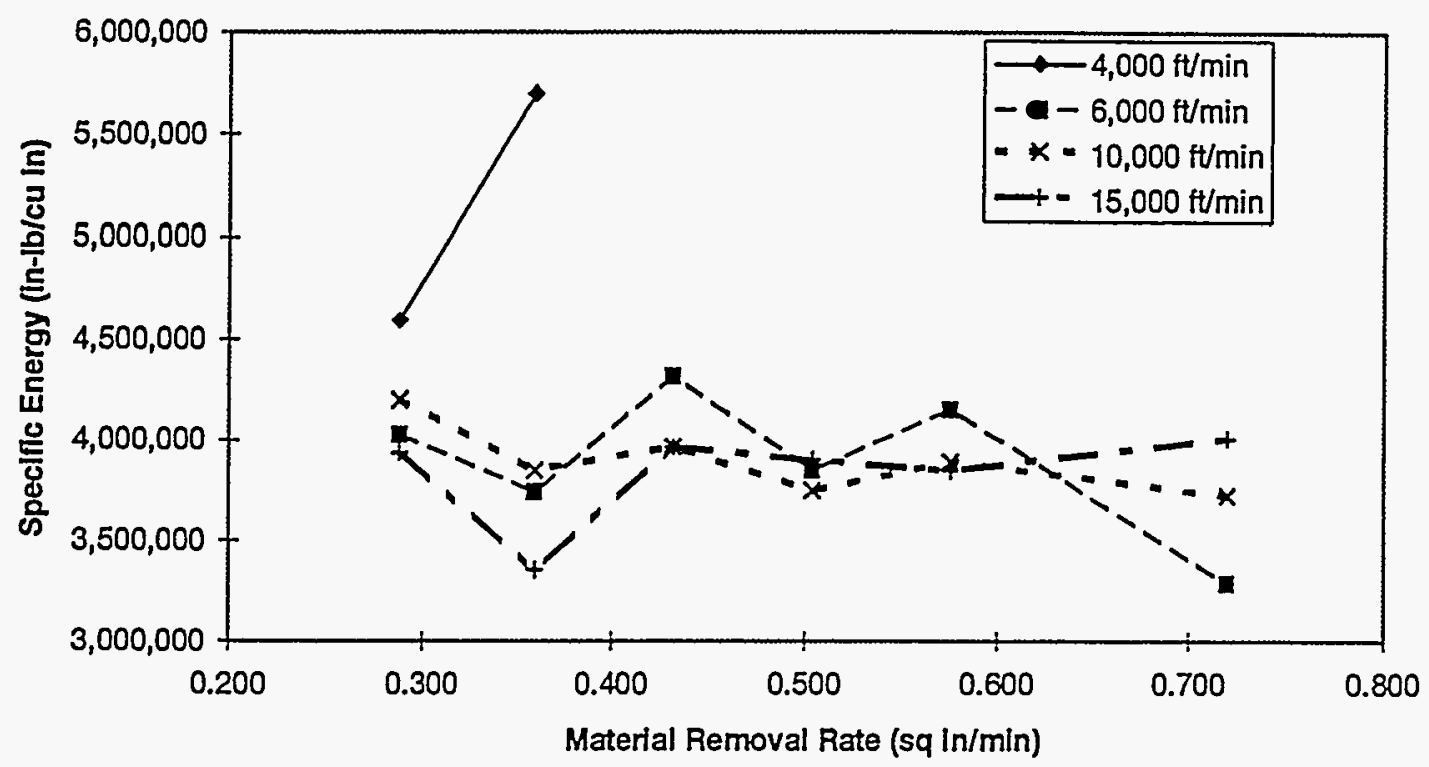

Figure 14

HSLD OD Grinding

400 Grit Dlamond Resin Bond Wheel $(15,000 \mathrm{ft} / \mathrm{mln})$

S/RBSN Cylinders (300 ft/min)

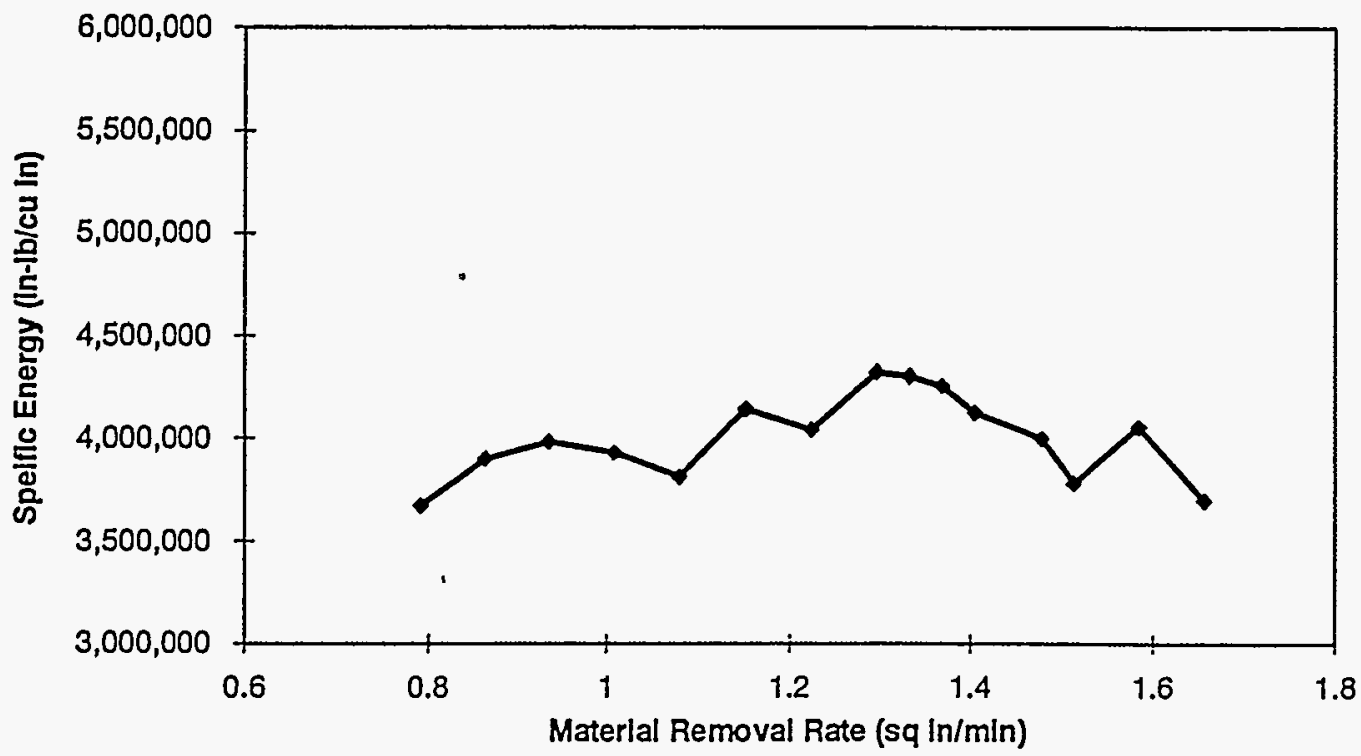

Figure 15 


\section{Chemically Assisted Machining of Ceramics}

WBS Element 1.5.0.3 (SC-G)

S.M.Hsu, Y.Wang and R.S.Gates

(National Institute of Standards and Technology)

\section{Objective/Scope}

The machining of ceramics is very difficult and costly because ceramics are hard, wear-resistant, and chemically stable, even at high temperature. The ceramics industry has identified the lack of a rapid low cost ceramic machining technology as a major barrier for widespread use of ceramics. Current machining technology is slow and labor intensive. Residual surface damage is a primary concern. This project aims to increase the machining rate of ceramics by using chemical reactions at the interface. The chemical reactions at the interface produce a reaction layer that may function in several ways. It may behave as a lubricating layer, barrier film, passive protective film reducing the wear of the diamond, or it may reduce the contact stresses, therefore minimizing the surface damage. $\mathrm{Si}_{3} \mathrm{~N}_{4}$ is the main material of focus.

The project involves several subtasks including:

1. Develop a bench test simulation to allow screening of chemistries under wellcontrolled conditions.

2. Identify new chemistries that can significantly improve the machining rate of ceramics, especially for silicon nitrides.

3. Provide understanding on the working mechanisms of the chemistries identified and . develop correlations with the surface quality of the machined surface.

4. Establish limits of performance and applicability of the chemistry on different material compositions and processes. Establish optimum machining conditions for each chemistry/material combination.

5. Examine the environmental impact of the chemistry and work with industrial partners to optimize the chemistry and validate the concepts and methodology in industrial practice.

\section{Technical Highlights}

Previously, we have reported the results of diamond grinding tests on silicon nitride using a vertical grinder lent to us by Kennametal and specially instrumented to evaluate developed coolants. Using a test procedure designed to measure the material removal rate and $\mathrm{G}$ ratio for this configuration, we demonstrate the improvement in grinding for the experimental grinding coolants. We also examined the performance of an experimental fluid for grinding cemented tungsten carbide using a metal-bonded diamond wheel on the vertical grinder. In the current period, we have modified and instrumented a commercial surface grinder to allow controlled 
grinding experiments to further evaluate coolant chemistry effects. Using this apparatus, the experimental coolant has been optimized in formulation to include a corrosion inhibitor, biocide, and antimisting additive with little sacrifice in enhanced grinding performance. A field trial has begun at Kennametal to evaluate the experimental fluid in actual production grinding operations. The initial tests, consisting of diamond grinding of cemented tungsten carbide materials, suggest that the experimental coolant may have significant benefits for grinding of this material also. Work has also begun on investigation of chemical means to influence particle agglomeration for the organic-based experimental fluid.

\section{Modification of Surface Grinder}

A commercial surface grinder was modified and instrumented to provide continuous information on the forces (normal and tangential) and grinding rates present during grinding operations. The apparatus, depicted in figure 1, consists of a three dimensional force transducer, mounted on a grinding bed slide-way. A sample is fixed inside a trough, immersed in the test coolant. By supplying a horizontal force to the upper half of the slide-way via a dead weight, a controlled load is applied to the specimen-grinding wheel interface. A displacement transducer monitors the movement of the slider during grinding operations, thus providing a continuous measure of the grinding rate. The severity of the test is determined by the horizontal load applied to the specimens and the dimensions of the grinding interface. These dimensions are determined by the width and depth of the overlap between the specimens and the grinding wheel.

\section{Experimental Design and Test Procedure}

1) Test material: Kennametal Silicon nitride cutting inserts.

2) Geometry of the test samples: $20 \mathrm{~mm} \times 20 \mathrm{~mm} \times 6 \mathrm{~mm}$.

3) Three samples were arranged in a row and firmly glued on a flat surface, providing a total surface of $20 \mathrm{~mm} \times 60 \mathrm{~mm}$ was formed.

4) Grinding speed: $23 \mathrm{~m} / \mathrm{s}$.

5) Tangential load: $2 \mathrm{~kg}$, applied by deadweight on the sample test bed to drive the horizontal movement.

6) Grinding width: $4 \mathrm{~mm}$.

7) Preset vertical overlap between the sample surface and grinding wheel surface is $1.5 \mathrm{~mm}$.

8) The normal force, tangential force, and the movement of the ground sample are measured continuously during each test.

9) Cutting fluid: $-500 \mathrm{ml}$ of coolant are used for each test. This results in specimens that are submerged $2-3 \mathrm{~mm}$ into the coolant.

The diamond grinding wheel is trued using an abrasive trueing wheel. A final hand dressing with a silicon carbide stick exposes the fresh diamond and the wheel is ready for testing. An imprint is made on the specimen to provide a before-test profile of the diamond grinding wheel. The test is started and runs for approximately 75 seconds. At the end of the test, the load is removed and a second imprint is made in the specimens. The difference in the two imprints provides a measure 
of the wear of the diamond wheel. Using this information, the "G ratio" (sample wear/diamond wheel wear) can be estimated.

\section{Surface Grinder Performance Measurement}

Figure 2 shows the type of data acquired during this test for the commercial coolant. The load is applied and the wheel begins to grind into the specimen. As material is ground away, the sample moves and the locations are recorded by the displacement transducer. The initial grinding rate, indicated by the slope of displacement line, is fairly high. As the specimen is ground, the grinding rate decreases rapidly, until at the end of the test it has dropped near to zero. At the end of the test, the diamond grinding wheel has traversed a distance of $25 \mathrm{~mm}$ along the length of the specimens. This behavior is consistent with what we have observed for this coolant with both the diamond cutting test and vertical grinding tests. In these cases, the reduction of grinding efficiency has been attributed to the dulling of the diamond and buildup of a siliceous layer on the diamond wheel.

When the experimental coolant is used, a different grinding behavior is seen, as shown in Figure 3. The grinding rate remains high throughout the test. At the end of the test, the diamond wheel has traversed a distance of $55 \mathrm{~mm}$ along the silicon nitride specimens.

A convenient way of comparing the data is to calculate the volume of silicon nitride material removed during the test. Initially, the volume of material is estimated as:

$$
V_{s}=w d l
$$

where $w$ is the set width $(4.0 \mathrm{~mm}), d$ is the set depth $(1.5 \mathrm{~mm})$ and $l$ is the grinding length. This value must then be corrected for the geometry of the grinding wheel-sample contact. Figure 4 shows the geometry of the surface grinder-sample contact. The shaded portion of the sample block represents the overestimation that must be corrected for. Given the geometry and size of the grinding wheel, a $1.5 \mathrm{~mm}$ overlap will provide a contact length of approximately $19.5 \mathrm{~mm}$. The volume correction that must be subtracted from each test is $39 \mathrm{~mm}^{3}$.

\section{Coolant Formulation}

A series of surface grinder tests was conducted to observe the effect of various coolant formulation components on the grinding performance. The results are summarized in Table 1. The repeatability of the surface grinder test can be estimated using the set of four repeat tests conducted on the developed formulation. The repeatability was estimated at $270 \pm 12 \mathrm{~mm}^{3}$, which is a relative standard deviation of about $4 \%$.

The results indicate that the experimental fluid removed approximately two to three times more silicon nitride during the test than the commercial fluid. There appears to be a very slight 
degradation in the performance of the experimental fluid due to the inclusion of the corrosion inhibitor and biocide; however, it represents only a $10 \%$ decrease. It appears that both the corrosion inhibitor and the biocide have effects in this test. Previous testing using the vertical grinding apparatus had demonstrated a decrease of about $20 \%$ with these same fluids. This suggests that while there are some variations from different test configurations, the overall trends are very consistent and demonstrate considerable benefit from the new experimental coolant.

The surface grinder test results (Table 1 ) also indicate that the addition of $0.1 \%$ antimisting additive had no discernable effect on the ability of the developed coolant to grind silicon nitride at accelerated rates.

Table 1

Surface Grinder Test Data Summary

Coolant

Individual Test

111

111

111

Experimental Base Fluid

291

302

312

Base $+1 \%$ Corrosion Inhibitor

292

292

Base $+0.05 \%$ Biocide

287

287

Base $+0.15 \%$ Biocide

286

286

Base $+1 \%$ Corrosion Inhibitor

$+0.1 \%$ Biocide

279

279

Developed Coolant

281

$271 \pm 12$

261

281

261

Developed Coolant

274

$+0.1 \%$ Antimist Additive

295

Conditions: Surface grinder, silicon nitride specimens, diamond grinding wheel, $23 \mathrm{~m} / \mathrm{s}, 1.5 \mathrm{~mm}$ overlap, $4 \mathrm{~mm}$ grinding width. 
It should be kept in mind that the volumes calculated for these tests represent the AVERAGE rates over the duration of the test. The results, therefore represent a very conservative estimate of the possible benefits of this fluid.

\section{Kennametal Plant Trial of NIST Coolant}

A 100-gallon sample of the NIST experimental coolant was blended and shipped to a Kennametal plant in North Carolina for testing in an automated production grinding machine (Kenmatic Endform Grinder). Kennametal had decided in the last minute to conduct the plant trial of NIST coolant on their standard production cemented tungsten carbide insert materials. This decision in part was based on our hypothesis that our coolant primarily functions by protecting the diamond surface. If this were true, then any operation using diamond tools could benefit. Since the cemented tungsten carbide represents the bulk of their operations, a successful demonstration of our coolant would yield the highest economic impact for them. They also promised that regardless of the outcome of this trial, another trial on silicon nitride will be conducted sometime in the future. Under this arrangement, a three-member team from NIST visited the plant on March 13 to set up the plant trial.

The industrial grinder used for this trial was a specially designed, computer controlled, enclosed, robotic apparatus capable of grinding inserts at a rate of more than a thousand pieces a day. The machine used a commercial organic coolant for its normal operation. So the first step was to drain and flush the system with 100 gallons of the base oil used in the NIST coolant. This was done to reduce the possible contamination to an acceptable $0.25 \%$.

For the operation of the machine, the operator periodically fed a rack of blank insert parts for grinding to the specified dimensions. The machine had various optical sensors so that when the final dimensions were reached, the machine stopped and removed the part. The time it took from beginning to finish was called the cycle time. The finished part was inspected optically under magnification to ensure dimensional conformity within set tolerances. Figure 5. illustrates a typical cross section of the tool insert and the diamond wheel used during the plant trial. The diamond wheel used was $250 \mathrm{~mm}$ resin-bonded wheel rotating at $1900 \mathrm{rpm}(\sim 25 \mathrm{~m} / \mathrm{s}$ surface speed). During operation, a stream of coolant was sprayed into the contact region between insert and diamond wheel. The shapes and dimensions of critical surfaces of the insert (surfaces 1-7) were determined by the critical surfaces of the diamond grinding wheel (surfaces a-c). Inside corner " 1 " depended on the shape of diamond wheel edge " $a$ ". Outside corner " 3 " depended on flat surface " $b$ " as it turned the corner on its way to grind flat surface " 4 ". Outside corner " 5 " depended on flat surface " $b$ " as it turned the corner on its way to grind flat surface " 6 ". Inside corner " 7 " depended on diamond wheel edge " $c$ ". The grinder was specially designed to final

grind three faces of a tool insert in a complex sequence of passes as depicted in Figure 6. Tests were conducted using blanks and programming for top notch threading and grooving style inserts. The insert material being ground was a cemented tungsten carbide with nominal $8.5 \%$ Cobalt, known as KC810. 
The first test conducted was the cycle time test. Since the machine operated on variable power, the cycle time per piece therefore represented the material removal rate. The test result was identical to the commercial organic coolant used previously.

As we remembered the NIST coolant test data, the higher material removal rate from the NIST coolant primarily was a result of retaining the initial cutting rate without deterioration of the material removal rate. So we asked their personnel how they determined the dressing cycle interval. They responded that they dressed their wheel after grinding 30 inserts. The key indicator for the need to redress the wheels was the burn marks appearing on the ground surfaces. Redressing was also necessary to remove debris and sharpen the diamond. Since each insert had two working ends, this represented 60 individual sequences of grinding.

The dressing interval test was conducted to compare the NIST coolant with the commercial coolant on a nearby machine which was identical to the test machine. The experimental NIST coolant went on to finish the batch of 500 inserts without the need for redressing. Comparable interval tests on the other machine yielded an average of 79 pieces with the lowest number of 40 . This was probably how the original 30 was set.

For several days, the automatic redress cycle was set to 500 inserts without incident. This represented a significant improvement over the normal 30 insert cycles used for the commercial coolant and confirmed the results produced in our laboratory. There are two aspects to this result that are beneficial to plant production grinding. First, since the diamond stays sharper longer, there is less overall wear of the diamond wheel and longevity is increased. Second, fewer diamond dressing steps are needed. Thus the number of inserts that can be ground in a set amount of time can be increased. Since the initial tests are promising, longer term testing is continuing. A second test will be conducted on silicon nitride inserts.

Several unforseen issues arose during the trial that needed immediate attention. For example, it was not known initially that the coolant also serves some lubricating function in the grinder. In actual operation, a separate reservoir of coolant serves to lubricate the slideways and grinding spindle. A special lubricant was therefore quickly developed which could lubricate these parts and was compatible with the coolant. Another problem arose with regard to chilling of the coolant. In actual use, the coolant recirculation system travels through a refrigeration unit, where it is chilled. The current coolant formulation will become very viscous when exposed to temperatures as low as $10^{\circ}$ to $15^{\circ} \mathrm{C}$. The walls of the chiller unit are significantly lower than this therefore it will not effectively cool the experimental coolant during testing. As a result, during the plant trial the experimental coolant had to be run at approximately $27^{\circ} \mathrm{C}$ instead of the usual $21^{\circ} \mathrm{C}$. Attempts were made to use several pour point depressants to maintain fluidity at reduced temperatures; however, this approach was unsuccessful.

\section{Particle Agglomeration Issues}

One of the most critical issues in the diamond grinding of silicon nitride ceramics involves particle interactions of suspensions: more specifically, the interparticle forces that lead to dispersion and 
agglomeration. Early in our study of chemically assisted ceramic machining we noted that silicon nitride grinding effectiveness was being hampered by formation of siliceous films on the diamond wheel and work piece surfaces.

Commonly used techniques to agglomerate the particles include:

i) Electrolytic coagulation

ii) Surfactants (both ionic and nonionic)

iii) Polymers

Electrolytic coagulation involves using inorganic salts such as ferric chloride to reduce the thickness of the electrical double layer. This technique is more specific to aqueous media and was not pursued. The use of ionic surfactants is also more suited to polar media like water-based fluids and was not pursued for our organic-based coolant. The polymer agglomeration technique was pursued as the best option to try initially.

The polymer agglomeration technique involves adding a high molecular weight polymer to the coolant in an attempt to promote flocculation of the particles. In this technique, polymers adsorb onto the surface of several particles, bridging them and destabilizing the suspension. The first polymer used was the same one used for antimisting. It was hoped that this polymer would be multi-functional and serve as both agglomeration and antimisting agents.

A sample of used grinding fluid was collected from the surface grinder apparatus. The fluid contained significant amounts of silicon nitride grinding debris. These tests were conducted using the experimental fluid containing a biocide and corrosion inhibitor, but not any antimisting agent. The used coolant sample was homogenized with mechanical agitation to disperse the particles throughout the fluid and then portioned into small individual vials of about $10 \mathrm{ml}$. Several different polymers were dissolved in a base organic fluid compatible with the experimental coolant at a concentration of $5 \%$ by mass. These dissolved polymer solutions were then added to the used grinding coolant to bring the polymer concentration to $0.1 \%$ in the final fluid. The vials were agitated vigorously, and then allowed to stand for several days to observe the time required for the particles to settle out of suspension. A summary of polymers investigated for this study is presented in Table 2.

None of the polymers accelerated the settling of the silicon nitride grinding debris appreciably. The used grinding fluid without polymers served as a baseline in this study. Within a day, some settling had occurred. By three days, most of the particles had settled to the bottom of the vial, leaving a clear supernatant fluid. One of the polymers ( one million MW polyisobutylene) was evaluated over a concentration range of $0.01 \%$ to $1.0 \%$; however, none of these concentrations caused agglomeration. Work is continuing with different polymers in the hope that a combination of polymer chemical type, molecular weight, and concentration can be found that will settle out the particles in a matter of hours instead of days. 
Table 2

Effect of Polymers on Settling of $\mathrm{Sin}_{3} \mathrm{~N}_{4}$ Grinding fluid Particles

\begin{tabular}{|c|c|c|}
\hline Polymer & Concentration & Settling Time \\
\hline NONE & - & 1-3 days \\
\hline Polypropylene Glycol Diol & $0.1 \%$ & $1-3$ days \\
\hline Polypropylene Glycol Triol & $0.1 \%$ & $1-3$ days \\
\hline Poly(methyl acrylate) & (solubility") & N/A \\
\hline Poly(ethyl acrylate) & (solubility") & N/A \\
\hline Poly(butyl acrylate) & (solubility") & N/A \\
\hline Poly(2-ethylhexyl acrylate) & $0.1 \%$ & 1-3 days \\
\hline Poly(methyl methacrylate) & (solubility") & $\mathrm{N} / \mathrm{A}$ \\
\hline Poly(butyl methacrylate) & (solubility") & N/A \\
\hline Poly(isobutyl methacrylate) & (solubility $\left.{ }^{*}\right)$ & N/A \\
\hline Poly(Lauryl methacrylate) & $0.1 \%$ & 1-3 days \\
\hline Polyisobutylene & $\begin{array}{l}0.01 \% \\
0.03 \% \\
0.10 \% \\
0.30 \% \\
1.0 \%\end{array}$ & $\begin{array}{l}\text { 1-3 days } \\
1-3 \text { days } \\
1-3 \text { days } \\
1-3 \text { days } \\
1-3 \text { days }\end{array}$ \\
\hline Poly(vinyl alcohol) & (solubility") & N/A \\
\hline
\end{tabular}




\section{Status of Milestones}

On schedule

\section{Communications/Visits/Travel}

Stephen Hsu, Richard Gates, and You Wang visited the Kennametal plant in Roanoke Rapids, North Carolina on March 13 to supervise the beginning of the plant trial on the experimental NIST coolant.

\section{Problems Encountered .}

Work was interrupted due to the Federal Government furlough that closed NIST from December 19, 1995 through January 5, 1996.

\section{Publications}

None 


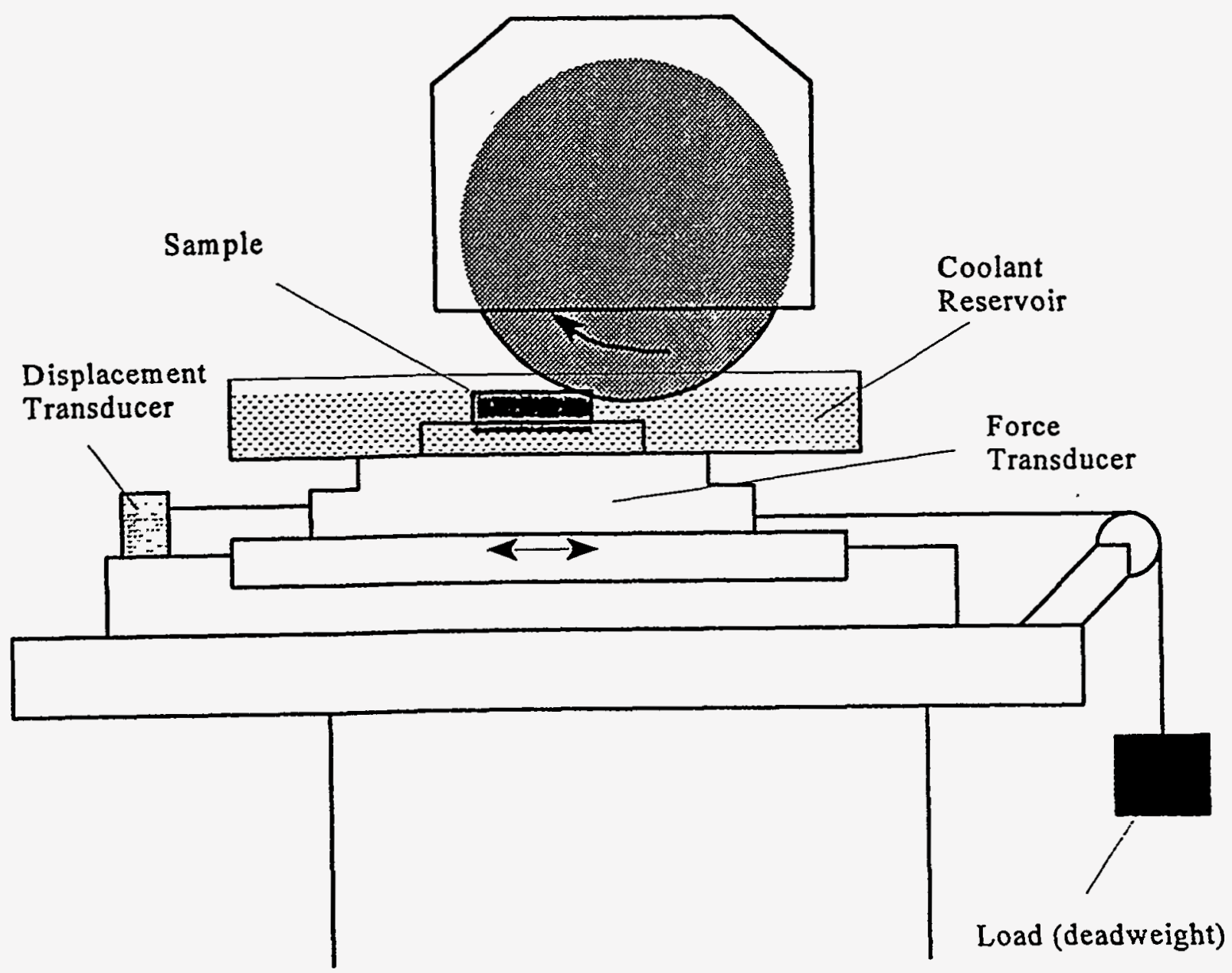

Figure 1. Surface Grinder apparatus. 


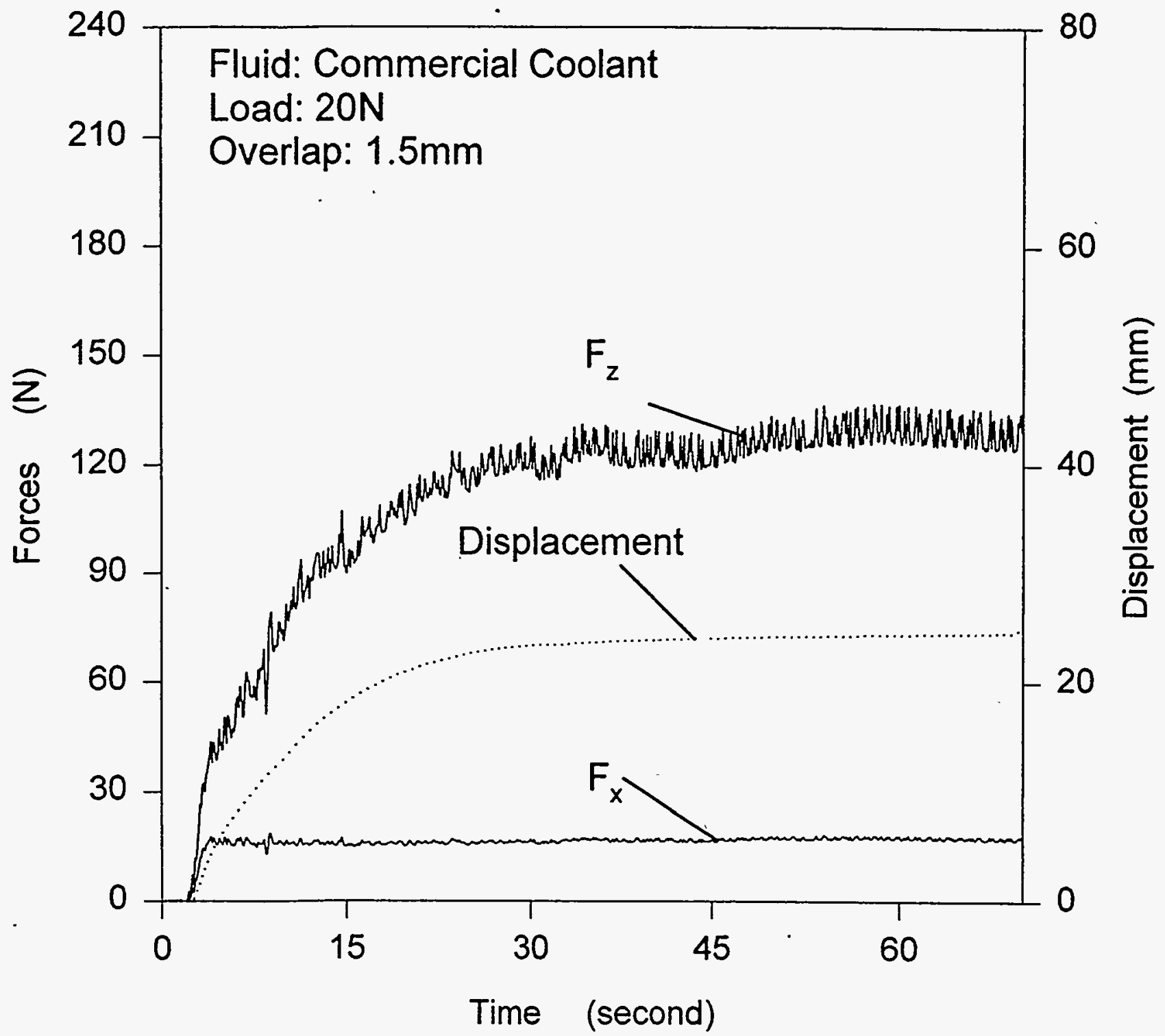

Figure 2 Surface Grinder test on commercial coolant 


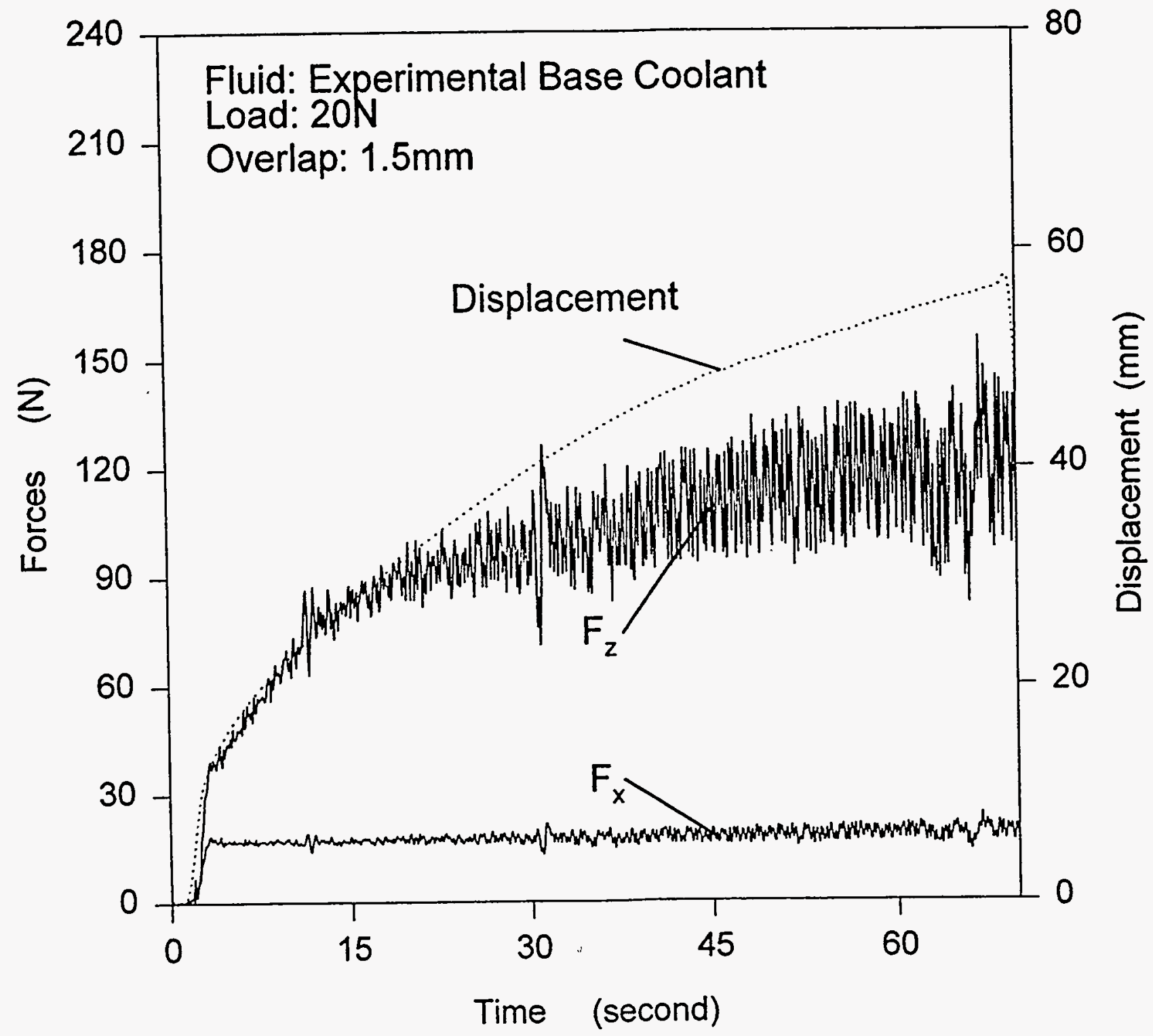

Figure 3. Surface Grinder test on Experimental NIST base coolant. 


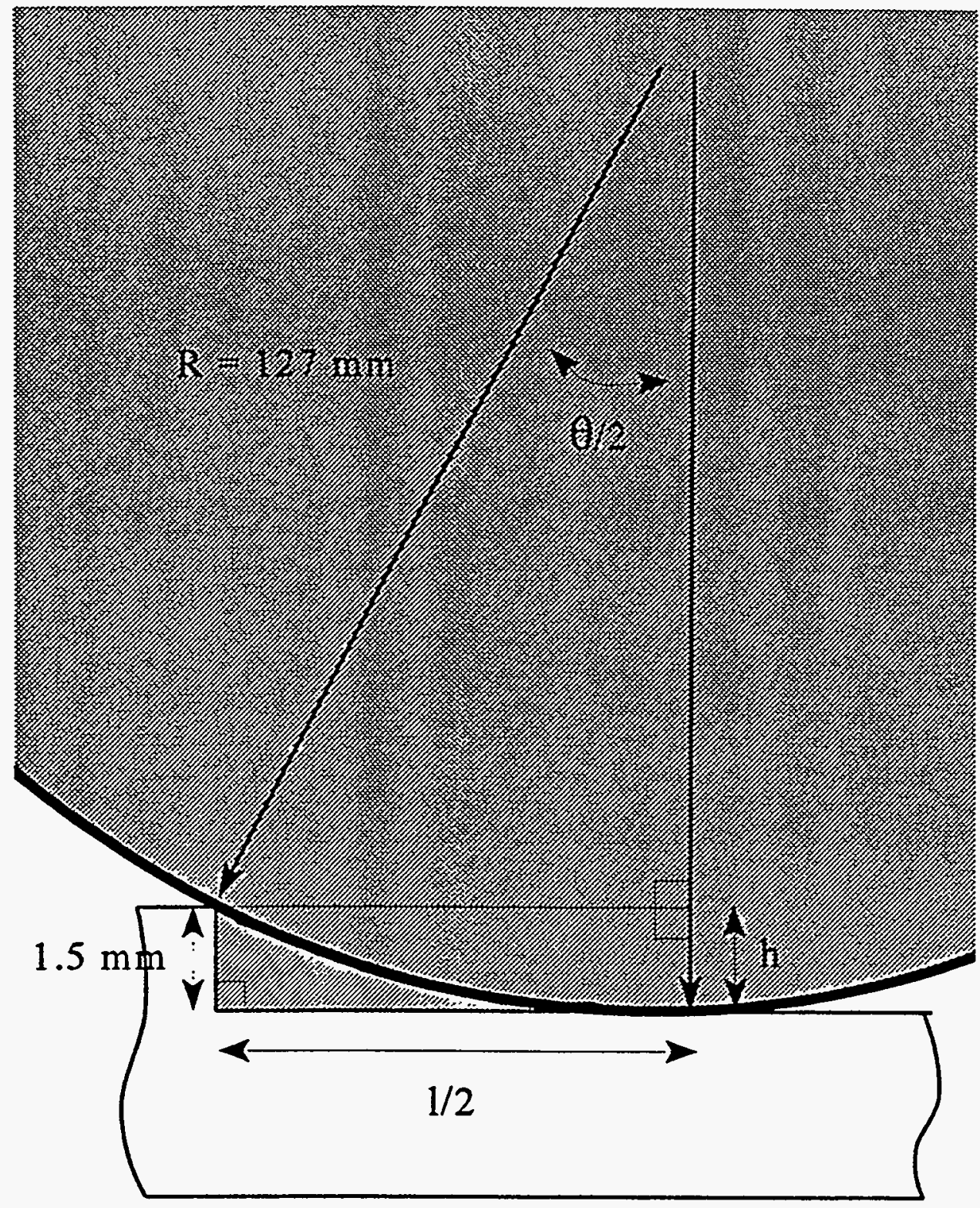

Figure 4 Surface Grinder Volume Correction 


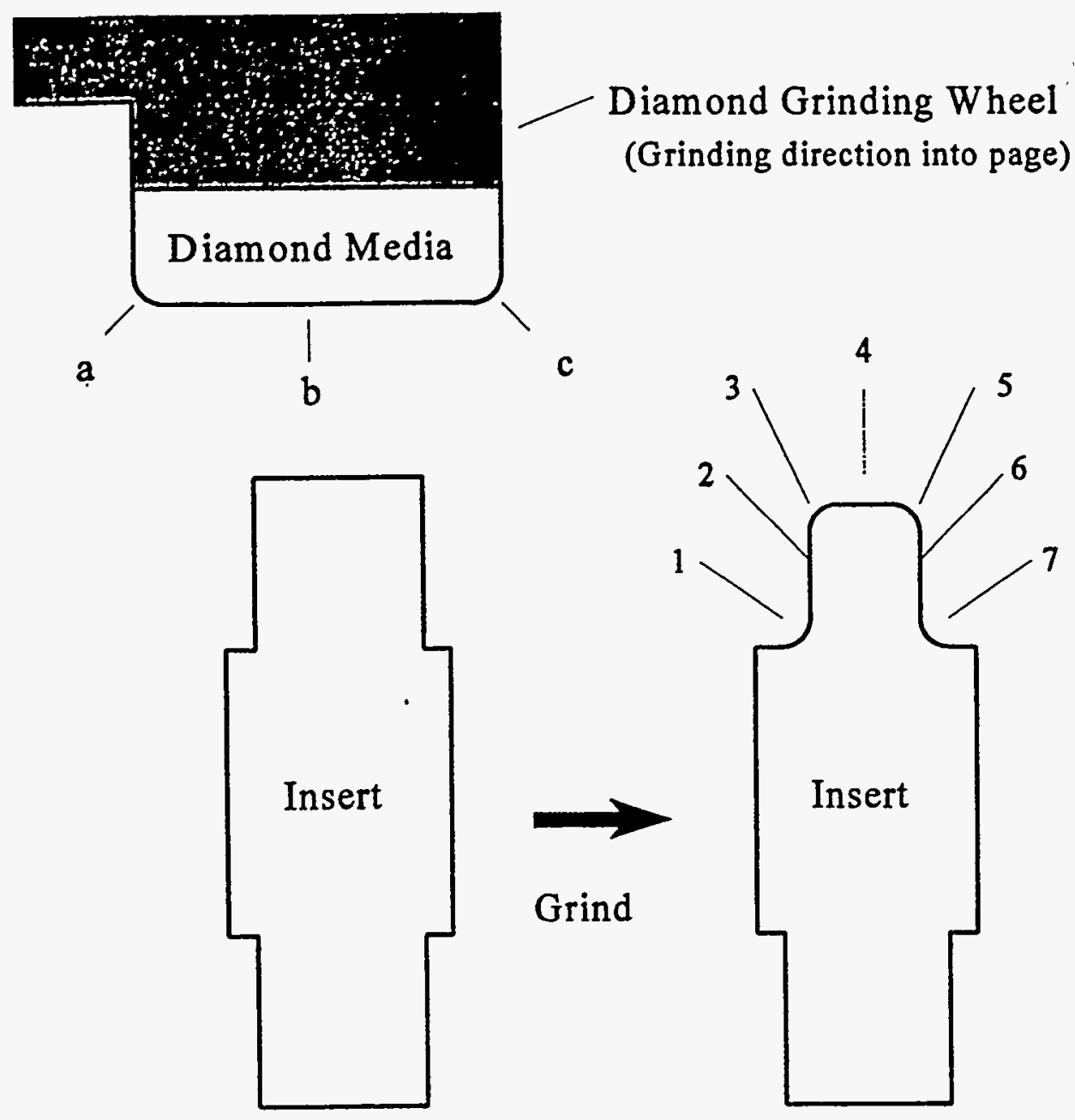

Figure 5 Cross sections of diamond grinding wheel and tool inserts with important surfaces labeled. 
I Side Face
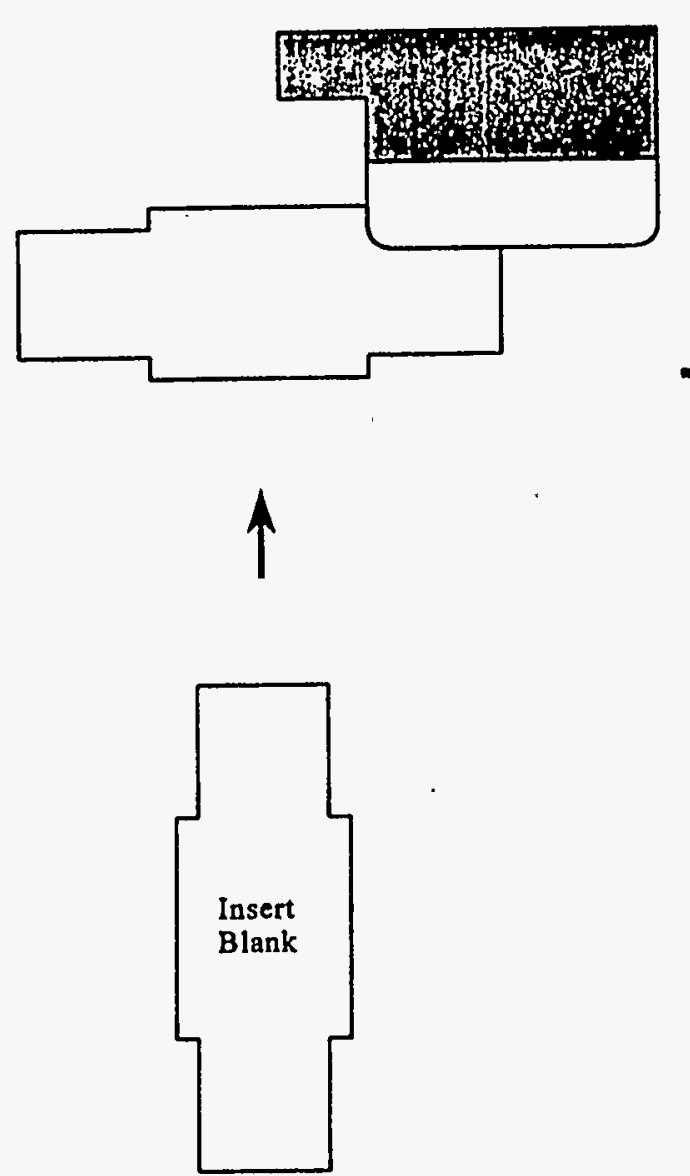

II End Face

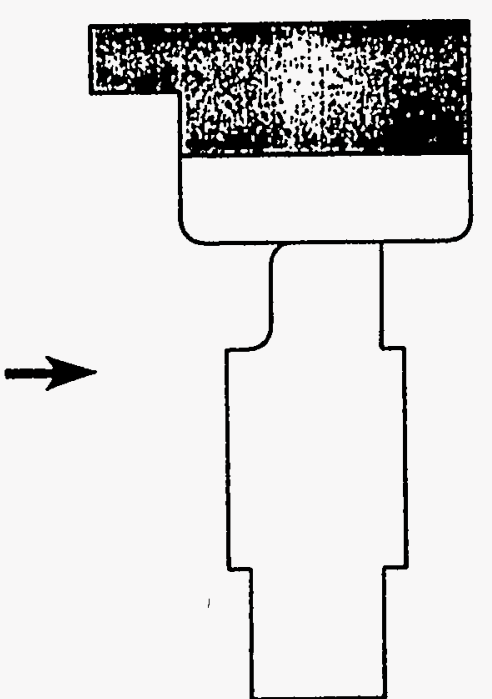

III Side Face \#2
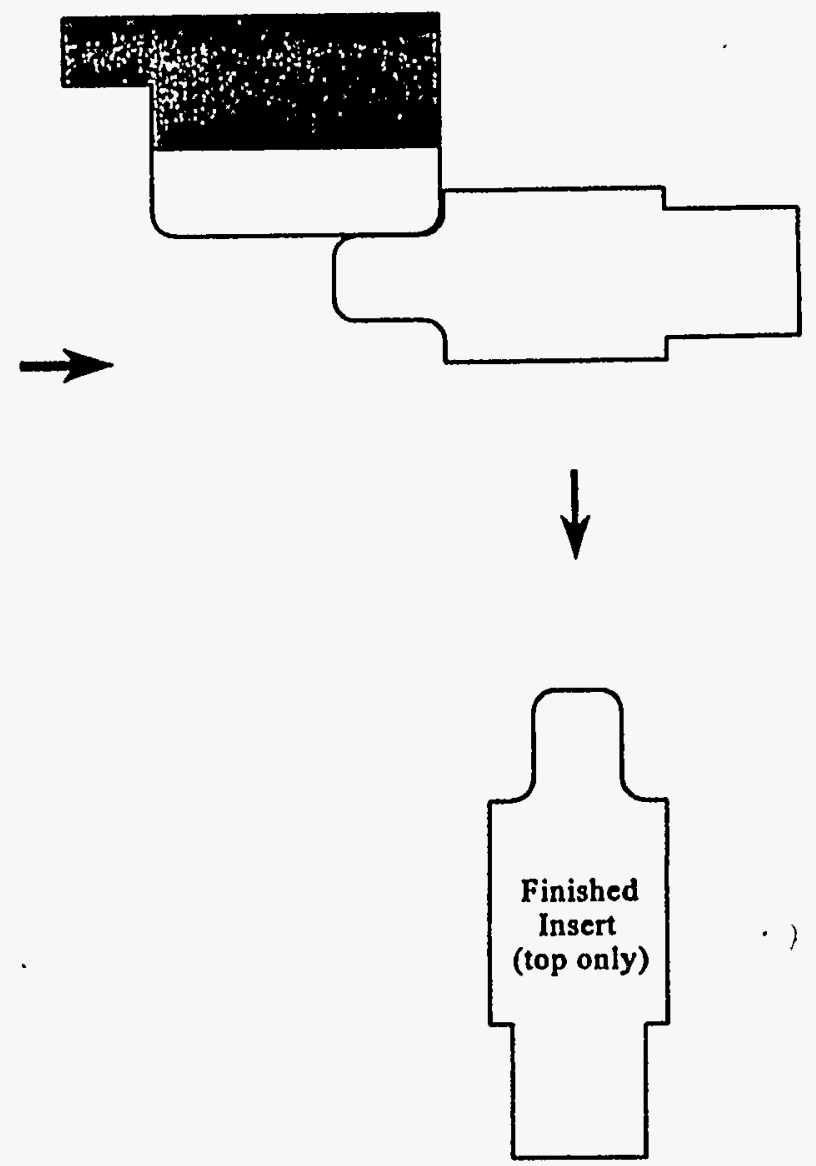

Figure 6 Diamond grinding sequence for tool inserts in plant trial. 
Laser Scatter Methods for Detecting Subsurface Machining Damage in Ceramics - Jiangang Sun, William A. Ellingson, George A. Forster (Argonne National Laboratory), Michael H. Haselkorn, and Charles J. Anderson (Caterpillar Inc.)

\section{Objective/scope}

The primary objective of this program is to develop a laser scattering procedure that would provide a direct (near-real-time) indication of changes in the subsurface (and surface) during machining. These changes include machining-induced damage (such as median crack formation) and surface roughness. A second objective is to evaluate dye penetrant technology as an off-line indicator of surface-breaking cracks. The laser program is being executed in three steps. The first is evaluating optimization of the laser scattering procedure to examine specimens machined by innovative techniques. The second step will involve correlation of the laser scattering results with mechanical properties in "real" machined ceramic specimens. The final step will be to develop a prototype instrument to be evaluated for on-line implementation in a production environment. The investigation into dye penetrants for surface-defect detection is being conducted in three steps: review of literature, off-site visits to appropriate current users (e.g., Norton) and vendors (e.g., Sherwin, Inc.), and laboratory experiments.

\section{Technical progress}

\section{A1. Elastic Optical Scattering results}

In this reporting period, nine samples were received from Dr. Nanu Menon at Allied Signals, Inc. for subsurface defect detection. The gray specimen were $25.4 \mathrm{~mm} \times 2.4 \mathrm{~mm}$ with a thickness of $1.6 \mathrm{~mm}$. The laser scans were conducted on select machined sections corresponding to the regions for the profilometry studies provided by Allied Signal, Inc. Figures 1 and 2 show the ratio and sum and images respectively of the Allied Signals specimens with details about median cracks (ratio images) and the lateral cracks (sum images). The resolution of all the images was $20 \mu \mathrm{m}$ and the specimen image size was consistently $16 \mathrm{~mm} \times 1 \mathrm{~mm}$. The images suggest the presence of smudges or ink-marks which were not visible on the surface but may have penetrated the surface to become sub-surface anomalies. Median and lateral cracks are visible in most of the specimens with streaks being more or less pronounced in one direction. 


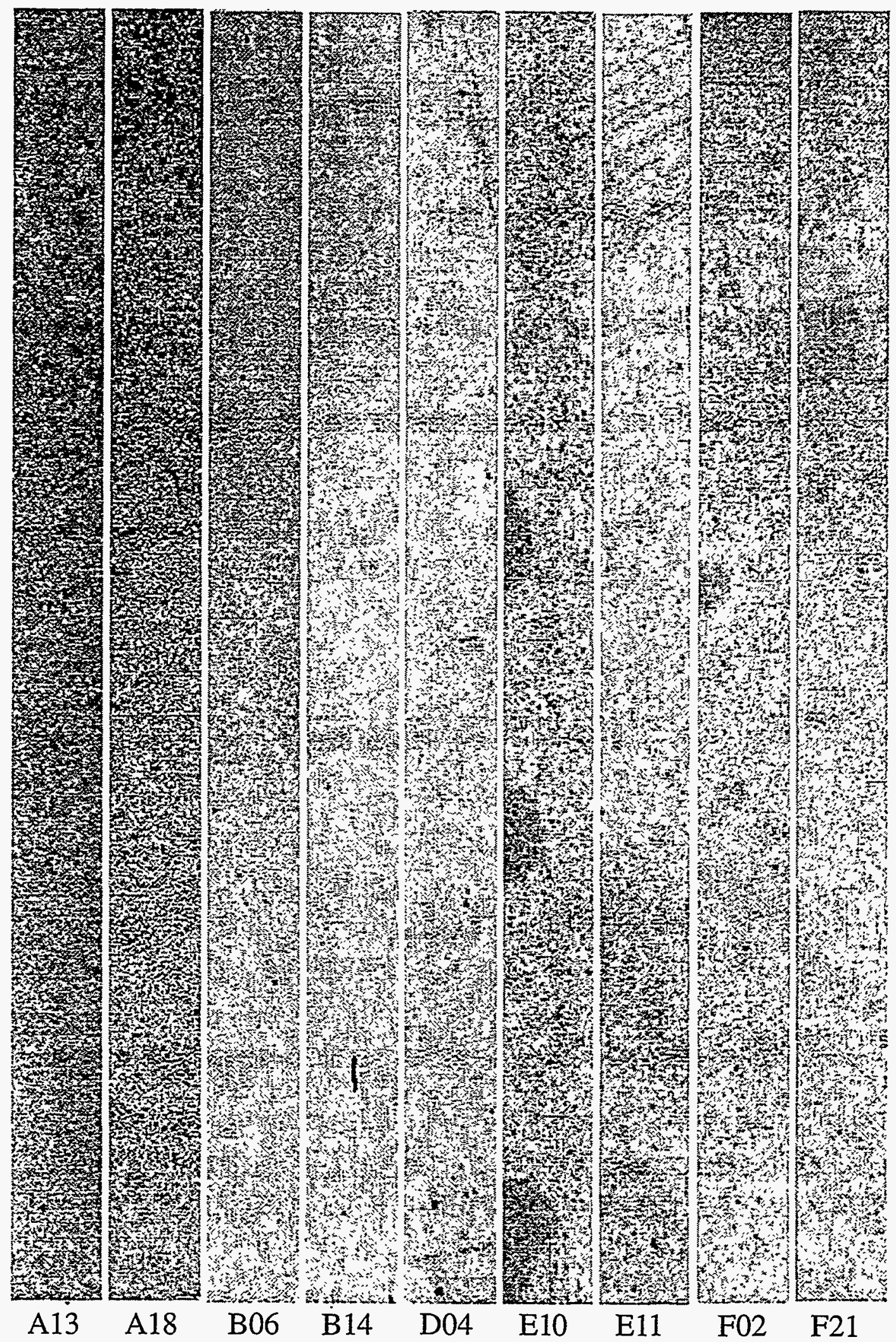

Figure 1: Ratio images (sensitive to median cracks) of the nine Allied Signals specimen. All images are $16 \mathrm{~mm} \times 1 \mathrm{~mm}$ and were acquired at $20 \mu \mathrm{m}$ resolution. 


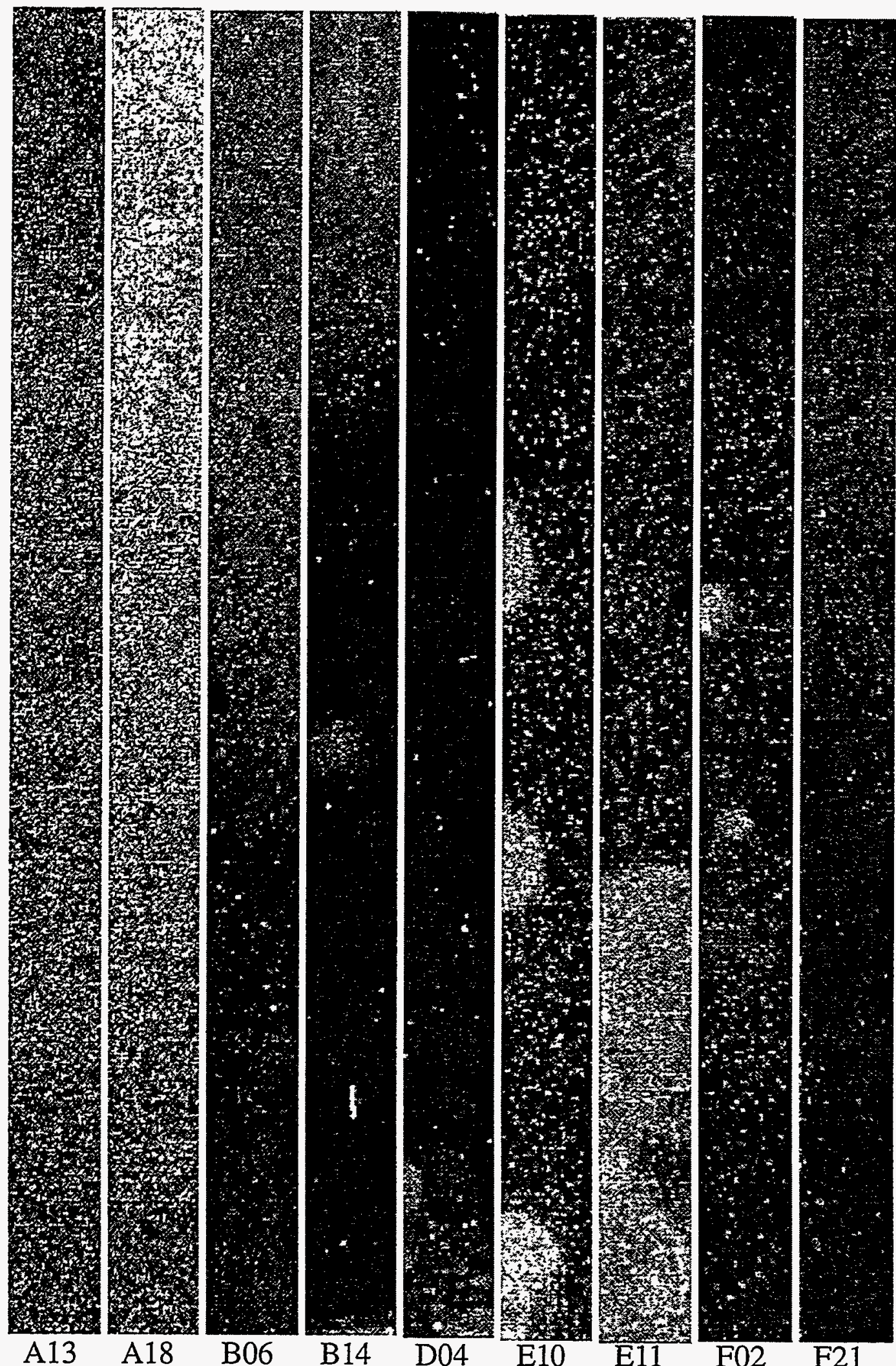

Figure 2: Sum images (sensitive to lateral cracks) of the nine Allied Signals specimen. All images are $16 \mathrm{~mm} \times 1 \mathrm{~mm}$ and were acquired at $20 \mu \mathrm{m}$ resolution. 
The elastic optical scattering data obtained from the four rotary ultrasonic machined specimens from Caterpillar Inc. were analyzed. Figure 3 shows the ratio images (sensitive to median cracks) and Fig. 4 shows the sum images (sensitive to lateral cracks). The resolution of all images was $15 \mu \mathrm{m}$ and the specimen image size was consistently $3 \mathrm{~mm} \times 3 \mathrm{~mm}$. The sum images suggest the presence of two basic regions: (1) white spots (high scatter intensity) and (2) the background.

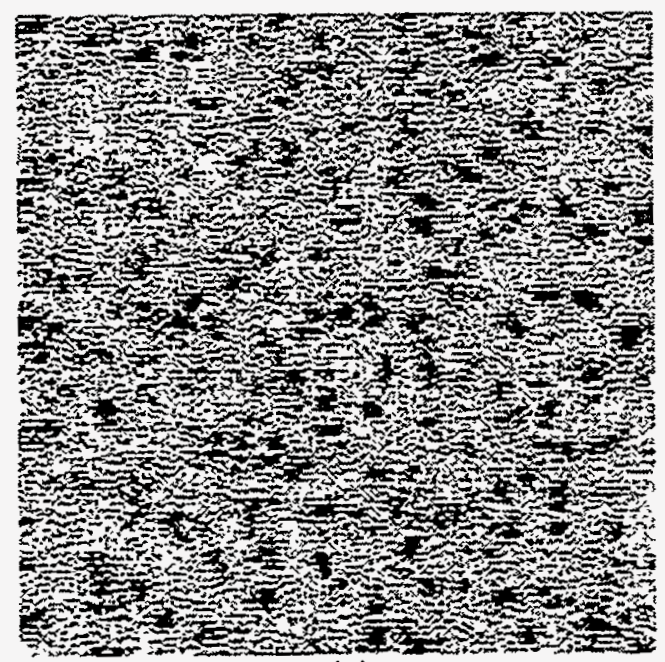

(a)

HP38AAA1

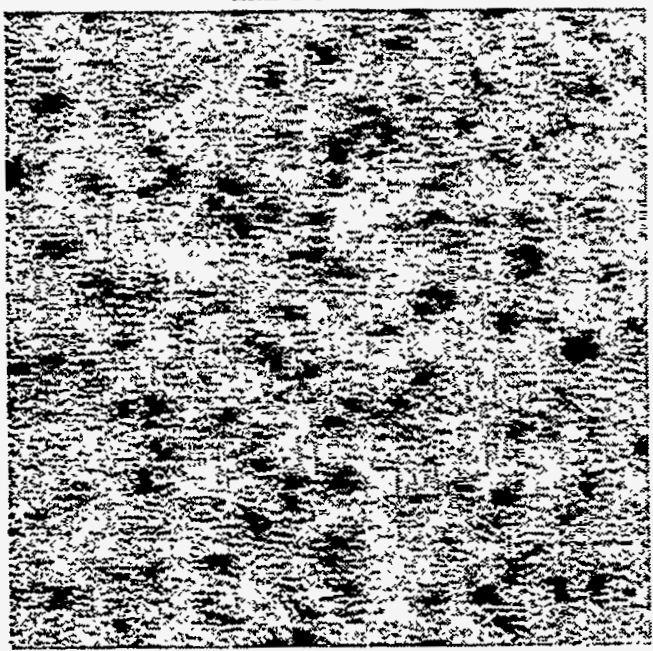

(c)

HP38BAB1

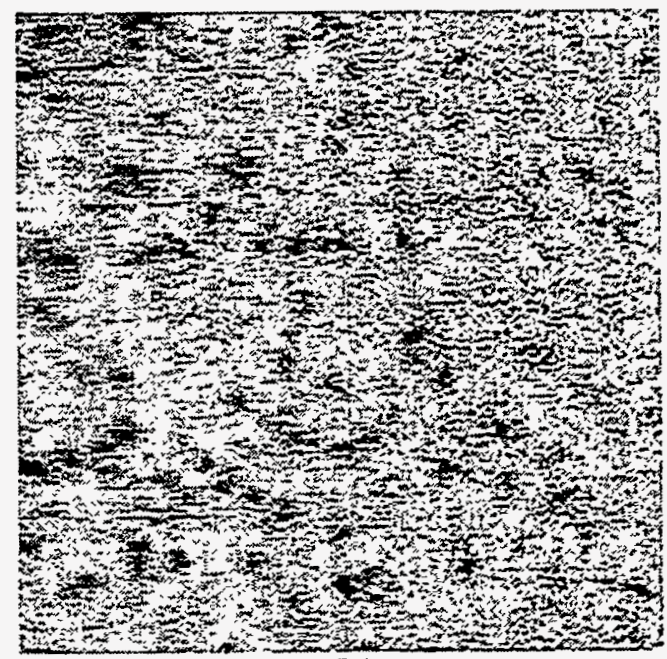

(b)

HP38BAA1

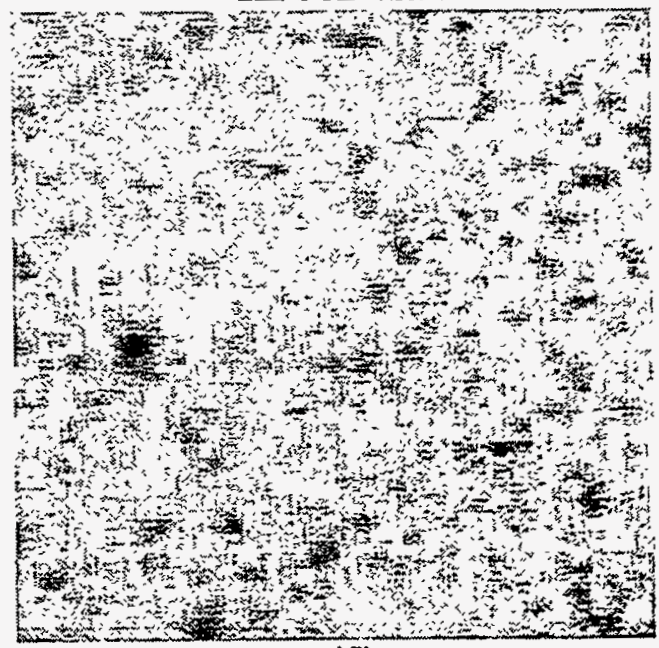

(d)

\section{HP38BBB2}

Figure 3: Ratio images of Caterpillar specimen: (a) HP38AAA1, (b) HP38BAA1, (c) HP38BAB1 and (d) HP38BBB2. $3 \mathrm{~mm} \times 3 \mathrm{~mm}$ scans at $15 \mu \mathrm{m}$ resolution. 


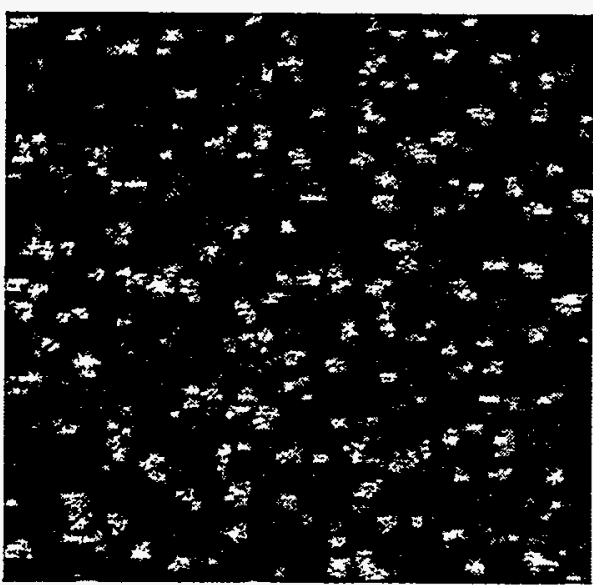

(a)

HP38AAA1

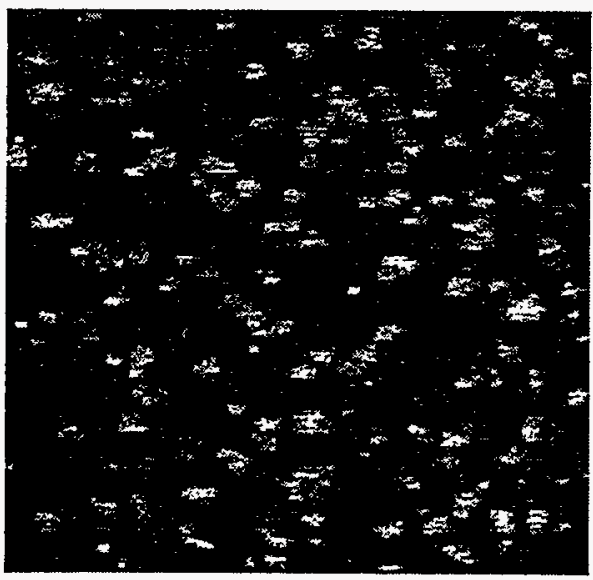

(c)

HP38BAB1

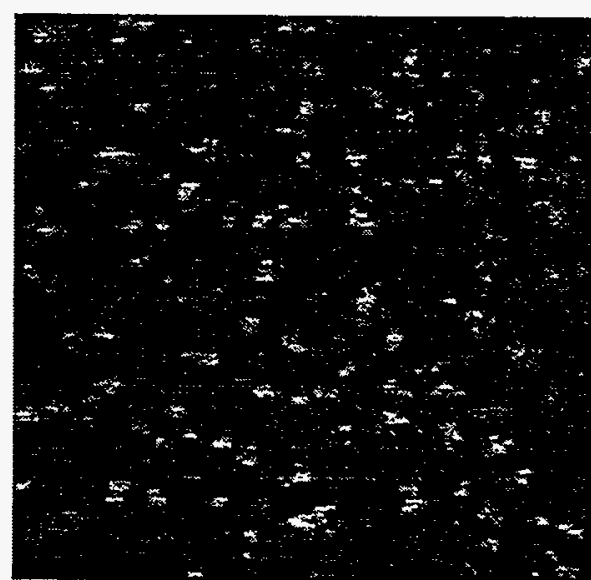

(b)

HP38BAA1

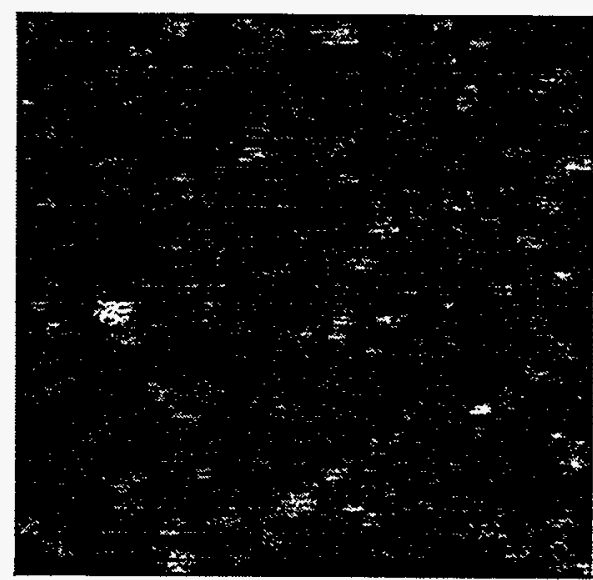

(d)

Figure 4: Sum images of Caterpillar specimen: (a) HP38AAA1, (b) HP38BAA1, (c) HP38BAB1 and (d) HP38BBB2. $3 \mathrm{~mm} \times 3 \mathrm{~mm}$ scans at $15 \mu \mathrm{m}$ resolution.

As shown in Fig. 5, an optical photomicrograph of a surface of one of the specimens (HP38BAB1) shows "white" regions corresponding to the "white" spots in the "sum" images and "dark" spots in the "ratio" images. It was suggested earlier that the spots were generated during machining of the specimen. The background of the ratio images may further be differentiated as having a smooth texture and bearing higher intensity inherent spots ("freckles"). In Fig. 3(a) (HP38AAA1), the amount of "freckled" background is observed to a larger extent when compared to Fig. 3(b) (HP38BAA1). The "freckle" intensity is the maximum in Fig. 3(a) diminishing in order from HP38AAA1, HP38BAA1, HP38BAB1 and HP38BBB2 or from Fig. 3(a) through Fig. 3(d). The amount of "freckles" correspond directly to more scattered intensity and consequently more damage. From the images, it can be tentatively concluded that Fig. 3(d) indicates the least amount of damage whereas Fig. 3(a) has the most amount of damage. 


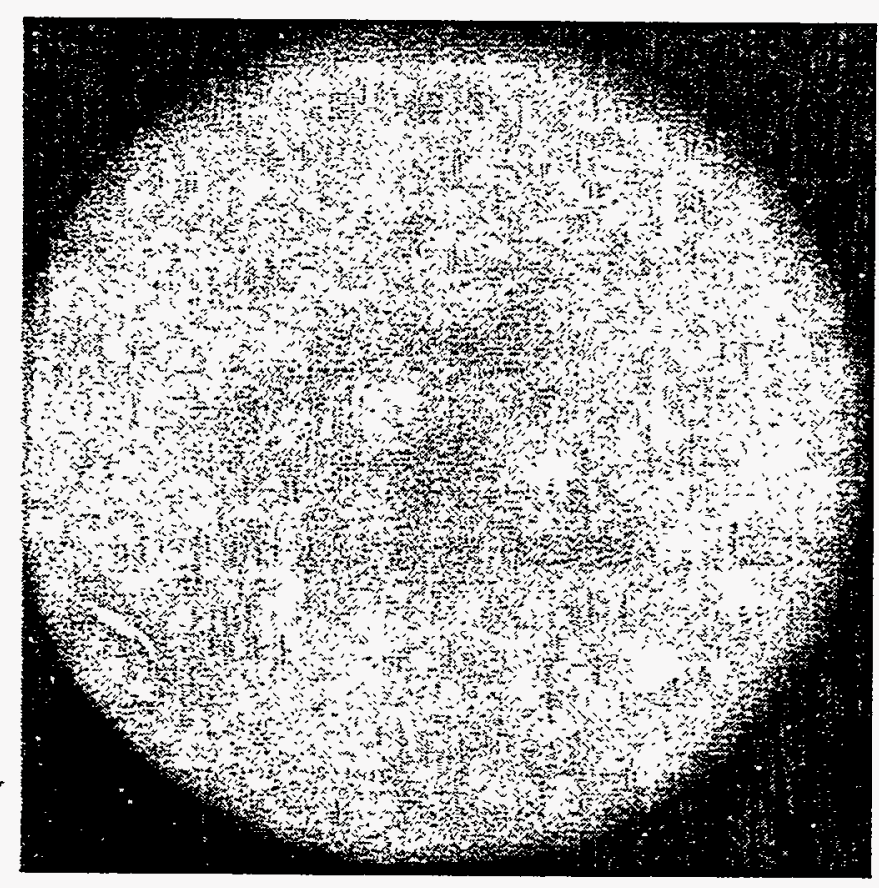

Figure 5: Photomicrograph of the Caterpillar specimen HP38BAB1 at 20x indicating the presence of machining induced spots.

Table I: Details of machining conditions used for the four hot-pressed $\mathrm{Si}_{3} \mathrm{~N}_{4}$ specimens evaluated by optical scatter.

\begin{tabular}{|c|c|c|c|c|c|c|c|}
\hline Sample & Run & Order & MRR & Max Force (N) & Feed & Grit Size & Amplitude \\
\hline HP38AAA1 & 13 & Tool \#7 & 108 & 168 & 100 & $60 / 80$ & 33 \\
\hline HP38BAA1 & 3 & Tool \#5 & 108 & 236 & 100 & $170 / 200$ & 33 \\
\hline HP38BAB1 & 2 & Tool \#2 & 54 & 101 & 50 & $170 / 200$ & 33 \\
\hline HP38BBB2 & 5 & Tool \#5 & 54 & 132 & 50 & $170 / 200$ & 23 \\
\hline
\end{tabular}

$* \mathrm{MRR}=$ Material Removal Rate $\left(\times 10^{-3} \mathrm{~mm}^{3} / \mathrm{s}\right)$

The image data have been correlated according to the machining conditions of the specimen given in Table I. Machining conditions are indeed correlated to the scatter data with respect to the material removal rate (MRR) of the specimen. Samples HP38AAA1 and HP38BAA1 (Figs. 3(a) and (b)) had MRR's of $108 \times 10^{-3} \mathrm{~mm}^{3} / \mathrm{s}$ and samples HP38BAB1 and HP38BBB2 (Figs. 3(c) and (d)) had MRR's of $54 \times 10^{-3} \mathrm{~mm}^{3} / \mathrm{s}$. A higher MRR seems to generate less prominent dark spots (region (1) of the image) whereas a lower MRR generated more prominent dark spots. The background (region (2) of the image) variation is however, different. 
Knowing that the amount of "freckles" correspond directly to more scattered intensity and consequently more damage, a lower MRR has actually decreased the amount of "freckles" in the background whereas a higher MRR has increased the number of "freckles". From the images, Figs. 3(c) and (d) or specimens HP38BAB1 and HP38BBB2 have lower number of "freckles" when compared to Figs. 3(a) and (b) or specimens HP38AAA1 and HP38BAA1. Therefore, Fig. 3(d) (HP38BBB2) indicates the least amount of damage and Fig. 3(a) (HP38AAA1) indicates the most amount of machining damage. For the same MRR, increasing the maximum force consistently increases the number of "freckles" in the matrix.' This fact is visible in Figs. 3(a) and (b) (specimens HP38AAA1 and HP38BAA1) and in Figs. 3(c) and (d) (specimens HP38BAB1 and HP38BBB2).

The acquired elastic optical image data were analyzed further using histogram analysis. Figures 6 and 7 show the histograms of each of the images shown correspondingly in Figs. 3 and

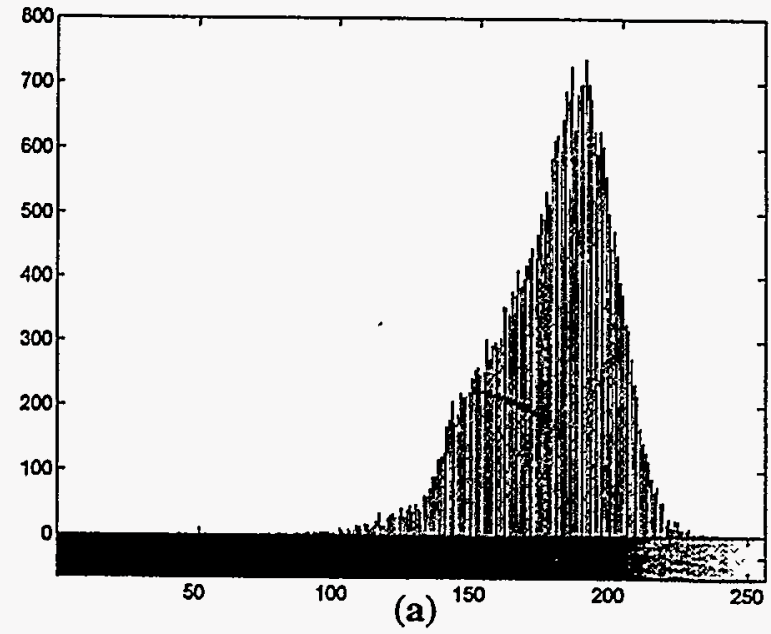

HP38AAA1

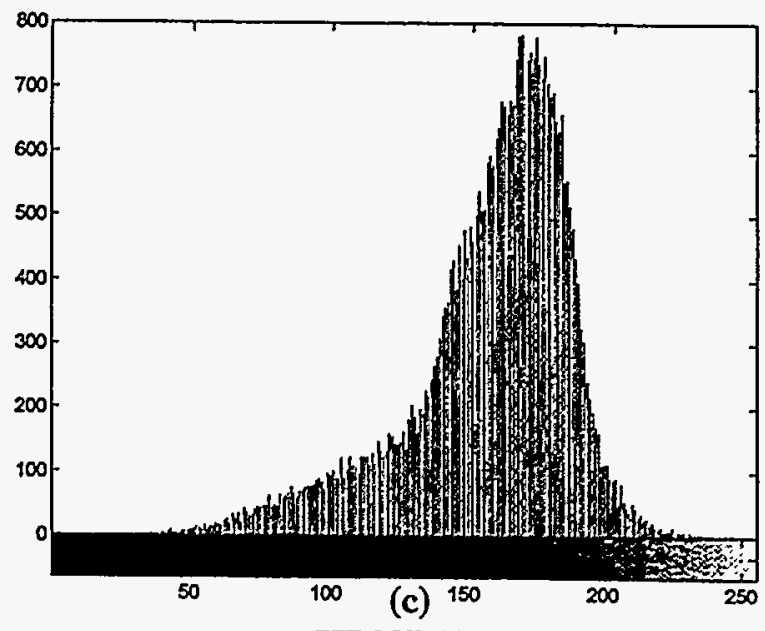

HP38BAB1

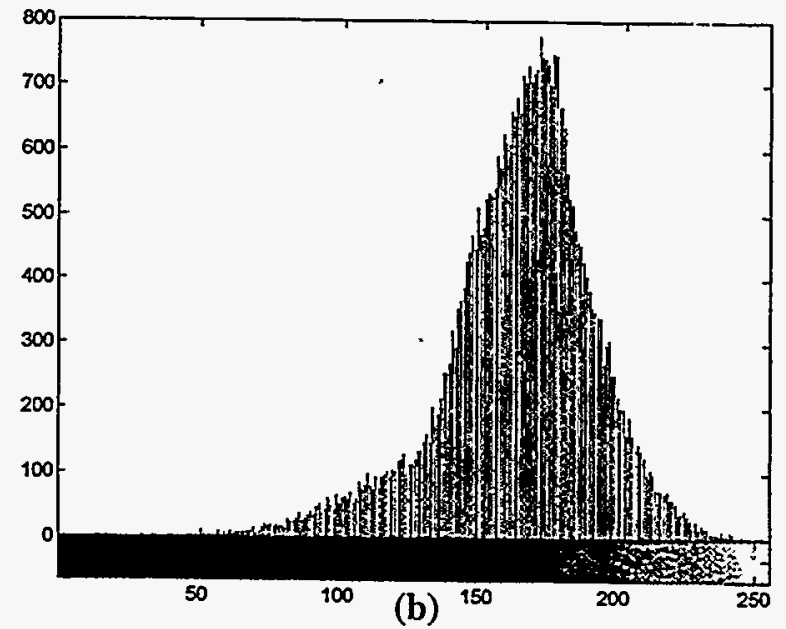

HP38BAA1

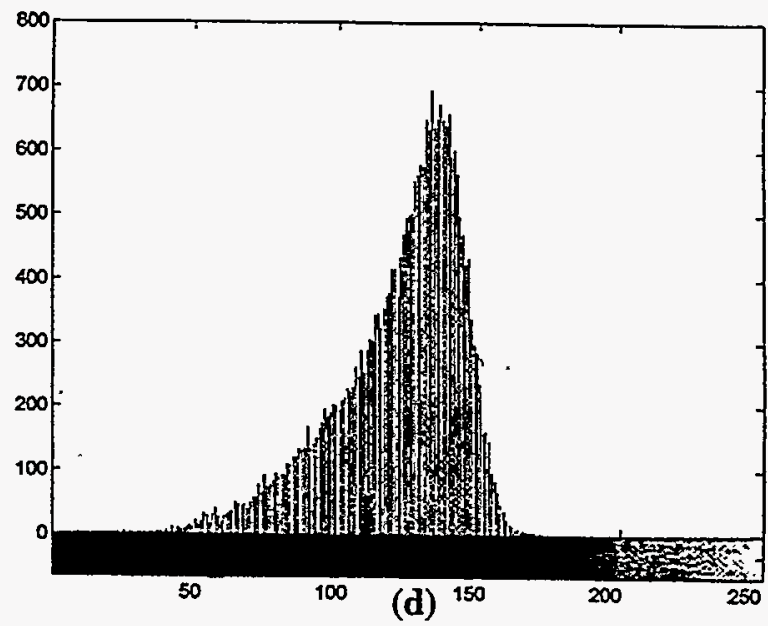

HP38BBB2

Figure 6: Histograms of images corresponding to the ratio images in Fig. 3: (a) HP38AAA1, (b) HP38BAA1, (c) HP38BAB1 and (d) HP38BBB2. 

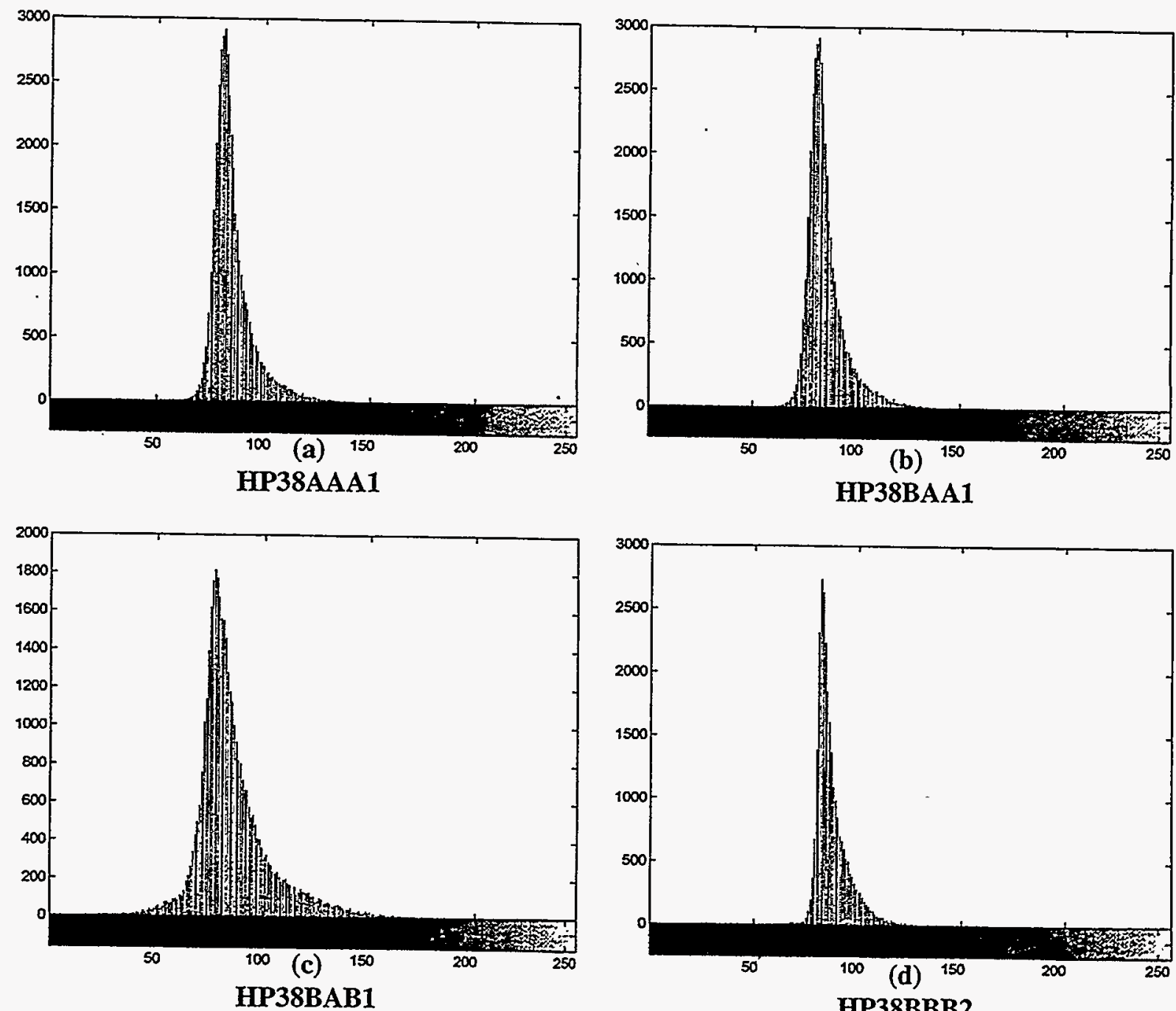

HP38BBB2

Figure 7: Histograms of images corresponding to the sum images in Fig. 4: (a) HP38AAA1, (b) HP3,8BAA1, (c) HP38BAB1 and (d) HP38BBB2.

Table II: Full width at half maximum $(\lambda)$ and the peak intensities (I) of the histograms shown in Figs. 6 and 7 corresponding to images in Figs. 3 and 4.

\begin{tabular}{|c|c|c|c|c|}
\hline Sample & $I$ (Ratio) & $\lambda$ (Ratio) & $I$ (Sum) & $\lambda$ (Sum) \\
\hline HP38AAA1 & 738 & 39.1 & 2898 & 10.9 \\
\hline HP38BAA1 & 778 & 45.6 & 2909 & 9.6 \\
\hline HP38BAB1 & -776 & 47.8 & 1811 & 15.2 \\
\hline HP38BBB2 & 700 & 32.6 & 2735 & 6.1 \\
\hline
\end{tabular}


4. Table II shows the full width at half maximum $(\lambda)$ and the peak intensities (I) of the histograms shown in Figs. 6 and 7 corresponding to images in Figs. 3 and 4. The histograms for the "sum" images (lateral cracks) show good correlation with the machining conditions. As seen in Fig. 7 and Table II, the peak intensity of the sum images correlate with the MRR of the specimens. A higher MRR $\left(108 \times 10^{-3} \mathrm{~mm}^{3} / \mathrm{s}\right)$ provided a larger overall intensity of the sum images and a lower $\operatorname{MRR}\left(54 \times 10^{-3} \mathrm{~mm}^{3} / \mathrm{s}\right)$ gave a smaller intensity of the sum image. When compared to increasing the maximum force for the same MRR, there is a corresponding increase in the peak intensity and a corresponding decrease in the full width at half maximum.

These conclusions, however, are tentative and only a part of the overall correlation between the scattered intensity and machining damage. Additional specimens need to be analyzed before statistically valid statements can be established correlating the scattered intensity of the "sum" and "ratio" images with machining induced damage.

New GS44 specimens were also obtained from Caterpillar Inc. in this period. These include 16 diamond-ground flat specimens and 1 tensile rod. The flat specimens and their machining conditions are listed in Table III. Some of the specimens were machined at the same condition for machining reproducibility assessment. These specimens are part of the original specimen test matrix.

Table III List of the 16 diamond-ground GS44 specimens and their machining conditions

\begin{tabular}{|l|l|l|l|l|l|l|}
\hline Specimen ID & $\begin{array}{l}\text { diamond con- } \\
\text { centration (\%) }\end{array}$ & bond & $\begin{array}{l}\text { diamond } \\
\text { type }\end{array}$ & $\begin{array}{l}\text { depth of } \\
\text { cut (inch) }\end{array}$ & $\begin{array}{l}\text { feed rate } \\
\text { (inch/sec) }\end{array}$ & $\begin{array}{l}\text { run } \\
\text { No. }\end{array}$ \\
\hline S125AAA1 & 125 & soft & friable & 0.001 & 40 & 1 \\
\hline S125AAA2 & 125 & soft & friable & 0.001 & 40 & 2 \\
\hline S125AAA3 & 125 & soft & friable & 0.001 & 40 & 3 \\
\hline S125AAB2 & 125 & soft & friable & 0.002 & 20 & 2 \\
\hline S125AAB3 & 125 & soft & friable & 0.002 & 20 & 3 \\
\hline S50ABA2 & 50 & soft & non friable & 0.001 & 40 & 2 \\
\hline S50ABA3 & 50 & soft & non friable & 0.001 & 40 & 3 \\
\hline S125BAA1 & 125 & hard & friable & 0.001 & 40 & 1 \\
\hline S125BAA2 & 125 & hard & friable & 0.001 & 40 & 2 \\
\hline S125BAA3 & 125 & hard & friable & 0.001 & 40 & 3 \\
\hline S50BAA2 & 50 & hard & friable & 0.001 & 40 & 2 \\
\hline S50ABB1 & 50 & soft & non friable & 0.002 & 20 & 1 \\
\hline S50ABB2 & 50 & soft & non friable & 0.002 & 20 & 2 \\
\hline S125BAB1 & 125 & hard & friable & 0.002 & 20 & 1 \\
\hline S125BAB2 & 125 & hard & friable & 0.002 & 20 & 2 \\
\hline S50BAB3 & 50 & hard & friable & 0.002 & 20 & 3 \\
\hline
\end{tabular}




\section{A2. Automation for on-line inspection}

Development continued this period for implementation of the elastic optical scattering technique to on-line inspection of machining induced damage. During the machining of a cylindrical specimen, e.g., a tensile rod, the specimen is continuously rotated and often translated in the axial direction (depending upon the grinding machine type), while the grinding wheel on the grinding machine is operated at a fixed location (may translate depending upon machine). The entire machined surface of the specimen will be inspected by the elastic optical scattering technique. The laser light is directed on the specimen surface at a fixed position just behind the grinding wheel where newly machined surface can be examined. As the cylindrical specimen is rotated and axially translated, its surface is continuously scanned by the elastic optical scattering system to obtain 2-D images. In order to correctly construct the images, it is important to know precisely the rotational speed of the specimen. However, during on-line machining process this speed can only be approximately obtained. Therefore, adjustment or correction of the images is required which is described below.

The machining set-up has been reproduced in the laboratory using a lathe rotated by a variable speed $D C$ motor and axially moved by a translation stage as illustrated in Fig. 8 . The operating speed of the motor should be constant but need not be known precisely, a condition similar to that on a grinding machine. At present, because the speed of the data acquisition system is slow, the motor is operated at its lowest rotational speed which is not very stable.

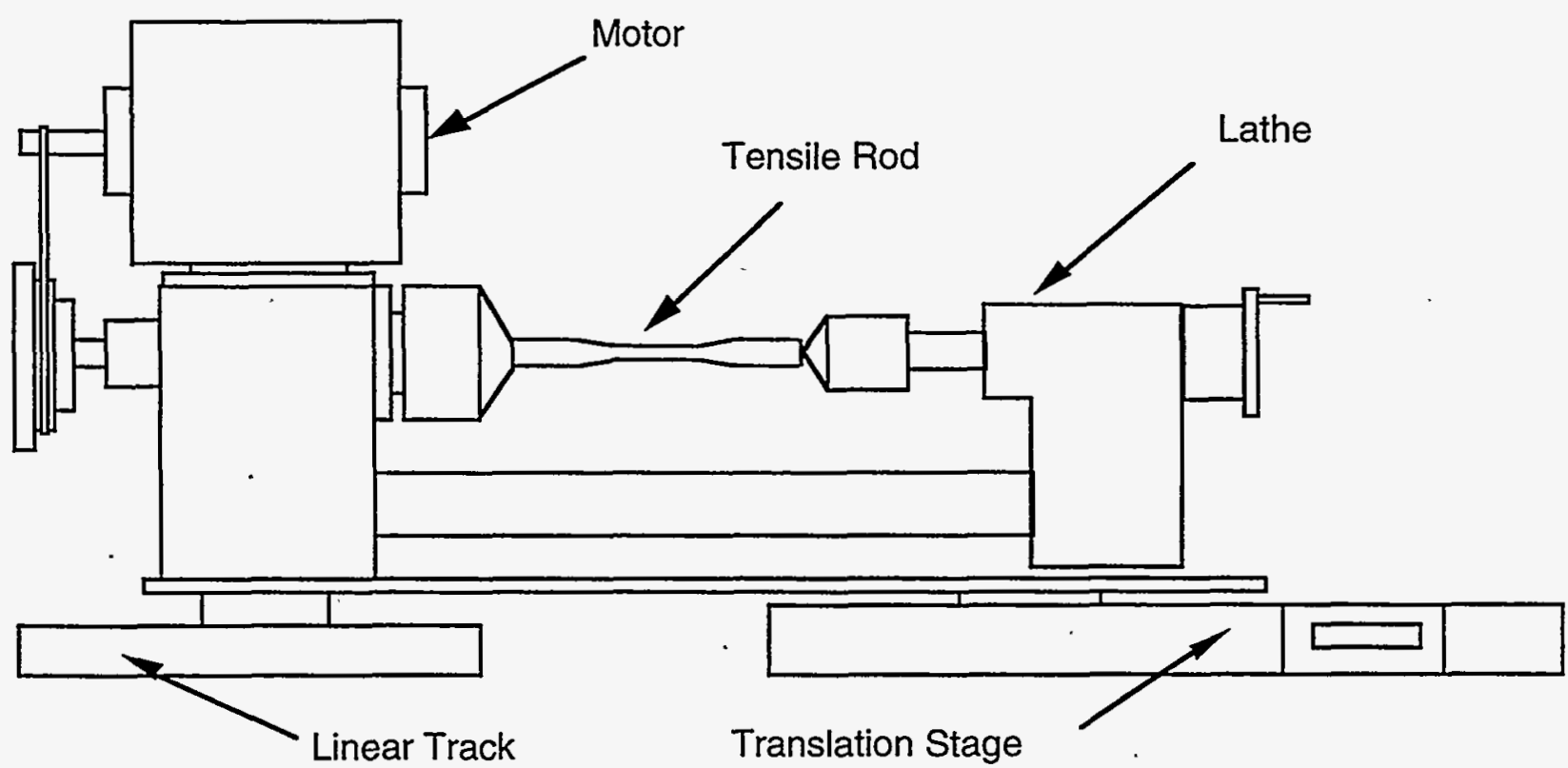

Figure 8: Schematic illustration of the rotational-translational lathe for elastic optical scattering scanning of a tensile rod

October 1995 - March 1996 


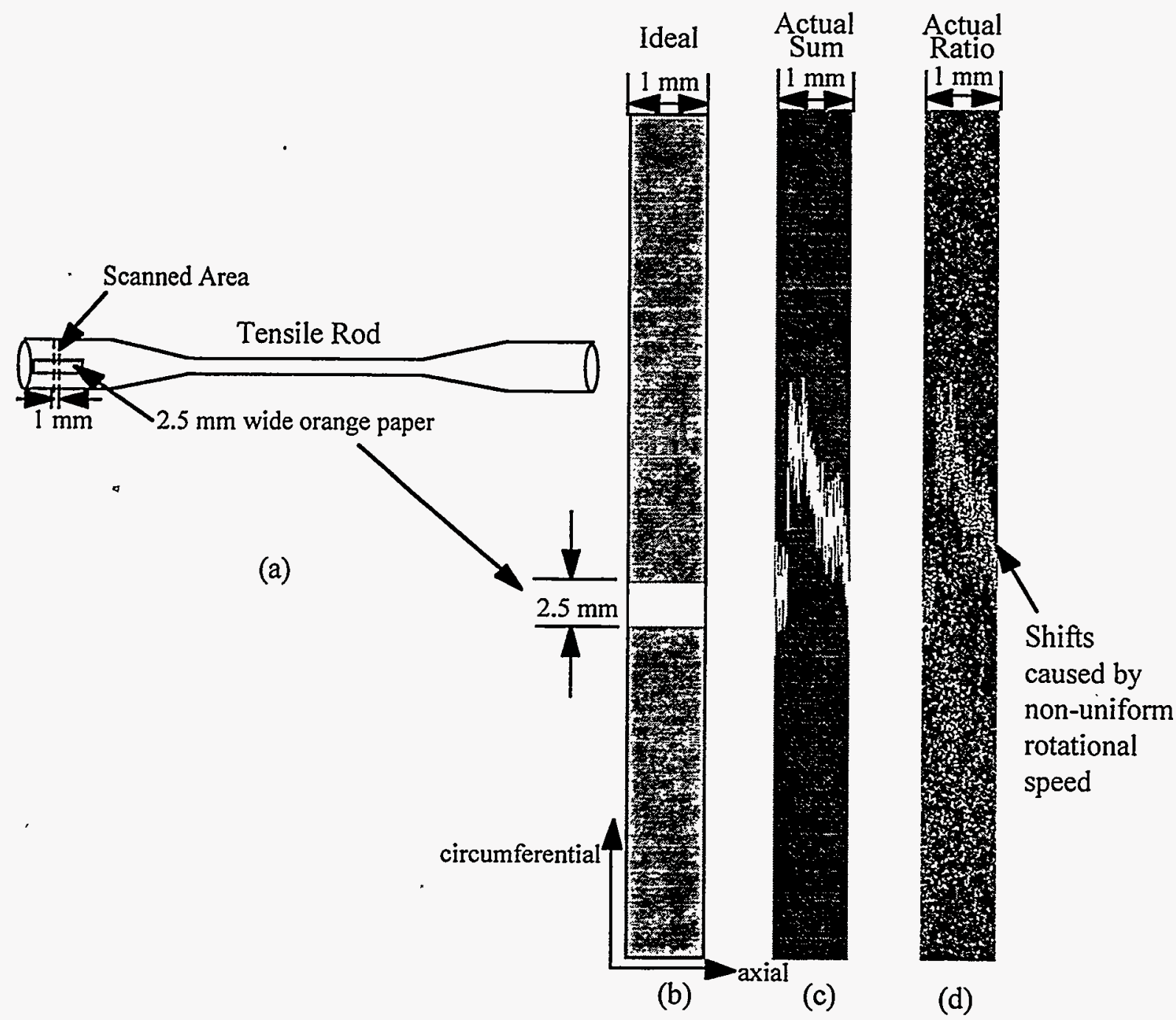

Figure 9: First dynamic elastic optical scatter data from rotating $\mathrm{Si}_{3} \mathrm{~N}_{4}$ specimen (a) a tensile rod indicating the scanned area, (b) expected ideal image, (c) dynamic elastic optical scattering sum image showing detection of surface marker, (d) dynamic elastic optical ratio image showing detection of surface marker (Note: skewed marker scatter caused by non-uniform rotation speed)

Figure 9 shows initial dynamic ratio and sum images of our first elastic optical scattering result from a tensile rod. The scanned area was near the end of the rod, with an axial width of about $1 \mathrm{~mm}$ and the entire circumference, as indicated in Fig. 9a. A $2.5 \mathrm{~mm}$ wide paper was attached on the surface to enhance the images. If the rod rotational speed and the data acquisition speed are synchronized, a band of increased scattering intensity in the axial direction should be shown in the images, as illustrated as the expected ideal image in Fig. 9b, whereas if the speeds are not synchronized an inclined band should be observed. In Figs. 9c-d, the elastic optical scattering 
sum and ratio images, a dominant inclined band is shown, indicating the non-synchronization of data measurement. The fluctuations and, at one instance, an jump of the band is clearly due to the nonuniform speed of the DC motor.

As indicated above, it is necessary to know the exact rotational speed of the specimen during a machining process, so that the data äcquisition speed can be appropriately adjusted. Although a highly accurate speed measurement device should be considered to be coupled with the current system in the future, a simple method to circumvent this problem is to dynamically adjust the data acquisition speed or, equivalently, to adjust the number of pixels corresponding to the length of the circumference.

Figure 10 shows a photograph of a Brown \& Sharpe grinding machine at ANL where online inspection of machining damage is planned to be demonstrated.

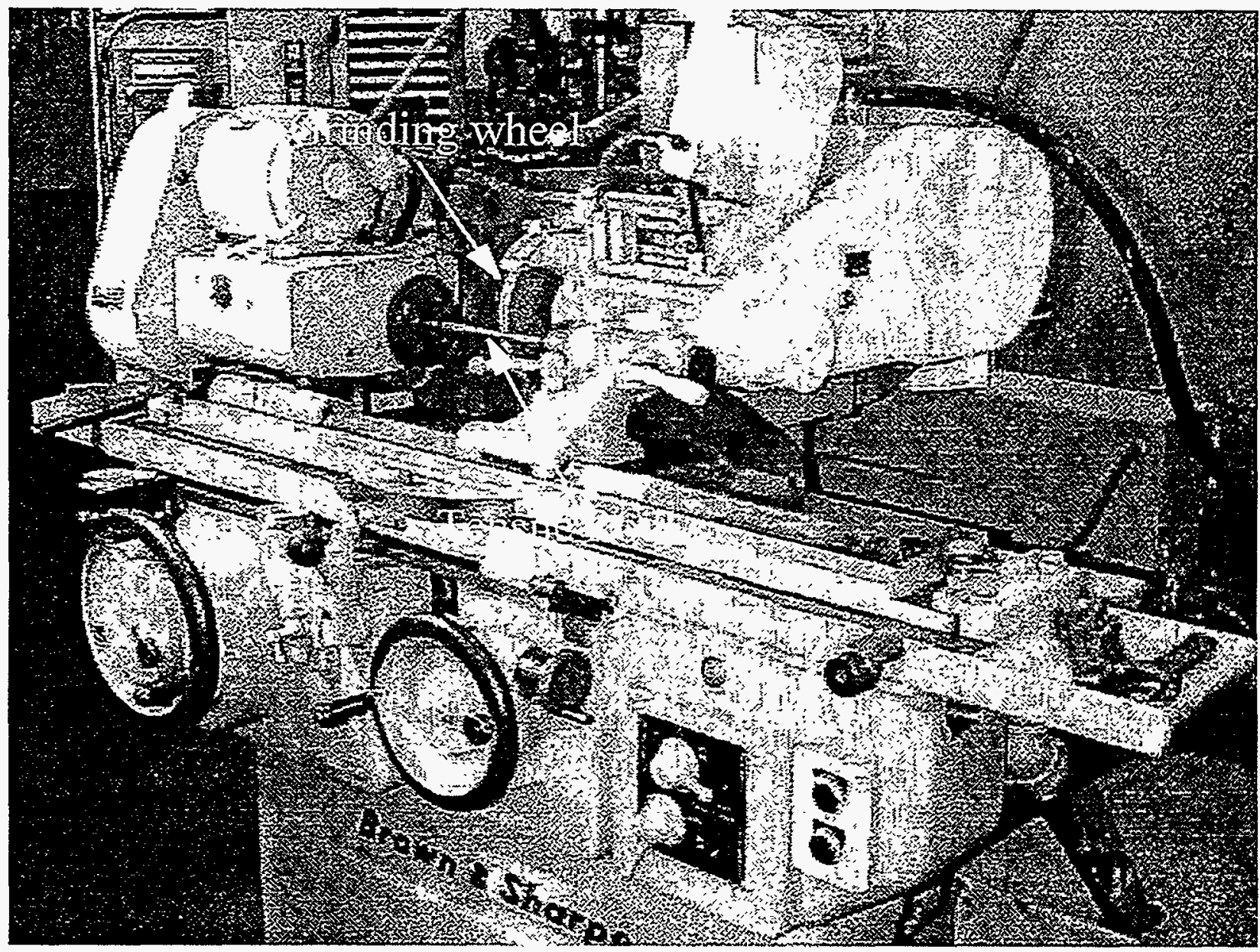

Figure 10: Photograph of a Brown \& Sharpe grinding machine at ANL showing ceramic tensile rod 


\section{B. Dye Penetrant}

B1. Facility Upgrade

The new Newport-Klinger Motion Control stage received for the dye penetrant laboratory allows automated data acquisition and automated pattern recognition work is in progress.

B2 Report

The final report on Phase I has been submitted.

B3. Technology Transfer

The development of the initial aspects of the dye penetrant work were successfully transferred.

\section{$\underline{\text { Status of Milestones }}$}

Milestone 150701 is complete. Milestone 150702 (Correlate Argonne National Laboratory (ANL) laser scatter results with Caterpillar (CAT) mechanical properties) has begun by receipt of specimens from Caterpillar, Inc. Communication continues with CAT on the delivery of additional specimens. All other ANL milestones are on or ahead of schedule.

\section{Communications/Visits/Travel}

W. A. Ellingson and J. G. Sun visited Caterpillar Technical Center on March 22, 1996 and obtained new specimens and presented and discussed results to date.

\section{Problems Encountered}

One translation stage of the X-Y-Z- $\theta$ translation/rotation was damaged and sent back to the manufacturer for repair. The stage is expected to be shipped back in the next reporting period.

\section{Publications}

None this period. 


\section{Milestone Schedule}

Milestone

Date

Status

Determine optical properties of SiAION and GS-44 for optimum optical detection parameters (polarization, wavelength, angle of incidence, etc.).

Feb. 28, 1994

Completed

Conduct exploratory studies of dye penetrant on machined surfaces.

May 31, 1994

Completed

Submit report on dye penetrants.

Dec. 1,1994

Completed

Correlate laser scatter analysis (ANL) of contoured specimens with mechanical properties, residual stress measurements, and mechanical surface roughness measurements (CAT).

Correlate laser scatter results (ANL) with mechanical properties (CAT): Flat Specimens

On schedule

Install and demonstrate prototype laser scatter device.

Aug. 31, 1996

On schedule

Modify the laser system with a tunable dye laser to increase applications

Mar. 30, 1997 Part of planned Phase II 
Cost Modeling Analysis of Fabrication Approaches for Silicon Nitride Components - Barry S. Draskovich (AlliedSignal, Inc.) and Julie M. Schoenung (California State Polytechnic University at Pomona)

\section{Objective/Scope:}

A number of diesel, automotive, and gas turbine engine manufacturers have become interested in implementing structural ceramic components into their products due to the weight, wear, and temperaturecapability benefits that ceramics exhibit over current metal parts. A variety of fabrication approaches can be employed for a given part. Information, based on the desired production volumes, costs, delivery schedules, and performance, on the most suitable combination of fabrication processes would be very useful to ceramic component manufacturers. Although simplistic cost analysis of potential production costs is done routinely, more sophisticated and comprehensive cost models are needed.

Al1iedSignal Ceramic Components (CC), in conjunction with the California State Polytechnic University at Pomona (Cal Poly Pomona). will refine and utilize a process cost model for the evaluation of various fabrication methods used to manufacture ceramic diesel engine and aerospace/industrial gas turbine engine components. This ceramic component cost model will be configured to evaluate the benefits and trade-offs of a variety of fabrication routes for three specific components that have been selected to represent a wide range of potential structural ceramic part features - a turbocharger wheel. a diesel engine cam roller follower, and an auxiliary power unit gas turbine stator. The focus of the cost model will be to determine the relative benefits and trade-offs of net-shape forming versus extensive machining of simple stock shapes for each component type. The model will analyze and determine the potential low-cost manufacturing method and identify aspects of the manufacturing process that are cost reductionlimiting. The model will also be used to predict component cost as a function of production volume and to indicate whether customer cost targets are realistic. AlliedSignal will prepare a final report containing an analysis of the process cost modeling effort. The program entails four major technical tasks:

Task 1 - Development of a Baseline Model Baseline process cost models will be developed to evaluate a number of fabrication approaches for the three diesel engine and aerospace/industrial turbomachinery application structural ceramic components. The model will include the following capabilities: 
- a variety of manufacturing processes and unit operations, including, but not limited to. powder blending, molding, green machining, sintering, hot pressing, hot isostatic pressing, coarse and fine grinding. and finishing

- flexibility to activate the unit operations of interest for a given analysis

- fixed cost elements including cost of capital, maintenance, auxiliary equipment. installation. building space, and tooling

- variable cost elements including materials. labor, and utilities

- process parameter inputs including cycle time, and grinding wheel composition, cost, and performance

- process yields (rejection rates) for each unit operation and for the entire process stream.

Task 2 - Evaluation of the Model

The model developed in Task 1 will be tested to establish its performance. Applicability of the model to ceramic component manufacturing shall be assessed based on historical information in all areas of ceramic component manufacture from production of powder compacts to machining and marketing/sales. Any areas which may require revision will be identified.

Task 3 - Revision of the Model

Based on input from the operational evaluation (Task 2), the model will be revised as necessary.

Task 4 - Final Evaluation Using Sample Components

The cost model will be exercised to evaluate the effects of using alternate processing routes on the cost of the three target components. Following the analysis of the results, a final report, suitable for public distribution. will be prepared.

\section{Technical Progress:}

Task 1, Development of a Baseline Mode1, is complete. The baseline model consists of eight case studies. The descriptions of the case studies are shown in Table 1. The input data to the technical cost model was supplied by industrial representatives (including AlliedSignal Ceramic Components) and from archived data base information at California State Polytechnic University at Pomona and IBIS Associates.

Data collection and analysis focused on the equipment used for forming, heat treating, and machining. The model structure was expanded to encompass the process flow for each of the production case studies. The model template represents the unit operations and cost elements that were defined during the first two months of the project. and the logic within the model was reviewed for accuracy, especially for the linkage between unit operations. 
Table 1: Summary of the Technical Cost Model Case Studies

\begin{tabular}{|c|c|c|c|c|c|}
\hline Component & $\begin{array}{c}\text { Target } \\
\text { Production } \\
\text { Volumes } \\
\end{array}$ & $\begin{array}{l}\text { Forming } \\
\text { Process } \\
\end{array}$ & $\begin{array}{l}\text { Formed } \\
\text { Shape }\end{array}$ & $\begin{array}{c}\text { Bisque } \\
\text { Machining }\end{array}$ & $\begin{array}{c}\text { Final } \\
\text { Machining }\end{array}$ \\
\hline \multirow[t]{4}{*}{ Turbine Stator } & \multirow[t]{4}{*}{$3.000 / y r$} & Slip Casting & Billet & Yes & Yes \\
\hline & & Gel Casting & Billet & Yes & Yes \\
\hline & & Gel Casting & $\begin{array}{l}\text { Near Net } \\
\text { Shape }\end{array}$ & No & Yes \\
\hline & & $\begin{array}{l}\text { Injection } \\
\text { Molding }\end{array}$ & $\begin{array}{l}\text { Near Net } \\
\text { Shape }\end{array}$ & No & Yes \\
\hline \multirow[t]{2}{*}{$\begin{array}{c}\text { Turbocharger } \\
\text { Wheel }\end{array}$} & \multirow[t]{2}{*}{$50.000 / \mathrm{yr}$} & Gel Casting & $\begin{array}{c}\text { Near Net } \\
\text { Shape }\end{array}$ & No & Yes \\
\hline & & $\begin{array}{l}\text { Injection } \\
\text { Molding }\end{array}$ & $\begin{array}{l}\text { Near Net } \\
\text { Shape }\end{array}$ & No & Yes \\
\hline \multirow[t]{2}{*}{ Cam Roller } & \multirow[t]{2}{*}{$500.000 / y r$} & $\begin{array}{c}\text { Injection } \\
\text { Molding }\end{array}$ & $\begin{array}{l}\text { Near Net } \\
\text { Shape }\end{array}$ & No & Yes \\
\hline & & Dry Pressing & $\begin{array}{l}\text { Near Net } \\
\text { Shape }\end{array}$ & No & Yes \\
\hline
\end{tabular}

Task 2, Evaluation of the Model, is also complete. Representatives from Cal Poly Pomona gave a formal presentation to the CC manufacturing and management team. The review provided preliminary output from the model case studies and provided a starting point for critical model reviews. Various sensitivity analyses were conducted on the 8 case studies to determine the effect of operational reject rates, component selection, forming process selection, and material composition on the cost distribution. Although these sensitivity studies were based on preliminary, and sometimes incomplete, data, analysis of the results identified the following trends:

- variation of reject rates from values now typical of the processes to rates typical of full-scale manufacturing resulted in cost reductions ranging from $74 \%$ to $89 \%$ ( $84 \%$ on average for all the case studies). It was noted that reject rates near the end of the manufacturing flow were more influential on cost than those at the front end of the process.

- as anticipated, lowest costs were achieved with the near-net-shape forming methods

- the main drivers associated with the cost elements were generally governed by direct labor costs, equipment costs, material costs, and cost of capital

- the main drivers associated with the process steps were generally inspection. machining, and heat treatment.

The input data provided for the generation of the baseline model was carefully reviewed for accuracy and new, or missing, data was supplied. The revised data was forwarded to Cal Poly Pomona to be used 
in Task 3 (Revision of the Model) efforts. Task 3 efforts are presently underway.

During the next next reporting period the mode 1 wi 11 be revised to include new and updated input parameters in addition to slight changes to the model architecture. Additional sensitivity studies will be conducted and the model will be exercised to evaluate its validity against actual manufacturing cost data. The final cost model will be configured and exercized with the latest process input data available and the final report will be prepared.

Status of Milestones:

Table 2 details the status of the scheduled milestones for this program.

Table 2: Status of Scheduled Program Mi lestones

\begin{tabular}{|c|l|l|}
\hline Milestone \# & Milestone Title: & Milestone Status: \\
\hline \hline 151201 & $\begin{array}{l}\text { Complete development of baseline } \\
\text { process cost model }\end{array}$ & Completed 14 Mar 96 \\
\hline 151202 & $\begin{array}{l}\text { Complete evaluation of baseline } \\
\text { process cost model }\end{array}$ & Completed 29 Mar 96 \\
\hline 151203 & $\begin{array}{l}\text { Complete revision of optimized } \\
\text { process cost model }\end{array}$ & $\begin{array}{l}\text { Scheduled for completion 1 May } \\
96\end{array}$ \\
\hline 151204 & $\begin{array}{l}\text { Complete evaluation of optimized } \\
\text { process cost model }\end{array}$ & No activity scheduled to date \\
\hline 151205 & Deliver final report & No activity scheduled to date \\
\hline
\end{tabular}

\section{Publications:}

No publications have been authored during this reporting period. 


\subsubsection{Advanced Manufacturing Technology}

W.B.S. 1.5 .2 .0

Advanced Manufacturing Technology for Ceramic Heavy Duty Diesel Turborotors

E. Kraft, Kyocera Industrial Ceramics Corp.

S. Roby, Schwitzer U.S., Inc.

J. McCornack, Caterpillar, Inc.

\section{Objective / Scope}

The objective of this program is to develop the cost effective manufacturing technology required for ceramic turbine rotors for use in turbochargers for heavy duty diesel truck and bus applications. A team, led by Kyocera (KICC, the ceramic component manufacturer) and including Schwitzer U.S., Inc. (the turbocharger manufacturer) and Caterpillar, Inc. (the diesel engine manufacturer) will develop and demonstrate production readiness for reliable, cost affordable turbochargers with ceramic turborotors. Program goals include a nominal order of magnitude reduction in cost over the present cost for small quantities, and process capability for critical component attributes which is adequate for the performance and reliability specifications of the application. Silicon nitride, SN 235, is the material of choice for this application. Program goals are to be achieved utilizing Kyocera's production proven Hybrid Molding, gas pressure sintering and cylindrical grinding processes. Yield, quality and cycle time improvements will be achieved through process modeling, statistical process control and intelligent processing.

\section{Technical Highlights}

\section{Task 1 Component Design and Specification}

Caterpillar has confirmed the application of the ceramic rotor turbocharger to the newest version of their 3176 highway truck engine. They have also supplied the turbo requirements such as air flow to Schwitzer. The design of a new rotor has been received from Schwitzer. Tip diameter has been increased to $91 \mathrm{~mm}$, with nearly the same blade thickness. Since forming trials have indicated a required blade thickness for complete blade fill which is considerably thicker, further analysis was performed. This analysis consisted of further forming trials with the old rotor mold, analytical modeling using the Technalysis model and comparison of blade aspect ratio with fillable geometries. The ability to fill the present mold was compared to successful production of automotive turborotors, and to the proposed new geometry. Successfully molded rotors have a blade thickness only slightly greater than the present rotor of this program. However, the tip diameter and blade length for the previous rotor are considerably less than the present rotor. Thus, the aspect ratio of blade length to thickness appears to be a critical factor. Previous production parts had an aspect ratio of 15.6, whereas the present rotor aspect ratio is 30.9 . In addition, the proposed new rotor design would have an even higher aspect ratio of 33.7. Clearly a thicker blade is required for successful fill and quality. A minimum value of blade thickness has been supplied to Schwitzer for their investigation. Schwitzer is planning a determination of aerodynamically acceptable thickness through flow testing of a series of metal rotors fabricated with several blade thickness'.

\section{Task 2 Component Manufacturing Technology Development}

Task 2.1 Cost Model

No further work during this reporting period.

Task 2.2 Environmental Safety and Health

All activities have been completed.

\section{Task 2.3 Process Control}

Task 2.3.1 Statistical Process Control:

An SPC deployment plan has been completed. It is now available and in use for each item in production. Both conventional and short run methods are utilized. It is utilized in pre-production situations where processes have been developed and are stabilized to the point where the state of control may be determined. 
Task 2.3.2 Raw Material Preparation:

In the production case cost model results, reported previously, the relative importance of raw material cost increased over the prototype case. The analysis of lower $\operatorname{cost} \mathrm{Si}_{3} \mathrm{~N}_{4}$ is continuing. Results of chemical analysis on material which had been attrition milled was received. Unfortunately, an elevated level of carbon showed that there was contamination by the polymer lining and arms of the mill. Additional samples of powder have been received from the vendor in both the partially and fully milled condition. The vendor's proposed specification and our analysis are as follows:

\begin{tabular}{|c|c|c|c|c|}
\hline & $\begin{array}{l}\text { Fully Milled } \\
\text { Specification }\end{array}$ & $\begin{array}{l}\text { Partially Milled } \\
\text { Specification }\end{array}$ & $\begin{array}{l}\text { Fully Milled } \\
\text { As Received }\end{array}$ & $\begin{array}{l}\text { Partially Milled } \\
\text { As Received }\end{array}$ \\
\hline Oxygen & 2.0 & 1.2 & 0.95 & 0.46 \\
\hline Carbon & 0.10 & 0.15 & 0.43 & 0.13 \\
\hline Aluminum & - & - & 300 & 300 \\
\hline Iron & 1500 & 100 & 200 & 200 \\
\hline Chlorine & - & - & & - \\
\hline Calcium & - & - & 200 & 200 \\
\hline Magnesium $\quad \mathrm{ppm}$ & - & - & ND & ND \\
\hline Alpha content $\%$ & $>90$ & $>90$ & 88.6 & 89.0 \\
\hline Surface area $\mathrm{m}^{2} / \mathrm{g}$ & $10-15$ & $>2$ & & \\
\hline Avg. Particle Size $\mu$ & 0.5 & $<5$ & 0.93 & 5.4 \\
\hline
\end{tabular}

The fully milled material is improved over the previous sample, but carbon is still elevated, particle size too large, and the oxygen content lower than desired. Further communication with the vendor is underway to resolve these issues. Forming and sintering trials will be held once acceptable powder is received.

Task 2.3.3 Slip Preparation:

The cost model also showed the benefit of improved sinterability. An improved sinterability body was therefor made into a hybrid molding slip using the standard procedure. Rotors were molded using this slip, but visual inspection of the surface indicated unacceptable granularity, indicating the need for a modified procedure. No additional trials of the improved sinterability body have been performed in order to focus on blade fill experiments.

Task 2.3.4 Forming:

Technalysis Subcontract: The model has been used to help determine the cause of some defects seen in parts molded under various conditions. As previously reported, the blade tips could only be filled with very high molding pressure, with the result that other molding defects were encountered. Different defects have been produced with very low molding pressure. One defect encountered with low viscosity slip and high molding pressure is a void near the rotor nose, seen in x-ray cross section to have a bow tie shape. This region was therefor analyzed with the results shown in Figure 1. While an actual void is not seen, strong recirculation is evident, which could contribute to void formation. High forming pressures have also been shown to lead to a weld line defect on the hub surface between blades. The model does indicate the possibility of converging slip flow fronts under these conditions, and the position of the weld line on the hub is consistent with the observed correlation with forming pressure. The previously discussed "fountain" defect on the back face at high forming pressure was again confirmed in this analysis.

Analysis of slip flow and solidification at very low pressures also gave results consistent with experimental observation of weld lines on blade surfaces. Figure 2 shows the solid fraction contours of a blade at approximately the same point in filling, but under two forming pressures. Figure 3 shows the cross section of a blade at low forming pressure and about the same filling amount. It is apparent that with low forming pressure, flow is slow enough that significant solidification occurs at the blade surface next to the slip front. Under such conditions, slip may flow between the solidified material and the mold, or the flow front may become unsteady. 


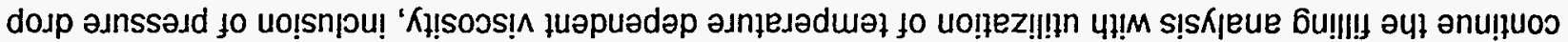

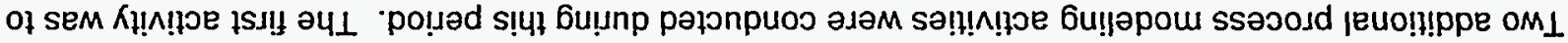

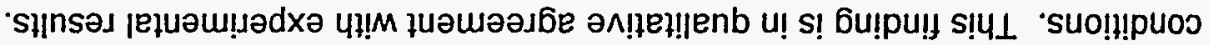

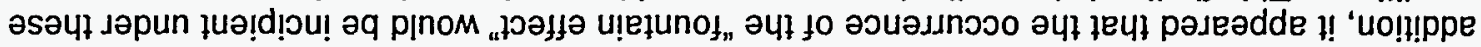

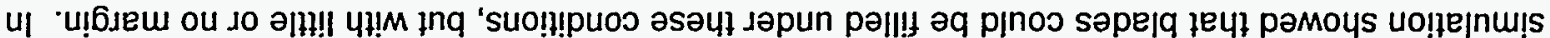

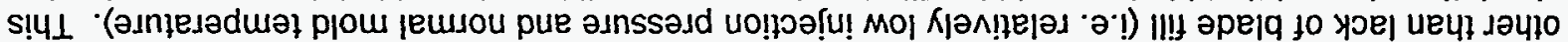

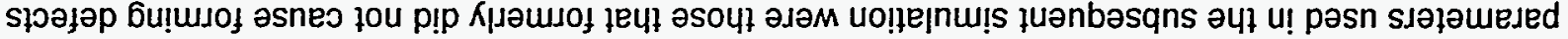

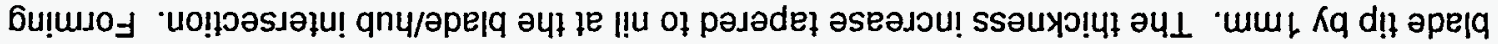

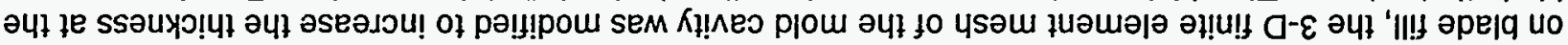

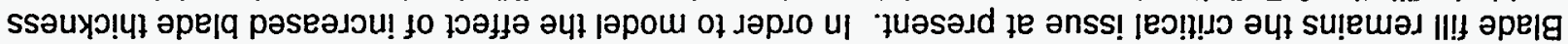

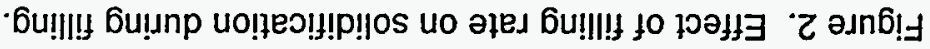

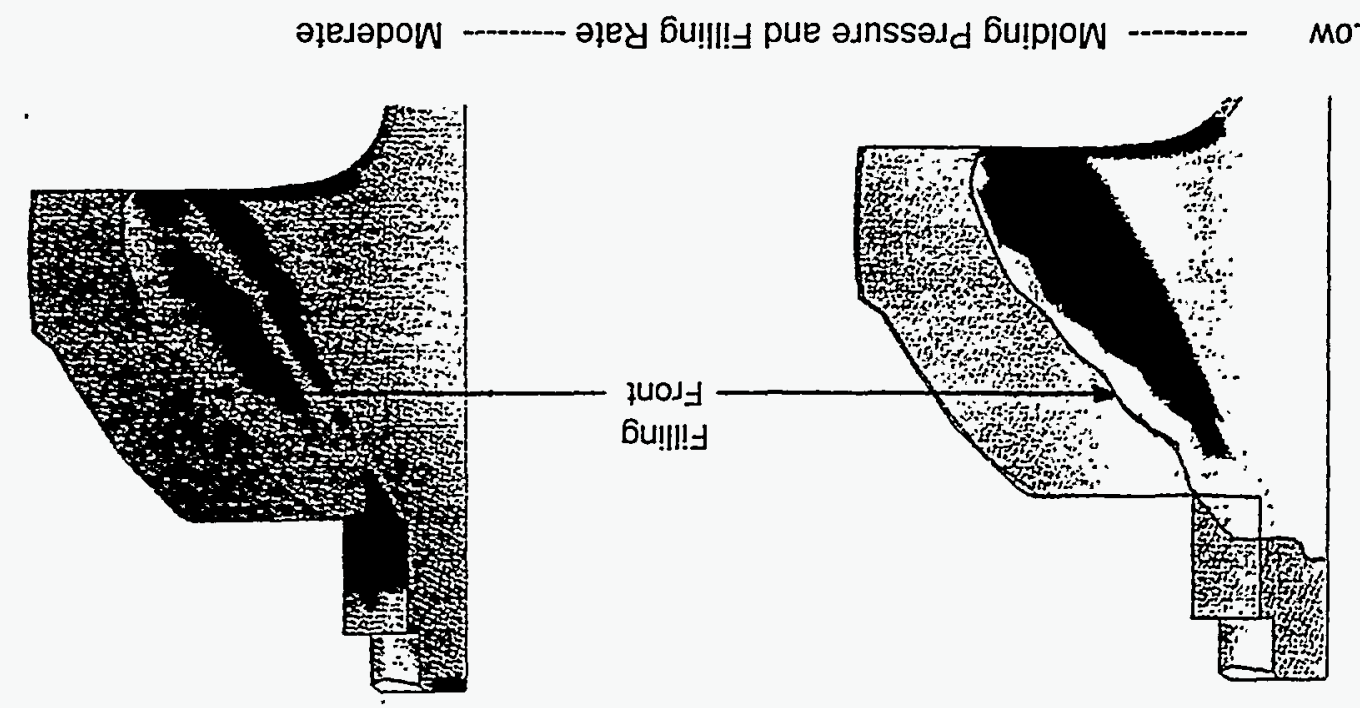

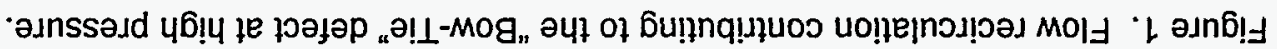

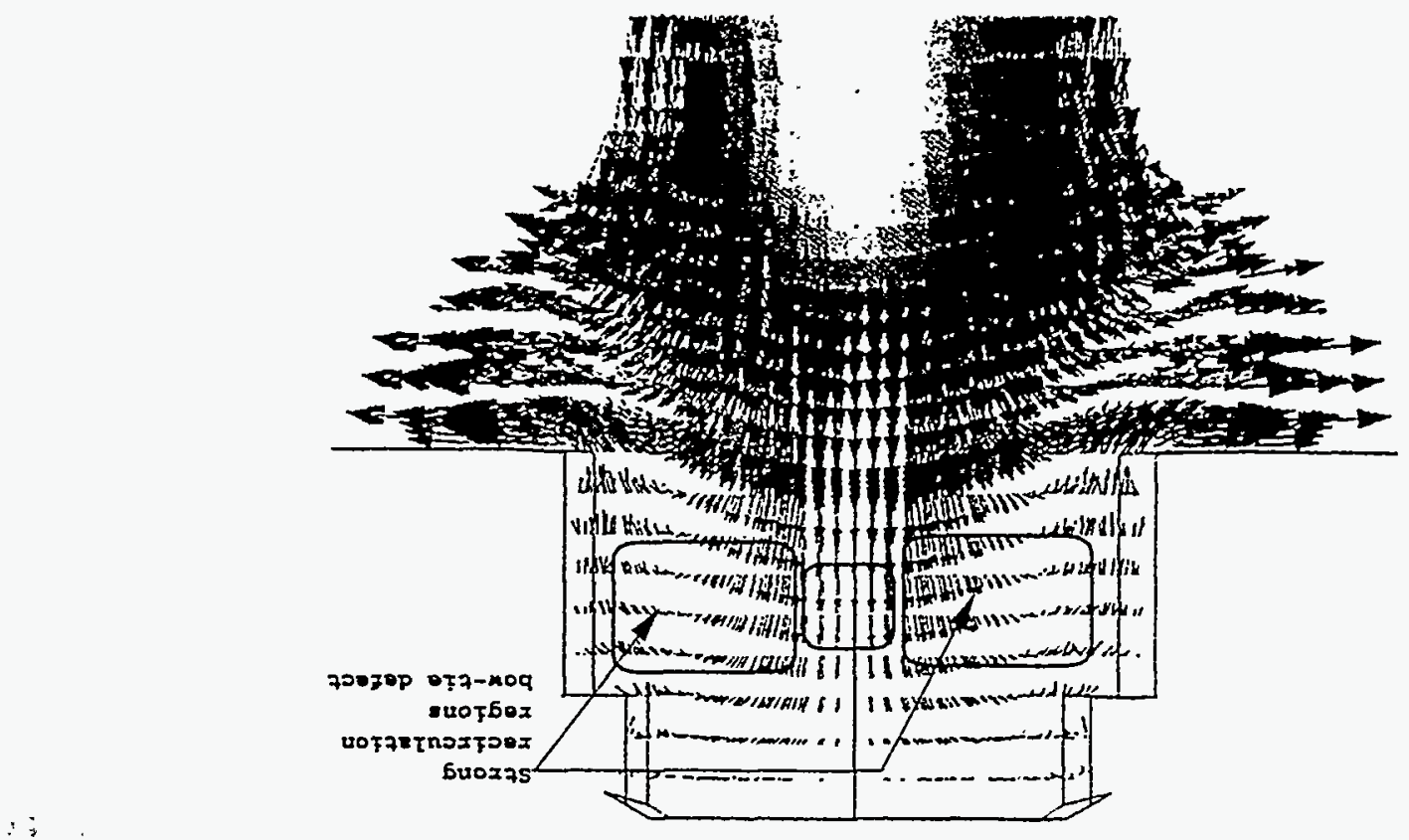




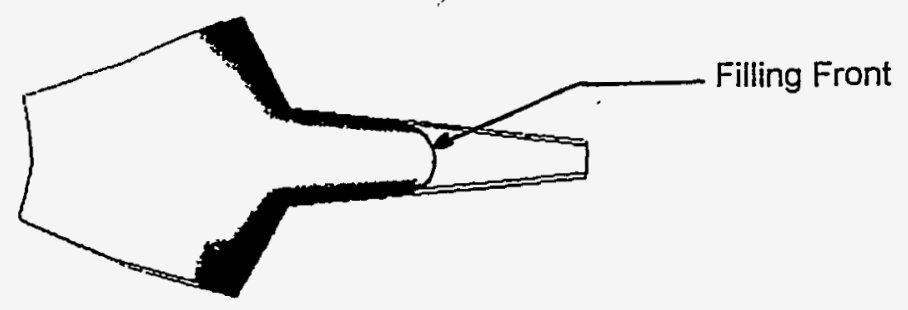

Figure 3. Blade surface solidification up to fill front under low molding pressure.

in the injection column, and utilization of non-isothermal analysis. A typical result of this analysis is shown in Figure 4 for the flow velocity history at the exit of the injection column during filling of the mold. Flow decreases rapidly up to Point $A$, which represents filling of the extended rotor shaft, and is due to increasing head height and friction. The region between Points $A$ and $B$ represents the filling of the hub and nose portion of the die, where there is little resistance to flow and velocity is maintained. At Point $B$, the hub and nose are filled and blade filling begins. Velocity decreases due to flow constriction, and viscosity increase as the slip cools. Analysis of the effect of this flow history on blade fill and solidification has provided a more detailed understanding of the premature solidification which results in incomplete blade fill for the present geometry.

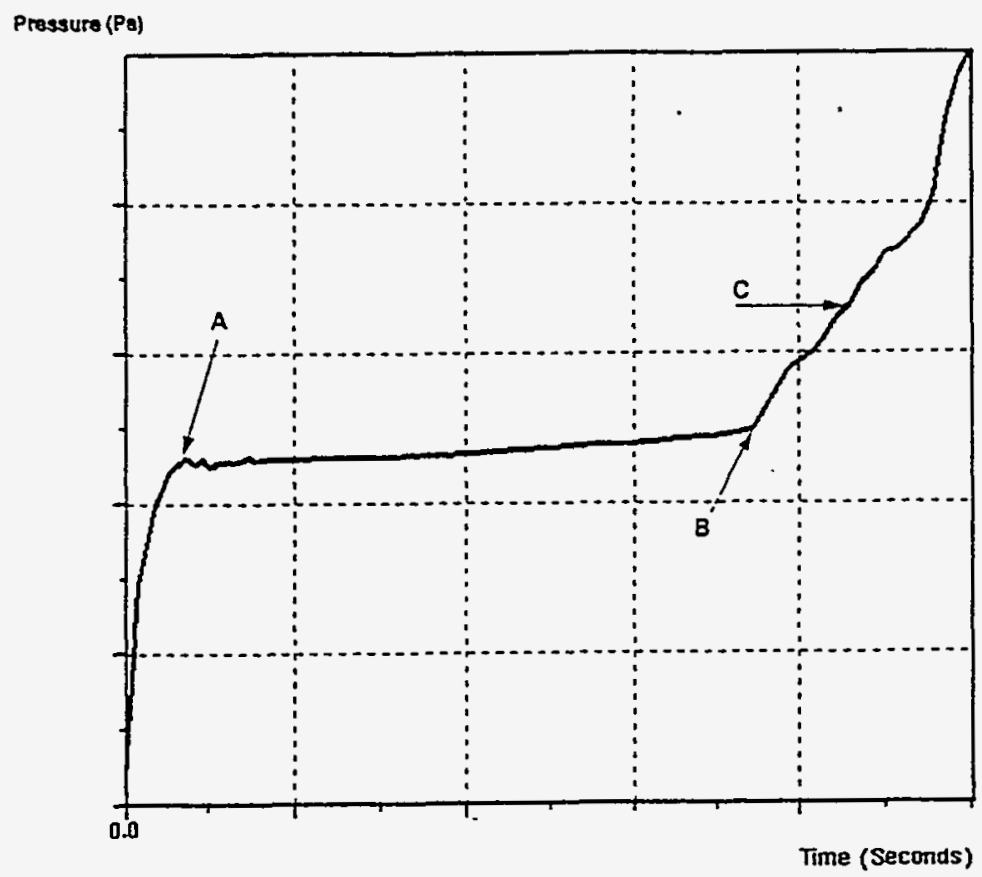

Figure 4. Pressure history at the exit of the injection column.

A study was conducted of the possibility of reversing the mold fill to fill from the nose instead of from the shaft end. It had been suggested that this flow direction could reduce the formation of molding defects and enhance blade fill. The FEM model of the mold cavity and injection system was therefor altered to this geometry, which uses a larger diameter interface between mold and injection system, which is untested. Isothermal filling analysis has been performed using this model. Fill velocity would be higher with this geometry, which may improve blade fill, but there were indications of potential molding defects in the hub which would be increased at higher fill velocities if they were required, just as with the original geometry. In view of the non-isothermal analysis reported above, the root problem in blade filling is the flow, viscosity increase and simultaneous solidification in the thin blade region. While filling from the 
nose may produce an incremental improvement in this situation, it would not change the basic problem factors. Considerable development would be required to investigate this potentially marginal improvement. This additional effort is not considered warranted.

Task 2.3.5 Drying: Effort on this operation has been postponed due to its low contribution to cost.

Task 2.3.6 Binder Removal Investigation:

Several de-wax runs have been performed with reduced cycle times using rotors formed during the process demonstration. Since most of these rotors contained molding defects, results are not conclusive. In these accelerated cycles, most rotors cracked or burst, but the locations of the cracks could usually be identified as containing molding defects. Several apparently defect free rotors did not crack. These trials will be continued with defect free rotors from future runs using the new rotor design.

Task 2.3.7 Sintering Investigation:

The largest potential decrease in cost in the sintering operation would be accomplished through a simplification and shortening of the densification process. A modified SN235 body has been used with other forming processes to accomplish this objective, but has never been used in Hybrid Molding. Rotors were formed from a slip prepared using this body. This attempt was unsuccessful due to poor mixing in slip preparation. As a result, the material was granular in nature so that test bars cut from formed rotors were rejected. New trials will be carried out following resolution of the blade fill issue.

Task 2.3.8 Grinding:

A study visit was made to the Schwitzer manufacturing facility in Ashville, NC to examine practices used in machining, joining and assembling metal rotors. While specific machining processes are not applicable to ceramic, the overall approach to amount and locations of stock removal, and some setup procedures were observed which may be applicable. If this is found to be the case, several operations in our present grinding sequence may be eliminated. These issues will be discussed during a design review following resolution of the blade thickness issue.

Issues relating to referencing and centering the rotor, and required tolerances were discussed in a design review. Modified grinding operations are being reviewed with the objective of eliminating unnecessary operations. Grinding time on required operations is expected to be significantly reduced through use of formed grinding wheels, and future reduction of grinding stock as forming and sintering experience is gained.

Task 2.3.9 Joint Fabrication Development

Potential joining cost reductions include use of friction welding to replace electron beam welding, laser * welding and lower cost electron beam welding. Laser welding has been rejected due to penetration depth limitations. While friction welding has several inherent problems, trials may be held to test feasibility with rotors of the new design. Lower cost electron beam welding technology will also be investigated.

\section{Task 2.4 Intelligent Processing}

Sonoscan Subcontract - The data acquisition and analysis have been improved to yield a better resolution of the amplitudes in the frequency domain through the use of a digital oscilloscope and modified FFT techniques. Eventually, both the data acquisition and analysis would be integrated into a single computer. Solid glass spheres embedded in epoxy disks have been used in the calibration runs to determine the population of bubbles. Two types of transducers, PZT and Lithium Niobate, have been evaluated for use in bubble detection. It was found that the PZT transducer has more energy output at the fundamental frequency, while the Lithium Niobate transducer has a broader frequency range of operation when harmonics are included. Lithium Niobate is therefor best suited to measurement of bubble population, where a broad frequency range is desired. PZT is superior for single bubble detection in the highly attenuated hybrid molding slip. Simulation experiments for the estimation of a population of bubbles using solid glass spheres in epoxy have been completed. Figure 5 shows the results for $100 \mu m$ glass spheres. The slope of the linear portion to the frequency dependent attenuation curve is directly related to the volume fraction of the bubbles and the point where the curve flattens out at the higher 
frequencies is related to the size of the bubbles. When the slope of each curve, derived using linear regression on the data of Figure 5, is plotted with the volume fraction of glass spheres, the correlation of Figure 6 results. Good correlation is found for the lower volume fractions, which is the region of interest for application to determining the deairing end point. The deviation at higher volume fraction is attributed to multiple scattering.

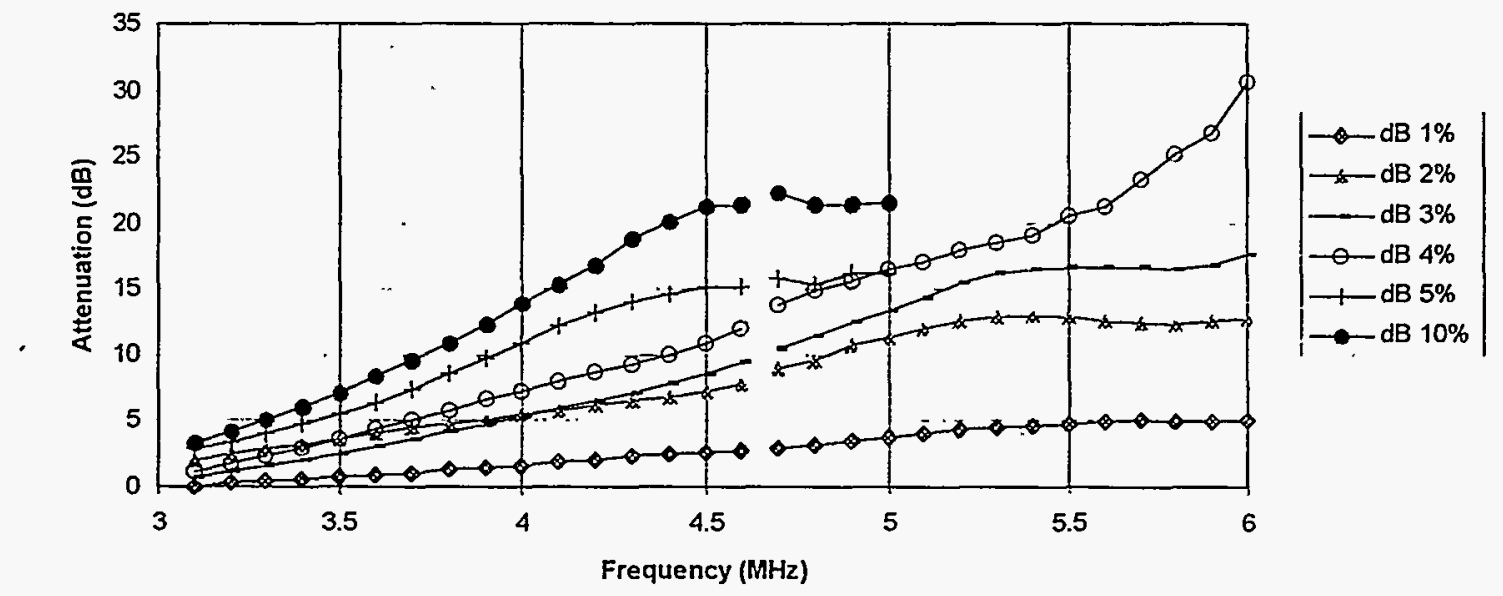

Figure 5. Frequency dependent attenuation data for the case of $100 \mu \mathrm{m}$ glass spheres in epoxy collected using a $3.5 \mathrm{MHz}$ and a $5 \mathrm{MHz}$ transducer.

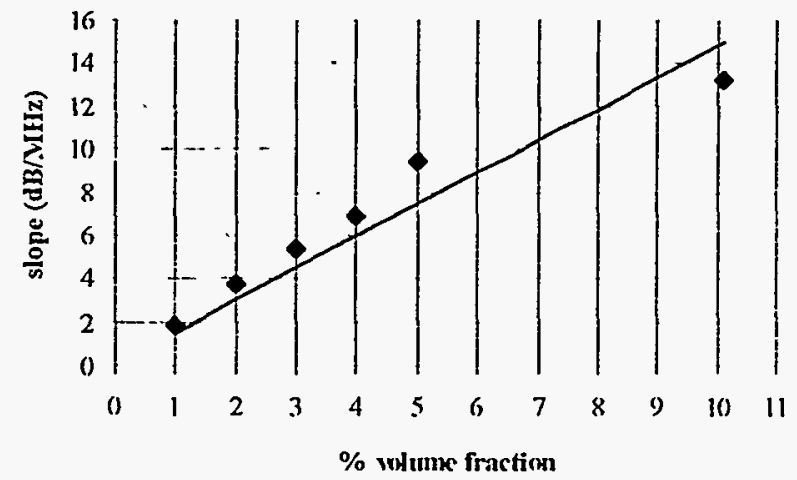

Figure 6. The slopes of the frequency dependent attenuation curves in Figure 5 are shown as a function of the volume fraction. Good correlation with a straight line indicates that the technique is reliable and consistent, especially for the lower volume fractions.

To achieve our other objective, namely the detection of individual bubbles in the $\mathrm{Si}_{3} \mathrm{~N}_{4}$ material, a nondestructive test station was developed. Hollow glass spheres have been procured to serve as "simulated" bubbles. It is believed that these will more closely simulate the bubbles that will be encountered in the slip material as compared to the solid spheres. It was found that bubbles comparable to twice the wavelength can be detected in the presence of noise. Glass spheres of the order of one wavelength of sound could be distinguished from the epoxy materials' background noise, but further signal processing would be needed to improve the resolution. Suitable signal processing approaches are being investigated for situations where the signal to noise ratio is lower than was found in the initial experiments. The size and volume fraction of the glass spheres and bubbles will be varied in further experiments in conjunction with transducers of different frequencies to arrive at the best parameters for detection of defects even in the presence of background noise. A broad band transducer that is capable of withstanding temperatures of $80^{\circ} \mathrm{C}$ is desirable because of the relatively high attenuation of ultrasound 
in the slip ( $3.3 \mathrm{~dB} / \mathrm{mm}$ at $5 \mathrm{MHz})$. To this end, different transducer materials are being evaluated for use in the sheet beam transducers proposed in this study.

\section{Task 3 Inspection and Test}

Several lots of parts have been inspected by $x$-ray radiography during the forming trials in attempts to achieve complete blade fill while avoiding other defects. The results of these inspections are reported along with the forming results. All lots are visually inspected.

\section{Task 4 Process Demonstration}

A lot of parts using the baseline SN235 body was formed using all of the data on blade fill and defect formation obtained from previous lots. A viscosity was selected which represented the best balance of blade fill capability and green density. A range of forming pressures and temperatures were investigated, also based on the results of previous runs. While blade fill could be achieved with the highest forming pressure and mold temperature, this condition led to void and knit line defects previously reported. It has therefor been concluded that the design for the new rotor must include considerably thicker blades. The present mold was therefor sent to the moldmaker for rework of blade inserts to provide a range of blade thickness'. Blade thickness' available with this mold are $t$ (original thickness), 1.25t, 1.375t, 1.5t and 1.625t. Three groups of parts were formed. The first two groups were formed from the same slip lot, but with different size injection port. Multiple parts were formed using successively higher injection pressure. Only the two thickest blades could be filled using the larger port, and only the thickest using the small diameter port without inducing other molding defects such as those described in previous reports.

The third group used a new slip lot with higher viscosity, and utilized the large injection port. With this high viscosity, blade fill could not initially be achieved for the thickest blade even at maximum injection pressure. Three additional sets of parts were then molded in which the slip temperature was increased by even increments up to the maximum allowable operating temperature. In each case, using the maximum allowable pressure, blades could be filled without the formation of observable molding defects. This result has been interpreted using the measured temperature dependence of viscosity. However, operating at this extreme of pressure and temperature is undesirable since it significantly reduces the control parameters available, resulting in a non-robust process. Additional forming trials with lower starting viscosity, and using the smaller injection port were conducted to define the most robust and least costly operating envelope. While the original blade thickness cannot be filled without producing other defects, the operating envelope has been expanded so that with a thicker blade, a more robust process will be available.

Final trials with this mold involved use of a Teflon coating on the blade inserts to allow further expansion of the machine operating parameter envelope. No benefit was obtained from these trials. No further trials are planned with this mold. Molding and other process demonstration efforts will be performed on a mold of the new geometry when it is available.

\section{Status of Milestones}

Milestone 1, Design Package, was completed and submitted on time. The design package was approved. Milestone 2, Process Improvement Goals, has been submitted based on the initial process demonstration effort. Further milestones as well as task content and structure are expected to be reconsidered as a result of findings to date, and the decision to redesign the rotor for the new engine configuration. 


\title{
W.B.S. Element 1.5.2.1
}

\section{DEVELOPMENT OF \\ ADVANCED CERAMIC MANUFACTURING TECHNOLOGY \\ Subcontract No.86X-SP234C}

C.Burk, T.P. Leo, L.D. Lynch, B.J. McEntire - SGNICC, Norton Advanced Ceramics

Y. Kalish, R. Begin - Detroit Diesel Corporation

C. Bida, M. Hauptman, L.E. Mains - Deco Grand, Inc.

M. Tricard, D. Graham, J. Picone - Norton Compay, World Grinding Technology

Center

J. Kellogg- CentorrNacuum Industries

V.K. Pujari, W.T. Collins, R.L. Yeckley - SGNICC, Northboro R\&D Center

P. Parrish - BDM Federal, Inc.

T. Zahrah, S. Hollo - MATSYS, Inc.

A.E. Mascarin - IBIS Associates, Inc.

D. Wittmer - Wittmer Consultants

\author{
Report Prepared by \\ Vimal Pujari \\ Saint-Gobain/Norton Industrial Ceramics Corporation \\ Northboro Research and Development Center \\ Goddard Road \\ Northboro, MA 01532
}

Semi-Annual Technical Progress Report

October 1995 - March 1996

\section{Objective/Scope}

The objectives of this program are to design, develop and demonstrate advanced manufacturing technology for the production of ceramic valves. A production manufacturing process for a ceramic exhaust valve for DDC's Series 149 diesel engine is being developed under this program. Specific objectives are: (1) To reduce manufacturing cost by at least an order of magnitude over current levels; (2) To develop and demonstrate process capability values $\left(\mathrm{C}_{\mathrm{pk}}\right)$ of 0.7 or less for all critical component attributes; and (3) To validate performance, durability, and reliability of this ceramic valve in rig and engine testing. 


\section{Technical Highlights}

\section{Task 1 - Component Design and Specification}

\section{Task 1a - Preliminary Design}

This task has been completed. Based upon this activity, valves were fabricated for the 500 hours durability test described below.

\section{Task $1 \mathrm{~b}$ - Final Design Analysis}

The series 149 engine valve design will be finalized at the completion of valve train dynamic modeling and 500 hour engine durability test.

Series 149 valve train model was used to predict the dynamic characteristics with the ceramic valves. Following improvements were predicted:

- ceramic valve has lower seating velocity, thus reducing valve to seat impact force

- with ceramic valve, no-follow speed is increased, thus valve train can sustain faster engine speeds.

- Reduced rocker arm loads, as well as other valve train components loads are reduced with ceramic valve due to lower valve train inertia

The 500 hour durability test of the ceramic valve in $8 \mathrm{~V}-149$ engine has also been complete without any adverse incidents. The valves are currently being analyzed in the materials laboratory at DDC.

\section{Task 2. - Component Manufacturing Technology Development}

\section{Task 2a - Environmental Safety and Health}

During this reporting period, a related audit was performed by Norton Company's Health and Safety Department. Two specific areas included the powder processing laboratory at NRDC and the machining center at the World Grinding Technology Center (WGTC). Results of this audit are summarized below.

The manufacture and machining of the silicon nitride engine components does not present an increased risk of injury or illness over traditional metal manufacturing and finishing operations.

Health concerns center around the operators exposure to hazardous chemicals. The primary constituent in the ceramic is silicon nitride powder, which is non-combustible, non-toxic and is considered a nuisance dust. Chemical additives include low molecular weight binders and antifoaming agents that are relatively non-toxic. 
Fine particulates may become airborne during the milling and machining operations. As with any airborne particulate, measures are taken to minimize the inhalation of the dust. Local exhaust ventilation and good housekeeping practices maintain dust levels at concentration well below the occupation exposure limits. Pyrolysis products generated during the furnace operation are verited out of the building.

Chemical protective gloves minimize the operator's contact with cutting oils, coolants and dye penetrates that may result in contact dermatitis.

Safety concerns encompass factors that may physically harm the operators. Operators are required to wear safety glasses and safety shoes. Chemical protective gloves are selected based on their compatibility with the materials. Hot pieces are handled with heat protective gloves.

A ceramic component may fail catastrophically during a machining process. This may results in ceramic pieces being projected from the machine. Therefore, it is imperative that the machine have barriers or enclosures to deflect the projectiles. The enclosures are interlocked to prevent accidental access while the machine is running. The operators wear safety glasses with side shields to protect the eyes.

The ceramic components are formed in an isostatic press under great pressures $(30,000 \mathrm{psi})$. The press is periodically (annually) inspected and dye check according to manufacturing recommendations.

The risk of fire or explosion is substantially reduced in that the powder is noncombustible and is milled in water.

The ceramic manufacturing process does not generate hazardous waste as defined by the Resource Conservation and Recovery Act (RCRA). The dry Silicon Nitride powder is suitable for landfill disposal. Machine oils and coolants are regulated at the state level and handled according to state waste disposal regulations and guidelines.

Particulate emissions are controlled by a dust collection system that provides a great than $99.999 \%$ collection efficiency at a 0.5 micron particle size. During the sintering process the binder is pyrolyzed. Partial pyrolysis occurs while the furnace is ramping up to the final operating temperature, at which point the binders are pyrolyzed to carbon dioxide and water vapor. The product of incomplete combustion are absorbed in the vacuum pump oil.

Waste water discharges are limited to the dye penetrant used in the inspection process. The dye is a water soluble oil that is sufficiently removed from the waste stream via a cross-flow hollow fiber filtration system. 
NAC is developing a Technical Cost Model for the Series 149 exhaust valve in conjunction with IBIS Associates. As reported previously, IBIS has completed the development and.documentation of the base cost model. Preliminary cost sensitivity analyses were performed and reported for various valve grinding processes using this base model. IBIS is now working on their Task 2 (Cost and Sensitivity Analysis) and Task 3 (Ongoing Analysis and Support). The focus of this current activity is on: (1) Incorporation of continuous sintering into the model; (2) Addition of a learning curve analysis to estimate the effect of production quantities; (3) Revision of the preliminary cost estimates for centerless grinding using inputs from Deco Technologies; and (4) Refinement of a stock removal versus process yield cost sensitivity analysis. During the reporting period, the continuous sintering portion of the model was completed, and a cost sensitivity analysis was performed. The continuous sintering cost sensitivity analysis included assessing the effect of capital investment, gas consumption, electricity cost, crucible cost,, product throughput rate, and other inputs. Nominal values for cost model inputs were estimated from actual continuous sintering trials at SIU. The most critical input to the cost model was determined to be valve blank throughput rate. An initial cost comparison of large-scale batch firing versus continuous sintering using the nominal cost model inputs was generated. As shown in figure 1 , the continuous sintering throughput rate must be greater than approximately eight valves per hour to achieve lower cost than large-scale batch sintering. At relatively high throughput rates (10-15 valve blanks/hour), the cost analysis indicates that continuous sintering reduced sintering cost by approximately a factor of two over batch firing.

\section{Task 2c - Process Control}

\section{i.) Milling and Spray Drying Process Control}

Efforts are in progress to optimize the milling and spray-drying process steps using low cost raw materials. Two batches of NT551 silicon nitride slurry were prepared using NAC's high energy attrition mill to: (1) Examine the effects of slurry formulation and processing on spray dried granule properties, and (2) Support the development of the spray drying intelligent control system (ICS). One batch was prepared using a control treatment (Milling Treatment No. 1), and the second batch employed a novel processing technique aimed at producing uniform shape and size agglomerates that "crush" easily during isostatic pressing (Milling Treatment No. 2). Slurry from each of the two milling treatments was spray-dried over a relatively narrow range of spray drying conditions. The spray dried powder from the two milling treatments was characterized as part of the milling and spray drying process control activity. Characteristics of the spray dried powder form each treatment appeared to be independent of spray drying conditions. However, as summarized in Table 1, loose packing density, spray dried powder moisture content, and agglomerate shape were found to be significantly different between the two treatments. Figures 2 and 3 provide an illustration of the difference in the shape of the spray dried agglomerates. Milling treatment No. 2 produced more ideally spherical shaped agglomerates (i.e., no 
dimpled or donut-shaped particles) compared to Milling Treatment No. 1. Valve blank dry-bag pressing trials are in progress to assess the pressability of these two powders. Fracture surface of CIP'ed valve blanks made from spray-dried powder from Milling Treatment No. 2 shows no undesirable granular relics: Pressure versus density relationships of CIP'ed powder compacts are also being determined to support the dry bag isopressing modeling effort

A matrix of experiments (L8) was performed to further optimize and fine tune the spray dried granule properties of NT551 (fixed ) composition. Flowability, pressability, sinterability (both batch and continuous) and the resultant mechanical properties were examined with respect to dispersant and surfactant types and their levels. The most significant results obtained to date from these sets of experiments are summarized in Table 2. Following salient conclusions may be drawn from the resultant sintered properties:

a) Slurry chemistry has been optimized yielding consistent batch-sintered densities $\geq$ $99.4 \%$ T.D. $(551-10,14,15,17,21)$

b) Mechanical properties of batch-sintered NT551 meet DDC's material specifications $(551-10,15,17)$

c) dominant failure origins of the batch-sintered NT551 are relics (residual defects from spray dried granules).

d) NT551 tiles from these batches did not reach a density greater than 99\% T.D. (551$11,16)$ in continuous sintering. Powder produced from Milling Treatment No. 2 consistently produced higher density during continuous sintering.

e) Post HIP treatment following continuous sintering yields full density and significant improvement in mechanical properties and consequently reliability (551-12B). Similar results (not shown) are also realized from batch-sintered HIP treated NT551 material.

f) Based upon these key experiments, the slurry chemistry, the spray drying and the sintering procedures for the NT551 material have been established and an S.O.P. is currently in the process of being prepared. As mentioned in Task 2(b), the cost models for the alternative sintering procedures (i.e., continuous vs. continuous plus HIP) are being discussed with IBIS to establish cost vs performance comparisons.

\section{ii) Continuous Sintering}

Development of continuous sintering continued during the reporting period in conjunction with Centorr/Vacuum Industries (CVI) and Wittmer Consultants. The CVIMittmer team is performing work under their Sub-task 1.3. (Continuous Sintering Optimization); and Task 2 (Continuous Furnace Design Study for SiAION Exhaust Valves). Under the continuous sintering optimization sub-task, the CVINittmer team completed a series of 19 sintering runs to identify an optimum cycle for NAC's low cost silicon nitride, designated NT551. A summary of the density results from these trials is provided in Tables 3 and 4 . Sintering to closed porosity was achieved for some of the continuous sintering. 
Table 3 gives the continuous sintering results for the preliminary NT551 formulation and processing condition. The coded data show that a density of $98-99 \%$ T.D. was obtained for $3 \mathrm{~T} / \mathrm{t}$ conditions $(5 / 4,4 / 4$, and $4 / 3$ ) ofthe $12 \mathrm{~T} / \mathrm{t}$ sintering conditions run.

The results given in Table 4 are the density data for two sintering time/temperature conditions (t4/T5 and t3/T5) for both billets and valves that represented three processing/formulation variations $(10,11$ and 12). Two different belt speeds ( 3 and 4$)$ were used in conjunction with two hot zone configurations to provide two heating rates for the same $t / T$ conditions. These results show that there were significant differences in the densities obtained for the variations in thermal conditions. The processing batch 12 produced the highest density in both billet and valve forms.

Based on results obtained from the post continuous sintered/HIP'ed trials by NAC, a processing route has been defined for valve fabrication. The target density of 9899\% T.D. was obtained for T5/t4 continuous sintering conditions. Additional billets and valves of NT551 is being pressed from a larger lot by NAC to achieve full density and appropriate micro structure for strength and fracture toughness determination (to be performed at ORNL).

These results will then be used to determine the sintering conditions for continuously sintering the forty valves (Task 2) prior to the 100 valve demonstration run (Task 3 ).

The design for continuous sintering furnace, capable of sintering 30,000 valves per year was completed and delivered to NAC. IBIS was also visited and their cost model for sintering of valves was examined. Suggestions were made to better represent both continuous and batch sintering costs.

\section{iii) Machining}

Work is ongoing in the development of a cost effective machining process for valves. This activity is being performed in conjunction with Norton's World Grinding Technology Center (WGTC) and Deco Technologies. Work at the WGTC has focused on (1) Development of a centerless plunge grinding approach for ceramic valves; and (2) Assessment of various alternative valve grinding technologies. Centerless grinding simulation screening experiments have been completed and summarized in previous bi-monthly reports. Plans to conduct larger-scale centerless grinding trials at the WGTC have now been abandoned in favor of going directly to full-scale ceramic valve grinding demonstrations at Deco Technologies. Efforts at the WGTC have focused on wokring with personnel from Deco Technologies to specify and fabricate the centerless grinding wheels for valve grinding. Specifications for a total of three centerless grinding wheels were completed for Deco's valve grinding unit operation No's 20, 40, and 50. These wheels were ordered from Norton Superabraives divison, and were fabricated during the reporting period. Dellivery of these wheels to Deco is pending receipt and assembly of these wheels onto mounts compatible with Deco's Lidkoping centerless grinder. 
Efforts at Deco Technologies are focused on applying the centerless grinding technology being developed at the WGTC to full-size components. During the last reporting period, Deco purchased a used Lidkoping centerless grinder for performing ceramic valve grinding trials. A process routing for centerless grinding Series 149 valves was finalized, including detailed wheel specifications for each grinding operation. A total of three centerless grinding wheels for rough and finish stem, underhead, and head grinding were fabricated by Norton's Superabrasives Division. The balance of the tooling required for ceramic valve grinding trials including a rotary diamond wheel dresser, an infeed controller for the Lidkoping centerless grinder and wheel mounts were specified and ordered during the reporting period. Centerless grinding trials of ceramic valves is currently underway at Deco. Valve stem plunge grinding was successfully demonstrated during the semi-annual review meeting held on March 7, 1996 at Detroit.

In parallel to the centereless grinding development activity, several alternative grinding technologies have been assessed. WGTC and Deco completed a review of ceramic valve grinding processes offered by Studer, Junker, Micron, and other machine tool builders. A Studer S40 CNC grinder was received on consignment at the World Grinding Technology Center, and an initial demonstration of high speed CNC profile grinding of ceramic valves was performed.

Work has continued at the WGTC on the Studer machine to reduce the profile grinding process cycle time. During the reporting period, work focused on optimizing the roughing operation using a diamond $\mathrm{MSL}$ wheel operating at $150 \mathrm{~m} / \mathrm{s}$. The following two approaches are being evaluated in order to increase the material removal rate (MRR) without causing additional deflection in the workpiece: Adding a steady rest to the rough profiling setup; and (2) Changing the method of holding the part form non-integral dead centers to a precision collet on the head end and a live center on the tip end. A steady rest was installed on the Studer, and this devise was used in a preliminary grinding demonstration summarized in Table 5. Despite adding a grinding operation for placement of the steady rest, the shortest process cycle time achieved to date on the Studer corresponds to a factor of four reduction over NAC's current prototype process. Changing the method of holding the part requires minor modifications to the design of the fired blank. These design changes were finalized, and a limited number of blanks for grinding trials are being fabricated. Work during the next reporting period will focus on completing optimization of the rough and finish profiling operations. Three additional grinding wheels will be evaluated, including one roughing wheel rated for high speed, and two finish wheels (one high speed, one conventional speed). Upon completion of optimizing this valve grinding process, a demonstration run of 30 valves will be performed on the Studer machine.

In addition to assessing the Studer machine tool at the WGTC, NAC worked with Junker to complete a ceramic valve grinding demonstration at Junker Machinen in Nordrach Germany. The purpose of these trials was to evaluate the Junker Quickpoint high speed grinding technology with respect to grinding cycle time, dimensional control process capability, and surface finish. A total of 35 Series 149 
NT451 SiAION valve blanks were ground on a Junker Quickpoint Model 5004 machine tool. A schematic of the grinding process used for these trials is shown in Figure 4. On a separate machine tool, the blanks were first placed in a fixture locating on their stem O.D. Chamfers were ground on each end for holding the part in the Model 5004 during the profile grinding operation. Profile grinding consisted of: (1) A single rough profile pass with a diamond metal bond wheel (left side) that traversed the seat, underhead radius, and stem; and (2) A single finish profile pass with a diamond metal bond wheel (right side) that traversed only the straight portion of the stem. A total of 15 valves were profile ground to final tolerance and finish using fixed grinding parameters. These valves were returned to NAC for detailed characterization of dimensions and surface finish. All of the profiled valve blanks met surface finish and dimensional specifications.

A comparison of stem diameter dimensional control down the length of the valve is shown in Figure 5 for the Junker process versus NAC's current prototype process. Although there is no apparent difference in the profile of stem diameter down the length of the valve, the Junker process exhibits less process variability. A comparison of stem diameter process capability for the two profile grinding processes, shown in Figure 5, indicates that the Junker process has superior process potential $\left(C_{p}\right)$. In addition, the Junker process reduced the profile grinding cycle time by a factor of 16 over NAC's current prototype process. The evaluation of these valves will be completed during the next reporting period. This work will include grinding in lock grooves using NAC's standard procedure, and purposely proof testing the valves to failure to assess mechanical integrity of the machined surfaces.

\section{Task 2d - Intelligent Processing}

NAC is working in conjunction with its research and development group located at SGNICC's Northboro, MA Research and Development Center (NRDC) and MATSYS (formerly BDM Federal, Inc.) to develop intelligent processing methodologies for ceramic valve manufacturing. The objectives of this effort are to: (1) Develop, implement, and demonstrate an intelligent control system (ICS) for milling and spray drying of silicon nitride powder; and (2) Adapt existing consolidation models to the valve dry-bag iso-pressing. The objectives of the ICS effort for spray drying are to establish intelligent, closed-loop control of the spray drying process in order to produce dried spherical silicon nitride agglomerates with: (1) A controllable mean size; (2) Narrow size distribution; (3) High CIP density (i.e., minimize agglomerate hardness and the occurrence of dimpled and/or doughnut-shaped agglomerates and internal voids); (4) High flowability; and (5) High yield.

Milling ICS System - Sensors corresponding to the three key sensing parameters ( $\mathrm{pH}$, temperature, and pumping rate) are fully operational and communicative with the central computer through FIX DMACS graphic interface software. Programming has been completed to allow for communication of corrective signals from the ICS system computer to the three dedicated pumps (to adjust $\mathrm{pH}$, temperature and pumping rate). These sensors were utilized in a process monitoring mode in 
preparation of Milling Treatment No's 1 and 2 summarized under the process control section of this report.

Spray Drying Intelligent control System (ICS) - During the reporting period, MATSYS and NRDC personnel focused on: (1) Operation and calibration of the infrared moisture sensor; and (2) Development and integration of a fuzzy logic control model with the spray drying ICS.

Previous attempts to calibrate the infrared moisture sensor during a series of experiments performed in September were unsuccessful. The sensitivity of the optical device to the moisture content of spray dried silicon nitride powder was demonstrated. However, the measured infrared absorbance ratio of the powder could not be reliably correlated to the actual moisture content measured using standard thermogravimetric techniques. After reviewing the data from these experiments, MATSYS identified two potential reason for the difficult in calibrating the sensor: 1) An inhomogeneous distribution of moisture within the spray dried agglomerates; and 2) The variation of the focal distance between the sensor and the surface of the powder. Considering the drying mechanisms involved, it is conceivable that moisture gradients exist within individual agglomerates and that the surface moisture may not be representative of the total moisture content of the powder. If the measured infrared absorbance is a function of surface moisture, it may not be possible to correlate the measured absorbance with the total moisture content of the spray dried powder. A review of the data from the IR sensor recorded on-line also revealed a systematic increase in the measured absorbance ratio over time. A potential cause of the systematically increasing absorbance ratio was identified to be the decreasing focal distance between the optical moisture sensor and the surface of the powder as it collects in the bucket below the spray dryer.

The original installation of the infrared moisture sensor was redesigned to ensure that the focal distance between the sensor optics and the silicon nitride powder collected at the bottom of the spray dryer remained constant. A prototype powder chute was designed and fabricated by MATSYS for installation at NRDC: As shown in Figure 7, the chute was designed to maintain a relatively constant level of spray dried powder on the lower sloped surface. Fresh powder from the spray dryer is deflected at the top of the chute and cascades down the sloped section and out into a collection bag. A horizontal lip ensures that powder builds up to a thickness several orders of magnitude deeper than the penetration depth of the infrared radiation.

The operation of the powder chute was successfully demonstrated using previously dried powder and during actual operation of the spray dryer. The powder level within the chute remained relatively constant with maximum variations in height of less than $5 \mathrm{~mm}$. Figure 8 shows the infrared absorbance ratio measured on-line for powder produced at three different slurry flow rates. The on-line measurements are plotted against the moisture content of the collected powder as measured using NRDC's standard thermogravimetric technique. The absorbance ratio and moisture content of the powder are linearly correlated when the variation in focal distance is eliminated. 
The data from experiments performed at NRDC has been used to develop fuzzy logic control rules that will adjust the slurry flow rate to maintain the powder moisture content at the desired level. The inputs to the controller are the moisture content error (i.e., the difference between the measured moisture and the setpoint), the rate of change of the powder moisture content and the rate of change of the outlet air temperature. The fuzzy logic control rules have been implemented using Cubicalc, a MS-Windows fuzzy logic development software package, and have been integrated with the FIX DMACS data acquisition and control system using the Dynamic Data Exchange (DDE) feature of MS-Windows. FIX DMACS passes data (e.g., the current slurry flow rate, air temperatures, powder moisture content, etc.) to Cubicalc using DDE. Cubicalc performs the fuzzy logic calculations necessary to calculate the required adjustment to the slurry flow rate. FIX DMACS retrieves the results of this calculation via DDE and sends the required commands to the slurry pump.

During the reporting period. MATSYS and NRDC personnel demonstrated closedloop control of the key spray dried powder attribute, residual moisture content. Figure 9 illustrates the ability of the spray drying ICS to control residual moisture content by varying the slurry flow rate into the dryer. Recommendations from this spray drying ICS demonstration included: (1) Implementation of an industrialized version of this system on a larger diameter production dryer; (2) Incorporation of screens before the powder travels by the window of the IR moisture sensor; and (3) Utilization of signal conditioning of the powder moisture content error signal.

Process Model for Dry-Bag Iso-Pressing - Current process valve blanks formed by dry-bag iso-pressing (CIP) exhibit distortions such as narrowing of the stem near the valve underhead radius, "elephant's feet" at the end of the stem, and chipping around the valve head. In addition, density and stress gradients exist within the CIP'ed part which contribute to warpage during the presinter and sintering operations. The dimensional distortions and density and stress gradients make it necessary to fabricate the pressed blank significantly larger than required. At present, the formed blank to finished part weight ratio is 2.75. Presintering and single-point green machining are required to remove stock from the oversized pressed blank. NAC envisions CIP'ing followed immediately by automated single pass green machining or green grinding as a more cost effective method for producing near net shape valve blanks. This approach can be employed only if the CIP'ed blanks are produced with less stock. NAC has established the following process performance goals for valve blanks: (1) A finished part weight ration of $\leq 1.8$; and (2) A reduction in stem total indicated runout (TIR) by least a factor of two over the current process.

To achieve these goals, MATSYS is using BDM's PDTTM and PROSIM ${ }^{\mathrm{TM}}$ process simulation tools to guide design of the dry-bag tooling and pressing schedule. During previous reporting periods, MATSYS completed several iterative simulations of the dry-bag geometry to arrive at an improved tool design. A new dry-bag design was finalized with input from NAC personnel. This revised design tool was fabricated and delivered to NAC through a subcontracted effort. Valve blank pressing trials were conducted with this new tool design. This revised design tool eliminated chipping on 
the head $O D$ and reduced the pressed part weight by greater than $20 \%$. However, necking down of the stem diameter near the head was not reduced.

A subsequent dry-bag tool design iteration is in progress using actual versus predicted geometry obtained from the first iteration design. The modeling work for this second iteration design was completed by MATSYS during the reporting period. The calculated weight of the second iteration of the CIP'ed valve blanks is reduced by an additional $12 \%$. NAC is in process of finalizing the drwing of this second iteration bag.

\section{Task 3 - Inspection and Testing}

Analysis of the fixture test results has been completed. Scanning electron microscope (SEM) analysis of the valves that had failed on the overspeed fixture test was conducted at the High Temperature materials Lab (HTML) at ORNL under the User Agreement Program. Keeper groove failures were induced by the deterioration of the keeper. Softer keeper will be considered in the future design. Stem failures were bending related with the failure plane being parallel to the grinding marks on the stem surface.

Air flow testing of $30^{\circ}$ seat and $45^{\circ}$ seat ceramic valves was conducted and compared to baseline air flow rate (Figure 10 ). While $30^{\circ}$ valves showed flow rates very close to baseline, flow rate of the $45^{\circ}$ valves was lower than baseline at low lifts (where the good flow rate is especially important) and better than baseline for high lifts.

Modeling of the Series 149 valve train using ADAMS software has continued. Cam, rocker arm with adjusting screw and the valve bridge have been modeled with their appropriate boundary conditions. This model has been simulated kinematically to verify cam lift, velocity and acceleration. ADAMS kinematics results are identical to DDC available spreadsheet results. Intermittent contact which allows for separation of follower from cam during high cam speed motion was modeled. This baseline mode was used to predict the dynamic characteristics with the ceramic valves. Improvements in valve train dynamics at 1900 RPM due to lower ceramic valve weight include (Figure 11).

- 300 RPM increase in engine speed before reaching zero valve spring force (an indication of overspeed capability)

- $146 \mathrm{lb}$ force decrease at peak load on rocker arm during valve opening

- $223 \mathrm{lb}$ force decrease at peak load on rocker arm during closing

Cam profile is being modified in order to take advantage of these improvements.

8V-149 engine has been built at DDC Redford manufacturing plant. Engine was assembled with thermocouples and other instrumentation. Sixteen $30^{\circ}$ seat and sixteen $45^{\circ}$ seat ceramic valves were assembled in eight cylinder heads. These cylinder heads were provided to the production facility to be used during the engine assembly. Serial numbers of the valves were recorded in relation to the valve's position in the engine. Engine calibration was modified to correspond to the highest 
power rating available in production for Series 149 engine. $8 \mathrm{~V}-149$ engine with thirtytwo ceramic valves was subjected to the mine haul truck durability cycle. Five hundred hour durability test of the ceramic valves has been completed without any incident. Valves were removed from the cylinder heads, and are currently being anlayzed in the Materials laboratory at DDC.

\section{Task 4 - Process Demonstration}

Task $4 \mathrm{a}$-- This task has been completed.

Task $\mathbf{4 b}$ - No activity to report.

\section{$\underline{\text { Status of Milestones }}$}

Milestones No's 1-4 are complete. Due to a delay in engine durability testing of the preliminary design ceramic valves, Milestone No. 5 is behind schedule by approximately one month. Milestones No's 6 through 8 are on schedule.

\section{Communications/Visits/Travel}

10/18/95 - EBright (NAC) visited DWittmer at Southern Illinois University to conduct continuous sintering runs and to review CVl's proposed belt furnace specifications.

10/18-10/19/95 - JEckalbar (NAC) visited Junker Machinen in Nordrach, Germany to wintness ceramic valve grinding trials.

10/23/95 - EBright (NAC) visited BBenoit, MHauptman and LMains at Deco Technologies in Troy, MI Detroit to review ACMT program plans for centerless grinding of ceramic valves.

10/23 - 10/26/95 - EBright (NAC) and VKPujari (SGNICC) attended the 1995 DOE Contractor's Coordination Meeting, Dearborn, MI.

10/23 - 1/27/95 - SHollo (MATSYS) visited VKPujari (SGNICC) and WTCollins (SGNICC) at the NRDC to install a new powder chute and test the infrared powder moisture sensor.

11/17/95 - JEckalbar (NAC) met with MTricard (WGTC) at the WGTC to review plans for ceramic valve grinding development.

11/21/95 - VShanbhag, AHorn, and MTricard met with BBenoit, MHauptman, and LMains at Deco in Detroit to discuss the upgrade of Deco's centerless grinder and grinding wheel specifications.

12/12 - 12/13/95 - EBright (NAC) visited DWittmer at Southern Illinois University to conduct NT551 continuous sintering runs. 
12/13/95 - Steve Hollo of BDM Corp. Visited NRDC to conduct spray drying experiments in support of the ICS development activity.

1/11/96 - MTricard visited Studer in Dayton, $\mathrm{OH}$ to discuss the status of the $\mathrm{S} 40$ grinder on consignment at the WGTC.

1/29/96 - DWittmer visited SGNICC's Northboro, MA R\&D Center to discuss sintering results and modification of the work plan.

1/30/96 - EBright (NAC) and DWittmer (Wittmer Consultants) visited TMascarin at lbis Associates, Wellesley, MA to review the batch versus continuous sintering cost analyses.

3/7/96 - The semi-annual review meeting was held in Detroit, $\mathrm{Ml}$ at DDC and Deco Grand's facilities. Key personnel from NAC and all other sub-contractors attended and made technical presentations.

3/13/96 V.K. Pujari (NRDC) visited David Graham at WGTC to review progress toward CNC profile grinding activities at WGTC.

3/15/96 - V.K.Pujari (NRDC) and Linda Broderick (SGNICC) communicated with Debi Baar of CVI to discuss cost to complete budget for CVI's activities.

3/18/96 - V.K. Pujari (NRDC) visited T.Mascarin at IBIS Associates, Wellesley, MA to review and initiate cost analyses of (a) continuous plus HIP processing, and (b) Studer CNC profile grinidng of valves at WGTC.

3/21/96 - V.K.Pujari (NRDC) communicated with Dale Wittmer of Wittmer Associates to discuss (a) cost to complete budget

\section{Problems Encountered}

None.

\section{Publications/Presentations}

E. Bright, J.F. Eckalbar, B.J. McEntire, V.K. Pujari, and M. Tricard, "Advanced Ceramic Manufacturing of SiAION Exhaust Valves," SAE paper 960051, 1996.

G:Igovinacacmtisemi9604.doc 
Figure 1 - Estimated Sintering Cost for Batch versus Continuous Firing

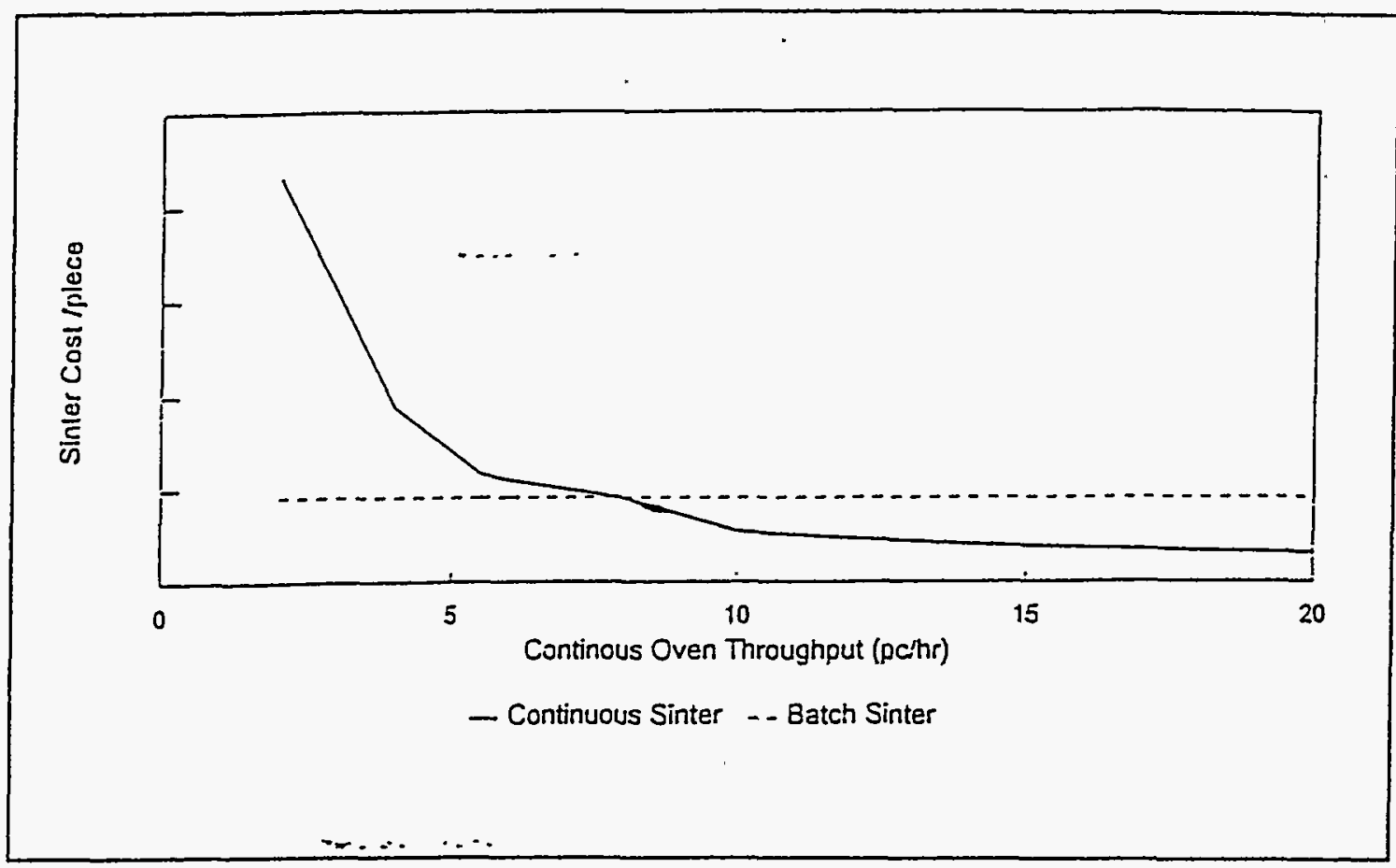



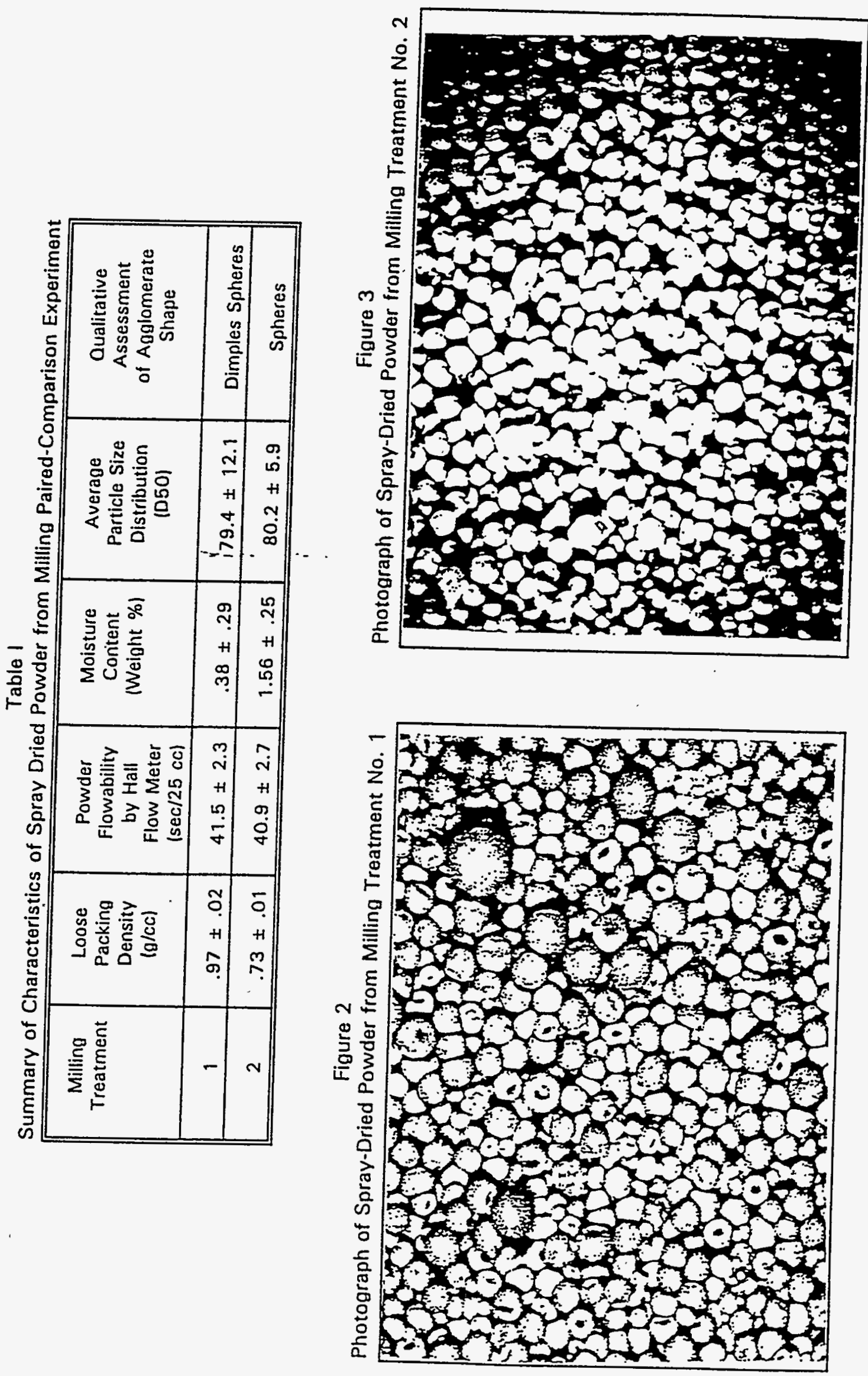
TABLE 2

SUMMARY. OF NT551 PROPERTIES OBTAINED TO DATE

\begin{tabular}{|c|c|c|c|c|c|c|c|}
\hline & & & & \multicolumn{4}{|c|}{ ROOM TEMPERATURE FLEXURE STRENGTH } \\
\hline $\begin{array}{c}\text { PROCESSED } \\
\text { POWDER } \\
\text { BATCH }\end{array}$ & $\begin{array}{l}\text { SINTERING } \\
\text { CONDITIONS }\end{array}$ & $\begin{array}{l}\text { DENSITY } \\
\text { (\%T.D.) }\end{array}$ & $\begin{array}{c}\text { FRACTURE } \\
\text { TOUGHNESS } \\
(\mathrm{MPa} \sqrt{\mathrm{m})}\end{array}$ & $\begin{array}{c}\text { AVG. MOR } \\
(\mathrm{MPa})\end{array}$ & $\begin{array}{c}\text { B1 MOR } \\
\text { (MPa) }\end{array}$ & $\begin{array}{l}\text { WEIBULL } \\
\text { MODULUS }\end{array}$ & $\begin{array}{l}\text { NO. OF } \\
\text { SAMPLES }\end{array}$ \\
\hline$\overline{551-10}$ & Batch & 99.4 & 6.7 & 797 & 648 & 19.6 & 30 \\
\hline $551-11$ & Continuous & 99.2 & N/A & N/A & N/A & N/A & 30 \\
\hline $551-12 B$ & $\begin{array}{l}\text { Continuous } \\
\text { Sinter + HIP }\end{array}$ & 99.99 & 6.4 & 940 & 757 & 18.6 & 30 \\
\hline $551-14$ & Batch & 99.4 & 6.5 & 751 & 565 & 14.0 & 30 \\
\hline $551-15$ & Batch & 99.5 & 6.5 & 753 & 640 & 24.8 & 20 \\
\hline $551-16$ & Continuous & 97.4 & & & & & \\
\hline $551-17 \mathrm{~B}$ & Batch & 99.7 & 7.5 & 740 & 636 & 26.6 & 30 \\
\hline $551-21$ & Batch & 99.7 & & & & & \\
\hline
\end{tabular}


Table 3 Continuous Sintering Results for Preliminary Lot of NT-551

\begin{tabular}{|c|c|c|c|}
\hline \multicolumn{2}{|c|}{ Sintering Conditions } & \multirow{2}{*}{$\begin{array}{c}\text { Immersion } \\
\text { Density (g/cc) }\end{array}$} & $\begin{array}{c}\text { Weight Loss } \\
(\%)\end{array}$ \\
\cline { 1 - 2 } Temp. Code & Time Code & 3.20 & 0.67 \\
\hline 2 & 3 & 3.18 & 0.63 \\
\hline 3 & 2 & 3.20 & 0.67 \\
\hline 3 & 3 & 3.22 & 0.68 \\
\hline 4 & 4 & 3.18 & 0.64 \\
\hline 4 & 1 & 3.20 & 0.66 \\
\hline 4 & 3 & 3.26 & 0.91 \\
\hline 4 & 4 & 3.26 & 0.73 \\
\hline 5 & 1 & 3.17 & 0.68 \\
\hline 5 & 2 & 3.23 & 0.86 \\
\hline 5 & 3 & 3.25 & 0.94 \\
\hline 5 & 4 & 3.26 & 1.02 \\
\hline
\end{tabular}


Table 4 . Results of Continuous Sintering of NT-551 Billets and Valves

\begin{tabular}{|c|c|c|c|c|}
\hline $\begin{array}{l}\text { Billet } \mathrm{D} / \\
\text { Composition }\end{array}$ & Time/Temp. & Belt Speed & Wt. Loss (\%) & $\begin{array}{l}\% \text { of Target } \\
\text { Density }\end{array}$ \\
\hline 10 & $\mathrm{t} 4 / \mathrm{T} 5$ & 3 & $1.02-1.03$ & 96.5 \\
\hline 11 & $\mathrm{t} 4 / \mathrm{T} 5$ & 3 & $1.11-1.48$ & 97.9 \\
\hline 12 & $\mathrm{t} 4 / \mathrm{T} 5$ & 3 & $0.89-1.11$ & 98.8 \\
\hline 10 & $\mathrm{t} 3 / \mathrm{T} 5$ & 4 & $0.92-1.07$ & 94.8 \\
\hline 11 & $\mathrm{t} 3 / \mathrm{T} 5$ & 4 & $0.88-1.02$ & 96.6 \\
\hline 12 & $\mathrm{t} 3 / \mathrm{T} 5$ & 4 & $0.74-0.87$ & 97.9 \\
\hline \multicolumn{5}{|l|}{$\begin{array}{l}\text { Valve } \mathrm{ID} / \\
\text { Composition }\end{array}$} \\
\hline 10 & $\mathrm{t} 4 / \mathrm{T} 5$ & 3 & 1.00 & 93.9 \\
\hline 11 & $\mathrm{t} 4 / \mathrm{T} 5$ & 3 & 1.22 & 95.4 \\
\hline 12 & $\mathrm{t} 4 / \mathrm{T} 5$ & 3 & 0.95 & 96.6 \\
\hline 10 & $\mathrm{t} 3 / \mathrm{T} 5$ & 4 & 0.92 & 92.3 \\
\hline 12 & $\mathrm{t} 3 / \mathrm{T} 5$ & 4 & 0.81 & 95.4 \\
\hline
\end{tabular}


202

$\cdots$

Table 5

Summary of Studer Grinding Trials Performed to Date

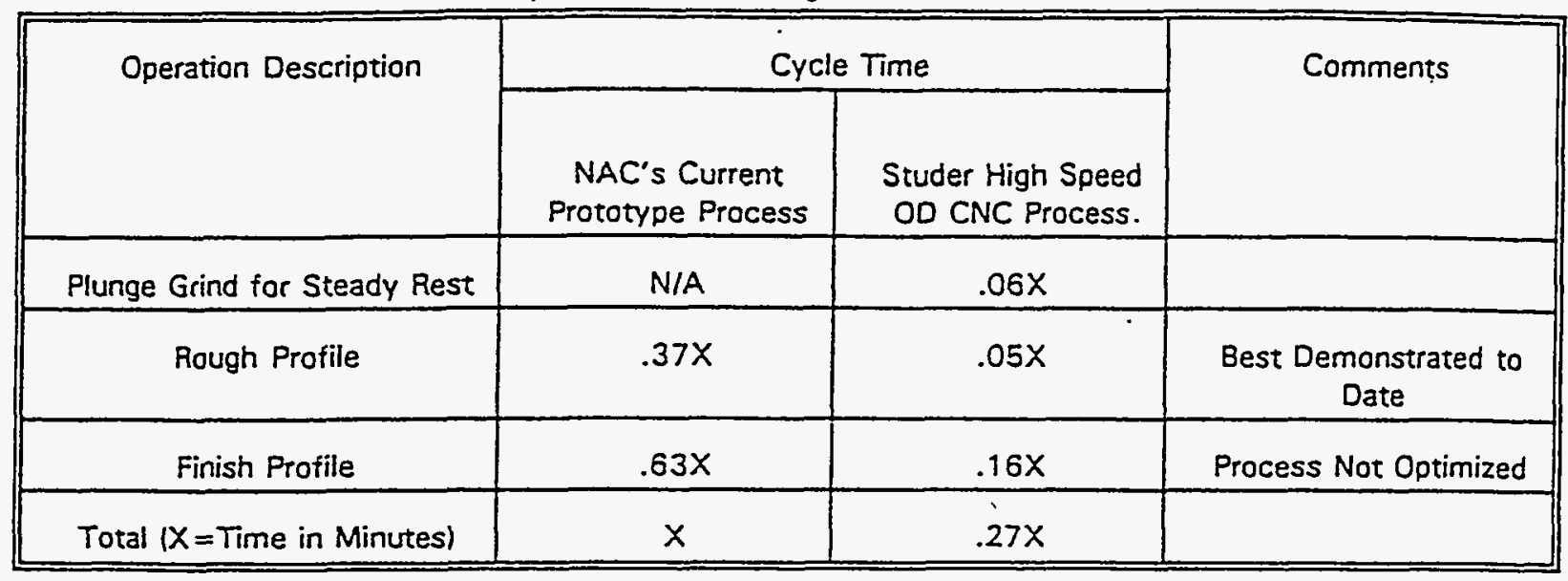

Figure 4

Schematic of Junker Profile Grinding Process

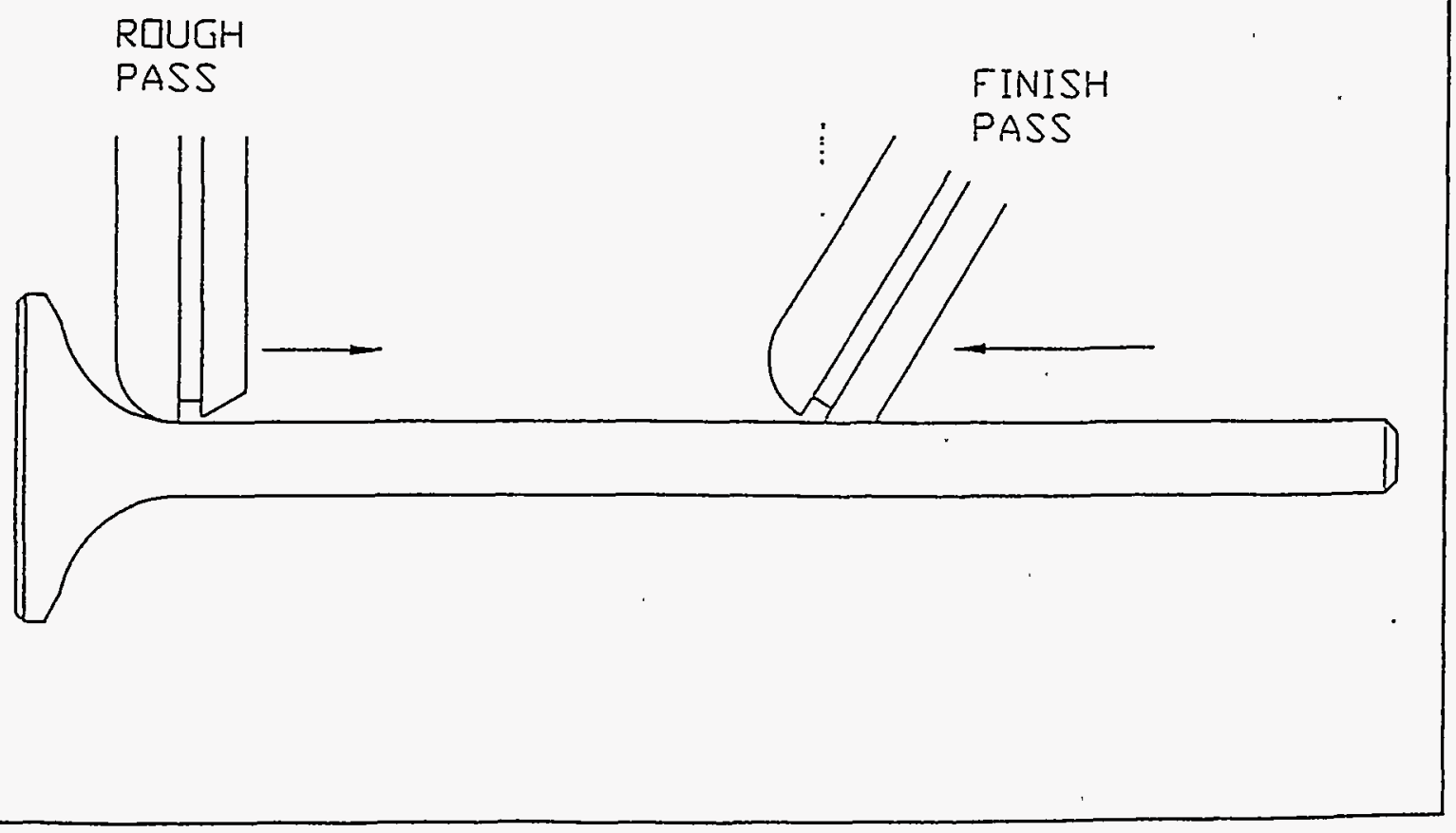


Figure 5 - Stem Diameter as a Function of Location on the Stem

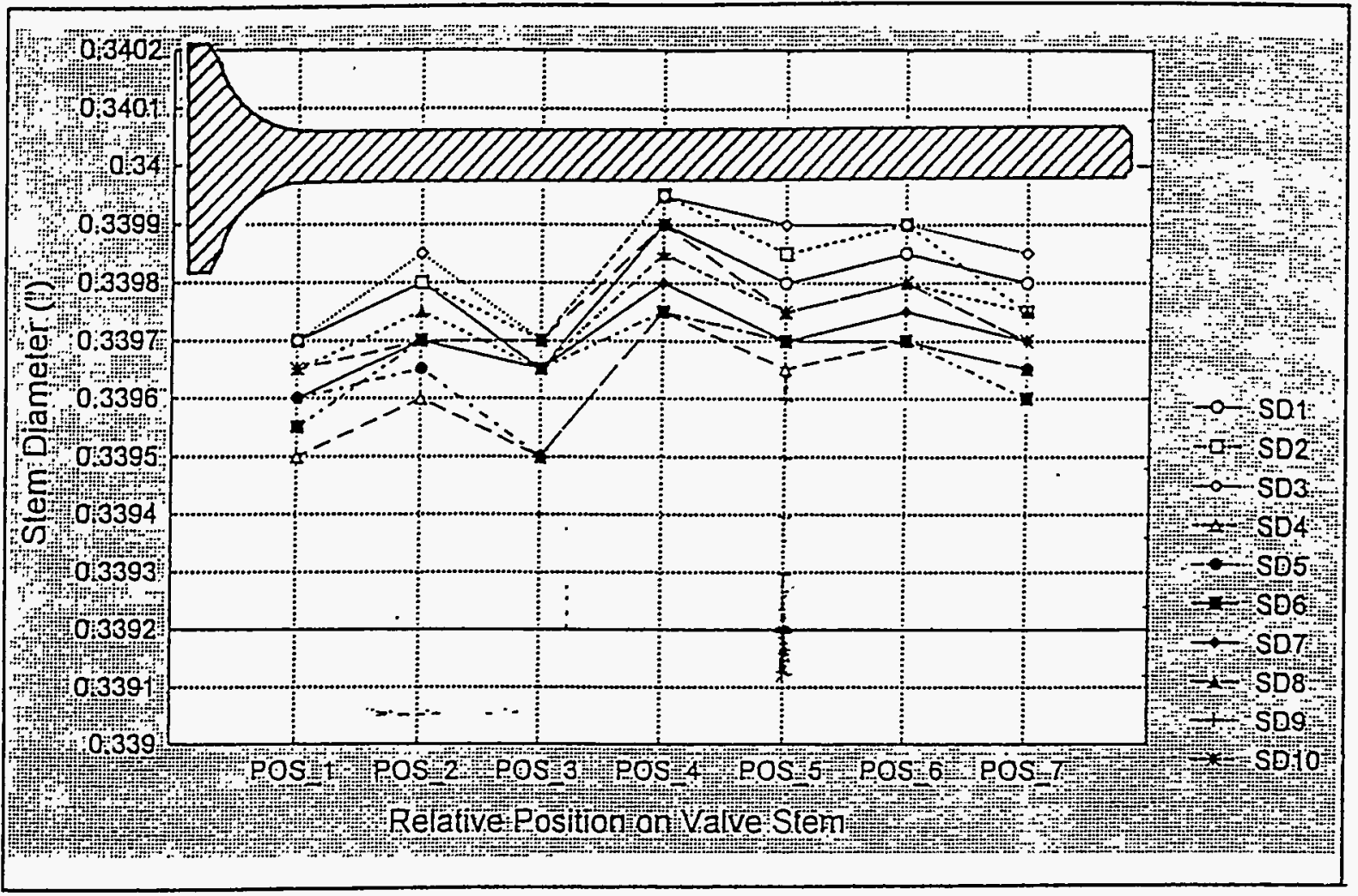

Figure 6 - Summary of Stem Diameter Process Capability

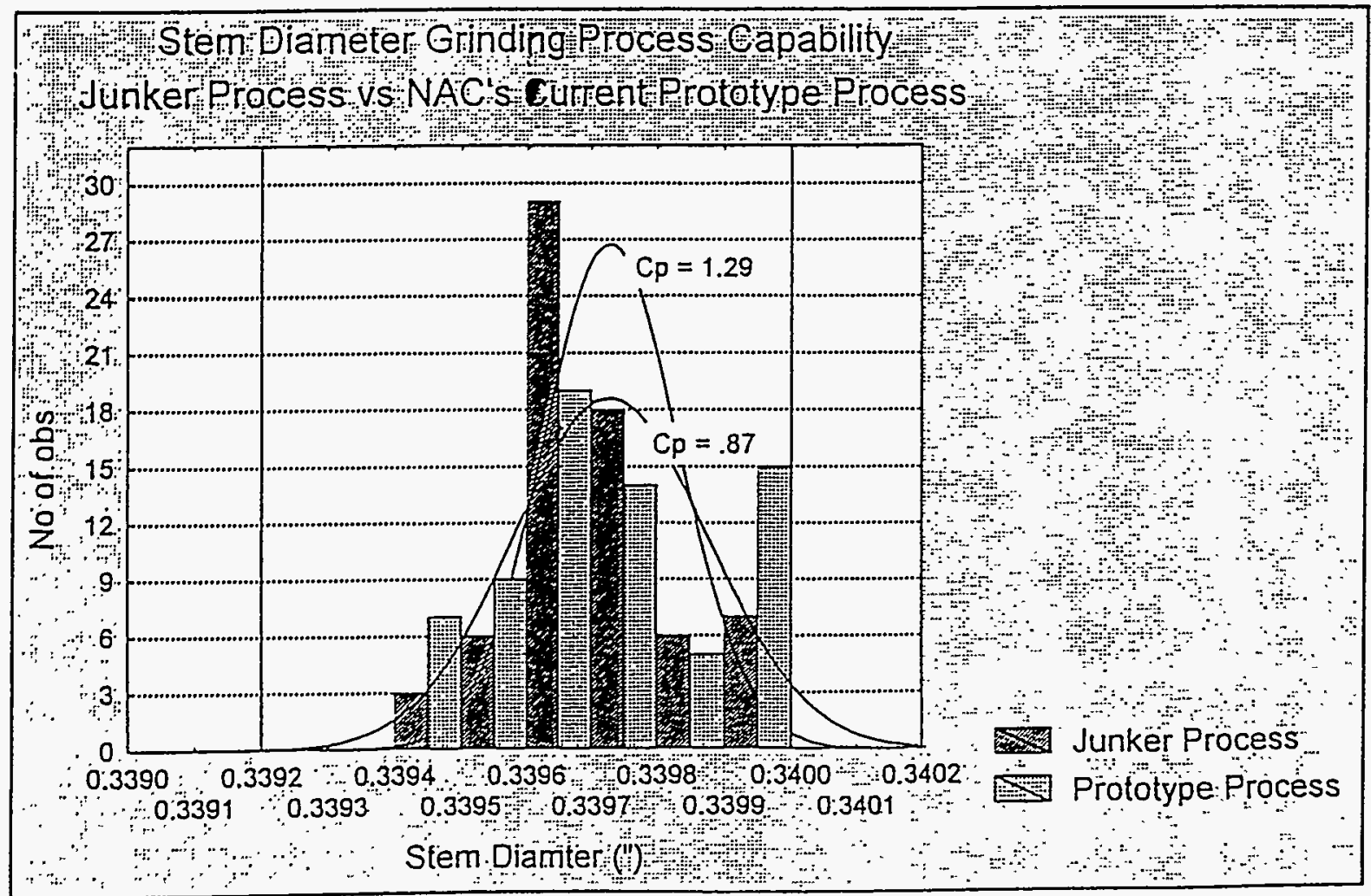


Figure 7 - Schematic of Infrared Moisture Sensor on NRDC's Spray Dryer

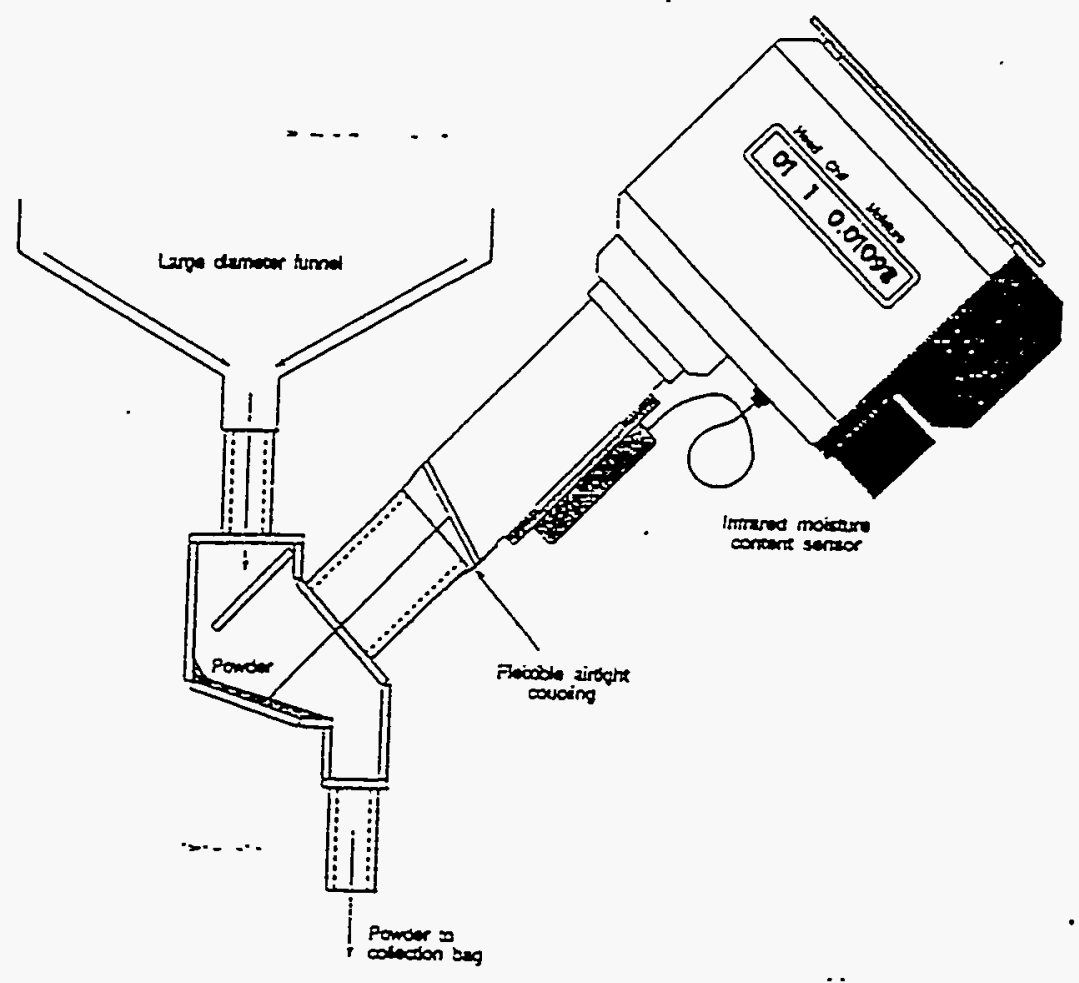

Figure 8 - (a) Infrared Absorbance as Measured by Kett On-Line IR Moisture Sensor Versus Powder Moisture Content Measured by Thermogravimetric Method;

(b) Powder Moisture Content Versus Slurry Flow Rate.

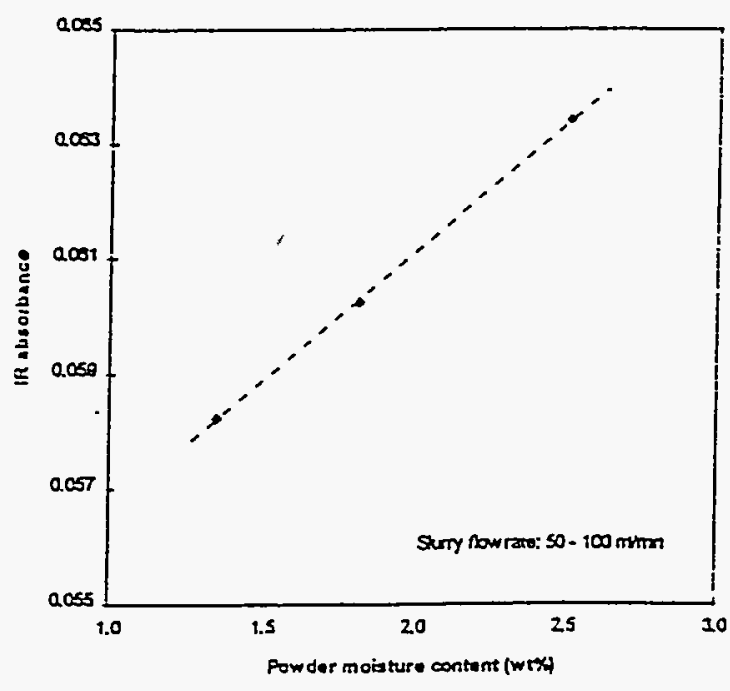

(A)

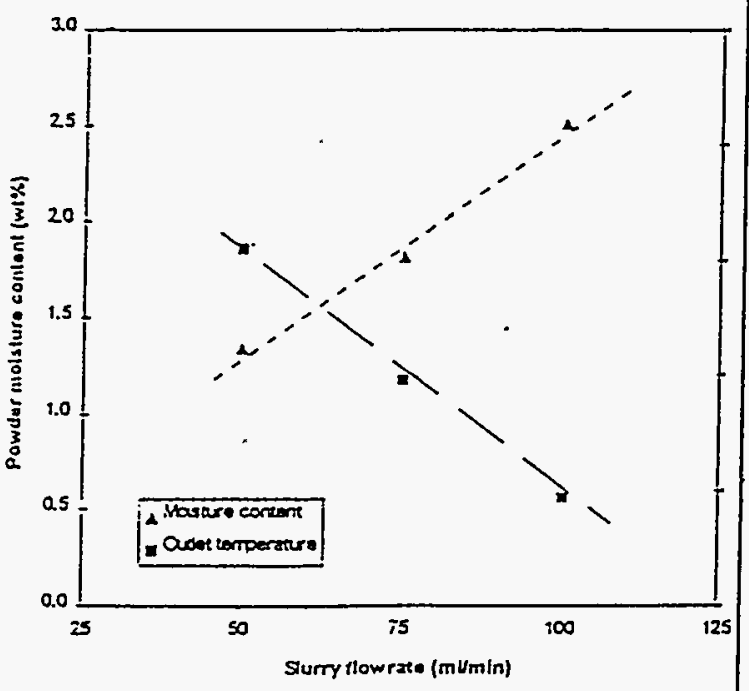

(B) 
Moisture content (IR absorbance

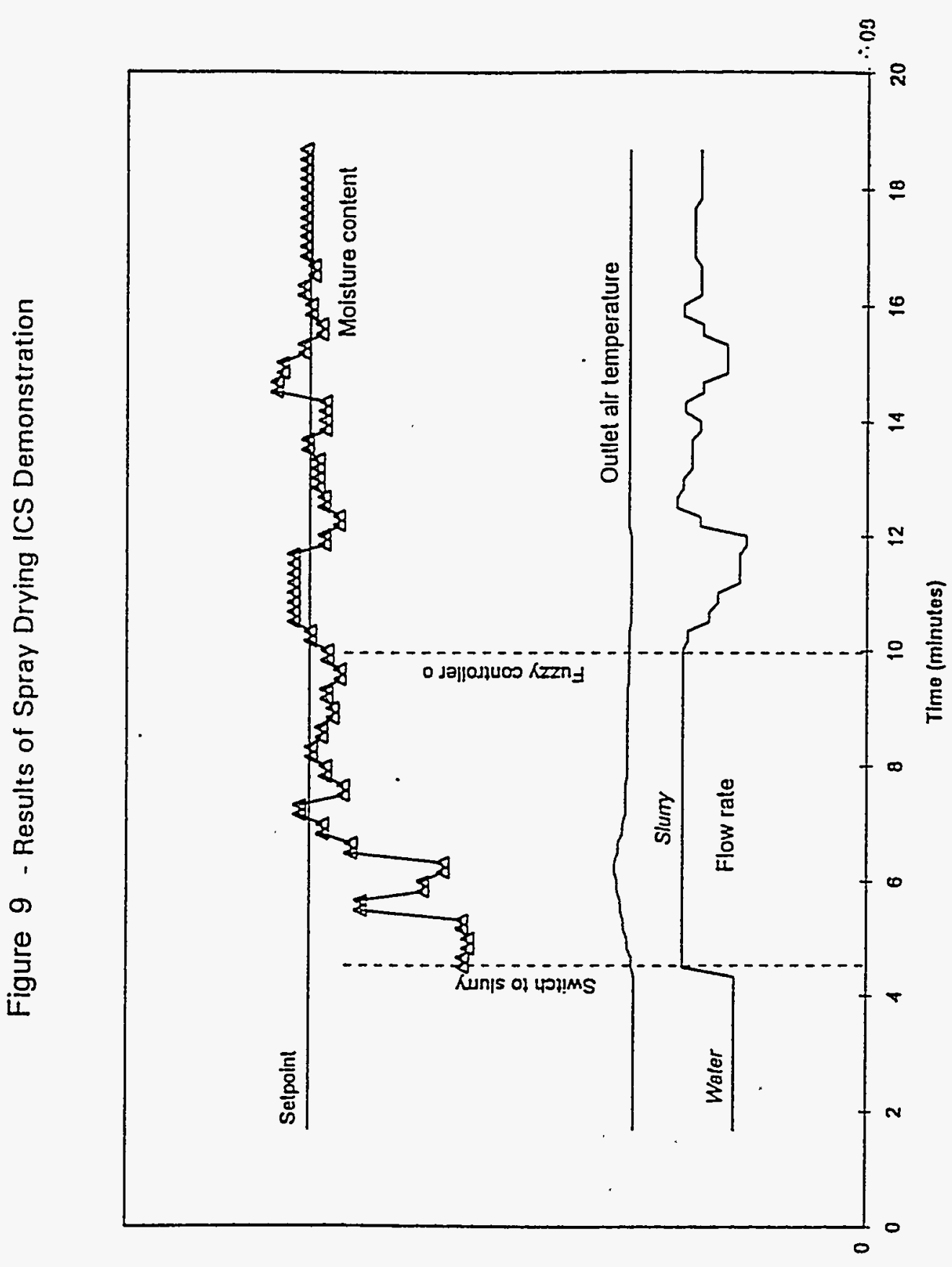

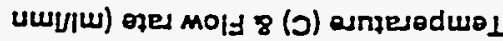




\section{Series 149 exhaust air flow with various valve}

$$
\longrightarrow \text { Production —C Ceramic, } 30 \text { deg. —— Ceramic, } 45 \text { deg. }
$$

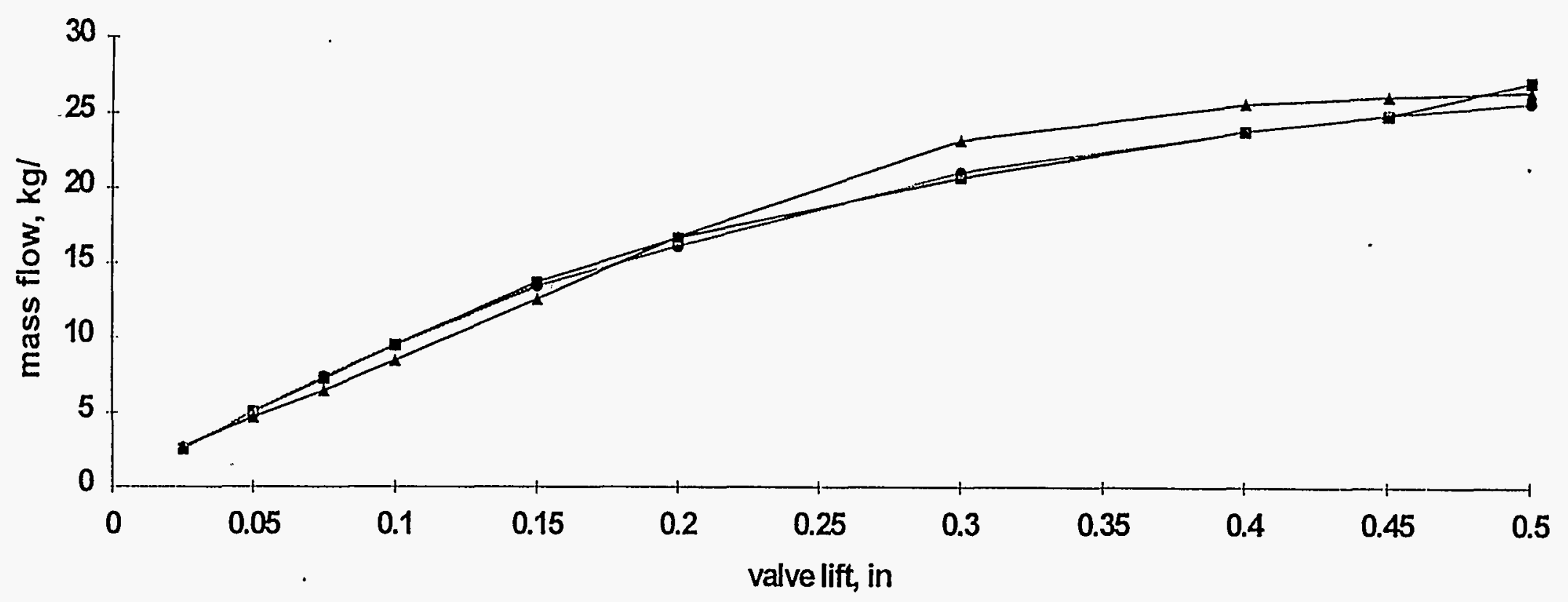

Figure 10. Air flow testing results 


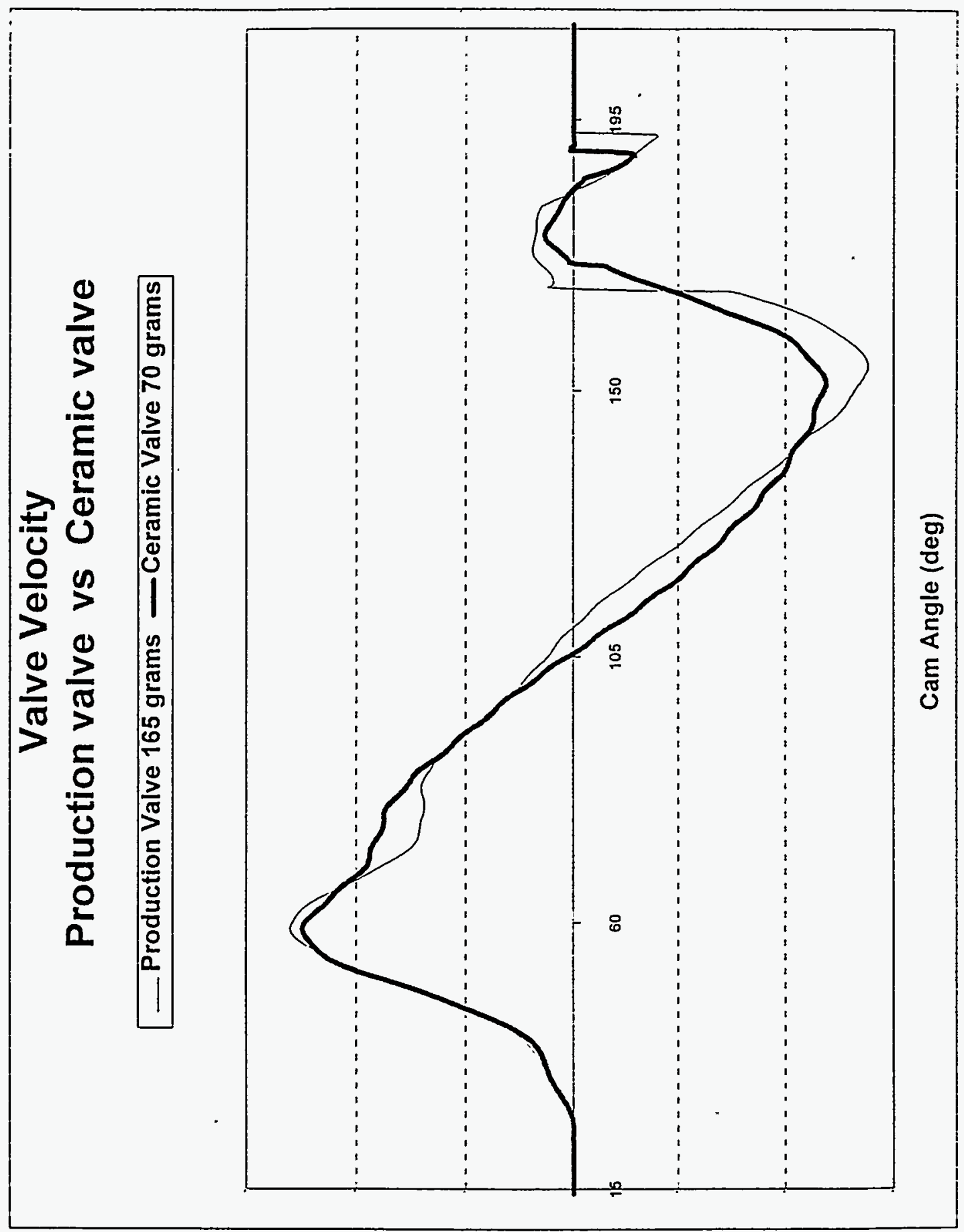

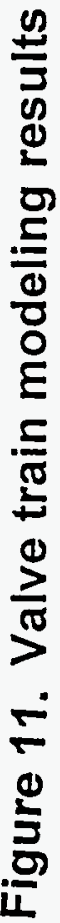





\subsection{MATERIALS DESIGN METHODOLOGY}

\section{INTRODUCTION}

This portion of the program is identified as program element 2 within the work breakdown structure (WBS). It contains three subelements: (1) Modeling, (2) Contact Interfaces, and (3) New Concepts. The sub-elements include macromodeling and micromodeling of ceramic micro-structures, properties of static and dynamic interfaces between ceramics and between ceramics and alloys, and advanced statistical and design approaches for describing mechanical behavior and for employing ceramics in structural design.

The major objectives of research in Materials Design Methodology elements include determining analytical techniques for predicting structural ceramic mechanical behavior from mechanical properties and microstructure, tribological behavior at high temperatures, and improved methods for describing the fracture statistics of structural ceramics. Success in meeting these objectives will provide U.S. companies with methods for optimizing mechanical properties through microstructural control, for predicting and controlling interfacial bonding and minimizing interfacial friction, and for developing a properly descriptive statistical data base for their structural ceramics. 


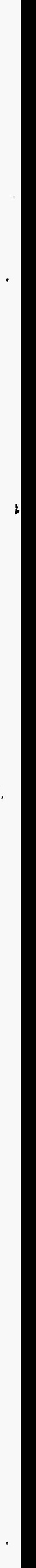




\title{
2.2 CONTACT INTERFACES
}

2.2.2 Dynamic Interfaces

W.B.S. Element 2.2.2.2

Development of a Standard Test Method for Evaluating the Wear Performance of Ceramics

\author{
P. J. Blau \\ Oak Ridge National Laboratory
}

\section{Objective/Scope}

The objective of this effort is to improve consistency in reporting ceramic wear data by helping to develop one or more standard test methods for quantitatively determining the wear resistance of structural ceramics, in reciprocating sliding, a type of motion which is experienced by several types of automotive and truck engine wear parts. ORNL is working with ASTM in meeting this objective. Wear-test development normally falls within the scope of ASTM's G-2 Committee on "Wear and Erosion," and in 1990, P. J. Blau was appointed chairman of a newlyestablished Task Group G02.40.07 "Reciprocating Sliding Wear Testing." This report describes the activities of that Task Group.

\section{Technical Highlights}

Work on this WBS element has been completed. A new ASTM standard G-133, applicable to wear testing of ceramics, will appear in the ASTM Annual Book of Standards Vol. 03.02 on "Wear and Erosion, Metal Corrosion" when it is printed this coming summer. The title of the new standard is "Standard Test Method for Linearly Reciprocating Ball-on-Flat Sliding Wear." The test method contains two procedures. These are summarized in Table 1.

Table 1. Summary of Standard Wear Testing Procedures A and B

\begin{tabular}{|l|c|c|}
\hline \multicolumn{1}{|c|}{ Test Conditions } & Procedure A & Procedure B \\
\hline \hline ball specimen & $\begin{array}{c}\text { tip radius } 4.76 \mathrm{~mm} \\
\text { (or } 0.375 \text { in diameter ball) }\end{array}$ & $\begin{array}{c}\text { tip radius } 4.76 \mathrm{~mm} \\
\text { (or } 0.375 \text { in diameter ball) }\end{array}$ \\
\hline normal force & $25 . \mathrm{N}$ & $200 . \mathrm{N}$ \\
\hline oscillating frequency & $5.0 \mathrm{~Hz}$ & $10.0 \mathrm{~Hz}$ \\
\hline stroke length & $10.0 \mathrm{~mm}$ & $10.0 \mathrm{~mm}$ \\
\hline test duration & $16 \mathrm{~min} 40 \mathrm{~s}$ & $33 \mathrm{~min} 20 \mathrm{~s}$ \\
lubrication state & none & immersion in oil \\
\hline temperature & $22 \pm 3{ }^{\circ} \mathrm{C}$ & $150 \pm 3{ }^{\circ} \mathrm{C}$ \\
\hline relative humidity range & $40-60 \%$ & $40-60 \%$ \\
\hline
\end{tabular}

Publication of the new standard completes work on this task. It is hoped that this new, validated wear test method will be widely used by the ceramics and transportation industries. 
•

-

: 
3.1 STRUCTURAL QUALIFICATION

WBS Element 3.1.1.4

MECHANICAL PROPERTIES AND MICROSTRUCTURAL
CHARACTERIZATION OF $\mathrm{Si}_{3} \mathrm{~N}_{4}$ CERAMICS

and

\begin{abstract}
ANALYTICAL ELECTRON MICROSCOPY FOR
CHARACTERIZATION OF CATALYST MICROSTRUCTURES
\end{abstract}

\author{
K.L. More, L. F. Allard, and T. A. Nolan
}

\title{
OBJECTIVE/SCOPE
}

The objective of the research is to use analytical and high resolution electron microscopy to characterize the microstructures of creep-tested NT-154 silicon nitride. More recently, the objective of the research has broadened to include the use of analytical and high resolution electron microscopy to characterize the microstructures of emission control catalysts. Emphasis is placed on relating microstructural changes to performance. Materials include three-way automotive catalysts and diesel oxidation catalysts.

\section{TECHNICAL HIGHLIGHTS}

\section{Characterization of Silicon Nitride Ceramics}

Three NT-154 tensile rods, creep tested at $1250^{\circ} \mathrm{C}$ and either 150 or $175 \mathrm{MPa}$, have been received from Ken Liu, Oak Ridge National Laboratory, for microstructural evaluation to determine creep mechanisms in these samples. All three samples ran under the given creep conditions for $>3$ years without failure, which is a significant result for any silicon nitride ceramic. A typical strain vs. time curve for one of the tensile creep specimens is shown in Figure 1. Past results have indicated that the most prevalent creep/failure mechanism in NT-154 is the formation of voids at the tensile boundaries during testing/use at elevated temperatures $\left(>1150^{\circ} \mathrm{C}\right)$ and that times to failure are usually relatively low $(<1000 \mathrm{~h})$ at these temperatures. Thus, it is important to determine what is microstructurally different in these NT-154 specimens which may result in a change in creep mechanism. In order to evaluate the microstructural changes, specimens were cut from each tensile rod from several different areas within the hot zone, which will be compared to the buttonhead material that was not exposed to high temperatures. This is illustrated in Figure 2. Both TEM and SEM specimens are currently being prepared. 
ORNL-DWG 91-16681R3

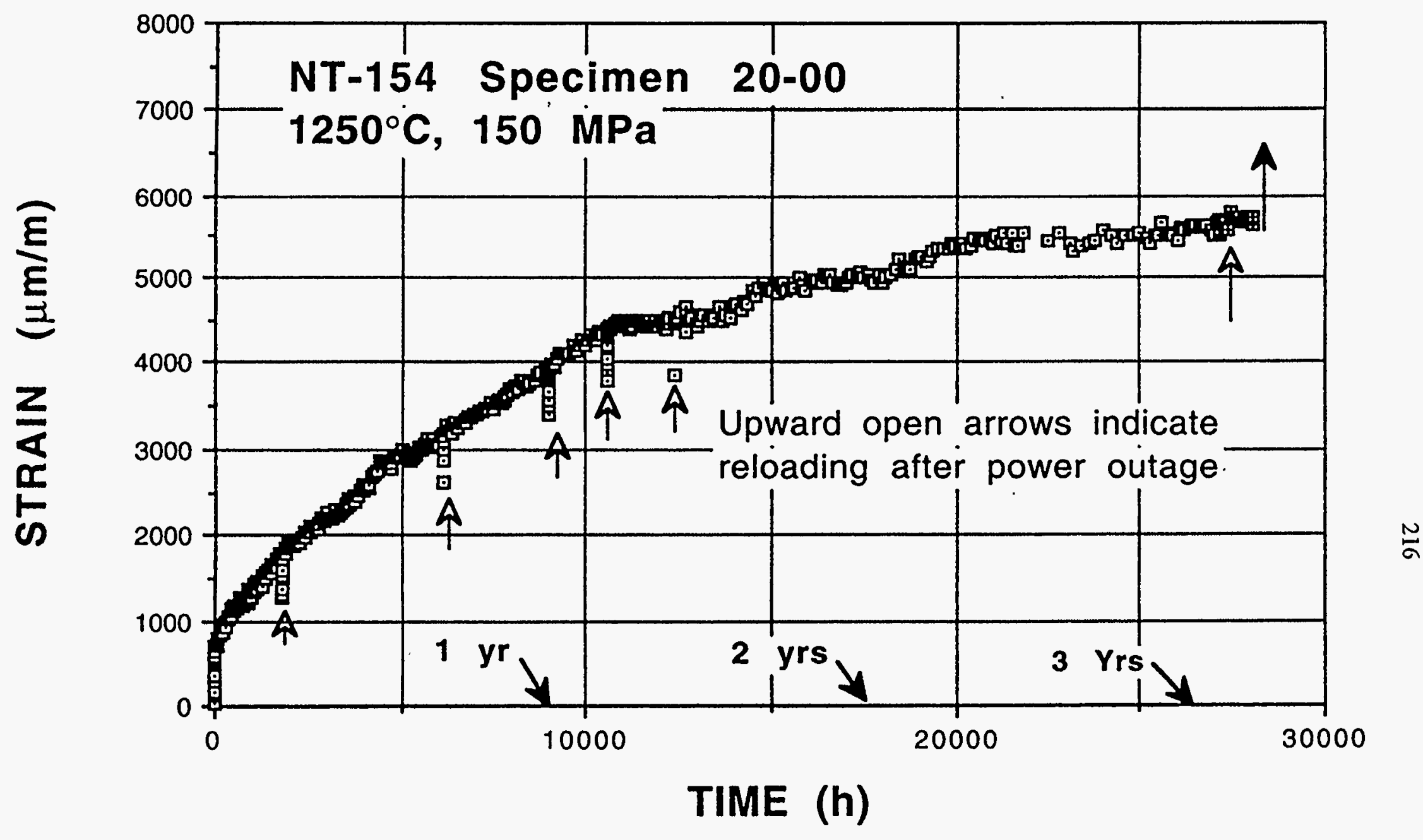

Figure 1. Typical creep behavior for NT-154 specimens which ran for $>3$ years. 


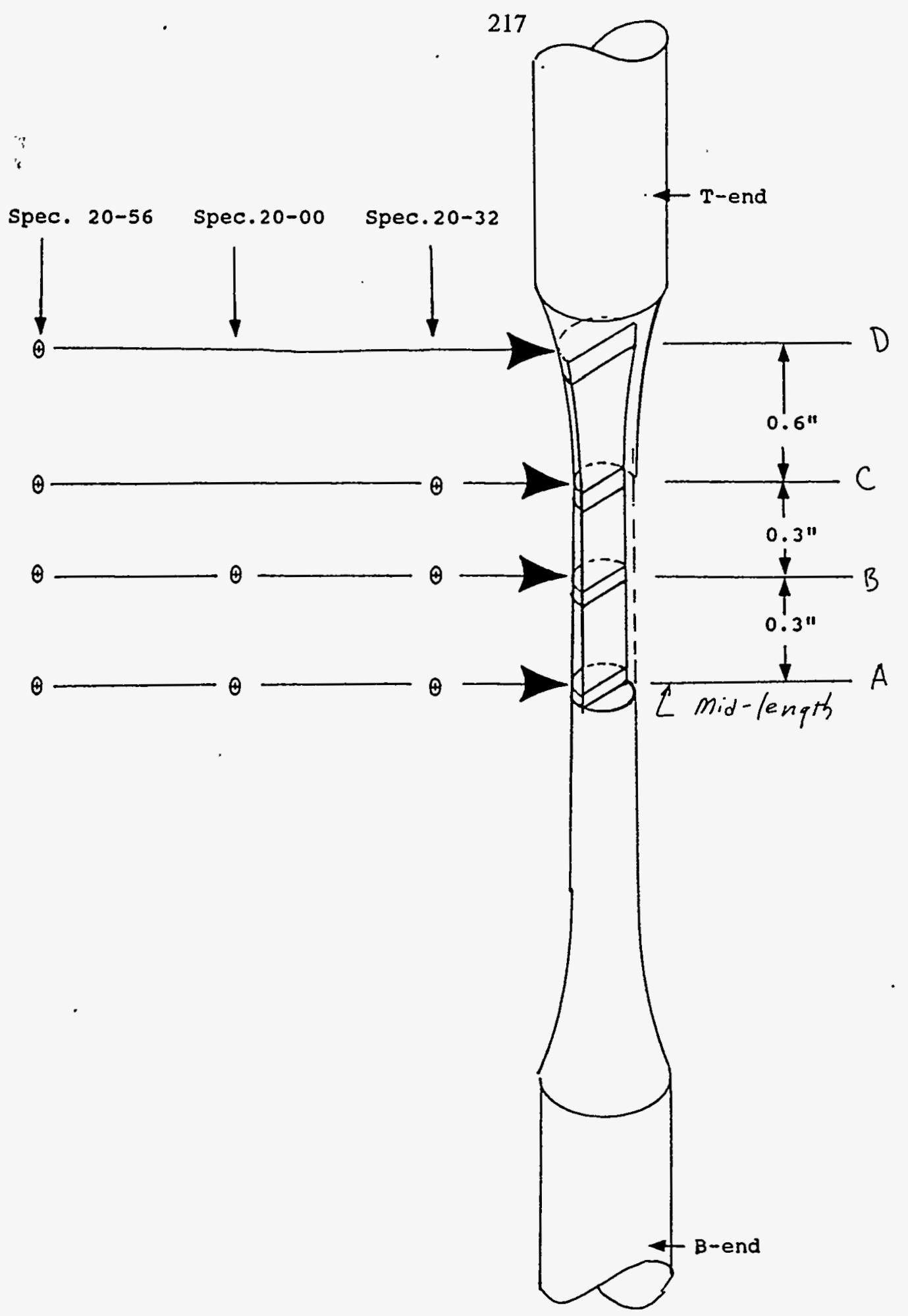

Figure 2. Specimens for TEM and SEM analysis were cut from selected areas within the hot zone for comparison with the buttonhead material. 


\section{Characterization of Catalyst Materials}

Catalyst characterization is a major new research area for this microscopy program; it was initiated in FY 1995 and is planned to be the single largest component of this Task for FY 1996. During FY-1995 Materials Analysis Group staff visited a number of both end users of catalysts and catalyst manufacturers to determine, among other things, areas of research that would be appropriate for DOE support through the Ceramic Technology Program and that would have significance in reducing automotive and transportation diesel emissions. Several research thrusts were identified that involved significant longterm effort and that were appropriate for this program. The first need identified was for a method to observe the effects of use wherein specific regions of a catalyst specimen could be observed before and after exposure to gas mixtures at temperatures and pressures that simulate use. Exposure and observation sequences needed to be accomplished without exposure to ambient air. To this end an ex-situ reactor and TEM specimen holder (compatible with both the reactor and the Hitachi HF-2000 FEG-TEM) have been designed and constructed which allow chosen sample areas on catalyst specimens to be examined in the FEG-TEM prior to and after an exposure cycle, with this sequence repeated as desired to record information on the changes that take place in the catalyst structure with repeated treatments. The specimen grid is protected by an inert atmosphere (argon gas) which is encapsulated around it by a special sealing mechanism on the specimen holder during the transfer to and from the microscope.

The design concept of using an "ex-situ" rather than an in-situ approach provides two major benefits. First, the gas compositions, pressures and exposure temperatures are not limited by materials and vacuum requirements of the TEM. Second, the specimen holder that positions the specimen in the TEM can closely approximate the geometry and construction of the standard holder of the microscope both in materials and design. Thus, unlike some commercially available specimen holders designed for particular specimen transfer operations, the ultimate spatial resolution of specimen structure provided by the microscopes is not compromised. We have recently demonstrated $0.2-$ $\mathrm{nm}$ resolution on a simulated catalyst specimen using this holder. The resources for the construction of the reactor/holder were provided through a Laboratory Directed Research and Development project. Ceramic Technology supports the research projects that use this facility.

As of this report construction is complete. Figure 3 shows the reactor and specimen holder. Figure 4 shows the specimen holder tip, with the specimen carrier in the retracted position as required for extraction from the holder and deposition into the reactor heater. As was stated previously, we have demonstrated that the holder does not compromise the ultimate spatial resolution of the microscope either by excessive mechanical vibration or drift. Temperature calibration has been completed, and it is found that a thermocouple attached to a monitoring point on the reactor furnace matches the temperature recorded on a thermocouple attached to the specimen carrier plate within a few degrees $\mathrm{C}$ at all temperatures up to $900^{\circ} \mathrm{C}$. Tests of the efficacy of the inert gas transfer system are underway, using as test specimens nanometer-scale iron oxide 
particles which are first reduced in hydrogen then transferred into the microscope. Since:: such particles undergo rapid oxidation and subsequent structural change with any exposure to oxygen, they are considered ideal for this experiment.

Researchers from Ford, W. R. Grace, AlliedSignal, and other catalyst manufacturers/end users are providing input for determining appropriate specimens and exposure conditions for the initiation of beneficial operation of the reaction system.

\section{PUBLICATIONS}

None

\section{PRESENTATIONS}

1. L. F. Allard, "Modern Field Emission Electron Microscopy Techniques Applied to Catalyst Characterization", Invited Talk at Catalyst Club of Philadelphia, Jan. 18, 1996.

2. L. F. Allard, P. A. Teague and T. A. Nolan, "Catalyst Research at the High Temperature Materials Laboratory", Seminar at Dupont Experimental Station, Wilmington, DE, Nov. 3, 1995.

3. L. F. Allard, "Catalyst Research at the High Temperature Materials Laboratory", presentation to Hoechst-Celanese researchers as part of H-C Government Day, Nov. 2, 1995. 

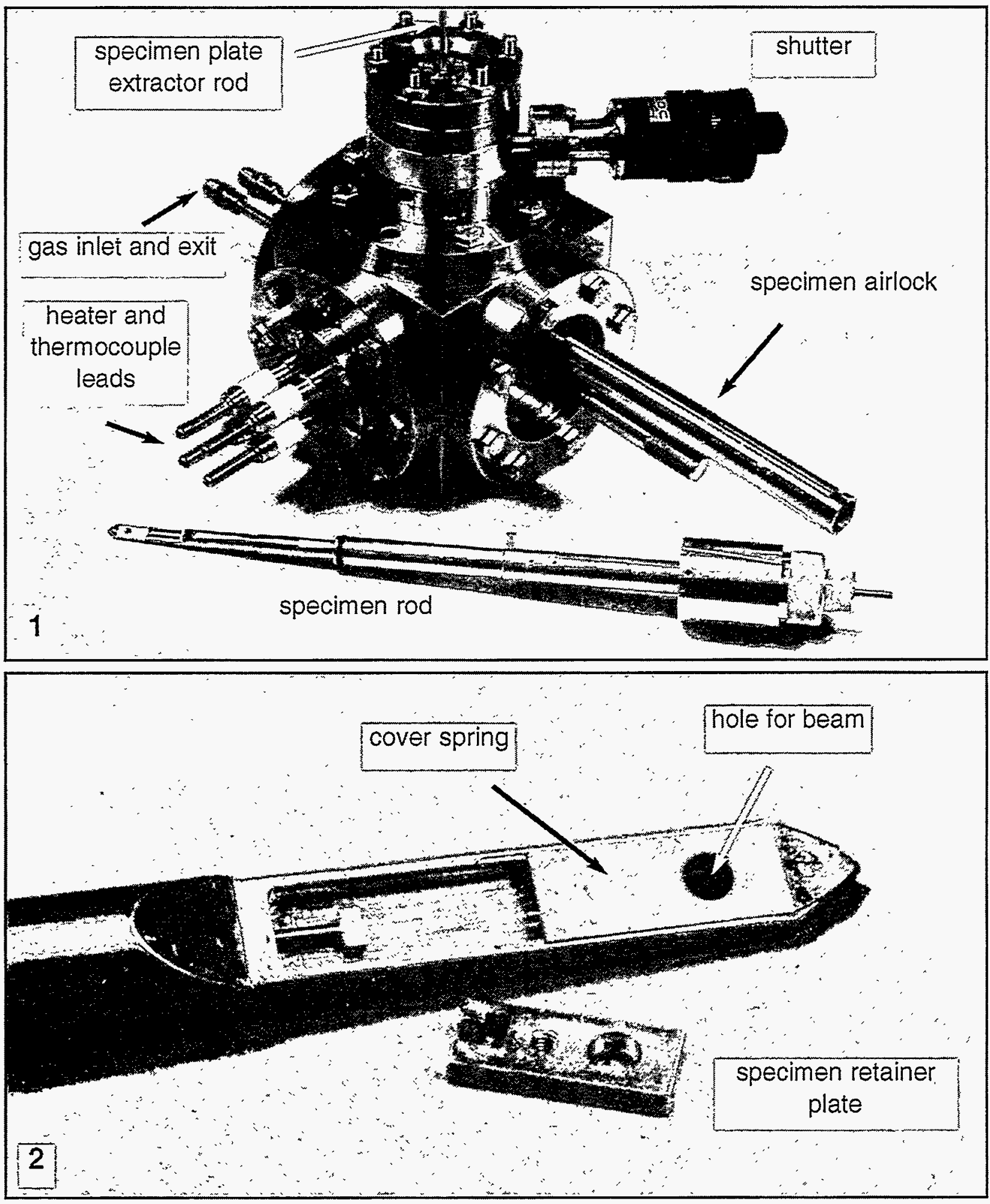

Fig. 3. Reactor showing major components and specimen rod assembly.

Fig. 4. Tip of specimen rod with specimen retainer plate removed. This plate is positioned under the cover spring during transfer and under hole during observation. 


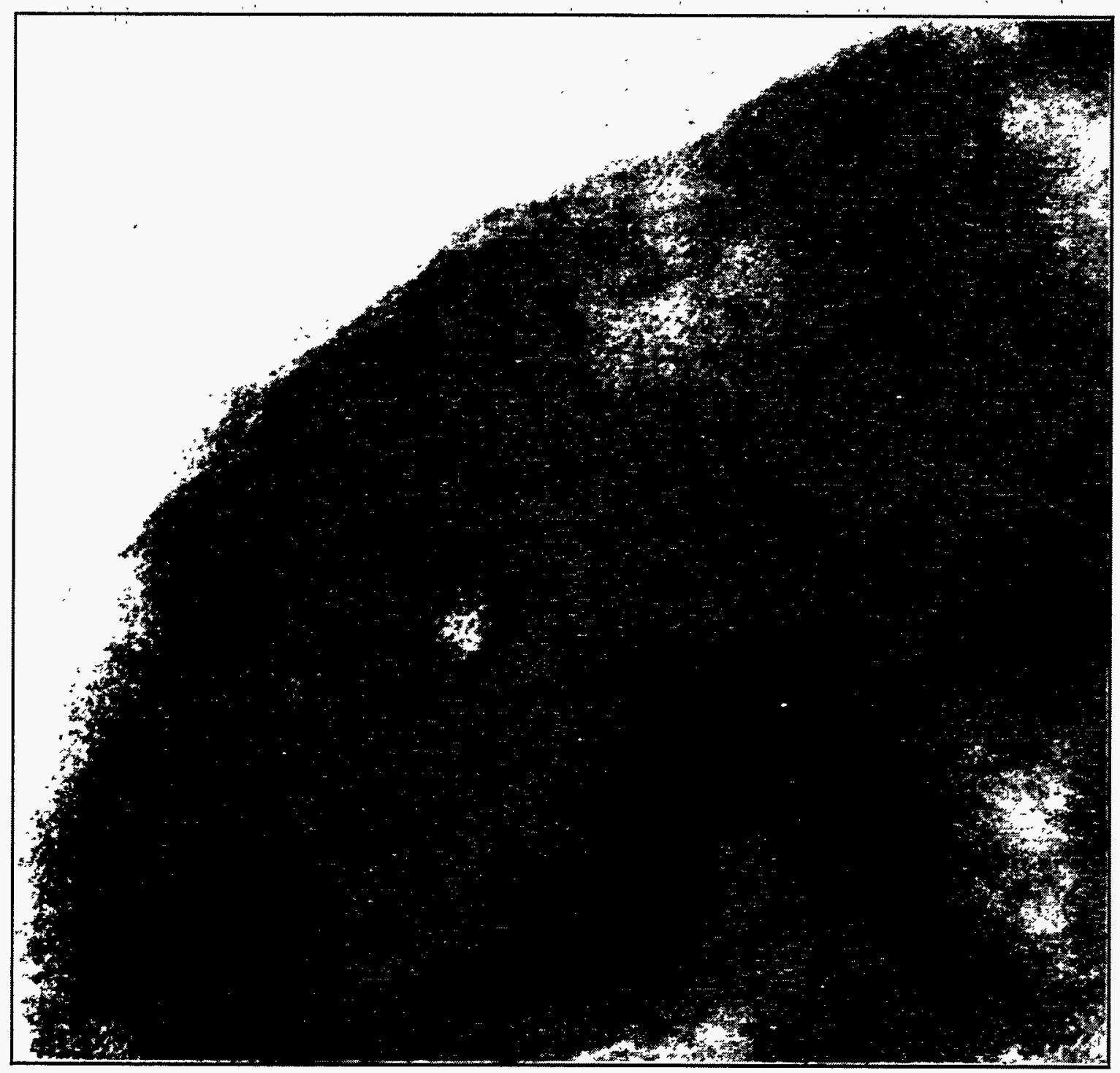

Fig. 5. Particle of $\mathrm{Fe}_{2} \mathrm{O}_{3}$ catalyst showing $0.25 \mathrm{~nm}$ lattice iringe spacing. Image taken with specimen in new specimen holder. 


\section{Project Database}

\section{B. L. Keyes (Oak Ridge National Laboratory) \\ Objective/Scope}

The objective of this task is to develop a comprehensive computer database containing the experimental data on properties of ceramic materials generated in the total effort. This computer system should provide a convenient and efficient mechanism for the compilation and distribution of the large amounts of data involved. The database will be available in electronic form to all project participants. In addition, periodic hard copy summaries of the data, including graphical representation and tabulation of raw data, will be issued to provide convenient information sources for project participants.

\section{Technical Highlights}

A new PC-type computer system needed to develop the proposed web version of the database was ordered and received during December 1995. The new system, a pentium with a much larger hard disk and four times more memory, was necessary because the new software required much more space in both RAM and on disk than the old system had, and the complexity of the latest programs required faster processors. Minor delays occurred during transitioning from the old system to the new system, due to peripheral device driver incompatibilities and a few other new-system nuisances.

Database personnel attended an off-site course on the new Visual FoxPro 3.0 (VFP) programming techniques. VFP possesses a versatile, more powerful programming language than earlier versions, with deep roots in object-oriented structure. Interfaces developed in this program should be more user friendly as well as more programmer friendly, thus better interfaces faster. Changes in some of the interfile linking keys have been made for the proposed interface to function properly.

Cold Fusion was selected as the best program to handle the web interface for the database and early results looked promising.

Data input during this period included adding more graphics from some of the earlier semiannual progress reports and low expansion ceramics information requested by a customer. Placing the graphics in FoxPro files made the files too large to handle for shipment to customers at the present $(>10 \mathrm{MB}$ ). For now, the graphics (micrographs, drawings, data plots, etc.) will continue to be stored in image files cataloged by both FoxPro and Kodak's Shoebox software on the Macintosh.

This effort will end in FY 1996, and future work on the database will consist of wrap-up and shutdown tasks only. The wrap-up version will consist of an interface written in VFP and all the data files stored in Lotus 1-2-3, FoxPro (Mac), FoxPro (PC), and ASCIl formats, along with documentation. Images will be in PICT (Mac) or TIF (PC) format if not contained in FoxPro files (due to size considerations). 
Communications/Visits/Travel

A presentation on the database was made to DOE and ORNL officials on April 4.

Status of Milestones

Wrap-up tasks are scheduled for completion on July 31, 1996.

Publications

None. 


\subsection{TIME-DEPENDENT BEHAVIOR}

W.B.S. ELEMENT 3.2.1.3

FRACTURE BEHAVIOR OF TOUGHENED CERAMICS

H. T. Lin, P. F. Becher, T. N. Tiegs, and J. O. Kiggans

\section{Objective /Scope}

Ceramics with reinforcing microstructures and ceramic composites offer important advantages for heat engine applications. Chief among these is the improved fracture toughness that can be achieved by appropriate design of microstructural and material parameters. Previous studies show that these materials often exhibit substantial improvement in damage, thermal shock, and slow crack growth resistances. However, design of such systems must also consider those factors influencing their performance at intermediate, as well as, elevated temperatures experienced in a variety of current and advanced engine applications.

In response to these needs, studies are conducted to determine the mechanical properties, (e.g., creep, delayed failure, strength, and toughness) at intermediate and elevated temperatures for these toughened ceramics. Particular emphasis is placed on understanding how microstructure and composition influence the mechanical performance at elevated temperatures and the stability of these properties for extended periods at these temperatures. The knowledge gained from these studies provides input on how to modify materials to optimize their mechanical properties for the temperature ranges of interest.

\section{Technical Highlights}

During this six-month reporting period the research efforts in this WBS Element were aimed to (1) complete a tensile creep round-robin test on a candidate silicon nitride and (2) evaluate the creep response of sintered reaction-bonded silicon nitride (SRBSN) materials as functions of powder processing routes and heating furnaces.

\section{Tensile Creep Round-Robin Test}

The measured creep results (i.e., creep rates and lifetimes) for a given silicon nitride material often vary by one to two orders of magnitude among different testing laboratories. At present, there is lack of an understanding of what factors contribute to this variability in creep results. A creep round-robin test was therefore initiated by' NIST to verify the accuracy and precision of the tensile creep test methods and to optimize the tensile specimen design. The participating laboratories in the current work included NIST, ORNL, AlliedSignal, St. Gobain/Norton, and Lehigh university. The participants and others in the materials community will then be able to obtain information both on the nature of the reproducibility about the testing techniques and equipment used at the various laboratories. Reliable creep databases can, therefore, be established for engineering design. The small dog-bone type creep specimen and laser-based optical extensometer were employed in this special creep round-robin test. The material selected for the creep round-robin test is the NGK SN88 and the test condition employed is $1400^{\circ} \mathrm{C}$ and $150 \mathrm{MPa}$ in air. The creep specimens were 
equilibrated at $1400^{\circ} \mathrm{C}$ in air for $24 \mathrm{~h}$ under an applied load of $10 \mathrm{MPa}$ before loading the specimen to the desired load of $150 \mathrm{MPa}$.

Figure 1 shows the creep strain versus time curves obtained by the participant for the SN88 ceramic tested at $1400^{\circ} \mathrm{C}$ under an applied stress of $150 \mathrm{MPa}$. The creep curves exhibited a primary stage followed by a secondary creep stage prior to failure. The results indicate that the SN88 exhibited little variation in creep response among the test specimens, which was consistent with that was reported by NIST. ${ }^{1}$ In addition, the measured creep rates $\left(1.48 \pm 0.22 \times 10^{-7} 1 / \mathrm{s}\right)$ and lifetimes $(39.6 \pm 4.4 \mathrm{~h})$ were within a factor of two of those obtained by NIST. The various measurements of the strain to failure (i.e., $2.53 \% \pm 0.32 \%$ average value) were comparable to that obtained at NIST.

\section{Creep Response of Sintered Reaction-Bonded Silicon Nitride}

Sintered reaction-bonded silicon nitride (SRBSN) offers an alternative, low-cost approach to fabricate the ceramic components for automotive propulsion system applications. However, the mechanical performance and reliability of SRBSN are greatly influenced by flaws introduced during the powder preparation. A uniform particle packing within the green bodies is necessary to achieve high quality sintered materials and thus consistent mechanical properties. The research efforts were, therefore, directed at the understanding of effects of powder processing routes, such as spray drying, die pressing, and gelcasting, on the creep properties of SRBSN. The influence of heating furnaces, i.e., brew furnace, graphite furnace, and microwave furnace, employed for nitridation and sintering cycles were also evaluated. The SRBSN materials investigated contain oxide additives of $3 \mathrm{wt} \% \mathrm{Al}_{2} \mathrm{O}_{3}-9 \mathrm{wt} \% \mathrm{Y}_{2} \mathrm{O}_{3}$ and are developed under the WBS Element 1.1.2.4. (Cost-Effective SRBSN). This is part of a larger effort in the development of cost-effective silicon nitride ceramics in propulsion system materials program.

(1). Processing effect. Figure 2 shows the creep results at $1200^{\circ} \mathrm{C}$ in air of SRBSN materials, which were processed by dry spraying, die pressing, or gelcasting methods. All the SRBSN materials studied were nitrided and sintered in a tungsten mesh resistance heated furnace in a nitrogen environment (designated as BFSRBSN). Results showed that both the spray dry and gelcast BFSRBSN materials exhibited a similar threshold stress $(\sim 125 \mathrm{MPa})$ above which both materials revealed high creep rates accompanied by short rupture lives $(<3 \mathrm{~h})$. In addition, the threshold stress obtained for both the spray dry and gelcast BFSRBSN materials was higher than that for the die press BFSRBSN ( $\sim 75 \mathrm{MPa})$. The rupture life and creep rate at stress levels above the threshold were found to be associated with enhanced creep cavitation and crack generation, noted in previous studies. ${ }^{2}$ On the other hand, both the spray dry and gelcast BFSRBSN materials also exhibited similar creep properties (creep rates and stress exponents) at stress levels below the threshold. However, the die press BFSRBSN material showed relative high creep rates with respect to those obtained from both the dry spray and gelcast BFSRBSN materials in this stress regime. The improved creep properties exhibited by both the dry spray and gelcast BFSRBSN materials are due to the more homogeneous powder packing and less impurities in green bodies as compared with the BFSRBSN using the die pressing process. 
(2) Heating furnace effect. Figure 3 shows the creep results at $1200^{\circ} \mathrm{C}$ in air of SRBSN materials, which were sintered in a nitrogen environment in a graphite (GFSRBSN), a microwave (MWSRBSN), or a tungsten mesh resistance heated furnace (BFSRBSN). All the SRBSN materials were processed by a gelcasting method. Results show that MWSRBSN material exhibits creep rates that are 7-times to 3-orders of magnitude lower than both the GFSRBSN and BFSRBSN materials under the similar test conditions. In addition, the MWSRBSN material exhibits a higher threshold stress $(\sim 175 \mathrm{MPa})$ than BFSRBSN $(\sim 125 \mathrm{MPa})$ or GFSRBSN $(\sim 100 \mathrm{MPa})$ material. Above the threshold stress the SRBSN materials reveal high creep rates accompanied by short creep lives $(<3 \mathrm{~h})$, which are again associated with enhanced creep cavitation and crack generation, as noted in previous studies. ${ }^{2}$ The improved creep performance in MWSRBSN material is attributed to the presence of larger, highly-developed elongated grains, which were not observed in either the GFSRBSN or BFSRBSN materials. The presence of larger elongated grains could improve the fracture toughness and resistance to creep deformation process by grain boundary sliding. In addition, the differences in content of glassy phase(s) and impurities due to different sintering furnace (thus, environment) could also influence the creep rate and life.

\section{Status of Milestones}

1. A modification of Milestone No. 321320: "Complete evaluation of the effect of an oxidizing, moist environment on the lifetime of candidate engine valve materials" has been requested due to the consistent difficulty in obtaining the candidate SiAION valve materials. An alternative Milestone No. 321320 entitled "complete evaluation of elongated grain morphology and oxide additives on creep of silicon nitride ceramics" will be initiated to investigate the effect of large elongated grain distribution and orientation on creep of beta- $\mathrm{Si}_{3} \mathrm{~N}_{4}$ seeded silicon nitride ceramics with different $\mathrm{Al}_{2} \mathrm{O}_{3} \mathrm{Y}_{2} \mathrm{O}_{3}$ ratios.

2. Milestone No. 321321: "Complete the tensile creep round-robin test for $\mathrm{SN} 88 \mathrm{Si}_{3} \mathrm{~N}_{4}$ ceramic to verify the accuracy and precision of the tensile creep test method" was completed.

\section{$\underline{\text { Publications }}$}

1. H. T. Lin and P. F. Becher, "Creep Behavior in SiC Whisker-Reinforced Alumina Composites," invited talk, pp. 543-553 in Plastic Deformation of Ceramics, J. Routbort, R. C. Bradt, and C. Brook, eds., Plenum Press, New York, 1995.

2. S. L. Hwang, H. T. Lin, and P. F. Becher, "Mechanical Properties of $\mathrm{B}_{-} \mathrm{Si}_{3} \mathrm{~N}_{4}$ Whisker Reinforced $\alpha$-SiAION Ceramics," J. Mater. Sci. , 30 (1995) 6023-6027.

3. H. T. Lin, K. A. Alexander, and P. F. Becher, "Grain Size Effect on Creep Deformation of Alumina-SiC Composites" accepted for publication in the J. Am. Ceram. Soc. (in press). 


\section{References}

1. S. Malghan, S. Weiderhorn, B. Hockey, and G. Quinn, "Ceramic Characterization and Standards for Heat Engines," pp. 120-125 in Ceramic Technology Project Bimonthly Technical Progress Report, June-July, 1995, ORNL/CF-95/77, Oak Ridge National Laboratory, August 31, 1995.

2. H. T. Lin, P. F. Becher, and W. H. Warwick "Fracture Behavior of Toughened Ceramics," in Ceramic Technology Project Semiannual Progress Report, October 93March 94.

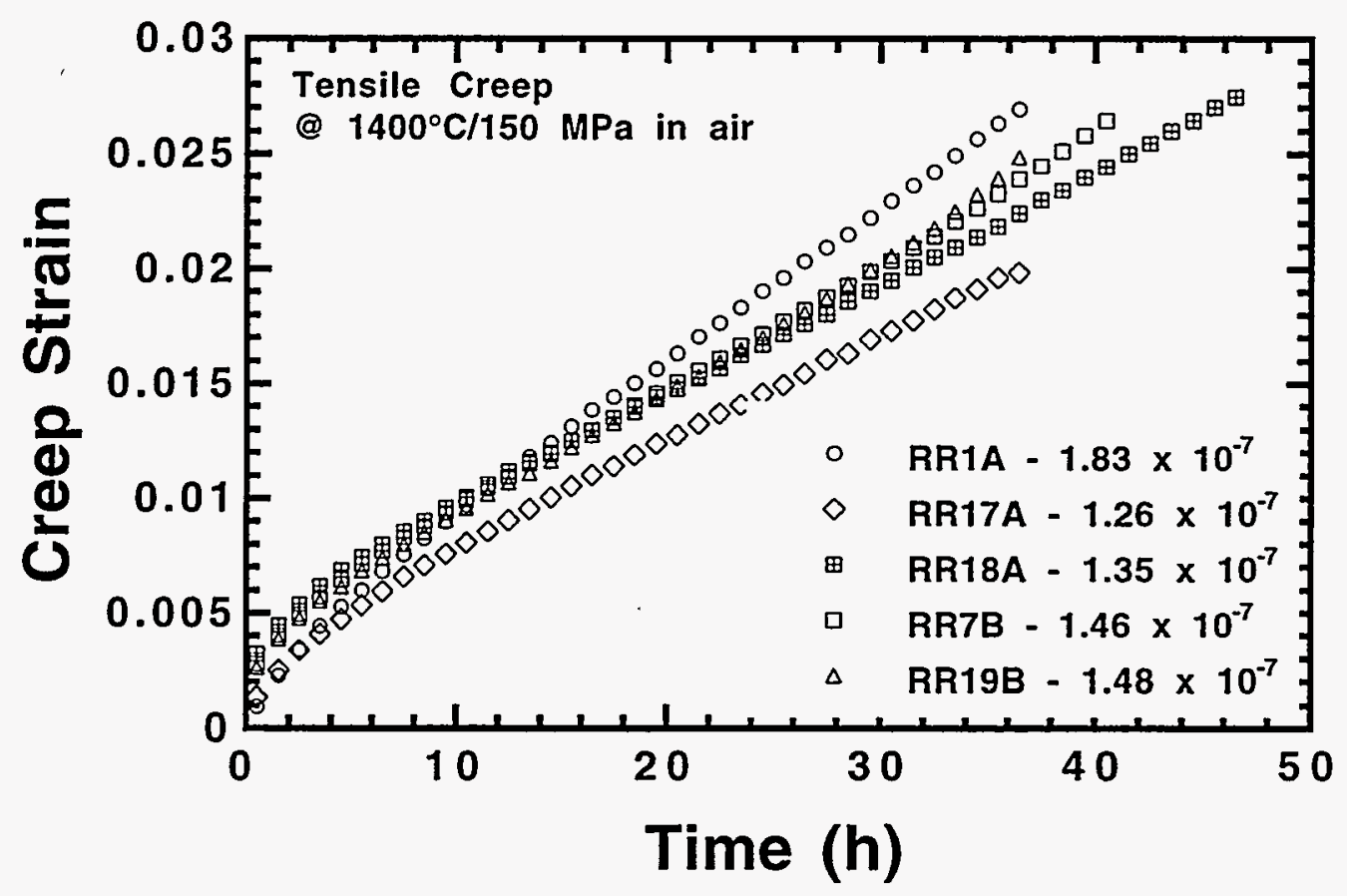

Figure 1. Creep strain versus time curves obtained by five different SN88 specimens tested at $1400^{\circ} \mathrm{C}$ and at $150 \mathrm{MPa}$ in air. 


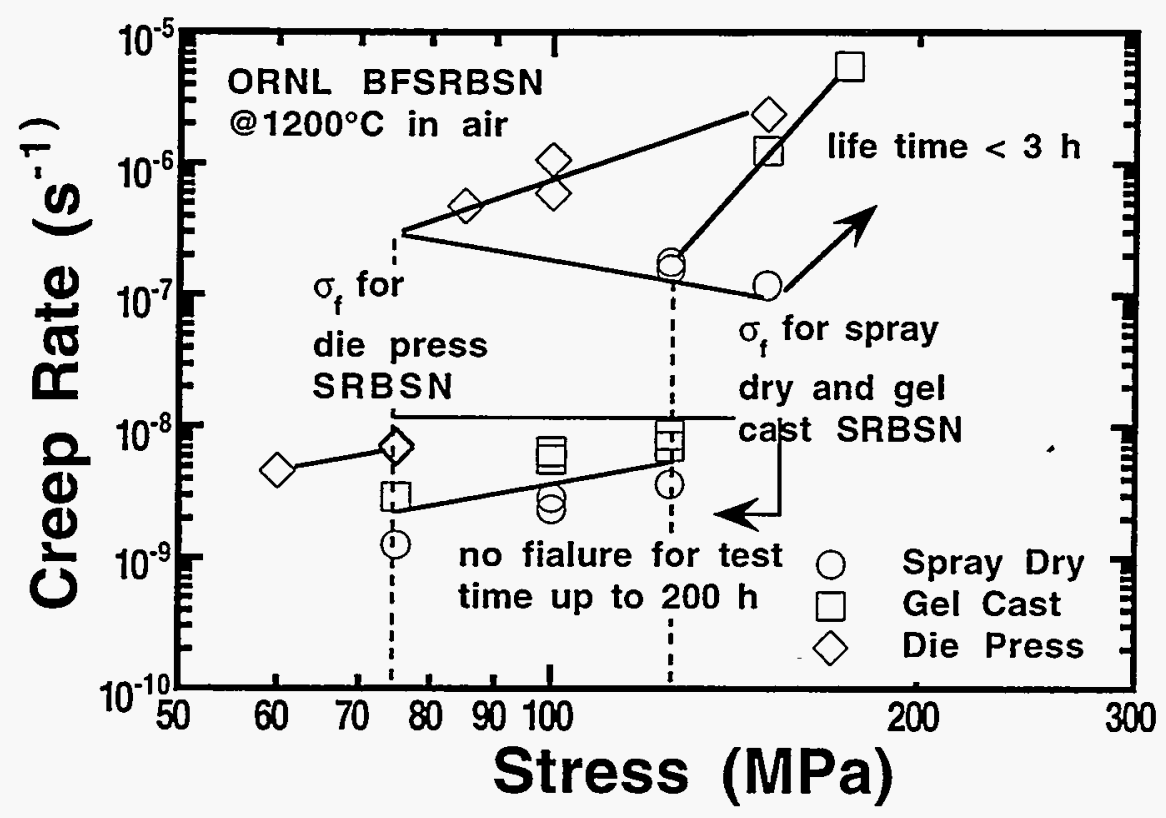

Figure 2. Creep rate versus stress curves for brew-furnace sintered reaction bonded silicon nitride materials processed by spray drying, die pressing, and gel casting methods.

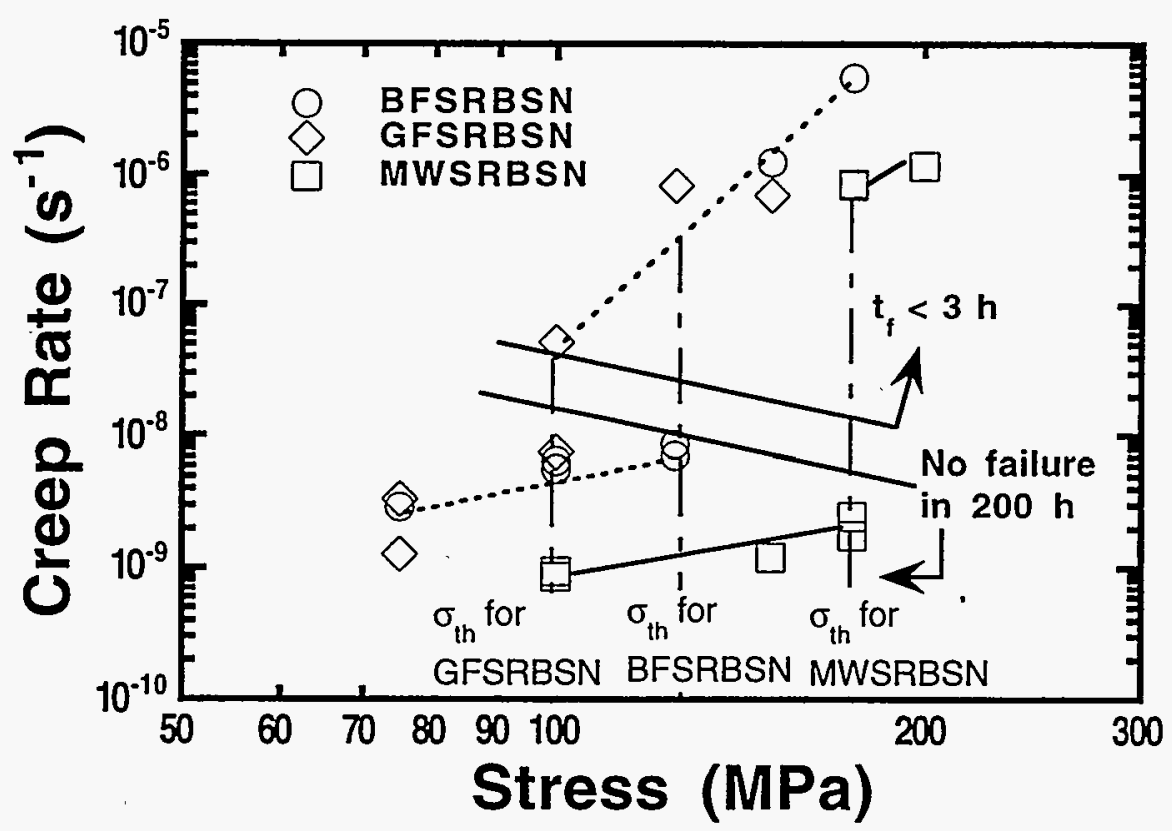

Figure 3. Creep rate versus stress curves at $1200^{\circ} \mathrm{C}$ in air for reaction bonded silicon nitride materials sintered in a graphite furnace (GFSRBSN), microwave furnace (MWSRBSN), and brew furnace (BFSRBSN). All the SRBSN materials were processed by a gelcasting method. 
Cyclic Fatique of Toughened Ceramics

K. C. Liu, C. O. Stevens, and C. R. Brinkman (Oak Ridge National Laboratory)

\section{objective/Scope}

The objective of this task is multifold:

1. To develop, design, fabricate, and demonstrate the capability of performing cyclic fatigue in tension-tension/compression and static fatigue testing in uniaxial tension/compression on candidate structural ceramics at elevated temperatures. significant progress has been made in several areas on the experimental front (such as specimen/grip alignment, specimen heating, and high-temperature extensometry), including recent introduction of new testing capabilities in fully reversed tension-compression cyclic fatigue and compressive creep in the uniaxial mode.

2. To develop baseline information on cyclic fatigue behavior of candidate ceramics and, in turn, to establish a design database.

3. To develop creep and creep-rupture databases for advanced heatengines design applications in the 1150 to $1370^{\circ} \mathrm{C}$ range.

4. To evaluate and refine existing constitutive models based on the information generated above.

5. To develop new constitutive models to facilitate design analyses of high-temperature structural components and improve their reliability.

\section{Technical Highlights}

Cyclic fatigue of $\mathrm{GS}-44 \mathrm{Si}_{3} \mathrm{~N}_{4}$ at $1200^{\circ} \mathrm{C}$

The objective of the tests described in this section is to determine the cyclic fatigue behavior and the influence of cyclic waveform on the fatigue of GS-44 Si $\mathrm{S}_{3} \mathrm{~N}_{4}$ ceramics. The waveforms shown in Fig. 1 were used to control cyclic fatigue testing in: (a) fully reversed tension-compression ( $T / C)$ mode with $R$-ratio (= $\min . / \max$. stress amplitude) $=-1$, (b) tension-tension $(\mathrm{T} / \mathrm{T}$ ) mode with $R=0.1$, and (c) compression-compression (C/C) mode with $R=$ 0 . A small R-ratio was used to prevent load-train backlash during T/T fatigue loading. Hourglass-shaped (HG) specimens (Fig. 2a) were used in all three modes of fatigue testing and buttonhead (BH) specimens (Fig. $2 \mathrm{~b}$ ) in $\mathrm{T} / \mathrm{T}$ mode testing only.

Results of previous cyclic fatigue tests using hourglass-shaped (HG) specimens showed that fatigue data obtained from cyclic loading in T/C mode (Fig. Ia) mode fell consistently on the upper bound curve of the shaded band shown in Fig. 3. However, T/T fatigue data obtained from the same type of specimens, but not made from the same stock tile, fell above the upper bound curve by 20 to $40 \mathrm{MPa}$, suggesting that cyclic loading in $\mathrm{T} / \mathrm{C}$ mode may be more 
detrimental to cyclic fatigue of GS-44 Si $\mathrm{S}_{3}$ compared to that in $\mathrm{T} / \mathrm{T}$ mode. Subsequently, more $T / T$ tests were performed using $B H$ specimens, and results (filled-square symbols) are plotted in Fig. 3. The $B H$ fatigue data do not support the earlier finding. Since the $\mathrm{BH}^{\cdot}$ specimens were fabricated from a third tile, the inconsistent test results are suspected to have resulted from material variations. To clear this contradictory finding, two $\mathrm{BH}$ specimens and three HG specimens were fabricated from blanks sectioned-from a tile as shown in Fig. 4.

Fatigue data for the two HG and three BH specimens are plotted with partially-filled circles and squares, respectively, as shown in Fig. 3. Numbers in Fig. 3 refer to specimen numbers. Specimens HG-13 and $B H-17$ were fabricated from two adjacent blanks and tested with the same stress amplitude of $300 \mathrm{MPa}$. Specimen $\mathrm{BH}-17$ failed in 52 cycles, the lowest fatigue life among four tested on the five specimens fabricated from the same tile. Specimen HG-14 failed in 148 cycles. It should be noted that specimen HG-14 was precycled to $280 \mathrm{MPa}$ for about 1 million cycles before the cyclic stress was increased to $300 \mathrm{MPa}$. This test condition is represented by an open circle shown in Fig. 3. The arrow. indicates the data point does not represent its fatigue life which would be longer if the test continued at the condition indicated. For the sake of comparison, the cyclic life of HG-14 was plotted as if no damage had been introduced by the precycling at $280 \mathrm{MPa}$. Contrastingly, specimen $\mathrm{BH}-16$ which was also tested with a stress amplitude of $280 \mathrm{MPa}$ failed after completing 134,842 cycles.

According to the new fatigue data obtained from the same tile, the HG specimens showed fatigue performance better than the $\mathrm{BH}$ specimens but only marginally. Besides, the overall fatigue behavior was consistent with the three filled square data obtained previously from specimens which were made from a different tile. In summary, it may be concluded that the cyclic fatigue in $T / C$ mode is probably as damaging as that in $\mathrm{T} / \mathrm{T}$ mode.

Cyclic fatigue of microwave-annealed GS-44 Si $\mathrm{S}_{3} \mathrm{~N}_{4}$ at $1200^{\circ} \mathrm{C}$

Three microwave-annealed (MW/A) BH specimens were fatigue tested at $1200^{\circ} \mathrm{C}$ in $\mathrm{T} / \mathrm{T}$ mode. The specimens were made from a tile having been microwave annealed at $1200^{\circ} \mathrm{C}$ for $10 \mathrm{~h}$ with preannealing at $1100^{\circ} \mathrm{C}$ for $10 \mathrm{~h}$. Specimens MA12-11, -12 , and -14 were cycled to stress amplitudes of $300,280^{\circ}$, and $260 \mathrm{MPa}$, and failed at 21242 , 12955, and 52 cycles, respectively. The data are plotted in Fig. 3. Overall test results show the microwave annealing did not change or enhance the fatigue properties of this material at $1200^{\circ} \mathrm{C}$. However, the influence of microwave annealing on the fatigue behavior at other temperatures below $1200^{\circ} \mathrm{C}$ remains to be investigated.

Predictions of cyclic fatique behavior of $\mathrm{GN}-10 \quad \mathrm{Si}_{3} \mathrm{~N}_{4}$ at $1200^{\circ} \mathrm{C}$ based on the ORNL viscoplastic model ${ }^{1}$ 
Previously, tensile fast fracture behavior was successfully simulated for $\mathrm{GN}-10 \mathrm{Si}_{3} \mathrm{~N}_{4}$ tested with a low stressing rate of 7.5 $\mathrm{MPa} / \mathrm{min}$ at elevated temperatures based on the viscoplastic constitutive model ${ }^{2}$.' An exploratory study was made to predict the cyclic fatigue lives of $\mathrm{GN}-10 \quad \mathrm{Si}_{3} \mathrm{~N}_{4}$ at four temperatures using the viscoplastic model. Predictions (lines) are compared with experimental data (symbols) as shown in Fig. 5. The data points plotted on the $\mathrm{Y}$-axis represent the tensile fast fracture strength of the material tested at 1200 and $1250^{\circ} \mathrm{C}$ with a high stressing rate of $2,100 \mathrm{MPa} / \mathrm{min}$. The model predicted high-cycle fatigue behavior somewhat conservatively; however, it overestimated the $1200^{\circ} \mathrm{C}$ tensile strength. Based on available tensile data, the model may overestimate the low-cycle fatigue lives at 1150 and $1200^{\circ} \mathrm{C}$, but will predict those at 1250 and $1300^{\circ} \mathrm{C}$ reasonably well. Poor predictions of high-cycle fatigue behavior at the lower two temperatures was not unexpected since the model was primarily developed for creep behavior predictions at high temperatures.

\section{High-frequency dynamic cyclic fatique}

Installation work of the high-frequency dynamic fatigue testing system has been completed, but the system will not be in operation until the final system checkout tests are completed. Current efforts are to become familiar with the operating procedure and to design a test jig that can maintain pristine uniaxiality while a test specimen is subjected to high-frequency cycling.

Tensile stress-rupture testing of NT-154 $\mathrm{Si}_{3} \mathrm{~N}_{1}$ in support of the Ceramic Turbine Engine Demonstration Project (CTEDP)

The objective of this Project is to understand the effect of proof testing on the reliability of turbine engine components such as blades and stators. ORNL has agreed to conduct thirty tests on NT-154 tensile specimens at elevated temperatures in support of the program. This phase (Phase III since the ATTAP) of testing is to establish the baseline properties. All the tests have been successfully completed. Results of some long-term tests $(>400 \mathrm{~h})$ obtained at $1204^{\circ} \mathrm{C} / 310 \mathrm{MPa}(45 \mathrm{ksi})$ are summarized in Fig. 6. The creep curves are clearly separated in two groups. Specimens in Group I crept faster than those in Group II; however, creep behavior within each group appeared to be consistent. One specimen (\#35354) showed much better resistance to creep than others. The reason for the excellent creep performance is not known at this time. In Fig. 6, the downward arrow indicates specimen failure at the condition indicated and the upward one indicates the test was discontinued with no specimen failure.

Less than $40 \%$ of tests performed at $1315^{\circ} \mathrm{C}$ yielded useful data as shown in Fig. 7. Many specimens failed prematurely on loading to the intended test stress because of preexisting contaminants in the specimens. Despite the creep curves shown in Fig. 7 are short, less than $1 \mathrm{~h}$ in most cases, the creep curves are shown to be 
separated in two groups also. The difference in creep performance observed from test results shown in Figs. 6 and 7 may be attributed to the post fabrication heat treatment of the ceramic material. Test data have been transmitted to Alliedsignal Engines for review and inclusion in their database.

\section{Creep testing of $\mathrm{NT}-154 \quad \mathrm{Si}_{3} \mathrm{~N}_{4}$}

All the three long-term creep tests on NT-154 specimens have been discontinued, and test results are summarized in Figs. 8 to 10. The final dimensions of the tested specimens are being measured for comparison with the original dimensions to cross check the creep strain measured with the optical extensometer. The tested specimens have been transferred to $K$. More for detailed microstructural studies.

Creep testing of GS-44 Si${ }_{3} \mathrm{~N}_{4}$ in the as-sintered (or as-fabricated), microwave-annealed, and furnace-annealed conditions

Creep behavior of GS-44 in the above stated conditions was investigated extensively. Results are summarized in Appendix I, which was presented to the Annual Cocoa Beach Meeting held in Cocoa Beach, Fl on January 7-11, 1996.

Compressive creep testing of ceramic materials at elevated temperatures

A compressive creep test on GS-44 Si $\mathrm{I}_{3}$ was initiated. Test results obtained to date are shown in Fig. 11. Since the beginning of the test, applied stress has been increased in steps of $20 \mathrm{MPa}$ each time the specimen completed a period of 1000 to $2000 \mathrm{~h}$ of testing. After the test specimen completed $2000 \mathrm{~h}$ of testing with an applied stress of $-140 \mathrm{MPa}$, the applied stress was increased to $-160 \mathrm{MPa}$, and the test is currently ongoing. Although the creep curve is somewhat wavy, steady-state creep rates under different applied stresses can be determined approximately from the creep data obtained during the last $500 \mathrm{~h}$ of each test segment.

Pronounced transient creep was observed during the first $500 \mathrm{~h}$ of testing at $100 \mathrm{MPa}$, followed by slow creep at a substantially low rate. Transient creep was again observed following the increase in applied stress to $-120 \mathrm{MPa}$, but the intermittent transient creep period following each small load increment became short to none as applied stress increased. The creep behavior following the transient creep range can not be well defined due to the erratic behavior, which is believed to be true behavior. However, an approximate steady-state creep rate can be determined approximately for each loading segment. Results are tabulated and plotted in a log-log diagram shown in Fig. 12. A least squares fit on the data yields a stress exponent of $n=\sim 1$, which implies that 
the steady-state creep rate is linearly proportional to the applied, stress.

\section{Important Findings and observations}

None

\section{Status of Milestones}

The following three milestones have been completed on schedule.

Milestone 321423 - Completion of technical report describing an innovative load train assembly and a technique to achieve uniform compressive stress testing - due on October 31, 1995.

Milestone 321518 - completion of tensile creep tests on microwave annealed GS-44 Si ${ }_{3} \mathrm{~N}_{4}$ at elevated temperatures and prepared a draft report containing results - due on November 30, 1995.

Milestone 321520 - completion of a technical paper describing a multiaxial creep model based on results of compression creep tests on $\mathrm{Si}_{3} \mathrm{~N}_{4}$ at elevated temperatures - due on December 30, 1995.

\section{References}

1. Ding, J. L., Liu, K. C., and Brinkman, C. R., "Development of a High temperature Deformation and Life Prediction Model for Advanced Silicon Nitride Ceramics," Journal of the American Ceramic Society, Vol. 78, No. 11, 1995, pp. 3057-66.

2. K. C. Liu, C. R. Brinkman, J. L Ding, and S. B. Lin, "Predictions of tensile behavior and strengths of a $\mathrm{Si}_{13} \mathrm{~N}_{4}$ ceramic at high temperatures based on a viscoplastic model," the International Gas Turbine and Aeroengine Congress \& Exposition, held on June 5-8, 1995 Houston, TX (Paper No. 95-GT-388); will appear in the Transactions of the ASME.

\section{Publications}

1. Kuanghsi Wu, K. C. Liu, and M. L. Santella, "Indentation Fracture Assessment of Residual stress in $\mathrm{Si}_{3} \mathrm{~N}_{4}$," in the Proceedings of the 1996 Annual Conference \& Exposition on Composite, Advanced Ceramics, Materials and Structures at cocoa Beach, FL, January 7-11, 1996. (in-press)

2. J. L. Ding, K. C. Liu, and C. R. Brinkman, "A Multiaxial Viscoplastic Model for Advanced $\mathrm{Si}_{3} \mathrm{~N}_{4}$ Ceramics," in the proceedings of the 1996 Annual Conference and Exposition on Composites, Advanced Ceramics, Materials and structures at cocoa Beach, FL on January 7-11, 1996. (in-press) 
3. K. C. Liu, C. O. Stevens, C. R. Brinkman, J. O. Kiggans, and T. N. Tiegs, "Influence of Heat Treatment on Creep Behavior of a Sintered $\mathrm{Si}_{3} \mathrm{~N}_{4}$ Ceramic," in the proceedings of the 1996 Annual Conference and Exposition on Composites, Advanced Ceramics, Materials and Structures at cocoa Beach, FI on January 7-11, 1996. (in-press)

4. K. C. Iiu, N. E. Holshauser, C.O. Stevens, C. R. Brinkman, "A Technique to Achieve Uniform Stress Distribution in Compressive Creep Testing of Advanced Ceramics at High Temperatures," has been accepted for publication and oral presentation at the 41 st ASME Gas Turbine and Aeroengine congress to be held in Birmingham, UK on June 10-13, 1996, Paper No. 96-GT-341

5. C. R. Brinkman, G. D. Quinn, and R. W. Mcclung, "Overview of ASTM Standard Activities in support of Advanced structural Ceramics Development, in challenges in ceramic product Development, Manufacture, and commercialization, vol. 66, Ceramic Transaction Series, American Ceramic Society, pp 97-108, 1996

\section{LIST OF FIGURES}

Fig. 1 - Triangular wave forms used in fatigue tests: (1) for fully reversed tension-compression, (b) tension-tension, and (c) compression-compression fatigue testing.

Fig. 2 - Specimen geometries: (a) an hourglass-shaped and (b) a buttonhead specimen.

Fig. 3 - Cyclic fatigue behavior of GS-44 Si $\mathrm{N}_{4}$ tested at $1200^{\circ} \mathrm{C}$. Test results show the microwave annealing did not change or enhance the fatigue properties of this material at $1200^{\circ} \mathrm{C}$. Numbers refer to specimen numbers; filled symbols indicated rupture at the test condition indicated, and unfilled indicated no specimen failure when the test condition was changed; partially-filled symbols indicate the test specimens were made from one tile.

Fig. 4 - Layout diagram showing the locations of specimens.

Fig. 5 - Comparison between experimental data (symbols) and theoretical predictions (lines) indicates that the model predicts the high-cycle fatigue lives at 1200 and $1250^{\circ} \mathrm{C}$ somewhat conservatively. However, it may overestimate the low-cycle fatigue lives at temperatures at or below $1200^{\circ} \mathrm{C}$ based on the tensile fast fracture data plotted on the $\mathrm{Y}$-axis. 
Fig. 6 - Creep curves of NT-154 specimens tested at $1204^{\circ} \mathrm{C}$ with an applied stress of $310 \mathrm{MPa}(45 \mathrm{ksi})$. Creep curves are separated in two groups, except that one (\#35354) shows creep resistance better than the others.

Fig. 7 - Creep curves of NT-154 specimens tested at $1315^{\circ} \mathrm{C}$ with an applied stress of $276 \mathrm{MPa}(40 \mathrm{ksi})$. Creep curves are also separated in two groups, suggesting that the difference in creep performance may be attributed to the post fabrication heat treatment.

Fig. 8 - Creep curve of $\mathrm{NT}-154 \mathrm{Si}_{3} \mathrm{~N}_{4}$ (specimen 20-56) tested at $1250^{\circ} \mathrm{C}$ with an applied stress of $175 \mathrm{MPa}$. The test was discontinued after completing $37,800 \mathrm{~h}(4.32$ years) of testing with no specimen failure.

Fig. 9 - Creep curve of $\mathrm{NT}-154 \mathrm{Si}_{3} \mathrm{~N}_{4}$ (specimen 20-00) tested at $1250^{\circ} \mathrm{C}$ with an applied stress of $150 \mathrm{MPa}$. The test was discontinued after completing $28,270 \mathrm{~h}(3.23$ years) of testing with no specimen failure.

Fig. 10 - Creep curve of $\mathrm{NT}-154 \mathrm{Si}_{3} \mathrm{~N}_{4}$ (specimen 20-32) tested at $1250^{\circ} \mathrm{C}$. The specimen was tested initially at $225 \mathrm{MPa}$ followed by partial unloading in steps of $25 \mathrm{MPa}$ at the end of each $1000 \mathrm{~h}$ of testing until the applied stress decreased to $150 \mathrm{MPa}$. Since then the specimen has completed $28,800 \mathrm{~h}(3.3$ years) of testing until the test was discontinued recently with no specimen failure.

Fig. 11 - Creep curve of GS-44 Si $\mathrm{N}_{4}$ tested at $1200^{\circ} \mathrm{C}$ with applied stresses of $100,120,140$, and $160 \mathrm{MPa}$ in compression for periods as indicated.

Fig. 12 - The minimum creep rate determined from each segment of the creep curve shown in Fig. 1 indicates that the creep rate of GS-44 Si $\mathrm{Si}_{4}$ at $1200^{\circ} \mathrm{C}$ under compression is proportional to the applied stress. 


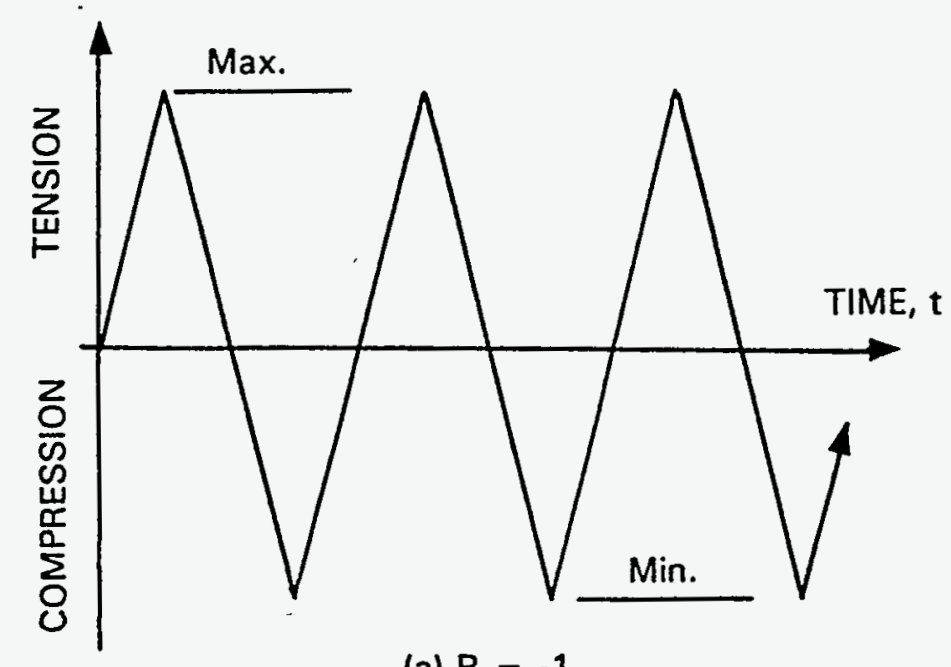

(a) $R=-1$

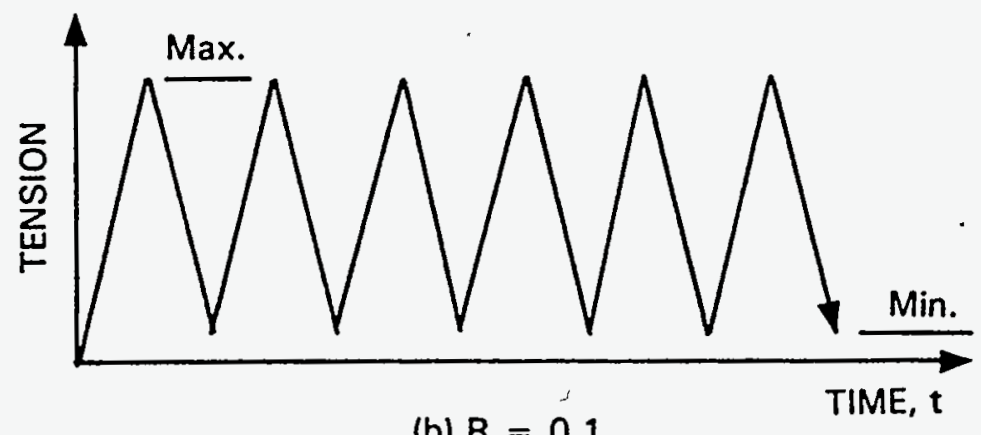

(b) $R=0.1$

TIME, $t$

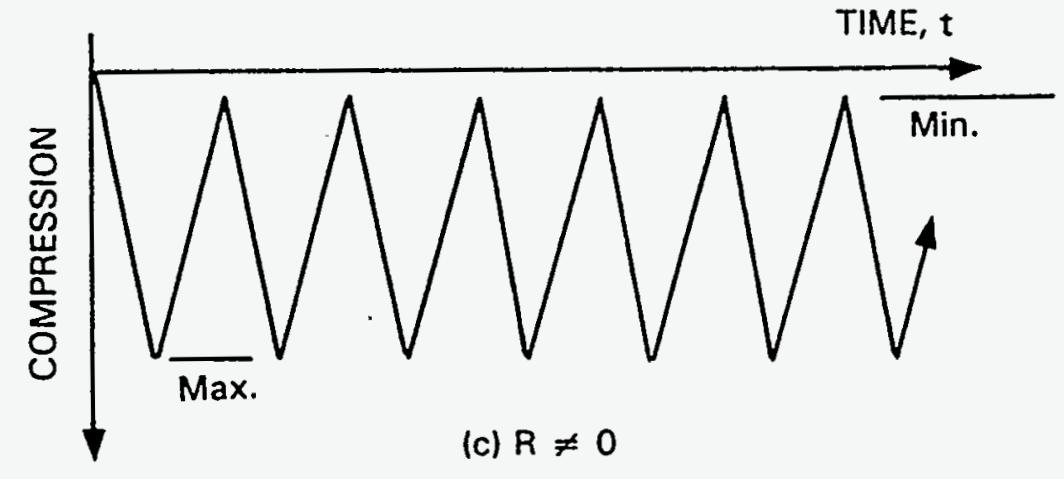

Stressing Rate $=21,000 \mathrm{MPa} / \mathrm{min}$.

$R=$ Minimum/Maximum Stress

Fig. 1 - Triangular wave forms used in fatigue tests: (1) for fully reversed tension-compression, (b) tension-tension, and (c) compression-compression fatigue testing. 

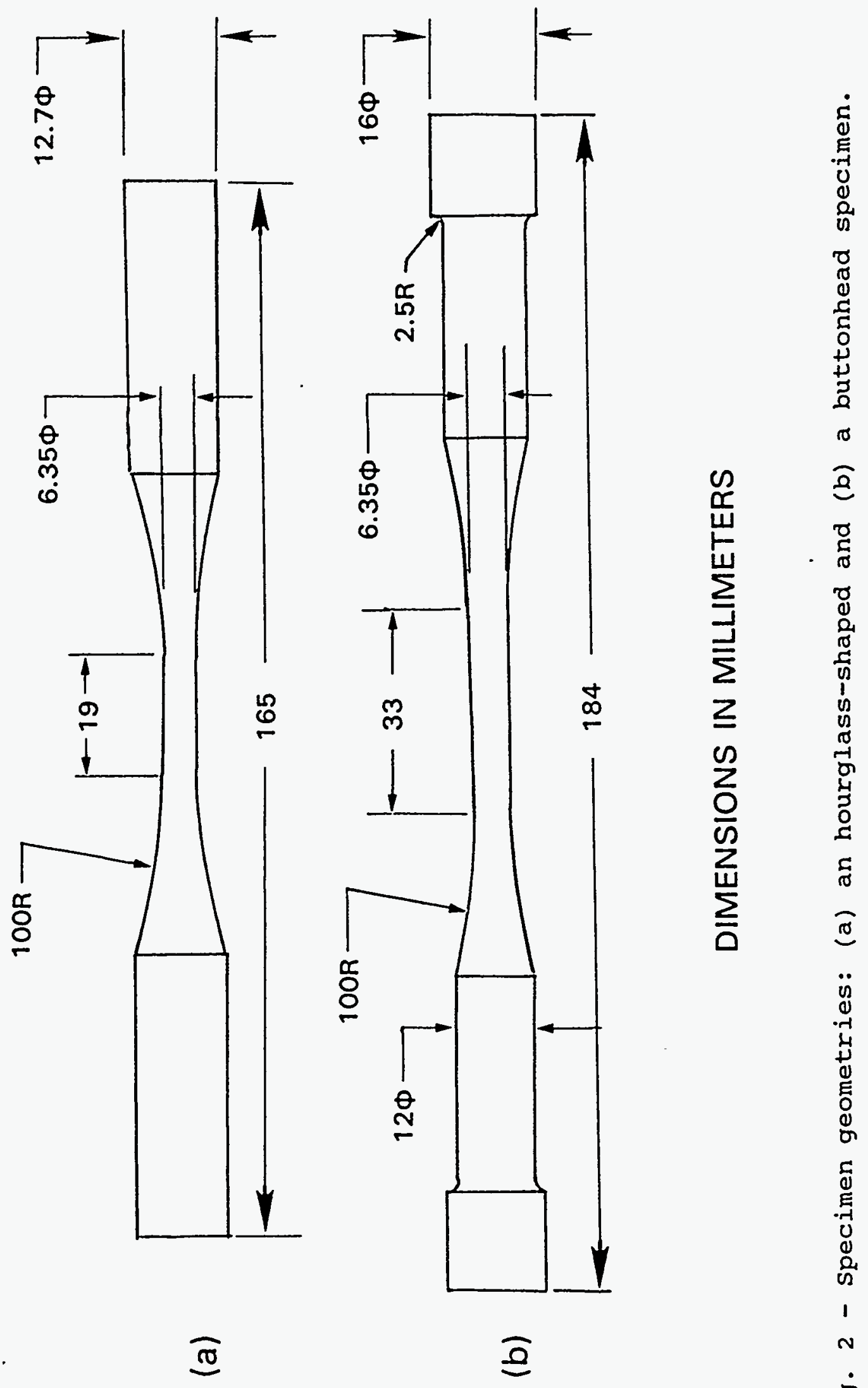

טֶ

怘 
ORNL-DWG 94-8035

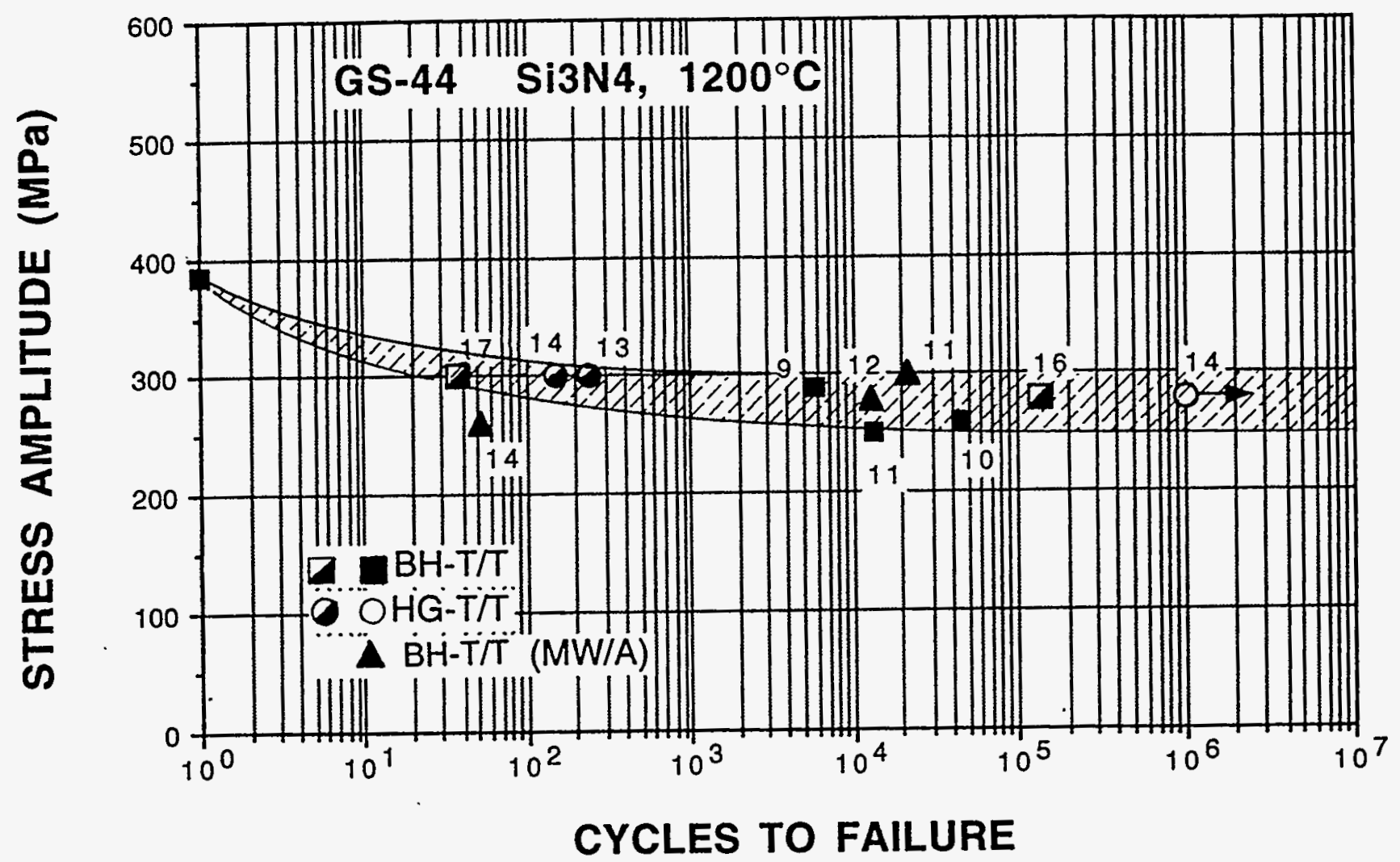

Fig. 3 - Cyclic fatigue behavior of GS-44 $\mathrm{Si}_{3} \mathrm{~N}_{4}$ tested at $1200^{\circ} \mathrm{C}$. Test results show the microwave annealing did not change or enhance the fatigue properties of this material at $1200^{\circ} \mathrm{C}$. Numbers refer to specimen numbers; filled symbols indicated rupture at the test condition indicated, and unfilled indicated no specimen failure when the test condition was changed; partially-filled symbols indicate the test. specimens were made from one tile.

\begin{tabular}{|c|}
\hline BH specimen $A S-16$ \\
\hline BH specimen $A S-17$ \\
\hline HG specimen $H G-13$ \\
\hline HG specimen $H G-14$ \\
\hline HG specimen $H G-15$ \\
\hline
\end{tabular}

Tile No. S94-0125-3

i

Fig. 4 - Layout diagram showing the locations of specimens. 


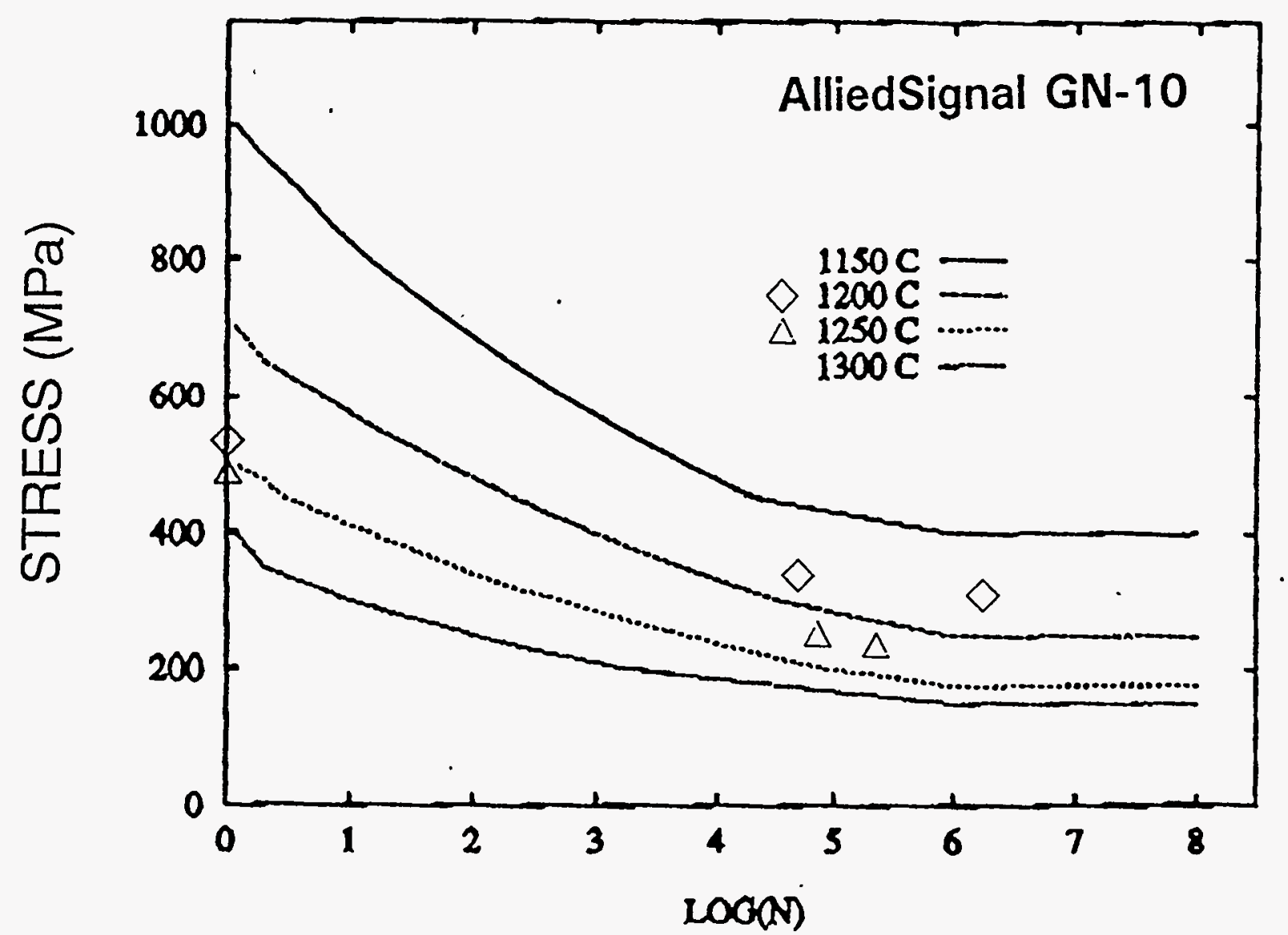

Fig. 5 - Comparison between experimental data (symbols) and theoretical predictions (lines) indicates that the model predicts the high-cycle fatigue lives at 1200 and $1250^{\circ} \mathrm{C}$ somewhat conservatively. However, it may overestimate the low-cycle fatigue lives at temperatures at or below $1200^{\circ} \mathrm{C}$ based on the tensile fast fracture data plotted on the $\mathrm{Y}$-axis. 


\section{CTEDP, NT-154 Si3N4, $1204^{\circ} \mathrm{C} / 45 \mathrm{ksi}$}

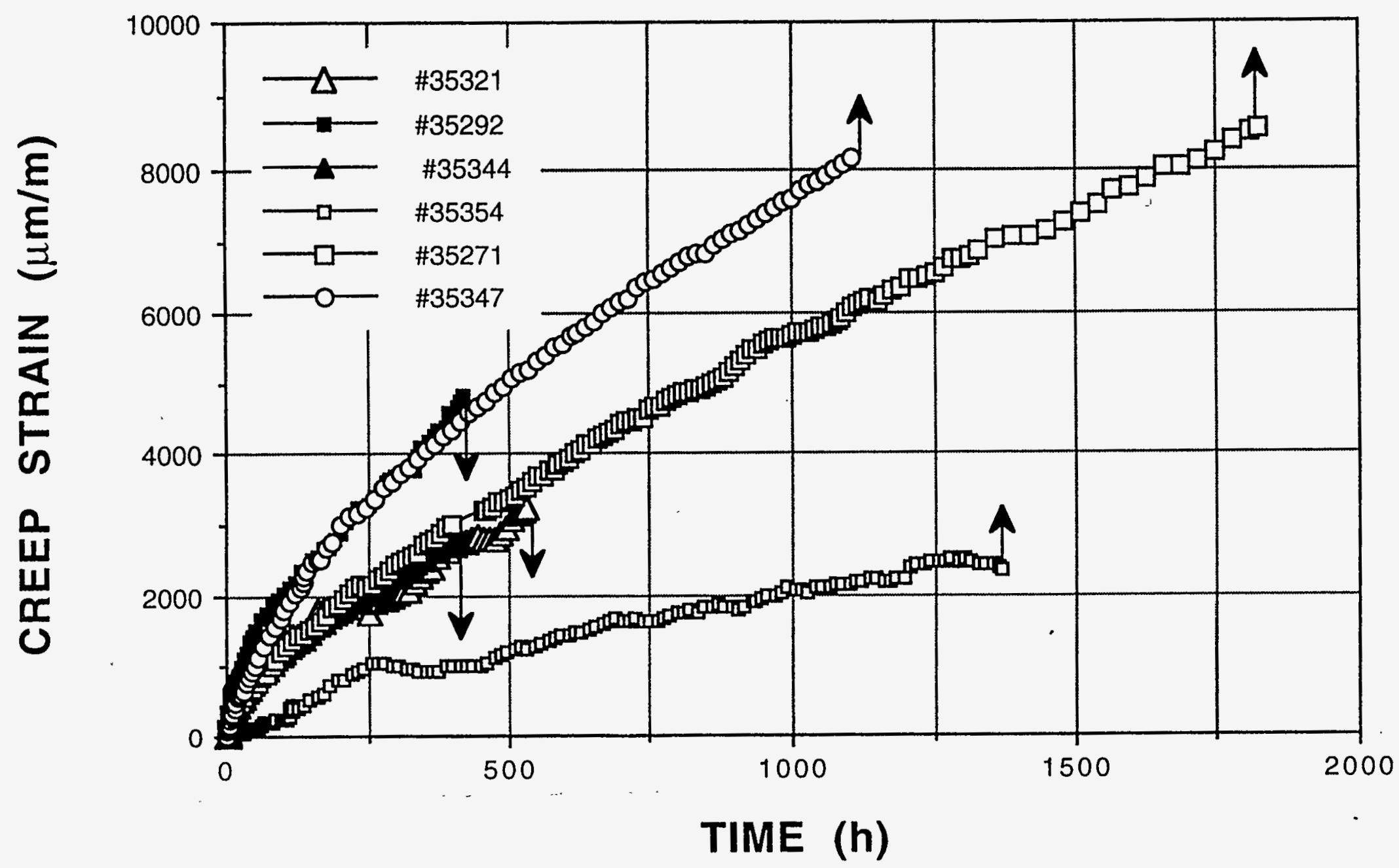

Fig. 6 - Creep curves of NT-154 specimens tested at $1204^{\circ} \mathrm{C}$ with an applied stress of 310 MPa $(45 \mathrm{ksi})$. Creep curves are separated in two groups, except that one (\#35354) shows creep resistance better than the others. 


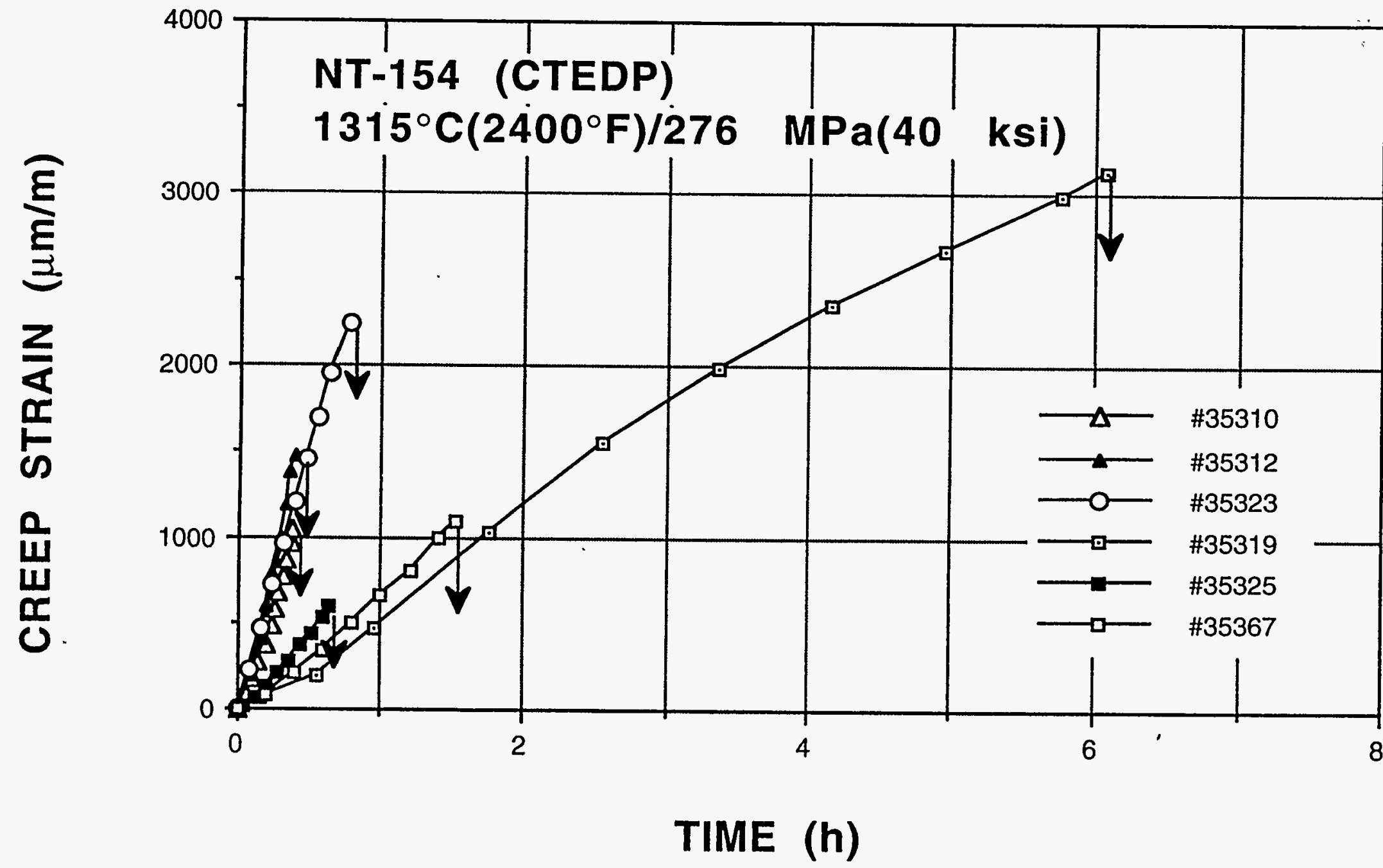

Fig. 7 - Creep curves of NT-154 specimens tested at $1315^{\circ} \mathrm{C}$ with an applied stress of $276 \mathrm{MPa}$ $(40 \mathrm{ksi})$. Creep curves are also separated in two groups, suggesting that the difference in creep performance may be attributed to the post fabrication heat treatment. 
ORNL-DWG 91-116014R6

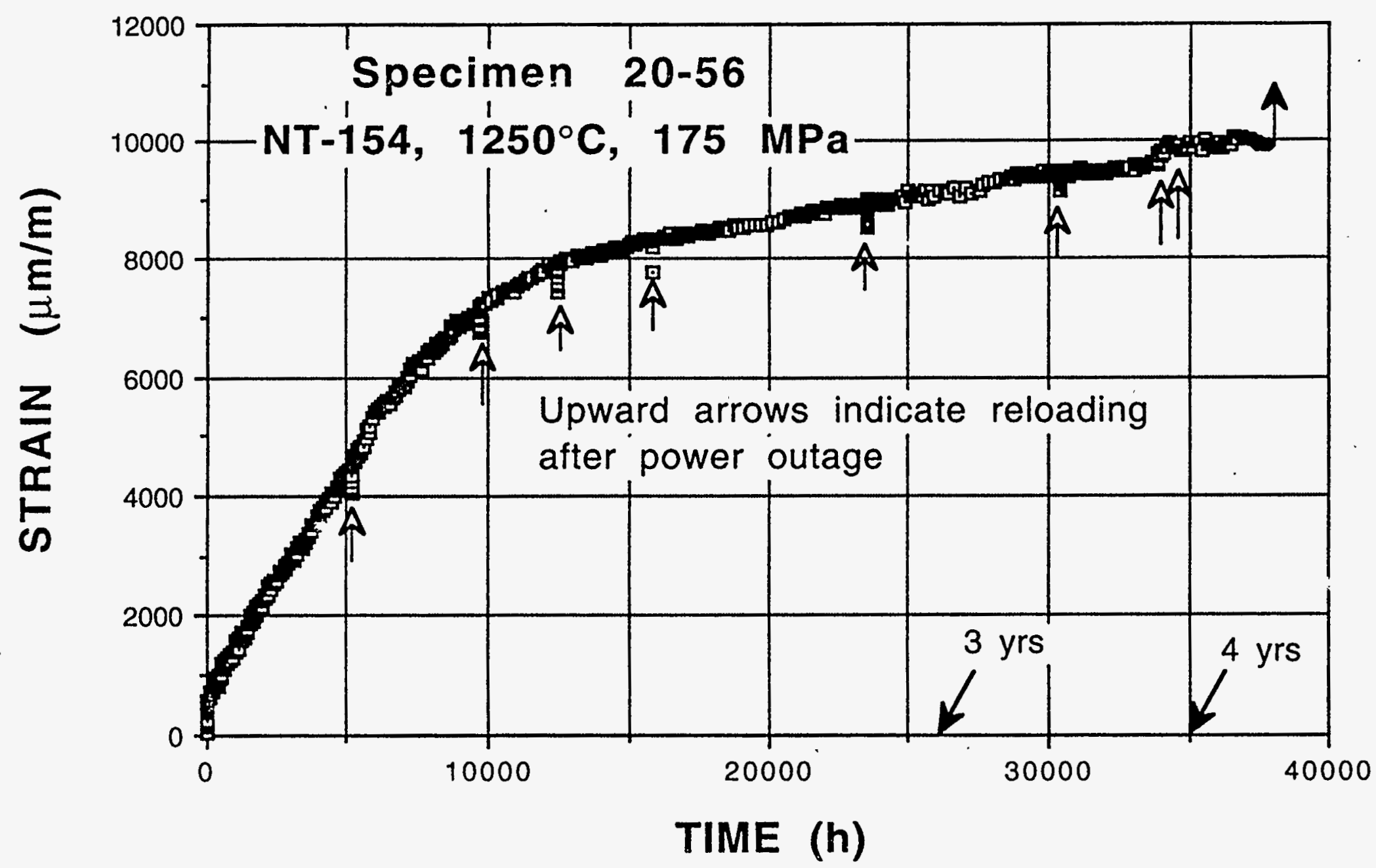

Fig. 8 - Creep curve of $\mathrm{NT}-154 \mathrm{Si}_{3} \mathrm{~N}_{4}$ (specimen $20-56$ ) tested at $1250^{\circ} \mathrm{C}$ with an applied stress of $175 \mathrm{MPa}$. The test was discontinued after completing $37,800 \mathrm{~h}(4.32$ years) of testing with no specimen failure. 


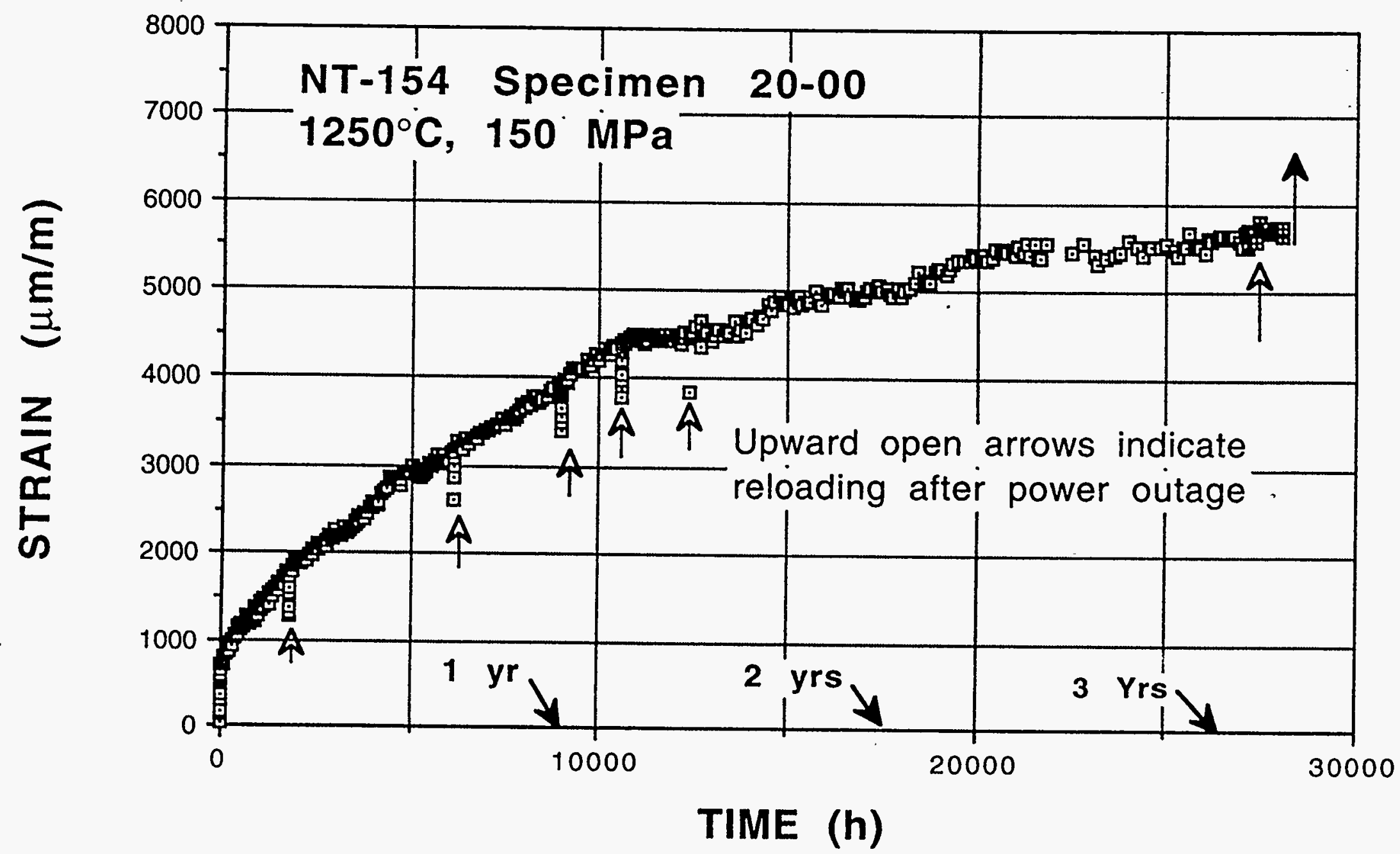

Fig. 9 - Creep curve of $\mathrm{NT}-154 \mathrm{Si}_{3} \mathrm{~N}_{4}$ (specimen 20-00) tested at $1250^{\circ} \mathrm{C}$ with an applied stress of $150 \mathrm{MPa}$. The test was discontinued after completing $28,270 \mathrm{~h}(3.23$ years) of testing with
no specimen failure. 
ORNL-DWG 92-14551R4

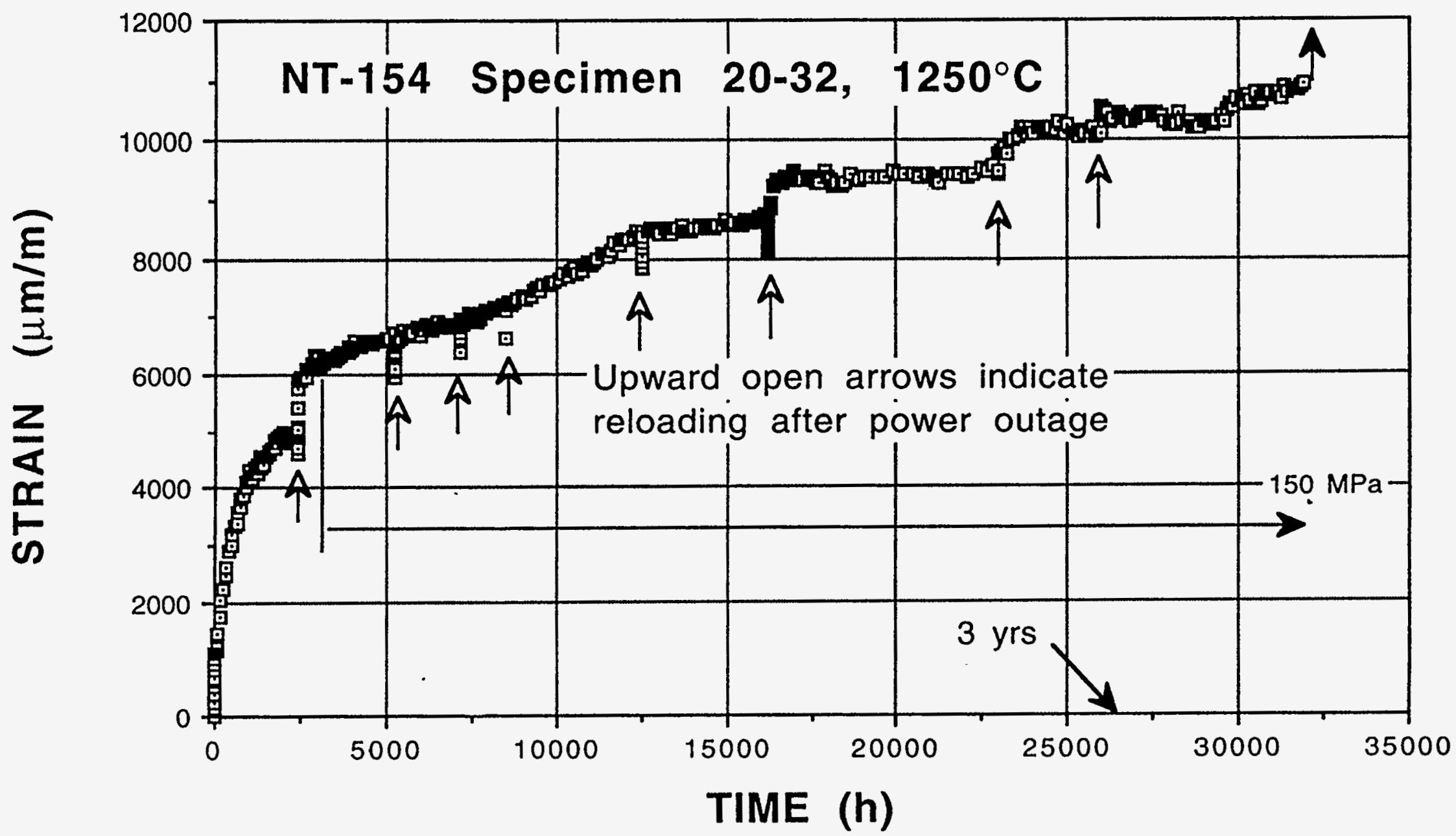

Fig. 10 - Creep curve of $\mathrm{NT}-154 \quad \mathrm{Si}_{3} \mathrm{~N}_{4}$ (specimen 20-32) tested at $1250^{\circ} \mathrm{C}$. The specimen was tested initialiy at $225 \mathrm{MPa}$ followed by partial unloading in steps of $25 \mathrm{MPa}$ at the end of each $1000 \mathrm{~h}$ of testing until the applied stress decreased to $150 \mathrm{MPa}$. Since then the specimen has completed $28,800 \mathrm{~h}(3.3$ years) of testing until the test was discontinued recently with no specimen failure. 


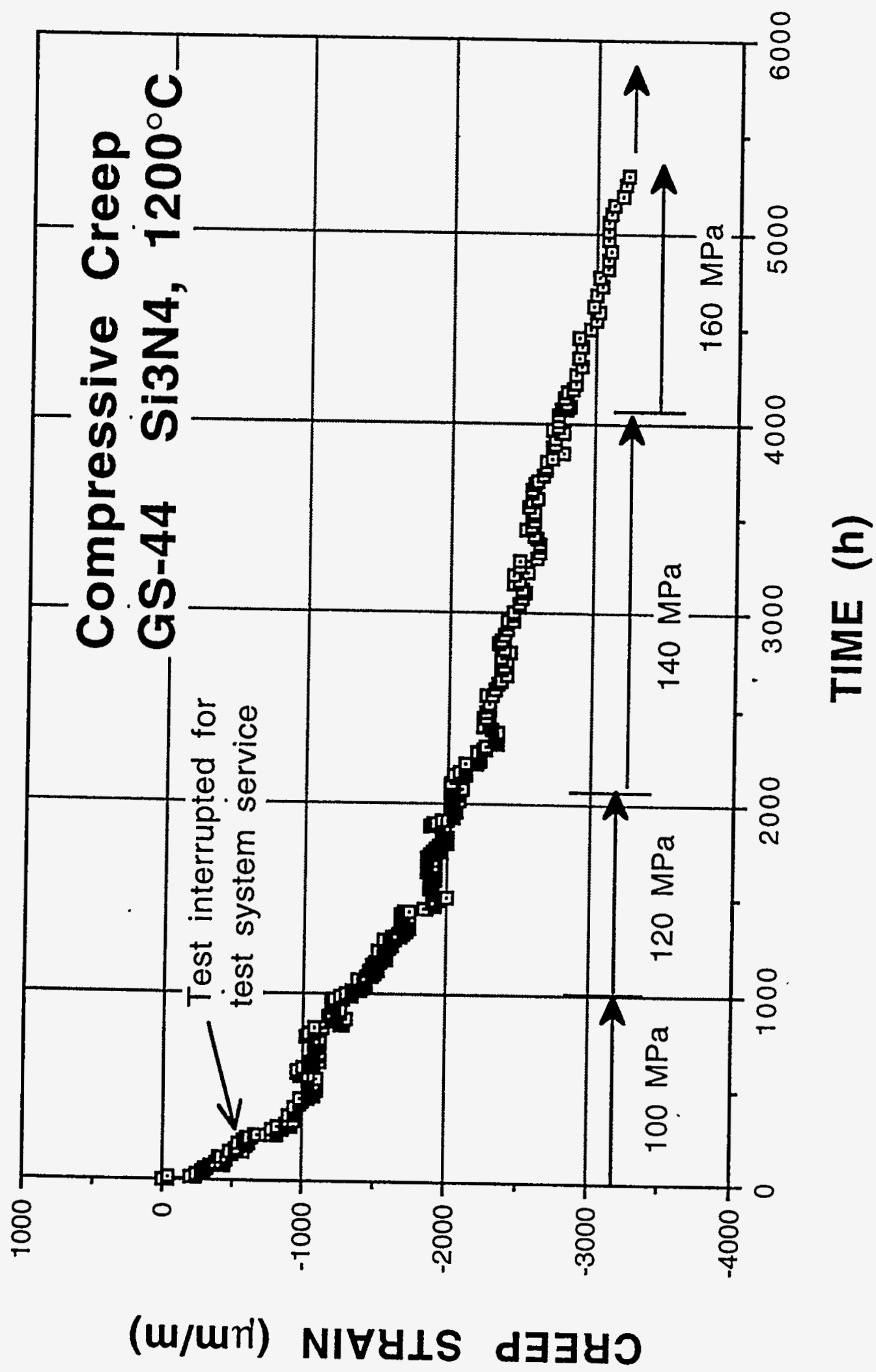

$\underset{7}{0}$

N

0

4

o

0
0
0
0
0
1
1
-1
-1

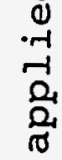

0

$0+$

ㅇำ

न

+

ठ

is $v$

잉

z

की है

$\approx 00$

$\nabla 4$

ป

फ्न

o U

$\stackrel{0}{4}$

논

요

ฏ.

H 0

, 点

거욕

कृ

[4 
STRESS (MPa)

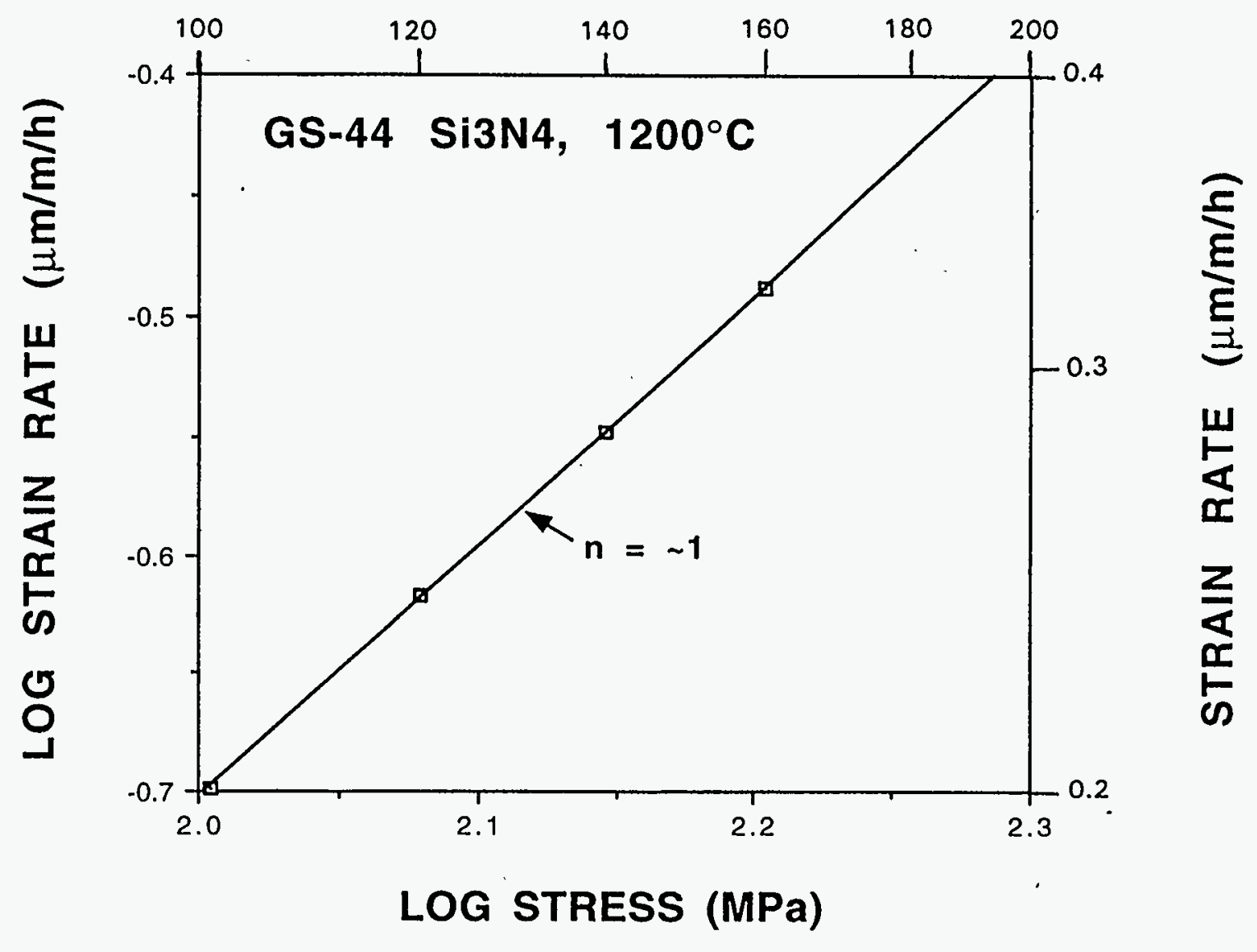

Fig. 12 - The minimum creep rate determined from each segment of the creep curve shown in Fig. 11 indicates that the creep rate of $\mathrm{GS}-44 \mathrm{Si}_{3} \mathrm{~N}_{4}$ at $1200^{\circ} \mathrm{C}$ under compression is proportional to the applied stress. 


\title{
Appendix 1
}

\section{INFLUENCE OF HEAT TREATMENT ON CREEP BEHAVIOR OF A SINTERED $\mathrm{Si}_{3} \mathrm{~N}_{4}$ CERAMIC}

\author{
K. C. Liu, C. O. Stevens, C. R. Brinkman, J. O. Kiggans, and T. N. Tiegs
}

Oak Ridge National Laboratory, P. O. Box 2008

Oak Ridge, TN 37831

\begin{abstract}
Creep behavior was investigated for a sintered $\mathrm{Si}_{3} \mathrm{~N}_{4}$ ceramic having been subjected to various post-fabrication heat treatments: microwave annealing at $1200^{\circ} \mathrm{C}$ (with preannealing at $1100^{\circ} \mathrm{C}$ for $10 \mathrm{~h}), 1400,1500$, and $1600^{\circ} \mathrm{C}$ for $10 \mathrm{~h}$, and resistance-heating furnace annealing at $1200^{\circ} \mathrm{C}$ for $100 \mathrm{~h}$. Test results at $1200^{\circ} \mathrm{C}$ showed that microwave annealing at $1200^{\circ} \mathrm{C}$ can significantly enhance the creep resistance of this material, but showed adverse effects for the material annealed at $1400^{\circ} \mathrm{C}$ or higher. Fumace annealing at $1200^{\circ} \mathrm{C}$ for $100 \mathrm{~h}$ was somewhat effective in lowering creep rate, hence, resulted in longer creep life compared to that of the unannealed material, but was far less effective than microwave annealing at $1200^{\circ} \mathrm{C}$. Some inconsistency in creep behavior was observed, most likely resulting from nonuniformity in microwave annealing, material variation, and bias due to test machines or heating methods. This paper is an interim report which will be finalized upon completion of ongoing microstructural studies.
\end{abstract}

\section{INTRODUCTION}

Significant improvement in high temperature strength has been made for advanced silicon nitride $\left(\mathrm{Si}_{3} \mathrm{~N}_{4}\right)$ ceramics in recent years. However, the high cost remains a hindrance to the commercial use of the material in high temperature structural components, which in many cases demand good resistance to creep. To make ceramic materials economically attractive and viable, the final products must be cost effective. Sintered $\mathrm{Si}_{3} \mathrm{~N}_{4}$ ceramics can be produced at a much lower cost compared to hot-isostatically-pressed (HIP) ceramics because of the ease of manufacturing processes. However, sintered $\mathrm{Si}_{3} \mathrm{~N}_{4}$ ceramics do not have the mechanical strength and reliability of $\mathrm{HIP} \mathrm{Si}_{3} \mathrm{~N}_{4}$ ceramics. Studies were made to enhance the creep resistance of low-cost ceramics by post-fabrication heat treatments.

A study was previously reported on the creep behavior of a low-cost, commercial, sintered $\mathrm{Si}_{3} \mathrm{~N}_{4}$ ceramic (Wesgo SNW-1000 furnished by WESGO, Inc. of Belmont, California) subjected to postsintered heat treatments by microwave annealing [1]. Results of creep testing at $1200^{\circ} \mathrm{C}$ showed that microwave annealing can enhance the creep resistance of the material in terms of lowering creep rate, hence, extending creep rupture life. Annealing at $1400^{\circ} \mathrm{C}$ for $20 \mathrm{~h}$ was found to be more effective compared to that at $1500^{\circ} \mathrm{C}$ for $20 \mathrm{~h}$. However, creep behavior was more consistent and predictable for the specimens annealed at $1500^{\circ} \mathrm{C}$ compared to that observed for those annealed at $1400^{\circ} \mathrm{C}$. While the primary objective of improving creep resistance was 
achieved, further studies were needed to determine the optimum annealing temperature/time schedule and to identify the causes of some inconsistent creep data obtained from the specimens annealed at $1400^{\circ} \mathrm{C}$. Unfortunately, production of the material was discontinued by the manufacturer. For this reason, another commercial sintered $\mathrm{Si}_{3} \mathrm{~N}_{4}$ equivalent to $\mathrm{SNW}-1000$ was used in the present study.

\section{EXPERIMENTAL DETAILS}

\section{Material and Heat Treatment}

A commercial grade of sintered $\mathrm{Si}_{3} \mathrm{~N}_{4}$ was used, known as GS-44 furnished by AlliedSignal Ceramic Components of Torrance, California. The material is known to contain small amounts of $\mathrm{Y}_{2} \mathrm{O}_{3}, \mathrm{Al}_{2} \mathrm{O}_{3}$, and other minor impurity constituents as densification aids. Information concerning the exact composition is proprietary and unavailable. The material was received in the product form of rectangular tiles having nominal dimensions of $190 \times 100 \times 20$-mm thickness in the as-sintered condition.

Based on knowledge gained from the previous study on $\mathrm{SNW}-1000 \mathrm{Si}_{3} \mathrm{~N}_{4}$, a tile each was microwave annealed at 1400,1500 , and $1600^{\circ} \mathrm{C}$ for $20 \mathrm{~h}$ in search of the optimum annealing temperature. However, these annealing schedules (which will be referred thereafter as 'hightemperature or HT annealing') were found later to be detrimental to the creep resistance of GS- 44 . As a result, the scope of this study was broadened and the annealing schedule was revised downward. Two of the as-furnished tiles were annealed initially at $1100^{\circ} \mathrm{C}$ for $10 \mathrm{~h}$ followed by final annealing at $1200^{\circ} \mathrm{C}$ for $10 \mathrm{~h}$ (which will be referred as 'low-temperature or LT annealing'). Both tiles were annealed individually. The tile was sandwiched between two plates of boron dioxide to facilitate heat conduction in order to anneal the tile as evenly as possible and to avoid severe localized heating. A molybdenum-sheathed thermocouple was used to monitor and control the annealing temperatures. A detailed discussion on microwave annealing can be found elsewhere [2]. To evaluate the effectiveness of microwave annealing compared to conventional annealing, a tile was aged at $1200^{\circ} \mathrm{C}$ in air for $100 \mathrm{~h}$ in a conventional furnace.

To facilitate identification of each specimen with its background, microwave annealed specimens were designated with a prefix of "MA" followed by the first and second digits of its annealing temperature with a specimen number trailing a hyphen, as "MA12-4" symbolizing microwave annealed at $1200^{\circ} \mathrm{C}$ - specimen No. 4; "FA" symbolizing conventional furnace annealing and " $A S^{n}$ as-sintered or as-fabricated.

\section{Specimen and Test Machines}

Five buttonhead specimens were machined from each tile. A typical buttonhead specimen is shown in Fig. 1, having a uniform gage section of $6.3-\mathrm{mm}$ diam by $25-\mathrm{mm}$ length. Specimens were numbered consecutively in a series to aid in identifying specimens that were immediate neighbors.

Most creep tests were performed in lever-arm creep machines equipped with a low-profile, 2-zone controlled, resistance-heating furnace [3], unless indicated otherwise. Creep strain was measured with an in-house developed mechanical extensometer [4]. A limited number of specimens were tested in an electrohydraulic controlled machine using an induction heater [5] as shown in Fig. 2. 
Previously, an exceptional creep performance was exhibited by an SNW-1000 specimen which was heated by the induction heater. The induction heating was again used in the present study to determine if the good creep performance could be reproduced.

\section{TEST RESULTS AND DISCUSSIONS}

All specimens were tested at $1200^{\circ} \mathrm{C}$ mostly under constant loads until rupture occurred. A few MA specimens were tested with a step-up load history in order to complete the tests in a reasonable time period. Control tests were performed on three AS specimens (AS-6 to -8) each subjected to a constant stress of 80,100 , and $120 \mathrm{MPa}$. Two FA specimens (FA-1 and -2) were at $100 \mathrm{MPa}$, and one each at $120 \mathrm{MPa}$ (FA-3) and $140 \mathrm{MPa}$ (FA-4). All creep data are plotted in Fig. 3. The creep curve of specimen FA-1 appears to be an aberration. Remaining FA specimens show significant improvement in resistance to creep when each of the FA creep curves is compared respectively to the corresponding control creep curve. Creep behavior of AS specimens was consistent, however.

Creep tests were then performed on HT annealed specimens with applied stresses of 80 or 100 $\mathrm{MPa}$. Test results are compared with the corresponding control data, as shown in Figs. 4 and 5. Examination indicated that $\mathrm{HT}$ annealing did not only fail to enhance the creep resistance but made the material less resistant to creep. The situation worsened under $100 \mathrm{MPa}$ compared to that under $80 \mathrm{MPa}$. Comparison shows that the creep behavior of specimen AS-8 tested at $120 \mathrm{MPa}$ (shown in Fig. 3) was about the same as that of specimen MA15-7 (Fig. 4), indicating a significant down grading in load carrying capacity by about $50 \%$.

Because of the negative HT annealing effect, the LT annealing was given to a tile (designated as tile A) from which five specimens (MA12-1 to -5) were machined. Test parameters are described in the following sections and test data are summarized in Figs. 6 to 8.

Results of Tests on MA12-series Specimens

Specimen MA12-1: This test was intended as exploratory in nature so that the specimen was tested in the electrohydraulic machine. An applied stress of $100 \mathrm{MPa}$ was selected as a starting point. Subsequently, the applied stress was increased intermittently in steps of $20 \mathrm{MPa}$ at the end of each test period of 100 to $140 \mathrm{~h}$ until the specimen failed at $240 \mathrm{MPa}$ after completing $812 \mathrm{~h}$ of testing, as shown in Fig. 6. The rupture strength of $240 \mathrm{MPa}$ is $\sim 62 \%$ of reported tensile strength for GS- 44 in the as-sintered condition. On a percentage basis, $62 \%$ is considerably higher than static fatigue strength, which is usually $\sim 40 \%$ of the tensile strength, of most $\mathrm{Si}_{3} \mathrm{~N}_{4}$ ceramics in unannealed condition.

Specimen MA12-2: This specimen was initially tested with an applied stress of $120 \mathrm{MPa}$. The stress was increased intermittently in steps of $20 \mathrm{MPa}$ as was done to specimen MA12-1 until the specimen ruptured at $180 \mathrm{MPa}$ with a total accumulated test time of $475 \mathrm{~h}$, as shown in Fig. 6 . Specimen MA12-2 was obviously less creep resistant compared to specimen MA12-1 in terms of creep rupture life and total accumulated creep strain. As usual, high creep rate yielded a shorter rupture life for MA12-2 compared to a much longer life for MA12-1 which crept much slower than MA12-2.

Specimen MA12-3: The specimen was tested with an applied stress of $140 \mathrm{MPa}$. The creep data 
upto $600 \mathrm{~h}$ are shown in Fig. 7. The specimen crept at high creep rate during the first $50 \mathrm{~h}$, but the creep rate changed rather suddenly thereafter to a slow pace equivalent to the creep rate observed in the preceding test under the same stress.

Specimen MA12-4: The specimen was also tested with an applied stress of $140 \mathrm{MPa}$. Unlike specimen MA12-3, this specimen exhibited low resistance to creep and failed in $142 \mathrm{~h}$ of testing, as shown in Fig. 7. The reason for the contrasting creep behavior will not be known until results of ongoing $\mathrm{X}$-ray analyses become available.

Specimen MA12-5: This specimen was tested with a constant applied stress of $100 \mathrm{MPa}$. To facilitate comparison, test results are plotted in Fig. 6. The creep resistance of MA12-5 was obviously lower than that of MA12-1. Although not shown, if the time scale of this creep curve is compressed to match the rupture time of specimen MA12-4, both creep curves are virtually identical. This implies that the creep resistance of both specimens was about the same since they were made from the neighboring blanks.

To investigate the influences of material variation and test machine bias on creep properties, a second tile (designated as tile B) was microwave treated with the LT annealing schedule. Five specimens, MA12-6 to -10 , were machined from the tile and all tested at $1200^{\circ} \mathrm{C}$.

Specimen MA12-6: This specimen is clearly the weakest one among the three specimens in this series of tests at $140 \mathrm{MPa}$, as shown in Fig. 7. A visiual examination showed that the creep curve of specimen MA12-6 will fall on the far left of the three creep curves for AS specimens shown in Fig. 3. Although no AS specimens were tested at $140 \mathrm{MPa}$ for a direct comparison, the above observation implies that tile B gained little or no benefit of microwave annealing in terms of enhancing its creep resistance.

Specimens MA12-7, -9, -10: These specimens were tested with an applied stress of 100 MP in the same machine using the same extensometer and test method in an attempt to examine the influences of material variation and various heat treatment methods on creep behavior. Consistency of test results demonstrated in Fig. 8 confirm that data are reproducible under the controlled test environment. However, the results are disheartening when compared with the creep curve of specimen MA12-5 also shown in Fig. 8. Again a comparison reveals that these three curves are about the same as the one for specimen AS-7 shown in Fig. 3. This observation further reinforces the finding cited in the preceding section that tile B may be different from tile A or have not received proper annealing.

Specimen MA12-8: This specimen was machined from the middle strip of tile B. It was reasonable to assume that the material properties are the same as those of specimens MA12-7 and -9 which are immediate neighbors. To investigate the possible machine bias, this specimen was tested in the electrohydraulic machine with the induction heater. Results are plotted in Fig. 8. Surprisingly, the specimen performed better than expected but not as well as specimen MA12-5 which was tested in a lever-arm machine. The difference in creep performance within tile B may have been biased by the test machines. However, factors such as the difference in heating methods and the influence of inductive electric field on the material can not be ruled out.

To facilitate comparison and discussion, the creep data obtained from specimens having different heat treatments are replotted in two groups, 100 and $120 \mathrm{MPa}$, as shown in Figs. 9 and 10, 
respectively. Creep data for specimens tested at $140 \mathrm{MPa}$ are already given in Fig. 7. Overall observations indicate microwave annealing can effectively enhance the creep resistance of $\mathrm{Si}_{3} \mathrm{~N}_{4}$ ceramics, but the optimum annealing temperature varies with products. Annealing at $1400^{\circ} \mathrm{C}$ was found to be effective for $S N W-1000 \mathrm{Si}_{3} \mathrm{~N}_{4}$ [1] but detrimental to GS-44 $\mathrm{Si}_{3} \mathrm{~N}_{4}$.

The creep data shown in Figs. 6 and 7 suggest that the LT annealing at $1200^{\circ} \mathrm{C}$ can enhance the creep resistance of GS- 44 , but the heat treatment was probably not ideally uniform over the entire surface of tile A. As a result, strong resistance to creep was exhibited by specimens MA12-1 and -2 made from one half of the tile, but relatively weak resistance to creep was shown by specimens MA12-4 and 5 made from the another half. Variation of material within the as-fabricated tile and that from one tile to another were other factors that could have resulted in nonuniform microwave annealing. Severe differences in creep behavior exhibited by specimens made from tile $A$ as a group and those from tile B shown in Fig. 9 may be an example of the latter case. A careful study also indicates that no discernible enhancement of creep resistance was noticed from the test data of specimens made from tile B. Tile B may have been improperly heat treated since the current annealing technique is still experimental in nature and needs further improvement.

Comparisons of creep behavior exhibited by specimens with three different backgrounds of heat treatment histories, i.e., no annealing, furnace annealing, and microwave annealing, indicate that moderate enhancement of creep resistance can be achieved by furnace annealing but far less effective compared to what has been done by microwave annealing. Since specimens MA12-1 and -8 , both tested in the electrohydraulic machine, show better creep properties than comparable specimens, biases due to test machines and, in particular, heating methods are probable. Postmortem examinations of tested specimens by $\mathrm{X}$-ray diffraction are currently ongoing.

\section{CONCLUSION}

Enhancement of resistance to creep by microwave annealing has been studied on a commercially available sintered $\mathrm{Si}_{3} \mathrm{~N}_{4}$ ceramic at $1200^{\circ} \mathrm{C}$. The optimum annealing temperature was found to vary from one product to another. Decreased creep resistance was exhibited by GS-44 $\mathrm{Si}_{3} \mathrm{~N}_{4}$ having been microwave annealed in the temperature range of 1400 to $1600^{\circ} \mathrm{C}$. Contrastingly, an impressive improvement in creep resistance was observed for a batch of specimens fabricated from a tile having been subjected to an annealing schedule of $1200^{\circ} \mathrm{C}$ for $10 \mathrm{~h}$ with preannealing at $1100^{\circ} \mathrm{C}$ for $10 \mathrm{~h}$ in a microwave oven. However, results of another series of creep tests on specimens having gone through the same annealing schedule failed to reproduce the results. Moderate enhancement of resistance to creep was exhibited by specimens having been subjected to resistance-heating furnace annealing at $1200^{\circ} \mathrm{C}$ in air for $100 \mathrm{~h}$. However, overall creep performance of fumace annealed specimens was far less effective compared to that by microwave annealing provided microwave annealing was done properly. Data biases due to test machines and heating methods are discerned, but the cause of the inconsistent creep behavior will not be known until ongoing microstructural studies are completed.

\section{ACKNOWLEDGEMENT}

This research was sponsored by the U.S. Department of Energy, Assistant Secretary for Energy Efficiency and Renewable Energy, Office of Transportation Technologies, as part of the Ceramic Technology Project of the Propulsion System Materials Program, under contract DE-AC05960R22464 with Lockheed Martin Energy Research Corporation. 


\section{REFERENCES}

1. K. C. Liu, C. O. Stevens, C. R. Brinkman, K. L. More. J. O. Kiggans, and T. N. Tiegs, "Enhancement of Creep Resistance of a Sintered $\mathrm{Si}_{3} \mathrm{~N}_{4}$ Ceramic by Microwave Annealing, ${ }^{n}$ in the Proceedings of 5 th International Symposium on Ceramic Materials \& Components for Engines, Shanghai, China, May 29-June 1, 1994. (in press)

2. T. N. Tiegs, K. L. Ploetz, J. O. Kiggans, and R. L. Yeckley, "Crystallization of Grain Boundary Phases in Silicon Nitride with Low Additive Contents by Microwave Annealing, " pp. 259-263, Ceramic Transaction, Microwaves: Theory and Application in Materials Processing II, Vol. 36, Eds. D. E. Clark et al., Am. Ceramic Society, 1993.

3. K. C. Liu, H. Pih, C. O. Stevens, and C. R. Brinkman, "Tensile Creep Behavior and Cyclic Fatigue/Creep Interaction of Hot-Isostatically Pressed $\mathrm{Si}_{3} \mathrm{~N}_{4}$," pp. 213-220 in Proceedings of the Annual Automotive Technology Development Contractors' Coordination Meeting, P-243, Society for Automotive Engineers, Warrendale PA, 1991.

4. K. C. Liu and J. L. Ding, "A Mechanical Extensometer for High Temperature Tensile Testing of Ceramics," J. Testing and Evaluation, 21[5], pp. 406-413, September 1993.

5. K. C. Liu, "Specimen Heating by Induction Power," Int. J. High Technology Ceramics, Vol. 4, pp. 203-210, 1988

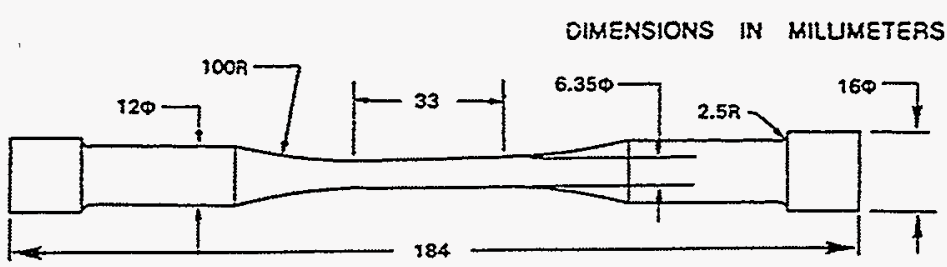

Fig. 1 - Geometry of buttonhead tensile specimen

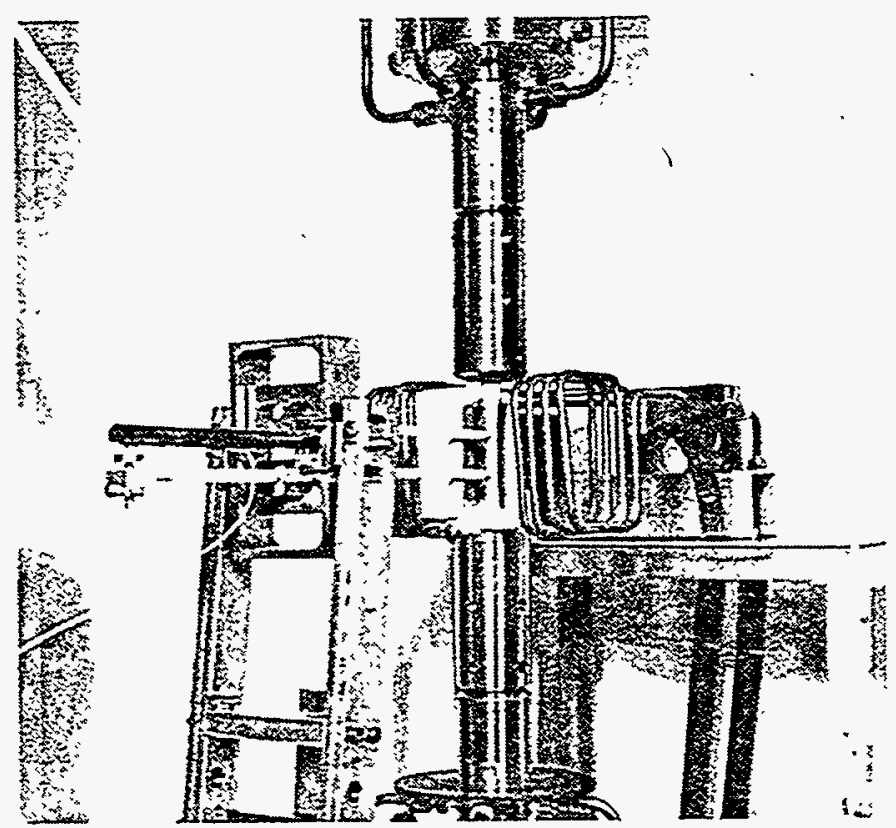

Fig. 2 - A load train assembly showing a specimen being placed between two wings of induction coils with an mechanical extensometer installed at the testing position. 


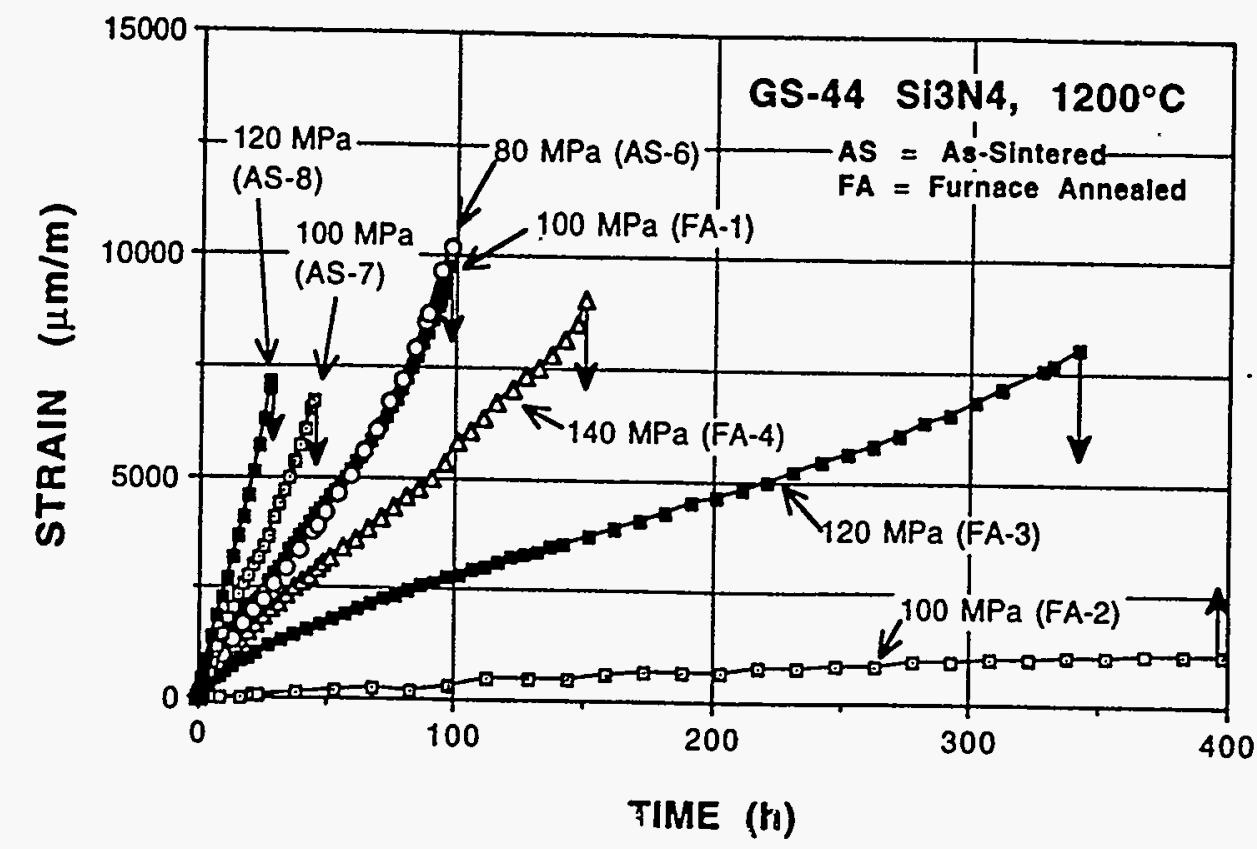

Fig. 3 - Creep curves of AS- and FA-specimens tested at $1200^{\circ} \mathrm{C}$.

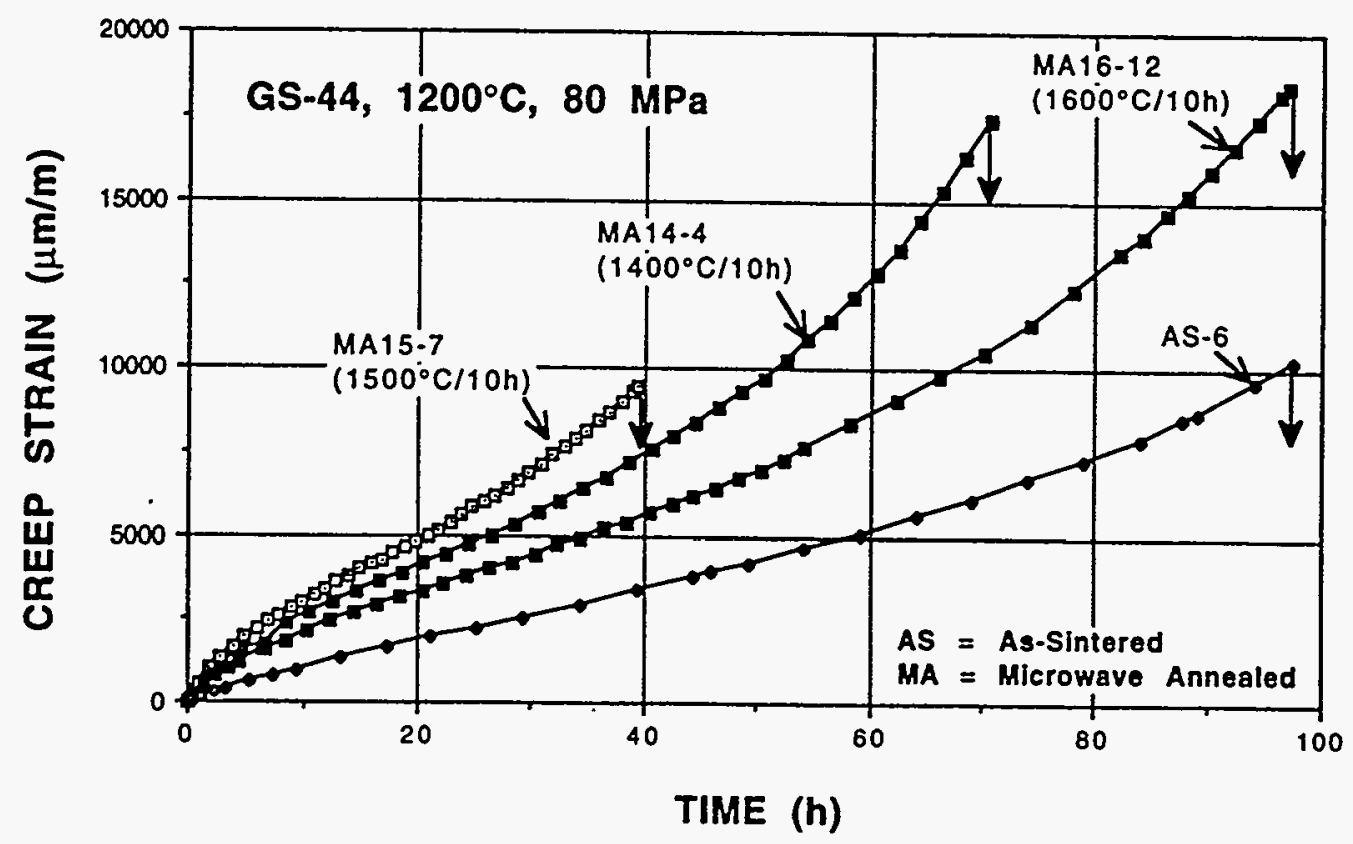

Fig. 4. Comparison of creep curves showing that annealing at high temperatures resulted in some loss of creep resistance. 
ORNL-DWG 94-8025R2

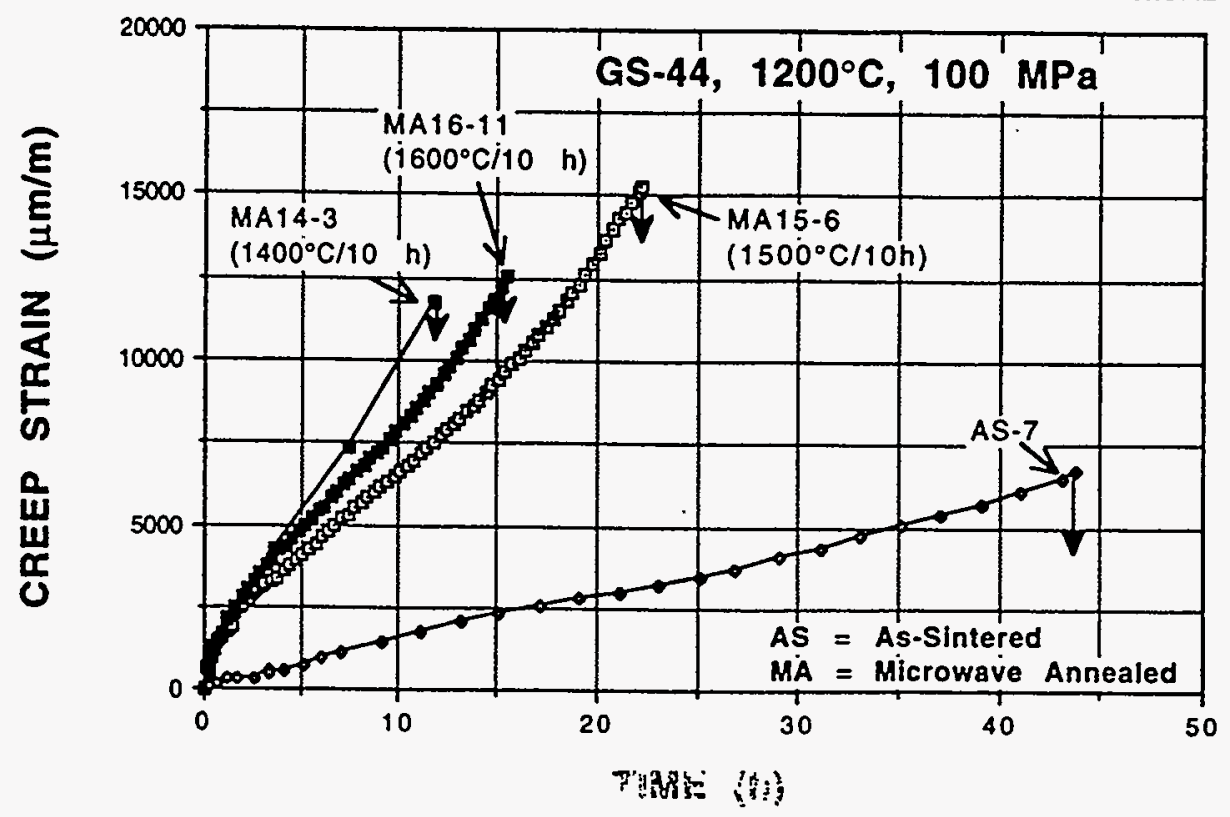

Fig. 5 - The adverse effect observed in Fig 4 became more discernible when specimens were tested at $100 \mathrm{MPa}$.

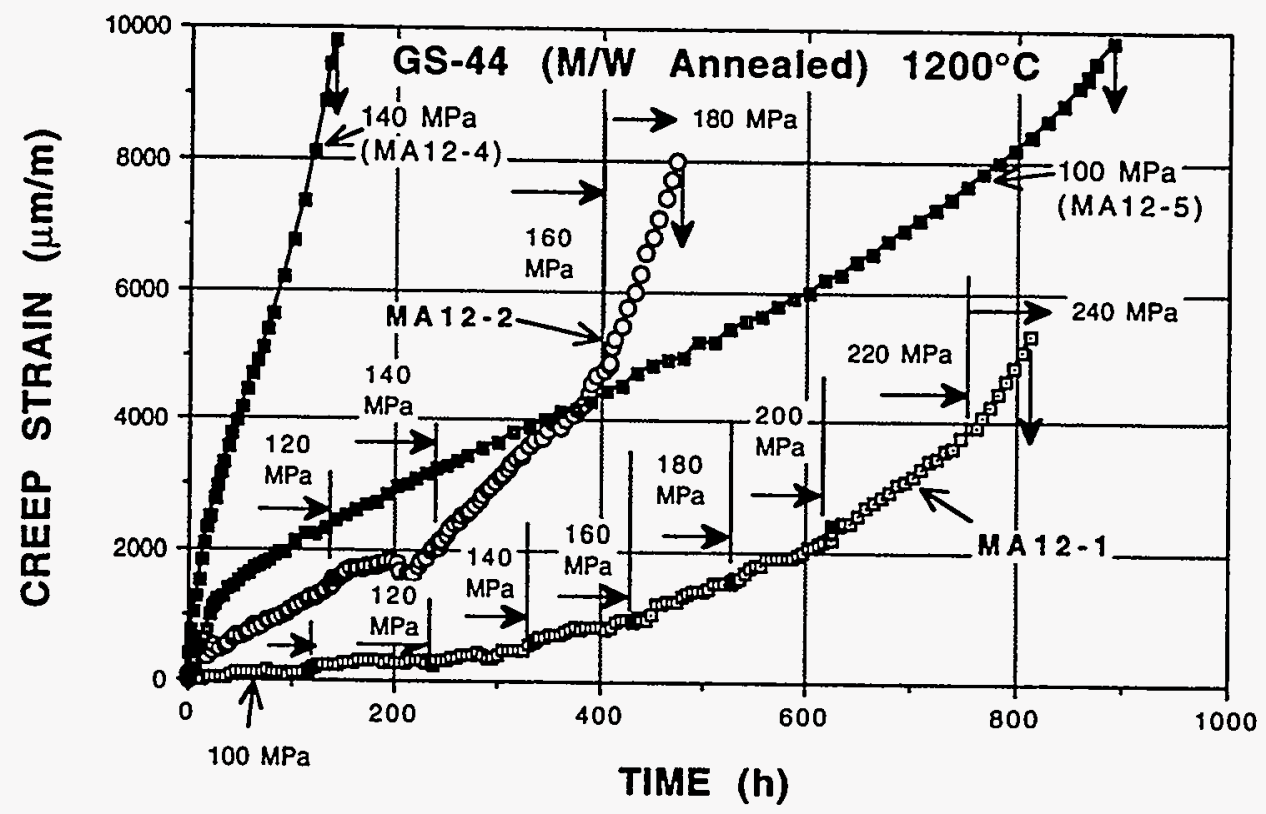

Fig. 6 - Creep curves of the five specimens made from tile "A" which had been subjected to the LT annealing. A comparison with the control creep curves shows that the LT annealing has effectively enhanced the creep resistance of the material, but somewhat lacks the desired uniformity. 


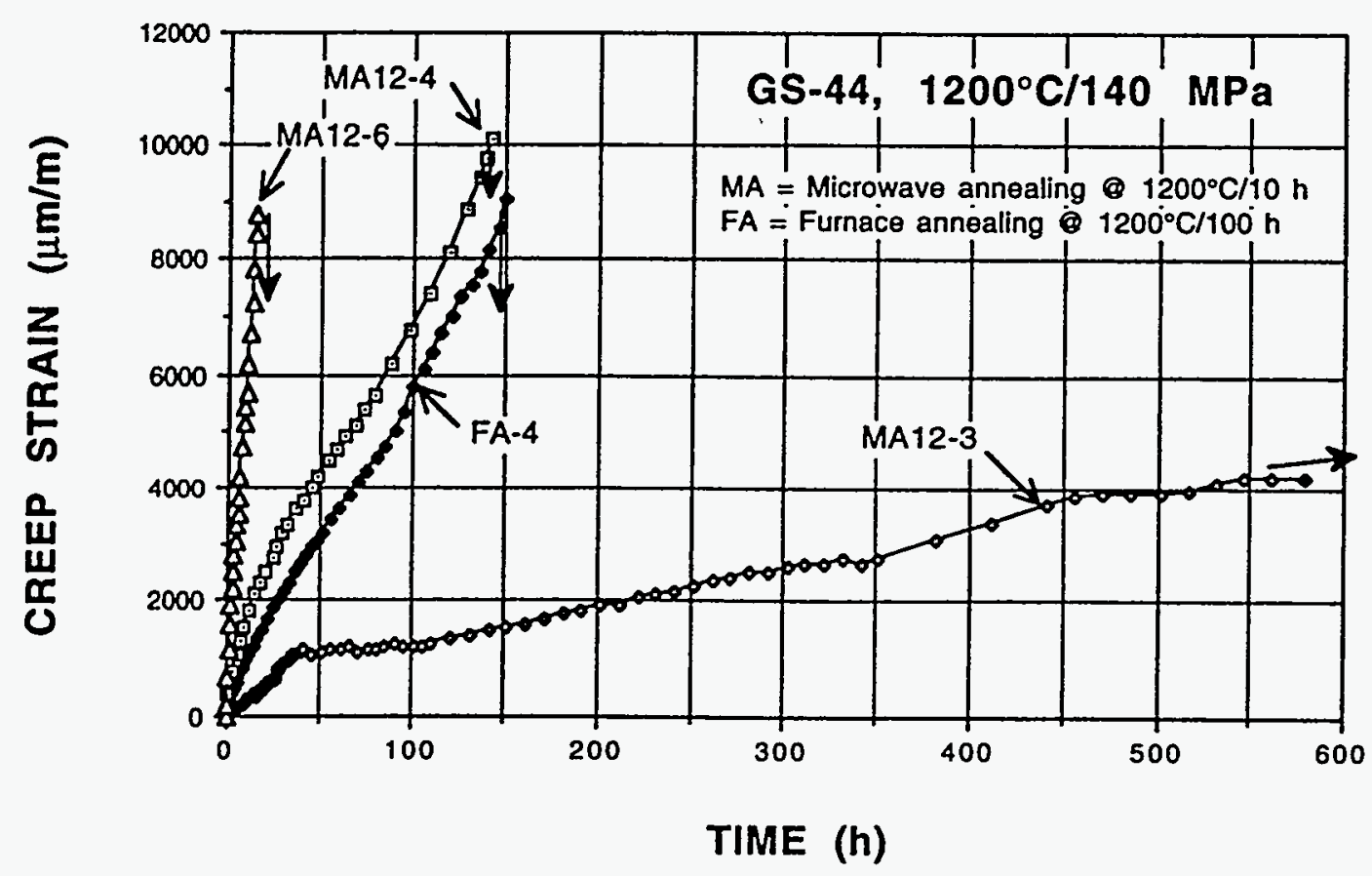

Fig. 7 - Comparison of creep curves of furnace annealed and microwave annealed specimens tested at $140 \mathrm{MPa}$.

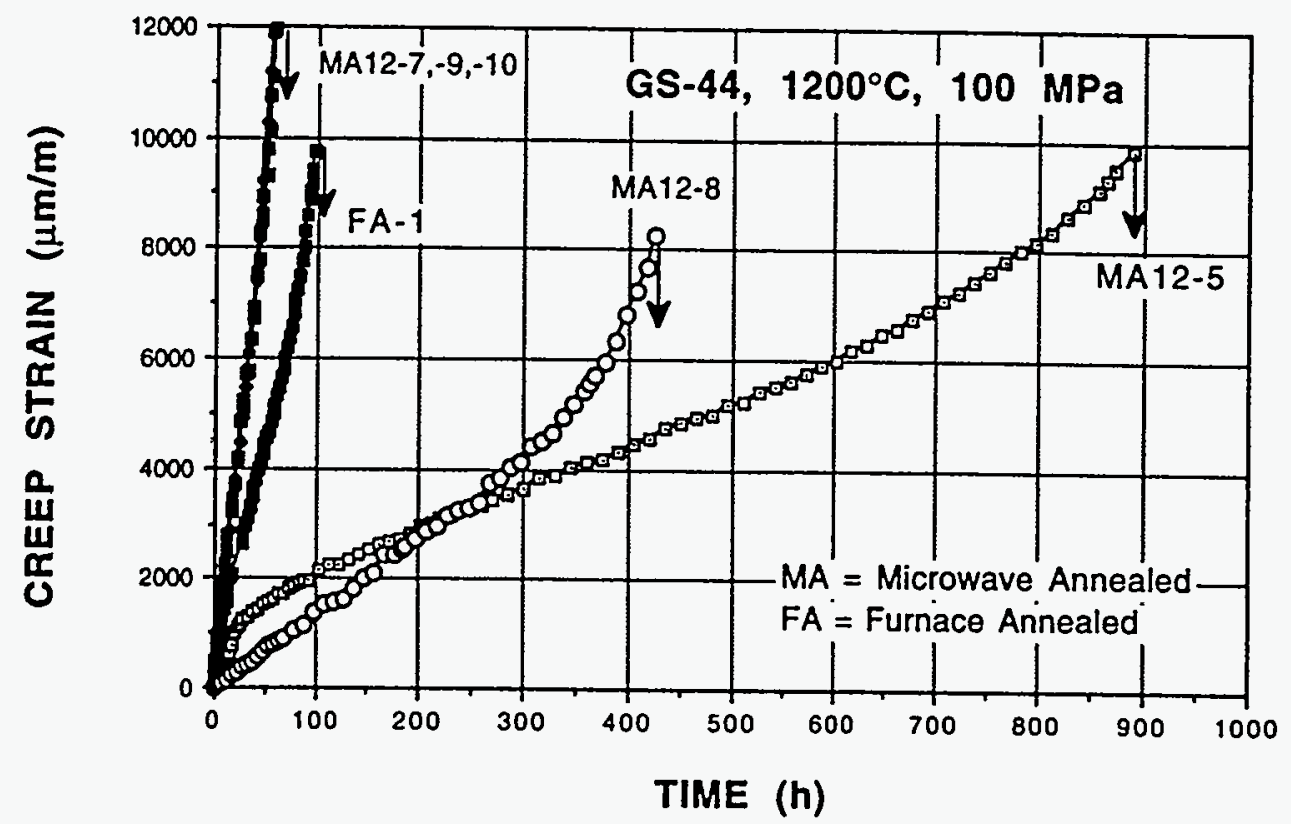

Fig. 8 - Inconsistent creep behavior exhibited by the above data indicates that the current technique of microwave annealing remains very much experimental and further improvement is needed. 


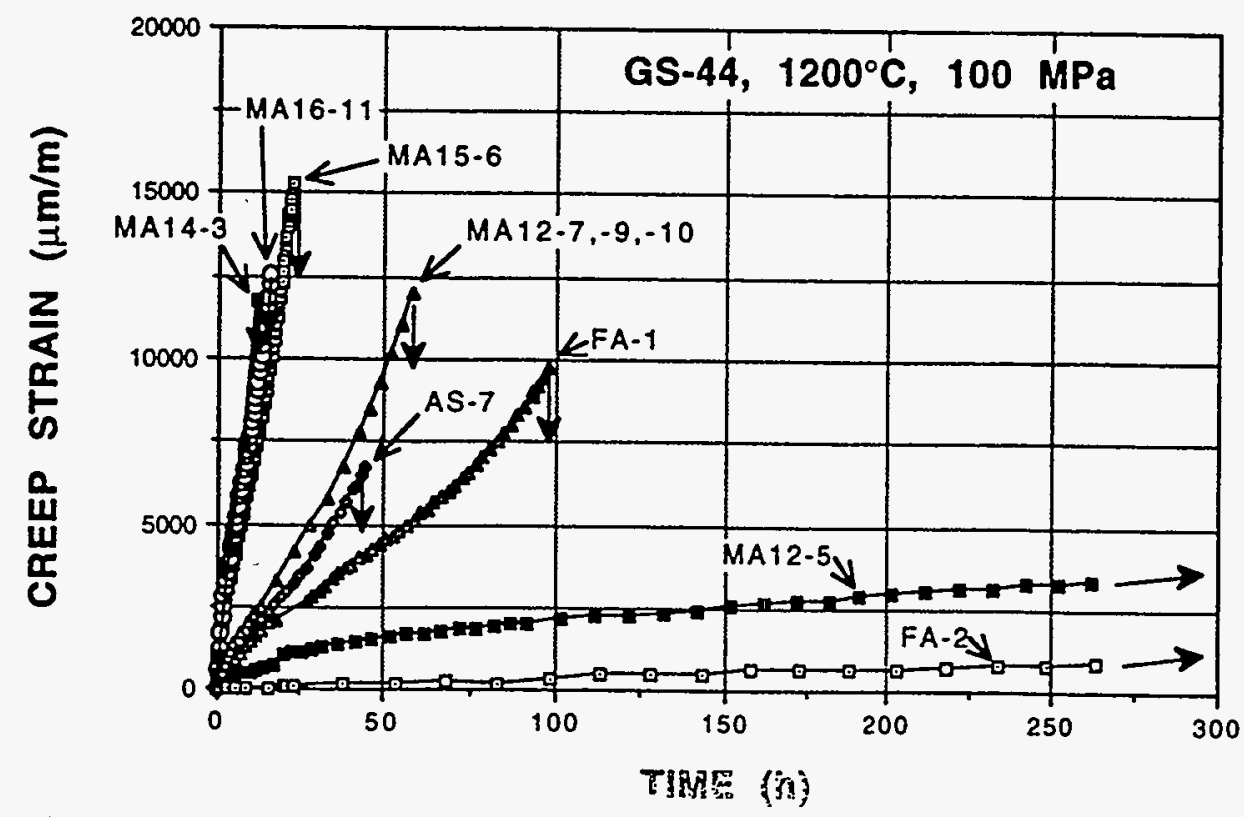

Fig. 9 - Comparison of creep curves for specimens tested in the as-sintered (or unannealed), furnace annealed, and various microwave annealed conditions as indicated with a base stress of $100 \mathrm{MPa}$.

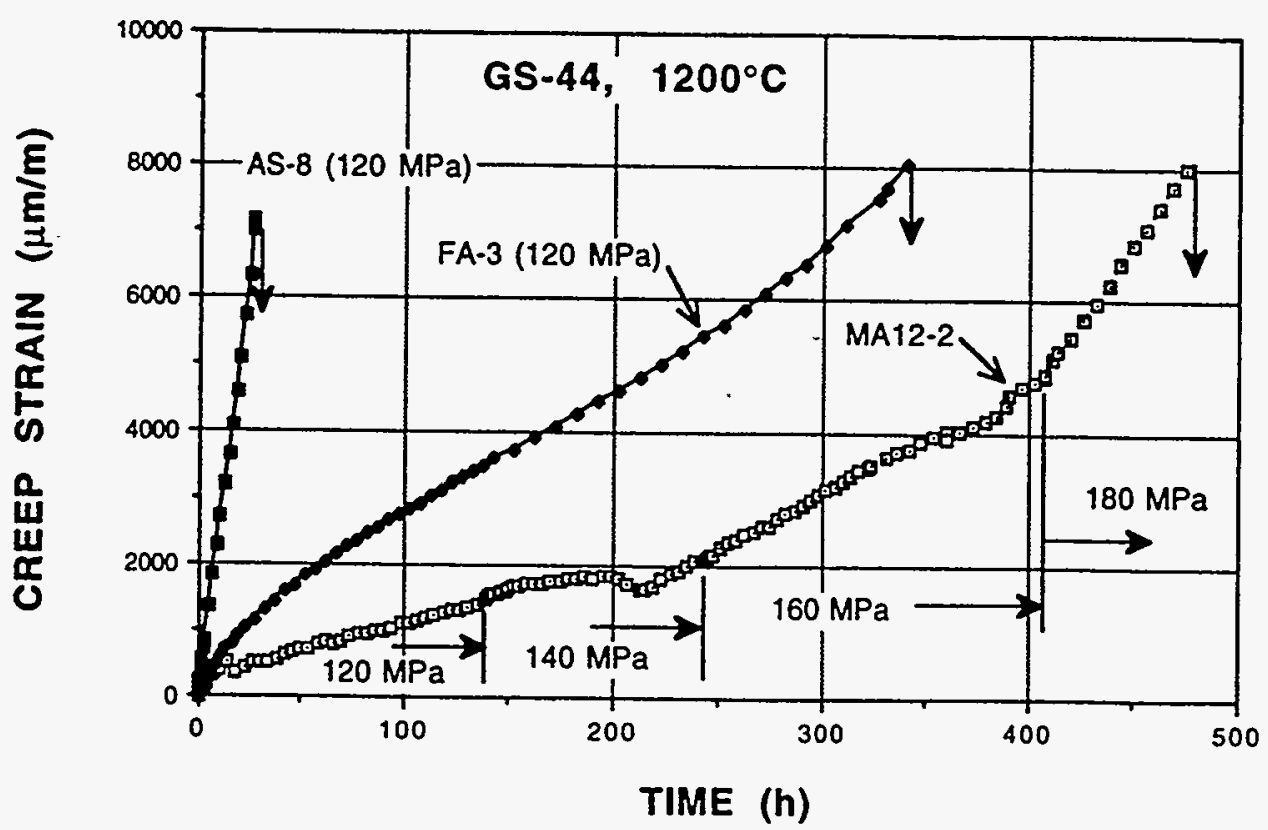

Fig. 10 - Comparison of creep curves for specimens tested in the as-sintered (or unannealed), furnace annealed, and microwave annealed conditions as indicated with a base stress of $120 \mathrm{MPa}$. 


\subsubsection{Life Prediction Verification}

A. A. Wereszczak, T. P. Kirkland, and M. K. Ferber (ORNL)

\section{Objective/Scope}

There are three central goals of the proposed research program: the generation of engineering data from high temperature mechanical testing; microstructural characterization of failure phenomena; and the implementation and verification of life prediction methods involving structural ceramics. Ultimately, the prediction of the high temperature mechanical performance and service life is information that is critical for the progress towards implementation of structural ceramics as components in internal combustion and automotive gas turbine engines.

The systematic study of the high temperature mechanical performance of a silicon nitride and a SIAION is undertaken as a function of temperature and time. A different temperature regime will serve as an independent parameter for each material. Studies on both SiAION and silicon nitride will be conducted at temperatures $\approx<1000^{\circ} \mathrm{C}$, while studies with only silicon nitride will be at temperatures $\approx>1000^{\circ} \mathrm{C}$; these are likely operating temperature thresholds for internal combustion and automotive gas turbine engines, respectively. For the lower temperature regime, properties such as strength and fatigue life will be measured in the SIAION and silicon nitride material as a function of temperature. For the higher temperature regime, tensile stress-rupture data will be generated on silicon nitride by measuring fatigue life at a constant or cyclic stress. The time-dependent deformation will also be monitored so that high-temperature creep and its effects may be studied.

The second goal of the program is to characterize the evolution and role of damage mechanisms associated with high temperature deformation. The damage will be examined using established ceramographic, SEM, TEM, and non-destructive acoustic techniques. Several microstructural aspects of high-temperature failure will be examined:

(1) the extent of slow crack growth;

(2) the evolution of cavitation-induced damage and fracture;

(3) the transition between brittle crack extension and cavitation-induced growth;

(4) crack blunting; and

(5) the evolution and role of oxidation assisted damage.

Lastly, available analytical and numerical models will be utilized to predict the life of complex-shaped components and prototype engine parts (e.g., valves). The applicability of analytical models such as the Monkman-Grant (represents a creep rate to time-to-failure 
relationship) and the Sherby-Dorn models (represents a temperature compensated relationship of time-to-failure and applied stress) to structural ceramics will be examined and modifications will be made where necessary to refine the models and improve their predictive capabilities. Numerical models (i.e., life prediction codes) will also be used in conjunction with generated strength data from standard test specimens to predict the failure probability and reliability of complex-shaped components subjected to mechanical loading, such as a SIAION or silicon nitride diesel engine valve. As a consequence of these efforts, the data generated in this program will not only provide a critically needed base for component utilization in internal combustion and automotive gas turbine engines, but also facilitate the development of a design methodology for structural ceramics subjected to mechanical loading in general.

\section{Technical Progress}

A substantial amount of mechanical testing, Weibull analysis, and fractography on NT451 SiAION was conducted during the present reporting period. The results from these efforts are required as input in order to use the life prediction algorithms that are being explored in this subtask. The results obtained during the present reporting period are summarized with respect to the specific specimen geometries that were mechanically tested. Lastly, a preliminary life prediction exercise is presented, along with discussion of near-future work.

\section{Testing and Analysis with Mil-B-Std Bend Bars}

To examine what effects grinding direction and post-machining anneal had on NT451 SiAION (and ultimately on the determination of life or reliability), four different sets of flexure bars were prepared and examined. The four different conditions were:

(1) longitudinally machined bend bars using a 320 grit size grinding wheel specified in ASTM standards for the machining of structural ceramics, with no anneal,

(2) longitudinally machined bend bars using a 700 grit size grinding wheel with the same grinding procedures specified used for the valves* with a post-machining anneal,

- Note that the valves were transversely ground though. This set of specimens was ground in this manner to see what difference existed compared with the 320-grit ASTM specified procedure (set \#1). 
(3) transversely machined bend bars using the same valve grinding procedure, with no anneal, and

(4) transversely machined bend bars using the same valve grinding procedure with a post-machining anneal.

The bend bar specimens from sets 2, 3, and 4 were machined in a two-step process. The first step was a transverse "rough" grinding step where material was removed using a 320-grit resin-bonded wheel (Type B) using a feed rate of $0.0005 \mathrm{in} /$ wheel rev. The second step was a "finish" grinding step where material was removed using a 700-grit resin bonded wheel (Type $B$ ) again employing the same transverse feed rate used in the "rough" grinding step. The edges of all specimens, regardless of whether they were longitudinally or transversely ground, were beveled in the longitudinal direction. Lastly, sets 2 and 4 were subjected to a post-machining anneal consisting of a $10^{\circ} \mathrm{C} /$ minute heating rate to $850^{\circ} \mathrm{C}$, followed by a soak for 14 hours at $850^{\circ} \mathrm{C}$, then natural cooling to room temperature inside the furnace. The NT451 valves for this study were subjected to such an anneal [1] and it was desired to repeat this for the test coupons in sets 2 and 4.

At least thirty bend bars of each set were tested in four-point flexure. The resulting strength values were examined employing Weibull Analysis. These results in turn will later be used and described in future reports in the life prediction code CERAMIC to predict the reliability of NT451 SiAION valves machined from any one of these four grinding conditions. ${ }^{* *}$

The grinding procedure and the employment of an anneal were found to affect the flexure strength of NT451 SiAION. The probability of failure as a function of stress for each of the four listed grinding sets are shown in Figs. 1-4, respectively. The uncensored Weibull Modulus, Weibull scaling parameter $\left(\sigma_{0}\right), 95 \%$ confidence bounds, and the data scatter from the flexure tests are shown in these figures, and summarized in Table 1 as well. To help with the discussion of how these four sets compare, the maximum likelihood functions for all sets are shown in Fig. 5. The two longitudinal sets (320 grit grinding versus 700 grit grinding with a post-machining anneal) yielded very similar functions as illustrated in Figs. 1 and 3 . This shows that as long as longitudinal machining was performed on NT451 SiAION, that decreasing the grit size of the grinding wheel and performing a post-machining anneal did not substantially improve the strength performance. The two sets longitudinally and transversely machined with the 700 grit

"* Only the fourth set listed is truly representative of how the valves were ground. The other sets are being examined to illustrate the importance of acknowledging proper grinding and its effects in the overall life prediction exercise. 
grinding wheel with a post-machining anneal yielded similar results as well, as illustrated by the comparison of Figs. 2 and 4. This shows that as long as 700 grit grinding with postmachining annealing was performed, that the strength of NT451 SiAION was not grindingdirection dependent (although the transverse grinding may have resulted in slightly less strengths as evidenced in Fig. 5). Lastly, annealing was observed to have a strengthening effect on transversely ground NT451 SiAION, as illustrated by the comparison of Figs. 3 and 4 . The reason(s) behind this strengthening are currently being explored.

Specimens from sets 1,2, and 4 failed from corners, surfaces, or volumes, while all specimens from set 3 failed at their surfaces with the exception of one. These trends in failure locations are consistent with the grouping of material design data in Fig. 5. Volume and surface failures were frequently caused by volume pores or inclusions. Small pores (about 10-15 $\mu \mathrm{m}$ in diameter) were found in the material and were believed to be homogeneously distributed; their effect as failure-causing flaws were more prevalent in the sets 1,2, and 4 . With the naked eye, these pores appeared as small dark spots on the machined surfaces of the specimens. These pores in question, along with transverse grinding grooves, are shown in Fig. 6(a). The pores at the ground surfaces were not believed to be created by the machining because they were found in the bulk of the material as well, as evidenced by their presence at fracture surfaces, such as that shown in Fig. 6(b).

\section{Testing and Analysis with Tensile Specimens}

Weibull analysis of the tensile strength data yielded an unbiased Weibull Modulus and characteristic strength of 8.8 and $791 \mathrm{MPa}$, respectively. The graphical representation of this information, along with the fractographical results, are shown in Fig. 7. All but one tensile specimen failed from a volume pore or inclusion; an example of which is shown in Fig. 8. The analysis for $95 \%$ confidence bounds yielded lower and upper bounds on the Weibull Modulus and characteristic strength of 5.1 and 15.7, and 738 and $861 \mathrm{MPa}$, respectively; these large ranges were due to the small number of specimens (7) that were tested. The gage sections of these tensile specimens were longitudinally ground (i.e., they were ground like ceramic tensile specimens typically are) and were not subjected to a post-machining anneal; however, additional tensile specimens are being machined as of this writing, and will be transversely ground in the same manner as the valves and annealed. Tensile strength tests will be repeated using these specimens. The comparison of tensile strengths generated from specimens whose gage sections are 
machined via conventional means (i.e., longitudinal) and those that are machined like the NT451 SiAION valves (i.e., transversely machined and annealed) will provide critical insight into the importance of recognizing machining condition as an independent parameter in successful life prediction.

\section{Testing and Analysis with Rotary Bend Fatigue Specimens}

Initial rotary bend fatigue tests were conducted at $50 \mathrm{~Hz}$ during the present reporting period on NT451 specimens and the results are summarized in Fig. 9. The rotary bend fatigue test subjects a rotary bend fatigue specimen to fully reversed cyclic loading and the advantage of the apparatus is that large number of cycles can be generated in a relatively short period of time to capabilities of high rotational frequencies. Rotary bend strength tests were conducted on a couple specimens (i.e., one cycle in Fig. 9) by monotonically loading the rotary bend fatigue specimen to failure in the absence of any rotation. The rotary bend strengths were equivalent to the average flexure strength observed on the bend bars. Fatigue failures from machining damage were produced in a couple specimens after tens-of-thousands of cycles. Runout was observed as well after $10^{7}$ cycles and a preliminary fatigue limit of approximately $600 \mathrm{MPa}$ was identified.

Optical fractography was also performed during the present reporting period on rotary bend fatigue specimens that were cycled to failure. The rotary bend specimen geometry was reported in a past report [2]. The gage section of these specimens is cylindricallyshaped and is flexed while rotating. All failures originated at the surface or near-surface, an example of the latter is shown in Fig. 10.

\section{Testing and Analysis with Biaxial Flexure Specimens}

The last series of Weibull analyses examined during the present reporting period involved biaxial flexure strength data. A ball-on-ring test was employed (test schematic shown in Fig. 11) to measure the biaxial flexure strength of thin disks ( $0.76 \mathrm{~mm}$ thickness $\times 31.75 \mathrm{~mm}$ diameter) of NT451 SiAION using the analysis of Shetty et al. [3]. The unbiased Weibull Modulus and characteristic strength were determined to be 6.7 and $856 \mathrm{MPa}$, respectively. The graphical representation of this information, along with the fractographical results, are shown in Fig. 12. All specimens failed at the tensile surface from optically unidentifiable defects or machining damage. An example of such a fracture surface is shown in Fig. 13. With $95 \%$ confidence, the lower and upper bounds for the Weibull Modulus and characteristic strength were found to be 
4.3 and 10.6 , and 791 and $935 \mathrm{MPa}$, respectively. The large bounding ranges were a consequence of two sources: (1) only.10 specimens were tested, and (2) the requested machining conditions were insufficiently explicit, and some of the specimens were ground differently to adhere to the desired specimen thickness. In particular, two of the specimens were evidently lapped at their centers to satisfy the thickness requirement, and not surprisingly these same two specimens had the highest biaxial flexure strengths.

\section{A Preliminary Life Prediction Estimate and Near-Future Work}

The unannealed, transversely ground bend bars characteristically yielded the lowest strengths as shown in Fig. 5, so with the intent to predict the most conservative valve reliability, a prediction exercise was conducted using this data. The material design data (uncensored) from the fast-fracture bend tests shown in Fig. 3 was used with finite element analysis described in a previous report [2] and ERICA analysis, to predict the reliability of a NT451 SiAION Series 149 valve using CERAMIC. The probability of failure for a valve as a function of "combustion pressure" is shown in Fig. 14. For a maximum design or combustion stress of $16 \mathrm{MPa}$, there is a very low probability that the valve will fail.

The NT451 SiAION strength data, Weibull information, and fractography results from the various specimen geometries will be pooled into AlliedSignal's CERAMIC code during the next reporting period. That resulting information will then be used with (1) finite element analysis of a NT451 SiAION valve with appropriate boundary conditions and (2) AlliedSignal's ERICA code to more confidently predict the life of the NT451 valves.

Experimental tests on valves will then commence during the next reporting period and the results will be compared with those predicted.

\section{Status of Milestones}

The new electroservohydraulic test frame was received and installed during the present reporting period. Operation specifications were satisfied. This frame will be used for much of the mechanical testing on standard specimens of the NT451 SiAION and NT551 silicon nitride materials, as well as the valves made from these materials. The original frame that did not satisfy specifications was returned to the vendor at the vendor's expense. 
After some valves are mechanically tested during the next reporting period, a communications-type paper will be submitted for publication in the open literature (Milestone 3.2.1.6.12) comparing the reliability prediction with experimental results.

All other milestones are on schedule.

\section{Communications / Visitors / Travel}

A. A. Wereszczak traveled to the Annual Automotive Technology Development Contractors' Coordination Meeting, in Dearborn, MI, Oct 23-27, 1995, to give a presentation entitled "Verification of Life Prediction Methodology as Applied to a Ceramic Valve."

A. A. Wereszczak traveled to AlliedSignal, Phoenix, AZ, Nov. 13-14, to work with A. Peralta, who is an AlliedSignal engineer responsible for the life prediction codes CERAMIC and ERICA.

The new NT551 silicon nitride composition from Saint Gobain/Norton should be made available to this subtask around June 1996. Bend bars, rotary bend, tensile, and biaxial flexure specimens will be prepared from NT551. Data generated from tests using these specimens will be used to predict the mechanical performance of NT551 valves, which will also be acquired and mechanically tested; the predicted mechanical performance of these valves will be compared with that experimentally measured.

\section{Problems Encountered}

None.

\section{Publications}

A presentation entitled "Verification of Life Prediction Methodology as Applied to a Ceramic Valve," by A. A. Wereszczak, H. Cai, and M. K. Ferber, was given at the Annual Automotive Technology Development Contractors' Coordination Meeting, Dearborn, MI, Oct 23-27, 1995. 


\section{References}

[1] Personal communication with Eric Bright, Saint-Gobain / Norton Industrial Ceramics Corporation, January, 1996.

[2] A. A. Wereszczak, H. Cai, M. K. Ferber, and T. P. Kirkland, "Life Prediction Verification," in the Ceramic Technology Project Bimonthly Technical Progress Report to DOE Office of Transportation Technologies, Aug. - Sep. 1995.

[3] D. K. Shetty, A. R. Rosenfield, P. McGuire, G. K. Bansal, and W. H. Duckworth, "Biaxial Flexure Tests for Ceramics," Ceramic Bulletin, 59 [12] 1193-97 (1980).

Table 1. Summary of Weibull parameter values with $95 \%$ confidence generated from uniaxial flexure tests.

\begin{tabular}{c|c|c|c|c|c|c|}
$\begin{array}{c}\text { Set } \\
\text { Number }\end{array}$ & $\begin{array}{c}\mathrm{m} \\
95 \%\end{array}$ & $\mathrm{~m}$ & $\begin{array}{c}\mathrm{m} \\
\text { (Lo est) }\end{array}$ & $\begin{array}{c}\sigma_{0} \\
95 \% \\
\text { (Hi est) }\end{array}$ & $\begin{array}{c}\sigma_{0} \\
\text { (Lo est) }\end{array}$ & $\begin{array}{c}\sigma_{0} \\
95 \% \\
\text { (Hi est) }\end{array}$ \\
\hline 1 & 14.1 & 19.0 & 24.4 & 1057 & 1092 & 1154 \\
\hline 2 & 16.3 & 21.9 & 28.5 & 1051 & 1081 & 1132 \\
\hline 3 & 9.8 & 13.1 & 16.9 & 992 & 1043 & 1134 \\
\hline 4 & 12.6 & 16.9 & 22.0 & 1054 & 1096 & 1166 \\
\hline
\end{tabular}

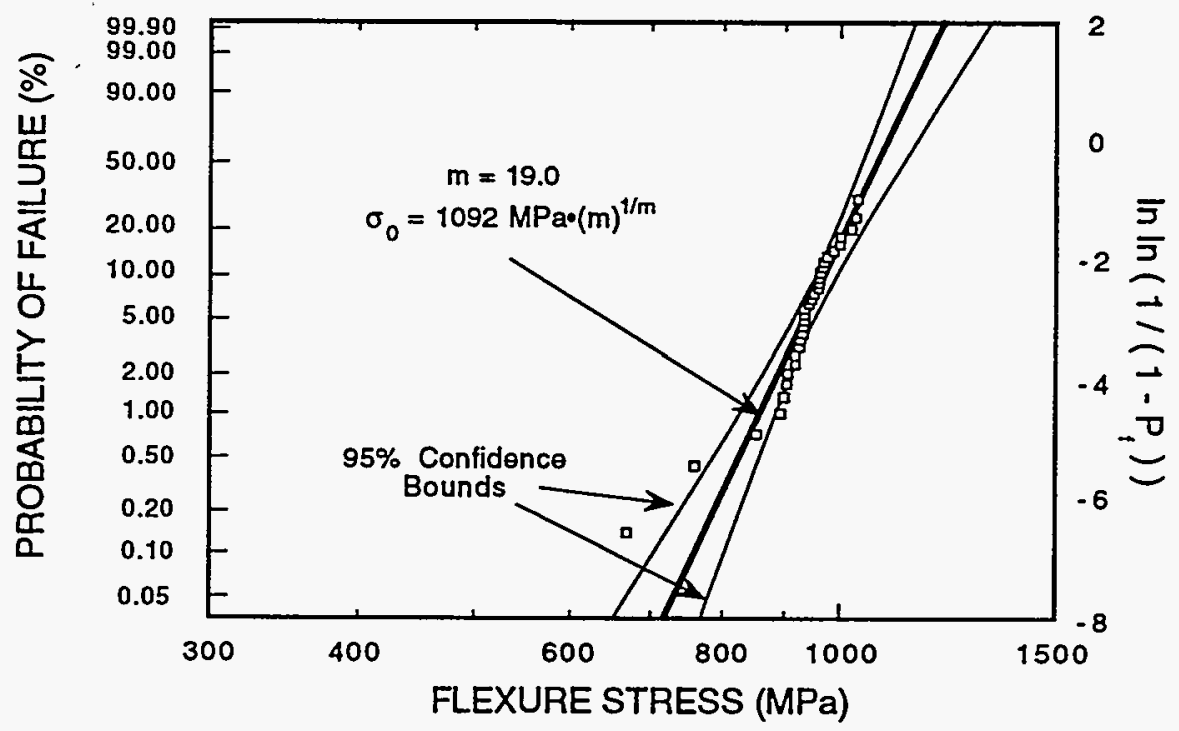

Fig. 1. Weibull analysis of flexure data generated from specimens that were longitudinally ground with a 320 grit wheel (ASTM). These bend bars were not subjected to an anneal. 


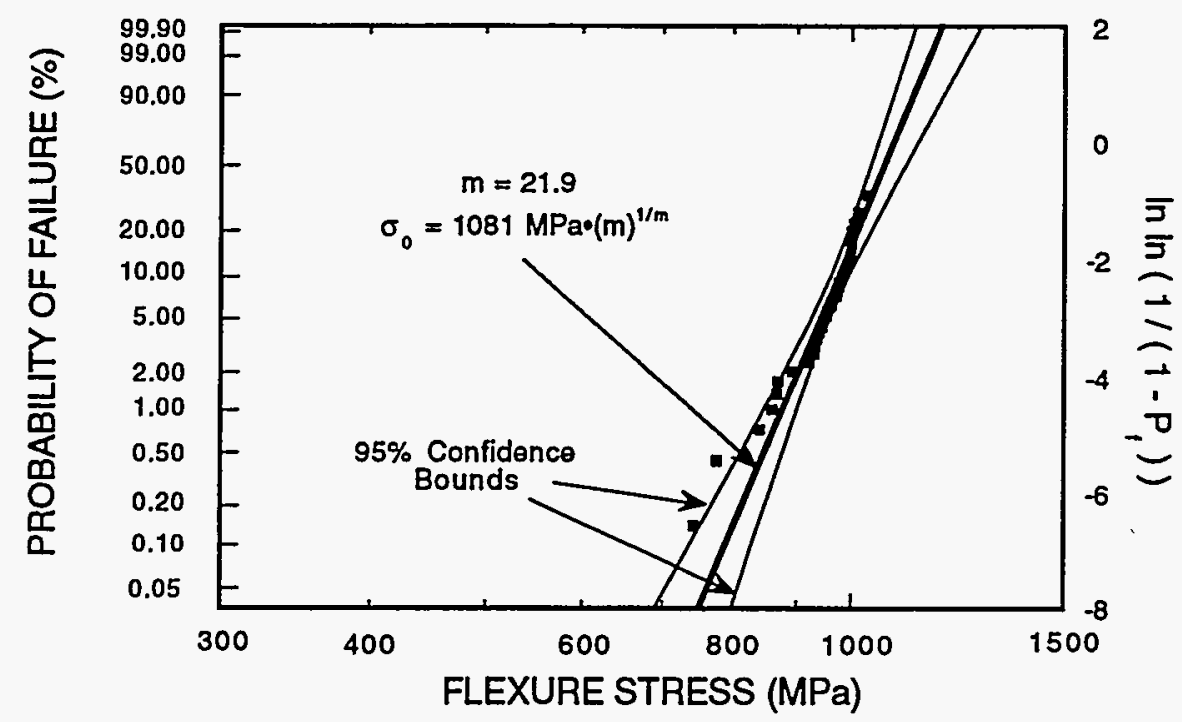

Fig. 2. Weibull analysis of flexure data generated from specimens that were longitudinally ground with a 700 grit wheel using the same grinding conditions as the study's valves. These bend bars were annealed using the same conditions that the valves were annealed at.

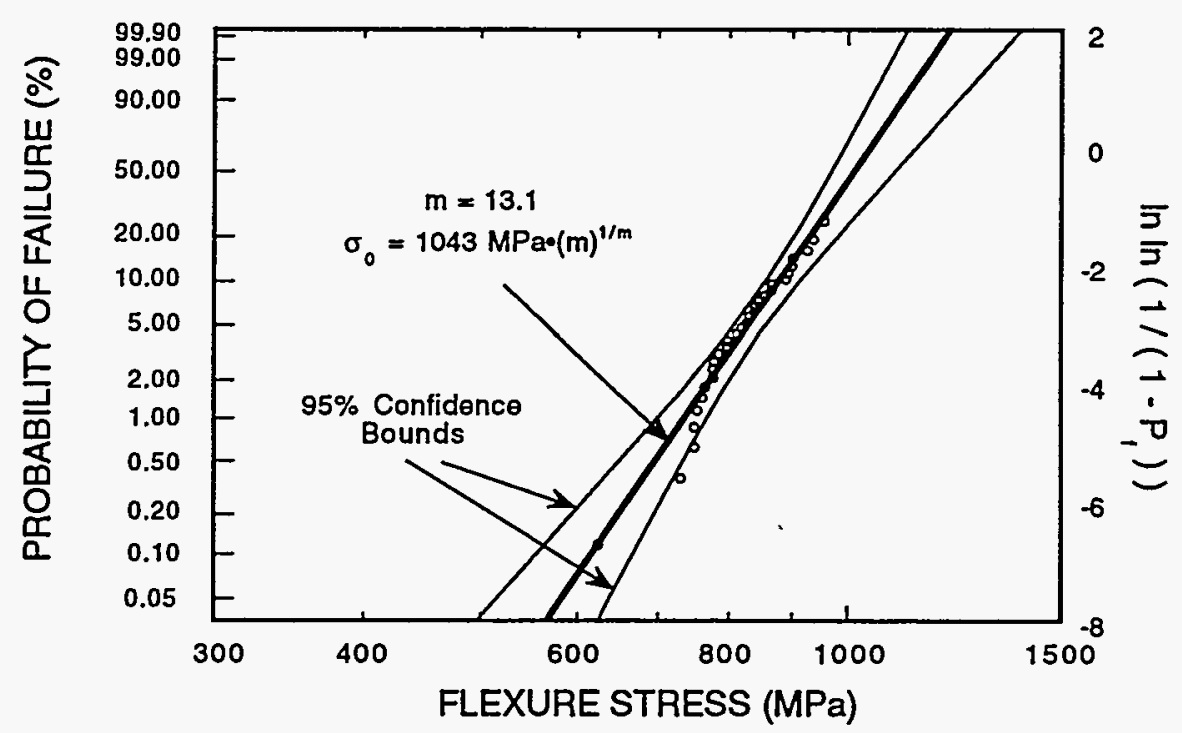

Fig. 3. Weibull analysis of flexure data generated from specimens that were transversely ground with a 700 grit wheel using the same grinding conditions as the study's valves. These bend bars were not annealed. 


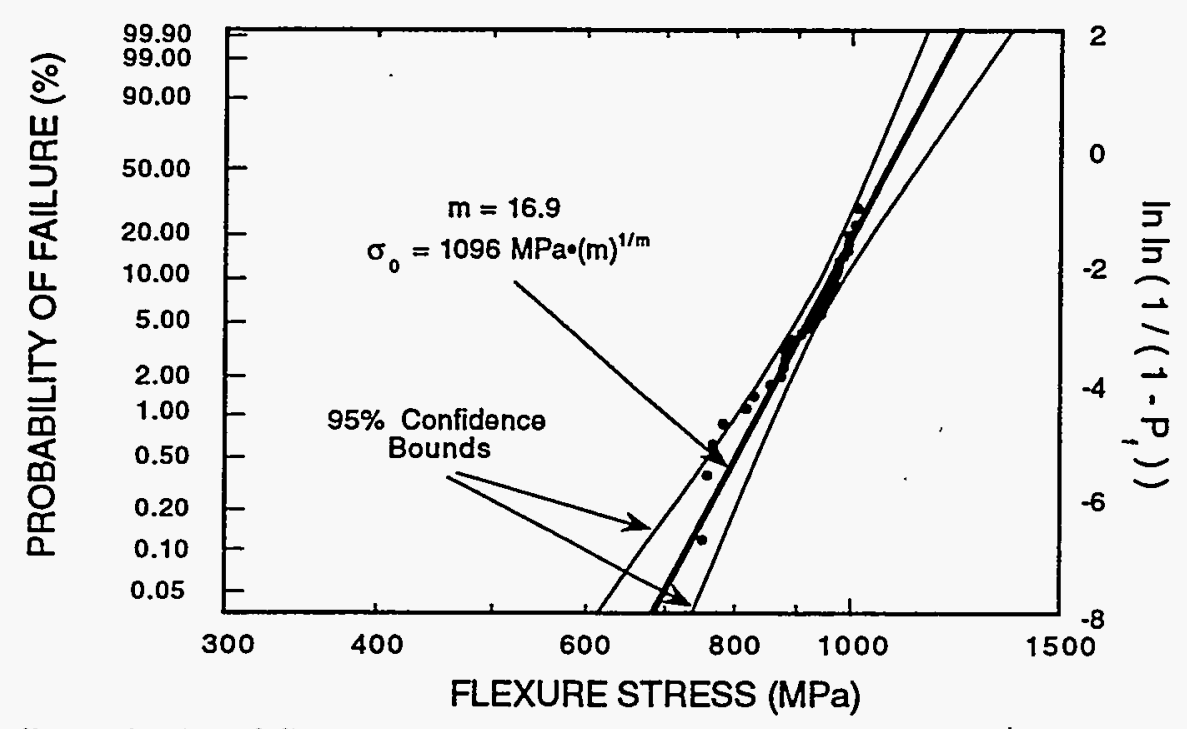

Fig. 4. Weibull analysis of flexure data generated from specimens that were transversely ground with a 700 grit wheel using the same grinding conditions as the study's valves. These bend bars were annealed using the same conditions that the valves were annealed at. This data is the most representative of the material state in the study's valves.

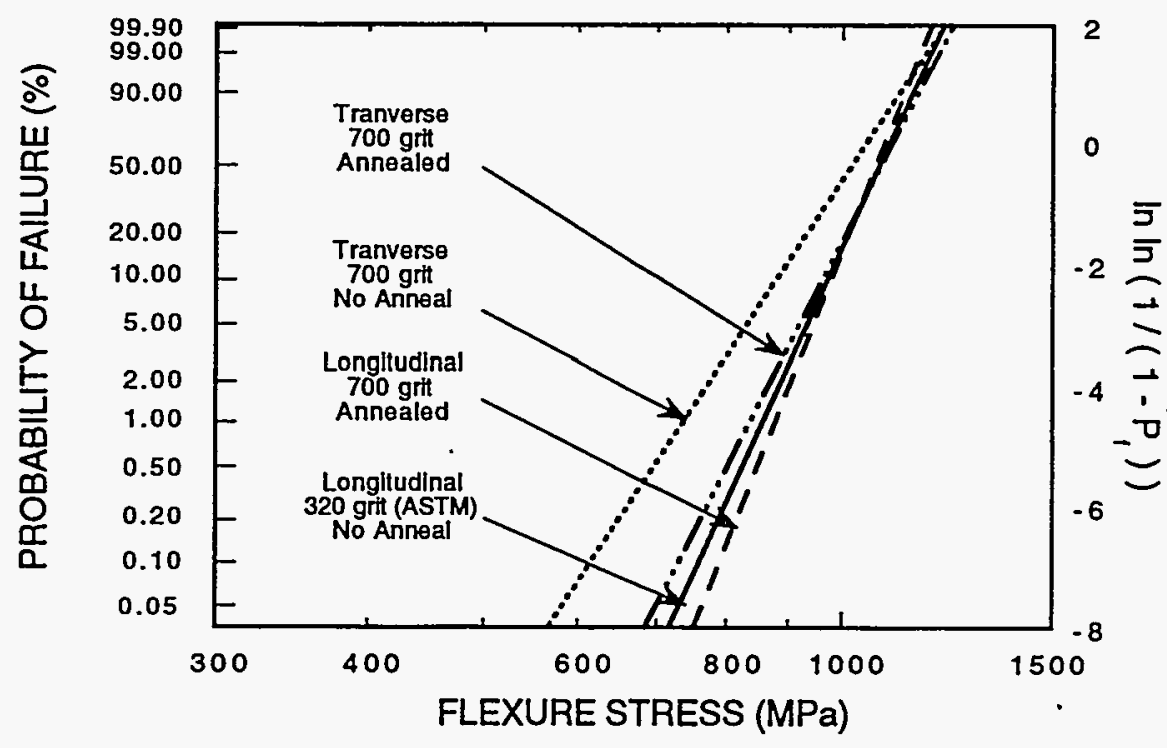

Fig. 5. Comparison of the determined maximum likelihood functions for the four sets of uncensored data shown in Figs. 1-4. The unannealed, transversely ground NT451 specimens yielded the lowest strengths, while the strengths of the other three sets were not significantly different. 


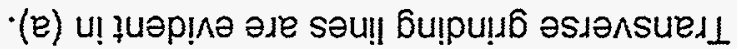

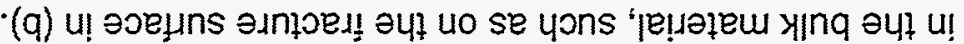

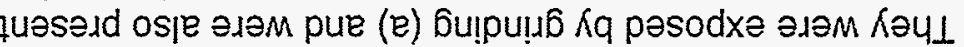

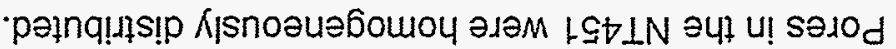

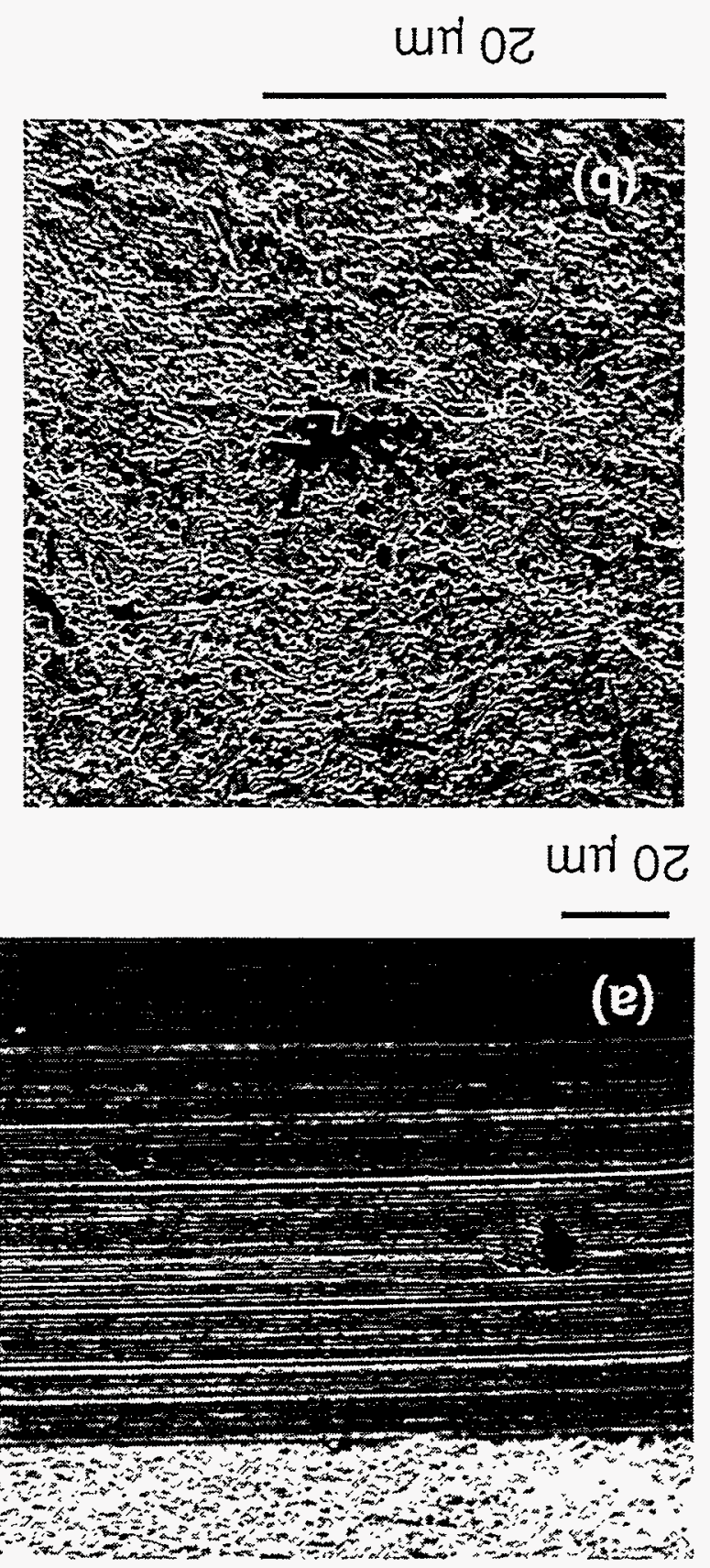




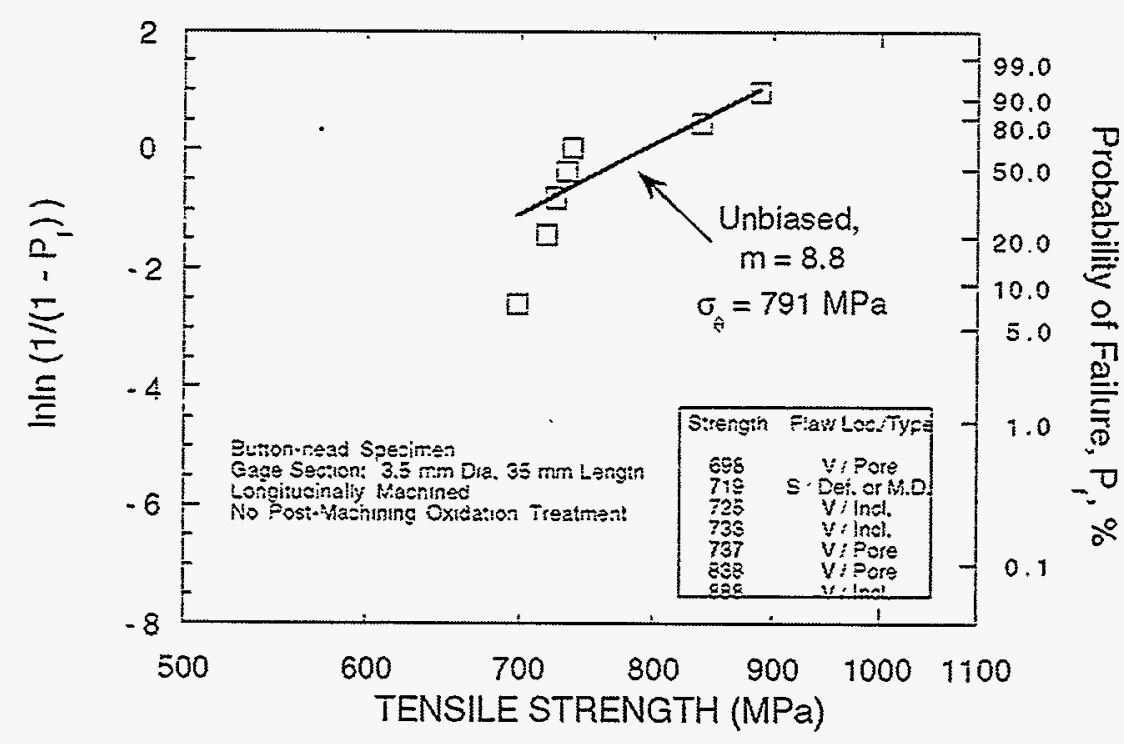

Fig. 7. Weibull and Fractographical Analysis of Tension Testing of NT451 SIAION.

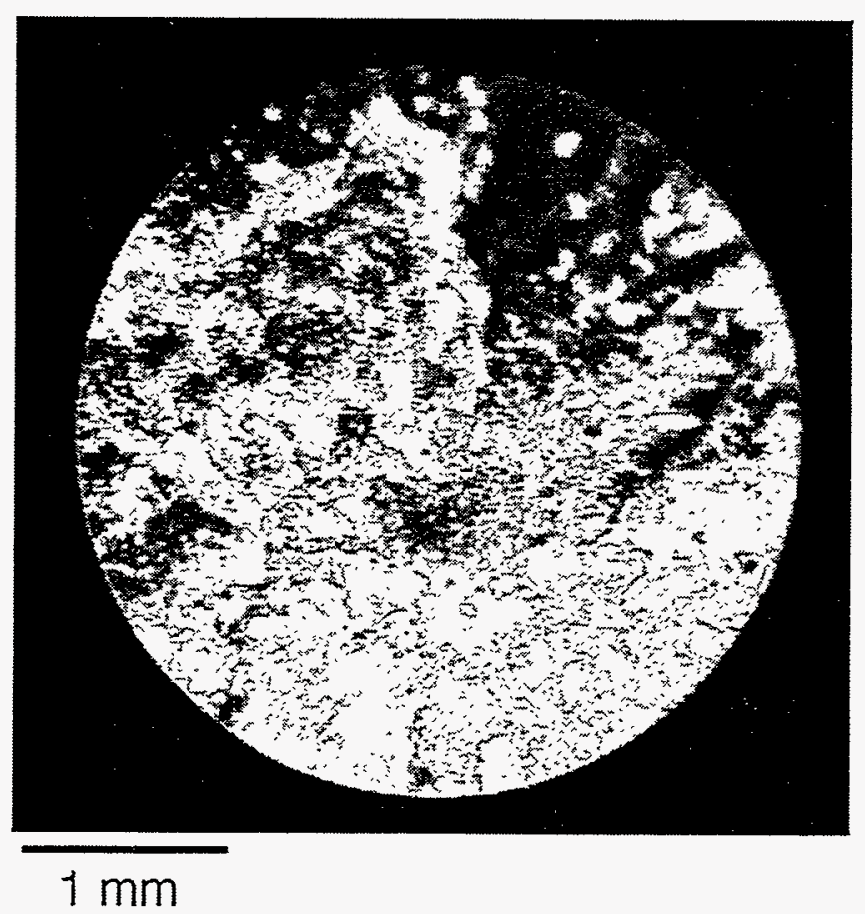

Fig. 8. Tension specimens typically failed from volume pores or inclusions. The specimen shown failed at $737 \mathrm{MPa}$ from a volume pore. 


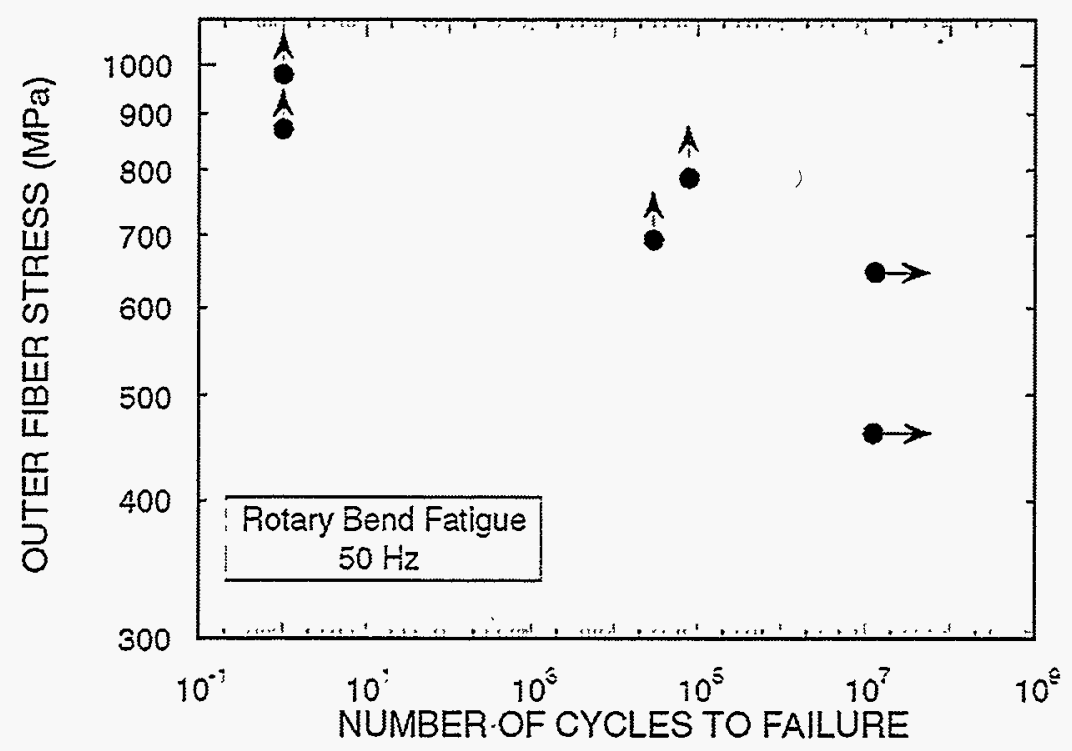

Fig. 9. Rotary bend fatigue results to date. Horizontal arrows designate runout (i.e., non-failures) after $10^{7}$ cycles and vertical arrows designate failures. Failures at 1 cycle represent monotonic load to failure tests in the test frame with no specimen rotation.

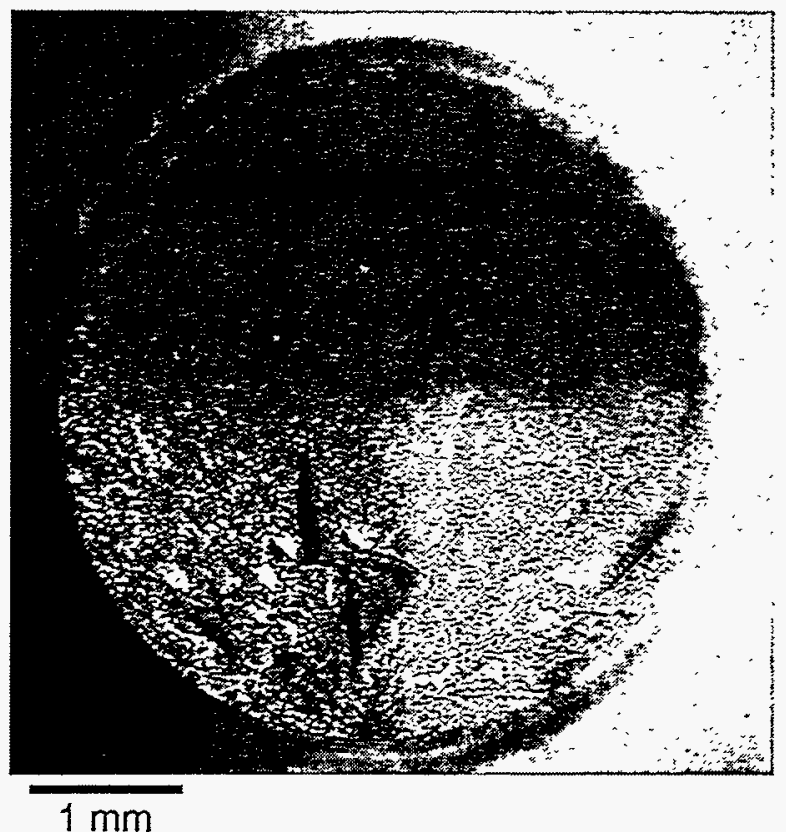

Fig. 10. Fracture surface of a rotary bend fatigue specimen that failed after 189300 cycles $(50 \mathrm{~Hz})$ at $648 \mathrm{MPa}$. 

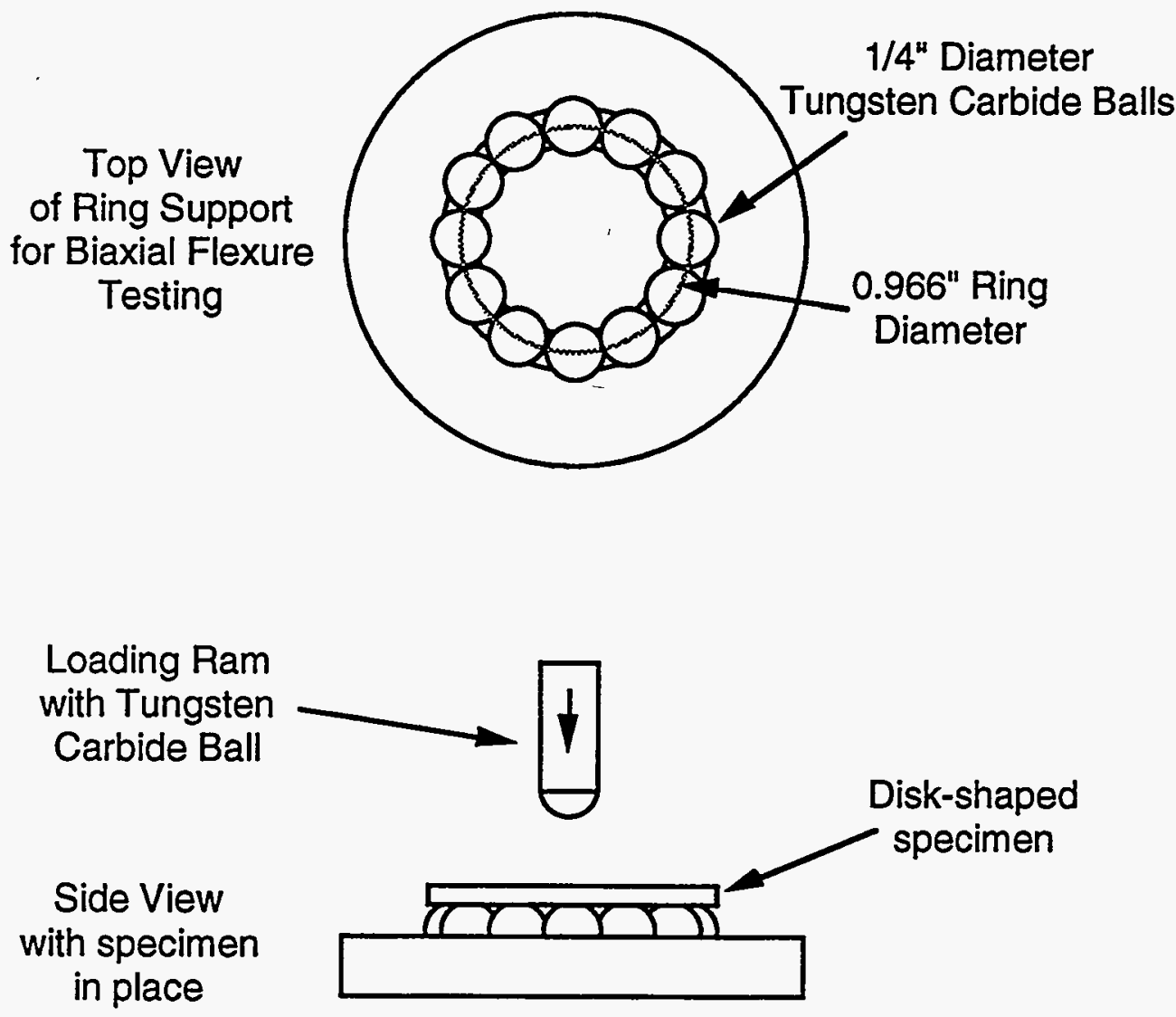

Fig. 11. Schematic of the Ball-on-Ring Fixture used for the Biaxial Flexure Strength Tests.

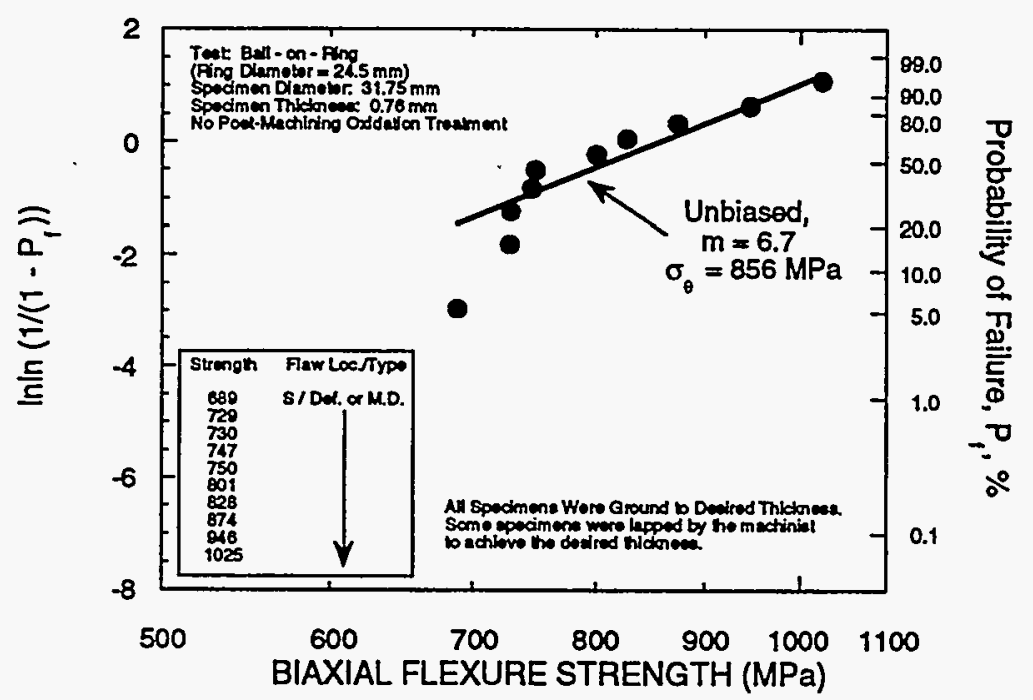

Fig. 12. Weibull and Fractographical Analysis of Biaxial Flexure Testing of NT451 SiAION. 


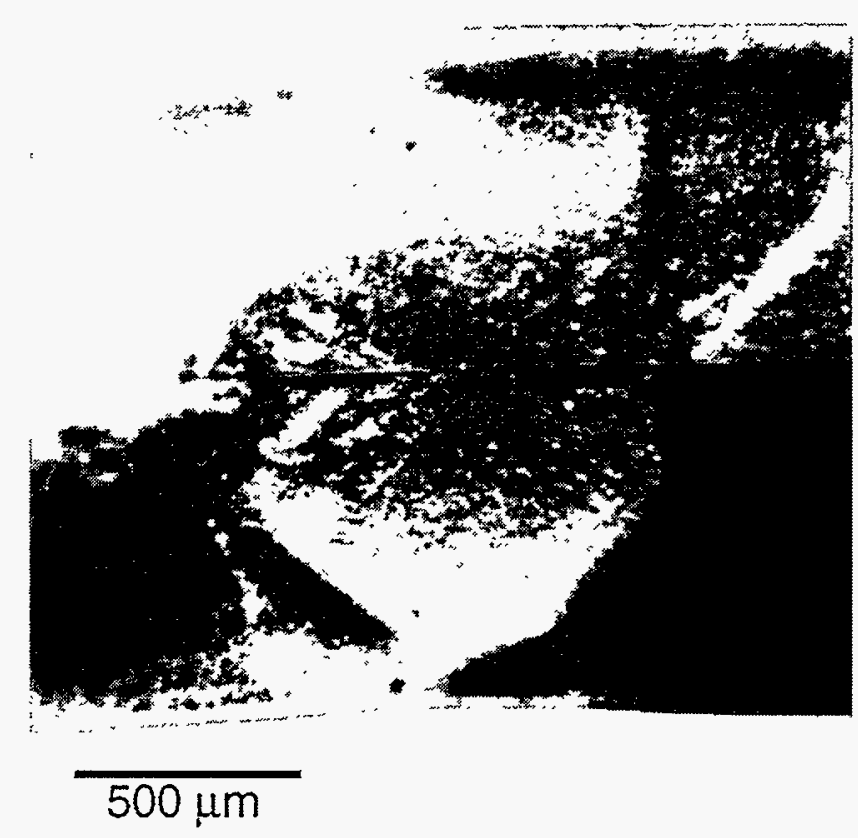

Fig. 13. Matching pair of fracture surfaces showing the mirror on a specimen that was biaxially flexed to failure. Shown specimen failed at $828 \mathrm{MPa}$.

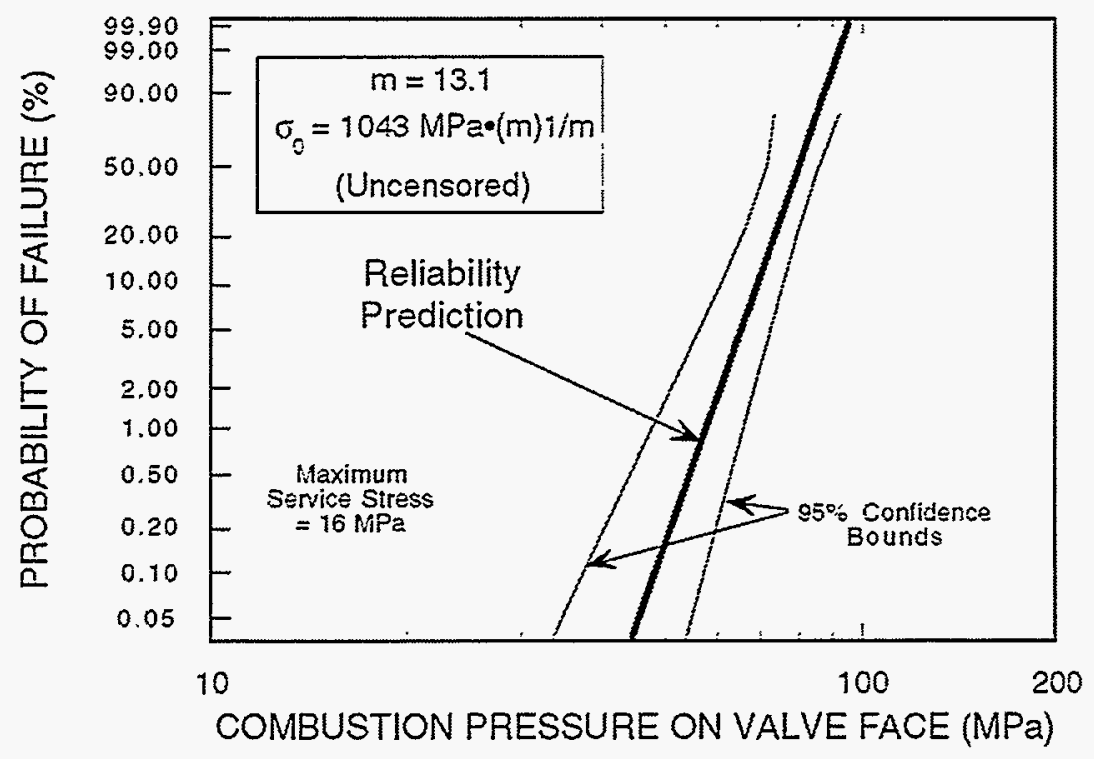

Fig. 14. Reliability prediction of a NT451 SiAION Series 149 valve using the boundary conditions described previously [2] and from input data generated from unannealed, transversely ground bend bars. 
TOUGHENED CERAMICS LIFE PREDICTION

Jonathan A. Salem and Sung R. Choi (NASA Lewis Research Center)

\section{Objective/Scope}

The purpose of this research is to understand the room temperature and high temperature I $\leq$ $1370^{\circ} \mathrm{C}\left(2500^{\circ} \mathrm{F}\right)$ ] behavior of toughened ceramics as the basis for developing a life prediction methodology. A major objective is to understand the relationship between microstructure and mechanical behavior within the bounds of a limited number of materials. A second major objective is to determine the behavior as a function of time and temperature. Specifically, the room temperature and elevated strength and reliability, the fracture toughness, slow crack growth and the creep behavior will be determined for the as-manufactured material. The same properties will also be evaluated after long-time exposure to various high temperature isothermal and cyclic environments. These results will provide input for parallel materials development and design methodology programs. Resultant design codes will be verified.

\section{TECHNICAL HIGHLIGHTS}

The inert strength of a ceramic material at room temperature is typically regarded as free of the effects of slow crack growth (fatigue). Hence, the inert strength is the maximum attainable strength for given flaw configuration. The room-temperature inert strength can be determined either by eliminating active species (especially water) via an appropriate inert medium, or by using a very high loading rates, which minimizes the time for fatigue by inducing failure faster than active species can be transported to the crack tip.

At high temperatures, however, the definition of "inert" strength is not clear, since temperature itself is the active degradation mechanism. Hence, the only approach for determining the "inert" strength is the use of a series of high stressing rates. Little study has been done on the concept and few experiments measuring the high temperature "inert" strength of ceramic materials have been performed. The purpose of this work is to better understand high temperature "inert" strength behavior of advanced ceramic materials. For this purpose, high- temperature, high-rate dynamic fatigue testing (also called constant stress-rate testing) of one alumina, two silicon nitrides, and one silicon carbide material was conducted with flexure. The experimental data was analyzed with a numerical solution of dynamic fatigue strength as a function of stressing rate.

\section{ANALYSIS}

For most ceramics and glasses, slow crack growth rate under Mode I loading above the fatigue limit can be expressed by the following power-law relation ${ }^{1}$ 


$$
v=\frac{d a}{d t}=\Lambda\left[\frac{K_{l}}{K_{I C}}\right]^{n}
$$

where $v, a$ and $t$ are crack velocity, crack size and time, respectively. $A$ and $n$ are the material/environment dependent fatigue parameters, and $K_{\mathrm{I}}$ and $K_{\mathrm{IC}}$ are, respectively, the Mode I stress intensity factor and the critical stress intensity factor or fracture toughness of the material under Mode I loading. For dynamic fatigue testing which employs constant loading or stressing rate $(\sigma)$, the corresponding fatigue strength $\left(\sigma_{\mathrm{f}}\right)$ is expressed as a function of stressing rate as follows ${ }^{2}$

$$
\sigma_{f}=\left[B^{\prime} \dot{\sigma}\right]^{\frac{1}{1+n}}
$$

where $B^{\prime}$ is a parameter associated with $A, n$, fracture toughness, inert strength, crack geometry and loading configuration. The fatigue parameter $n$ can be determined from the slope of $\log \sigma_{\mathrm{f}}$ plotted as a function of $\log \sigma$ and Eq. (2).

The dynamic fatigue strength can also be determined numerically by solving the differential equation of slow crack growth, Eq. (1). To minimize the number of specified parameters, it is convenient to utilize the normalization scheme applied previously in the fatigue analysis of indentation flaws ${ }^{3}$ and subthreshold flaws. ${ }^{4}$ With reference to the previous studies, ${ }^{3,4}$ the normalized variables are as follows:

$$
K^{*}=\frac{K_{I}}{K_{I C}} ; J=\frac{A}{a_{h}} t ; \sigma^{*}=\frac{\sigma_{a}}{S_{l}} ; C^{*}=\frac{a}{a_{f}} ; \delta^{*}=\frac{\sigma^{*}}{J}
$$

where $K^{*}, J, \sigma^{*}, C^{*}$ and $\sigma^{*}$ are, respectively, normalized stress intensity factor, normalized time, normalized applied stress, normalized crack size and normalized stressing rate. $S_{\mathrm{i}}$ is the inert strength, $a_{\text {fi }}$ the critical crack size in an inert environment and $\sigma_{\mathrm{a}}$ the remote applied stress. Using these variables, the power-law crack velocity (Eq. (1)) yields

$$
\begin{aligned}
& \frac{d C^{*}}{d J}=\left[K^{*}\right]^{*} \\
& K^{*}=\sigma^{*} C^{* \frac{1}{2}}
\end{aligned}
$$

A solution of the differential equation in Eq. (4) in terms of normalized variables such as failure time, fatigue strength and critical crack size was obtained by stepwise numerical integration using a fourthorder Runge-Kutta method. The initial and instability conditions were $C^{*}=1$ at $J=1$ and $K^{*}=1$ with $d K^{*} / D c^{*}>0$, respectively.

The numerical solution of normalized fatigue strength $\left(\log \sigma_{\mathrm{f}}^{*}\right)$ as a function of normalized stressing rate $\left(\log \sigma^{*}\right)$ is presented in Fig. 1. Here, the fatigue strength normalized with the inert strength (Eq. 3). It is evident that fatigue strength is a linear function of stressing rate in a $\log \sigma_{\mathrm{f}}-\log \sigma$ scheme, except at high very stressing-rates, verifying the analytical solution (Eq. (2)) for $n \geq 5$. It is important to note that the dynamic fatigue strength converges to a specific value, defining the inert strength, regardless of $n$, when the stressing rate is sufficiently high and slow crack growth is inhibited by the 
extremely short failure time. Therefore, high temperature dynamic fatigue testing with a series of very high stressing rates is required to reach the strength convergence and measure the "inert" strength.

\section{EXPERIMENTAL PROCEDURE}

To verify the convergence concept, dynamic fatigue testing of one alumina, two silicon nitrides and one silicon carbide material was carried out in flexure at elevated temperatures. The basic physical and mechanical properties of the four materials are shown in Table 1. Isopressed $96 \mathrm{wt} \%$ alumina (General Electrical Ceramics, Laurens, SC, designated as ALSIMAG 614) was extensively used in this study. The nominal dimensions of the alumina specimens were $4.0 \mathrm{~mm} \times 3.0 \mathrm{~mm} \times 25 \mathrm{~mm}$ in width, height and length, respectively. Dynamic fatigue testing was carried out in an electromechanical testing machine (Model 8562, Instron) at five different temperatures ranging from 700 to $1100^{\circ} \mathrm{C}$. A SiC four-point bend fixture with 10/22 mm spans was used. A 'load-controlled' mode was used to apply six loading rates ranging from 0.4 to $4 \times 10^{5} \mathrm{~N} / \mathrm{min}$, corresponding to stressing rates of 0.2 to $2 \times 10^{3} \mathrm{Mpa} / \mathrm{min}$, at each temperature. A total of three to five specimens were used at each loading rate. The room-temperature inert strength was determined using silicon oil (Type 704, Dow) at $4000 \mathrm{~N} / \mathrm{min}$.

Fatigue strengths of SN 252 silicon nitride (Kyocera, Japan) were determined in flexure at $1371^{\circ} \mathrm{C}$ using three loading rates ranging from 2.4 to $2.4 \times 10^{6} \mathrm{~N} / \mathrm{min}$. Three to four specimens with nominal dimensions of $4.0 \mathrm{~mm}$ by $3.0 \mathrm{~mm}$ by $50 \mathrm{~mm}$, respectively, in width, height and length were tested at each loading rate with a SiC four-point bend fixture. The inner and outer spans of the test fixture were 20 $\mathrm{mm}$ and $40 \mathrm{~mm}$, respectively.

Flexural fatigue strengths of NC 132 silicon nitride (Norton Co., MA) and NC 203 silicon carbide (Norton Co., MA) were obtained at a stressing rate of $2 \times 10^{6} \mathrm{MPa} / \mathrm{min}$ in order to supplement data, previously measured at loading rates of 2 to $2 \times 10^{5} \mathrm{~N} / \mathrm{min}$. The test temperatures were $1100^{\circ} \mathrm{C}$ and $1300^{\circ} \mathrm{C}$, respectively, for NC 132 and NC 203. The test fixture was the same as that used for the alumina specimens. A servohydraulic testing machine (Model 8501, Instron) was used for testing both of the materials. The nominal dimensions (width $x$ height $x$ length) of the test specimens were $6.0 \mathrm{~mm}$ by $3.0 \mathrm{~mm}$ by $25 \mathrm{~mm}$ for NC 132, and $5.08 \mathrm{~mm}$ by $2.54 \mathrm{~mm}$ by $25 \mathrm{~mm}$ for NC 203 . A total of four and five specimens was used at each stressing rate, respectively, for NC 132 and NC 203. Because of the high Weibull modulus $(m \geq 19)$ of the alumina and silicon nitrides, the three to five specimens used per rate in this series of tests were considered statistically sufficient. All specimens were kept at the test temperature for about 20 minutes prior to testing.

The electromechanical testing machine was unable to load at stressing rates greater than $2 \times 10^{5}$ $\mathrm{MPa} / \mathrm{min}$. Thus the servohydraulic testing machine, which exhibited better high-rate load-controlling capability than the electromechanical machine, was exclusively used for testing at the very high stressing rate of $2 \times 10^{6} \mathrm{MPa} / \mathrm{min}$. The wave forms for stressing rates greater than $2 \times 10^{5} \mathrm{MPa} / \mathrm{min}$ were recorded and checked with a digital storage oscilloscope.

\section{RESULTS AND DISCUSSION}

A summary of the dynamic fatigue results obtained for $96 \mathrm{wt} \%$ alumina is shown in Fig. 2, where $\log \sigma_{\mathrm{f}}$ (fatigue strength) was plotted as a function of $\log \sigma$ (stressing rate) based on Eq. (2). The decrease in fatigue strength with decreasing stressing rate, which represents fatigue susceptibility, was enhanced with increasing temperature. At $700^{\circ} \mathrm{C}$, the material exhibited almost no fatigue and a very large fatigue parameter of $n=124$. However, the fatigue parameter $n$ decreased rapidly from $n=124$ to $n=6.3$ with increasing temperature from 700 to $1100^{\circ} \mathrm{C}$. A summary of $n$ as a function of 
temperature as well as the coefficients of correlation for the curve fits to Eq. (2) are presented in Table 2.

It is important to note from Fig. 2 that, regardless of temperature, the fatigue strength converges to a specific value. Therefore, the hypothesis based on the result of Fig. 1, that increasing stressing rates would cause convergence to a specific strength value is justified even for high temperatures. A similar convergence was found by Jakus et al. with $99.5 \mathrm{wt} \%$ alumina. ${ }^{8}$ The specific value, defining a high temperature "inert" strength, approximately corresponds to the room-temperature inert strength of this material.

Figure 3 shows the results of SN 252 silicon nitride tested $1371^{\circ} \mathrm{C}$ in air. The estimated fatigue parameter $n$ was $n=40.8 \pm 11.1$ with a coefficient of correlation of 0.9662 . The room temperature strength, determined previously with a 10/30 mm span configuration, ${ }^{5}$ was scaled to that of a $20 / 40 \mathrm{~mm}$ spans configuration by using Weibull statistics: The strength was estimated to be $648 \pm 40 \mathrm{MPa}$. The trend shown in Fig. 2 implies that a further increase in stressing rate from $2 \times 10^{6} \mathrm{MPa} / \mathrm{min}$ should result in a fatigue strength close to the room temperature strength of the material. The dynamic fatigue results of NC 132 silicon nitride at $1100^{\circ} \mathrm{C}$ are depicted in Fig. 4. The data fit Eq. (2) very well, with a coefficient of correlation of 0.997 . The estimated fatigue parameter was $n=18.6 \pm 1.7$. This figure also shows that the fatigue strength approximately converges to the room-temperature strength at stressing rates greater than $2 \times 10^{6} \mathrm{MPa} / \mathrm{min}$.

The dynamic fatigue results of NC 203 silicon carbide at $1300^{\circ} \mathrm{C}$ are shown in Fig. 5. The estimated fatigue parameter was $n=32.5 \pm 2.8$, with a coefficient of correlation of 0.9862 for the data fit to Eq. (2). The figure also shows a possible convergence of fatigue strength to the room-temperature strength. A series of dynamic fatigue tests at stressing rates higher than $2 \times 10^{6} \mathrm{MPa} / \mathrm{min}$ would be required for clarification. The current testing machine, however, is unable to achieve stressing rate tests greater than $2 \times 10^{6} \mathrm{MPa} / \mathrm{min}$, as will be discussed later.

All of the high-temperature dynamic fatigue results of alumina, SN 252 and NC 132 silicon nitrides, and NC 203 silicon carbide show that, despite possible changes in flaw populations at elevated temperatures, fatigue strength, in general, converges to the corresponding room-temperature inert strength at stressing rates greater than or equal to $2 \times 10^{6} \mathrm{MPa} / \mathrm{min}$. This indicates that slow crack growth, which is a dominant mechanism in the high-temperature strength of a ceramic material, is minimized or eliminated at sufficiently high stressing rates, thereby allowing a determination of hightemperature "inert" strength. Similar results of convergence to the room-temperature strength have been observed for other silicon nitride ceramics in a companion study by the current authors, as shown in Fig. 6. Figure 6, without exception, shows a definite convergence of high-temperature fatigue strength to the room-temperature strength for three other materials.

Typical wave forms for loading rates of $4 \times 10^{5} \mathrm{~N} / \mathrm{min}$ from the electromechanical testing machine and of $4 \times 10^{6} \mathrm{~N} / \mathrm{min}$ from the servohydraulic testing machine are shown in Fig. 7. The figures are from the alumina testing at $1000^{\circ} \mathrm{C}$. At the loading rate of $4 \times 10^{5} \mathrm{~N} / \mathrm{min}$, the output wave form remained accurate. By contrast, at $4 \times 10^{6} \mathrm{~N} / \mathrm{min}$, it exhibited nonlinearity at the initial stage of loading. This indicates that although the loading capability of the servohydraulic testing machine was far better than that of the electromechanical testing machine at loading rates greater than $4 \times 10^{5} \mathrm{~N} / \mathrm{min}$, the latter machine still could not produce an exact wave form in response to the command signal. The stressing rate in Fig. 7 was thus calculated from the straight portion in the load-time curve, which was $1.5 \times 10^{6}$ $\mathrm{MPa} / \mathrm{min}$. A test facility capable of high rate dynamic loading is thus a prerequisite for determining the so-called high-temperature "inert" strength of a ceramic material.

Based on the above high-temperature dynamic fatigue results for several ceramics, it is evident that 
fatigue strength of a material depends on the stressing rate used. For example, for a material exhibiting moderate fatigue susceptibility of $n \approx 20-50$ at elevated temperatures, the strength degradation as a function of temperature could be appreciable if one chooses a low stressing rate; whereas, the degradation could be insignificant if 'one selects a very high stressing rate. This is clearly seen in the following example. Figure 8, constructed from Fig. 2, shows the fatigue strength as a function of temperature for the different applied stressing rates. The strength degradation with respect to the room-temperature strength is dependent on both temperature and stressing rate. A remarkable difference in strength degradation with temperature between the stressing rates of 0.2 and $2 \times 10^{5}$ $\mathrm{MPa} / \mathrm{min}$ is evident, due to fatigue: A considerable strength degradation of about $90 \%$ from the roomtemperature strength occurred at the low stressing rate of $0.2 \mathrm{MPa} / \mathrm{min}$; while, a slight degradation of about $26 \%$ took place at the high stressing rate of $2 \times 10^{5} \mathrm{MPa} / \mathrm{min}$. Hence, entirely different information on strength degradation behavior of a material could be obtained if one chooses different stressing rates. The results in Fig. 8, therefore, indicate that care should be taken in choosing the appropriate stressing rates to determine the strength as a function of temperature. At least two (highest and lowest) or three stressing rates (highest, intermediate, and lowest), depending on the degree of fatigue susceptibility of a material, should be utilized to completely characterize high temperature strength behavior. The use of only one low or moderate stressing rate to measure the strength degradation behavior is unreliable.

\section{CONCLUSIONS}

(1) The numerical solution of dynamic fatigue shows that fatigue strength converges with increasing stressing rates to a specific value, defining an inert strength.

(2) 96 wt \% alumina and SN 252 and NC 132 silicon nitrides showed that the elevated temperature "inert" strength of each material approaches its room-temperature strength at stressing rates greater than $2 \times 10^{6} \mathrm{MPa} / \mathrm{min}$, consistent with the results of three different silicon nitride ceramics from a companion study ${ }^{9}$. NC 203 silicon carbide showed a similar but less clear trend.

(3) The servohydraulic testing machine exhibited a higher load-controlling capability than the electromechanical testing machine. The maximum attainable stressing rate was about $2 \times 10^{5} \mathrm{MPa} / \mathrm{min}$ and $2 \times 10^{6} \mathrm{MPa} / \mathrm{min}$, respectively, for the electromechanical and the servohydraulic testing machines.

(4) Special care must be taken when evaluating high temperature strength behavior as a function of temperature. Because of fatigue, at least two or three stressing rates should be used to characterize the strength degradation behavior of a given material.

\section{REFERENCES}

1. E. R. Fuller, B. R. Lawn, and R. F. Cook, "Theory of Fatigue for Brittle Flaws Originating from Residual Stress Concentrations," J. Am. Ceram. Soc., 66[5] 314-21 (1983).

2. J. E. Ritter, "Engineering Design and Fatigue Failure of Brittle Materials," pp. 661-686 in Fracture Mechanics of Ceramics, Vol. 4, R. C. Bradt, D. P. H. Hasselman, and F. F. Lange, Eds., Plenum Publishing Co., NY (1978).

3. B. R. Lawn, D. B. Marshall, G. R. Anstis, and T. P. Dabbs, "Fatigue Analysis of Brittle Materials Using Indentation Flaws, Part 1. General Theory," J. Mater. Sci., 16[10] $2846-54$ (1981).

4. S. R. Choi, J. E. Ritter, and K. Jakus, "Failure of Glass with Subthreshold Flaws," J. Am. Ceram. Soc., 73[2] 268-274 (1990).

5. J. A. Salem, S. R. Choi, M. R. Freedman, and M. G. Jenkins, "Mechanical Behavior and Failure Phenomenon of an In Situ Toughened Silicon Nitride," J. Mater. Sci., 27 4421-28 (1992).

6. S. R. Choi and J. A. Salem, "Effect of Preloading on Fatigue Strength in Dynamic Fatigue Testing 
of Ceramic Materials at Elevated Temperatures," Ceram. Eng. Sci. Proc., 16[4] 87-94 (1995).

7. J. A. Salem and S. R. Choi, Bimonthly Progress Report, June-July/1994, Ceramic Technology Project, Oak Ridge National Laboratory, Oak Ridge, TN (1994).

8. K. Jakus, T. Service, and J. E. Ritter, "High-Temperature Fatigue Behavior of Polycrystalline Alumina," J. Am. Ceram. Soc., 63 [1-2] $4-7$ (1980).

9. S. R. Choi and J. A. Salem, "Inert" Strength of Silicon Nitride Ceramics at Elevated Temperatures," presented to the Cocoa Beach Conference, January 7-11, 1996, Cocoa Beach, FL, American Ceramic Society, to be published in Ceram. Eng. Sci. Proc. (1996).

\section{Status of Milestones}

Milestones are on time.

Communication/Visits/Travel

The ASTM draft standard on constant stress-rate ('dynamic fatigue') testing of ceramics was submitted for subcommittee ballot.

\section{Problems Encountered}

Severe machining damage to NC 132 test specimens has eliminated tensile testing from the test matrix.

\section{Publications}

1. S. R. Choi and J. A. Salem, "Preloading Technique in Dynamic Fatigue Testing of Glass and Ceramics with an Indentation Flaw System," in print, J. Am. Ceram. Soc. (1996).

2. S. R. Choi and J. A. Salem, "Cyclic Fatigue of Brittle Materials with an Indentation-Induced Flaw System," in print, Mat. Sci. Eng., A (1996) 
Table 1. Room-temperature density, Young's modulus, fracture toughness and strength of 96 wt \% alumina, SN 252 and NC 132 silicon nitrides, and NC 203 silicon carbide

\begin{tabular}{|l|l|l|l|l|}
\hline & Density & $\begin{array}{l}\text { Young's } \\
\text { Modulus, } \mathrm{E} \\
(\mathrm{GPa})^{\mathrm{b}}\end{array}$ & $\begin{array}{l}\text { Fracture } \\
\text { Toughness, } \mathrm{K}_{\mathrm{IC}} \\
(\mathrm{MPa} / \mathrm{m})^{\mathrm{c}}\end{array}$ & $\begin{array}{l}\text { Strength, } \\
\sigma_{\mathrm{f}}(\mathrm{MPa})^{\mathrm{d}}\end{array}$ \\
\hline 96 wt \% $\mathrm{Al}_{2} \mathrm{O}_{3}$ & 3.67 & 309 & $3.43 \pm 0.11^{*}$ & $343.9 \pm 14.7$ \\
\hline $\mathrm{SN} 252 \mathrm{Si}_{3} \mathrm{~N}_{4}^{5}$ & 3.39 & $321 \pm 2$ & $7.40 \pm 0.50$ & $648.0 \pm 40.0$ \\
\hline $\mathrm{NC} 132 \mathrm{Si}_{3} \mathrm{~N}_{4}$ & 3.20 & $315 \pm 1$ & $4.60 \pm 0.30$ & $1018.3 \pm 35.3$ \\
\hline $\mathrm{NC} \mathrm{203} \mathrm{SiC}$ & 3.31 & $443 \pm 2$ & $3.99 \pm 0.20$ & $655.0 \pm 57.6$ \\
\hline
\end{tabular}

Notes:
a. By the specimen mass/volume method
b. By the impulse excitation technique
c. By the SEPB method
d. By four-point flexure tests
* represents \pm 1.0 standard deviation.

Table 2. Summary of the fatigue parameter $n$ and the coefficients of correlation for 96 wt \% alumina determined at five different test temperatures

\begin{tabular}{||c|c|c|c||}
\hline Temp $\left({ }^{\circ} \mathrm{C}\right)$ & $\begin{array}{c}\text { No. of } \\
\text { Stressing Rates }\end{array}$ & $n$ & $\mathbf{r}_{\text {coef }}^{*}$ \\
\hline 700 & 5 & $124.4 \pm 98.9^{*}$ & 0.5905 \\
800 & 4 & $11.5 \pm 1.7$ & 0.9813 \\
900 & 5 & $8.0 \pm 0.4$ & 0.9972 \\
1000 & 6 & $7.3 \pm 0.2$ & 0.9986 \\
1100 & 7 & $6.3 \pm 0.2$ & 0.9980 \\
\hline
\end{tabular}

Notes:

\# represents the coefficient of correlation of the data fit to Eq. (2).

- represents \pm 1.0 standard deviation. 


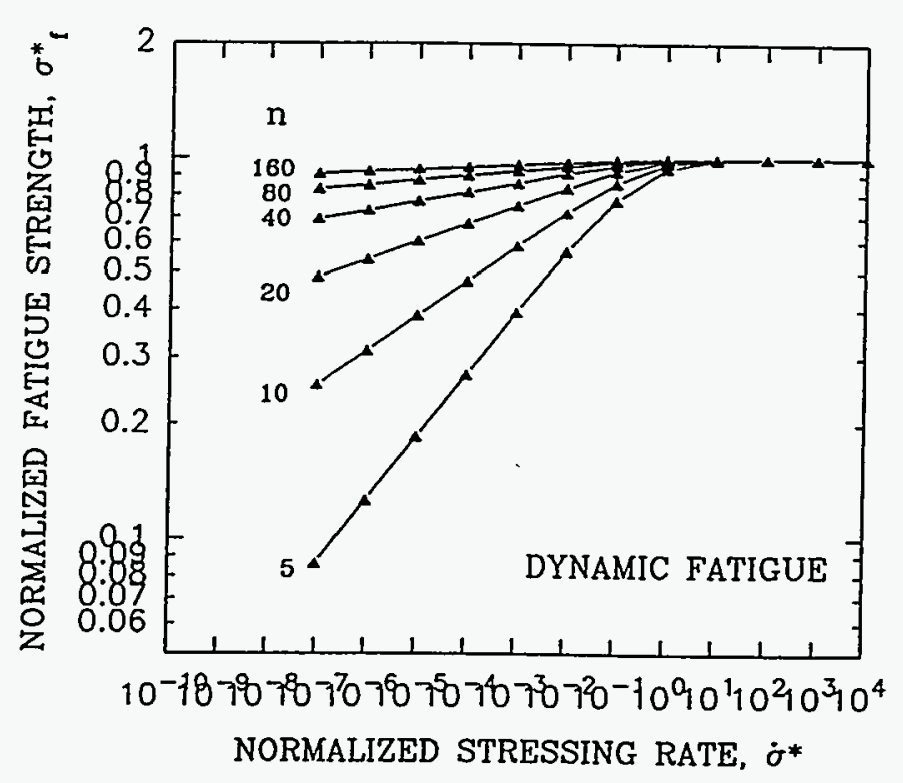

Figure 1. Normalized fatigue strength as a function of normalized stressing rate (numerical solution). Note that fatigue strength converges to a single value (inert strength) with increasing stressing rates.

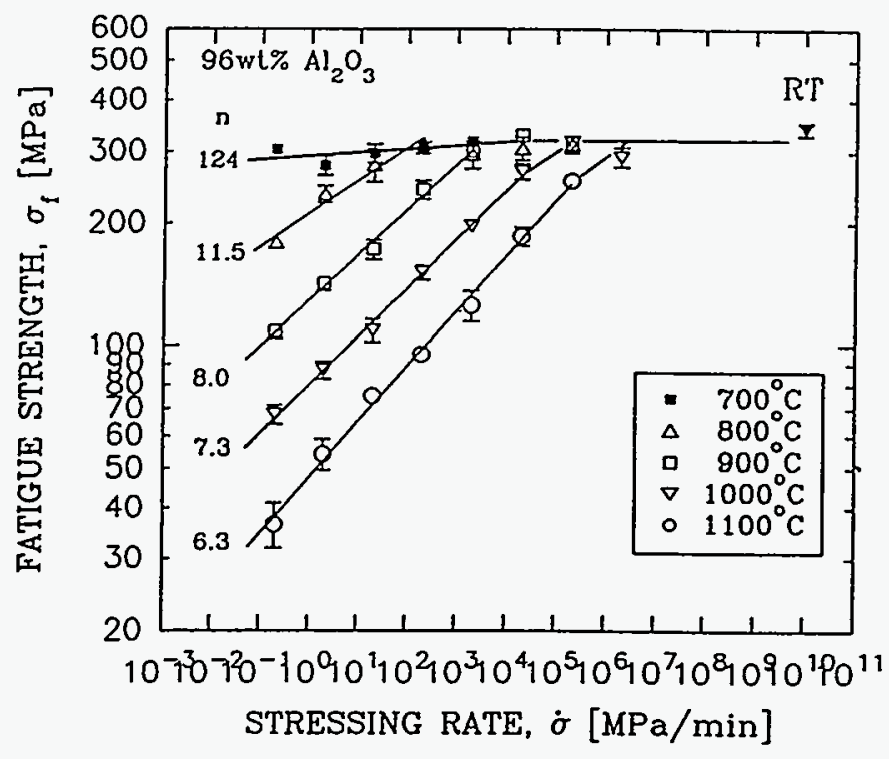

Figure 2. High-temperature dynamic fatigue results of $96 \mathrm{wt} \%$ alumina in flexure in air. The solid lines represent the best-fit lines based on Eq. (2). 


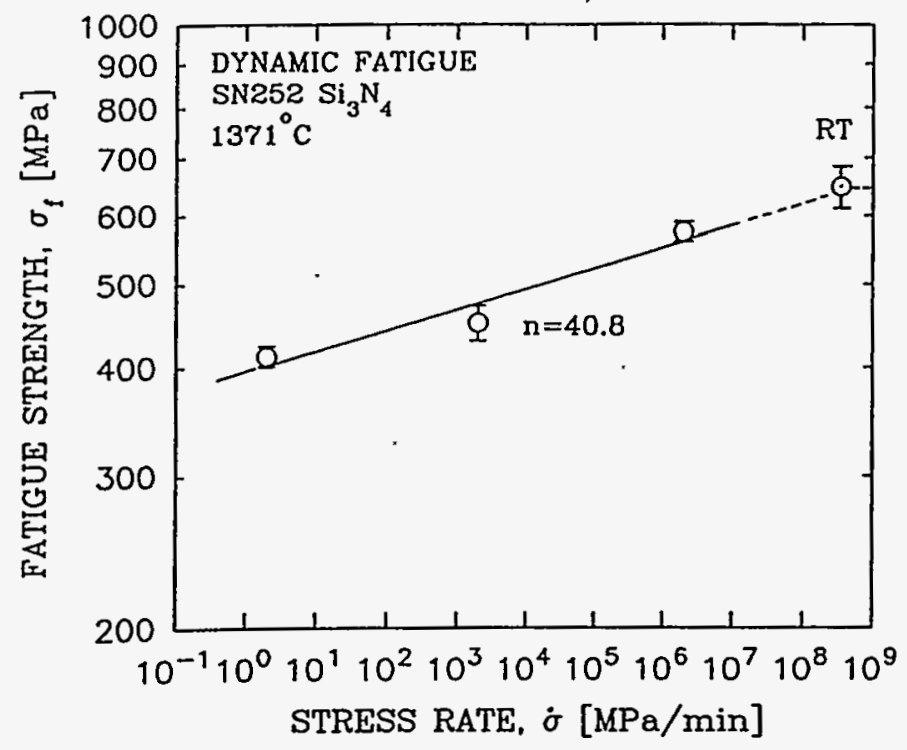

Figure 3. High-temperature dynamic fatigue results of SN 252 silicon nitride in flexure at $1371^{\circ} \mathrm{C}$ in air. The solid line represents the best-fit line based on Eq. (2).

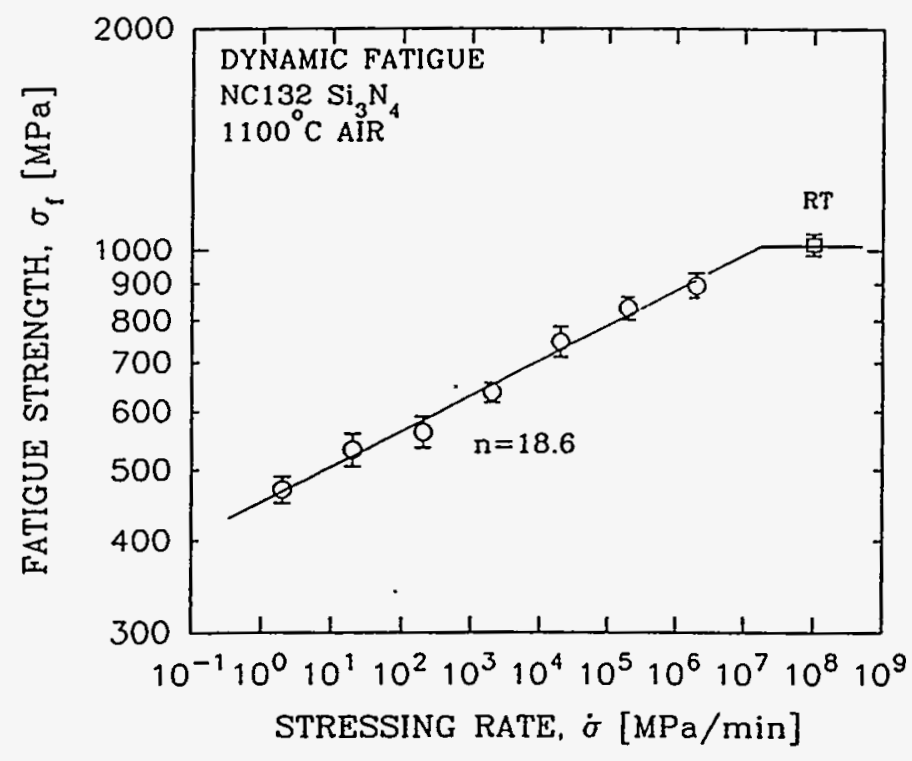

Figure 4. High-temperature dynamic fatigue results of NC 132 silicon nitride in flexure at $1100^{\circ} \mathrm{C}$ in air. The solid line represents the best-fit line based on Eq. (2). 


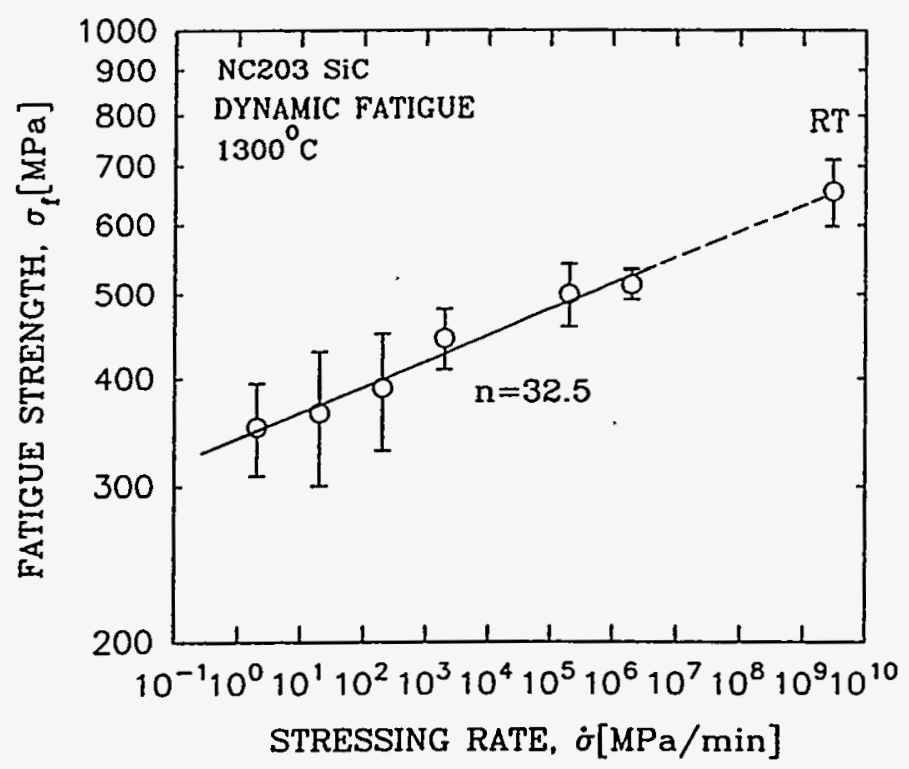

Figure 5. High-temperature dynamic fatigue results of NC 203 silicon carbide in flexure at $1300^{\circ} \mathrm{C}$ in air. The solid line represents the best-fit line based on Eq. (2).

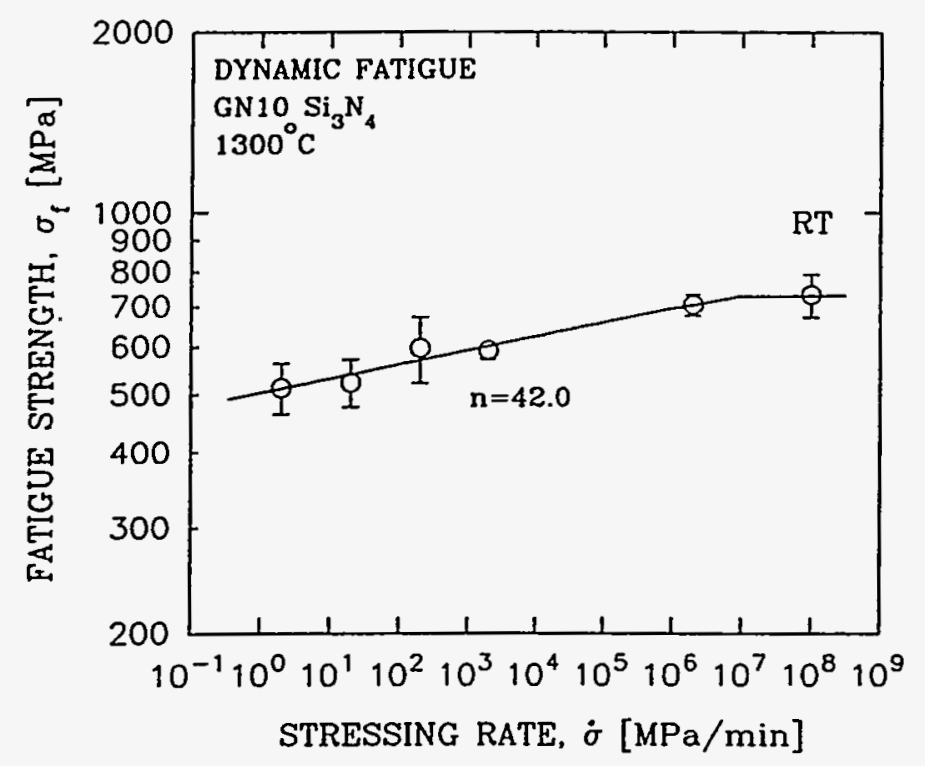

(a)

Figure 6. High-temperature dynamic fatigue results of three different silicon nitrides ${ }^{9}$ : (a) GN 10 silicon nitride at $1300^{\circ} \mathrm{C}$; (b) GN $10 \mathrm{SiC}\left(30 \mathrm{vol} \%\right.$ ) whisker-reinforced silicon nitride at $1300^{\circ} \mathrm{C}$; (c) NCX 34 silicon nitride at $1200^{\circ} \mathrm{C}$. 


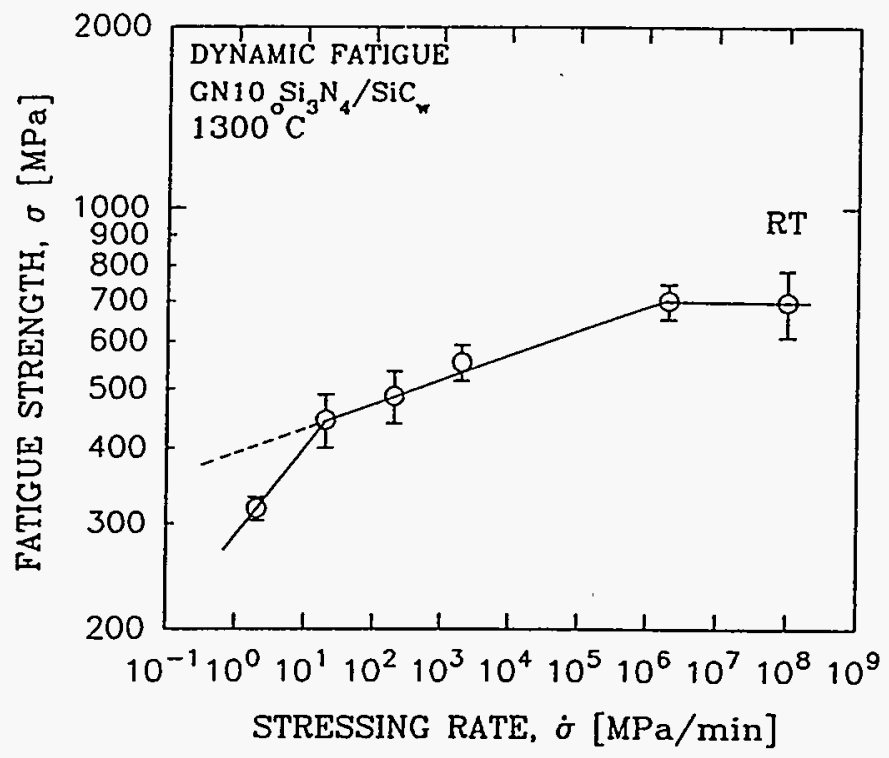

(b)

Figure 6. (Continued) High-temperature dynamic fatigue results of three different silicon nitrides ${ }^{9}:$ (a) GN 10 silicon nitride at $1300^{\circ} \mathrm{C}$; (b) GN $10 \mathrm{SiC}(30 \mathrm{vol} \%)$ whisker-reinforced silicon nitride at $1300^{\circ} \mathrm{C}$; (c) NCX 34 silicon nitride at $1200^{\circ} \mathrm{C}$.

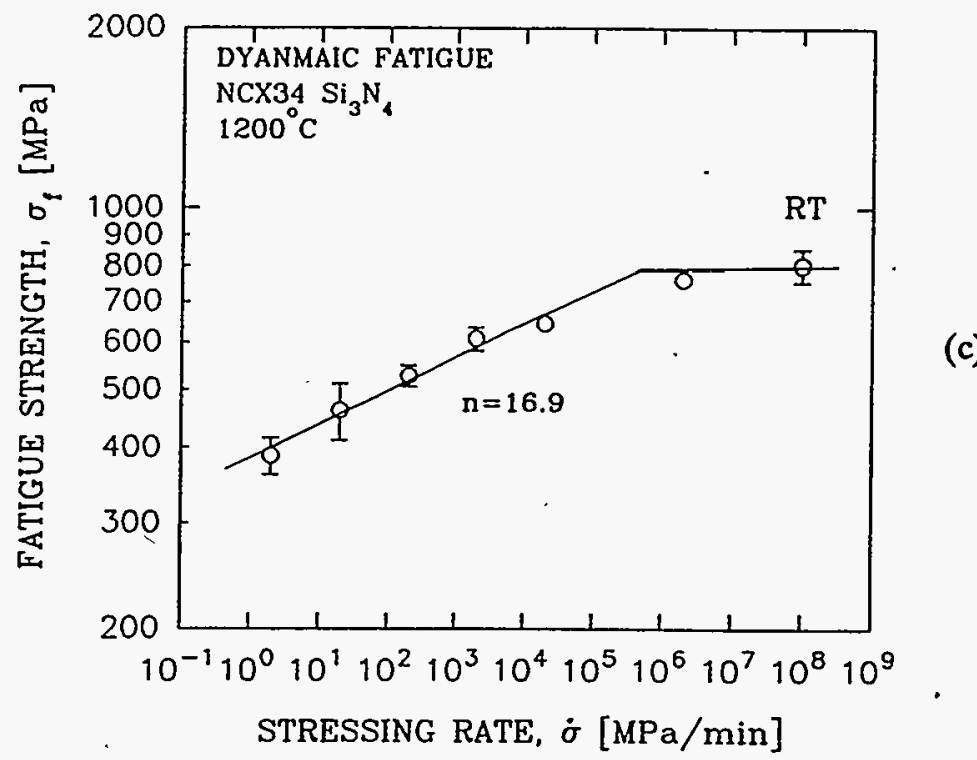

Figure 6. (Continued) High-temperature dynamic fatigue results of three different silicon nitrides ${ }^{9}$ : (a) GN 10 silicon nitride at $1300^{\circ} \mathrm{C}$; (b) GN $10 \mathrm{SiC}(30 \mathrm{vol} \%)$ whisker-reinforced silicon nitride at $1300^{\circ} \mathrm{C}$; (c) NCX 34 silicon nitride at $1200^{\circ} \mathrm{C}$. 


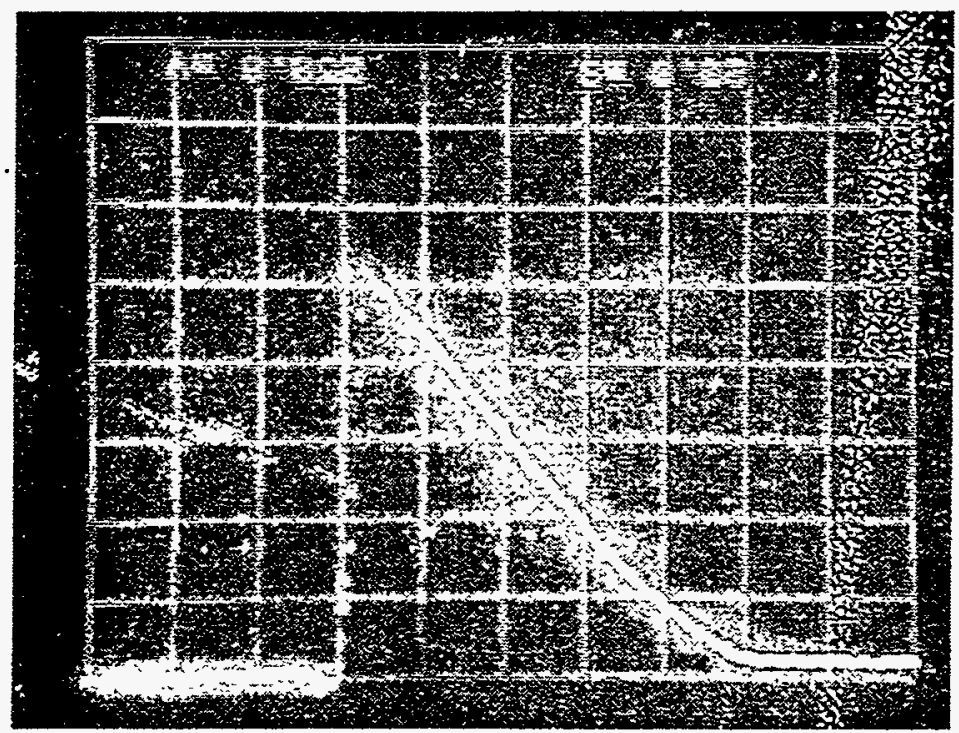

(a)

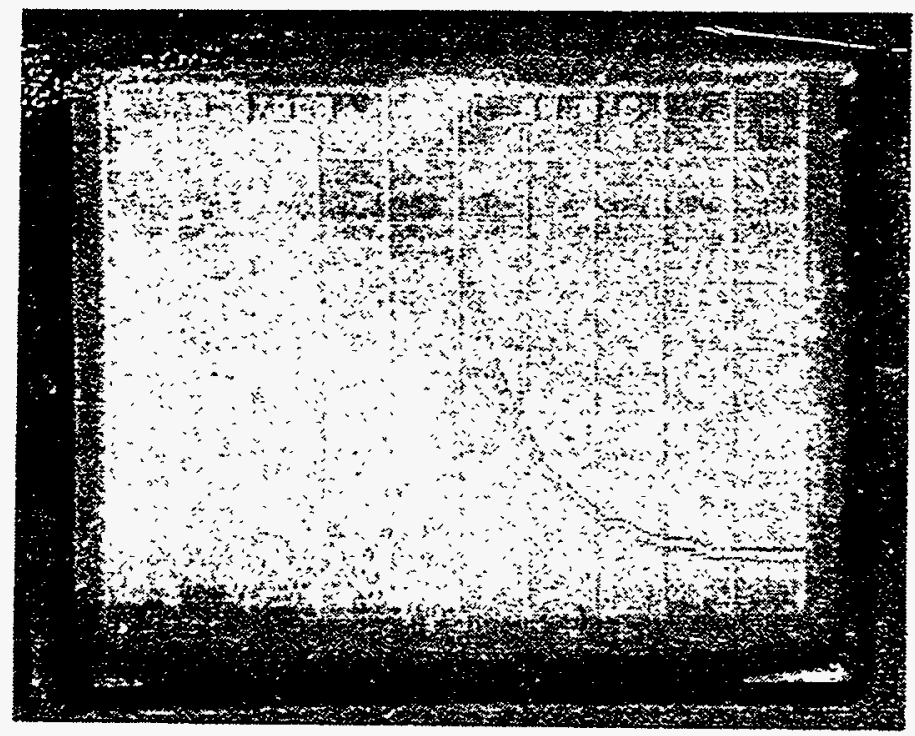

(b)

Figure 7. Typical examples of output wave forms obtained from the alumina testing at $1000^{\circ} \mathrm{C}$ : (a) 4 $x 10^{5} \mathrm{~N} / \mathrm{min}$ with the electromechanical testing machine; (b) $4 \times 10^{6} \mathrm{~N} / \mathrm{min}$ with the servohydraulic testing machine. 


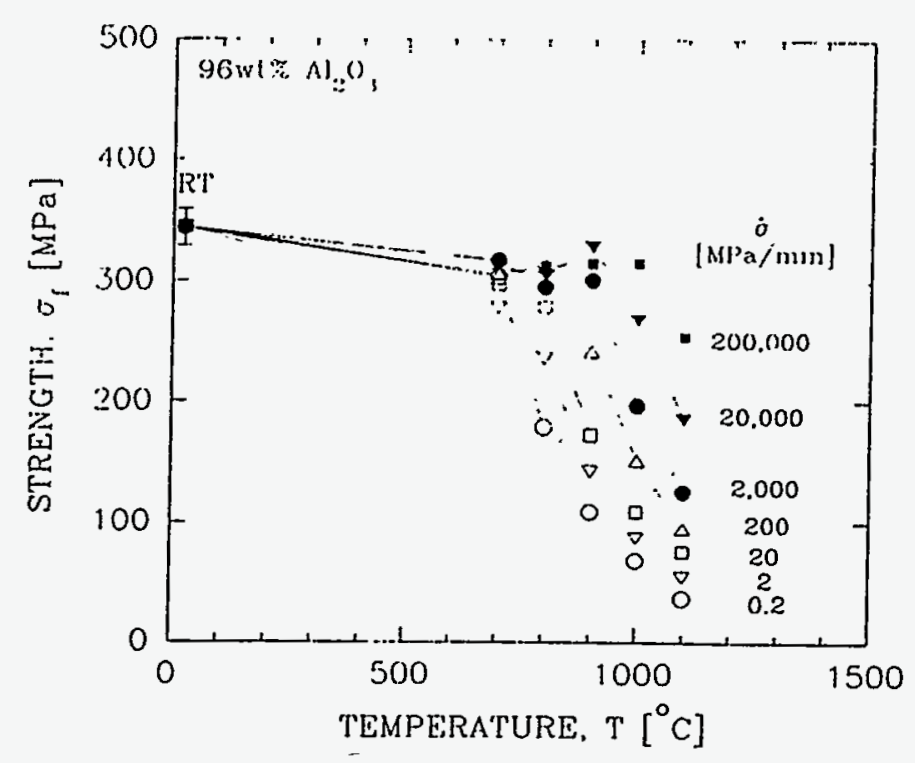

Figure 8. High-temperature strength of $96 \mathrm{wt} \%$ alumina as a function of temperature for different stressing rates. The curves were constructed from the results in Fig. 2. 
W.B.S. Element 3.2.2.3

\title{
LIFE PREDICTION METHODOLOGY FOR CERAMIC COMPONENTS OF ADVANCED HEAT ENGINES -- PHASE II
}

\author{
FIFTH SEMIANNUAL PROGRESS REPORT \\ OCTOBER 1995 - MARCH 1996
}

PRINCIPAL INVESTIGATORS:

N. Menon, A. Peralta, H. Cai,, P. Brehm, W. Meade,
M. Gomez, J. Cuccio, J. Wade, and G. Lucas

AlliedSignal Engines

111 S. 34th Street

MS 57-72/1303-203

P.O. Box 52181

Phoenix, Arizona 85072-52181

\section{Objectives/Scope}

AlliedSignal Engines (AE) has defined a program that builds on the progress made in Phase I of the Life Prediction Methodology for Ceramic Components of Advanced Vehicular Heat Engines program. This Phase II program will develop the methodology required to adequately predict the useful life of ceramic components used in advanced heat engines. Phase II will concentrate on predictive methodology for time- and cycle-dependent failure modes, as well as proof testing and nondestructive evaluation (NDE) methodology to enhance component reliability through screening out of low-strength components.

The life prediction methodologies developed will be generic and hence will be applicable to ceramic components that operate under known temperature and stress conditions.

The technical effort has been organized into six tasks, as follows:

1) Material Baseline

2) Compressive Creep Methodology

3) Flaw Growth Methodology

4) Cyclic Fatigue Methodology

5) Proof Test Methodology

6) NDE Reliability Methodology.

Integration of the methodologies will be undertaken through continued development of the statistical and risk integration computer codes previously developed during the Phase I program. Progress made under these objectives during the October, 1995 through March, 1996 semiannual reporting period is described in the following sections. 


\section{Technical Highlights}

\subsection{Material Baseline}

An order for fabrication and delivery of various quantities of AS-800 silicon nitride test specimens was placed with AlliedSignal Ceramic Components (ACC), Torrance, CA on November 17, 1995. The test specimen quantities on order are as follows: 910 flexure, 96 tensile, 64 cyclic fatigue, 86 notched, and 100 plate bending specimens.

Dr. J. Wimmer and Mr. B. Busovne of ACC visited AlliedSignal Engines (AE) in Phoenix, AZ on November 1, 1995 , to inform AE of their plans for qualifying the process to be used in fabricating the AS-800 test specimens. Subsequently, Dr. M. N. Menon, Mr. J. Schienle, and Mr. A. Peralta of AE visited ACC in Torrance on November 15, 1995 to further discuss the necessary processing steps, and to discuss with Ms. D. Murphy of Chand-Kare the proposed strategy for machining the test specimens. As a result of these discussions, a plan was defined for specimen mapping and randomizing of the specimens; the latter effort will be performed to distribute the unwanted variability from different specimen processing batches.

Ceramic AS-800 silicon nitride test specimen fabrication is now expected to commence in April, 1996. A fixed process has been established at ACC Torrance, CA for fabrication of the AS- 800 silicon nitride test tiles from which the specimens will be machined. According to the current estimates, the first lot of flexure test specimens will be delivered in June, 1996 and the remainder in August, 1996.

\subsection{Compressive Creep Methodology}

Compressive creep tests at $1371 \mathrm{C}$ are continuing at the Oak Ridge National Laboratory High Temperature Materials Laboratory (ORNL-HTML) in Oak Ridge, TN, under the direction of Dr. A. A. Wereszczak. Tests will also be initiated at other temperatures in the near future.

\subsection{Flaw Growth Methodology}

A draft technical report was submitted by Professor R. Dauskardt of Stanford University on experimental work in flaw growth methodology conducted for this program. This work involved both static and cyclic fatigue testing at room and elevated temperatures using small indentation flaws on Mil-B flexure bars of NT154 silicon nitride. In addition to a summary of the unique crack growth measurements achieved, the report also addressed the coupling between residual stresses and applied stresses which can significantly reduce the crack driving force compared to that expected from linear superposition of stress intensity factors. It was reported that the results of experiments involving measurements of crack opening displacements suggest relaxation of the residual stress field around the indent at temperatures above $1000 \mathrm{C}$.

The small-flaw growth rates measured in this study were found to display considerable scatter. A key observation was that the crack growth rates typically occurred at stress intensities below the threshold, $\mathbf{K}_{\mathbf{t h}}$, for the growth of long cracks under static or cyclic loading.

Overall, the work conducted by Professor Dauskardt suggests that the crack growth rates may have a slope, $\mathbf{N}$, (from the relationship da/dt $=\mathbf{A K} \mathbf{N}^{\mathbf{N}}$, where: $\mathbf{a}$ is the crack length, $t$ is the time, $\mathbf{A}$ is a constant, and $\mathbf{K}$ is the stress intensity factor) larger than that which may be deduced based on an assumption that crack growth comprises the entire stress-rupture life of a smooth tensile bar. Therefore, Professor Dauskardt's results, when taken in conjunction with earlier AE results from Phase $\mathrm{I}^{(1)}$ which also showed well-defined slow crack growth 
regimes in all stress-rupture bars, seem to suggest that a considerable portion of the smooth tensile bar: stressrupture life may involve an incubation period during which a definable crack is being formed.

The draft report on the Stanford University activities has been reviewed by AE., and AE's comments were submitted to Professor Dauskardt. The Final Report is expected in April, 1996.

\subsection{Cyclic Fatigue Testing}

A review of literature is being conducted on topics related to the cyclic fatigue of ceramics. The objective is to determine and document current understanding of the mechanisms underlying fatigue of high-strength silicon nitride ceramics, and approaches which have been previously explored to date for cyclic fatigue model development.

The efforts reported above under flaw growth methodology are to be closely coordinated with planned cyclic fatigue testing of unflawed flexure and tensile specimens. Delivery of the AS-800 silicon nitride test specimens for the planned cyclic fatigue testing is expected in August, 1996. Specimen testing will be initiated following delivery of the test specimens. The plans include testing a portion of the specimens at ORNL-HTML and a portion in-house.

\subsection{Proof Testing Methodology}

Efforts during this period have concentrated on incorporation of the methods developed to date into the CERAMIC code and on further investigation and refinement of statistical methods enabling incorporation of Probability Of Detection (POD) functions into the overall reliability predictions.

\subsection{NDE Reliability}

Twenty MIL-B ceramic test bars were sent to Resonetics, Inc. (Nashua, NH) for use in developing laser machining parameters for creating simulated linear defects. In addition, a three-point bending test fixture was sent with the specimens, to aid in the destructive analysis. This fixture will permit more rapid analysis of the specimens, by inducing controlled fracture through the laser-machined defect cross sections.

A NORTRAN Model TN-8500 image analyzer is being evaluated as a possible tool for characterization of the defect populations in specimens with as-processed surfaces. If this approach proves to be viable, it may save time when compared to the present method of manual, magnified visual inspection and replication of the specimens.

\section{Status of Milestones}

(No change since previous report.)

\section{Communications/Visits/Travel}

Dr. M. N. Menon and Mr. A. Peralta of AlliedSignal Engines attended the annual Dept. of Energy (DOE) sponsored Contractors Coordination Meeting (CCM) conference at Dearborn, MI on October 24-26, 1995. Mr. Peralta made a presentation on "Progress And Challenges In Life Prediction Of Ceramic Components" on October 25, 1995. On the same day, Dr. Menon and Mr. Peralta presented a progress report on the work conducted during the past six months in the current program to a group which included the DOE Program Manager, Dr. R. Johnson; the DOE Technical Monitor, Dr. C. Brinkman; and other representatives from DOE, NASA, and the Oak Ridge National Laboratory (ORNL). 
Dr. M. N. Menon, Mr. A. Peralta, and Mr. J. Schienle of AlliedSignal Engines visited AlliedSignal Ceramic Components in Torrance, CA on November 15, 1995 to discuss fabrication of AS-800 silicon nitride test specimens for the Materials Baseline, Cyclic Fatigue, and Proof Testing Methodology Development efforts.

\section{Problems Encountered}

(None).

\section{Publications}

(None).

\section{Reference}

(1) J. C. Cuccio, et. al., "Life Prediction Methodology For Ceramic Components Of Advanced Heat Engines Phase I Final Report, Contract No. 86X-SC674C," DOE/ORNL Report No. ORNL/Sub/89-SC674/1/V1\&V2, March 1995; (AlliedSignal Report No. 31-11591 (Two Volumes), AlliedSignal Engines, Phoenix, AZ, March 1, 1994). 


\subsection{ENVIRONMENTAL EFFECTS}

\subsection{ENVIRONMENTAL EFFECTS}

\section{Environmental Effects in Toughened Ceramics*}

N. L. Hecht (University of Dayton)

\section{Objective/scope}

Since December 1984, the University of Dayton has been involved in a project to investigate the effects of environment on the mechanical behavior of ceramics being considered for heat engine applications. In the first phase of this project, the effects of environment on the mechanical behavior of transformationtoughened $\mathrm{ZrO}_{2}$ ceramics were investigated. In subsequent phases, $\mathrm{Si}_{3} \mathrm{~N}_{4}$ and $\mathrm{SiC}$ ceramics were evaluated. Tensile, flexural, and fatigue strength of the $\mathrm{SiC}$. and $\mathrm{Si}_{3} \mathrm{~N}_{4}$ ceramics were evaluated at temperatures ranging from 20 to $1400^{\circ} \mathrm{C}$. Microstructure, chemistry, and physical properties were also investigated. In the current phase, newly developed or enhanced $\mathrm{SiC}$ and $\mathrm{Si}_{3} \mathrm{~N}_{4}$ ceramics are being investigated. In addition, the effects of different machining processes on the mechanical behavior of selected $\mathrm{SiC} / \mathrm{Si}_{3} \mathrm{~N}_{4}$ ceramics are being studied.

\section{Technical progress}

During the past six months of the project, the investigation of the mechanical behavior of a new batch of Allied Signal's AS-800 was initiated, and Ceradyne's Ceralloy 147-3 was completed. Flexural and tensile strength were measured. The flexural strength was measured using B-type test bars following ASTM C-1161 in an Instron Model 5500R123. All of the tensile property measurements were made using buttonhead specimens in an Instron 8561 with supergrips and a high-temperature short furnace. Elastic modulus was measured using a Grindo-sonic (Model MR35T) Transient Impulse Elastic Modulus Apparatus. In addition, the investigation of the effects of machining methods on the mechanical behavior of Hexoloy SA and Kyocera SN-252 were completed. The status of the workscope tasks are outlined below:

1. Investigation of the $1994 / 95$ vintage AS-800 has been completed.

2. Investigation of the new generation Hexoloy SA has also been completed.

3. Investigation of Ceralloy 147-3 has been completed.

4. Investigation of Golden Technologies' MgO PSZ rods has been initiated.

5. Investigation of the 1996 vintage AS- 800 has been initiated. 
6. Investigation of the effects of machining on the flexural strength of Hexoloy SA and SN-252 have been completed. The results of this phase of the project and the earlier two phases investigating machining effects have been reviewed and are summarized in Appendix 1.

7. As part of this project, efforts were initiated to revise and update the compendium. Both the flexural and tensile strength data for all the $\mathrm{SiC}$ and $\mathrm{Si}_{3} \mathrm{~N}_{4}$ ceramics were re-evaluated by regression analysis. In addition, the tensile and flexural dynamic fatigue data were used to estimate life time as a function of applied stress and temperature.

\section{$\underline{\mathrm{AS}-800}$}

Investigation of the 1996 vintage AS-800 was initiated. Fifteen tensile specimens were tested at $982^{\circ} \mathrm{C}\left(1800^{\circ} \mathrm{F}\right)$ using a stressing rate of $150 \mathrm{MPa} / \mathrm{s}$. The results of these strength measurements are compiled in Table 1.

Table 1. Tensile Strength of AS- 800 at $982^{\circ} \mathrm{C}\left(1800^{\circ} \mathrm{F}\right)$

\begin{tabular}{|c|c|c|c|}
\hline \multirow{2}{*}{$\begin{array}{l}\text { Specimen } \\
\text { Number }\end{array}$} & \multicolumn{2}{|c|}{ Tensile Strength } & \multirow{2}{*}{$\begin{array}{c}\text { Fracture } \\
\text { Origin }\end{array}$} \\
\hline & $\mathrm{MPa}$ & ksi & \\
\hline 4-96P & 521 & 75.6 & Volume@ @White" Spot \\
\hline 4-96E & 538 & 78.1 & Surface@ Inclusion \\
\hline 4-96G & 479 & 69.5 & Volume @ "White" Spot \\
\hline 4-96D & 524 & 76.0 & Volume \\
\hline 4-96J & 479 & 69.5 & Volume \\
\hline S96018-4 \#13 & 527 & 76.4 & Volume \\
\hline S96018-4 \#4 & 558 & 80.9 & Volume \\
\hline S96027-3 \#17 & 552 & 80.1 & Volume \\
\hline $4-96 A$ & 552 & 75.7 & Volume @ "White" Spot \\
\hline S96018-1 \#1 & 581 & 84.3 & Volume \\
\hline $596027-4$ \#20 & 582 & 84.4 & Volume @ "White" Spot \\
\hline S96018-4 \#11 & 569 & 82.6 & Volume @ "White" Spot \\
\hline S96018-3 \#5 & 572 & 83.0 & Volume \\
\hline $4-960$ & 553 & 80.2 & Volume \\
\hline S96018-3 \#7 & 550 & 79.7 & Surface \\
\hline Average & 541 & 78.4 & \\
\hline St. Dev. & 32.3 & 4.7 & \\
\hline
\end{tabular}

Note: Specimens 4-960 and S96018-3 \#7 both had surface inclusions identified during pre-test inspection. 
Ceralloy $147-3$

The flexural strength measurements of Ceralloy 147-3 have been completed. The results of these strength measurements are compiled in Table 2.

Table 2. Flexural Strengths Measured for Ceralloy $147-3$ from $20^{\circ} \mathrm{C}$ to $1250^{\circ} \mathrm{C}$

\begin{tabular}{|c|c|c|c|c|}
\hline $\begin{array}{c}\text { Temperature } \\
{ }^{\circ} \mathrm{C}\end{array}$ & $\begin{array}{c}\text { Loading Rate } \\
(\mathrm{MPa} / \mathrm{s})\end{array}$ & $\begin{array}{c}\text { Average Flexural } \\
\text { Strength (MPa) }\end{array}$ & $\begin{array}{c}\text { Std. Deviation } \\
(\mathrm{MPa})\end{array}$ & $\begin{array}{c}\text { Weibull } \\
\text { Modulus }\end{array}$ \\
\hline 20 & 500 & 762 & 65 & 18 \\
& 0.1 & 691 & 44 & 20 \\
\hline 800 & 500 & 690 & 35 & 29 \\
& 0.1 & 601 & 46 & 17 \\
\hline 1000 & 500 & 592 & 58 & 15 \\
& 0.1 & 469 & 13 & 37 \\
\hline 1150 & 500 & 480 & 37 & 19 \\
& 0.1 & 358 & 17 & 23 \\
\hline 1250 & 500 & 440 & 27 & 20 \\
& 0.1 & 240 & 15 & 18 \\
\hline
\end{tabular}

\section{Compendium Re-evaluation}

As part of the efforts to revise and update the compendium, the flexural and tensile data for the major candidate $\mathrm{SiC}$ and $\mathrm{Si}_{3} \mathrm{~N}_{4}$ ceramics tested to date were reviewed and updated. Using the average tensile and flexural strength values measured at the fastest stressing rate, linear plots of strength versus temperature were prepared by regression analysis (see Figures 1 through 9). For those materials for which both flexural and tensile strength measurements were obtained, the regression line equations were plotted on the same graph and compared. Similar linear plots were also determined for the average tensile and flexural strength versus temperature at the slowest rates. Comparison of these equations provides some insight into the correlations between flexural and tensile strength measurements versus temperature and rapid and slow stressing rates. The results of these regression analyses are compiled in Table 3.

Using the tensile and flexural dynamic fatigue data, estimated life predictions for NT-154, NT-164, PY6, 147-3, and SN-253 $\mathrm{Si}_{3} \mathrm{~N}_{4}$ ceramics were plotted as a function of applied stress for the different testing temperatures (see Figures 10 through 18). These life prediction estimates are based on the calculated time to failure, $t_{t}$, which is determined from the relationship:

$$
t_{f}=B \sigma_{i} N^{-2} \sigma_{a}^{-N}
$$


where: $\quad \sigma_{\mathrm{i}} \quad=$ the inert strength.

$\sigma_{\mathrm{a}} \quad=$ the applied stress

$\mathrm{B} \quad=2 /\left[\mathrm{AY} \mathrm{Y}^{2}(\mathrm{~N}-2) K_{k c}^{N-2}\right]$

$\mathrm{Y} \quad=$ geometric factor for the flaw shape

$\mathrm{K}_{\mathrm{Ic}} \quad=$ fracture toughness

A\&N = material and environmental constants related to crack growth behavior

The trend lines obtained at each temperature were generated by reducing the starting value (fracture strength) by increments of $10 \%$. Since the specimen population evaluated at each of the test conditions was limited (no more than 10), we did not attempt to determine confidence limits for each trend line. It should be noted that this effort is a preliminary attempt to characterize the fatigue behavior of these candidate ceramics. The life predictions will be compared with reported data for these ceramics.

Table 3. Regression Analysis for Mechanical Strength Measurements at Selected Temperatures

\begin{tabular}{|c|c|c|c|c|}
\hline Material & Fast Flexure & Fast Tensile & Slow Flexure & Slow Tensile \\
\hline NT-154 & $922.3-0.204 x$ & $750.5-0.247 x$ & $811.7-0.199 x$ & $652.1-0.254 x$ \\
\hline NT-164 & $1099-0.331 x$ & $726.6-0.221 x$ & $954.2-0.288 x$ & $565.2-0.144 x$ \\
\hline PY6 & $890-8.0 .225 x$ & $657.0-0.306 x$ & $876.1-0.306 x$ & $582.8-0.341 x$ \\
\hline SN-253 & $866-7.0149 x$ & $640.2-0.132 x$ & $826.7-0.205 x$ & $613.6-0.179 x$ \\
\hline $147-3$ & $850.9-0.3316 x$ & $605.7-0.220 x$ & $772.9-0.3669 x$ & $559.5-0.317 x$ \\
\hline GN-10 & $783.4-0.172 x$ & $666.0-0.151 x$ & & \\
\hline AS-800 & $701.8-0.148 x$ & $617.3-0.126 x$ & & \\
\hline SA-88 & $393.9+0.030 x$ & $235.5+0.015 x$ & & $409.0-0.030 x$ \\
\hline SA-93 & $654.0-0.020 x$ & $455.7-0.002 x$ & $680.0-0.03 x$ & \\
\hline SN-252 & $710.6-0.188 x$ & & & \\
\hline GS-44 & $1168-0.388 x$ & & & \\
\hline NT-230 & $440.6+0.034 x$ & & & \\
\hline$\beta-S i C$ & $464.4-0.011 x$ & & & \\
\hline CVD SiC & $483+0.053 x$ & & & \\
\hline
\end{tabular}

Status of Milestones

Milestones 331418 and 331419 are in progress. 
Comparison of Fesural and Tensile Strength of NT-154

at Fast and Slow Loading

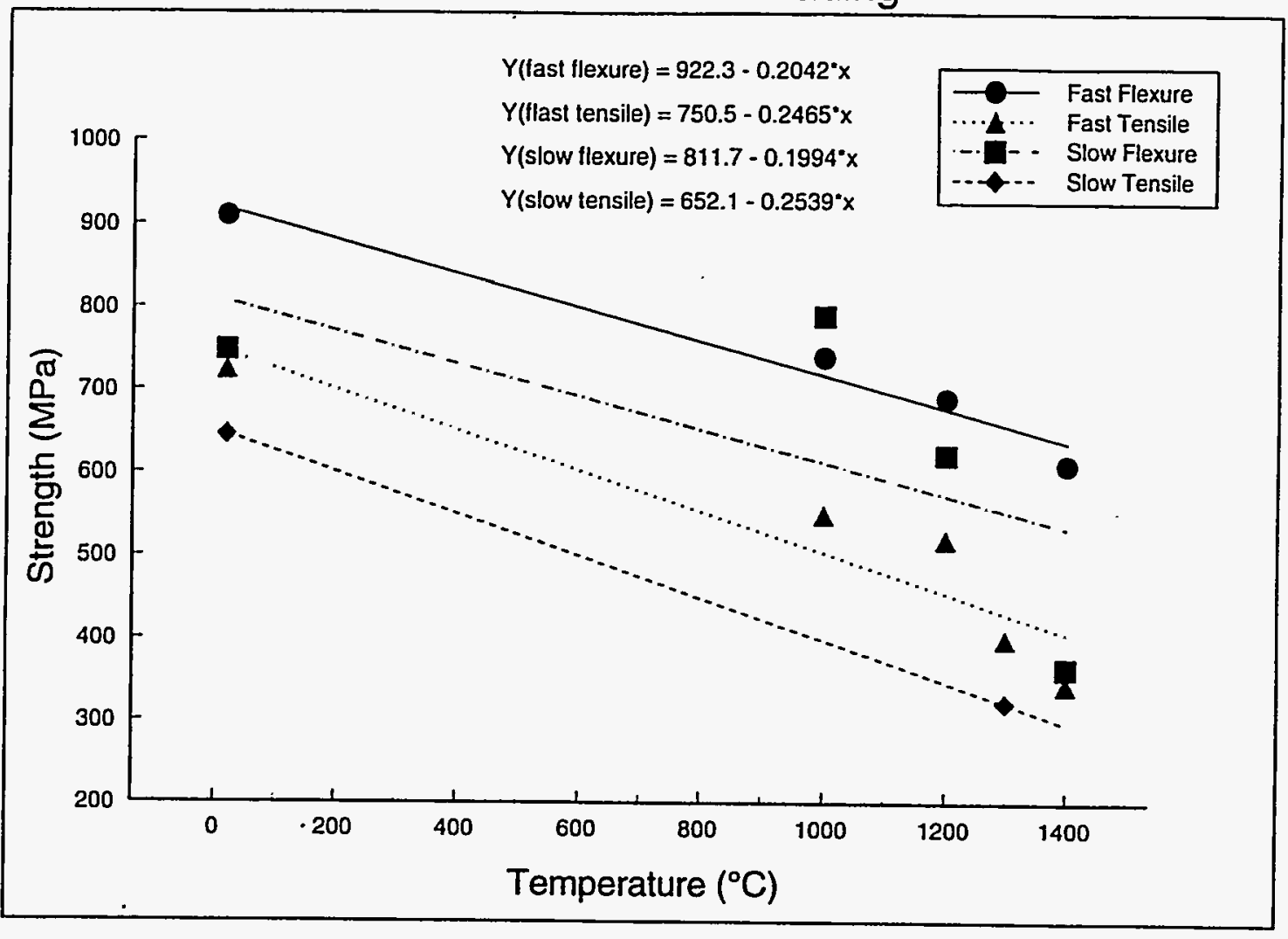

Figure 2

Comparison of Flexural and Tensile Strength of NT-164 at Fast and Slow Loading

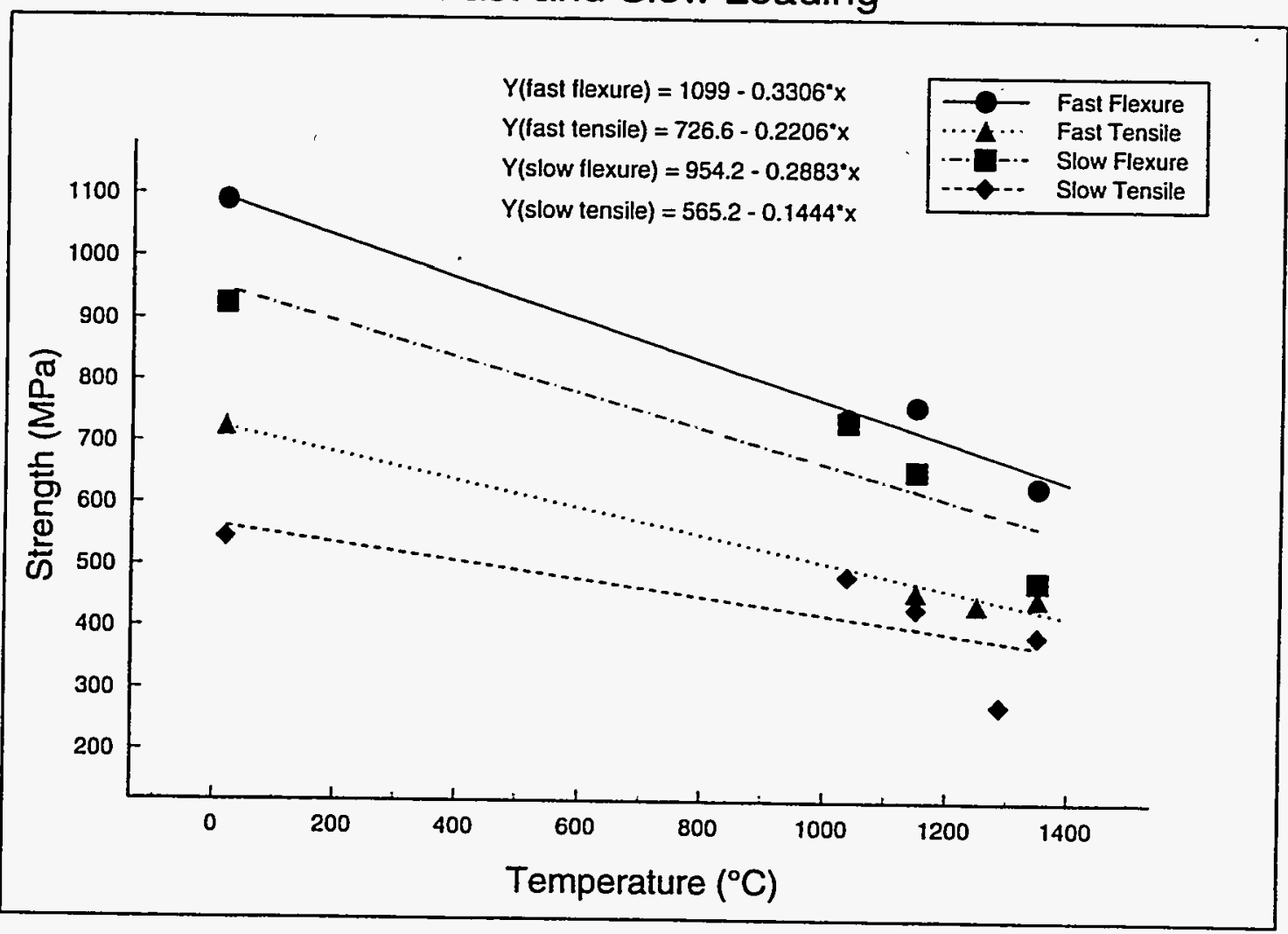




\section{Comparison of Flexural and Tensile Strength of PY6} at Fast and Slow Loading

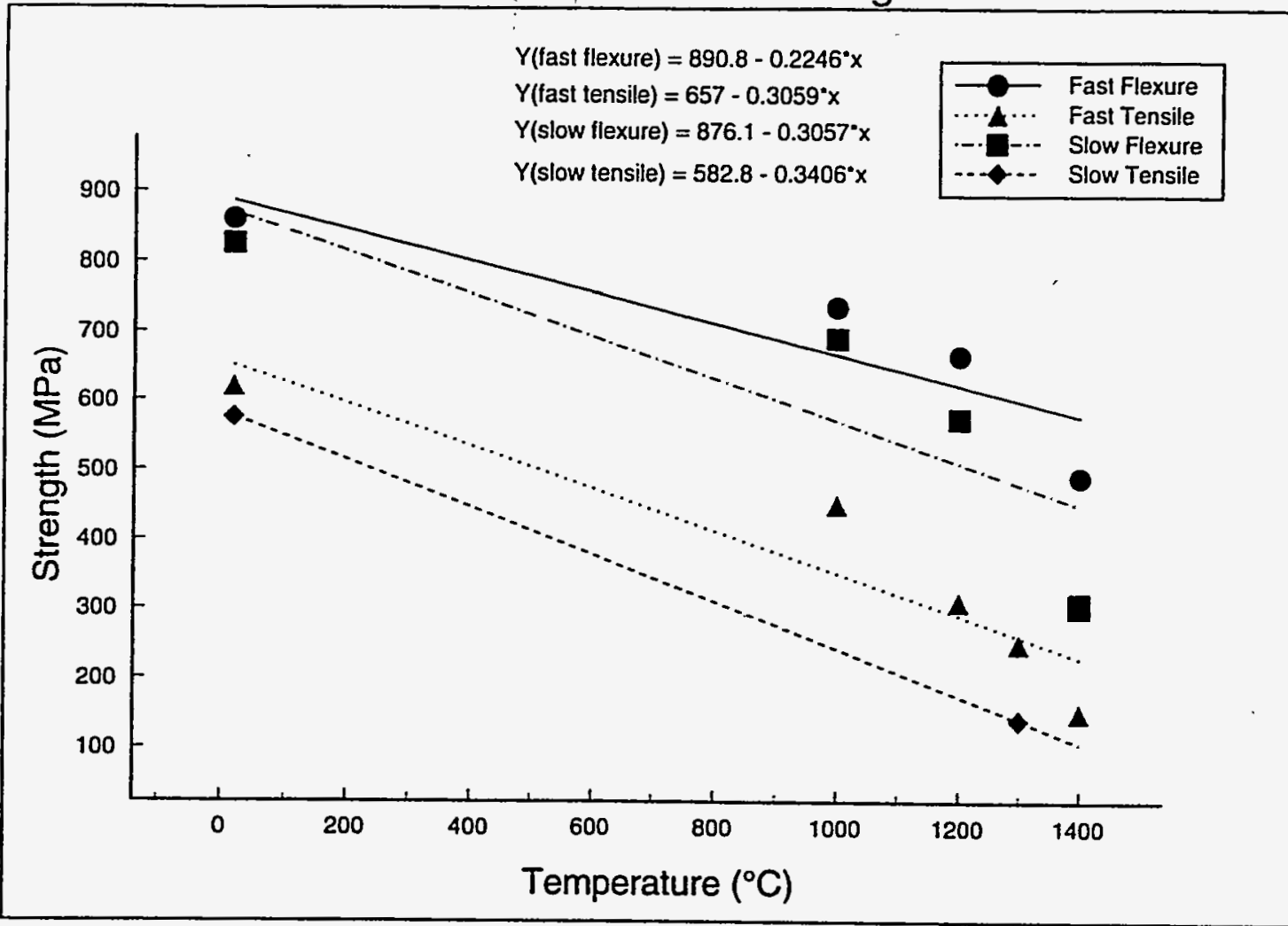

Figure 4

Comparison of Flexural and Tensile Strength of Cerraloy 147-3 at Fast and Slow Loading

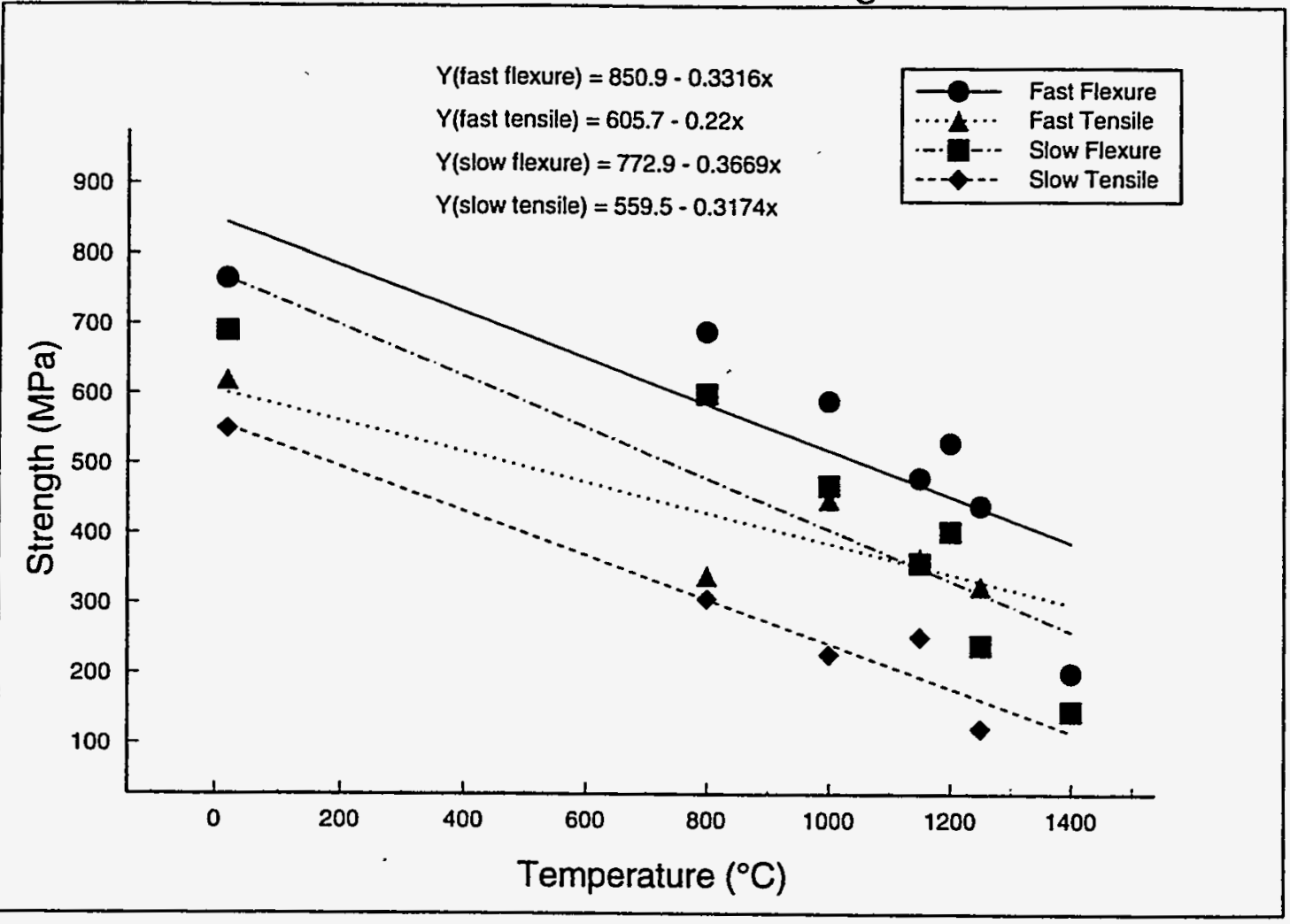


Comparison of Flexural and Tensile Strength of SN-253 at Fast and Slow Loading

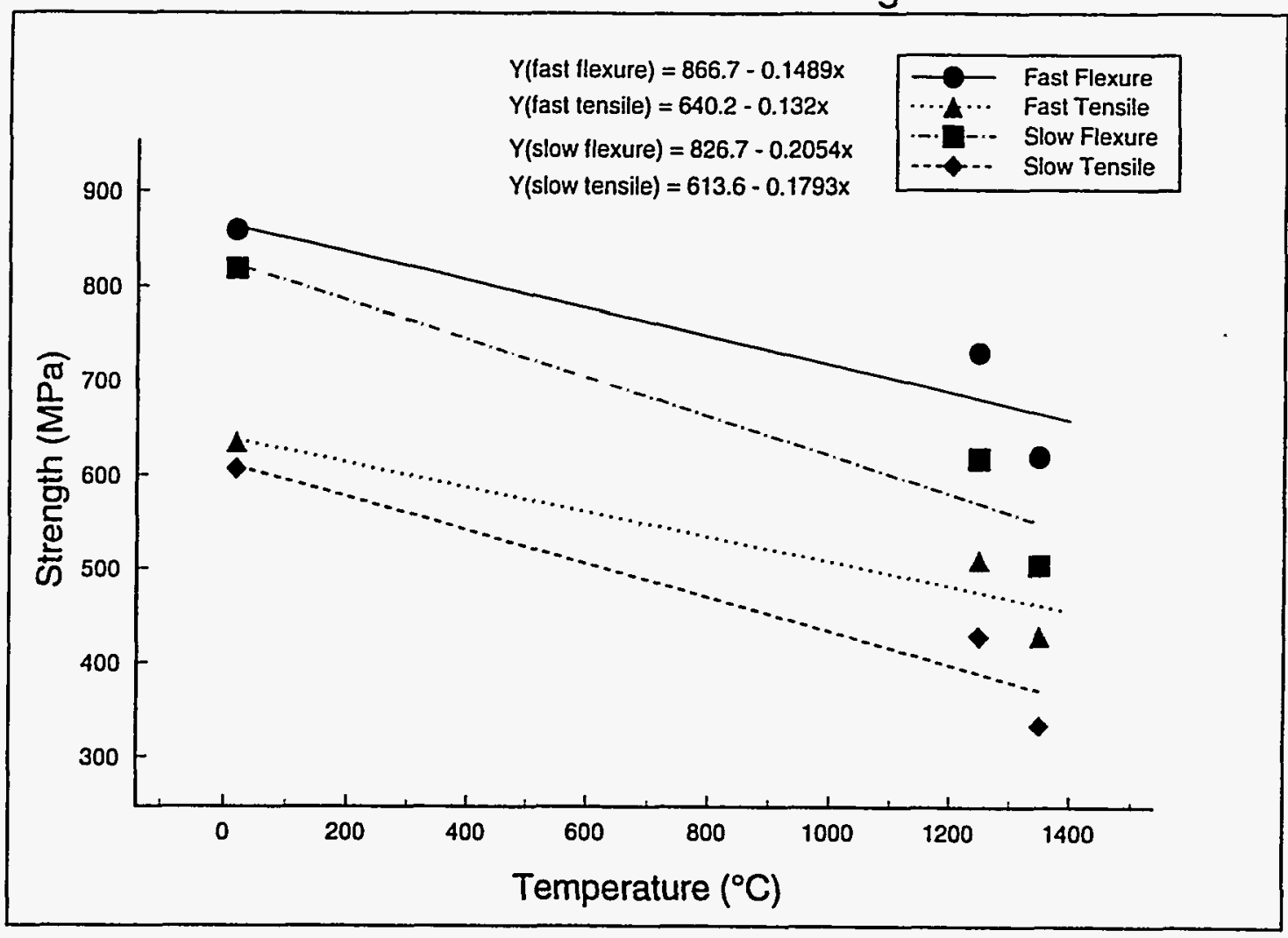

Figure 6

Comparison of Flexural and Tensile Strength of AS-800 at Fast Loading

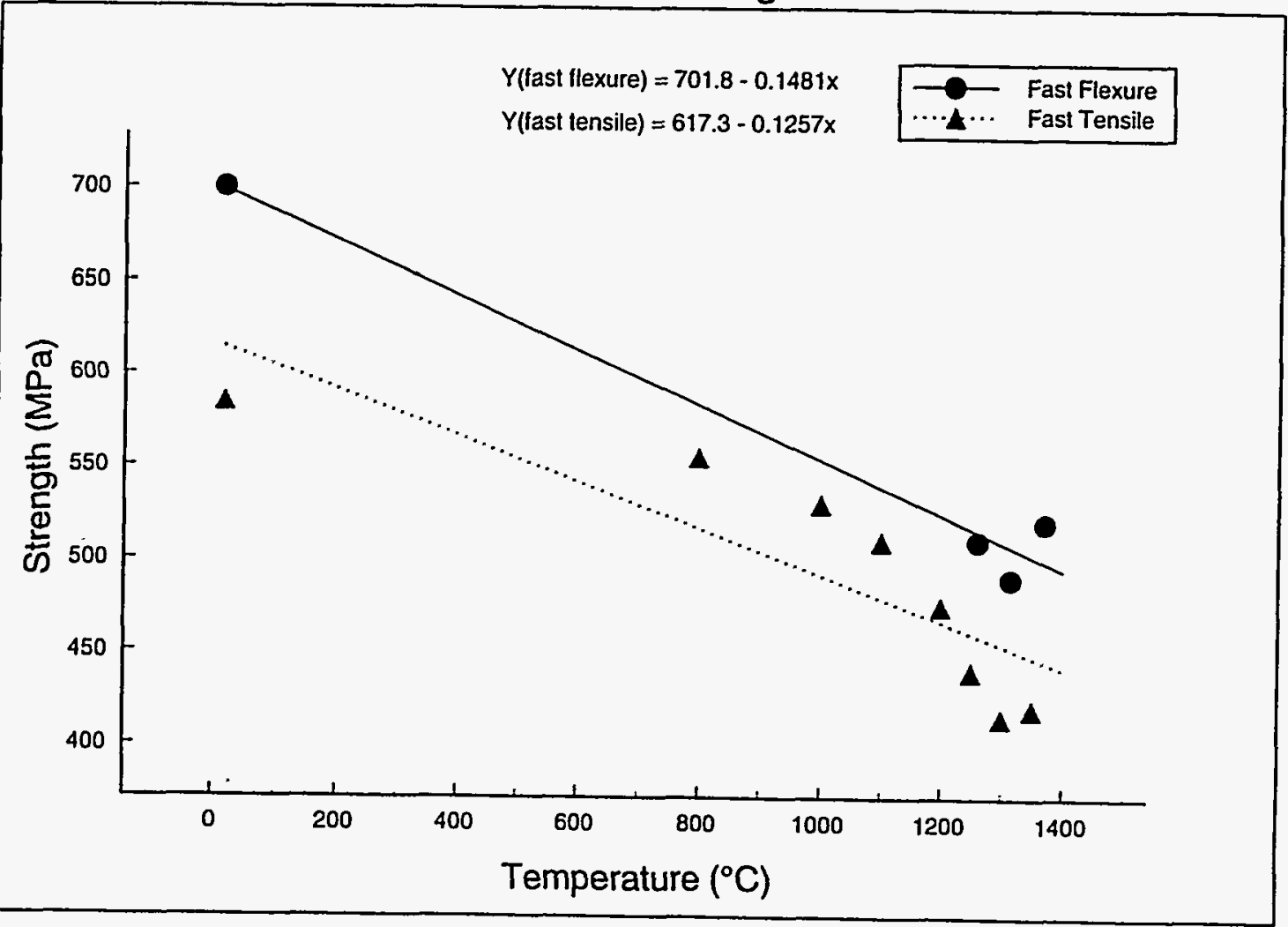


Comparison of Flexural and Tensile Strength of GN-10

at Fast Loading

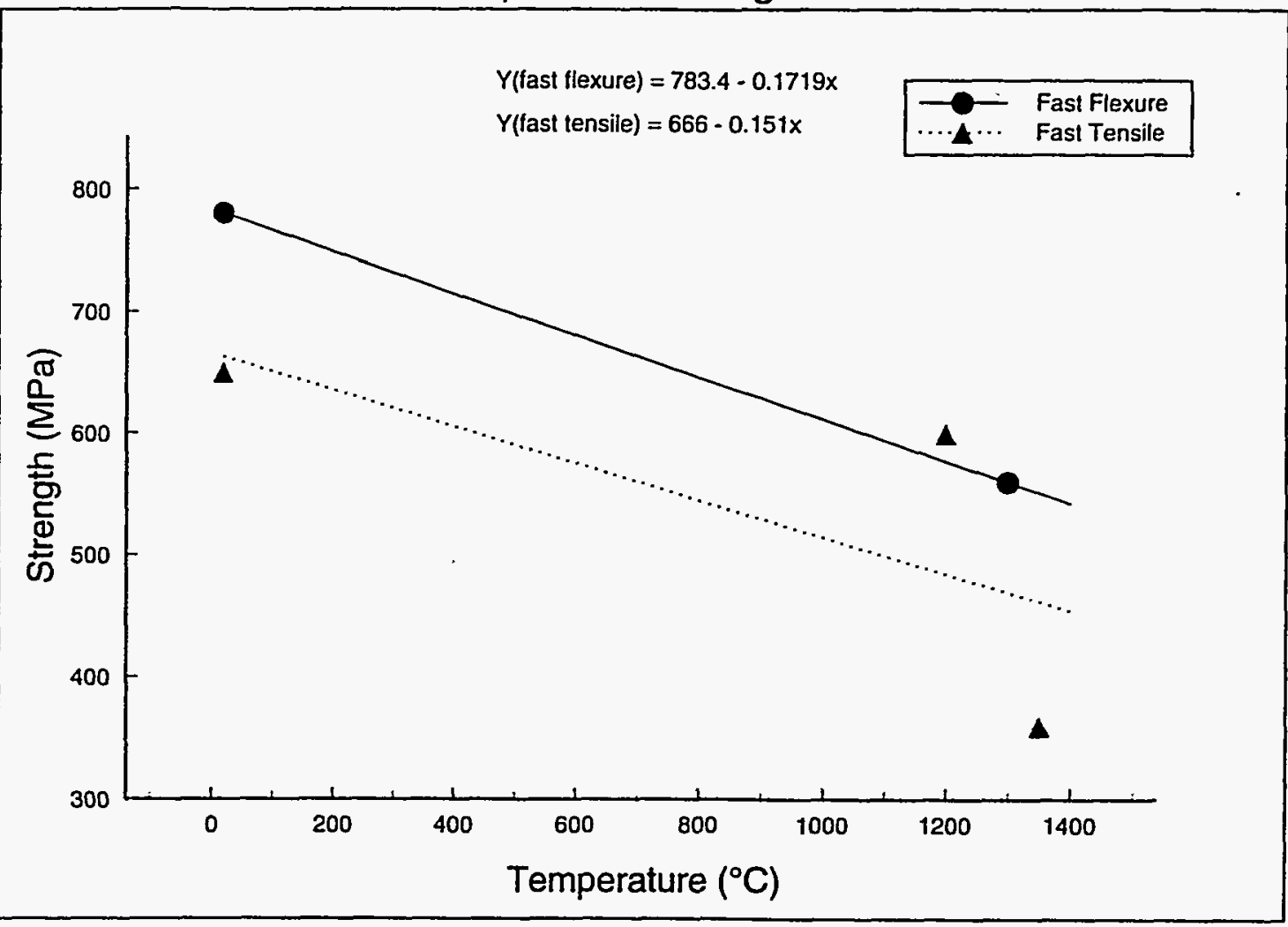

Figure 8

Comparison of Flexural and Tensile Strength of SA 93 at Fast Loading

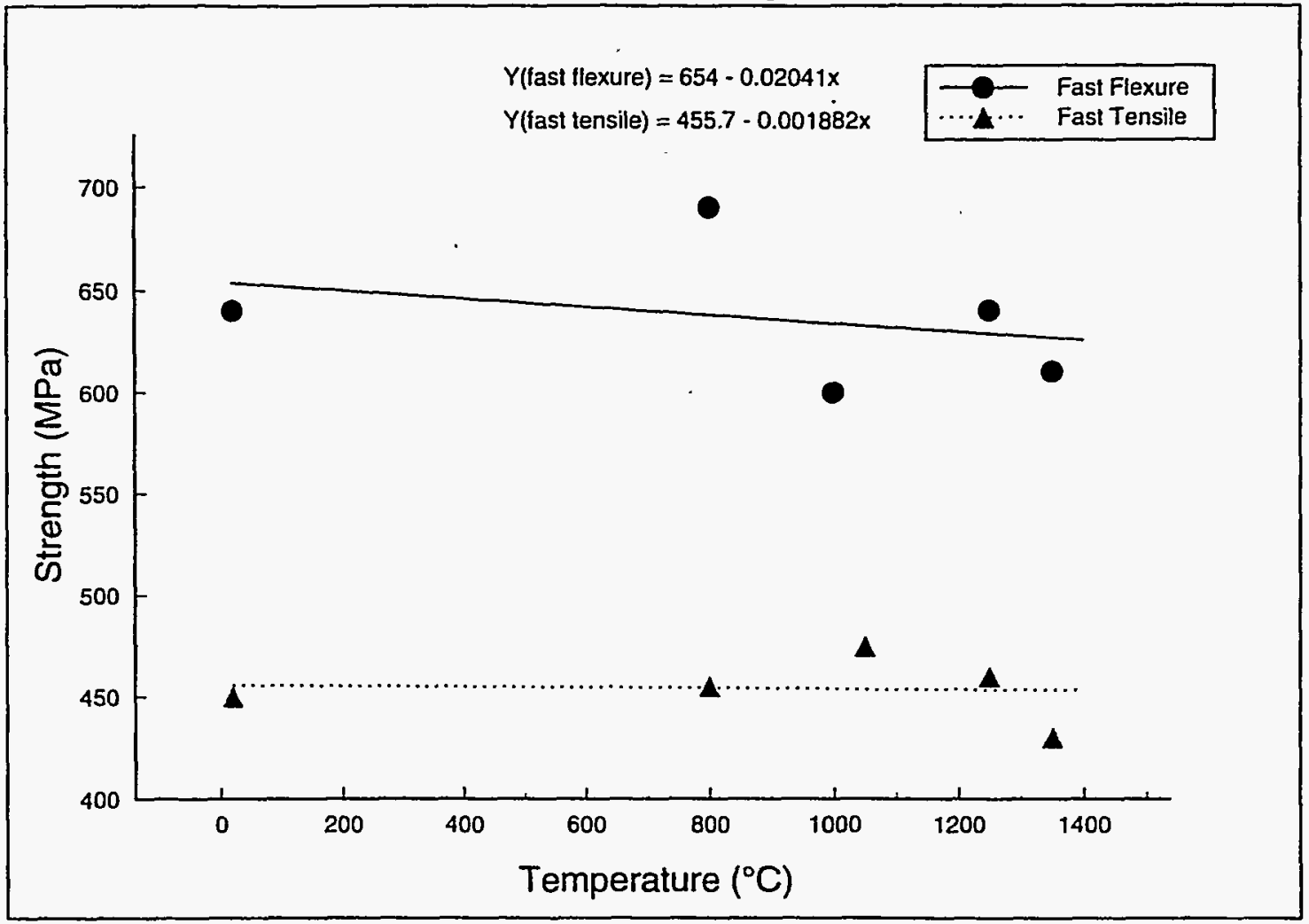


Comparison of Flexural and Tensile Strength of SA 88 at Fast Loading

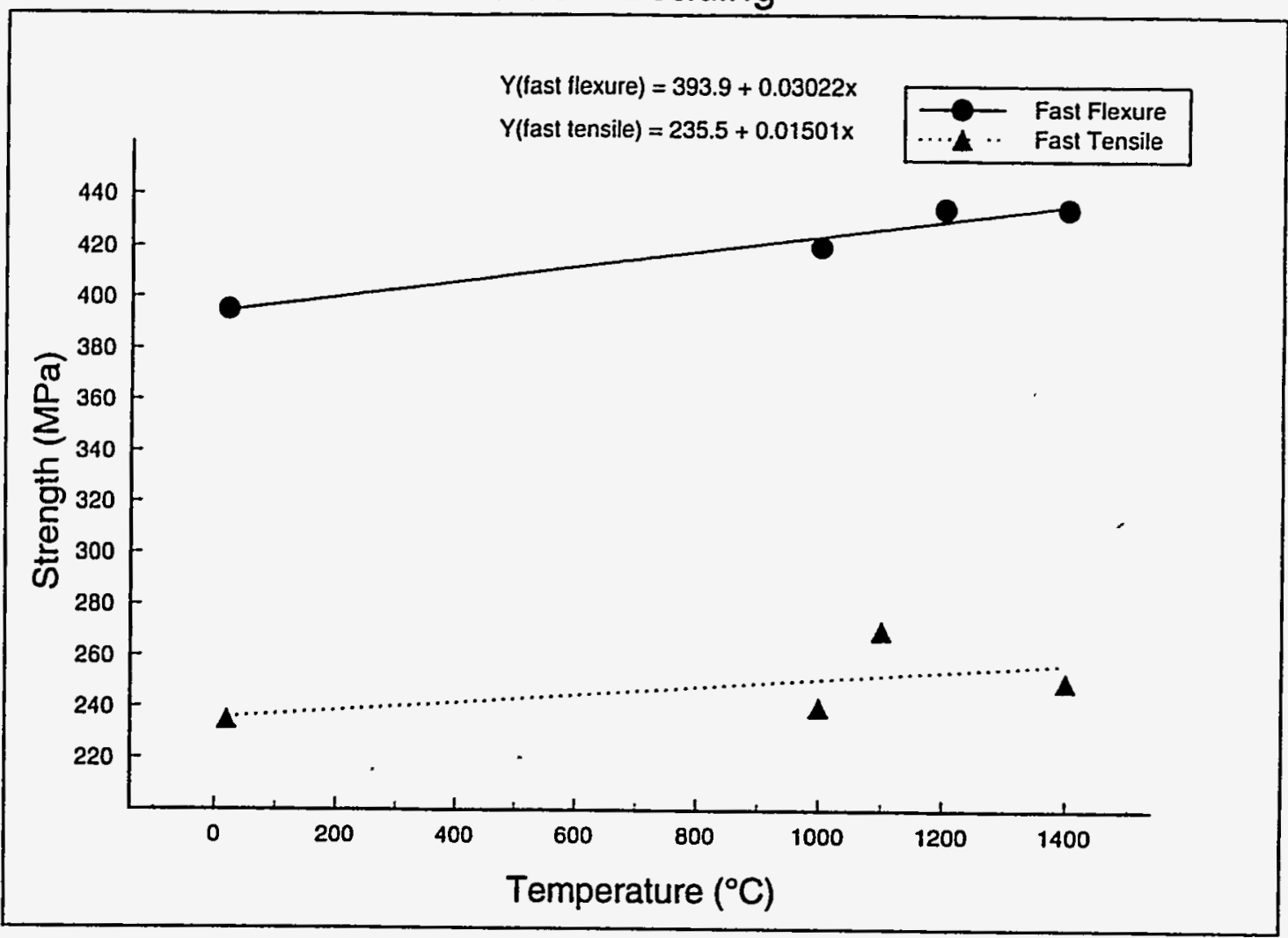

Figure 10

\section{Estimated Life Predictions of NT-154 Determined from Dynamic Fatigue Flexure Data}

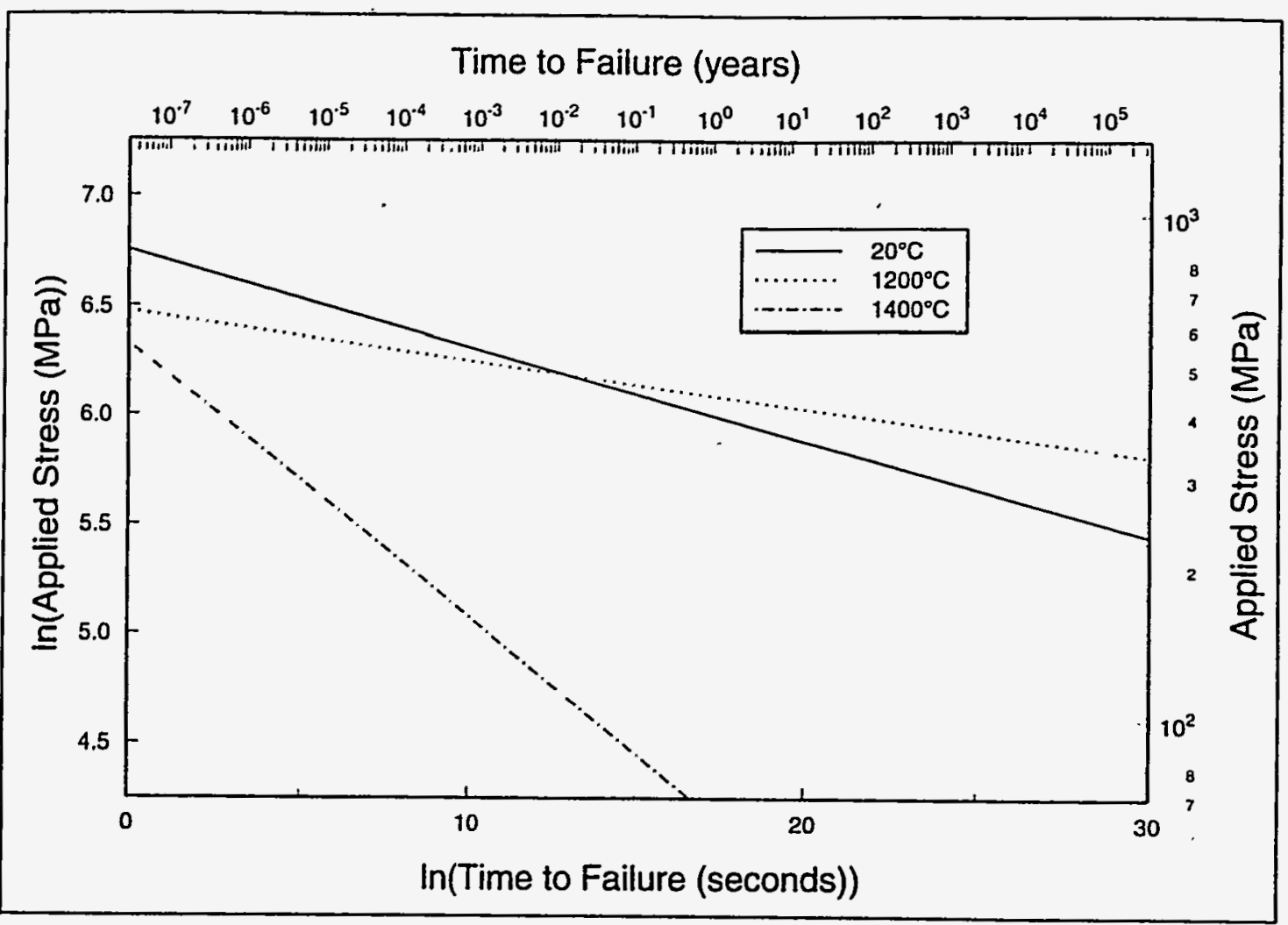


rigure 15

Estimated Life Predictions of 147-3 Determined from Dynamic Fatigue Flexural Data

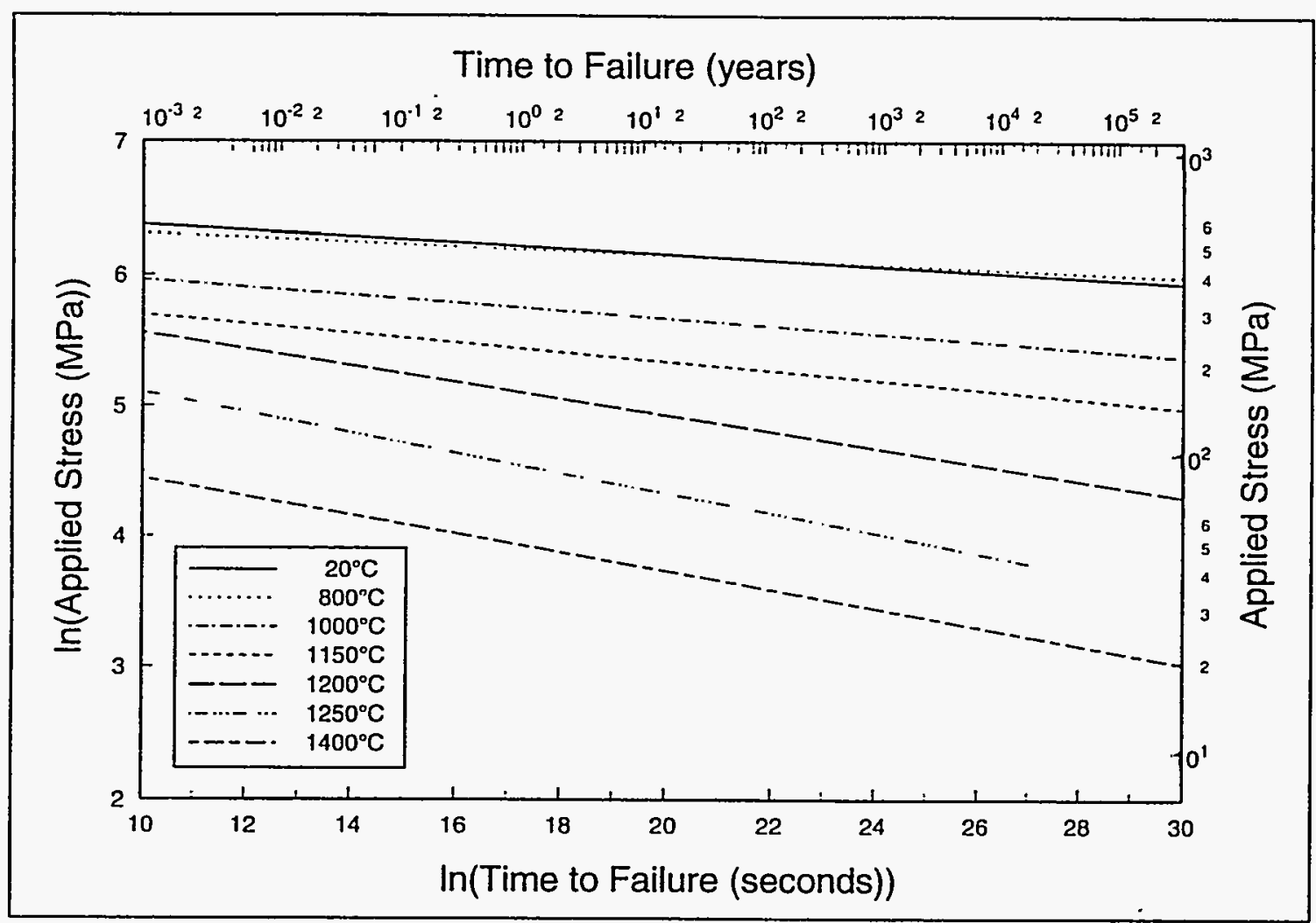

Figure 16

Estimated Life Predictions of 147-3 Determined from Tensile Dynamic Fatigue Data

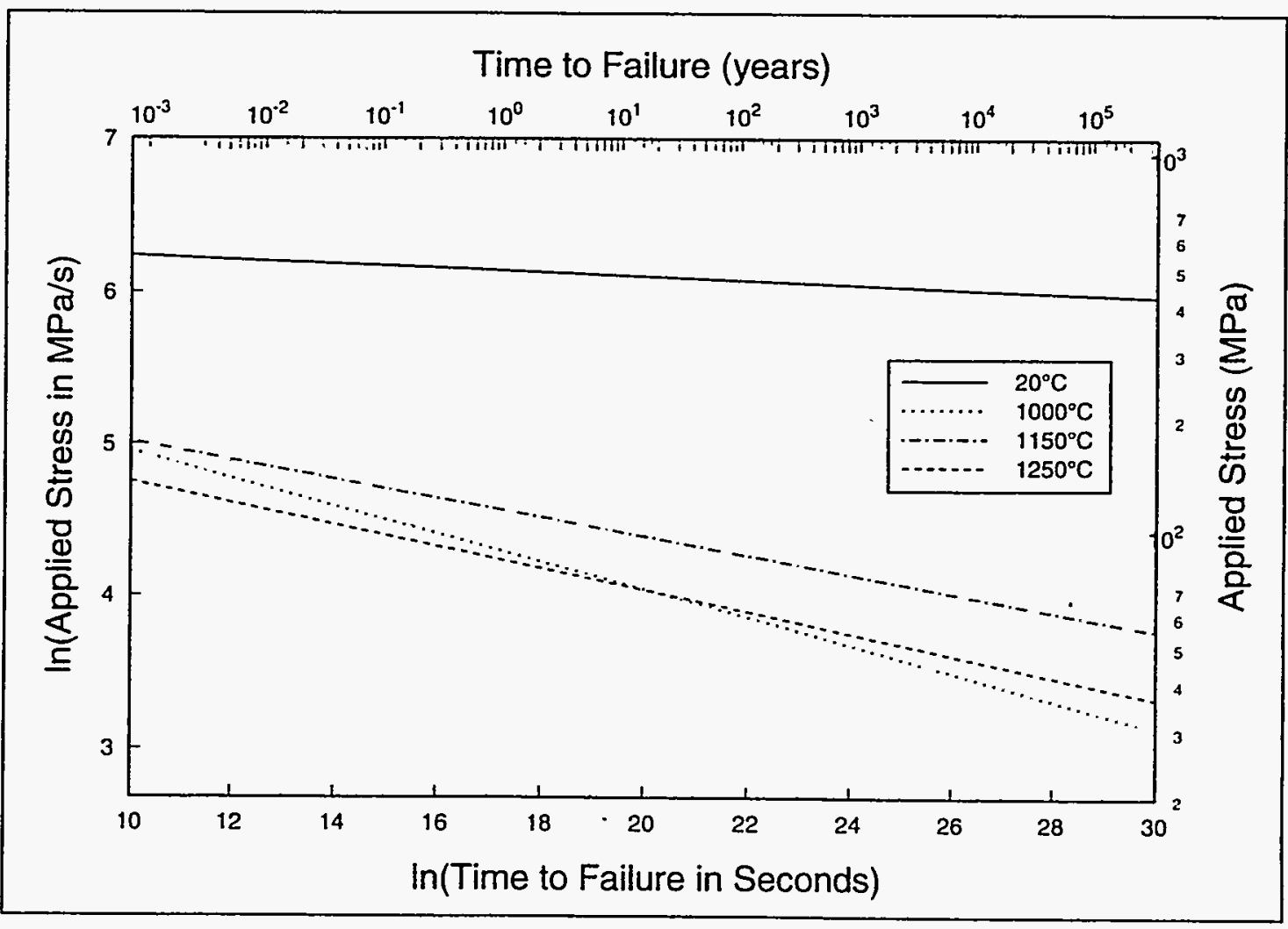


Figure 17

Estimated Life Predictions for SN-253 Determined from Dynamic Fatige Flexural Data

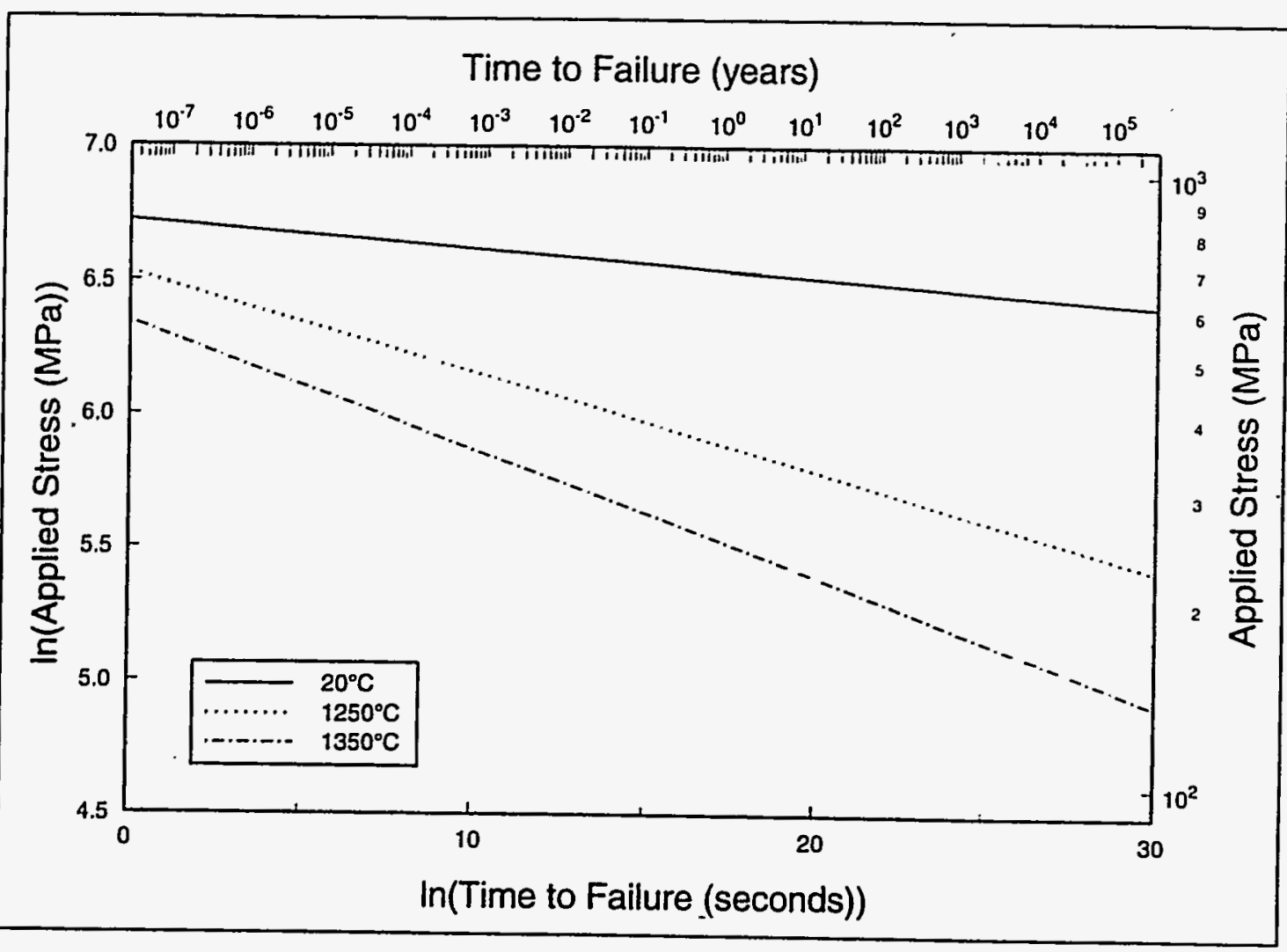

Figure 18

Estimated Life Predictions of SN-253 Determined from Dynamic Fatigue Tensile Data

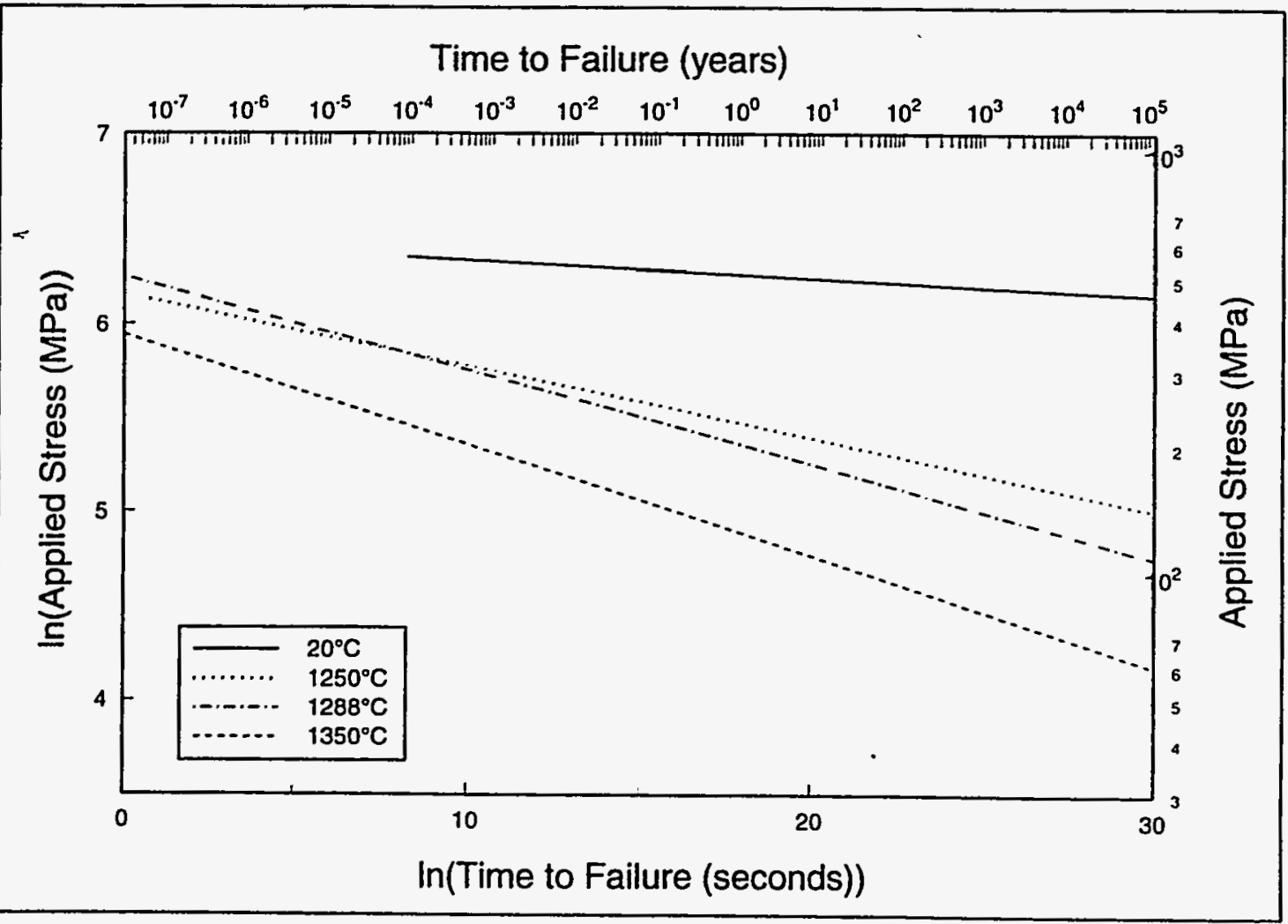




\section{APPENDIX 1}

\section{INVESTIGATION OF MACHINING TREATMENTS ON THE MECHANICAL}

\section{BEHAVIOR OF SiC AND Si, $\mathrm{N}_{4}$ CERAMICS}

\section{Introduction}

As part of the project investigating thermal mechanical behavior, the effects of machining treatments on the mechanical strength of two $\mathrm{SiC}$ and two $\mathrm{Si}_{3} \mathrm{~N}_{4}$ ceramics were studied. In the course of this project the effect of machining treatments (conventional grinding, creep feed grinding, and ultrasonic grinding), selected grinding conditions [abrasive grain size, grinding direction (longitudinal, transverse, and $15^{\circ}$ bias)], and post machining thermal treatments were investigated on four candidate ceramics. After the machining treatments, flexural strengths were measured, fracture analyses were conducted, and Raman microprobe spectroscopy was used to determine relative residual surface strain. Strength and relative residual strain measurements were correlated with the machining treatments employed. The results of these studies have been consolidated and are presented in this report.

\section{Experimental Procedure}

During the course of this project, four ceramic materials were studied;

(1) Allied Signal GS-44 $\mathrm{Si}_{3} \mathrm{~N}_{4}$

(2) Morton International CVD SiC (cubic)

(3) Kyocera SN-252 $\mathrm{Si}_{3} \mathrm{~N}_{4}$

(4) Carborundum Hexoloy SA SiC (hexagonal)

Four point flexural bend specimens $3 \times 4 \times 50 \mathrm{~mm}^{3}$ conforming to specifications in ASTM Standard Test Method C 1161 configuration B were prepared from the four ceramic materials using different machining treatments. In Phase 1 of this investigation, the effects of 
grinding direction (longitudinal versus transverse grind) and grinding process [standard

(baseline) grinding following ASTM - C 1161 versus creep feed grinding] were studied using

GS-44 $\mathrm{Si}_{3} \mathrm{~N}_{4}$. The matrix plan for machining treatments of GS-44 is summarized in Table 1 .

Table 1. Machining Treatments Matrix for GS-44

\begin{tabular}{|c|c|c|c|c|c|c|}
\hline Machining Source: & \multicolumn{2}{|c|}{$\begin{array}{l}\text { Chand Kare Technical } \\
\text { Ceramics }\end{array}$} & \multicolumn{2}{|c|}{ ORNL } & ORNL & ORNL \\
\hline Machine: & \multicolumn{2}{|c|}{ CC Surface Grinder } & \multicolumn{2}{|c|}{ Harig NC } & Harig NC & Nicco \\
\hline Grind Type: & \multicolumn{2}{|c|}{ Std. Grind } & \multicolumn{2}{|c|}{ Std. Grind } & Std. Grind & Creep Feed Grinc \\
\hline Grind Direction: & \multicolumn{2}{|c|}{ Longitudinal } & \multicolumn{2}{|c|}{ Longitudinal } & Transverse & Longitudinal \\
\hline $\begin{array}{l}\text { Post-Machining } \\
\text { Treatment: }\end{array}$ & -- & $\begin{array}{r}200 \mathrm{hrs} @ \\
1100^{\circ} \mathrm{C}\end{array}$ & -- & $\begin{array}{c}200 \mathrm{hrs} @ \\
1100^{\circ} \mathrm{C}\end{array}$ & -- & -- \\
\hline No. of Specimens: & 20 & 10 & 20 & 4 & 14 & 18 \\
\hline
\end{tabular}

In Phase 2 of this investigation the effects of abrasive grain size was investigated using CVD SiC prepared by Chand Kare Technical Ceramics. The machining treatments matrix used for CVD SiC in Phase 2 is summarized in Table 2.

Table 2. Machining Treatments Matrix for CVD SiC

\begin{tabular}{|c|c|c|c|c|}
\hline $\begin{array}{c}\text { Grinding } \\
\text { Wheel Type }\end{array}$ & $\begin{array}{c}\text { Abrasive } \\
\text { Grit Size } \\
\text { Mesh (um) }\end{array}$ & $\begin{array}{c}\text { Removal Rate } \\
\text { Per Pass } \\
\text { mm (in) }\end{array}$ & $\begin{array}{c}\text { Total Amount } \\
\text { Removed/Side } \\
\text { mm (in) }\end{array}$ & $\begin{array}{c}\text { Number } \\
\text { Specimens }\end{array}$ \\
\hline Norton SD 150 R75B99E-1/4 & $150(100)$ & $0.005(0.0002)$ & $0.025(0.001)$ & 15 \\
\hline Norton SD 320 R75B99E-1/4 & $320(45)$ & $0.005(0.0002)$ & $0.20(0.008)$ & 15 \\
\hline General Dia. CGD600 R75B-1/4 & $800(25)$ & $0.0025(0.0001)$ & $0.025(0.001)$ & 15 \\
\hline Norton SD 800 R50-1/32 & $1050(18.5)$ & $0.0025(0.0001)$ & $0.025(0.001)$ & 15 \\
\hline Norton SD 800 R75B56-1/4 & $1050(18.5)$ & $0.0025(0.0001)$ & $0.025(0.001)$ & 15 \\
\hline Norton D 3/6 mic R75B-1/4 & $1600(3.6)$ & $0.0025(0.0001)$ & $0.025(0.001)$ & 15 \\
\hline
\end{tabular}

In Phase 3 of this investigation, the effects of machining treatments were studied on flexural test specimens prepared by Chand Kare Technical Ceramics using SN-252 $\mathrm{Si}_{3} \mathrm{~N}_{4}$ and Hexoloy SA SiC. Using standard longitudinal grinding, flexural test specimens were prepared 
from SN-252 and Hexoloy SA to provide baseline data. In addition, flexural test specimens were standard ground in the transverse (perpendicular) direction and at a $15^{\circ}$ bias direction. Flexural specimens were also prepared by ultrasonic and creep feed grinding using two feed rates (88.9 $\mathrm{mm} / \mathrm{min}$ and $25.4 \mathrm{~mm} / \mathrm{min}$ ). Selected baseline ground, bias ground, creep feed ground, and ultrasonic ground specimens were heat treated or oxidized. A summary of the specific machining treatments for the Hexoloy SA and SN-252 flexural specimens is presented in Table 3.

Table 3. Machining Treatments for Hexoloy SA and SN-252

\begin{tabular}{|l|c|c|}
\hline \multirow{2}{*}{ Machining Treatments } & \multicolumn{2}{c|}{ Number of Specimens Prepared } \\
\cline { 2 - 3 } & Hexoloy SA & SN-252 \\
\hline Baseline Grind Longitudinal & 23 & 24 \\
\hline Transverse Baseline Grind & 16 & 15 \\
\hline $15^{\circ}$ Bias Grind & 21 & 8 \\
\hline Heat Treated Baseline Grind Longitudinal & 29 & 30 \\
\hline Oxidized Baseline Grind Longitudinal & 8 & 10 \\
\hline Oxidized $15^{\circ}$ Bias Grind & 8 & -- \\
\hline Creep Feed Grind $88.9 \mathrm{~mm} / \mathrm{min}$ Longitudinal & 23 & 10 \\
\hline Creep Feed Grind $88.9 \mathrm{~mm} / \mathrm{min}$ Transverse & 16 & --- \\
\hline Creep Feed Grind $88.9 \mathrm{~mm} / \mathrm{min}$ Oxidized & 8 & -- \\
\hline Creep Feed Grind $25.4 \mathrm{~mm} / \mathrm{min}$ Longitudinal & 22 & --- \\
\hline Creep Feed Grind $25.4 \mathrm{~mm} / \mathrm{min}$ Transverse & 15 & --- \\
\hline Creep Feed Grind $25.4 \mathrm{~mm} / \mathrm{min}$ Oxidized & 8 & -- \\
\hline Ultrasonic Grind & 30 & 11 \\
\hline Ultrasonic Grind Heat Treated & 15 & --- \\
\hline
\end{tabular}

Flexural strength of all the machined specimens was measured according to ASTM C 1161 in an Instron 5500R1023 Universal testing machine at room temperature. Two stressing rates were employed for determining dynamic fatigue behavior. In Phases 1 and 2 the stressing rate was controlled by crosshead displacement rates of $0.004 \mathrm{~cm} / \mathrm{s}$ and $0.00004 \mathrm{~cm} / \mathrm{s}$. In Phase 3 the stressing rate was controlled by stressing specimens at $100 \mathrm{MPa} / \mathrm{s}$ and $0.1 \mathrm{MPa} / \mathrm{s}$. The 
fracture origin was determined, where possible, by optical microscopy (Nikon Epiphot Metallograph). Selected fractured specimens were also examined by scanning electron microscope (JEOL/JSM-840 with EG\&G Ortec System 500 Microanalysis system). Strength values were evaluated by Weibull analysis, and the Weibull moduli were determined.

The surface roughness of Hexoloy SA specimens subjected to different machining treatments was measured using a Tencor Instruments Alpha-200 profilometer. Profilometer measurements were conducted to determine average roughness in both the transverse and lateral directions on the tensile surface of the flexural specimens.

Residual strain in GS-44, CVD SiC, and Hexoloy SA flexural test specimens machined by different methods was investigated by Raman microprobe spectroscopy. Data were acquired using a diode-laser pumped, doubled Nd:YAG laser. This laser provides $50 \mathrm{~mW}$ of highly stable, single-mode continuous wave (CW) power at $532 \mathrm{~nm}$ with a bandwidth of less than 2 MHz. The data obtained for each specimen typically represents an average of 20 or 21 recorded positions spaced 5 to $25 \mu \mathrm{m}$ apart. Spectral data were analyzed using a least squares fit of the Lorentzian line shape function. For each data set, the peak height above background, the center frequency position, the full width at half maximum (FWHM), and the background level were fit as free parameters.

For the GS-44 specimens, the width and the position of the $864 \mathrm{~cm}^{-1}$ line was investigated. For the CVD SiC specimens, the transverse optical (TO) mode at $795 \mathrm{~cm}^{-1}$ was studied. Two specimens from each group were evaluated, and each was probed on the tensile and compressive surfaces near one edge of the long dimension. For the Hexoloy SA, three Raman lines $\left(767,788\right.$, and $\left.799 \mathrm{~cm}^{-1}\right)$ were measured along a line running across the width (4 mm side) of the specimen. Typically, 21 locations spaced $25 \mu \mathrm{m}$ were recorded for each 
specimen. This $0.5 \mathrm{~mm}$ long region was centered on the width and centrally located along the length. The measurement probe (spot) size was approximately $2 \mu \mathrm{m}$ by $35 \mu \mathrm{m}$ and was oriented with the $35 \mu \mathrm{m}$ dimension parallel to the length of the specimen. This protocol ensured that each measurement was at a completely unique location. Of the three lines, the $788-\mathrm{cm}^{-1}$ line was the strongest and, therefore, resulted in the smallest errors.

\section{Results and Discussion}

Results of the flexural strength measurements and Weibull modulus, and identification of the fracture origins for GS-44, CVD SiC, Hexoloy SA and SN-252 machined specimens are compiled in Tables 4 through 7, respectively. The data presented in these tables were used to plot bar graphs comparing flexural strength with machining treatments. Bar graph plots for GS-44, CVD SiC, Hexoloy SA, and SN-252 ceramics are presented in Figures 1 through 4, respectively.

The flexural strength of ceramic components is determined by the flaw population at or near the tensile surface and the applied stress fields at these flaws. These flaws or damage zones are introduced into the specimens during processing, machining and in service. Pores, inclusions, elongated grains, and microcracks are generated at the surface and in the bulk of the ceramic specimens during processing. Similarly, during machining, microcracks, zones of plastic deformation (residual strain), and pits are introduced into the surface of the specimens. In service, surface and subsurface damage occurs by the generation of pits, microcracks, and growth of existing microcracks. As the applied stress field is increased the largest flaw or group of flaws grow to critical size resulting in specimen rupture. However, identification of the fracture origin cannot always be accomplished. Specimens with high fracture energy tend to break into a number of small fragments, complicating the analysis. 
Table 4. Flexural Strength of GS-44 Subjected to of Different Machining Methods

\begin{tabular}{|c|c|c|c|c|c|c|}
\hline $\begin{array}{c}\text { Machining Methods/ } \\
\text { Treatments }\end{array}$ & $\begin{array}{c}\text { Sample } \\
\text { Population (n) } \\
\end{array}$ & $\begin{array}{c}\text { Displacement } \\
\text { Rate }(\mathrm{cm} / \mathrm{s})\end{array}$ & $\begin{array}{c}\text { Average } \\
\text { Strengt }\end{array}$ & $\begin{array}{l}\text { exural } \\
\text { MPa) }\end{array}$ & $\begin{array}{l}\text { Weibull } \\
\text { Modulus }\end{array}$ & $\begin{array}{l}\text { Fracture } \\
\text { Origin }^{+}\end{array}$ \\
\hline Longitudinally & 10 & 0.004 & 1160 & \pm 162 & 12 & $10 ?$ \\
\hline ground by Chand * & 5 & 0.00004 & 1139 & \pm 42 & 35 & 3?, 1 surf, 1 edge \\
\hline $\mathrm{O}_{2} @ 1100^{\circ} \mathrm{C}$ & 5 & 0.004 & 984 & \pm 24 & 51 & 3 Surf, I ?, VI \\
\hline Longitudinally & 10 & 0.004 & 1135 & \pm 55 & 31 & 5 edge, 2 surf, $2 ?$ \\
\hline ground at ORNL & 10 & 0.00004 & 1054 & \pm 84 & 17 & 4 surf, 4 edge, $2 ?$ \\
\hline $\mathrm{O}_{2} @ 1100^{\circ} \mathrm{C}$ & 5 & 0.004 & 867 & \pm 67 & 15 & 4 surf \\
\hline Creep feed ground & 9 & 0.004 & 1183 & \pm 71 & 19 & 4 edge, 4 surf,? \\
\hline at ORNL & 9 & 0.00004 & 1073 & \pm 49 & 25 & 5 edge, 4 surf \\
\hline Transversely ground & 7 & 0.004 & 871 & \pm 141 & 8 & 4 surf, 2 edge, ? \\
\hline at ORNL & 7 & 0.00004 & 985 & \pm 53 & 24 & 4 surf, 3 ? \\
\hline & & & & & TOTALS: & $41 \%$ surf, $30 \%$ ? \\
\hline
\end{tabular}

* Chand Kare Technical Ceramics Baseline grind used grit size finer than 320 mesh

+ Fracture origin abbreviations; ? = origin undetermined, VI = volume inclusion, surf $=$ surface

Table 5. Flexural Strength of CVD SiC Subjected to of Different Machining Methods

\begin{tabular}{|c|c|c|c|c|c|c|c|}
\hline \multicolumn{2}{|c|}{$\begin{array}{l}\text { Machining Methods/ } \\
\text { Treatments }\end{array}$} & \multirow{2}{*}{$\begin{array}{c}\text { Displacement } \\
\text { Rate } \\
(\mathrm{cm} / \mathrm{s}) \\
\end{array}$} & \multirow{2}{*}{$\begin{array}{c}\text { Sample } \\
\text { Population } \\
\text { (n) }\end{array}$} & \multirow{2}{*}{\multicolumn{2}{|c|}{$\begin{array}{l}\text { Average Flexural } \\
\text { Strength } \\
(\mathrm{MPa}) \\
\end{array}$}} & \multirow{2}{*}{$\begin{array}{l}\text { Weibull } \\
\text { Modulus } \\
(\mathrm{m})\end{array}$} & \multirow[b]{2}{*}{$\begin{array}{c}\text { Fracture } \\
\text { Origin } \\
\end{array}$} \\
\hline $\begin{array}{c}\text { Grit Size } \\
\text { Mesh (um) } \\
\end{array}$ & $\begin{array}{l}\text { No. of } \\
\text { Passes }\end{array}$ & & & & & & \\
\hline $150(100)$ & 5 & $\begin{array}{l}0.004 \\
0.00004 \\
\end{array}$ & $\begin{array}{c}10 \\
5 \\
\end{array}$ & $\begin{array}{l}352 \\
340 \\
\end{array}$ & $\begin{array}{l} \pm 29 \\
\pm 23 \\
\end{array}$ & $\begin{array}{l}13 \\
16 \\
\end{array}$ & $\begin{array}{c}10 \text { surf } \\
4 \text { surf, } 1 \text { edge } \\
\end{array}$ \\
\hline $320(45)$ & 40 & $\begin{array}{l}0.004 \\
0.00004 \\
\end{array}$ & $\begin{array}{c}10 \\
5\end{array}$ & $\begin{array}{l}383 \\
369 \\
\end{array}$ & $\begin{array}{l} \pm 23 \\
\pm 15 \\
\end{array}$ & $\begin{array}{l}17 \\
47 \\
\end{array}$ & $\begin{array}{l}9 \text { surf, } 1 \text { edge } \\
4 \text { surf, } 1 \text { edge }\end{array}$ \\
\hline $800(25)$ & 10 & $\begin{array}{l}0.004 \\
0.00004 \\
\end{array}$ & $\begin{array}{c}10 \\
5 \\
\end{array}$ & $\begin{array}{l}454 \\
422 \\
\end{array}$ & $\begin{array}{l} \pm 17 \\
\pm 52 \\
\end{array}$ & $\begin{array}{l}26 \\
12 \\
\end{array}$ & $\begin{array}{c}10 \text { surf } \\
3 \text { surf, } 2 \text { edge }\end{array}$ \\
\hline $1050(18.5)$ & 10 & $\begin{array}{l}0.004 \\
0.00004\end{array}$ & $\begin{array}{c}10 \\
5\end{array}$ & $\begin{array}{l}389 \\
432\end{array}$ & $\begin{array}{l} \pm 32 \\
\pm 24\end{array}$ & $\begin{array}{l}11 \\
26\end{array}$ & $\begin{array}{l}9 \text { surf, } 1 \text { edge } \\
5 \text { surf }\end{array}$ \\
\hline $1050(18.5)$ & 10 & $\begin{array}{l}0.004 \\
0.00004\end{array}$ & $\begin{array}{c}10 \\
5\end{array}$ & $\begin{array}{l}478 \\
438 \\
\end{array}$ & $\begin{array}{l} \pm 52 \\
\pm 91\end{array}$ & $\begin{array}{c}12 \\
6\end{array}$ & $\begin{array}{l}9 \text { surf, } 1 \text { edge } \\
4 \text { surf, } 1 \text { edge }\end{array}$ \\
\hline $1600(3-6)$ & 10 & $\begin{array}{l}0.004 \\
0.00004 \\
\end{array}$ & $\begin{array}{c}10 \\
5\end{array}$ & $\begin{array}{l}298 \\
337\end{array}$ & $\begin{array}{l} \pm 65 \\
\pm 48\end{array}$ & $\begin{array}{c}5 \\
12\end{array}$ & $\begin{array}{c}5 \text { surf, } 4 \text { edge/ } / 1 ? \\
4 \text { surf, } 1 \text { edge }\end{array}$ \\
\hline & & & & & & TOTALS: & $\begin{array}{c}76 \% \text { surf } \\
13 \% \text { edge } \\
1 \% ?\end{array}$ \\
\hline
\end{tabular}


Table 6. Flexural Strength of Hexoloy SA as a Function of Different Machining Methods

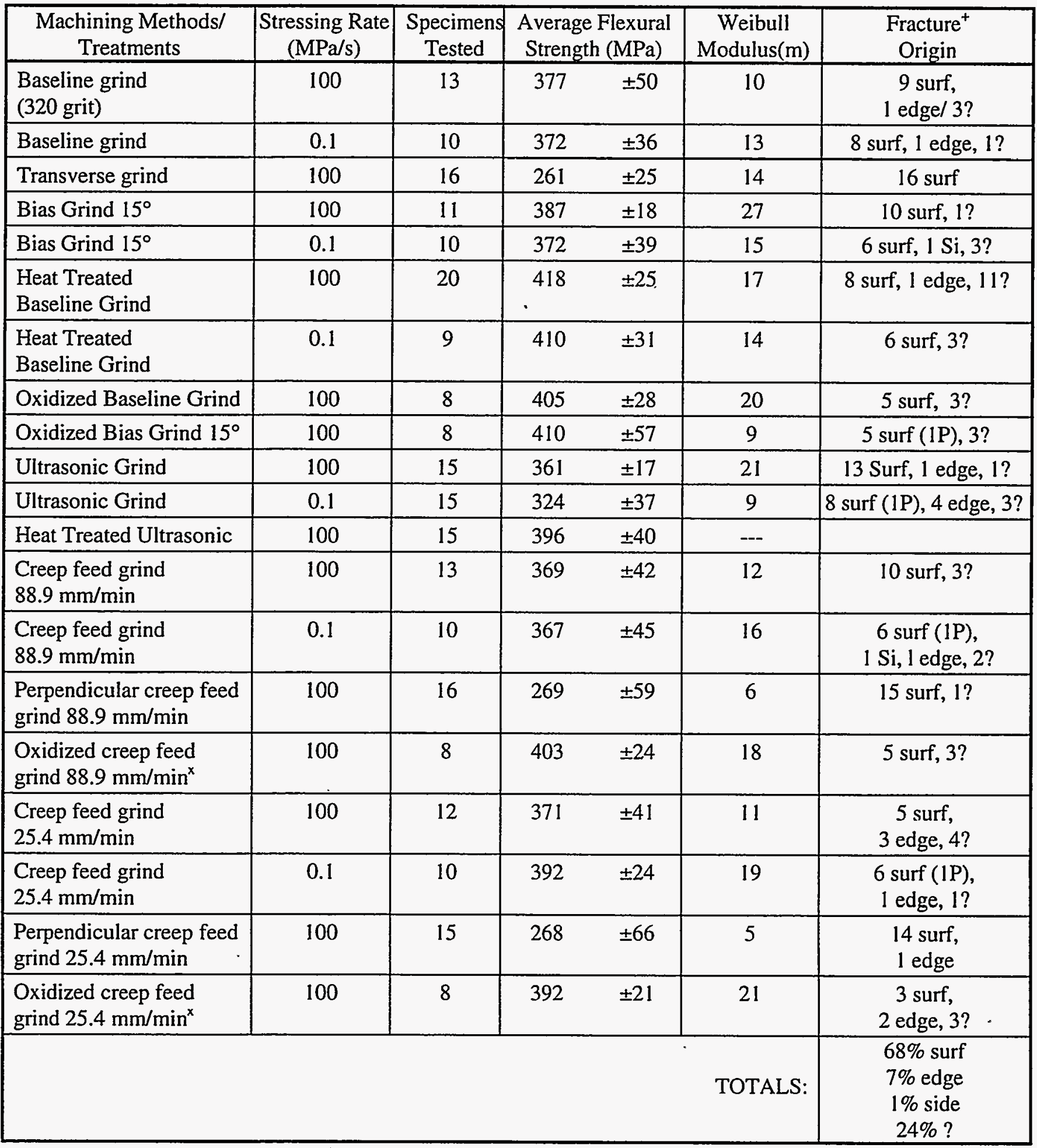

+ Fracture Origin Definitions:

Surf $=$ surface initiated fracture

$\mathrm{EG}=$ fracture initiation site at an elongated grain

$?=$ origin undetermined

$\mathrm{V}=$ volume initiated fracture

$\mathrm{Si}=$ side initiated fracture

Edge $=$ edge initiated fracture

$\mathrm{P}=$ fracture initiation site at a pit

I = Fracture initiation site at an inclusion 
Table 7. Flexural Strength of SN-252 Subjected to Different Machining Methods

\begin{tabular}{|c|c|c|c|c|c|c|}
\hline $\begin{array}{l}\text { Machining Methods/ } \\
\text { Treatments }\end{array}$ & $\begin{array}{c}\text { Stressing } \\
\text { Rate }(\mathrm{MPa} / \mathrm{s})\end{array}$ & \begin{tabular}{|c|} 
Sample \\
Population (n)
\end{tabular} & $\begin{array}{l}\text { Average } \\
\text { Strength }\end{array}$ & $\begin{array}{l}\text { xural } \\
\text { IPa) }\end{array}$ & $\begin{array}{l}\text { Weibull } \\
\text { Modulus } \\
(\mathrm{m})\end{array}$ & $\begin{array}{l}\text { Fracture } \\
\text { Origin }^{+}\end{array}$ \\
\hline $\begin{array}{l}\text { Baseline grind } \\
\text { ( } 320 \text { grit) }\end{array}$ & $\begin{array}{c}100 \\
0.1\end{array}$ & $\begin{array}{l}14 \\
10\end{array}$ & $\begin{array}{l}750 \\
698 \\
\end{array}$ & $\begin{array}{l} \pm 48 \\
\pm 83\end{array}$ & $\begin{array}{c}17 \\
9\end{array}$ & $\begin{array}{l}9 \text { surf (4 EG), 5?? } \\
8 \text { surf ( } 3 E G), 2 ?\end{array}$ \\
\hline Perpendicular grind & 100 & 15 & 753 & \pm 58 & 14 & $\begin{array}{c}6 \text { surf (4 EG), } \\
4 \text { edge, } 4 ?\end{array}$ \\
\hline Bias Grind $15^{\circ}$ & $\begin{array}{r}100 \\
0.1 \\
\end{array}$ & $\begin{array}{l}4 \\
4 \\
\end{array}$ & $\begin{array}{l}816 \\
683 \\
\end{array}$ & $\begin{array}{l} \pm 39 \\
\pm 44 \\
\end{array}$ & $\begin{array}{l}27 \\
19 \\
\end{array}$ & $\begin{array}{c}4 ? \\
1 \text { surf }(E G), 3 ?\end{array}$ \\
\hline $\begin{array}{l}\text { Baseline Grind } \\
\text { Heat Treated }\end{array}$ & $\begin{array}{r}100 \\
0.1 \\
\end{array}$ & $\begin{array}{l}19 \\
10 \\
\end{array}$ & $\begin{array}{l}661 \\
648 \\
\end{array}$ & $\begin{array}{l} \pm 43 \\
\pm 23 \\
\end{array}$ & $\begin{array}{l}15 \\
39 \\
\end{array}$ & $\begin{array}{c}12 \text { surf ( } 5 \mathrm{EG}), 3 \text { edge, } 4 \text { ? } \\
5 \text { surf }(\mathrm{EG}), 4 \text { edge, } 1 \text { ? }\end{array}$ \\
\hline $\begin{array}{l}\text { Baseline Grind } \\
\text { Oxidized }\end{array}$ & 100 & 10 & 530 & \pm 59 & -- & 8 edge, 1 surf, $1 ?$ \\
\hline $\begin{array}{l}\text { Creep feed grind } \\
88.9 \mathrm{~mm} / \mathrm{min}\end{array}$ & $\begin{array}{c}100 \\
0.1 \\
\end{array}$ & $\begin{array}{l}5 \\
5 \\
\end{array}$ & $\begin{array}{l}773 \\
742 \\
\end{array}$ & $\begin{array}{l} \pm 57 \\
\pm 81 \\
\end{array}$ & $\begin{array}{l}14 \\
10 \\
\end{array}$ & $\begin{array}{l}2 \text { surf (1 EG), } 3 \text { ? } \\
3 \text { surf, } 1 \text { edge, } 1 \text { ? }\end{array}$ \\
\hline Ultrasonic Grind & $\begin{array}{l}100 \\
0.1 \\
\end{array}$ & $\begin{array}{l}10 \\
1 \\
\end{array}$ & $\begin{array}{l}676 \\
701 \\
\end{array}$ & $\begin{array}{c} \pm 57 \\
- \\
\end{array}$ & $\begin{array}{r}19 \\
- \\
\end{array}$ & $\begin{array}{c}6 \text { surf (2 EG, } 1 \mathrm{I}) \\
3 \text { edge, } 1 ? \\
\text { Surf (EG) }\end{array}$ \\
\hline & & & & \multicolumn{2}{|c|}{ TOTALS: } & $\begin{array}{c}55 \% \text { surf }\left(-\frac{1}{3} E G\right) \\
10 \% \text { edge } \\
35 \% ?\end{array}$ \\
\hline
\end{tabular}

+ Fracture origin designation:

surf $=$ surface $\quad$ EG $=$ elongated grain $\quad ?=$ origin undetermined

The results of the Raman microprobe analysis for GS-44, CVD SiC, and Hexoloy SA are compiled in Tables 8 through 10. In Tables 8 and 9, only the Raman line width was measured at the major peak. In Table 10, both Raman line positions and Raman line widths are given for the strong transverse optical Raman line. Included in Table 10 are the Raman spectra for sintered and highly polished Hexoloy SA specimens and single crystal hexagonal $(6 \mathrm{H}) \mathrm{SiC}$. These spectra were added for purposes of comparison. 
Table 8. Raman Line Widths Measured for GS-44

\begin{tabular}{|l|c|}
\hline \multicolumn{1}{|c|}{ Machining Procedures } & Raman Line Width $\left(\mathrm{cm}^{-1}\right)$ \\
\hline Longitudinally Baseline Ground at Chand & $13.68 \pm 0.61$ \\
\hline Longitudinally Baseline Ground at ORNL & $5.46 \pm 81$ \\
\hline Creep feed Ground at ORNL & $13.63 \pm 1.29$ \\
\hline Transversely Ground at ORNL & $15.61 \pm 75$ \\
\hline
\end{tabular}

Table 9. Raman Line Widths Measured for CVD SiC

\begin{tabular}{|l|c|c|c|}
\hline $\begin{array}{c}\text { Grinding Wheel } \\
\text { Designation }\end{array}$ & $\begin{array}{c}\text { Abrasive grain } \\
\text { size (mesh) }\end{array}$ & $\begin{array}{c}\text { Grinding Wheel } \\
\text { Passes }\end{array}$ & $\begin{array}{c}\text { Raman Line width } \\
\left(\mathrm{cm}^{-1}\right)\end{array}$ \\
\hline Norton SD 150 & 150 & 5 & $3.20 \pm 0.19$ \\
\hline Norton SD 320 & 320 & 40 & $3.45 \pm 0.15$ \\
\hline CGD 500 & 800 & 10 & $3.11 \pm 0.10$ \\
\hline Norton SD 800 R50 & 1050 & 10 & $3.05 \pm 0.15$ \\
\hline Norton SD 800 R 75 & 1050 & 10 & $2.87 \pm 0.14$ \\
\hline Norton D 3/6 & 1600 & 10 & $2.83 \pm 0.12$ \\
\hline
\end{tabular}

Table 10. Raman Line Widths and Positions Measured for Hexoloy SA at, $788.08 \mathrm{~cm}^{-1}$

\begin{tabular}{|c|c|c|}
\hline Specimen & Position (Change in Position) $\left(\mathrm{cm}^{-1}\right)$ & Width $\left(\mathrm{cm}^{-1}\right)$ \\
\hline Base Line & $788.332 \pm 0.004(+0.247)$ & $5.27 \pm 0.01$ \\
\hline $15^{\circ}$ Bias & $788.327 \pm 0.003(+0.242)$ & $5.251 \pm 0.009$ \\
\hline Ultrasonic & $788.474 \pm 0.007(+0.389)$ & $4.97 \pm 0.01$ \\
\hline Creep Feed 88.9 $\frac{\mathrm{mm}}{\mathrm{min}}$ & $788.151 \pm 0.005(+0.065)$ & $4.660 \pm 0.006$ \\
\hline Creep Feed 25.4 $\frac{\mathrm{mm}}{\mathrm{min}}$ & $788.092 \pm 0.004(+0.006)$ & $4.642 \pm 0.007$ \\
\hline Heat Treated & $788.114 \pm 0.004(+0.029)$ & $4.54 \pm 0.01$ \\
\hline Oxidized & $788.145 \pm 0.005(+0.060)$ & $4.742 \pm 0.008$ \\
\hline Highly Polished & $788.123 \pm 0.002(+0.038)$ & $4.361 \pm 0.005$ \\
\hline As-Sintered & $788.085 \pm 0.006(0.000)$ & $4.35 \pm 0.01$ \\
\hline Single Crystal & $788.54 \pm 0.01(+0.45)$ & $2.294 \pm 0.003$ \\
\hline
\end{tabular}


The Raman line widths shown in Table 8 correlated well with the flexural strengths measured for GS-44. The specimens ground with the finer abrasive grains had lower residual strain and higher strengths. Raman microprobe results for the CVD SiC (Table 9) were similar to those for GS-44. Raman line widths decreased as abrasive grit size decreased. The largest line width (highest residual strain) was obtained for CVD SiC specimens subjected to excessive grinding passes (40 passes). Using the data from Tables 5 and 9, the strength values and Raman line width were plotted and are presented in Figure 5.

The flexural strengths measured for the Hexoloy SA specimens that were heat treated, exposed to an oxidizing environment, or ground on a $15^{\circ}$ bias were higher than the flexural strengths measured for the baseline specimens. Specimens machined in the transverse direction or ultrasonically ground had flexural strengths lower than the baseline machined specimens. Creep feed ground specimens had flexural strengths equivalent to the baseline ground specimens. The Raman data for Hexoloy SA specimens (Table 10) indicates some interesting correlations with the flexural strength data. This is particularly true for the line width data. Correlations with the line shift data, while more complex show that the machined specimens as compared to the "as-sintered" specimens all have residual compressive strains. Since the single crystal specimens are transparent, these values are for the bulk of the material. The sintered and highly polished specimens show very low residual strain. However, the reported flexural strengths for the assintered and very highly polished specimens are lower than the baseline ground specimens. Heat treated and oxidized specimens show lower residual strain than the baseline specimens and have higher flexural strength. Specimens machined on a $15^{\circ}$ bias had slightly lower levels of residual strain and slightly higher flexural strength than the baseline ground specimens. Ultrasonically ground specimens had lower residual strain and also lower flexural strengths. The creep feed 
ground specimens had significantly lower residual strain and flexural strengths equivalent to the baseline. This effect is attributed to a narrower damage distribution at the specimen surface. Using the data from Tables 6 and 10 the flexural strength values and Raman line width or line shift at the $788 \mathrm{~cm}^{-1}$ were plotted and are presented in Figures 6 and 7, respectively.

Surface roughness of the Hexoloy SA specimens subjected to different machining treatments was measured in the transverse and longitudinal directions. The results of these measurements are compiled in Table 11. The data obtained was insufficient to established strong correlations between the surface roughness and the flexural strengths measured. It did appear, however, that flexural strength tended to decrease with increasing transverse surface roughness measurements.

Table 11. Surface Roughness Measurements of Hexoloy SA Specimens Subject to Different Machining Treatments

\begin{tabular}{|c|c|c|c|}
\hline Machining Methods/Treatments & $\begin{array}{c}\text { Average } \mathrm{R}_{\mathrm{a}} \text { in the } \\
\text { Transverse } \\
\text { direction }(\mu \mathrm{m})\end{array}$ & $\begin{array}{c}\text { Average } \mathrm{R}_{\mathrm{a}} \text { in the } \\
\text { longitudinal } \\
\text { direction }(\mu \mathrm{m})\end{array}$ & $\begin{array}{c}\text { Flexural } \\
\text { Strength } \\
(\mathrm{MPa})\end{array}$ \\
\hline Baseline grind ( 320 grit) & 0.007 & 0.9 & 377 \\
\hline Perpendicular grind & 1.62 & 0.2 & 261 \\
\hline Bias Grind $15^{\circ}$ & 0.64 & 0.4 & 387 \\
\hline Oxidized Baseline Grind & -- & 0.65 & 418 \\
\hline Oxidized Bias Grind $15^{\circ}$ & --- & 0.9 & 410 \\
\hline Ultrasonic Grind & 1.79 & 2.5 & 361 \\
\hline Creep feed grind $88.9 \mathrm{~mm} / \mathrm{min}$ & 1.92 & 0.6 & 369 \\
\hline $\begin{array}{l}\text { Perpendicular creep feed grind } \\
89.9 \mathrm{~mm} / \mathrm{min}\end{array}$ & 2.69 & 0.3 & 269 \\
\hline $\begin{array}{l}\text { Oxidized creep feed grind } \\
88.9 \mathrm{~mm} / \mathrm{min}^{\mathrm{x}}\end{array}$ & --- & 1.0 & 403 \\
\hline Creep feed grind $25.4 \mathrm{~mm} / \mathrm{min}$ & 1.5 & 0.5 & 371 \\
\hline $\begin{array}{l}\text { Perpendicular creep feed grind } \\
25.4 \mathrm{~mm} / \mathrm{min}\end{array}$ & 1.4 & 1.9 & 268 \\
\hline $\begin{array}{l}\text { Oxidized creep feed grind } \\
25.4 \mathrm{~mm} / \mathrm{min}\end{array}$ & --- & 1.1 & 392 \\
\hline
\end{tabular}




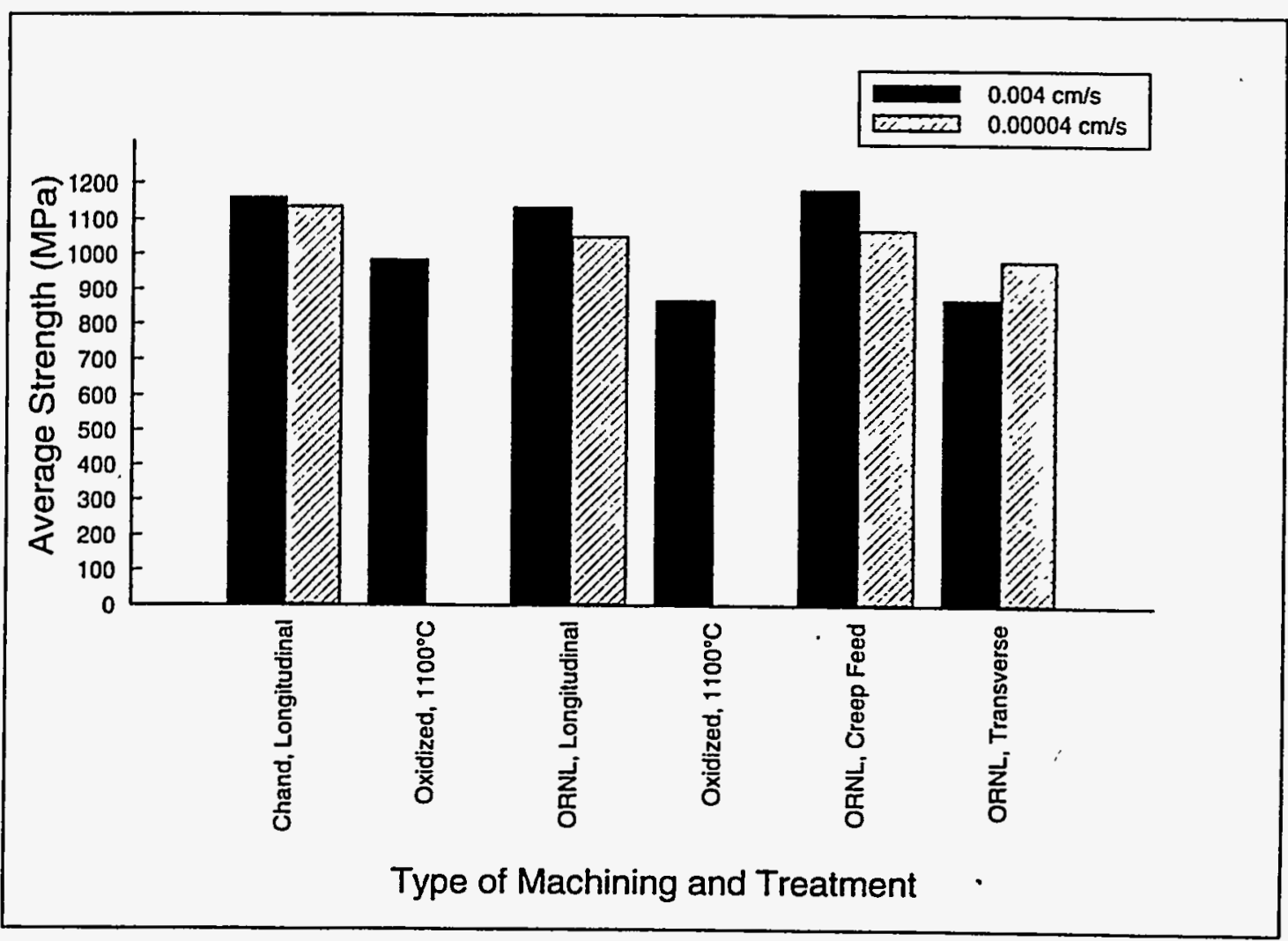

Figure 1. Flexural Strength of GS-44 for Different Machining Methods

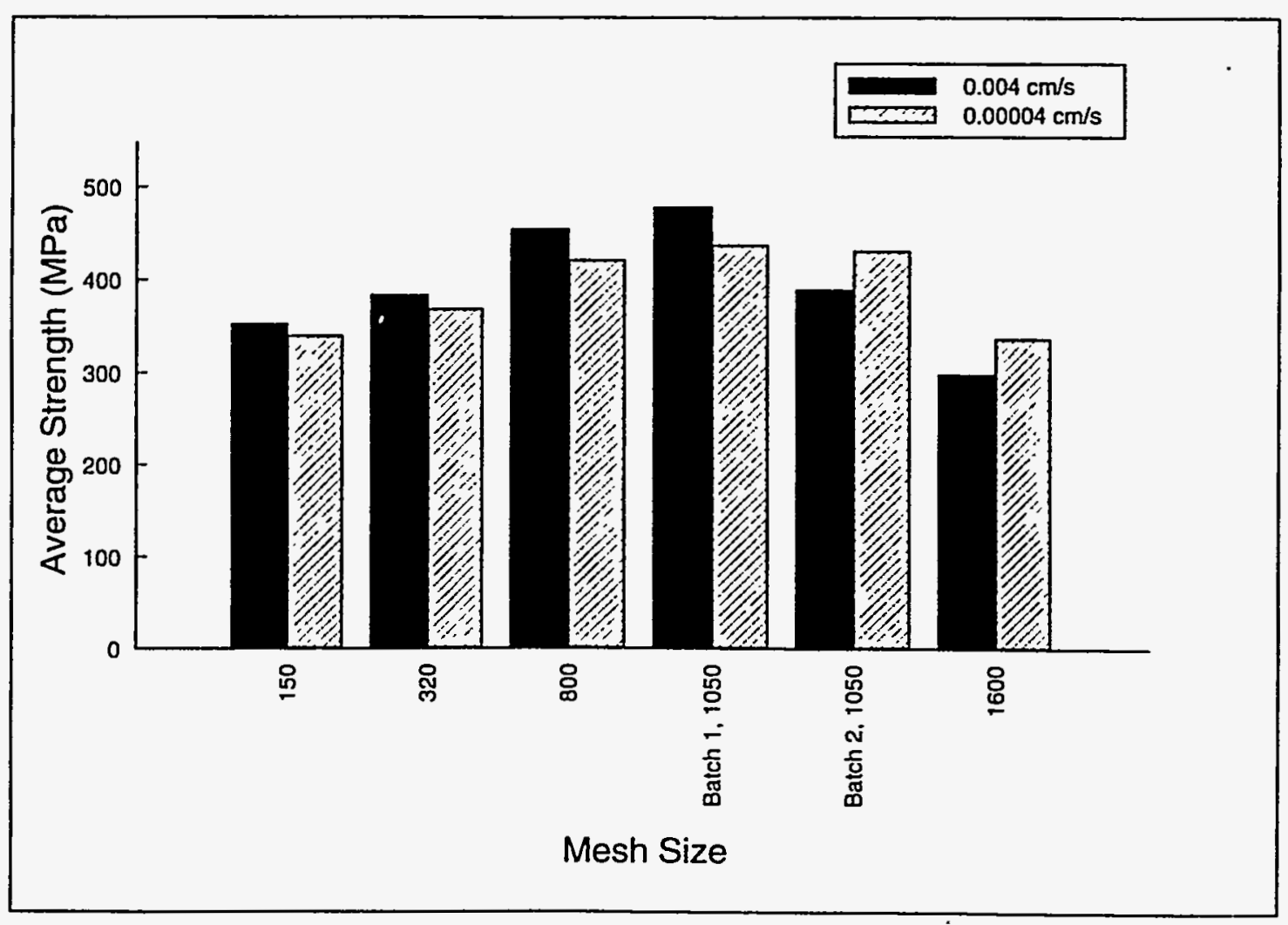

Figure 2. Flexural Strength of CVD SiC for Different Maching Methods 


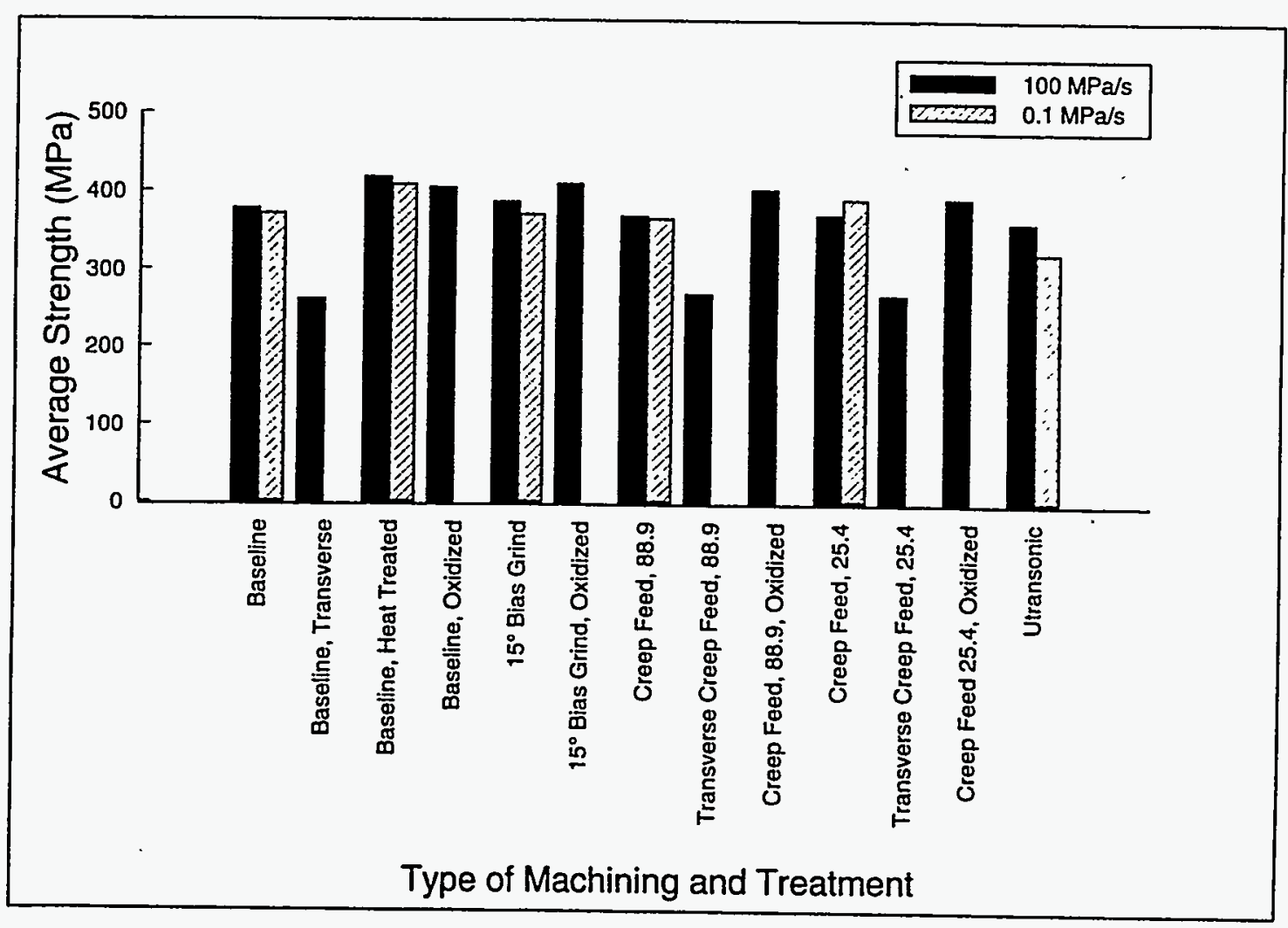

Figure 3. Flexural Strength of Hexoloy SA for Different Machining Methods

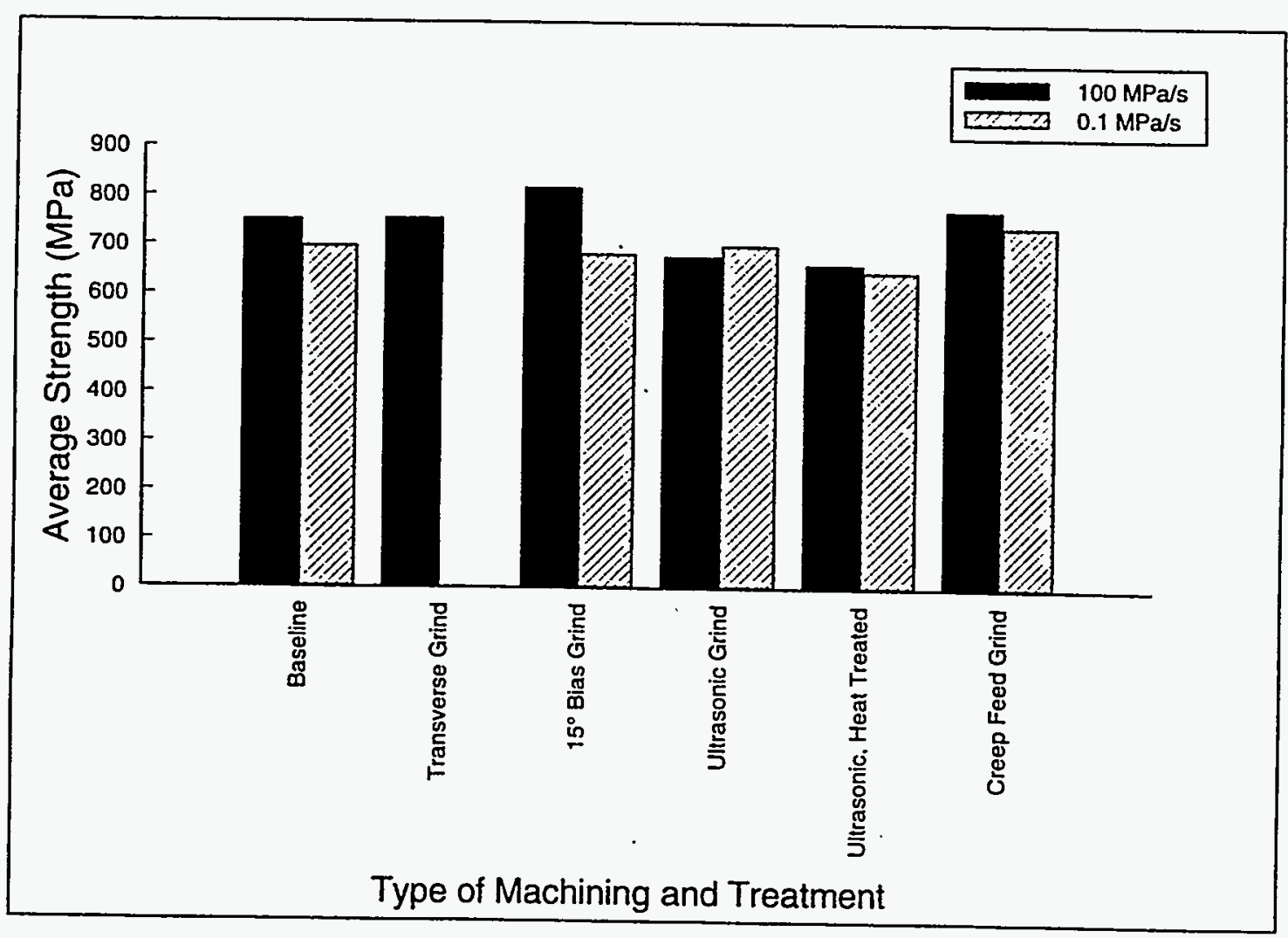

Figure 4. Flexural Strength of SN-252 for Different Machinging Methods 


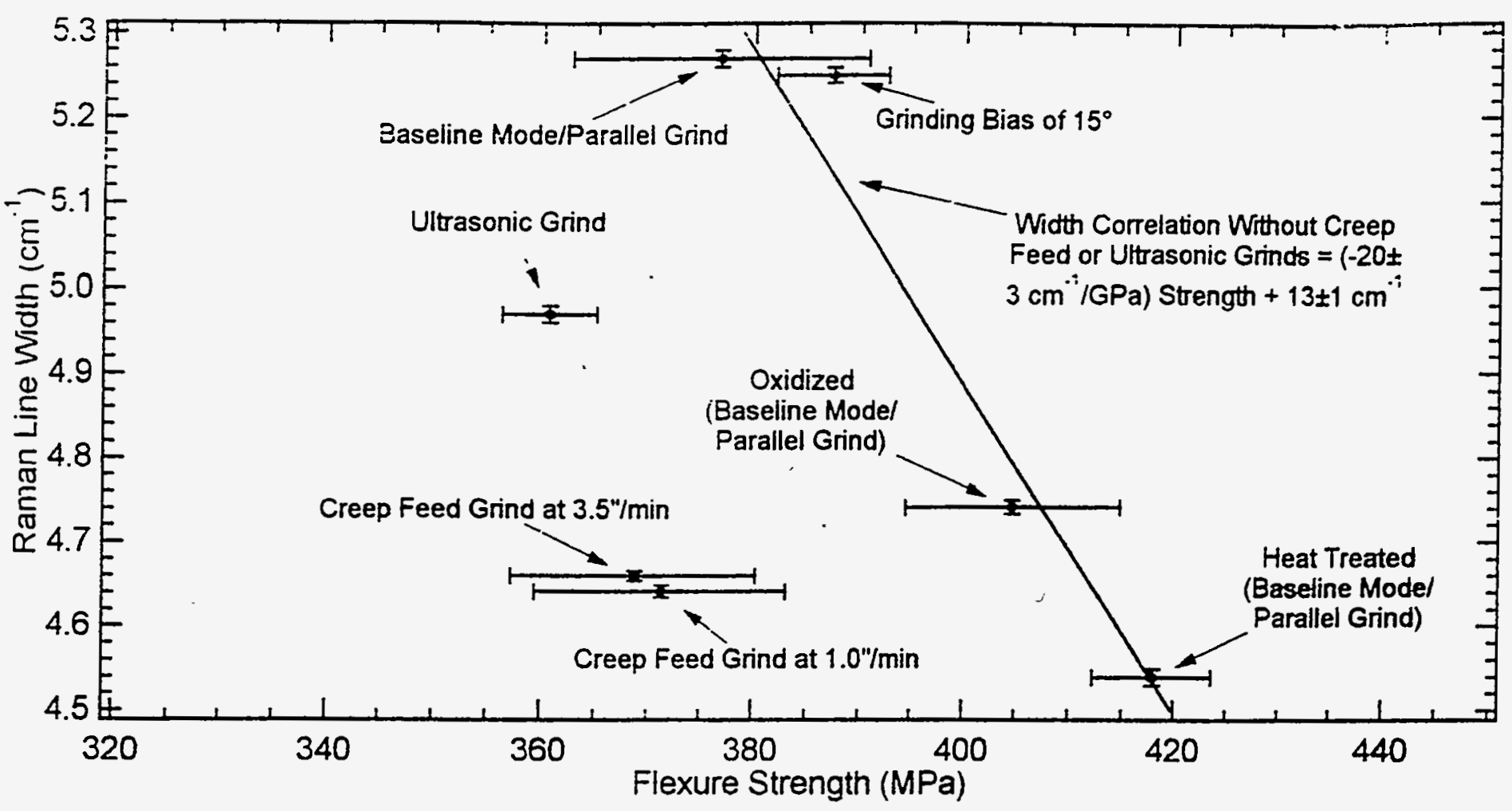

Figure 6. Correlation of the $788 \mathrm{~cm}^{-1}$ Raman Line Width with the Flexure Strength of Seven Types of $6 \mathrm{H} \mathrm{SiC} \mathrm{Ceramic} \mathrm{Specimens.}$

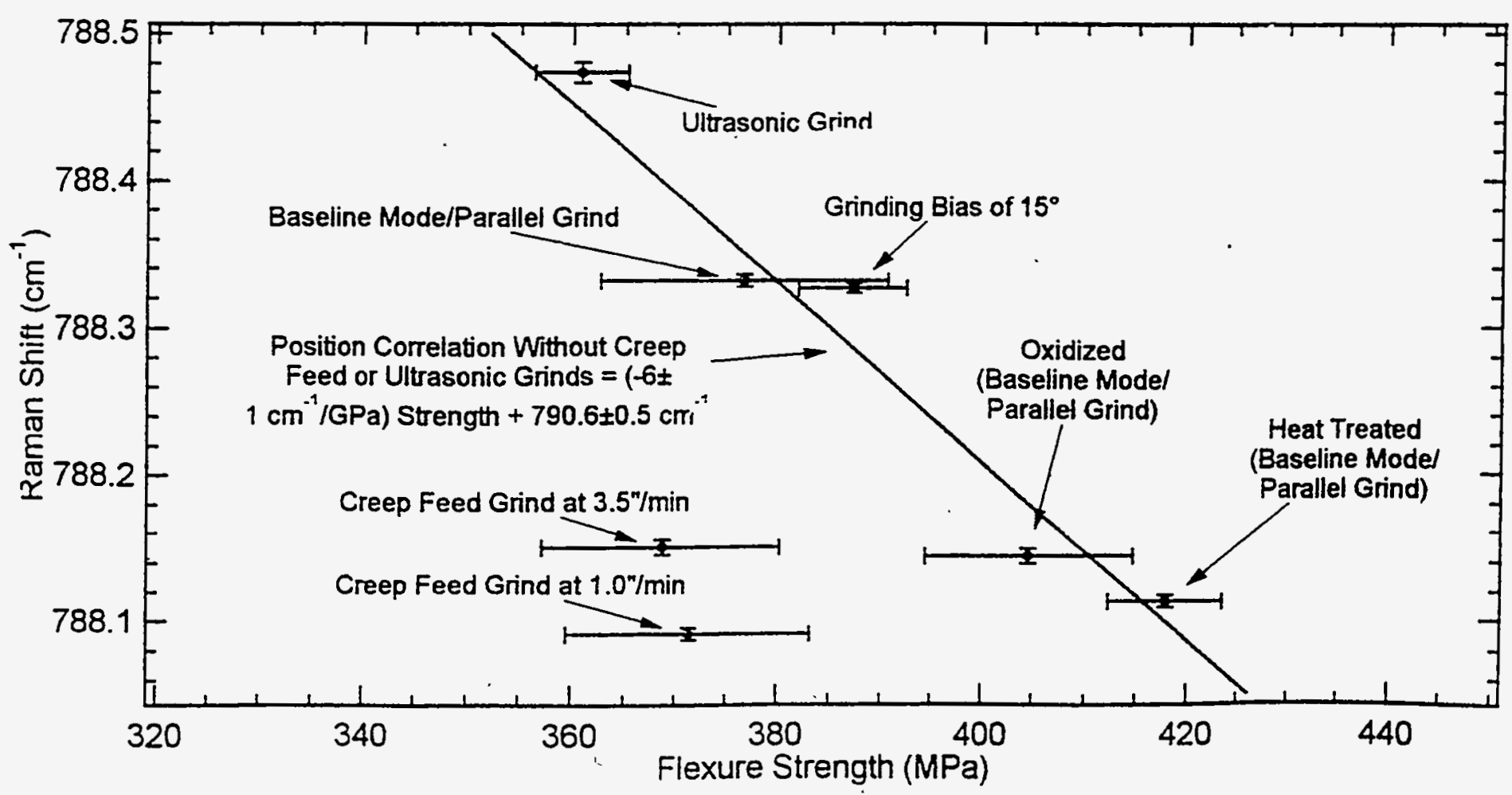

Figure 7. Correlation of the $788 \mathrm{~cm}^{-1}$ Raman Shift with the Flexure Strength of Seven Types of 6H SiC Ceramic Specimens. 


\section{Concluding Comments}

In these studies the effects of machining treatments on the mechanical behavior of two $\mathrm{SiC}$ and two $\mathrm{Si}_{3} \mathrm{~N}_{4}$ ceramics were investigated. Machining treatments were correlated with flexural strength and Raman spectroscopy was used as a tool to monitor residual strain due to machining treatment. The results of these investigations have demonstrated that there are significant correlations between machining treatments and measured strengths. In addition, the data obtained from the Raman microprobe analyses demonstrated the value of this equipment to gain a better understanding of the residual strains generated in the surface of the machined specimens.

In general, it was found that the finer the size of the abrasive grains used, the higher the flexural strength, except for when the very finest abrasive grain size (1600 mesh) is used. Finer grinding media results in lower residual strain in the specimen surface. Transverse grinding tended to reduce flexural strength and grinding at a $15^{\circ}$ bias resulted in equivalent or slightly higher strengths than obtained for baseline grinding. Heat treatments or oxidation increased the average strength measured for $\mathrm{SiC}$ but resulted in lower strength measured for $\mathrm{Si}_{3} \mathrm{~N}_{4}$. Raman microprobe spectroscopy of Hexoloy SA SiC showed that the residual surface strain is reduced due to thermal treatments.

Test specimens subjected to ultrasonic machining had lower strengths. It was also observed that the specimens tested at the faster stressing rates had higher strengths than those tested at the slower stressing rates. The effect of stressing rate was small for the $\mathrm{SiC}$ specimens and was more pronounced in the $\mathrm{Si}_{3} \mathrm{~N}_{4}$ ceramics. In general, the surface roughness values were not very conclusive. 


\subsection{FRACTURE MECHANICS}

TESTING AND EVALUATION OF ADVANCED CERAMICS AT HIGH TEMPERATURE

J. Sankar, A. D. Kelkar, S. Srinivasan, and V. Vijayrao (Department of Mechanical Engineering, North Carolina A \& T State University, Greensboro, NC 27406).

\section{Objective/Scope}

The objective of this research is to test and evaluate the long-term mechanical reliability of a $\mathrm{Si}_{3} \mathrm{~N}_{4}$ at temperatures up to $1300^{\circ} \mathrm{C}$.

The required research includes four (4) major tasks:

\section{Task 1. Cyclic Fatigue Testing of PY6}

Cyclic fatigue of GTE-PY6 silicon nitride shall be performed at lower temperatures to investigate $500^{\circ}-1100^{\circ} \mathrm{C}$ characteristics of the material at this temperature range. At these lower temperatures, there may be a true cyclic fatigue effect which enhances failure compared with the static load case.

\section{Task 2. Stress - Rupture Study of PY6}

Stress-rupture testing of GTE PY6 silicon nitride shall be performed at a lower temperature range of $500^{\circ}-1100^{\circ} \mathrm{C}$. Since there is little information about the time dependent behavior of this material is available at this temperature regime, this task should provide some valuable data.

\section{Task 3. Tensile Testing of GS 44}

Pure Uniaxial tensile testing of GS 44 silicon nitride will be carried out at both room and elevated temperature up to $1200^{\circ} \mathrm{C}$. The obtained data will be compared with other silicon nitride materials.

\section{Task 4 4. Stress - Rupture Study of GS 44}

Stress-rupture testing of GS 44 silicon nitride will be performed at various temperatures and stresses. 


\section{Technical Highlights}

\section{Creep Testing}

During this reporting period, creep tests were performed on GS-44 silicon nitride material. The testing temperatures were $1275^{\circ} \mathrm{C}, 1200^{\circ} \mathrm{Cand} 1100{ }^{\circ} \mathrm{C}$. The test was also performed for different loading conditions, namely $80 \mathrm{Mpa}, 100 \mathrm{MPa}$ and $120 \mathrm{MPa}$. Creep curves were generated from the tests for this material system (creep strain vs time for the given load). The time and stress dependencies of the tensile creep strain rates at $1200{ }^{\circ} \mathrm{C}$, and $1275^{\circ} \mathrm{C}$ are shown in Figure 1(a) and 1(b). Further, some tests were stopped during the secondary creep stage and were tested for tensile residual strength. All the residual strength tests were carried out at room temperature.

The long-time testing of materials for use in high temperature environments is limited due to practical considerations. Because of this reason, one should be able to determine the long-term life of a material using the data from a test which is conducted for a limited time period.

In a creep test the steady state creep rate dominates the overall behavior. The relationship between creep rate $\left(\varepsilon_{\mathrm{s}}\right)$ and rupture life $\left(\mathrm{t}_{\mathrm{f}}\right)$ is given as

$\log t_{f}+m \log \varepsilon_{s}=C$

where $t_{f}$ is the rupture life, $\varepsilon_{s}$ is the steady state creep rate, and $m$ and $C$ are constants. This relation known as Monkman equation can be derived by plotting rupture time versus minimum creep strain rate (log-log plot). The slope of the curve is $m$ and the intercept is $C$. To derive this relationship a mimimum of three test conditions are required.

Some samples were thermaly soaked at $1200^{\circ} \mathrm{C}$ for the same time as the creep tests. After the completion of the thermal soaking, the samples were tested for tensile residual strength at room temperature. The above process allows us to study the effect of creep at high temperature on the residual tensile strength of the material. The soaking time was varied between $32 \mathrm{hrs}$ and $217 \mathrm{hrs}$. Stress vs Strain plots were generated from the data obtained. The test conditions and the residual strengths at room temperature are shown in Table 1.

\section{Fatigue Testing}

Cyclic fatigue tests were performed on GS-44 $\mathrm{Si}_{3} \mathrm{~N}_{4}$. The temperature during the test was maintained at $1100^{\circ} \mathrm{C}$. The tests were performed in tension/tension $(\mathrm{T} / \mathrm{T})^{\circ}$ mode. A triangular waveform was used to determine and control the frequency and stress 
amplitude during testing. All tests were performed until failure occured. The fatigue limit of the sample was determined using the emperical formula:

$$
\sigma_{\mathrm{fl}}=70 \% \sigma_{\text {uts }} \text {. }
$$

where $\sigma_{\mathfrak{n}}$ is the maximum fatigue stress limit and $\sigma_{\mathrm{uts}}$ is the ultimate tensile strength at that temperature.

Also, the tests were performed at various stress levels including $70 \% \sigma_{\text {uts }}, 60 \% \sigma_{\text {uts }}$ and $50 \% \sigma_{\text {uts }}$ to enable us to determine the S-N curve for GS-44 at $1100^{\circ} \mathrm{C}$ (Fig. 3 ).

Table 1. Comparison fo Residual Strength for GS44 under different Conditions

\begin{tabular}{|c|c|c|}
\hline \multicolumn{2}{|c|}{ Room Temp Strength } & $=631 \mathrm{MPa}$ \\
\hline & Strength @, 1200C & $=450 \mathrm{MPa}$ \\
\hline \multicolumn{2}{|c|}{ Condition } & $\begin{array}{c}\text { Residual Strength @ } \\
\text { Room Temp(MPa) }\end{array}$ \\
\hline 1 & $\begin{array}{c}\text { Creep : 1100C, } \\
100 \mathrm{MPa} \\
-217 \mathrm{hrs}\end{array}$ & 472.121 \\
\hline 2 & $\begin{array}{c}\text { Creep : 1200C, } \\
\text { 100MPa } \\
-32 \mathrm{hrs}\end{array}$ & 525.781 \\
& $\begin{array}{c}\text { Thermal Soaking: } \\
1200 \mathrm{C}-32 \mathrm{hrs}\end{array}$ & 487.488 \\
\hline 3 & $\begin{array}{c}\text { Thermal Soaking : } \\
\text { 1200C - } 108 \mathrm{hrs}\end{array}$ & 531.372 \\
\hline
\end{tabular}

Effect of Oxidation on Sintered Silicon Nitride

Since the source of the specimen failure during creep testing is due to the stress oxidation damage zone which occurs when the test temperature is increased and the stresses are kept relatively low. Only $15-35 \%$ of the tensile strength was applied at high temperatures for the creep tests performed. In order to find the effect of oxidation the creep tested specimens were cut within their gage sections and metallographically polished to a $0.30 \mu \mathrm{m}$ finish. The polished cross-sections of the creep specimens tested at $1200{ }^{\circ} \mathrm{C}$ and $1275^{\circ} \mathrm{C}$ are shown in Figure 4. To study the effect of oxidation alone without any creep stress the specimens were thermally soaked for different periods of time at $1275^{\circ} \mathrm{C}$. Figure 5 shows the effect of oxidation for $16,24,32$ and $40 \mathrm{hrs}$ of thermal soaking.

\section{RESULTS AND DISCUSSION}


From Figure la (creep strain vs time at $1200^{\circ} \mathrm{C}$ and $120 \mathrm{Mpa}, 100 \mathrm{MPa}$, and 80 $\mathrm{MPa}$ of GS44), it can be seen that one of the specimen which was tested at $1200{ }^{\circ} \mathrm{C}$ and $100 \mathrm{MPa}$ broke in $5 \mathrm{hrs}$. This clearly shows that the properties of GS44 can vary from specimen to specimen. The GS-44 sample which was exposed to a constant load of 120 $\mathrm{MPa}$ at $1200^{\circ} \mathrm{C}$ exhibited a much higher strain rate than the one at $100 \mathrm{MPa}$. Figure 2 shows the creep strain rate for GS44 at different stress levels. Here, the secondary creep strain rate is increasing with an increase in the stress level. The Monkman equation will be plotted to after completion of creep tests for one more temperature. From this one can determine the effect of temperature on creep strain rate. Thermal soaking of the samples at the same temperature and time allows us to study the effect of creep on the room temperature residual strength. Based on the few tests performed, it was observed that the sample that had undergone creep $\left(1200{ }^{\circ} \mathrm{C}, 32 \mathrm{hrs}, 100 \mathrm{MPa}\right)$ had a higher room temperature residual strength than the thermaly soaked sample $\left(1200^{\circ} \mathrm{C}, 32 \mathrm{hrs}\right)$. More tests need to be performed to verify the above.

The residual strength of the sample which was tested at $1200^{\circ} \mathrm{C}$ after fatigue reduced from $450 \mathrm{MPa}$ to $200 \mathrm{MPa}$. But the sample which was tested for creep after fatigue showed a higher strain rate (Figure 1a) and much more resistance to creep. The dramatic reduction in the residual strength could be due to formation of cracks during the fatigue testing. But again the higher resistance to creep deformation could be due to the phase change from amorphous to crystalline. Obviously, we are observing two different behaviors for these fatigue samples. Our experience shows that this material GS44 behaves differently from sample to sample. Currently, tests are being performed to check the results we have obtained.

Figure 3 shows the S-N curve for GS-44. The data obtained from the high temperature fatigue tests $\left(1100^{\circ} \mathrm{C}\right)$ was plotted against the data obtained from ORNL. It can be seen from Fig. 5 that fatigue under tension/tension mode is detrimental to the material at high temperature. However, GS-44 shows more resistance to fatigue failure at $1100^{\circ} \mathrm{C}$ than at $1200^{\circ} \mathrm{C}$. This suggests that failure in GS-44 under fatigue mode is temperature dependent. It should be remembered here that most of these tests were performed between $50 \%$ and $70 \% \sigma_{\text {uts }}$ until failure. However, stress levels below $50 \%$ may not lead to failure as can be seen from Fig.2, which shows that below $50 \%$ of the ultimate tensile strength the curve levels off and is horizontal. More tests are being performed to verify the above.

As far as the effects of oxidation is concerned it can be seen from figure 4, both the creep specimens $\left(1200{ }^{\circ} \mathrm{C}\right.$, and $1275^{\circ} \mathrm{C}$ ) revealed three outer rings excluding the bulk interior region compared to the room temperature sample. The three outer rings consists of a thin white ring, darker ring, and a white oxide ring. The thickness of these annular rings were increasing with respect to temperature. The Vickers microhardness of the polished specimen was measured across the diameter. Figure 6 shows the resulting 
microhardness as a function of the radial distance. As it can be seen from the graph the microhardness is less in the outer rings than in the bulk interior. Since the specimens were tested in ambient air at elevated temperatures, the effect of oxidation will be higher and hence the less microhardness value in the outer rings. Comparing the microhardness between $1200{ }^{\circ} \mathrm{C}$ and $1275^{\circ} \mathrm{C}$ the microhardness value of $1275^{\circ} \mathrm{C}$ is well below the value at $1200^{\circ} \mathrm{C}$.

As can be seen from the figure 5, the outer rings thickness is increasing and it is approaching the center as the time is increased. Currently, these samples are being tested for microhardness to study the effect of oxidation.

\section{$\underline{\text { Status of Milestones }}$}

On schedule

\section{Communications/Visitors/Travel}

None

\section{Publications}

\section{Accepted for publication:}

J.Sankar, A.D.Kelkar, J.Neogi. "Fatigue, Creep and Fracture Behavior of Silicon Nitride Ceramics." ASME Winter Annual Meeting, San Francisco, Nov. 1995.

\section{References}

1. K.C. Liu, C.O. Stevens, and C.R. Brinkman, "Tensile cyclic fatigue of structural ceramics," Ceramic Technology Project Bimonthly Technical Progress Report, OctoberNovember 1995, pp. 37-40. 


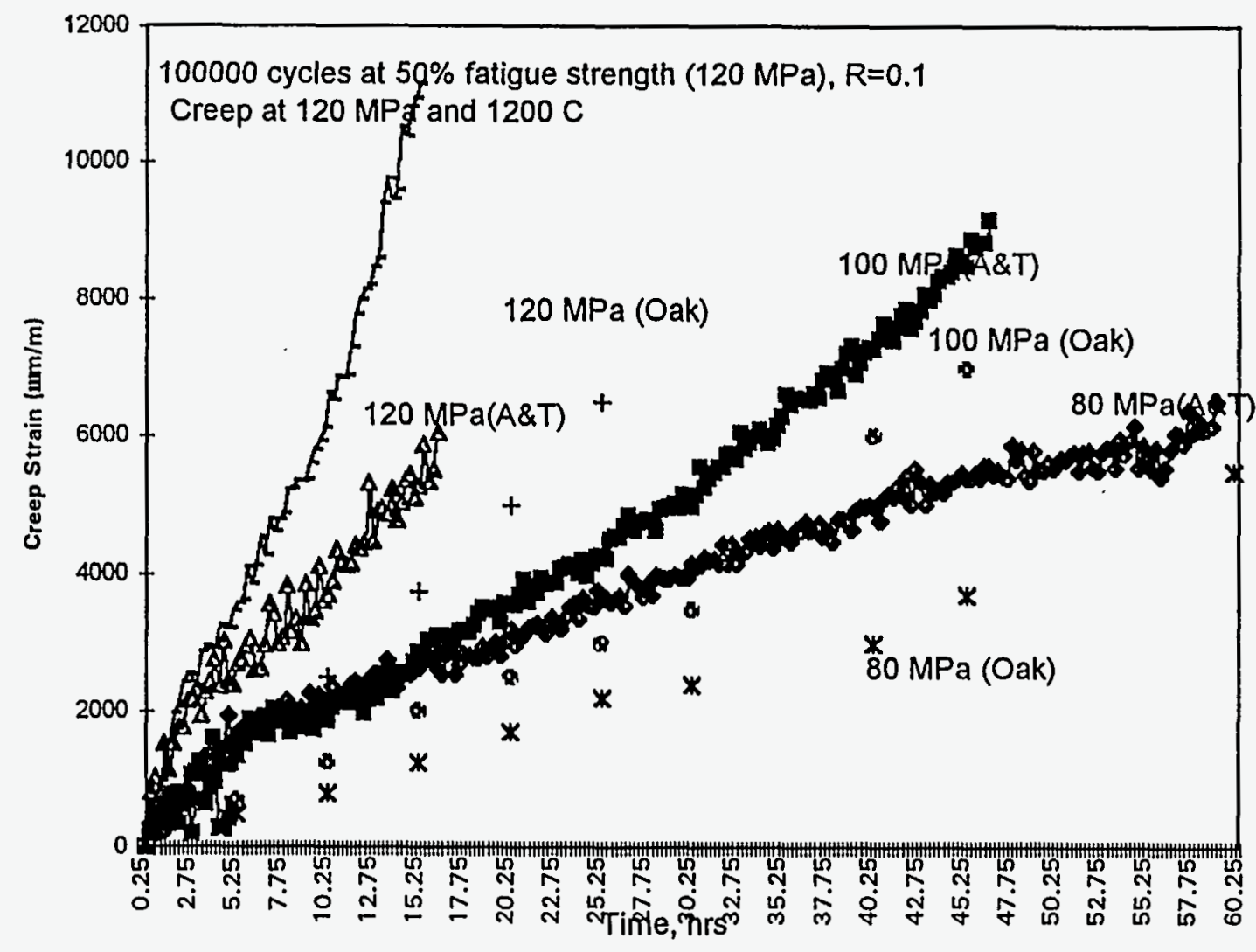

Figure 1a. Comparison of Creep strain vs time for GS44 tested at $1200 \mathrm{C}$ 


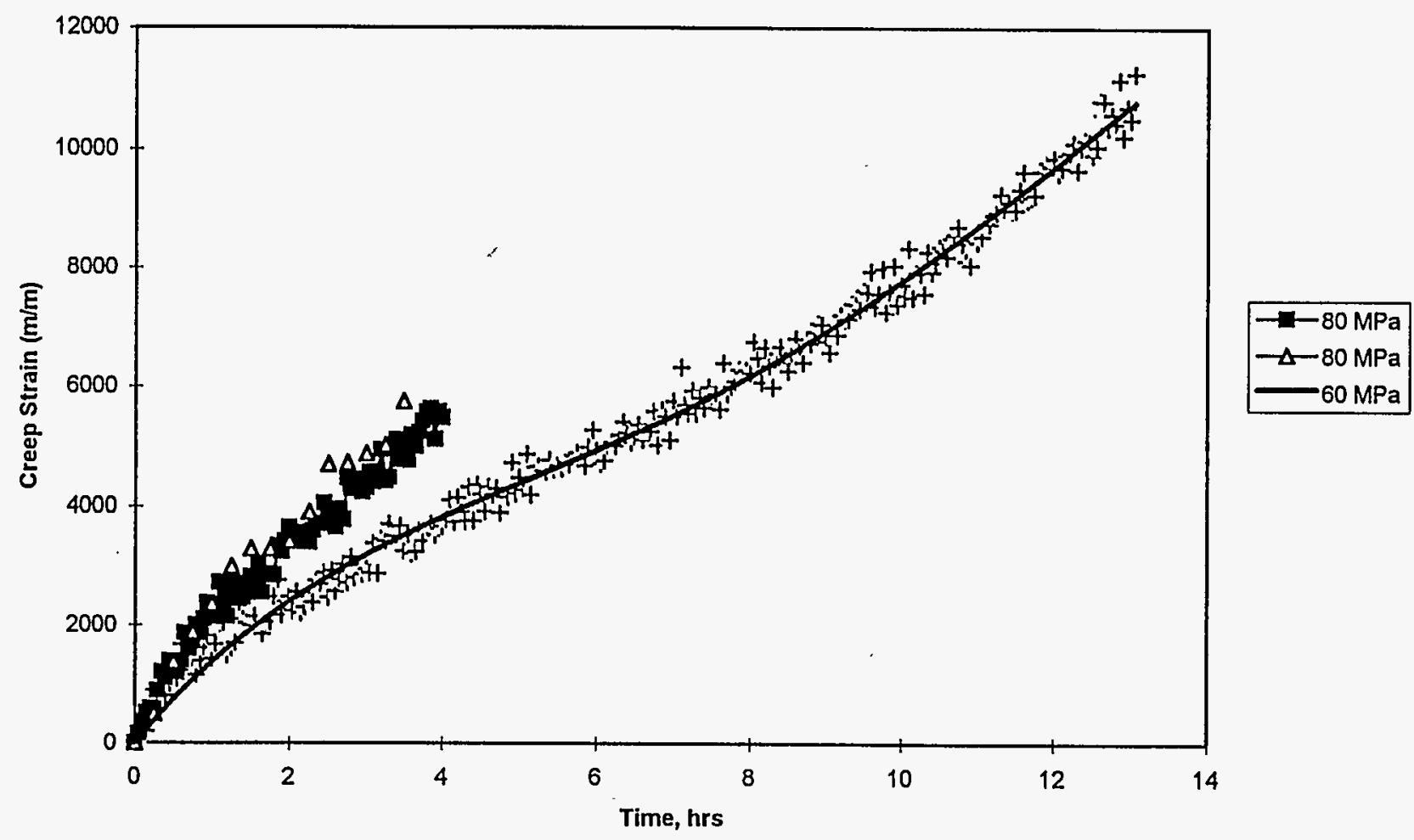

Figure 1b. Comparison of creep strain vs time for GS44 tested at $1275 \mathrm{C}$ 


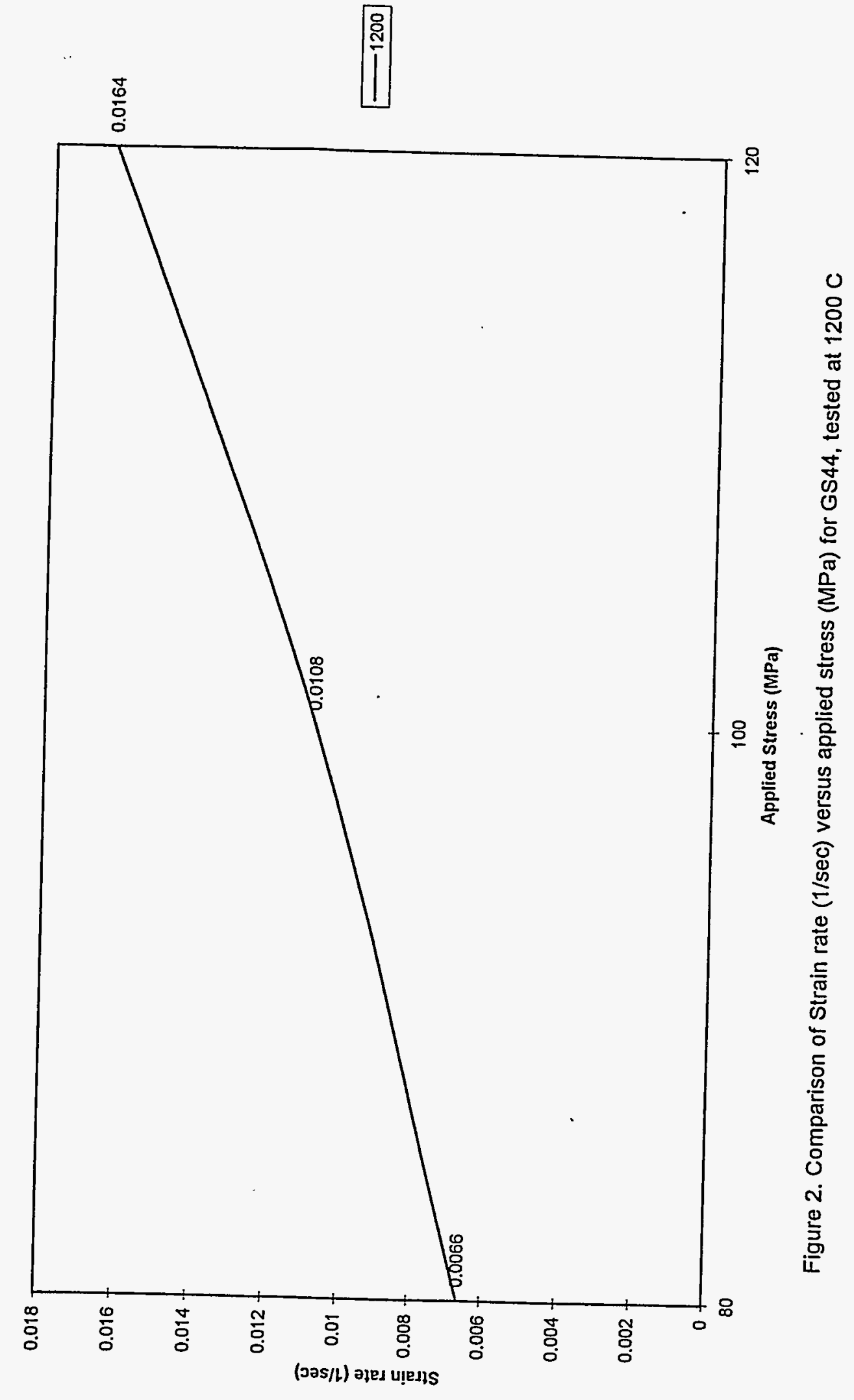




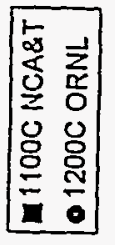

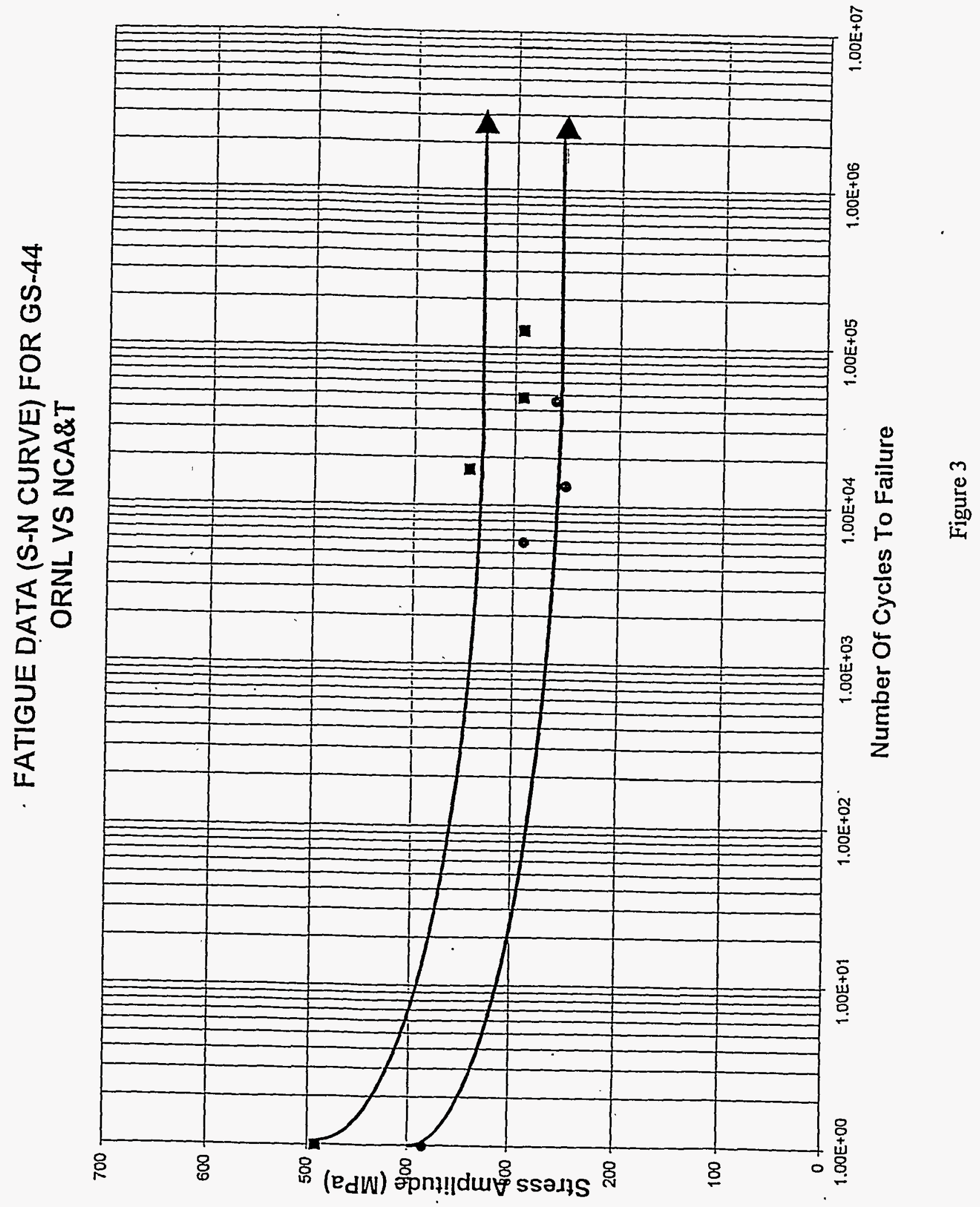



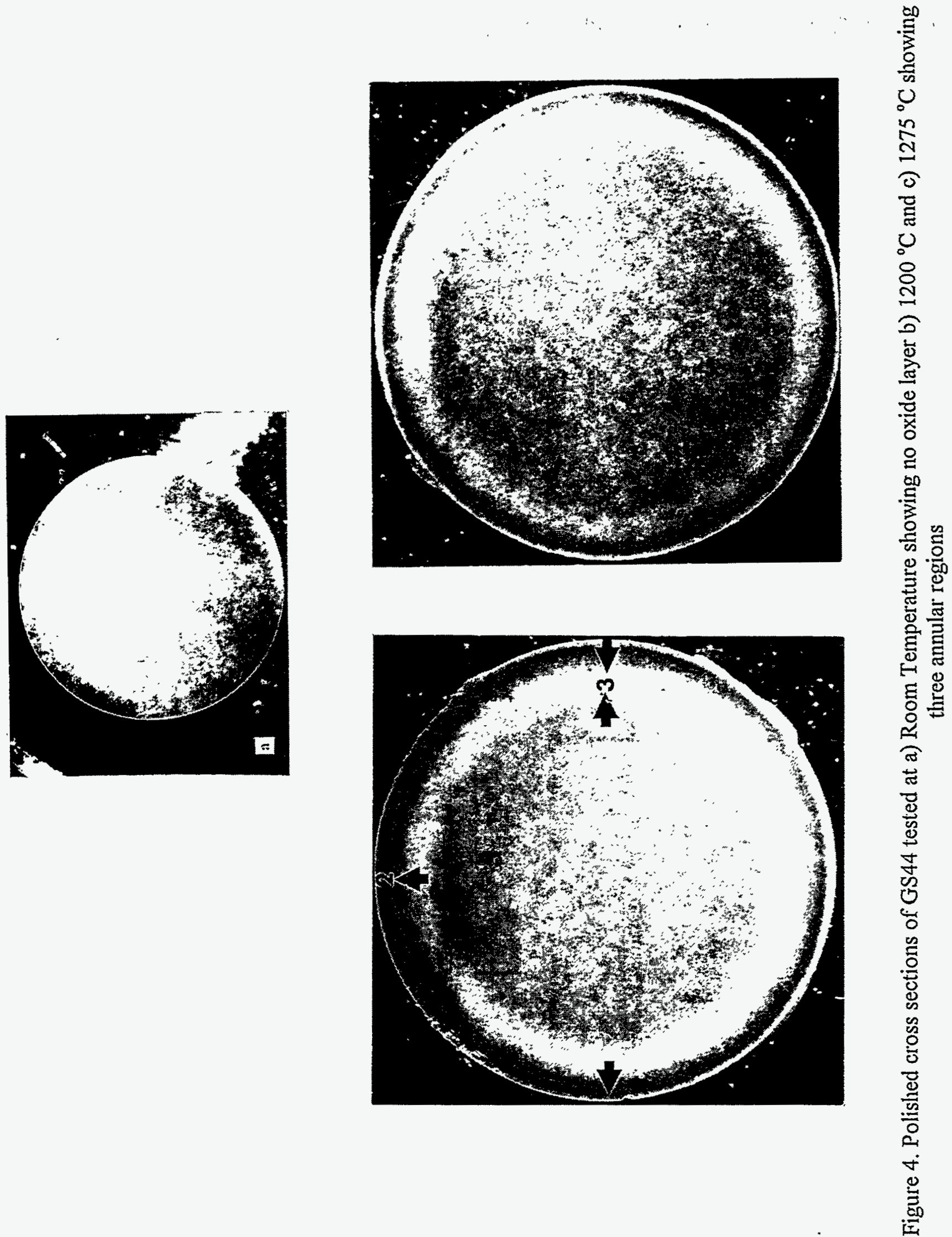

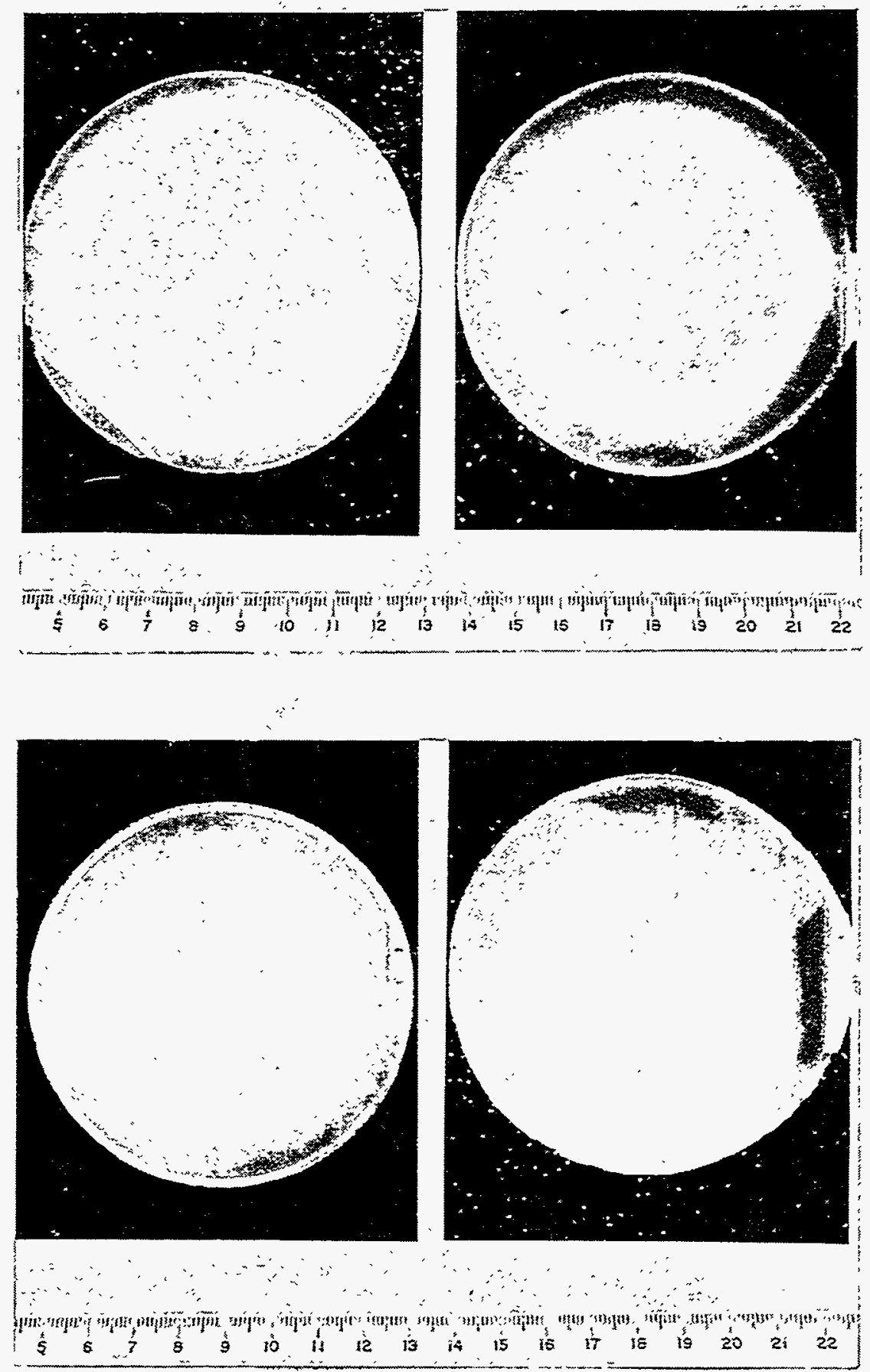

Figure 5. Polished cross sections of GS44 which was thermally soaked for 16, 24, 32, and $40 \mathrm{hrs}$ 
Surface of Specimen

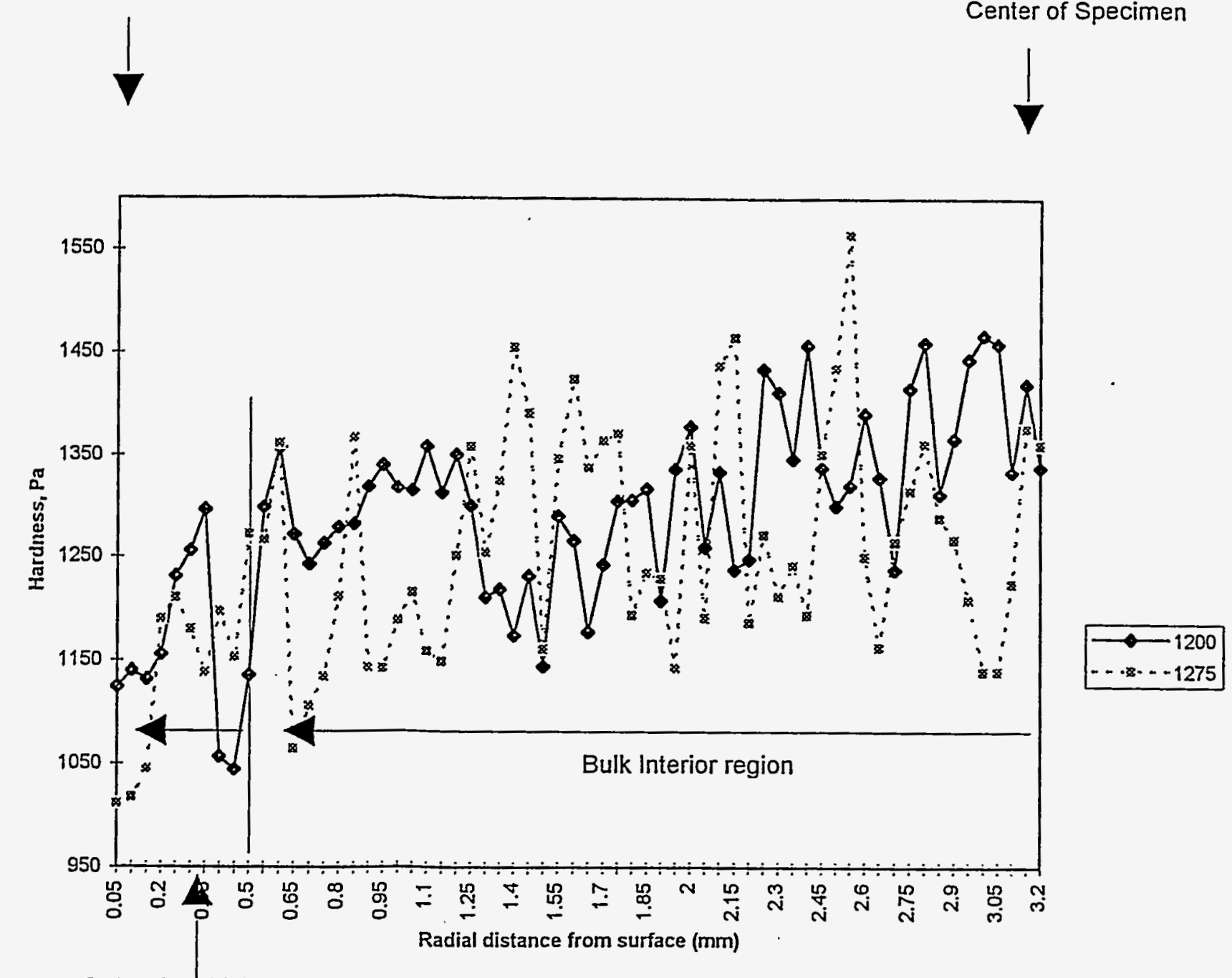

Center of Specimen

Outer ring thickness

Figure 6. Microhardness as a function of radial distance for GS44 tested at $120{ }^{\circ} \mathrm{C}$ and $1275^{\circ} \mathrm{C}$ 


\subsection{NONDESTRUCTIVE EVALUATION DEVELOPMENT}

Nondestructive Characterization

S. A. David (Oak Ridge National Laboratory)

\section{Objective/Scope}

The purpose of this program is to conduct nondestructive evaluation (NDE) development directed at identifying approaches for quantitative determination of conditions (including both properties and flaws) in ceramics that affect the structural performance. Those materials that have been seriously considered for application in advanced heat engines are all brittle materials whose fracture is affected by structural features whose dimensions are on the order of the dimensions of their microstructure. This work seeks to characterize those features using highfrequency ultrasonics and radiography to detect, size, and locate critical flaws and to measure nondestructively the elastic properties of the host material.

\section{Technical Progress}

Ultrasonics - W. A. Simpson, Jr.

We continued work on developing a nonlinear ultrasonic measurement system for characterization of advanced ceramics. There is growing evidence that material nonlinear response is very sensitive to changes occurring on the scale of the atomic lattice and that progressive damage in materials is reflected in a dramatic and monotonic increase of material nonlinearity, thus suggesting a basis for developing a predictive capability for material degradation. The measurement of elastic nonlinear response is much more difficult than that of the linear response, however, and generally requires high excitation powers and special transducers.

We have fabricated suitable quartz transducers for immersion nonlinear studies. Quartz was chosen as the element material on the basis of availability and very high $\mathrm{Q}$-factor. In our studies we transmit a quasi-monochromatic burst of high-power elastic wave energy and measure the second-harmonic energy produced by the ceramic nonlinearity with a separate transducer. Because the $Q$ of quartz is very high - as high as 50,000 under some conditions - the receiving transducer, which is tuned to twice the fundamental frequency, does not respond to the fundamental driving power at all. Conversely, the transmitting transducer produces elastic wave energy at the fundamental frequency and odd-harmonics only. Thus the detected secondharmonic energy originates entirely in the ceramic and may be measured without interference from the fundamental frequency. The units which we constructed have design frequencies of 5 $\mathrm{MHz}$ (transmitter) and $10 \mathrm{MHz}$ (receiver). Each element is enclosed in a phenolic case, edgemounted and air-backed for highest $Q$. Although the natural $Q$ of quartz is very high, the measured $Q$ in an ultrasonic system will be much lower because of both mechanical and electrical damping. In our system the observed $Q$ appears to be about 20 , which is sufficient to yield good rejection by the receiving transducer of the $5-\mathrm{MHz}$ fundamental. If conventional ultrasonic transducers are substituted instead, however, the low Q-factor (produced typically by damping the element heavily) means that the receiving transducer will respond to both the fundamental and second-harmonic energy simultaneously. For example, the measured response of one of our commercial $10-\mathrm{MHz}$ transducers at $5 \mathrm{MHz}$ was only about $20 \mathrm{~dB}$ below the response at $10 \mathrm{MHz}$. If this transducer were used to measure the second-harmonic energy (at $10 \mathrm{MHz}$ ) produced by a ceramic excited at $5 \mathrm{MHz}$, the fundamental response would greatly exceed that produced by true 
harmonic generation in the ceramic, reducing the sensitivity of the measurement. This situation could be improved by using a high-pass filter on the receiving transducer, but it is still possible that the broadband transmitting transducer could produce significant energy at the secondharmonic frequency.

Lithium niobate is also being examined as a possible candidate for fabricating suitable high-power transducers. It has good sensitivity and adequate selectivity for our purpose, but its mechanical stability is poor compared to quartz. Nevertheless, we are also discussing with two transducer vendors the possibility of fabricating units from lithium niobate elements.

We investigated the response of the $5-\mathrm{MHz} / 10-\mathrm{MHz}$ system using water, which is quite strongly nonlinear, as the coupling medium. Measurements of the second-harmonic amplitude were made as a function of both the fundamental driving amplitude and the propagation distance. In the latter case, the $10-\mathrm{MHz}$ harmonic amplitude could readily be seen to increase with transducer separation, in contrast to the usual case in linear ultrasonics in which the received signal amplitude decreases with increasing transducer separation. The nonlinear response as a function of both driving amplitude and propagation distance has been given previously; ${ }^{1}$ theory predicts that harmonic content increases linearly with propagation distance and quadratically with fundamental amplitude. The present configuration provided an excellent means of verifying this prediction.

Figure 1 shows the $10-\mathrm{MHz}$ harmonic amplitude as a function of propagation distance. The filled circles represent experimental data points, and the plotted line shows the predicted response. The harmonic amplitude was normalized to that obtained at the maximum transducer separation $(150 \mathrm{~mm})$, and the propagation distances were normalized to this value. As the figure shows, the measured results agreed quite well with theory.

Figure 2 shows the measured harmonic amplitude as a function of the amplitude of the fundamental wave. As before, filled circles represent experimental values, and the plotted line gives the predicted response. In obtaining these data, a high-power stepped attenuator was inserted in the line to the transmitting transducer, and measurements were taken at 2-dB increments of the applied voltage. Two independent measurements of the fundamental amplitude were available and agreed well with one another. As the figure shows, the harmonic amplitude dependence on driving amplitude was very nearly quadratic.

Theory also predicts that the harmonic amplitude increases quadratically with fundamental frequency, ${ }^{1}$ but this could not be verified with the hardware available in this study. Additional transducers having other frequencies will likely be constructed, as higher frequencies would definitely be advantageous for use in ceramics.

Although the present study was very useful for testing both our hardware and software, considerable work remains to be done before we can obtain accurate measurements of the nonlinearity parameter in ceramics. We still lack suitable contact transducers for such measurements, and it seems likely that we will have to fabricate our own. Nonlinearity measurements are far from standard in ultrasonics, and thus commercial hardware is not available. We have obtained piezoelectric elements of both quartz and lithium niobate which are suitable for fabricating the required transducers, but making such units in-house is expensive and time consuming. Accordingly, we are contacting possible vendors to determine if they can fabricate suitable transducers. 
As mentioned above, we noted previously that the amplitude of an elastic wave propagating in a solid is given by: ${ }^{2}$

$$
\xi=A_{1} \sin (k x-\omega t)-\left(K_{3} / K_{2}+3\right) \frac{A_{1}^{2} k^{2} x}{8} \sin 2(k x-\omega t) \ldots,
$$

where $A_{1}$ is the amplitude of the fundamental wave, $K_{3}$ and $K_{2}$ are combinations of the third- and second-order elastic constants, respectively, $\mathrm{k}$ is the wave vector of the fundamental component, $\omega$ is the angular frequency of the fundamental, and $\mathrm{x}$ is the distance through which the wave has propagated. The quantity $-\left(\mathrm{K}_{3} / \mathrm{K}_{2}+3\right)$ is dimensionless and is known as the nonlinearity parameter, $\beta$. This parameter is a convenient measure of the degree to which a given solid is nonlinear, and changes in this quantity with material degradation are indicative of the microstructural changes induced by in-service damage. This parameter also appears to be highly sensitive to material changes occurring at the atomic lattice level.

For fluids, the quantity $-\left(\mathrm{K}_{3} / \mathrm{K}_{2}+3\right)$ is replaced by the term $(B / A+2)$, where $B$ and $A$ are (temperature-dependent) first- and second-order coefficients of a Taylor expansion of fluid pressure in powers of the fluid density. ${ }^{3}$ Using the data from the experimental study of the nonlinearity of water, we have determined an approximate value of 5 for the quantity $(B / A+2)$, in reasonably good agreement with a published value ${ }^{2}$ of 6.96 at $20^{\circ} \mathrm{C}$. Our value was calculated using published piezoelectric constitutive relations rather than measured values for quartz, and there are other error sources as well. Nevertheless, it indicates that we are obtaining reasonable values for the nonlinearity parameter. These measurements will be refined considerably as our work progresses.

We also continued our attempt to solve the problems attendant to fabricating suitable ultrasonic transducers for high-power measurements. We previously noted that power levels in excess of about 1800 watts have led to arcing in our commercial quartz transducers. This corresponds to an applied potential of only about 425 volts peak, well below the breakdown potential of the quartz element. The source of the arcing was suspected to be insufficient electrode spacing on the quartz elements; the transducers are sealed units with an unusual ground contact that may be contributing to the problem. In addition, the voltage step-up behavior of the high-power matching network undoubtedly increases the voltage seen by the actual transducer element. To test this hypothesis, we sectioned one of the (nonfunctioning) commercial quartz transducers that have been used in our nonlinear work. It was noted that the electrode gap was indeed very small, indicating that the unit was not designed for high-power use. At the full $3.6 \mathrm{kw}$ output of our high-power generator, the voltage applied to the transducer would be about $1200 \mathrm{~V}$ peak-to-peak, assuming a $50 \mathrm{ohm}$ impedance. (In fact, the impedance matching circuitry would increase this value considerably in order to match the high impedance of the transducer.) Thus, it will definitely be necessary to fabricate our own transducers in order to obtain a unit suitable for high-power work. We have the transducer elements, both quartz and lithium niobate, and are looking for an installation that can produce the required electrode coatings.

A continuing source of annoyance on this program has been the inability to store highresolution ultrasonic images in a format which can be interpreted by our customers. The data are digitized to a depth of 8 bits ( 256 levels) and stored in a nonstandard format by the commercial software. This software can also store the images in standard PCX graphics format, but only to a depth of 4 bits (16 levels). We have thus been unable to provide customers with digital copies of the high-resolution images, relying instead on photographs of the display screen when 8-bit images were required. However, we have been able to determine the manner in which data are written 
to the raw data file, and we have written software to transiate this file to a 256-level PCX graphics file. We can also translate the data to other standard formats, such as TIFF, PICT, etc., giving us the ability to supply high-resolution images in whatever format is required by the customer. Depending on the amplitude variations of the image, the difference in the 4- and 8-bit images can be dramatic. Figure 3 shows a 4-bit image of the acoustic surface wave response obtained on a ceramic specimen. This image was written by the commercial software. Some variations can be seen in the figure, but the surface appears quite free of machining damage and porosity. Figure 4 is a high-resolution image of the same data as written by our new software. (We have not yet incorporated the scale information shown on fig. 3 but will do so in the future.) Note the subtle vertical lines (machining damage scratches); in addition, the indication of two surface or subsurface pores can be seen on the image, at the bottom center and the upper right. We have already received considerable positive response from two customers to whom we sent high-resolution images. Some information is invariably lost in photographing a computer display, and the new capability allows the customer to see precisely the same information that we do in the original data.

We have received three ceramic wrist pins for ultrasonic evaluation. Since these samples were aggressively machined, the primary concern was for possible grinding-induced cracking. As these specimens were also cylindrical rather than planar in shape, we scanned them using our inhouse designed modification to the primary inspection system. ${ }^{4}$ Both surface-wave and throughtransmission evaluations were performed to maximize the probability of detecting cracking at any point in the samples. Figure 5 shows the high-resolution surface-wave results on the first of the samples. On these figures, the horizontal axis corresponds to the wrist pin axis, and the vertical axis is the azimuthal (circumferential) direction. The criss-crossing lines seen on the figure are images of the grinding marks, and the approximately circular indications near the bottom center and left center are very small air bubbles adhering to the wrist pin surface. No cracks can be seen, but the acoustic surface wave penetrates only about $120 \mu \mathrm{m}$ into the sample.

Figure 6 shows the results obtained on the second sample. As before, grinding marks are evident, and the grinding pattern appears to be different than for the first pin. No cracks or serious flaws were detected in any of the wrist pins.

\section{Computed Tomography (CT) - D. J. McGuire and W. A. Simpson, Jr}

During this reporting period we have continued work to CT scan a series of SiAlON diesel engine valves as a part of a material integrity characterization program for these components. The valves are being scanned throughout their volume with a series of CT slices in two regions of interest where highest stress concentrations are anticipated. Scan information is being evaluated and archived in computer storage for later comparison with mechanical testing data. We will attempt to relate material condition indications as shown by CT to the mechanical testing results, thus gaining valuable insights into the interpretation of CT images for this material.

We have also re-installed the area detector on the CT system. The area detector is an accessory system supplied by the manufacturer (Scientific Measurement Systems) as a research add-on for the basic $101 \mathrm{~B}+$ linear array machine. The detector consists of a $2 \times 2$ inch phosphorescent screen that is illuminated by a cone-shaped beam of X-rays. Images of the sample object are made by focussing a high-resolution CCD camera on the phosphorescent screen and recording the pixel data via a frame-grabber in computer memory. Data in a given "slice" are processed to yield CT images. 
We have been experimenting with the area detector to develop techniques for CT analysis of small structural ceramic parts. The approaches and X-ray optics used for this detector are somewhat different from those used for the basic linear detector system of the 101B+. We hope to be able to achieve higher feature resolution with shorter analysis times by using the area capability to simultaneously scan larger cross-sections of the sample. Although we have been making acceptable CT images with the area detector, some artifacts such as circular scan lines, Xray scatter halos, poor feature contrast and excess integration time continue to plague the system. We plan to continue to work with the area detector on a periodic basis to optimize its performance and to become more familiar with its hardware and software features.

With the area detector in place again, the SiAlON valves mentioned above were rescanned and the results compared to the those obtained with the linear array detector. Circular artifacts and reconstruction problems in the area detector are still somewhat limiting for the fine detail needed to evaluate these samples. We have switched back to the linear array due to its more predictable results and greater scanning versatility.

Further work on tomographic evaluation of ceramic-to-metal brazed joints has been done for composite poppet valves and for metal/ceramic keyed shafts. We will need to optimize our techniques to better resolve the high-contrast X-ray density transition region between some metals and ceramics. We also will be working to resolve fine cracks in the ceramic materials that occur during the brazing heat cycle.

\section{$\underline{\text { References }}$}

1. W. A. Simpson, Jr., Ceramic Technology Project Bimonthly Progress Report, April-May, 1993, p. 51.

2. M. A. Breazeale, "Whither Nonlinear Acoustics?," Rev. Prog. in Quant. Nondest. Eval., 9B, pp. 1653-60, ed. D. O. Thompson and D. E. Chimenti, Plenum Press, New York (1990).

3. Robert T. Beyer, "Nonlinear Acoustics," ch. in Physical Acoustics, Vol. II (Part B), pp. 231-64, ed. by Warren P. Mason, Academic Press, New York (1965).

4. W. A. Simpson, Jr., Ceramic Technology Project Bimonthly Progress Report, February-March 1993, p. 66.

\section{Milestones}

On schedule.

\section{Publications}

None. 


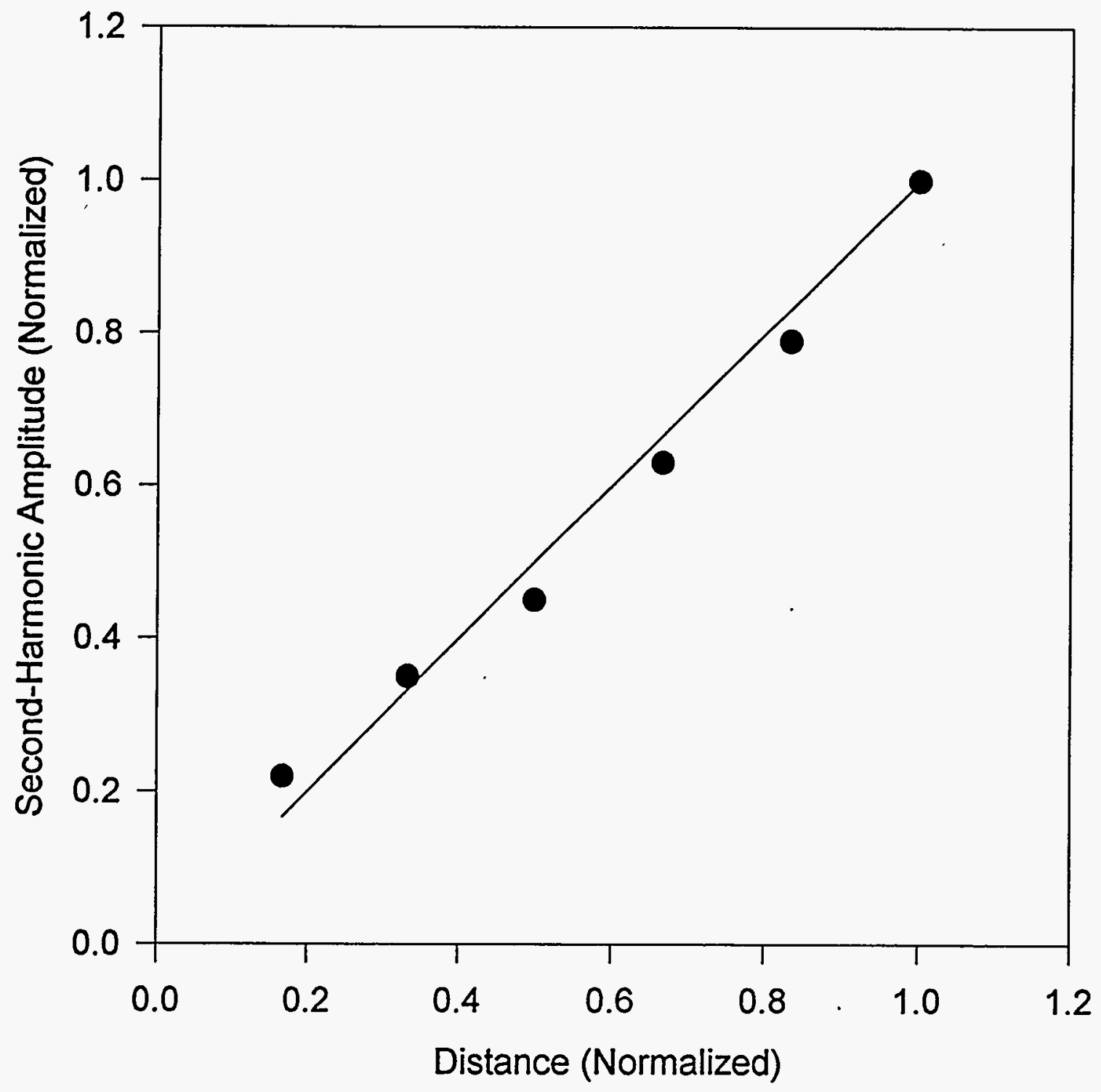

Figure 1. Measured ultrasonic second-harmonic amplitude as a function of propagation distance. 


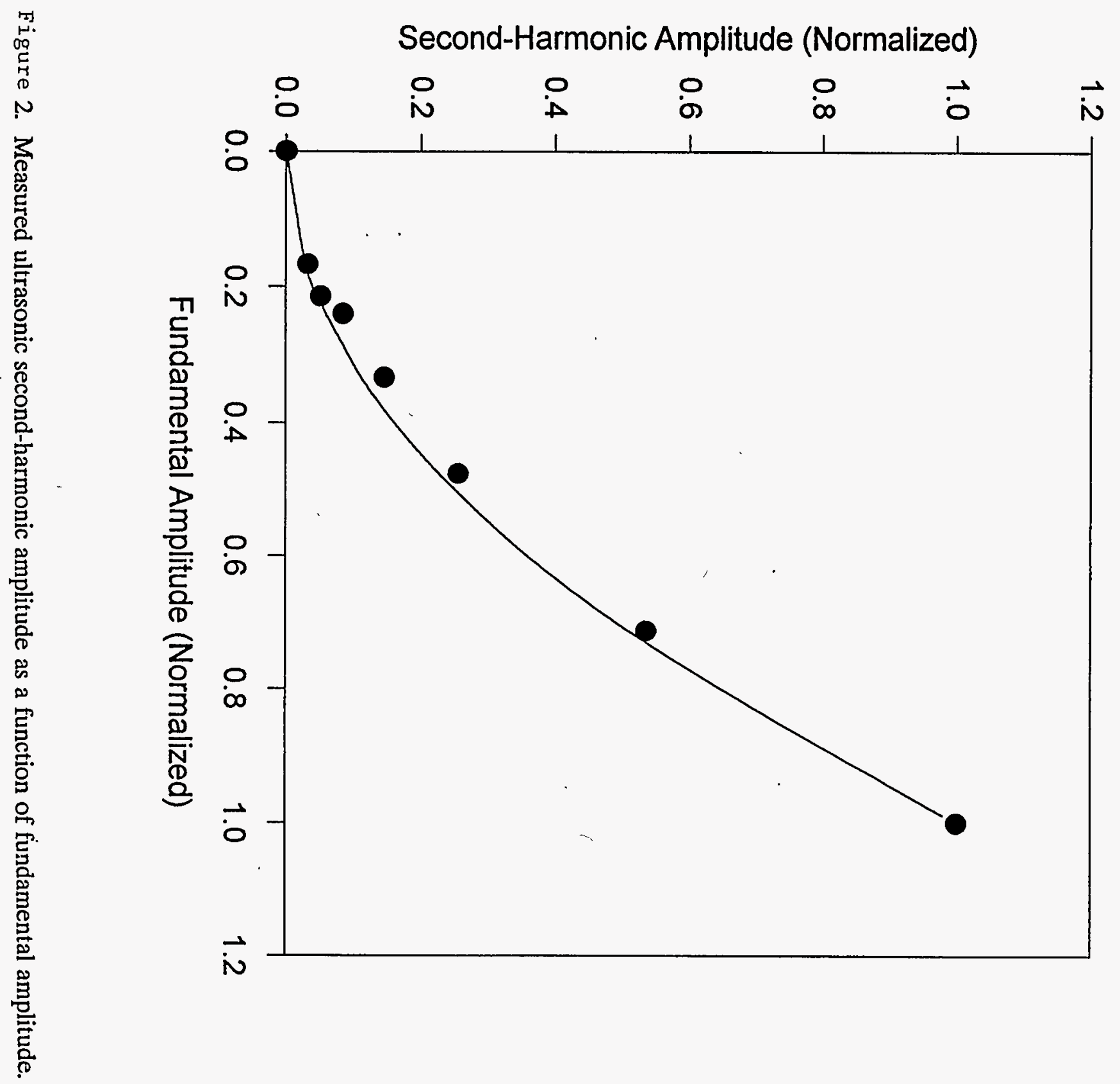




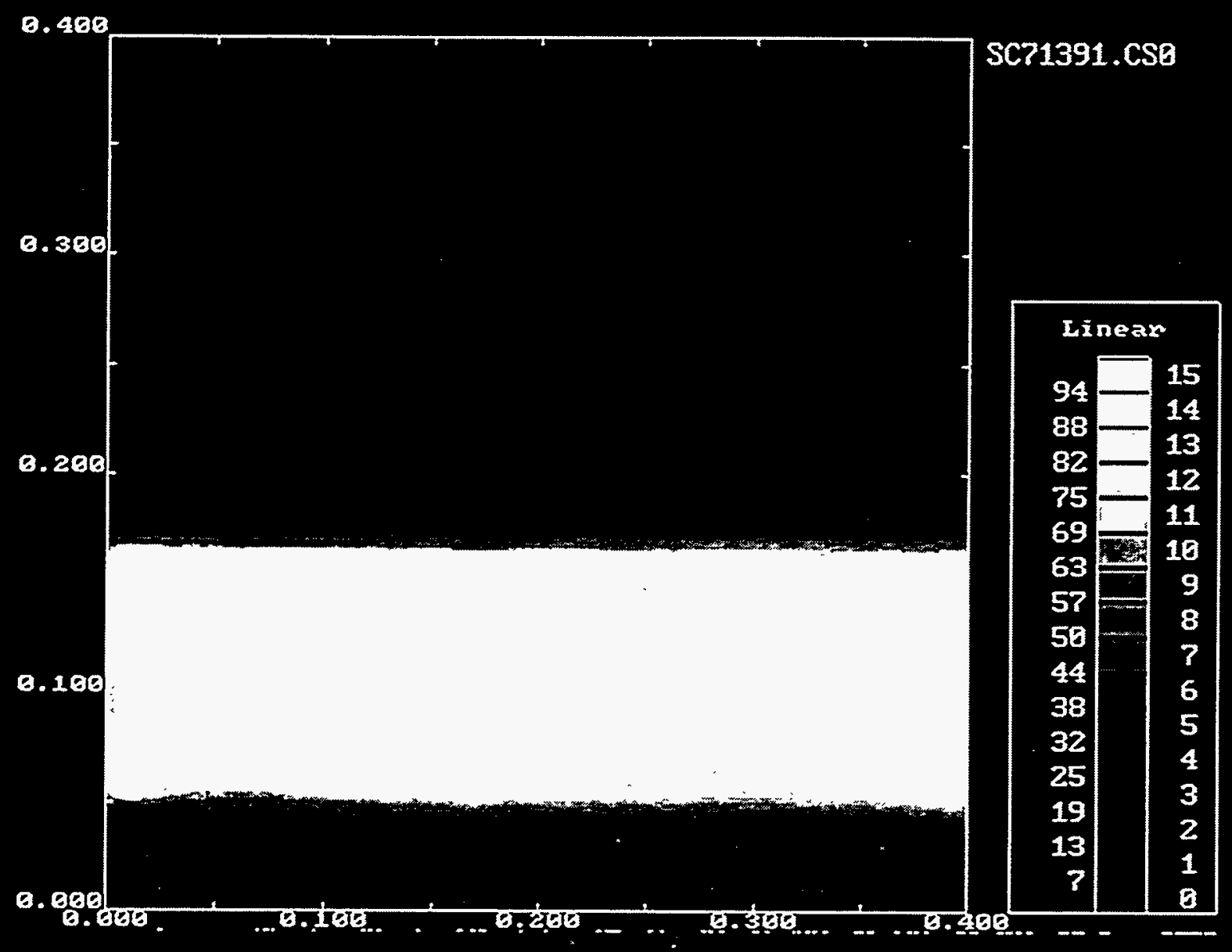

Figure 3. Four-bit ultrasonic surface wave image of a ceramic.
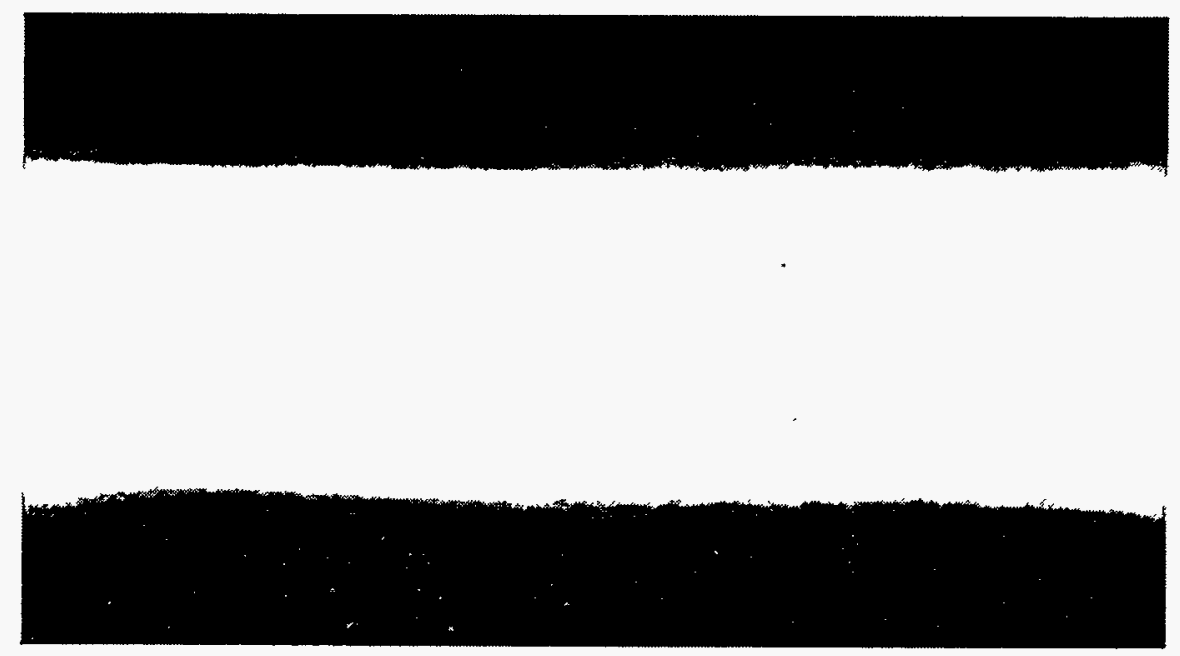

Figure 4. Eight-bit image of the sample shown in fig. 3. Note subtle machining damage and porosity indications. 
NDE STANDARDS FOR ADVANCED CERAMICS

\section{R. W. McClung (Oak Ridge National Laboratory)}

The development of standards is important for the establishment of reliability and acceptance of advanced structural materials. Committee C-28 on Advanced Ceramics is organized in the American Society for Testing and Materials (ASTM) to address this issue. One of the activities of the C-28 committee is nondestructive examination (NDE). The Section on NDE (SNDE) is reviewing existing standards on NDE (primarily developed for metals) to determine potential applicability for ceramics as well as preparing original standards. Use of existing or modified standards is more efficient than generation of new documents and will assure the input of a large body of NDE expertise. Close liaison is established with ASTM Committee E-7 on Nondestructive Testing and documents are in various stages of review, recommendations for modification, and balloting. R. W. McClung is a member of both committees and the official liaison.

Liaison and technical support have been continued between ASTM Committees C-28 and E-7. To date, thirty-six E-7 NDE standards have been reviewed in detail with recommendations made to E-7 for modifications to identified documents. Successful action is complete on thirty-two documents; the others require action by $\mathrm{C}-28$.

E-1324, "Standard Guide for Measuring Some Electronic Characteristics of Ultrasonic Examination Instruments," was revised to accommodate higher frequencies (e.g., to $100 \mathrm{MHz}$ ) needed for advanced ceramics and has been approved by committee E-7 and society ballot and ASTM. This was initiated by McClung through C-28, and he served on the E-7 task group making the change. A revision to a draft standard for making precise measurements of ultrasonic velocity in advanced ceramics (one application is determination of porosity in ceramics) was balloted at subcommittee/committee levels and society review. Comments received on both affirmative and negative ballots were discussed during the January 1996 C-28 meetings and necessary relevant action taken. The revised draft standard was approved by committee for final society approval and publication. C-1175, the standard guide for existing NDE standards, revised to enter five additional E-7 standards and successfully balloted at subcommittee/committee levels, has been approved by society ballot and received final society approval. A revision of a new draft standard on measurement of ultrasonic attenuation in advanced ceramics was also balloted at concurrent subcommittee/committee levels and society review. Comments received on both affirmative and negative ballots were discussed during the January 1996 C-28 meetings and necessary relevant action taken. The revised draft standard was approved by committee for final society approval and publication. During the January meeting a revision to a proposed draft standard "New Standard Practice for Fabricating Reference Specimens Containing Seeded Inclusions" was presented and discussed. The changes were in response to comments received on both negative and affirmative ballots on an earlier ballot at the committee. The revision was approved for a concurrent subcommittee/committee letter ballot. Standard C-1212 on reference specimens containing seeded voids will be reviewed with the intent of incorporating improvements from the new revised draft on inclusions.

A limited amount of data has been identified for establishing radiographic equivalence factors for advanced ceramics. Additional specimens will be sought for experimental radiography to develop additional data. A volunteer for the radiography has been recognized. The intent of this action is 
to provide data for a table in an E-7 standard E-94 on the radiographic method. Other work in progress includes an amplified outline for a draft standard for reference specimens containing laser-drilled holes and a possible standard on determination of porosity in ceramics using ultrasonic velocity. Preparation of a list of facilities and expertise for NDE of advanced ceramics at government laboratories is planned.

McClung reviewed several E-7 ballots containing proposed new standards of interest and value for advanced ceramics. There included documents on image quality indicators and computed tomography.

During meetings of Committee E-7 in January, participation by McClung as C-28 liaison included meetings of the subcommittee on radiology and ultrasonic. Significant activity is ongoing in both subcommittees that will result in standards of interest and value for advanced ceramics. Radiographic standards in progress include a new standard on radiological equivalent image quality indicators (directly relevant to current ceramic practice to place seeded flaws in actual specimens), a standard on low-energy X-ray focal spots and several standards in various stages of development or balloting on radiographic film including relative quality response, system performance, film processing control, classification of film systems, and storage of film. Radioscopic standards in various ballot stages include a guide, a practice, a guide for data transfer and storage and a standard on qualification of radioscopic systems. New computed tomography (CT) standards in progress include a draft on calibration and measurement of density by CT and a draft on CT file storage. Approved documents on CT imaging and CT examination are being submitted for consideration as international standards by ISO.

Subcommittee E-7.06 on Ultrasonic Methods has many standards in different stages of preparation on ballot. Those relevant to ceramics will be highlighted. A new draft guide is being prepared for the detection and evaluation of discontinuities by the contact method. A new draft guide will be prepared on the ultrasonic resonance technique. [R. W. McClung served as negotiator to establish meaningful communicaiton between the proponent \{of the Quatro Corporation \} and the ultrasonic subcommittee.] Several draft standards are in progress on the evaluation of ultrasonic search units including beam profile and beam angle of focused units. A modification of Standard E-1324 on evaluation of instruments to allow use at high frequencies (e.g., $100 \mathrm{MHZ}$ ) has been approved by ASTM. This was initiated by McClung through C-28, and he served on the task group making the change. An E7.06 standard on characterization of search units has been approved as an ISO standard. Other ultrasonic standards are in the ISO mill. 
X-Ray Computed Tomographic Imaging

W. A. Ellingson, E. R. KoehI, J. B. Stuckey (Argonne National Laboratory),

J. P. Pollinger and H. C. Yeh (AlliedSignal Ceramic Components)

\section{Objective/Scope}

The original objectives of the Phase III work of this project were to: (1) study the utilization of high-spatial-resolution 3-D X-ray micro computed tomography techniques to study density distributions (X-ray densitometry) in composite green-state (as cast) pressure slip-cast ATTAP rotors; and (2) correlate destructive density analysis (to be conducted by Allied-Signal Ceramic Components) of the as-cast ATTAP rotors with the 3-D microtomography density data. Because the large ATTAP rotors are no longer of technical interest, a change was made to refocus the work to the AS-800 $\mathrm{Si}_{3} \mathrm{~N}_{4}$ using special billets with final data acquisition on Series 85 nozzles being produced by Allied-Signal Ceramic Components.

\section{Technical Highlights}

During this period, we changed the focus of the effort to Allied-Signal's AS800 material for densitometry analysis. In addition, we are including here parts of the new ASTM "standard test method for calibrating and measuring CT density." We will be incorporating this standard to the extent it applies.

\section{Densitometry of AS-800 Materials}

The three pressure slip-case AS $800 \mathrm{Si}_{3} \mathrm{~N}_{4} 2 " \times 3^{\prime \prime} \times 2$ " blocks of different densities were cast and pre-sintered. 1 " diameter $\times 2$ " long cylinders were then machined from these blocks. These have been shipped to ANL. The new $133 \mathrm{MHz}$-dual pentium was made fully operational as the new software has now been "debugged." The X-ray CT scanner was totally reconfigured by raising the detector and $\mathrm{X}$-ray source so that objects up to $3^{\prime}$ long now can be accommodated.

The densitometer studies to be conducted has 2 parts: Part 1 studies well defined $2 " \times 3 "$ × 2" blocks which have "built-in" density gradients. From these blocks, 1" diameter $\times 2$ " long cylinders have been machined. The information on these cylinders is shown in Table 1 . These have been received by ANL and are shown in Fig. 1. These will subsequently be destructively sectioned for correlation to the X-ray CT data. Assuming we 
get good correlations, Part 2 will be a similar study for Sèries 85 nozzles which have been shown before in prior submissions.

Table 1. Densities of X-ray CT Densitometry Specimens

\begin{tabular}{|c|c|c|c|}
\hline $\begin{array}{c}\text { Specimen } \\
\text { ID }\end{array}$ & $\begin{array}{c}\text { Measured } \\
\text { Density } \\
\text { g/cc }\end{array}$ & \% Theoretical & Remarks \\
\hline S95 183 & 1.85 & 55.84 & Chipped \\
S95 184 & 1.93 & 58.44 & \\
S95 187 & 1.95 & 59.03 & \\
\hline
\end{tabular}

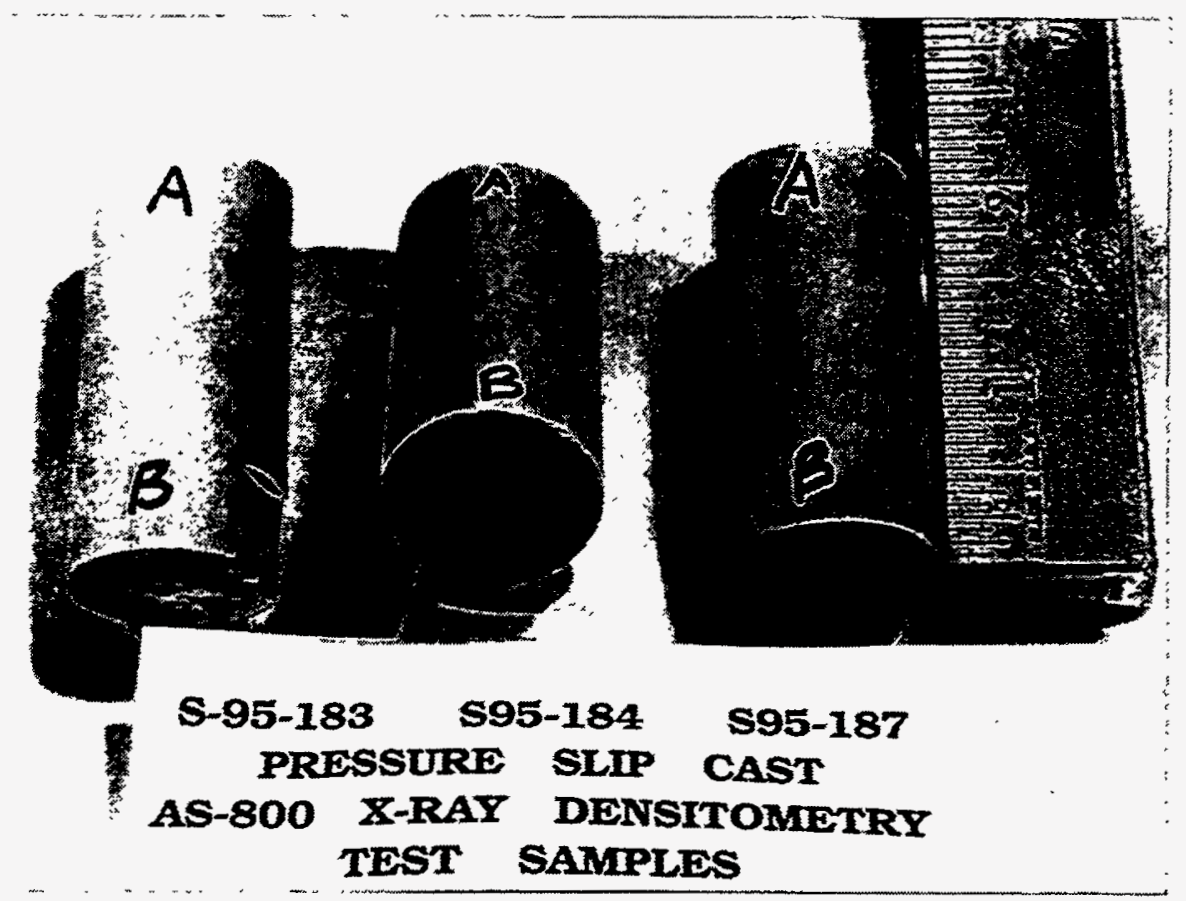

Fig. 1. Photograph of cylindrical specimens machined from $2 " \times 3 " \times 2$ " pressure slip-cast AS 800 blocks for X-ray CT densitometry studies.

b) System Modifications

Difficulties were encountered with some parts of the reconstruction software when using the new dual-pentium $133 \mathrm{MHz}$ computer. It seems that Windows-NT has certain limits which need to be handled with the new software. These are not significant issues. We also reconfigured the $3 D \mathrm{X}$ - 
.ray CT scanner this period by raising both detector and source by $14 "$. This allows a greater working space but also necessitated total realignment of the system. This realignment and recalibration was completed.

2. Brief Review of ASTM X-ray CT Densitometry Standard Test

The newest draft of the ASTM Standard for X-ray CT densitometry recommends that a density calibration phantom be used similar to that shown in Fig. 2.
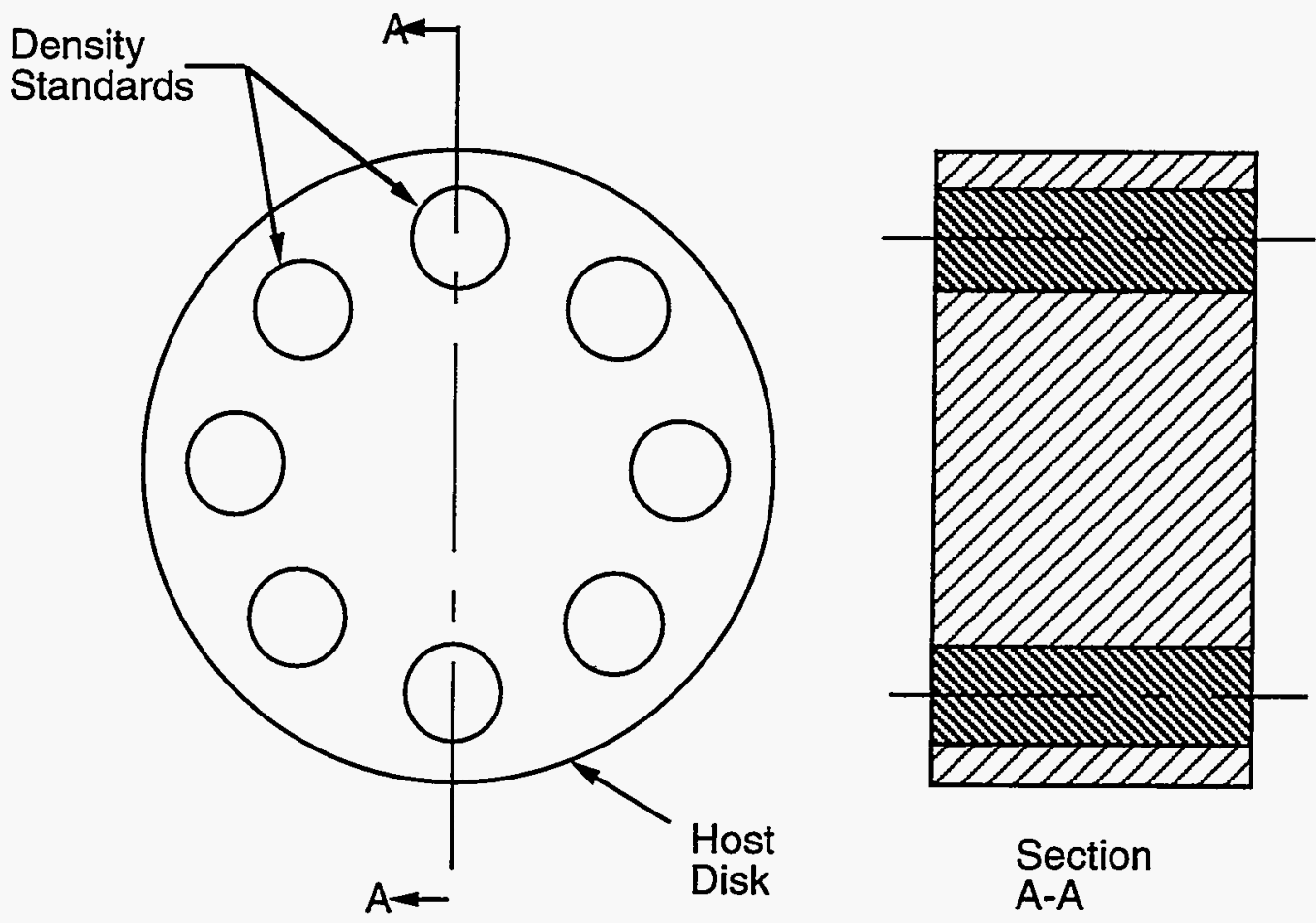

Fig. 2. Schematic Diagram of Proposed ASTM Density Calibration Phantom for X-ray.

ASTM is recommending that the host disc, which holds the density standards, be of a similar material to the object under study. Indeed, this is exactly what was done at ANL during the initial work funded by Norton Advanced Ceramics in the late 1980 s as part of the DOE-funded work on Reliability of Ceramic Processing. 
ASTM further recommends the following:

(a) Use a selection of density standards bracketing the range of densities of interest. Use materials of known composition which preferably are homogeneous on a scale comparable to the spatial resolution of the CT system.

(b) Use more than one density standard in the host disc. Cylinders are preferred over rectangles because of the uncertainties that sharp corners have on volumetric determination and verification methods.

(c) The physical density of each density should be determined empirically.

(d) Determine the mass attenuation coefficient, $\mu / \rho$, at the effective energy of the X-ray CT system. For compounds (e.g., $\mathrm{Si}_{3} \mathrm{~N}_{4}$ ), $\mu / \rho$, can be obtained by taking the weighted sum of its constituents.

This is all consistent with the way ANL has been conducting densitometry studies. However, since the initial calibration data on the earlier Ceramic Processing Reliability work with Norton, our detector has changed from an 8-bit dynamic range 512 x 512 CCD array to a 14-bit 1024 x 1024 array. 
MILESTONE SCHEDULE 3.5.1.5

351516 Slip cast three AS 800 $2^{\prime \prime} \times 3^{\prime \prime} \times 2$ " and presinter

DATE DUE

$4 / 30 / 96$

STATUS

Completed

351517 Conduct X-ray CT studies on blocks from above

$8 / 30 / 96$

Tentative milestones

351518 Correlate X-ray CT data with destructive analysis

$11 / 30 / 96$

Tentative milestones

351519 Cast and presinter two blocks of AS 800

$2 / 28 / 97$

Tentative milestones

351520 Conduct X-ray CT analysis of machined AS 800 from above

$8 / 30 / 97$

Tentative milestones

351521 Correlate X-ray CT analysis with destructive analysis of $12 / 30 / 97$ Tentative components from above milestone milestones 
Nuclear Magnetic Resonance Imaging

S. L. Dieckman, S. Ahuja, 0. 0. Omatete, $*$ A. C. Raptis, and W. A. E1lingson (Argonne National Laboratory; *Metals and Ceramics Division, Oak Ridge

National Laboratory)

\section{Objective/Scope}

The purpose of this work is to evaluate the potential of NMR imaging to affect the development and process control of near-net-shape gel-cast ceramic composites. Specific objectives of this work are to determine the utility of NMR imaging for (1) 3-D mapping of poly-merization homogeneity; (2) real-time imaging of the polymerization process; (3) non-destructive evaluation of voids and flaws in the resultant components; and (4) measurement of physical properties such as degree of polymerization, viscosity, and specimen strength via correlation of these properties with measurable NMR parameters $\left(T_{1}, T_{1 r}\right.$, and $\left.T_{2}\right)$. This work will be performed in conjunction with Dr. Ogbemi O. Omatate of the Materials and Ceramics Division at Oak Ridge National Laboratory.

\section{Technical Highlights}

In this and several previous reporting periods experimental NMR studies have been conducted on the methacrylamide- $N, N^{\prime}-$ methylene bisacrylamide (MAM-MBAM) copolymer system. These studies have included both spectroscopic and imaging experiments, and were designed to test the sensitivity of NMR measurements and operational parameters to the extent of polymerization. Such parameters include the appropriate pulse repetition rates, variations in chemical shift due to temperature and $\mathrm{pH}$, and expected relaxation rates. NMR images of spatial distribution of the standard MAMMBAM (13.3 wt.\% methacrylamide, $1.6 \mathrm{wt} . \% \mathrm{~N}, \mathrm{~N}^{\prime}$-methylene bisacrylamide, and $85.0 \mathrm{wt} . \% \mathrm{H}_{2} \mathrm{O}$ ) copolymer premix at a magnetic field strength of $2.35 \mathrm{~T}$ were conducted on an in-house-built probe tuned to the proton resonance frequency of $100.13 \mathrm{MHz}$. The results have qualitatively shown that NMR relaxation times are directly indicative of polymerization extent, and can therefore be used as an imaging modality showing polymerization rate and homogeneity. Further analysis was performed in this period to determine the mechanism of image contrast which will help optimize imaging parameters.

NMR imaging was conducted on MAA-MBAA prepared in solvent water to determine the variation in polymerization homogeneity. During imaging, the obtained NMR signal was largely due to $\mathrm{H}_{2} \mathrm{O}$ present in the premix and overwhelmed the signal due to other constituents in the premix. The standard inversion recovery NMR pulse technique, employed for the measurement of $T_{1}$, utilized a $180^{\circ}$ pulse, followed by a time delay, then another $90^{\circ}$ pulse $\left(180^{\circ}-t-90^{\circ}\right.$-acquire). The relaxation parameter $\mathrm{T}_{1}$ is a measure of the time taken for transfer of energy to or from the lattice (i. e., for the spin system to approach thermal equilibrium). Large values of $T_{1}$, existing at the onset of polymerization indicate very slow relaxation. $\mathrm{T}_{1}$

October 1, 1995 - March 31, 1996 
measurements can be used to determine changes in molecular motion caused by polymerization. $T_{1}$ increases with temperature and decreases during polymerization.

The variation of intensity has been indicated in Fig. 1, by a plot (intact line) of the intensity ratio vs. time as the polymerization occurred. The variation in intensity corresponds to that from a simple spherical domain. with an exterior sink. If the material is inhomogeneous, the magnetization or intensity decay can be expected to be a composite sum of two exponentials. The curvature in the intensity-vs-time plot for the MAA-MBAA system strongly indicates that the system is inhomogeneous. Inasmuch as the applied field is larger than the dipolar field, the shape of the decay of this spin-lattice relaxation depends on the small-scale morphology of the inhomogeneities.

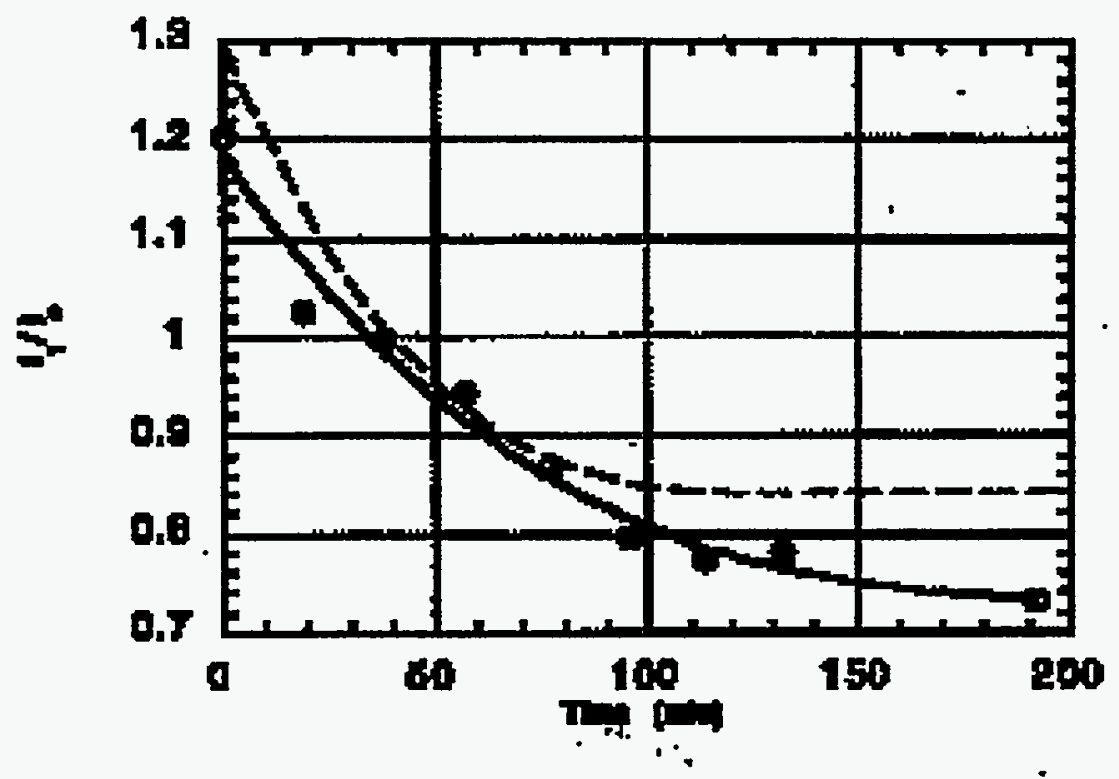

Figure 1. Normalized image intensity for polymerization of the gel as a function of time.

$$
M(t)=I(t)=\frac{2 a^{3}}{\pi} \sum_{n=1}^{\infty} \frac{1}{2} \exp \left\{-t\left[K\left(\frac{n \pi}{a}\right)^{2}+\frac{1}{T_{1}}\right]\right\}
$$

The magnetization can then be written as shown in equation 1 , where $a$ is the atomic radius, $n$ is the order and $\mathrm{K}$ is a normalization constant. Magnetization is directly related to the spin-echo intensity; therefore, it is possible to correlate the intensity obtained from the images with the magnetization. Because the fast inversion recovery pulse sequence was employed to determine TI, the peak intensity as a function of time, $t$, can be written as 


$$
M(t)=M_{0}\left(1-e^{-D / T_{1}}\right) e^{-\tau / T_{1}}
$$

where Mo is a normalization constant, D is the delay time, TI is the spinlattice relaxation time, and the total delay time, $\tau$, is the sum of the individual delays applied during the experimental pulse sequence. More accurately, the intensity variation can be verified by using the inversion recovery sequence, the variation in the spin-lattice, and the spin-spin relaxation times as a basis for calculating the image intensities in each voxel. For the standard inversion recovery NMR pulse technique employed to measure $\mathrm{Ti}$, the images were analyzed to relate the signal intensity to $\mathrm{TI}$ and the spin-spin relaxation time $\mathrm{T} 2$.

The signal intensity is

$$
S \propto p e^{-\tau / T_{2}}\left(1-\left(1+e^{-\tau / T_{2}}\right)\right)\left(2 e^{-\tau / 2 T_{1}}-1\right) e^{-T_{1} / T_{2}}+e^{-\tau / T_{2}}\left(2 e^{-\tau / 2 T_{1}}-1\right) e^{-T_{1 \alpha} / T_{1}}
$$

where the recovery process is inspected with a $90^{\circ}$ pulse applied at time TI following the inversion and Ttot is the total recovery time. Taking T2 $>1$ :,

$$
S \propto\left(2 e^{\tau / 2 T_{1}}-1\right)\left(p e^{-T_{1} / T_{1}}+e^{-T_{\text {tot }} / T_{1}}\right)
$$

The relationship in Eq. 4 shows the codependency of Ti with the intensity of the obtained images. The dashed line in Fig. 1 is the plot of the intensity vs. time according to Eq. 4 for corresponding values of TI. Experimental data is shown as the solid line in Fig. 1. The theoretical fit according to Eq. 4 breaks down with further elapse of time because of the assumption that $\mathrm{T} 2$ $\gg T 1$. Because this assumption is only valid for large values of T2, and therefore large values of $\mathrm{Tl}$, a better fit can be obtained if $\mathrm{T} 2$ is considered in the fitting analysis. To date, this work has been restricted to variation of TI. T2 values were not experimentally determined. A full publication concerning this work and the resultant analysis entitled " $1 \mathrm{H}$ NMR Imaging and Spectroscopy Studies of the Polymerization of Acrylamide Gels" by Ahuja et. al., will be published in Macromolecules, July, 1996.

In future work, we will analyze aqueous gel systems that involve alumina solid loading and composites as well as the concentration differences between the raw specimen and the polymerizing specimen. This work will be performed on large near-net-shape specimens as a function of reaction extent and temperature, and as a function of the concentration of individual reactants. This information is expected to provide details on molecular correlation times, sample viscosity, and reaction kinetics. In addition, the aqueous organic gel systems that involve the addition of solid particles to the copolymer premix of MAA-MBAA will be imaged and concentration differences of the polymer matrix will be analyzed. 
In addition to the experimental studies performed on the polymer systems, the Energy Technology Division at ANL is in the process of installing a commercial NMR spectrometer and imaging system. This system is capable of imaging large ceramic gelcast specimens with high resolution and speed. During this period several custom circuits have been designed to permit the operation of this system with ANL's custom amplifier and probe accessories. This system is thus nearly complete and should be performing imaging in the up coming reporting periods.

October 1, 1995 - March 31, 1996 
MILESTONE SCHEDULE (3.5.1.6)

Phase 3: Spectroscopy and Imaging of Gel Cast Ceramic Components:

Date Due

Status

3.5.1.6.11 Complete spectroscopic studies of two gel systems.

11/15/93 Completed.

3.5.1.6.12 Perform initial imaging studies on specimens composed of the most appropriate gel system.

4/15/94 Completed.

3.5.1.6.13 Complete real-time imaging studies of the gelation process on specimens composed of the most appropriate gel system.

9/15/94 Completed.

3.5.1.6.14 Report the conclusions of imaging studies of as-cast, prefired, and fired components.

7/15/96 Tentative.

3.5.1.6.15 Submit topical report on application of NMR to gel-cast ceramic processing.

7/15/95 Completed.

3.5.1.6.16 Perform initial real-time imaging studies on large specimens of industrial importance.

6/15/96 Tentative.

3.5.1.6.17 Evaluate capability of NMR for imaging a complex specimen (rotor)

8/15/96 Tentative.

3.5.1.6.18 Perform initial drying studies on complex gel-cast specimens.

10/15/96.

3.5.1.6.19 Evaluate the capability of NMR for analyzing the mold-component interface.

3/15/97. 



\subsection{TECHNOLOGY TRANSFER}

\subsection{TECHNOLOGY TRANSFER}

\subsubsection{Technology Transfer}

\section{Technologk Transfer}

\section{R. Johnson (Oak Ridge National Laboratory)}

Technology transfer in the Propulsion System Materials Program is accomplished by a number of mechanisms including the following:

Trade Shows - A portable display describing the program has been built and has been used at numerous national and international trade shows and technical meetings.

Newsletter - A Ceramic Technology Newsletter is published regularly and sent to a large distribution.

Reports - Semiannual technical reports, which include contributions by all participants in the program, are published and sent to a large distribution. Informal bimonthly management and technical reports are distributed to the participants in the program. Open-literature reports are required of all research and development participants.

Direct Assistance - Direct assistance is provided to subcontractors in the program via access to unique characterization and testing facilities at the Oak Ridge National Laboratory.

Workshops - Topical workshops are held on subjects of vital concern to the ceramics community.

International Cooperation - This program is actively involved in and supportive of the cooperative work being done by researchers in West Germany, Sweden, the United States, Japan, and, most recently, Belgium under an agreement with the International Energy Agency. This effort is ultimately aimed at development of international standards and includes physical, morphological, and micro-structural characterization of ceramic powders and dense ceramic bodies, and mechanical characterization of dense ceramics. 
IEA ANNEX II Management (October 1, 1995-March 31, 1996)

M. K. Ferber and K. Breder (Oak Ridge National Laboratory)

\section{Objeclive/Scope}

The purpose of this task is to organize, assist, and facilitate international research cooperation on the characterization of advanced structural ceramic materials. A major objective of this research is the evolution of measurement standards. This task, which is managed in the United States by ORNL, now includes a formal IEA Annex agreement identified as Annex II between the United States, Germany, Sweden, Japan, and Belgium. Annex II has been extended until June 30,1997. The original annex included four subtasks: (1) information exchange, (2) ceramic powder characterization, (3) ceramic chemical and physical characterization, and (4) ceramic mechanical property measurements. In the United States, a total of 13 industrial and government laboratories have participated and contributed their resources to this research. The research in Subtasks 2, 3, and 4 is now complete. In 1990, research in two new subtasks was initiated. These included, Subtask 5, Tensile and Flexural Properties of Ceramics, and Subtask 6, Advanced Ceramic Powder Characterization and were completed in 1993. Two new tasks, Subtask 7, on Ceramic Machining and, Subtask 8, on Ceramic Powder Characterization ' were proposed in late FY 1993 and the research is nearly complete. Subtask 7 in the United States includes eight companies and three federal laboratories. Subtask 8 includes six companies.

\section{$\underline{\text { Recent Devclopments }}$}

The 1995 Executive Committee Meeting was held on October 4, 1995, in conjunction with the European Ceramic Society Conference in Riccione, Italy. Working Group Meetings in both Subtasks were also held at the same meeting (October 1, 1995).

The next Executive Committee Meeting will be held in conjunction with the Annual Automotive Technology Development Contractors' Coordination Meeting in Dearborn (October 1996).

A brief revicw of the above meeting was outlined and there was some discussion on Subtask 9 (on-going work) at the working group meeting of the U.S. Participants which was held on October 25, 1995, in conjunction with the Annual Automotive Technology Development Contractors' Coordination Meeting in Dearborn (October 23-27).

\section{Technical Highlights}

\section{Subtask 7, Machining Effects on Strength of Structural Ceramics}

All machining work in this Subtask is now complete. The grinding was performed on a Harig surface grinder with numerical control. This machine can run at a surface wheel 
speed of up to $73 \mathrm{~m} / \mathrm{s}$ ( 14400 surface $\mathrm{ft} / \mathrm{min}$ ), it has a $0.25 \mathrm{~m}$ by $0.25 \mathrm{~m}$ ( $10^{\prime \prime}$ by $\left.10^{\prime \prime}\right)$ work area, $0.00025 \mathrm{~mm}(0.00001 ")$ downfeed resolution and up to $21 \mathrm{~m} / \mathrm{min}(70 \mathrm{ft} / \mathrm{min})$ table feed rate. The stiffness of the machine is $5600 \mathrm{~N} / \mathrm{mm}(32000 \mathrm{lb} / \mathrm{in})$, and the expended horse power during grinding could be monitored. The machine was fully instrumented with a dynamometer of the type Kistler $9255 \mathrm{~B}$ for measurement of three orthogonal forces, an accelerometer (Kistler 8652A50), and an acoustic emission sensor (Physical Acoustics Corporation, Model I15I). The data collection was performed using an IBM compatible PC using Labview data acquisition software (National Instruments). The Labview is a commercially available software package which consists of building blocks for manipulating instruments and performing data acquisition, and the particular application for the grinders was built by The Institute for Advanced Manufacturing Sciences Inc. (IAMS ) and modified in the HTML. The coolant used was Buehler (10-3330-128) soluble oil, with 1 part oil to 15 parts water, which was the coolant most frequently used with the surface grinder, and ample flow was maintained.

Statistical analyses of the strength data from all the runs have been performed using Statistica (Statsoft, Tulsa, OK), as described in earlier reports. Weibull analyses of the strength data have been performed in such a manner that specimens stemming from machining of the same billet (groups of 10 or 20 specimens) have been treated as separate groups, although at least two billets were machined under the same conditions. The Weibull analyses have been re-run using a new spread sheet macro written by S. Duffy at Cleveland State University. The spread sheet macros were written in Lotus and Excel, for DOS and Windows, and have been supplied to ORNL as part of the IEA project. The spread sheets are designed to calculate the Weibull parameters for a set of strength data according to the Maximum Likelihood method. The macros further supply both the biased and the unbiased parameters and are capable, through a set of built in look-up tables, to return the confidence bounds for both the Weibull parameters. This way it is possible to study the variability in the characteristic strength and the Weibull modulus, and make comparisons.

Figure 1 shows the Weibull characteristic strengths including the 95\% confidence bounds for the first (Sets of 20 specimens) and the second (Sets of 10 specimens) machining experiments performed in the HTML. The data are plotted in terms of decreasing grit size, so this graph also clearly shows the strong correlation between the strength and the grit size. It is seen that in most cases the characteristic strengths within each run are significantly different, indicating that the reproducibility of the grinding condition is not very good. Figure 2 shows the Weibull modulus, $\mathrm{m}$, for the same conditions. Almost all the Weibull moduli were high, ranging from 15 to 70 , but it is seen that due to the large confidence bounds for $\mathrm{m}$, there are no significant differences in $\mathrm{m}$ between the two similar conditions, and more importantly, there is virtually no significant difference in $\mathrm{m}$ between any of the grinding conditions. This result is important because it means that while the strength is a very sensitive indicator for the difference in machining (and hence, surface condition) the Weibull modulus is not. The results further have important implications for life prediction and design, where the Weibull modulus is utilized. 


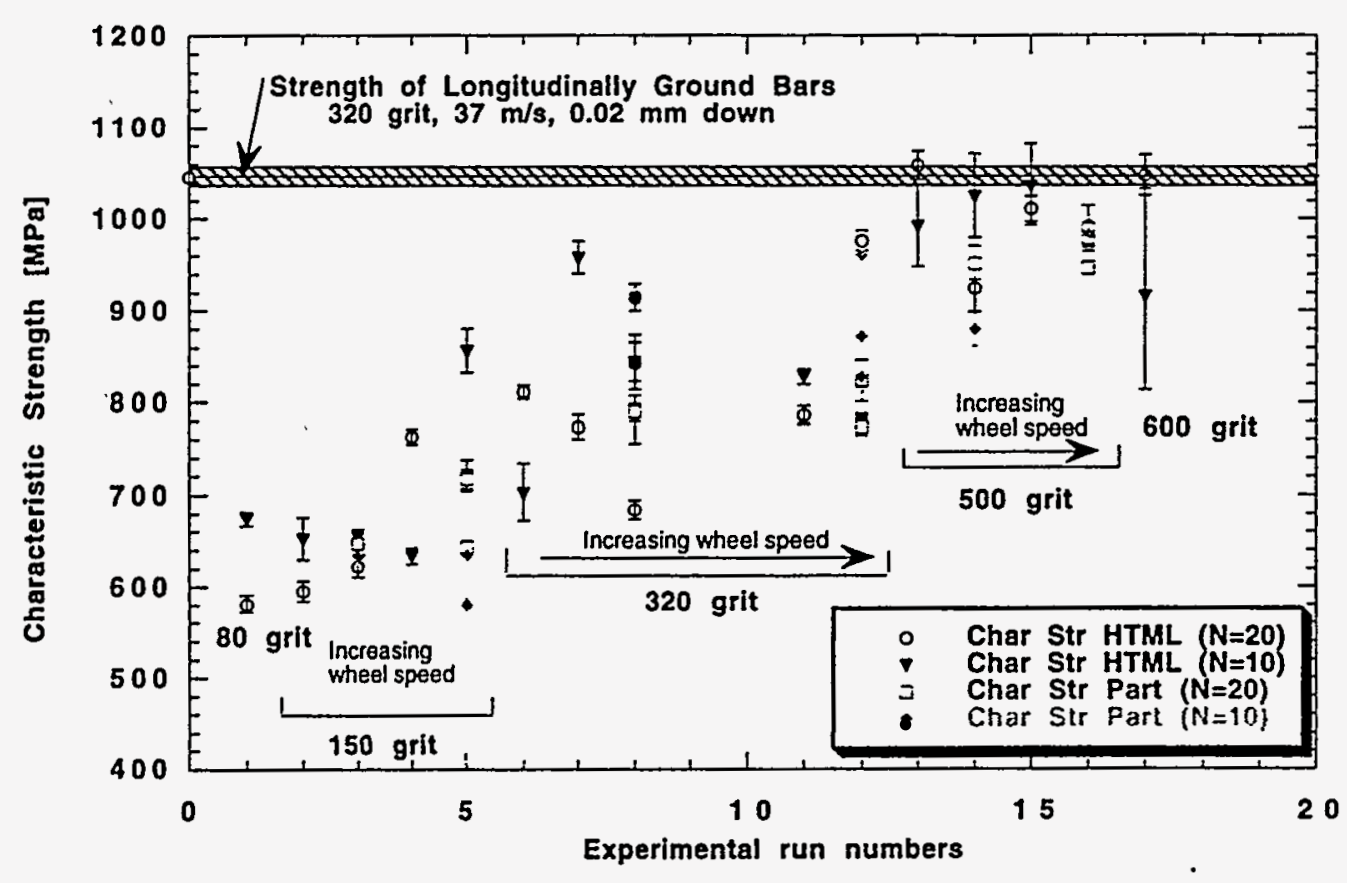

Fig. 1. Characteristic strengths with $95 \%$ confidence bounds for all the experimental conditions performed in the HTML, plotted in the order of decreasing grit size.

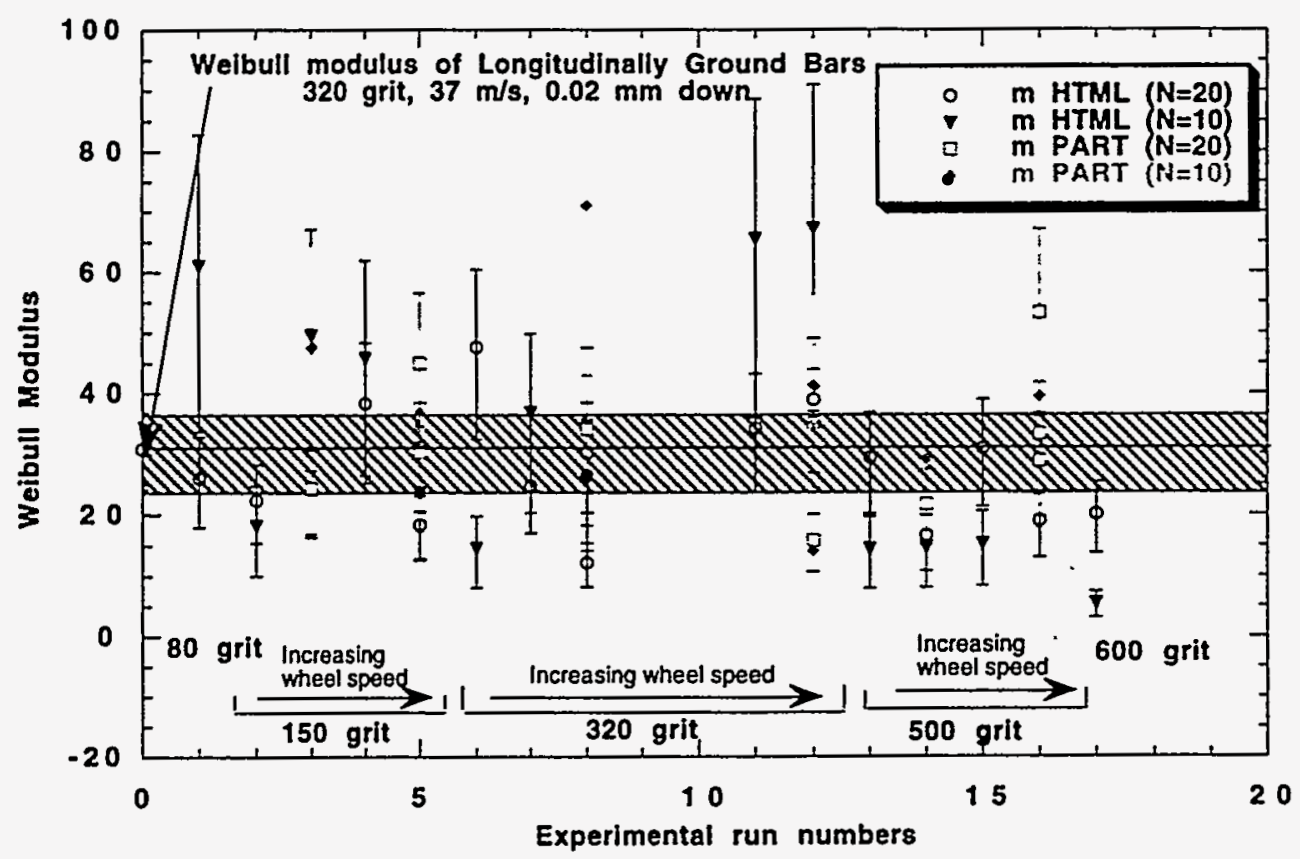

Fig. 2. Weibull moduli with $95 \%$ confidence bounds for all the experimental conditions performed in the HTML, plotted in the order of decreasing grit size. 
All the national participants have finished their work in the HTML. The analysis of the strength and Weibull data from these sets of experiments are complete. The results fall within the scatter of the sets machined previously, and the indication is that an important issue in the reproducibility question is the condition of the wheel. The Weibull moduli vary widely and at the present time no good correlation is obtained between the Weibull moduli and grinding parameters.

Optical fractography has been performed on most of the specimens machined by the participants. The specimens fail from the center of the experimental surfaces in the majority of the specimens, only in a few cases were fractures initiated from the chamfer. Further, in most cases the specimens seem to fail from the damage introduced by the grinding. It is very easy to determine the location of the fracture mirrors, and from that determine that the fracture origins are at the tensile surface of the specimens. The subsequent fractography using a scanning electron microscope (SEM) has met with limited success. Due to the existence of the well-defined fracture mirrors, it is very easy to find the general area of the fracture origin, however, within that area it is not possible to find features that clearly stand out as fracture origins. In several cases sub-surface damage is observed along the tensile surface, and in some cases the semi-elliptical shape of the fracture mirror indicates that the fracture originated from a long, shallow surface crack. Further fractography is ongoing.

The machining of the materials from Belgium, Germany, Japan, and Sweden has been completed in the HTML. The specific grinding conditions employed for the five different silicon nitrides are given in Table 1. Also in the table are strength results and Weibull analysis for the part of the specimen sets that were tested in the United States. The data for the GS44 Silicon Nitride machined and tests in the United States have been pooled from several billets all machined under the same conditions.

Specific problems were encountered for two of the materials. The conditions specified for the Belgian material led to problems with maintaining the table speed constant during up and down grinding. The downfeed was therefore reduced as indicated in the attached table. Even with the reduced downfeed, problems persisted to some degree, resulting in pronounced steps on the finished surface. Similar problems were encountered for the Swedish material, and these specimens also contain surfaces with steps. The normal grinding forces were initially very high for these two conditions; after the downfeed was reduced, the normal force for the Belgian material was lowered considerably, while the normal force measured for the Swedish material remained high. The force issues will be further addressed in the U.S. report.

The specimens of the U.S. material (GS44) that were machined abroad according to the U.S. instructions (see Table 1) have been returned to the U.S. and strength testing of the sets of 30 flexure bars have been performed in the HTML. A full summary of the actual 
Table 1. SUMMARY OF GRINDING CONDITIONS EMPLOYED IN THE USA

\begin{tabular}{|c|c|c|c|c|c|}
\hline $\begin{array}{l}\text { Country } \\
\text { Material } \\
\end{array}$ & \begin{tabular}{|l} 
Belgium \\
SN73 \\
\end{tabular} & $\begin{array}{l}\text { Germany } \\
\text { HOE } 120\end{array}$ & $\begin{array}{l}\text { Japan } \\
\text { SN-1 } \\
\end{array}$ & $\begin{array}{l}\text { Sweden } \\
\text { ACCerama } \\
\end{array}$ & $\begin{array}{l}\text { USA } \\
\text { GS44 } \\
\end{array}$ \\
\hline \multicolumn{6}{|c|}{ ROUGH GRINDING } \\
\hline Grinding Wheel & & $\begin{array}{l}\text { DN150 } \\
\text { R100B1/8 }\end{array}$ & $\begin{array}{l}\text { DN80 } \\
\text { R100B1/8 } \\
\end{array}$ & $\begin{array}{l}\mathrm{DN} 320 \\
\mathrm{R} 100 \mathrm{~B} 1 / 8 \\
\end{array}$ & \\
\hline Size & & $\begin{array}{l}152 \mathrm{~mm} \text { dia } \\
12.7 \mathrm{~mm} \text { wide }\end{array}$ & $\begin{array}{l}152 \mathrm{~mm} \text { dia } \\
12.7 \mathrm{~mm} \text { wide }\end{array}$ & $\begin{array}{l}152 \mathrm{~mm} \text { dia } \\
12.7 \mathrm{~mm} \text { wide }\end{array}$ & \\
\hline Grit Size & & 150 & 80 & 320 & \\
\hline Grit Size & & $100 \mu \mathrm{m}$ & $177 \mu \mathrm{m}$ & $44 \mu \mathrm{m}$ & \\
\hline Concentration & & 100 & 100 & 100 & \\
\hline Wheel Speed & & $44 \mathrm{~m} / \mathrm{s}$ & $33 \mathrm{~m} / \mathrm{s}$ & $30 \mathrm{~m} / \mathrm{s}$ & \\
\hline Table Speed & & $100 \mathrm{~mm} / \mathrm{s}$ & $167 \mathrm{~mm} / \mathrm{s}$ & $\begin{array}{l}200 \mathrm{~mm} / \mathrm{s} \\
\text { last passes } \\
60 \mathrm{~mm} / \mathrm{s}\end{array}$ & \\
\hline Cross feed & & $5 \mathrm{~mm}$ & $7.7 \mathrm{~mm}$ & $11 \mathrm{~mm}$ & \\
\hline Down feed & & $5 \mu \mathrm{m}$ & $80 \mu \mathrm{m}$ & $10 \mu \mathrm{m}$ & \\
\hline Spark out & & None & None & None . & \\
\hline Grinding Direction & & $\begin{array}{l}\text { Longitudinal } \\
\text { Up and Down }\end{array}$ & $\begin{array}{l}\text { Transversly } \\
\text { Up cut only }\end{array}$ & $\begin{array}{l}\text { Transversly } \\
\text { Up and Down }\end{array}$ & \\
\hline \multicolumn{6}{|c|}{ FINE GRINDING } \\
\hline Grinding Wheel & \begin{tabular}{|l} 
DN800 \\
R75B $1 / 8$ \\
\end{tabular} & $\begin{array}{l}\mathrm{DN} 1200 \\
\mathrm{R} 75 \mathrm{~B} 1 / 8 \\
\end{array}$ & $\begin{array}{l}\text { DN800 } \\
\text { R75B 1/8 } \\
\end{array}$ & $\begin{array}{l}\mathrm{DN} 1200 \\
\mathrm{R} 75 \mathrm{~B} 1 / 8 \\
\end{array}$ & $\begin{array}{l}\text { DN320 } \\
\text { R100B 1/8 }\end{array}$ \\
\hline Size & $\begin{array}{l}152 \mathrm{~mm} \text { dia } \\
12.7 \mathrm{~mm} \text { wide }\end{array}$ & $\begin{array}{l}152 \mathrm{~mm} \text { dia } \\
12.7 \mathrm{~mm} \text { wide }\end{array}$ & $\begin{array}{l}152 \mathrm{~mm} \text { dia } \\
12.7 \mathrm{~mm} \text { wide }\end{array}$ & $\begin{array}{l}152 \mathrm{~mm} \text { dia } \\
12.7 \mathrm{~mm} \text { wide }\end{array}$ & $\begin{array}{l}152 \mathrm{~mm} \text { dia } \\
12.7 \mathrm{~mm} \text { wide }\end{array}$ \\
\hline Grit Size & 800 & 1200 & 800 & 1200 & 320 \\
\hline Grit Size & $25 \mu \mathrm{m}$ & $15 \mu \mathrm{m}$ & $25 \mu \mathrm{m}$ & $15 \mu \mathrm{m}$ & $44 \mu \mathrm{m}$ \\
\hline Concentration & 75 & 75 & 75 & 75 & 100 \\
\hline Wheel Speed & $30 \mathrm{~m} / \mathrm{s}$ & $44 \mathrm{~m} / \mathrm{s}$ & $33 \mathrm{~m} / \mathrm{s}$ & $30 \mathrm{~m} / \mathrm{s}$ & $47 \mathrm{~m} / \mathrm{s}$ \\
\hline Table Speed & $400 \mathrm{~mm} / \mathrm{s}$ & $30 \mathrm{~mm} / \mathrm{s}$ & $167 \mathrm{~mm} / \mathrm{s}$ & $\begin{array}{l}200 \mathrm{~mm} / \mathrm{s} \\
\text { last passes } \\
60 \mathrm{~mm} / \mathrm{s}\end{array}$ & $200 \mathrm{~mm} / \mathrm{s}$ \\
\hline Cross feed & $10 \mathrm{~mm}$ & $5 \mathrm{~mm}$ & $7.7 \mathrm{~mm}$ & $11 \mathrm{~mm}$ & $1.8 \mathrm{~mm}$ \\
\hline Down feed & $5 \mu \mathrm{m}$ & $3 \mu \mathrm{m}$ & $2 \mu \mathrm{m}$ & $10 \mu \mathrm{m}$ & $18 \mu \mathrm{m}$ \\
\hline Spark out & None & None & None & Two passes & Three passes \\
\hline $\begin{array}{l}\text { Normal Force } \\
\text { (12.7 mm wheel) }\end{array}$ & $20 \mathrm{~N} / \mathrm{mm}$ & $44 \mathrm{~N} / \mathrm{mm}$ & $6 \mathrm{~N} / \mathrm{mm}$ & $>70 \mathrm{~N} / \mathrm{mm}$ & $3 \mathrm{~N} / \mathrm{mm}$ \\
\hline Grinding Direction & $\begin{array}{l}\text { Transversly } \\
\text { Up and Down }\end{array}$ & $\begin{array}{l}\text { Transversly } \\
\text { Up and Down }\end{array}$ & $\begin{array}{l}\text { Transversly } \\
\text { Up cut only }\end{array}$ & $\begin{array}{l}\text { Transversly } \\
\text { Up and Down }\end{array}$ & $\begin{array}{l}\text { Transversly } \\
\text { Up and Down }\end{array}$ \\
\hline \multicolumn{6}{|c|}{ CHAMFERING } \\
\hline Grinding Wheel & \begin{tabular}{|l|} 
DN800 \\
R75B L/8 \\
\end{tabular} & $\begin{array}{l}\text { DN1200 } \\
\text { R75B 1/8 } \\
\end{array}$ & $\begin{array}{l}\text { DN800 } \\
\text { R75B 1/8 } \\
\end{array}$ & $\begin{array}{l}\text { DN1200 } \\
\text { R75B1/8 } \\
\end{array}$ & $\begin{array}{l}\mathrm{DN} 320 \\
\mathrm{R} 100 \mathrm{~B} 1 / 8\end{array}$ \\
\hline Grit Size & 800 & 1200 & 800 & 1200 & 320 \\
\hline Grit Size & $25 \mu \mathrm{m}$ & $15 \mu \mathrm{m}$ & $25 \mu \mathrm{m}$ & $15 \mu \mathrm{m}$ & $44 \mu \mathrm{m}$ \\
\hline Wheel Speed & $30 \mathrm{~m} / \mathrm{s}$ & $44 \mathrm{~m} / \mathrm{s}$ & $33 \mathrm{~m} / \mathrm{s}$ & $30 \mathrm{~m} / \mathrm{s}$ & $47 \mathrm{~m} / \mathrm{s}$ \\
\hline Grinding Direction & $\begin{array}{l}\text { Longitudinally } \\
\text { Up and Down }\end{array}$ & $\begin{array}{l}\text { Longitudinally } \\
\text { Up and Down }\end{array}$ & $\begin{array}{l}\text { Longitudinally } \\
\text { Up and Down }\end{array}$ & $\begin{array}{l}\text { Longitudinally } \\
\text { Up and Down }\end{array}$ & $\begin{array}{l}\text { Longitudinally } \\
\text { Up and Down }\end{array}$ \\
\hline \multicolumn{6}{|c|}{ RESULTS OF FLEXURE TESTS AT ORNL } \\
\hline Strength (sd) & $917(38) \mathrm{MPa}$ & $897(125) \mathrm{MPa}$ & $901(29) \mathrm{MPa}$ & $639(108) \mathrm{MPa}$ & $842(88) \mathrm{MPa}$ \\
\hline $\begin{array}{l}\text { Weibull Modulus } \mathrm{m} \\
\text { (unbiased } \mathrm{m} \text { ) }\end{array}$ & $\begin{array}{l}25.5 \\
(24.3) \\
\end{array}$ & $\begin{array}{l}7.9 \\
(7.5) \\
\end{array}$ & $\begin{array}{l}33.9 \\
(32.3) \\
\end{array}$ & $\begin{array}{l}6.7 \\
(6.4) \\
\end{array}$ & $\begin{array}{l}9.9 \\
(9.7)\end{array}$ \\
\hline
\end{tabular}


conditions employed in each country was not available yet, however, the measured strengths for these sets fell well within the strength levels measured for specimens machined in the HTML under the same conditions. The Weibull graphs of the results for the GS44 machined abroad and tested in the United States are given in Fig. 3.

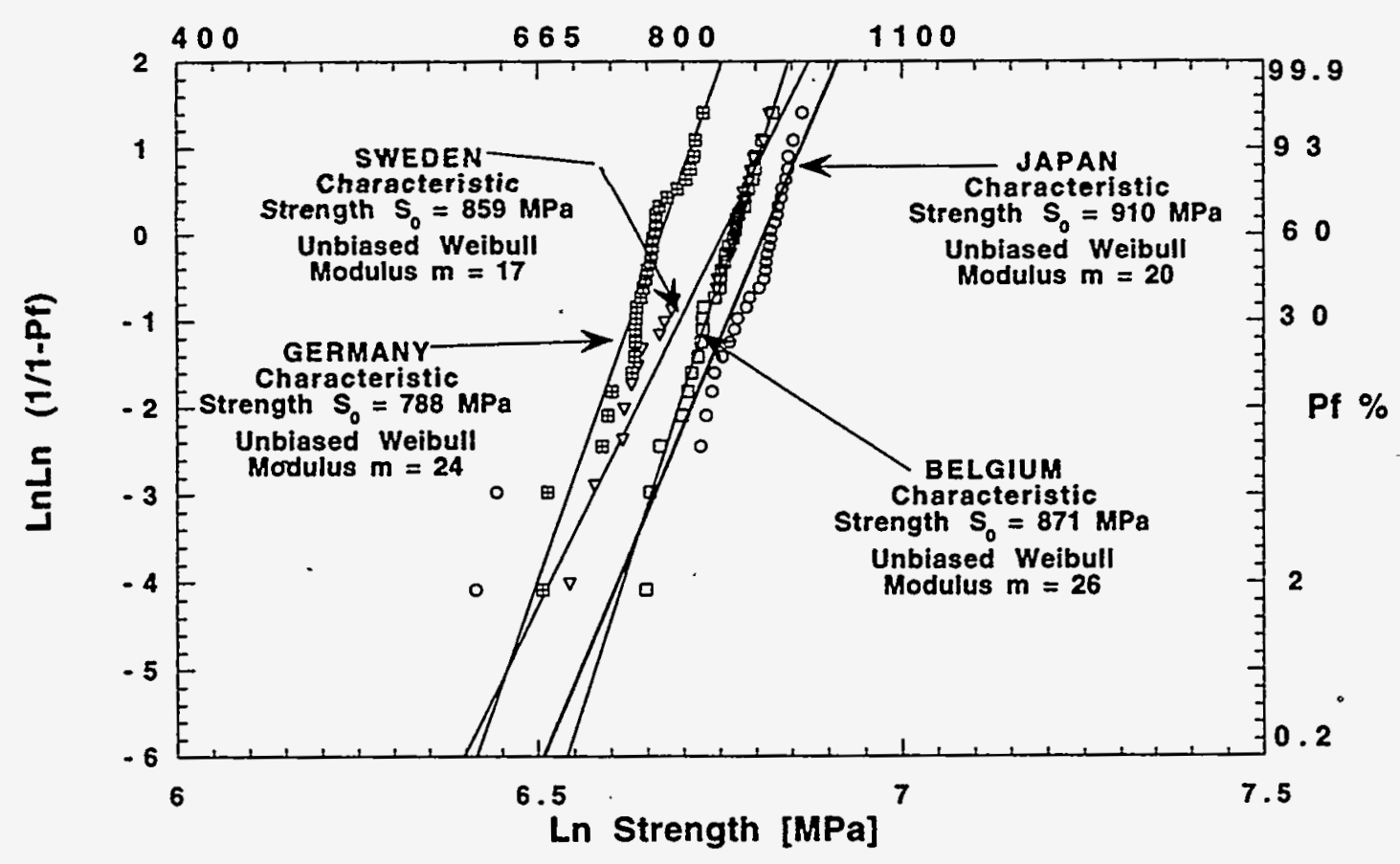

Fig. 3. Weibull graphs for GS44 machined abroad and tested in the United States.

Two sets of GS44 machined and tested abroad have been returned to the United States for fractography, and strength results for performing a full comparison of the interlaboratory exchange are being compiled. 


\section{Subtask 9, Thermal Shock}

The proposed new Subtask 9 was discussed at the Executive Committee meeting in Riccione on October 4, 1995. A brief outline of the proposed effort is given below.

\section{Purpose}

The purpose of Subtask 9 is to assess advanced techniques for the measurement of thermal shock of silicon nitride and other structural ceramics. These techniques will rely on the use of a disk specimen which is centrally heated by a laser, high intensity lamp, or other appropriate heating source. The assessment of these techniques will initially be based upon hardware verification studies conducted by each international participant. These verification studies will focus on (1) the ability of the heating source to generate sufficiently steep radial temperature gradients, (2) resolution of the temperature measurement device, and (3) repeatability of thermal shock measurements made on a material supplied by the international participant. Following completion of the hardware verification studies, a set of specimens prepared from a minimum of two standard materials will be supplied to all international participants for testing. The Operating Agent will be responsible for identifying and distributing these specimens. The data generated by the various participants will be compared to determine the extent of correlation between the various test techniques.

\section{Work Scope}

Subtask 9 will consist of three tasks. In Task 1 , the international participant will be responsible for identifying and establishing the experimental setup for the thermal shock measurements. (It is recognized that for those countries already actively involved in the application of advanced thermal shock methods, this task will not be required.) This will include defining (1) the heating method, (2) specimien geometry (dimensions), (3) the temperature measurement hardware, and (4) techniques for determining when fracture occurs. To facilitate the international round-robin (discussed below), we will standardize the specimen size as soon as possible.

Task 2 will consist of hardware verification studies conducted by each international participant. These verification studies will focus on (1) the ability of the heating source to generate sufficiently steep radial temperature gradients, (2) resolution of the temperature measurement device, and (3) repeatability of thermal shock measurements made on a material supplied by the international participant. Depending upon the interest by each country, Task 2 may be expanded to include other research interests such as thermal fatigue or the comparison of the advanced method with more conventional water-quench techniques.

Task 3 will involve an international round-robin in which specimens supplied by the Operating Agent will be evaluated by each international participant. A minimum of two materials (a silicon nitride and an aluminum oxide) will be selected. It is anticipated that a minimum of 20 specimens prepared from each material will be tested by each country. Fractography will be conducted by each participant on all specimens. 


\section{Reporting}

Each country shall be responsible for reporting the results obtained from their Tasks 1 and 2. A final report which evaluates the correlation of the round-robin exercise will be prepared by the Operating Agent.

We now have commitments to perform work in Subtask 9 from Germany, Japan, and Sweden.

In the U.S. progress has been made toward identifying an appropriate source for heating the center region of a thin ceramic disk to induce thermal shock. An SiC ignitor was found to provide a sufficient heat flux to induce cracking in aluminum oxide, silicon carbide, and silicon nitride. Methods for controlling the placement of the heating element against the disk will be investigated in the next few months. Further work on determination of an IR heating system was investigated.

\section{Subtask 8, Ceramic Powder Characterization}

Major responsibility for this subtask in the United States is at NIST, and a detailed report of progress on this subtask is provided in the section of this report submitted by NIST.

Status of Milestones - Milestone 411518 - Statistical analysis of U.S. measurements completed November 30, 1995. Milestone 411519 - Organize data and prepare outline for final reports - completed October 31, 1995. Other Milestones are on schedule.

Communications/Visits/Travel - Matt Ferber and Kristin Breder attended the IEA Subtask 7 Working group meeting and the IEA Executive Committee Meeting, European Ceramic Society Conference, Riccione, Italy, October 1 and 4, 1995.

Kristin Breder attended the Annual Automotive Technology Development Contractors' Coordination Meeting in Dearborn (October 23-27).

Publications and Presentations - Breder, K. and Ferber, M. K., "IEA Annex II CoOperative Programme on Ceramics for Advanced Engines and Other Conservation Applications - Status of Current Subtasks - Status of Subtask 7 in the U.S. - Subtask 9. A New Effort for Mechanical Properties," presented at the IEA Executive Committee Meeting, European Ceramic Society Conference, Riccione, Italy, October 4, 1995. 


\section{Characterization of Ceramic Powders}

S. G. Malghan and L.-S. Lum

(National Institute of Standards and Technology)

\section{Objective/Scope}

Ceramics have been successfully employed in engines on a demonstration basis. The successful manufacture and use of ceramics in advanced engines depends on the development of reliable materials that will withstand high, rapidly varying thermal stress loads. Improvement in the characterization of ceramic starting powders is a critical factor in achieving reliable ceramic materials for engine applications. The production and utilization of such powders require characterization methods and property standards for quality assurance.

The objectives of the NIST program are: (1) to assist with the division and distribution of ceramic starting powders for an international round-robin on powder characterization; (2) to provide reliable data on physical (dimensional), chemical and phase characteristics of powders; and (3) to conduct statistical assessment, analysis and modeling of round-robin data. This program is directed toward a critical assessment of powder characterization methodology and toward establishment of a basis for the evaluation of fine powder precursors for ceramic processing. This work will examine and compare by a variety of statistical means the various measurement methodologies employed in the round-robin and the correlations among the various parameters and characteristics evaluated. The results of the round-robin are expected to provide the basis for identifying measurements for which Standard Reference Materials are needed and to provide property and statistical data which will serve the development of internationally accepted standards.

\section{Technical Progress}

The primary activities during this period were on experimentation data compilation, statistical analysis, and report preparation. The draft report containing statistical analysis was completed and mailed to technical leaders for their review. Subsequently, Japan wanted to carry out the data evaluation and discussion in early March with all of their members. Therefore, the report was released to all participants in six countries. Similarly, Germany will conducted the review in March-April period.

Dr. Pompe represented Dr. Malghan at the CEN committee meeting in Paris during March where he presented a review of progress on Subtask 8 and planned activities under Subtask 10. The goal of this presentation was to keep the CEN members abreast of our progress and initiate discussions with CEN members to develop collaborative activities in the upcoming Subtask 10.

The planned meeting of IEA Subtask 8 technical leaders meeting at the American 
The planned meeting of IEA Subtask 8 technical leaders meeting at the American Ceramic Society was canceled due to unavailability of.Drs. Naito and Nietfeld. The group planned need to meet at a later date, preferably in conjunction with the next meeting of the CEN. Subsequently, we have made several efforts to hold a meeting of the technical leaders. Due to one or the other reasons, we have not seem to get all the technical leaders together. At present, we are trying for a meeting in early September.

When the interim draft report on data analysis was mailed to all participants, several participants had not submitted their data. However, there was sufficient urgency and need for preparation of the interim report containing all the data that was submitted up to December 1995. After sending the report to the participants, we have focussed our effort back on obtaining the data. There are two components to this task; one is to get the data from other participants who are yet to submit any data, and the other is to complete the remaining tests in NIST laboratories. The primary source of incomplete data submission is from several participants in Germany, Norway and United States. We have contacted all those participants by fax and alerted them to their commitments. Several of them have agreed that they will complete in a few weeks as much as possible of the promised data, and send to NIST. In addition, at NIST, several procedures are being reexamined to develop data. Two procedures in particular that needed more effort are phase composition by $\mathrm{x}$-ray diffraction and particle size distribution by scanning electron microscopy. These procedures are being studied to see if the accuracy of data can be improved over that of Subtask 6.

Japan's participants held a meeting in Nagoya to discuss the results of Subtask 8 described in the above mentioned report. Though their analysis is complete, the results are not sent to NIST, pending data from the remaining participants. Japan's participants believe that the data presented in the draft compilation does not reflect a fair contribution by all participants. This sentiment has been communicated to those participants that have not sent their data.

VITO in Belgium has contributed a fair amount of work during samples preparation of powders for secondary properties analysis. We are pleased that even during the data analysis phase, they have contributed significantly by analyzing slurry rheology data.

A meeting of the ASTM C-28.5 subcommittee was held in conjunction with the American Ceramics Society annual conference in Indianapolis. The primary agenda items are on resolving one negative vote on the particle size distribution measurement procedure by gravity sedimentation, and a discussion on analysis of $\mathrm{C}, \mathrm{N}, \mathrm{O}$ by combustion techniques. A draft procedure on the $\mathrm{C}, \mathrm{N}$, and $\mathrm{O}$ analysis has been completed by Dr. Robert Newman, Dow Chemical Company. The data and procedure used in this procedure derives its roots to the IEA Subtask 6 activity. 
We are in the final stages of completing the analysis work. Similarly, a number of participants in Germany are completing their obligation. The appointment of Prof. Meyer as a technical leader in place of Dr. G. Nietfeld should expedite activities in Germany. Due to commitments at Starck, Dr. Nietfeld was unable to spend anytime on the IEA powder characterization activity. As a result, German participants were without a leader for quite some time. This change in leadership is an excellent sign of sincere interest of the participants in this program. However, changes in the number of participants is continuing, which is a sign of industry downsizing and priority changes. A similar change in the US has forced us to make more modest progress. An example is termination of silicon nitride work at Golden Technologies in Golden, CO. In spite of these changes, we still have several highly interested participants who would like to see this activity continued.

At the upcoming technical leaders meeting, our goal is to develop preliminary conclusions for the Subtask 8 report and finalize technical plan of Subtask 10. All indications and discussions have been focused on emphasizing secondary properties of powders and decreasing the number of powders. Our goal is to complete these activities and present the results at the upcoming Executive Committee meeting in October 1996.

Status of Milestones

On target

Publications/Presentations

None

Communications/Visits

None 
Ceramic Mechanical Property Test Method Development

George D. Quinn

(National Institute of Standards and Technology)

objective/scope

This task is to develop mechanical test method standards in support of the Ceramic Technology Project and Advanced Turbine Technology Applications Programs. Test method development should meet the needs of the DOE engine community but should also consider the general USA structural ceramics community as well as foreign.laboratories and companies. Emphasis will be placed on the needs of the DOE community.

Draft recommendations for practices or procedures shall be developed based upon the needs identified above and circulated within the DOE ceramics heat engine community for review and modification. Round-robins will be conducted as necessary, but shall be well-focussed, limited in scope, and not interfere with ongoing IEA round-robins. Procedures developed in this program will be advanced for final standardization by ASTM.

\section{Technical Highlights and Results}

Earlier work in this project has contributed to the following completed standards:

1. ASTM C 1198-91 "Dynamic Young's Modulus, Shear Modulus, and Poisson's Ratio for Advanced Ceramics by Sonic Resonance," by $\mathrm{S}$. Gonczy, AlliedSignal; G. Quinn, NIST; and J. Helfinstine, Corning.

2. ASTM C 1161-90 "Standard Test Method for Flexural Strength of Advanced Ceramics at Ambient Temperature," G. Quinn, NIST.

3. ASTM C 1211-92 "Standard Test Method for FlexuraI Strength of Advanced Ceramic at Elevated Temperature, " by G. Quinn in cooperation with Mr. M. Foley, Norton; Mr. T. Richerson, Allied-Signal; and Dr. M. Ferber, ORNL.

4. MIL HDBK 790 "Fractography and Characterization of Fracture origins in Advanced Structural Ceramics," with J. Swab and M. Slavin, U.S. ARL.

5. ASTM C 1239-94a "Standard practice for Reporting Strength Data and Estimating Weibull Distribution Parameters," by S. Duffy, NASA-Lewis; G. Quinn, NIST; and C. Johnson, G.E.

6. ASTM C 1322-96 "Standard Practice for Fractography and Characterization of Fracture Origins in Advanced Ceramics," in cooperation with $\mathrm{Mr}$. J. Swab, U.S. ARL.

7. ASTM C 1326-96 "Standard Test Method for Knoop Indentation Hardness of Advanced Ceramics."

8. ASTM C 1327-96 "Standard Test Method for Vickers Indentation Hardness of Advanced Ceramics."

In addition, work on this task has contributed to the following draft standard:

1. ASTM C-xxxx "Standard Test Methods for the Determination of Fracture Toughness of Advanced Ceramics," in cooperation with Prof. Isa Bar-on, WPI; Prof. M. Jenkins, University of Washington, and J. Salem, NASA-Lewis.

\section{Fracture Toughness}

A draft fracture toughness standard was balloted for the second time in ASTM committees C-28, Advanced Ceramics and E-08, 
Fracture and Fatigue in October, 1995. Negative ballots and constructive comments were received and the document is being revised. The revisions that are necessary are refinements. The general framework and the three specific procedures in it (SEPB, CN, SCF) have been accepted. Professor Isa Bar-on of Worcester Polytechnic Institute is the overall coordinator of this activity as well as the $\mathrm{C}-28 / \mathrm{E}-8$ committee liaison. The initial plan was have a third ballot in the spring of 1996, but Professor Bar-on was unable to prepare the revised document for the March 12, deadline. The task group members scrutinized the document very carefully and have requested many changes to strengthen the document and to improve the consistency of style. our goal is to have a polished document available for a concurrent ballot in the Fall of 1996. Prof. Jenkins of University of Washington is preparing the final draft. During this period, G. Quinn critically reviewed the entire draft document and tried to devise a better orientation scheme.

Experimental work in this task has continued on refining the surface crack in flexure (SCF) method. We studied the halo which is visible on the fracture surface around the precrack in some ceramics. We also conducted interlaboratory experiments to check for consistency of results of Syalon 201. The toughness of several new ceramics has been evaluated.

The SCF method requires fractographic measurements of the precrack size on fracture surfaces. Sometimes there are interpretation problems due to the existence of a halo around the precrack. The halos may be detected with optical and/or scanning electron microscopy. The dilemma is whether to include the halo as part of the crack size. The halo may be caused by: 1. crack realignment to the direction of maximum principal stress during catastrophic fracture. This is a geometrical effect and the halo is due to variable light reflection or electron emission off the surfaces, or

2. stable crack extension either due to residual stresses, Rcurve, or slow crack growth phenomena.

For case 1, the correct fracture toughness should be calculated using the crack size without the halo. For case 2, the crack size should include the halo. Halos had been noted on several materials we tested previously, including NC 132 hot-pressed silicon nitride, Dow hot-pressed aluminum nitride, and Coors $\mathrm{AD}$ 999 aluminum oxide. The halos in the first two are purely geometric effects due to the intentional tilting of the specimen during precracking by $1 / 2$ degree. The fracture morphology was identical in the precrack, the halo, and the subsequent fastfracture zone. In contrast, a distinct increase in intergranular fracture was noted in the halo in the alumina which had been tested under laboratory ambient conditions. When new alumina specimens were tested under dry-nitrogen conditions, no halo was evident, either with an optical or scanning electron microscope. We conclude that the halo in the alumina is the result of moisture-assisted slow crack growth. Fracture toughnesses should be calculated on the basis of the crack size 
at instability, including the halo. Figure 1, which shows the toughness of this material without inclusion of the halo, implies there is an $\mathrm{R}$-curve for this material. When the results are corrected to include the halo (not shown), the R-curve is eliminated and toughness is independent of precrack size. A paper on this phenomena is in preparation. Recognition of this problem in interpreting precracks is important in obtaining correct fracture toughness results and will be incorporated into the draft ASTM standard for this method.

SCF results on Syalon 201 were reviewed and specimens from the University of Duisburg in Germany were tested at NIST. Ms. M. Bartsch had tested the syalon and had obtained results of 4.84 MPa $\sqrt{m}$, which was $10 \%$ higher than those from NIST. Much of this difference was traced to Duisburg using fixed pins in their flexure fixtures (with their attendant friction error), but some might have been due to precrack interpretation differences. Therefore we agreed to test some of the Duisburg syalon 201 . Table 1 shows the earlier NIST results, as well as new Duisburg and NIST results. The agreement is exceptional and there is no statistically-meaningful difference between the data sets.

Table 1

Comparative Fracture Toughness Results by the SCF Method

\begin{tabular}{|c|c|c|c|}
\hline $\begin{array}{c}\text { Specimen } \\
\text { Batch }\end{array}$ & Testing Conditions & $\begin{array}{c}K_{\mathrm{Ic}} \mathrm{MPa} \sqrt{\mathrm{m}} \\
( \pm \text { std. dev. })\end{array}$ & $\begin{array}{c}\text { Number of } \\
\text { specimens }\end{array}$ \\
\hline \hline NIST Batch & $\begin{array}{c}\text { Prepared and tested at NIST. } \\
\text { Stereo-SEM photos of precracks. }\end{array}$ & $4.41 \pm 0.12$ & 4 \\
\hline $\begin{array}{c}\text { Duisburg } \\
\text { Batch }\end{array}$ & $\begin{array}{c}\text { Machined and precracked by } \\
\text { Duisburg. Tested at NIST. } \\
\text { Optical photos of precracks. }\end{array}$ & $4.50 \pm 0.22$ & 5 \\
\hline $\begin{array}{c}\text { Duisburg } \\
\text { Batch }\end{array}$ & $\begin{array}{c}\text { Machined, precracked, and tested at } \\
\text { NIST. Optical photos. }\end{array}$ & $4.73 \pm 0.16$ & 7 \\
\hline $\begin{array}{c}\text { Duisburg } \\
\text { Batch }\end{array}$ & $\begin{array}{c}\text { Machined, precracked, and tested at } \\
\text { Duisburg. } \\
\text { Optical microscope, no photos. }\end{array}$ & $4.50 \pm 0.22$ & 7 \\
\hline
\end{tabular}

New test data has been collected on the following materials and results will be forthcoming in the next report:

1. Dow self-reinforced sintered silicon nitride,

2. Ceradyne Neddlelok 147-3 sintered reaction-bonded silicon nitride,

3. Cercom CIW15 SiC whisker-reinforced silicon nitride,

4. Wesgo SNW 1000 sintered silicon nitride,

5. Cercom Pad-B silicon carbide,

6. Ceradyne hot-pressed boron carbide,

7. Dow aluminum nitride,

8. ARL silicon oxynitride

The latter three were chosen in order to expand our data base to 
verify that the test method is applicable to low toughness materials.

A new round robin on the SCF method has started in Europe under the auspices of the German Ceramic society and is organized by Dr. E. Gehrke of GEMATERC and Dr. J. Rödel of Technical Hochschule, Darmstadt. It is an extension of the earlier successful VAMAS round robin that was organized by NIST. It appears that the SCF method is "catching-on."

\section{Hardness}

The two ASTM hardness standards were adopted by ASTM in January, 1996 as :

ASTM C 1326-96 "Standard Test Method for Knoop Indentation Hardness of Advanced Ceramics."

ASTM C 1327-96 "Standard Test Method for Vickers Indentation Hardness of Advanced Ceramics."

Work concluded at NIST on developing hardness standards for advanced ceramics. This is a two pronged program which has an effort performed under this task to prepare ASTM Knoop and Vickers standard test methods as well as a separate NIST program to develop two standard reference materials (SRM's). Figure I illustrates the two SRM's.

Knoop hardness certified hardness blocks, SRM \#2830, were prepared in a parallel program at NIST. These have passed the review and statistical evaluation process at NIST and were put on sale in January, 1996 at a unit cost of $\$ 555$. Hardness is certified to within 1\% at a 95\% confidence level. The knoop standard, SRM \#2830, uses a hipped silicon nitride and an indentation load of $2 \mathrm{kgf}(19.6 \mathrm{~N})$.

SRM \#2831, Vickers Indentation Hardness at $1 \mathrm{kgf}(9.8 \mathrm{~N})$, has been delayed. The material is a tungsten carbide, and was chosen since it has a hardness of $1500 \mathrm{~kg} / \mathrm{mm}^{2}$, has clean, crisp indentations, and is very uniform.

\section{Fractography}

The ASTM standard "Standard Practice for Fractography and Characterization of Fracture Origins in Advanced Ceramics," which is an improvement on MIL HDBK 790, was balloted in October 1995, and adopted by ASTM as standard Practice C 1322-96 in January, 1996. This work is a collaboration between G. Quinn of NIST and J. Swab of U. S. Army Research Laboratory (ARI). We reviewed the proof version of this document and recommended a number of layout and editorial corrections to ASTM.

The terms "fractography" and several flaw types such as "pore" or "inclusion" were balloted in subcommittee C 28.91 and approved as additions to the master terminology standard C 1145 .

This element is now complete. 
Diametral Compression

Information has been accumulated on the diametral compression test and approval to form a task group in C28.01 for this method was obtained. Mr. Quinn and Mr. Swab of the U. S. ARI will collaborate on a project to evaluate this method and prepare a draft standard. Materials are being accumulated and specimens are being prepared. Emphasis will be on applying sound fractographic techniques to the fractured disks. This may help clear up the question of why diametral compression strength often does not agree with results from other methods. Progress on this task has been hampered by the government shutdown and budget Iimitations.

Other Activitịes

Mr. Quinin continued to exchange detailed correspondence with Mr. Sakaguchi of NIRIN, Nagoya on questions pertaining to a proposed ISO standard for Vickers and Knoop hardness. Mr. Sakaguchi initially proposed cloning an IsO standard for the Vickers hardness of metals. We were able to convince him that this was not appropriate and that a new standard for ceramics was better. Mr. Sakaguchi has been very cooperative and the new draft ISO standard includes many elements from the new ASTM C-28 standards. The ASTM ceramic standards, when properly used, will have hardness precision and bias of less than $5 \%$. Such levels of precision would not have been achievable by simply cloning the metal Iso standard.

Several inquiries have been received regarding the applicability of the new NIST SRM 2830 silicon nitride certified hardness disks for instrumented hardness or nanoindentation testing. A prototype SRM silicon nitride specimen was sent to Dr. Christian Ullner of BAM, Germany who studied it with "recording hardness" testing. The disk was suitable and now a new VAMAS round robin was organized using 8 prototype silicon nitride disks from NIST, as well as a borosilicate crown glass specimens from Germany.

A new draft ISO standard for flexure strength of ceramics at room temperature was written for Technical Committee 206, Fine Ceramics. It combines the best elements of ASTM C 1161, C 1211, ENV 843, and JIS R 1601. The United States is the convener for this task, and $M r$. Quinn is the task group leader. A polished, first draft of this document was presented to ASTM Committee C28, subcommittee C28.94 ISO/TAG at Cocoa Beach for review. Figure 3 shows the specimen and fixture size schematics of this new draft standard.

A new draft ISO standard for fracture toughness was received from Dr. T. Nose in Japan.

\section{Status of Milestones}

Budget Iimitations due to the operation of NIST under a continuing resolution for FY 96 have restricted our ability to 
order mechanical test specimens. This has delayed some fracture toughness and diametral compression strength experiments. The government budget crisis shut NIST down for three weeks from mid-December to early January. This was followed by severe weather which shut NIST down for another 4 days.

412123 Conduct preliminary diametral compression strength tests

Delayed due to government shutdown in December 1995January 1996

412124

Prepare comprehensive paper on hardness testing of ceramics

Delayed due to problems in preparing SRM 2831, Vickers hardness of ceramics.

412125 Prepare draft Iso Flexure Strength Standard Completed April 1996

other Milestones are on schedule.

\section{Publications/Presentations}

1. C. R. Brinkman, G. D. Quinn, and R. W. McClung, "Overview of ASTM Standard Activities in Support of Advanced Structural Ceramics Development," pp. $97-108$ in Challenges in Ceramic Product Development, Manufacturing and Commercialization, Ceramic Transactions, Vol 66, American Ceramic Society, Westerville, OH, 1996.

2. G. D. Quinn and R. J. Gettings, "Fractography and the Surface Crack in Flexure (SCF) Method for Evaluating Fracture Toughness of Ceramics," pp 107 - 144 in "Fractography of Glasses and Ceramics," Ceramic Transactions, Vol. 64, ACS, Westerville, OH, 1996.

3. J. J. Swab and G. D. Quinn, "Findings of the VAMAS Fractography Round Robin Exercise," idem, pp $55-70$.

4. R. J. Gettings, G. D. Quinn, A. W. Ruff, and I. K. Ives "Hardness Standard Reference Materials (SRM's) for Advanced Ceramics," 9th International Symposium on Hardness Testing in Theory and Practice," VDI Berichte 1194, (1995) pp. 255-264.

5. G. D. Quinn and J. J. Swab, "Fractography and Estimates of Fracture Origin Size from Fracture Mechanics," presented at Cocoa Beach, Jan. 1996, to be publ. Ceram. Eng. and Sci. Proc., 1996.

\section{Communications/Visits}

Mr. Quinn communicated with S. Gonczy and A. Van Leuven regarding a revisions to ASTM standard C 1259, Test Method for Elastic Modulus by Impulse Excitation. This standard is being revised to incorporate disk-shaped specimens. Mr. Quinn had asked a Dr. Glandus in France (who had done the analytical and experimental work on this method for disk specimens) to review the revisions. Dr. Glandus was gratified that his work had been 
accepted by ASTM. He verified the equations and recommended that the specimen aspect ratio be limited relative to the initial ASTM guidelines. G. Quinn assisted $S$. Gonczy in analyzing the round robin results for the impulse excitation method. These round robin results are as the basis of the precision and bias statement in C 1259.

An article on Committee $\mathrm{C}-28$ was prepared by Prof. $\mathrm{M}$. Jenkins of University of Washington in cooperation with G. Quinn of NIST. This article was prepared for the upcoming ASME LandAir-Sea, Turbo Conference in Manchester in the spring of 1996.

Extensive communications were exchanged with Dr. R. Morrell of the National Physical Laboratory in England regarding wedging errors in flexure testing and friction errors in high temperature flexure strength testing.

G. Quinn consulted with $S$. Wiederhorn and $W$. Leucke on the topic of statistical analysis of interlaboratory test data. The famous statistician John Mandel of NIST was then consulted for further information. Mandel was the principal author of ASTM Standard E 691, which specifies how to analyze Precision of data from round robin projects. This standard has been the basis of our Precision estimates in several of our ASTM C-28, standards (fracture toughness, Knoop and Vickers hardness, and elastic modulus by resonance)? testing.

Andy Zumar of Eaton requested advice regarding biaxial disk

Information regarding CEN standards for thermal properties was delivered to M. Jenkins at University of Washington. 


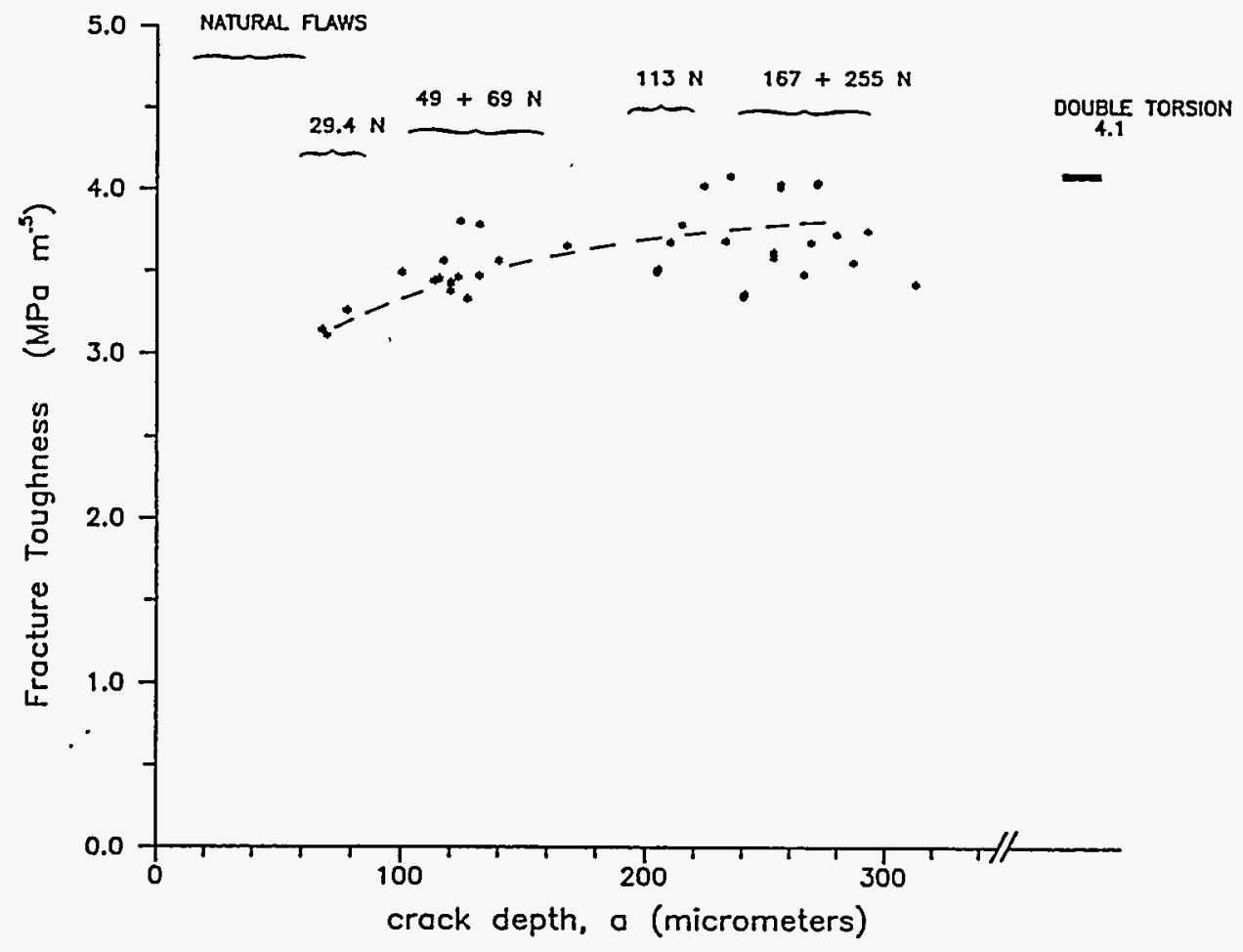

Figure 1

Apparent fracture toughness versus precrack size for coors sintered alumina, $A D-999$. These results, which do not include the halo in the precrack size measurement, incorrectly imply that the material may have an $\mathrm{R}$-curve. 


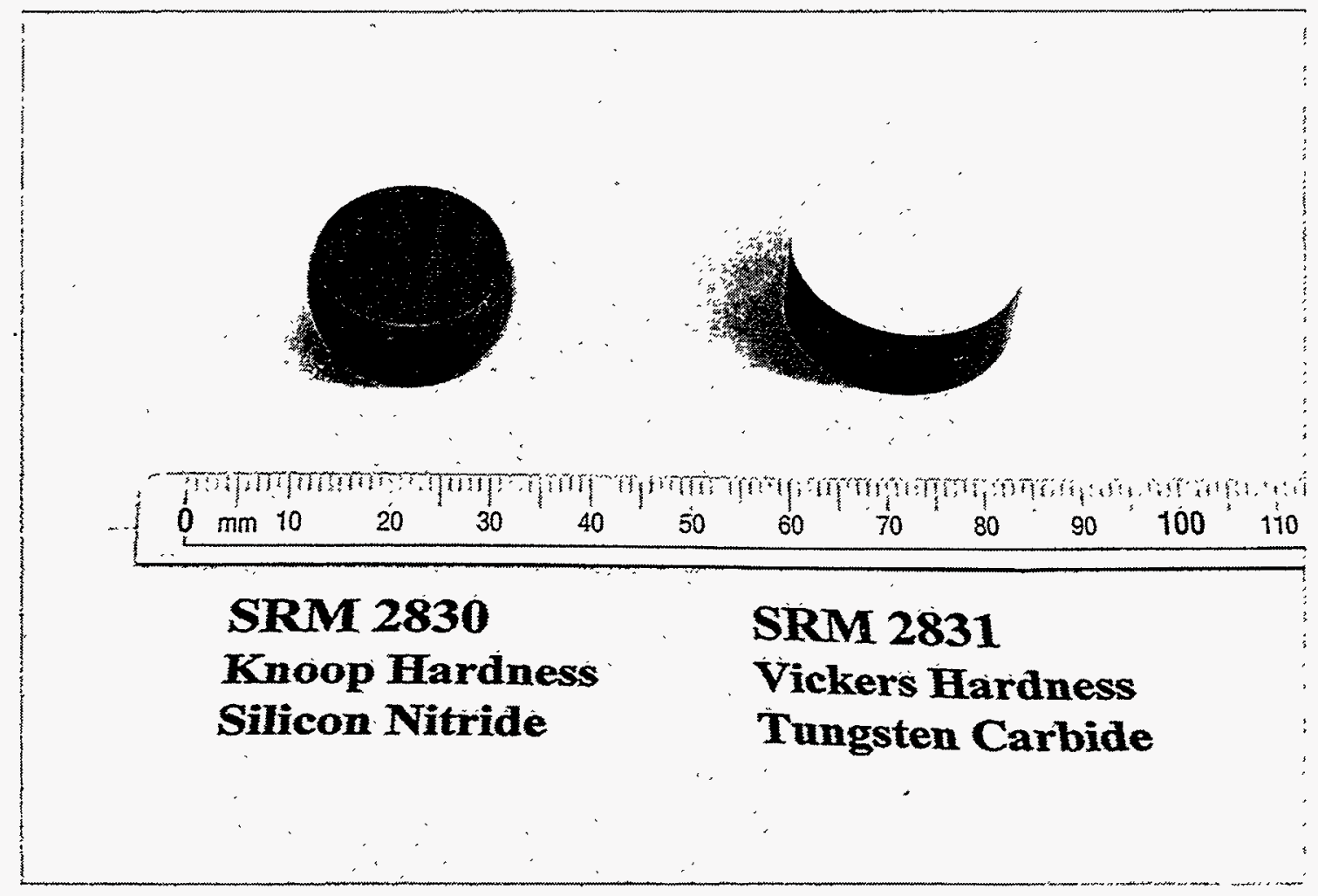

Figure 2

The two NIST haroness standard reference materials. \#2830 is a silicon nitride which will have knoop indents. \#2831 is a tungsten carbide with Vickers indents. 


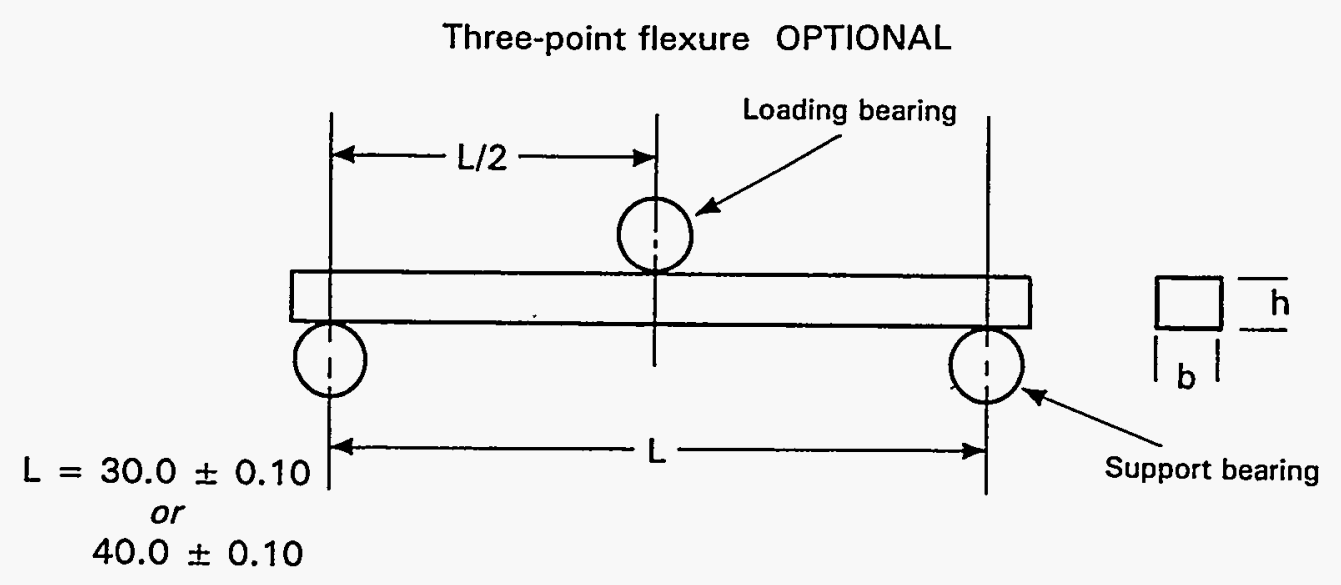

Four-point-1/4 point flexure. RECOMMENDED

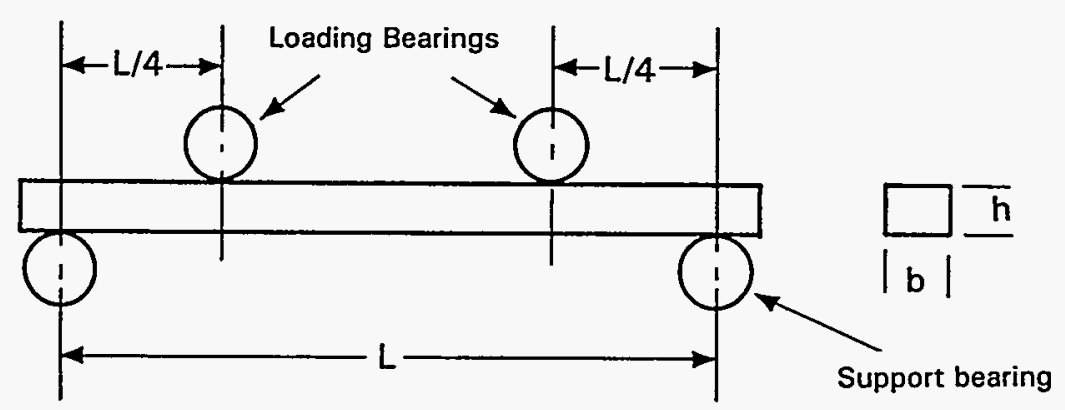

$L=40.0 \pm 0.10$

Four-point-1/3 point flexure

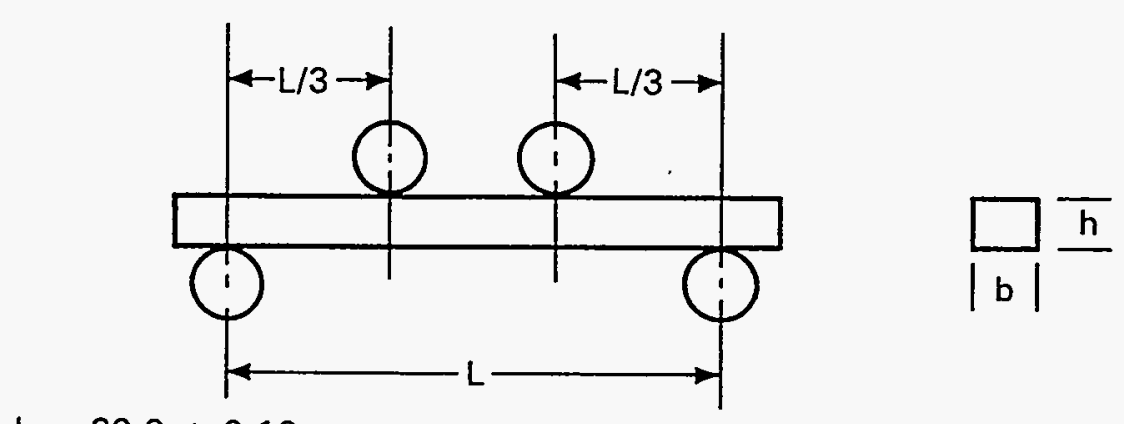

$L=30.0 \pm 0.10$

Figure 3

Specimen and fixture sizes from the new draft Iso flexure strength standard. 


\section{INTERNAL DISTRIBUTION}

Central Research Library (2)

Document Reference Section

Laboratory Records Department (2)

Laboratory Records, ORNL RC

ORNL Patent Section

M\&C Records Office (3)

L. F. Allard, Jr.

L. D. Armstrong

P. F. Becher

R. F. Bernal

T. M. Besmann

P. J. Blau

R. A. Bradley

K. Breder

C. R. Brinkman

V. R. Bullington

G. M. Caton

S. J. Chang

A. Choudhury

D. D. Conger

R. H. Cooper, Jr.

S. A. David

J. L. Ding

M. K. Ferber

R. L. Graves

H. W. Hayden, Jr.

C. R. Hubbard
M. A. Janney

D. R. Johnson (5)

D. Joslin

R. R. Judkins

M. A. Karnitz

B. L. Keyes

H. D. Kimrey, Jr.

R. J. Lauf

W. Y. Lee

K. C. Liu

E. L. Long, Jr.

W. D. Manly

R. W. McClung

D. J. McGuire

S. B. McSpadden

T. A. Nolan

A. E. Pasto

M. H. Rawlins

M. L. Santella

A. C. Schaffhauser

E. J. Soderstrom

D. P. Stinton

R. W. Swindeman

T. N. Tiegs

B. H. West

S. G. Winslow

J. M. Wyrick

R. E. Ziegler 
Pioneering Research Info. Ctr. E.I. Dupont de Nemours \& Co. Experimental Station P.O. Box 80302

Wilmington DE 19880-0302

Jeffrey Abboud

U.S. Advanced Ceramics Assoc. 1600 Wilson Blvd., Suite 1008

Arlington VA 22209

James H. Adair

University of Florida

Materials Science \& Engineering 317 MAE BIdg.

Gainesville FL 32611-2066

Donald F. Adams

University of Wyoming

Mechanical Engineering Dept.

P.O. Box 3295

Laramie WY 82071

Andrzej Aeamski

Materials Conversion Group

236-B Egidi Drive

Wheeling IL 60090

Jalees Ahmad

AdTech Systems Research Inc.

Solid Mechanics

1342 N. Fairfield Road

Dayton OH 45432-2698

Yoshio Akimune

NISSAN Motor Co., Ltd.

Materials Research Laboratory

1 Natsushima-Cho

Yokosuka 237

JAPAN

Mufit Akinc

Iowa State University

322 Spedding Hall

Ames IA 50011
Ilhan A. Aksay

Princeton University

A313 Engineering Quadrangle

Princeton NJ 08544-5263

Charles Aldridge

Heany Industries, Inc.

249 Briarwood Lane

Scottsville NY 14546

Joseph E. Amaral

Instron Corporation

Corporate Engineering Office

100 Royale Street

Canton MA 02021

Edward M. Anderson

Aluminum Company of America

N. American Industrial Chemical

P.O. Box 300

Bauxite AR 72011

Norman C. Anderson

Ceradyne, Inc.

Ceramic-to-Metal Division

3169 Redhill Avenue

Costa Mesa CA 92626

Don Anson

BCL

Thermal Power Systems

505 King Avenue

Columbus OH 43201-2693

Thomas Arbanas

G.B.C. Materials Corporation

580 Monastery Drive

Latrobe PA 15650-2698

Frank Armatis

3M Company

Building 60-1N-01

St. Paul MN 55144-1000 
Everett B. Amold

Detroit Diesel Corporation

Mechanical Systems Technology

13400 Outer Drive West

Detroit MI 48239-4001

Bertil Aronsson

Sandvik AB

S-12680

Stockholm Lerkrogsvagen 19

SWEDEN

Dennis Assanis

University of Michigan

Dept. of Mechanical Engineering

321 W.E. Lay, N.C.

Ann Arbor MI 48109

V. S. Avva

North Carolina A\&T State Univ.

Dept. of Mechanical Engineering

Greensboro NC 27411

Patrick Badgley

Sky Technologies, Inc.

2815 Franklin Drive

Columbus IN 47201

Sunggi Baik

Pohang Institute Sci. \& Tech.

P.O. Box 125

Pohang 790-600

KOREA

Bob Baker

Ceradyne, Inc.

3169 Redhill Avenue

Costa Mesa CA 92626

Frank Baker

Aluminum Company of America

Alcoa Technical Center

Alcoa Center PA 15069
Clifford P. Ballard

AlliedSignal Aerospace Company

Ceramics Program

P.O. Box 1021

Morristown NJ 07962-1021

B. P. Bandyopadhyay

University of North Dakota

Box 8359 University Station

Grand Forks, ND 58202-8359

P. M. Barnard

Ruston Gas Turbines Limited

P.O. Box 1

Lincoln LN2 5DJ

ENGLAND

Harold N. Barr

Hittman Corporation

9190 Red Branch Road

Columbia MD 21045

Renald D. Bartoe

Vesuvius McDanel

510 Ninth Avenue

Box 560

Beaver Falls PA 15010-0560

David L. Baty

Babcock \& Wilcox - LRC

P.O. Box 11165

Lynchburg VA 24506-1165

Donald F. Baxter, Jr.

ASM International

Advanced Materials \& Processes

Materials Park OH 44073-0002

M. Brad Beardsley

Caterpillar Inc.

Technical Center Bldg. E

P.O. Box 1875

Peoria IL 61656-1875 
John C. Bell

Shell Research Limited

Thornton Research Centre

P.O. Box 1

Chester $\mathrm{CH} 13 \mathrm{SH}$

ENGLAND

Larry D. Bentsen

BFGoodrich Company

R\&D Center

9921 Brecksville Road

Brecksville OH 44141

Tom Bernecki

Northwestern University

1801 Maple Avenue

Evanston IL 60201-3135

Charles F. Bersch

Institute for Defense Analyses

1801 N. Beauregard Street

Alexandria VA 22311

Ram Bhatt

NASA Lewis Research Center

21000 Brookpark Road

Cleveland OH 44135

William D. Bjorndahl

TRW, Inc.

One Space Park, MS:R6-2188

Building 01, Room 2040

Redondo Beach CA 90278

Keith A. Blakely

Advanced Refractory Technologies, Inc.

699 Hertel Avenue

Buffalo NY 14207

Edward G. Blanchard

Netzsch Inc.

119 Pickering Way

Exton PA 19341
Bruce Boardman

Deere \& Company Technical Ctr.

3300 River Drive

Moline IL 61265

Lawrence P. Boesch

EER Systems Corp.

1593 Spring Hill Road

Vienna VA 22182-2239

Donald H. Boone

Boone \& Associates

2412 Cascade Drive

Walnut Creek CA 94598-4313

Tom Booth

AlliedSignal, Inc.

AiResearch Los Angeles Division

2525 West 190th Street

Torrance CA 90509-2960

Raj Bordia

University of Washington

Roberts Hall

Box 35212

Seattle WA 98195-2120

Tibor Bornemisza

Energy Technologies Applications, Inc.

5064 Caminito Vista Lujo

San Diego CA 92130-2846

J.A.M. Boulet

University of Tennessee

Engineering Science \& Mechanics

Knoxville TN 37996-2030

Leslie J. Bowen

Materials Systems

53 Hillcrest Road

Concord MA 01742

Steven C. Boyce

Air Force Office of Scientific

Research

AFOSR/NA BIdg. 410

Bolling AFB DC 20332-6448 
Steve Bradley

UOP Research Center

50 E. Algonquin Road

Des Plaines IL 60017-6187

Michael C. Brands

Cummins Engine Company, Inc.

P.O. Box 3005, Mail Code 50179

Columbus IN 47201

Raymond J. Bratton

Westinghouse Science \& Technology

1310 Beulah Road

Pittsburgh PA 15235

John J. Brennan

United Technologies Corporation

Silver Lane, MS:24

East Hartford CT 06108

Gunnar Broman

317 Fairlane Drive

Spartanburg SC 29302

Alan Brown

P.O. Box 882

Dayton NJ 08810

Jesse J. Brown

VPI \& SU

Ctr. for Adv. Ceram. Mater.

Blacksburg VA 24061-0256

Sherman D. Brown

University of Illinois

Materials Science \& Engineering

105 South Goodwin Avenue

Urbana IL 61801

\section{S. L. Bruner}

Ceramatec, Inc.

2425 South 900 West

Salt Lake City UT 84119
Walter Bryzik

U.S. Army Tank Automotive

Command

R\&D Center, Propulsion Systems

Warren MI 48397-5000

Curt V. Burkland

AMERCOM, Inc.

8928 Fullbright Avenue

Chatsworth CA 91311

Bill Bustamante

AMERCOM, Inc.

8928 Fullbright Avenue

Chatsworth CA 91311

Oral Buyukozturk

Massachusetts Institute of Technology

77 Massachusetts Ave., Rm 1-280

Cambridge MA 02139

David A. Caillet

Ethyl Corporation

451 Florida Street

Baton Rouge La 70801

Roger Cannon

Rutgers University

P.O. Box 909

Piscataway NJ 08855-0909

Scott Cannon

P.O. Box 567254

Atlanta GA 30356

Harry W. Carpenter

1844 Fuerte Street

Fallbrook CA 92028

David Carruthers

Kyocera Industrial Ceramics

P.O. Box 2279

Vancouver WA 98668-2279 
Calvin H. Carter, Jr.

Cree Research, Inc.

2810 Meridian Parkway

Durham NC 27713

J. David Casey

35 Atlantis Street

West Roxbury MA 02132

Jere G. Castor

J. C. Enterprise

5078 N. 83rd Street

Scottsdale AZ 85250

James D. Cawley

Case Western Reserve University

Materials Science \& Engineering

Cleveland OH 44106

Thomas C. Chadwick

Den-Mat Corporation

P.O. Box 1729

Santa Maria CA 93456

Ronald H. Chand

Chand Kare Technical Ceramics

2 Coppage Drive

Worcester MA 01603-1252

William Chapman

Williams International Corp.

2280 W. Maple Road

Walled Lake MI 48390-0200

Ching-Fong Chen

LECO Corporation

3000 Lakeview Avenue

St. Joseph MI 49085

William J. Chmura

Torrington Company

59 Field Street

Torrington CT 06790-4942
Tsu-Wei Chou

University of Delaware

201 Spencer Laboratory

Newark DE 19716

R. J. Christopher

Ricardo Consulting Engineers

Bridge Works

Shoreham-By-Sea W. Sussex

BN435FG ENGLAND

Joel P. Clark

Massachusetts Institute of

Technology

Room 8-409

Cambridge MA 02139

Giorgio Clarotti

Commission of the European Comm

DGXII-C3, MO75, 1-53;

200 Rue de la Loi

B-1049 Brussels

BELGIUM

W. J. Clegg

ICI Advanced Materials

P.O. Box 11, The Heath

Runcom Cheshire WA7 4QE

ENGLAND

William S. Coblenz

Adv. Research Projects Agency

3701 N. Fairfax Drive

Arlington VA 22203

Gloria M. Collins

ASTM

1916 Race Street

Philadelphia PA 19103

William C. Connors

Sundstrand Aviation Operations

Materials Science \& Engineering

4747 Harrison Avenue

Rockford IL 61 125-7002 
Shawn Cooper

FEV Engine Technology

2285 Opdyke Road, Suite F

Auburn Hills, MI 48326

Normand D. Corbin

Norton Company

SGNICC/NRDC

Goddard Road

Northboro MA 01532-1545

Douglas Corey

AlliedSignal, Inc.

2525 West 190th Street, MS:T52

Torrance CA 90504-6099

Keith P. Costello

Chand/Kare Technical Ceramics

2 Coppage Drive

Worcester MA 01603-1252

Ed L. Courtright

Pacific Northwest Laboratory

MS:K3-59

Richland WA 99352

Anna Cox

Mitchell Market Reports

20 St. James Strect

Monmouth Gwent NP5 3DL

UNITED KINGDOM

J. Wesley Cox

BIRL

1801 Maple Avenue

Evanston IL 60201-3135

Art Cozens

Instron Corporation

3414 Snowden Avenue

Long Beach CA 90808

Mark Crawford

New Technology Week

4604 Monterey Drive

Annandale VA 22003
Richard A. Cree

Markets \& Products, Inc.

P.O. Box 14328

Columbus OH 43214-0328

Les Crittenden

Vesuvius McDanel

Box 560

Beaver Falls PA 15010

M. J. Cronin

Mechanical Technology, Inc.

968 Albany-Shaker Road

Latham NY 12110

Gary M. Crosbie

Ford Motor Company

20000 Rotunda Drive

MD-3182, SRL Building

Dearborn MI 48121-2053

Floyd W. Crouse, Jr.

U.S. Department of Energy

Morgantown Energy Tech. Ctr.

P.O. Box 880

Morgantown WV 26505

John Cuccio

AlliedSignal Engines

P.O. Box 52180, MS:1302-2Q

Phoenix AZ 85072-2180

Raymond A. Cutler

Ceramatec, Inc.

2425 South 900 West

Salt Lake City UT 84119

Stephen C. Danforth

Rutgers University

P.O. Box 909

Piscataway NJ 08855-0909

Sankar Das Gupta

Electrofuel Manufacturing Co.

9 Hanna Avenue

Toronto Ontario MGK-1W8

CANADA 
Frank Davis

AlliedSignal Aerospace Company 7550 Lucerne Drive, \#203

Middleburg Heights OH 44130

Robert F. Davis

North Carolina State University

Materials Engineering Department

P.O. Box 7907

Raleigh NC 27695

George C. DeBell

Ford Motor Company

Scientific Research Lab

P.O. Box 2053, Room S2023

Dearborn MI 48121-2053

Michael DeLuca

RSA Research Group

1534 Claas Ave.

Holbrook NY 11741

Gerald L. DePoorter

Colorado School of Mines

Metallurgical \& Materials Engr

Golden CO 80401

\section{J. F. DeRidder}

Omni Electro Motive, Inc.

12 Seely Hill Road

Newfield NY 14867

Nick C. Dellow

Materials Technology Publications

40 Sotheron Road

Watford Herts WD1 2QA

UNITED KINGDOM

L. R. Dharani

University of Missouri-Rolla

224 M.E.

Rolla MO 65401

Douglas A. Dickerson

Union Carbide Specialty Powders

1555 Main Street

Indianapolis IN 46224
John Dodsworth

Vesuvius Research \& Development

Technical Ceramics Group

Box 560

Beaver Falls PA 15010

B. Dogan

Institut fuer Werkstofforschung

GKSS-Forschungszentrum Geesthacht

Max-Planck-Strasse

D-2054 Geesthacht

GERMANY

Alan Dragoo

U.S. Department of Energy

ER-131, MS:F-240

Washington DC 20817

Jean-Marie Drapier

FN Moteurs S.A.

Material and Processing

B-4041 Milmort (Herstal)

BELGIUM

Kenneth C. Dreitlein

United Technologies Res. Ctr.

Silver Lane

East Hartford CT 06108

Robin A.L. Drew

McGill University

3450 University Street

Montreal Quebec H3A 2A7

CANADA

Winston H. Duckworth

BCL

Columbus Division

505 King Avenue

Columbus OH 43201-2693

Ernest J. Duwell

3M Abrasive Systems Division

3M Center

St. Paul MN 55144-1000 
Robert J. Eagan

Sandia National Laboratories

Engineered Mater. \& Proc.

P.O. Box 5800

Albuquerque NM 87185-5800

Harry E. Eaton

United Technologies Corporation

Silver Lane

East Hartford CT 06108

Harvill C. Eaton

Louisiana State University

240 Thomas Boyd Hall

Baton Rouge LA 70803

J. J. Eberhardt

U.S. Department of Encrgy

Office of Transportation Technologies

EE-33, Forrestal Building

Washington DC 20585

Jim Edler

Eaton Corporation

26201 Northwestern Highway

P.O. Box 766

Southfield MI 48037

G. A. Eisman

Dow Chemical Company

Ceramics and Advanced Materials

52 Building

Midland MI 48667

William A. Ellingson

Argonne National Laboratory

Energy Technology Division

9700 S. Cass Avenue

Argonne IL 60439

Anita Kaye M. Ellis

Machined Ceramics

629 N. Graham Street

Bowling Green KY 42101
Glen B. Engle

Nuclear \& Aerospace Materials

16716 Martincoit Road

Poway CA 92064

Art Erdemir

Argonne National Laboratory

9700 S. Cass Avenue

Argonne IL 60439

E. M. Erwin

Lubrizol Corporation

17710 Riverside Drive

Lakewood OH 44107

W. L. Everitt

Kyocera International, Inc.

8611 Balboa Avenue

San Diego CA 92123

Gordon Q. Evison

332 S. Michigan Avenue

Suite 1730

Chicago IL 60604

John W. Fairbanks

U.S. Department of Energy

Office of Transportation Technologies

EE-33, Forrestal Building

Washington DC 20585

Tim Fawcett

Dow Chemical Company

Advanced Ceramics Laboratory

1776 Building

Midland MI 48674

Robert W. Fawley

Sundstrand Power Systems

Div. of Sundstrand Corporation

P.O. Box 85757

San Diego CA 92186-5757

Jeff T. Fenton

Vista Chemical Company

900 Threadneedle

Houston TX 77079 
Raymond R. Fessler

BIRL

1801 Maple Avenue

Evanston IL 60201-3135

Ross F. Firestone

Ross Firestone Company

188 Mary Street

Winnetka IL 60093-1520

Sharon L. Fletcher

Arthur D. Little, Inc.

15 Acorn Park

Cambridge MA 02140-2390

Michael Foley

Norton Company

Goddard Road

Northboro MA 01532-2527

Thomas F. Foltz

Textron Specialty Materials

2 Industrial Avenue

Lowell MA 0185I

Renee G. Ford

Materials and Processing Report

P.O. Box 72

Harrison NY 10528

Edwin Frame

Southwest Research Institute

P.O. Drawer 28510

San Antonio TX 78284

Armanet Francois

French Scientific Mission

4101 Reservoir Road, N.W.

Washington DC 20007-2176

R. G. Frank

Technology Assessment Group

10793 Bentley Pass Lane

Loveland $\mathrm{OH} 45140$
David J. Franus

Forecast International

22 Commerce Road

Newtown CT 06470

Marc R. Freedman

NASA Lewis Research Center 21000 Brookpark Road, MS:49-3

Cleveland $\mathrm{OH} 44135$

Douglas Freitag

Bayside Materials Technology

17 Rocky Glen Court

Brookeville MD 20833

Brian R.T. Frost

Argonne National Laboratory

9700 S. Cass Avenue, Bldg. 900

Argonne IL 60439

Lawrence R. Frost

Instron Corporation

100 Royall Street

Canton MA 02021

Xiren Fu

Shanghai Institute of Ceramics

1295 Ding-xi Road

Shanghai 200050

CHINA

J. P. Gallagher

University of Dayton Research Institute

300 College Park, JPC-250.

Dayton OH 45469-0120

Richard Gates

NIST

Materials Bldg., A-256

Gaithersburg MD 20899

L. J. Gauckler

ETH-Zurich

Sonneggstrasse 5

CH-8092 Zurich 8092

SWITZERLAND 
D. Gerster

CEA-DCOM

33 Rue De La Federation

Paris 75015

FRANCE

John Ghinazzi

Coors Technical Ceramics Co. 1100 Commerce Park Drive

Oak Ridge TN 37830

Robert Giddings

General Electric Company

P.O. Box 8

Schenectady NY 12301

A. M. Glaeser

University of California

Lawrence Berkeley Laboratory

Hearst Mining Building

Berkeley CA 94720

Joseph W. Glatz

510 Rocksville Road

Holland PA 18966

W. M. Goldberger

Superior Graphite Company

R\&D

2175 E. Broad Street

Columbus OH 43209

Allan E. Goldman

U.S. Graphite, Inc.

907 W. Outer Drive

Oak Ridge TN 37830

Stephen T. Gonczy

Allied Signal Research

P.O. Box 5016

Des Plaines IL 60017

Robert J. Gottschall

U.S. Department of Energy

ER-131, MS:G-236

Washington DC 20585
Earl Graham

Cleveland State University

Dept. of Chemical Engineering

Euclid Avenue at East 24th St.

Cleveland OH 44115

John W. Graham

Astro Met, Inc.

9974 Springfield Pike

Cincinnati $\mathrm{OH} 45215$

G. A. Graves

U. of Dayton Research Institute

300 College Park

Dayton OH 45469-000 I

Robert E. Green, Jr.

Johns Hopkins University

Mater. Sci. and Engineering

Baltimore MD 21218

Alex A. Greiner

Plint \& Partners

Oaklands Park

Wokingham Berkshire RG11 2FD

UNITED KINGDOM

Lance Groseclose

Allison Engine Company

P.O. Box 420, MS:W-5

Indianapolis IN 46206

Thomas J. Gross

U.S. Department of Energy

Office of Transportation Technologies

EE-30, Forrestal Building

Washington DC 20585

Mark F. Gruninger

Union Carbide Corporation

Specialty Powder Business

1555 Main Street

Indianapolis IN 46224 
Ernst Gugel

Cremer Forschungsinstitut

GmbH\&Co.KG

Oeslauer Strasse 35

D-96472 Roedenta

GERMANY

John P. Gyekenyesi

NASA Lewis Research Center

21000 Brookpark Road, MS:6-1

Cleveland $\mathrm{OH} 44135$

Nabil S. Hakim

Detroit Diesel Corporation

13400 Outer Drive West

Detroit MI 48239

Philip J. Haley

Allison Engine Company

P.O. Box 420, MS:T12A

Indianapolis IN 46206-0420

Judith Hall

Fiber Materials, Inc.

Biddeford Industrial Park

5 Morin Street

Biddeford ME 04005

Y. Hamano

Kyocera Industrial Ceramics

5713 E. Fourth Plain Blvd.

Vancouver WA 98661-6857

Y. Harada

IIT Research Institute

10 West 35th Street

Chicago IL 60616

Norman H. Harris

Hughes Aircraft Company

P.O. Box 800520

Saugus CA 91380-0520

Alan M. Hart

Dow Chemical Company

1776 Building

Midland MI 48674
Pat E. Hart

Battelle Pacific Northwest Labs

Ceramics and Polymers Development

P.O. Box 999

Richland WA 99352

Michael H. Haselkorn

Caterpillar Inc.

Technical Center, Building E

P.O. Box 1875

Peoria IL 61656-1875

Deborah A. Haught

U.S. Department of Energy

Off. of Transportation Technologies

EE-32, Forrestal Bldg.

Washington DC 20585

N. B. Havewala

Corning Inc.

SP-PR-11

Corning NY 14831

John Haygarth

Teledyne WAA Chang Albany

P.O. Box 460

Albany OR 97321

Norman L. Hecht

U. of Dayton Research Institute

300 College Park

Dayton OH 45469-0172

Peter W. Heitman

Allison Engine Company

P.O. Box 420, MS:W-5

Indianapolis IN 46206-0420

Robert W. Hendricks

VPI \& SU

210 Holden Hall

Blacksburg VA 24061-0237

Thomas P. Herbell

NASA Lewis Research Center

21000 Brookpark Road, MS:49-3

Cleveland OH 44135 
Robert L. Hershey

Science Management Corporation 1255 New Hampshire Ave., N.W. Suite 1033

Washington DC 20036

Hendrik Heystek

Bureau of Mines

Tuscaloosa Research Center

P.O. Box L

University AL 35486

Robert V. Hillery

GE Aircraft Engines

One Neumann Way, M.D. H85

Cincinnati $\mathrm{OH} 45215$

Arthur Hindman

Instron Corporation

100 Royall Street

Canton MA 02021

Shinichi Hirano

Mazda R\&D of North 'America 1203 Woodridge Avenue

Ann Arbor MI 48105

Tommy Hiraoka

NGK Locke, Inc.

1000 Town Center

Southfield MI 48075

Fu H. Ho

5645 Soledad Mtn. Road

San Diego, CA 92037-7256

John M. Hobday

U.S. Department of Energy

Morgantown Energy Tech. Ctr.

P.O. Box 880

Morgantown WV 26507
Thomas Hollstein

Fraunhofer-Institut fuer

-Werkstoffmechanik

Wohlerstrasse 11

D-79108 Freiburg

GERMANY

Richard Holt

Natl. Research Council Canada

Structures and Materials Lab

Ottawa Ontario K1A OR6

CANADA

Woodie Howe

Coors Technical Ceramics

1100 Commerce Park Drive

Oak Ridge TN 37830

Stephen M. Hsu

NIST

Quince Orchard \& Clopper Road

Bldg. 223, Rm A256

Gaithersburg MD 20899

Hann S. Huang

Argonne National Laboratory

9700 S. Cass Avenue

Argonne IL 60439-4815

Gene Huber

Precision Ferrites \& Ceramics

5576 Corporate Drive

Cypress CA 90630

Fred R. Huettic

Advanced Magnetics Inc.

45 Corey Lane

Mendham NJ 07945

Brian K. Humphrey

Lubrizol Petroleum Chemicals

3000 Town Center, Suite 1340

Southfield MI 48075-1201 
Robert M. Humrick

Dylon Ceramic Technologies.

3100 Edgehill Road

Cleveland Heights OH 44118

Michael S. Inoue

Kyocera International, Inc.

8611 Balboa Avenue

San Diego CA 92123-1580

Joseph C. Jackson

U.S. Advanced Ceramics Assoc.

1600 Wilson Blvd., Suite 1008

Arlington VA 22209

Osama Jadaan

U. of Wisconsin-Platteville

1 University Plaza

Platteville WI 53818

Said Jahanmir

NIST

Materials Bldg., Room A-237

Gaithersburg MD 20899

Curtis A. Johnson

General Electric Company

P.O. Box 8

Schenectady NY 12301

Sylvia Johnson

SRI International

333 Ravenswood Avenue

Menlo Park CA 94025

Thomas A. Johnson

Lanxide Corporation

P.O. Box 6077

Newark DE 19714-6077

Walter F. Jones

AFOSR/NA

110 Duncan Ave., Ste. B115

Washington DC 20332-0001
Jill E. Jonkouski

U.S. Department of Energy

9800 S. Cass Avenue

Argonne IL 60439-4899.

\section{A. Joo}

Great Lakes Research Corporation 208 Chickasaw Street

Johnson City TN 37604-1409

Adam Jostons

Materials Division

ANSTO

PMB 1 Menal NSW 2234

AUSTRALIA

Lyle R. Kallenbach

Phillips Petroleum

Mail Drop:123AL

Bartlesville OK 74004

Nick Kamiya

Kyocera Industrial Ceramics Corp.

25 NW Point Blvd., \#450

Elk Grove Village IL 60007

Roy Kamo

Adiabatics, Inc.

3385 Commerce Park Drive

Columbus IN 47201

Chih-Chun Kao

Industrial Technology Research Institute

195 Chung-Hsing Road, Sec. 4

Chutung Hsinchu 31015 R.O.C.

TAIWAN

Keith R. Karasek

AlliedSignal Aerospace Company

50 E. Algonquin Road

Des Plaines IL 60017-5016

Robert E. Kassel

Ceradyne, Inc.

3169 Redhill Avenue

Costa Mesa CA 92626 
Allan Katz

Wright Laboratory

Metals and Ceramics Division

Wright-Patterson AFB OH 45433

R. Nathan Katz

Worcester Polytechnic Institute

100 Institute Road

Worcester MA 01609

Tony Kaushal

GE Transportation Systems

2902 East Lake Road

Building 14-0008

Erie, PA 16531

Ted Kawaguchi

Tokai Carbon America, Inc.

375 Park Avenue, Suite 3802

New York NY 10152

Noritsugu Kawashima

TOSHIBA Corporation

4-1 Ukishima-Cho

Kawasaki-Ku Kawasaki, 210

JAPAN

Lisa Kempfer

Penton Publishing

1100 Superior Avenue

Cleveland OH 44114-2543

Frederick L. Kennard, III

Delphi Energy \& Engine Mgmt. Systems

Division of General Motors

1300 N. Dort Highway

Flint MI 48556

David O. Kennedy

Lester B. Knight Cast Metals

549 W. Randolph Street

Chicago IL 60661

George Keros

Photon Physics

3175 Penobscot Building

Detroit MI 48226
Thomas Ketcham

Corning, Inc.

SP-DV-1-9

Corning NY 14831

Pramod K. Khandelwal

Allison Engine Company

P.O. Box 420, MS:T10B

Indianapolis IN 46206

Jim R. Kidwell

AlliedSignal Engines

P.O. Box 52180

Phoenix AZ 85072-2180

Shin Kim

The E-Land Group

19-8 Chang Jeon-dong

Mapo-gu, Seoul 121-190

KOREA

W. C. King

Mack Truck, Z-41

1999 Pennsylvania Avenue

Hagerstown MD 21740

Carol Kirkpatrick

MSE, Inc.

P.O. Box 3767

Butte MT 59702

Tony Kirn

Caterpillar Inc.

Defense Products Dept., JB7

Peoria IL 61629

James D. Kiser

NASA Lewis Research Center

21000 Brookpark Road, MS:49-3

Cleveland $\mathrm{OH} 44135$

Max Klein

900 24th Street, N.W., Unit G

Washington DC 20037 
Stanley J. Klima

NASA Lewis Research Center 21000 Brookpark Road, MS:6-1

Cleveland $\mathrm{OH} 44135$

Albert S. Kobayashi

University of Washington

Mechanical Engineering Dept.

Mail Stop:FU10

Seattle WA 98195

Shigeki Kobayashi

Toyota Central Research Labs

Nagakute Aichi, 480-1 l

JAPAN

Richard A. Kole

Z-Tech Corporation

8 Dow Road

Bow NH 03304

Joseph A. Kovach

Eaton Corporation

32500 Chardon Road

Willoughby Hills OH 44094

Kenneth A. Kovaly

Technical Insights Inc.

P.O. Box 1304

Fort Lee NJ 07024-9967

Edwin H. Kraft

Kyocera Industrial Ceramics

5713 E. Fourth Plain Boulevard

Vancouver WA 98661

Arthur Kranish

Trends Publishing Inc.

1079 National Press Building

Washington DC 20045

A. S. Krieger

Radiation Science, Inc.

P.O. Box 293

Belmont MA 02178
Pieter Krijgsman

Ceramic Design International, Holding B.V.

P.O. Box 68

Hattem 8050-AB

THE NETHERLANDS

Waltraud M. Kriven

University of Illinois

105 S. Goodwin Avenue

Urbana IL 61801

Edward J. Kubel, Jr.

ASM International

Advanced Materials \& Processes

Materials Park OH 44073

Dave Kupperman

Argonne National Laboratory

9700 S. Cass Avenue

Argonne IL 60439

Oh-Hun Kwon

North Company

SGNICC/NRDC

Goddard Road

Northboro MA 01532-1545

W. J. Lackey

GTRI

Materials Science and Tech. Lab

Atlanta GA 30332

Jai Lala

Tenmat Ltd.

40 Somers Road

Rugby Warwickshire CV22 7DH

ENGLAND

Hari S. Lamba

General Motors Corporation

9301 West 55th Street

LaGrange IL 60525

Richard L. Landingham

Lawrence Livermore National Lab

P.O. Box 808, L-369

Livermore CA 94550 
James Lankford

Southwest Research Institute 6220 Culebra Road

San Antonio TX 78228-0510

Stanley B. Lasday

Business News Publishing Co. 1910 Cochran Road, Suite 630

Pittsburgh PA 15220

S. K. Lau

Carborundum Company

Technology Division

P.O. Box 832, B-100

Niagara Falls NY 14302

J. Lawrence Lauderdale

Babcock \& Wilcox

1525 Wilson Blvd., \#100

Arlington VA 22209-2411

Jean F. LeCostaouec

Textron Specialty Materials

2 Industrial Avenue

Lowell MA 01851

Benson P. Lee

Technology Management, Inc.

4440 Warrensville Rd., Suite A

Cleveland $\mathrm{OH} 44128$

Burtrand I. Lee

Clemson University

Olin Hall

Clemson SC 29634-0907

June-Gunn Lee

KIST

P.O. Box 131, Cheong-Ryang

Seoul 130-650

KOREA

Stan Levine

NASA Lewis Research Center

21000 Brookpark Road, MS:49-3

Cleveland OH 44135
David Lewis, III

Naval Research Laboratory

Code 6370

Washington DC 20375-5343

Ai-Kang Li

Materials Research Labs., ITRI

195-5 Chung-Hsing Road, Sec. 4

Chutung Hsinchu 31015 R.O.C.

TAIWAN

Robert H. Licht

Norton Company

SGNICC/NRDC

Goddard Road

Northboro MA 01532-1545

E. Lilley

Norton Company

SGNICC/NRDC

Goddard Road

Northboro MA 01532-1545

Chih-Kuang Lin

National Central University

Dept. of Mechanical Engineering

Chung-Li 32054

TAIWAN

Laura J. Lindberg

AlliedSignal Aerospace Company

Garrett Fluid Systems Division

P.O. Box 22200

Tempe AZ 85284-2200

Hans A. Lindner

Cremer Forschungsinstitut

GmbH\&Co.KG

Oeslauer Strasse 35

D-8633 Rodental 8866

GERMANY

Ronald E. Loehman

Sandia National Laboratories

Chemistry \& Ceramics Dept. 1840

P.O. Box 5800

Albuquerque NM 87185 
Bill Long

Babcock \& Wilcox

P.O. Box 11165

Lynchburg VA 24506

L. A. Lott

EG\&G Idaho, Inc.

Idaho National Engineering Lab

P.O. Box 1625

Idaho Falls ID 83415-2209

Raouf O. Loutfy

MER Corporation

7960 S. Kolb Road

Tucson AZ 85706

Lydia Luckevich

Ortech International

2395 Speakman Drive

Mississauga Ontario L5K 1B3

CANADA

James W. MacBeth

Carborundum Company

Structural Ceramics Division

P.O. Box 1054

Niagara Falls NY 14302

George Maczura

Aluminum Company of America

3450 Park Lane Drive

Pittsburgh PA 15275-1119

David Maginnis

Tinker AFB

OC-ALC/LIIRE

Tinker AFB OK 73145-5989

Frank Maginnis

Aspen Research, Inc.

220 Industrial Boulevard

Moore OK 73160

Tai-il Mah

Universal Energy Systems, Inc.

4401 Dayton-Xenia Road

Dayton OH 45432
L. E. Mains

Deco-Grande

4850 Coolidge Highway

Royal Oak MI 48073-1023

Kenneth M. Maillar

Barbour Stockwell Company

83 Linskey Way

Cambridge MA 02142

S. G. Malghan

NIST

I-270 \& Clopper Road

Gaithersburg MD 20899

Lars Malmrup

United Turbine AB

Box 13027

Malmo S-200 44

SWEDEN

John Mangels

Ceradyne, Inc.

3169 Redhill Avenue

Costa Mesa CA 92626

Murli Manghnani

University of Hawaii

2525 Correa Road

Honolulu HI 96822

Russell V. Mann

Matec Applied Sciences, Inc.

75 South Street

Hopkinton MA 01748

William R. Manning

Champion Aviation Products Div

P.O. Box 686

Liberty SC 29657

Ken Marnoch

Amercom, Inc.

8928 Fullbright Avenue

Chatsworth CA 91311 
Robert A. Marra

Aluminum Company of America

Alcoa Technical Center

Alcoa Center PA 15069

Steve C. Martin

Advanced Refractory Technologies

699 Hertel Avenue

Buffalo NY 14207

Kelly J. Mather

William International Corp.

2280 W. Maple Road

Walled Lake MI 48088

James P. Mathers

3M Company

3M Center, Bldg. 201-3N-06

St. Paul MN 55144

Ron Mayville

Arthur D. Little, Inc.

15-163 Acorn Park

Cambridge MA 02140

F. N. Mazadarany

General Electric Company

Bldg. K-1, Room MB-159

P.O. Box 8

Schenectady NY 12301

James W. McCauley

Alfred University

Binns-Merrill Hall

Alfred NY 14802

Colin F. McDonald

McDonald Thermal Engineering

1730 Castellana Road

La Jolla CA 92037

B. J. McEntire

Norton Company

10 Airport Park Road

East Granby CT 06026
Thomas D. McGee

Iowa State University

110 Engineering Annex

Ames IA 50011

James McLaughlin

Sundstrand Power Systems

4400 Ruffin Road

P.O. Box 85757

San Diego CA 92186-5757

Matt McMonigle

U.S. Department of Energy

Office of Industrial Technologies

EE-234, Forrestal Building

Washington DC 20585

J. C. McVickers

AlliedSignal Engines

P.O. Box 52180, MS:9317-2

Phoenix AZ 85072-2180

D. B. Meadowcroft

"Jura," The Ridgeway

Oxshott

Leatherhead Surrey KT22 OLG

UNITED KINGDOM

Joseph J. Meindl

Reynolds International, Inc.

6603 W. Broad Street

P.O. Box 27002

Richmond VA 23261-7003

Michael D. Meiser

AlliedSignal, Inc.

Ceramic Components

P.O. Box 2960, MS:T21

Torrance CA 90509-2960

George Messenger

National Research Council of Canada

Building M-7

Ottawa Ontario K1A OR6

CANADA 
Arthur G. Metcalfe

Arthur G. Metcalfe \& Assoc:

2108 East 24th Street

National City CA 91950

R. Metselaar

Eindhoven University

P.O. Box 513

Endhoven $5600 \mathrm{MB}$

THE NETHERLANDS

David J. Michael

Harbison-Walker Refractories

P.O. Box 98037

Pittsburgh PA 15227

Ken Michaels

Chrysler Motors Corporation

P.O. Box 1118 , CIMS:418-17-09

Detroit MI 48288

D. E. Miles

Commission of the European

Community

rue de la Loi 200

B-1049 Brussels

BELGIUM

Carl E. Miller

AC Rochester

1300 N. Dort Highway, MS:32-31

Flint MI 48556

Charles W. Miller, Jr.

Harper International

West Drullard Avenue

Lancaster NY 14086-1698

R. Minimmi

Enichem America

2000 Cornwall Road

Monmouth Junction NJ 08852
Michele V. Mitchell

AlliedSignal, Inc.

Ceramic Components

P.O. Box 2960, MS:T21

Torrance CA 90509-2960

Howard Mizuhara

WESGO

477 Harbor Boulevard

Belmont CA 94002

Helen Moeller

Babcock \& Wilcox

P.O. Box 11165

Lynchburg VA 24506-1165

Francois R. Mollard

Concurrent Technologies Corp.

1450 Scalp Avenue

Johnstown PA 15904-3374

Phil Mooney

Panametrics

221 Crescent Street

Waltham MA 02254

Geoffrey P. Morris

3M Company

3M Traffic Control Materials

Bldg. 209-BW-10, 3M Center

St. Paul MN 55144-1000

Joel P. Moskowitz

Ceradyne, Inc.

3169 Redhill Avenue

Costa Mesa CA 92626

Brij Moudgil

University of Florida

Material Science \& Engineering

Gainesville FL 32611

Christoph J. Mueller

Sprechsaal Publishing Group

P.O. Box 2962, Mauer 2

D-8630 Coburg

GERMANY 
Thomas W. Mullan

Vapor Technologies Inc.

345 Route 17 South

Upper Saddle River NJ 07458

Theresa A. Mursick-Meyer

Norton Company

SGNICC/NRDC

Goddard Road

Northboro MA 01532-1545

M. K. Murthy

MkM Consultants International

10 Avoca Avenue, Unit 1906

Toronto Ontario M4T 2B7

CANADA

David L. Mustoe

Custom Technical Ceramics

8041 W I-70 Service Rd. Unit 6

Arvada CO 80002

Curtis V. Nakaishi

U.S. Department of Energy

Morgantown Energy Tech. Ctr.

P.O. Box 880

Morgantown WV 26507-0880

Yoshio Nakamura

Faicera Research Institute

3-11-12 Misono

Sagamihara, Tokyo

JAPAN

K. S. Narasimhan

Hoeganaes Corporation

River Road

Riverton NJ 08077

Robert Naum

Applied Resources, Inc.

P.O. Box 241

Pittsford NY 14534
Malcolm Naylor

Cummins Engine Company, Inc.

P.O. Box 3005, Mail Code 50183

Columbus IN 47202-3005

Dale E. Niesz

Rutgers University

Center for Ceramic Research

P.O. Box 909

Piscataway NJ 08855-0909

Paul W. Niskanen

Lanxide Corporation

P.O. Box 6077

Newark DE 19714-6077

David M. Nissley

United Technologies Corporation

Pratt \& Whitney Aircraft

400 Main Street, MS:163-10

East Hartford CT 06108

Daniel Oblas

50 Meadowbrook Drive

Bedford MA 01730

Don Ohanehi

Magnetic Bearings, Inc.

1908 Sussex Road

Blacksburg VA 24060

Hitoshi Ohmori

ELID Team

Itabashi Branch

1-7 13 Kaga Itabashi

Tokyo 173

JAPAN

Robert Orenstein

General Electric Company

55-112, River Road

Schenectady NY 12345

Richard Palicka

Cercom, Inc.

1960 Watson Way

Vista CA 92083 
Joseph N. Panzarino

JNP Research

379 Howard Street

P. O. Box 652

Northboro MA 01532-1545

Pellegrino Papa

Corning Inc.

MP-WX-02-1

Corning NY 14831

Terry Paquet

Boride Products Inc.

2879 Aero Park Drive

Traverse City MI 49684

$\checkmark$

E. Beth Pardue

MPC

8297 Williams Ferry Road

Lenior City TN 37771

Soon C. Park

3M Corporate Research

3M Center, Bldg. 251-3B-13

St. Paul MN 55144-1000

Vijay M. Parthasarathy

Caterpillar/Solar Turbines

2200 Pacific Highway

P.O. Box 85376

San Diego CA 92186-5376

Harmut Paschke

Schott Glaswerke

Christoph-Dorner-Strasse 29

D-8300 Landshut

GERMANY

Pandit G. Patil

Department of Energy

Ofc. of Transportation Technologies

EE-32, Forrestal Bldg.

Washington, DC 20585
James W. Patten

Cummins Engine Company, Inc.

P.O. Box 3005, Mail Code 50183

Columbus IN 47202-3005

Robert A. Penty

Penty \& Associates

38 Oakdale Drive

Rocester NY 14618

Robert W. Pepper

Textron Specialty Materials

2 Industrial Avenue

Lowell MA 01851

John J. Petrovic

Los Alamos National Laboratory

Group MST-4, MS:G771

Los Alamos NM 87545

Frederick S. Pettit

University of Pittsburgh

Pittsburgh PA 15261

Richard C. Phoenix

Ohmtek, Inc.

2160 Liberty Drive

Niagara Falls NY 14302

Bruce J. Pletka

Michigan Technological Univ.

Metallurgical \& Materials Engr.

Houghton MI 49931

John P. Pollinger

AlliedSignal, Inc.

Ceramic Components

P.O. Box 2960, MS:T21

Torrance CA 90509-2960

P. Popper

High Tech'Ceramics Int. Journal

22 Pembroke Drive - Westlands

Newcastle-under-Lyme

Staffs ST5 2JN

ENGLAND 
F. Porz

Universitat Karlsruhe

Institut fur Keramik Im Maschinendau

Postfach 6980

D-76128 Karlsruhe

GERMANY

Harry L. Potma

Royal Netherlands Embassy

Science and Technology

4200 Linnean Avenue, N.W.

Washington DC 20008

Bob R. Powell

General Motors Corporation

Metallurgy Department

Box 9055

Warren MI 48090-9055

Stephen C. Pred

Biesterfeld U.S., Inc.

500 Fifth Avenue

New York NY 10110

Karl M. Prewo

United Technologies Res. Ctr.

411 Silver Lane, MS:24

East Hartford CT 06108

Vimal K. Pujari

Norton Company

SGNICC/NRDC

Goddard Road

Northboro MA 01532-1545

Fred Quan

Corning Inc.

Sullivan Park, FR-02-08

Corning NY 14831

George Quinn

NIST

Quince Orchard \& Clopper Road

Ceramics Division, Bldg. 223

Gaithersburg MD 20899
Ramas V. Raman

Ceracon, Inc.

1101 N. Market Blvd., Suite 9

Sacramento CA 95834

Charles F. Rapp

Owens Corning Fiberglass

2790 Columbus Road

Granville OH 43023-1200

Dennis W. Readey

Colorado School of Mines

Metallurgy and Materials Engr.

Golden CO 80401

Wilfred J. Rebello

PAR Enterprises, Inc.

12601 Clifton Hunt Lane

Clifton VA 22024

Harold Rechter

Chicago Fire Brick Company

7531 S. Ashland Avenue

Chicago IL 60620

Robert R. Reeber

U.S. Army Research Office

P.O. Box 12211

Research Triangle Park NC

27709-2211

K. L. Reifsnider

VPI \& SU

Engineering Science and Mechanics

Blacksburg VA 24061

Paul E. Rempes

McDonnell Douglass Aircraft Co.

P.O. Box 516, Mail Code:0642263

St. Louis MO 63166-0516

Gopal S. Revankar

John Deere Company

3300 River Drive

Moline IL 61265 
K. Y. Rhee

Rutgers University

P.O. Box 909

Piscataway NJ 08854

Roy W. Rice

W. R. Grace and Company

7379 Route 32

Columbia MD 21044

David W. Richerson

2093 E. Delmont Drive

Salt Lake City UT 84117

Tomas Richter

J. H. France Refractories

1944 Clarence Road

Snow Shoe PA 16874

Michel Rigaud

Ecole Polytechnique

Campus Universite De Montreal

P.O. Box 6079, Station A

Montreal, P.Q. Quebec H3C 3A7

CANADA

John E. Ritter

University of Massachusetts

Mechanical Engineering Department

Amherst MA 01003

W. Eric Roberts

Advanced Ceramic Technology

990 "F" Enterprise Street

Orange CA 92667

Y. G. Roman

TNO TPD Keramick

P.O. Box 595

Einhoven $5600 \mathrm{AN}$

HOLLAND

Michael Rossetti

Arthur D. Little, Inc.

15 Acorn Park

Cambridge MA 01240
Barry Rossing

Lanxide Corporation

P.O. Box 6077

Newark DE 19714-6077

Steven L. Rotz

Lubrizol Corporation

29400 Lakeland Boulevard

Wickliffe OH 44092

Robert Ruh

Wright Laboratory

WL/MLLM

Wright-Patterson AFB OH 45433

Robert J. Russell

Riverdale Consulting, Inc.

24 Micah Hamlin Road

Centerville MA 02632-2107

Jon A. Salem

NASA Lewis Research Center

21000 Brookpark Road

Cleveland $\mathrm{OH} 44135$

J. Sankar

North Carolina A\&T State Univ.

Dept. of Mechanical Engineering

Greensboro NC 27406

Yasushi Sato

NGK Spark Plugs (U.S.A.), Inc.

1200 Business Center Dr., \#300

Mt. Prospect IL 60056

Maxine L. Savitz

AlliedSignal, Inc.

Ceramic Components

P.O. Box 2960, MS:T21

Torrance CA 90509-2960

Ashok Saxena

GTRI

Materials Engineering

Atlanta GA 30332-0245 
David W. Scanlon

Instron Corporation

100 Royall Street

Canton MA 02021

Charles A. Schacht

Schacht Consulting Services

12 Holland Road

Pittsburgh PA 15235

Robert E. Schafrik

Natl Materials Advisory Board

2101 Constitution Ave., N.W.

Washington DC 20418

James Schienle

AlliedSignal Engines

P.O. Box 52180, MS:1302-2P

Phoenix AZ 85072-2180

Gary Schnittgrund

PyroPacific Processes

16401 Knollwood Drive

Granada Hills, CA 91344

Mark Schomp

Lonza, Inc.

17-17 Route 208

Fair Lann NJ 07410

Joop Schoonman

Delft University of Technology

P.O. Box 5045

2600 GA Delft

THE NETHERLANDS

Robert B. Schulz

U.S. Department of Energy

Office of Transportation Technologies

EE-33, Forrestal Building

Washington DC 20585

Murray A. Schwartz

Materials Technology Consulting

30 Orchard Way, North

Potomac MD 20854
Peter Schwarzkopf

SRI International

333 Ravenswood Avenue

Menlo Park CA 94025

William T. Schwessinger

Multi-Arc Scientific Coatings

1064 Chicago Road

Troy MI 48083-4297

W. D. Scott

University of Washington

Materials Science Department

Mail Stop:FB10

Seattle WA 98195

Nancy Scoville

Thermo Electron Technologies

P.O. Box 9046

Waltham MA 02254-9046

Thomas M. Sebestyen

U.S. Department of Energy

Office of Transportation Technologies

EE-32, Forrestal Building

Washington DC 20585

T. B. Selover

AICRE/DIPPR

3575 Traver Road

Shaker Heights $\mathrm{OH} 44122$

Charles E. Semler

Semler Materials Services

4160 Mumford Court

Columbus OH 43220

Thomas Service

Service Engineering Laboratory

324 Wells Street

Greenfield MA 01301

Kish Seth

Ethyl Corporation

P.O. Box 341

Baton Rouge LA 70821 
William J. Shack

Argonne National Laboratory

9700 S. Cass Avenue, Bldg. 212

Argonne IL 60439

Richard K. Shaltens

NASA Lewis Research Center

21000 Brookpark Road, MS:302-2

Cleveland $\mathrm{OH} 44135$

Robert S. Shane

1904 NW 22nd Street

Stuart FL 34994-9270

Ravi Shankar

Chromalloy

Research and Technology

Blaisdell Road

Orangeburg NY 10962

Terence Sheehan

Alpex Wheel Company

727 Berkley Street

New Milford NJ 07646

Dinesh K. Shetty

University of Utah

Materials Science and Engineering

Salt Lake City UT 84112

Masahide Shimizu

New Ceramics Association

Shirasagi 2-13-1-208, Nakano-ku

Tokyo, 165

JAPAN

Thomas Shreves

American Ceramic Society, Inc.

735 Ceramic Place

Westerville OH 43081-8720

Johann Sicbels

Volkswagen AG

Werkstofftechnologie

Postfach 3180

Wolfsburg 1

GERMANY
George H. Siegel

Point North Associates, Inc.

P.O. Box 907

Madison NJ 07940

Richard Silberglitt

FM Technologies, Inc.

10529-B Braddock Road

Fairfax VA 22032

Mary Silverberg

Norton Company

SGNICC/NRDC

Goddard Road

Northboro MA 01532-1545

Gurpreet Singh

U.S. Department of Energy

Office of Transportation Technologies

EE-33, Forrestal Building

Washington DC 28505

Maurice J. Sinnott

University of Michigan

5106 IST Building

Ann Arbor MI 48109-2099

John Skildum

3M Company

$3 \mathrm{M}$ Center

Building 224-2S-25

St. Paul MN 55144

Richard H. Smoak

Smoak \& Associates

3554 Hollyslope Road

Altadena CA 91001-3923

Jay R. Smyth

AlliedSignal Engines

111 S. 34th Street, MS:503-412

Phoenix AZ 85034 
Rafal A. Sobotowski British Petroleum Company Technical Center, Broadway 3092 Broadway Avenue Cleveland $\mathrm{OH} 44115$

S. Somiya

Nishi Tokyo University

3-7-19 Seijo, Setagaya

Tokyo, 157

JAPAN

Boyd W. Sorenson

DuPont Lanxide Composites

1300 Marrows Road

Newark DE 19711

Charles A. Sorrell

U.S. Department of Energy

Office of Industrial Technologies

EE-232, Forrestal Building

Washington DC 20585

C. Spencer

EA Technology

Capenhurst Chester $\mathrm{CH} 1$ 6ES

UNITED KINGDOM

Allen Spizzo

Hercules Inc.

Hercules Plaza

Wilmington DE 19894

Richard M. Spriggs

Alfred University

Ctr. for Advanced Ceramic Tech.

Alfred NY 14802

Charles Spuckler

NASA Lewis Research Center

21000 Brookpark Road, MS:5-11

Cleveland OH 44135-3191

Gordon L. Starr

Cummins Engine Company, Inc.

P.O. Box 3005, Mail Code:50182

Columbus IN 47202-3005
Tom Stillwagon

AlliedSignal, Inc.

Ceramic Components

P.O. Box 2960, MS:T21

Torrance CA 90509-2960

H. M. Stoller

TPL Inc.

3754 Hawkins, N.E.

Albuquerque NM 87109

Paul D. Stone

Dow Chemical USA

1776 "Eye" Street, N.W., \#575

Washington DC 20006

F. W. Stringer

Aero \& Industrial Technology

P.O. Box 46, Wood Top

Burnley Lancashire BB11 4BX

UNITED KINGDOM

Thomas N. Strom

NASA Lewis Research Center

21000 Brookpark Road, MS:86-6

Cleveland $\mathrm{OH} 44135$

M. F. Stroosnijder

Institute for Advanced Matcrials

Joint Research Centre

21020 Ispra (VA)

ITALY

Karsten Styhr

30604 Ganado Drive

Rancho Palos Verdes CA 90274

T. S. Sudarshan

Materials Modification, Inc.

2929-P1 Eskridge Center

Fairfax VA 22031

M. J. Sundaresan

University of Miami

P.O. Box 248294

Coral Gables FL 33124 
Patrick L. Sutton

U.S. Department of Energy

Office of Transportation Technologies

EE-32, Forrestal Building

Washington DC 20585

Willard H. Sutton

United Technologies Corporation

411Silver Lane, MS:24

East Hartford CT 06108

Robert E. Swanson

Metalworking Technology, Inc.

1450 Scalp Avenue

Johnstown PA 15904

Yo Tajima

NGK Spark Plug Company

2808 Iwasaki

Komaki-shi Aichi-ken, 485

JAPAN

Fred Teeter

5 Tralee Terrace

East Amherst NY 14051

Victor J. Tennery

113 Newell Lane

Oak Ridge TN 37830

David F. Thompson

Corning Glass Works

SP-DV-02-1

Corning NY 14831

T. Y. Tien

University of Michigan

Materials Science \& Engineering

Dow Building

Ann Arbor MI 48103

D. M. Tracey

Norton Company

SGNICC/NRDC

Goddard Road

Northboro MA 01532-1545
Marc Tricard

Norton Company, WGTC

1 New Bond Street, MS-413-201

Worcester MA 01615-0008

L. J. Trostel, Jr.

Box 199

Princeton MA 01541

W. T. Tucker

General Electric Company

P.O. Box 8, Bldg. K1-4C35

Schenectady NY 12301

Masanori Ueki

Nippon Steel Corporation

1618 Ida

Nakahara-Ku Kawasaki, 211

JAPAN

Filippo M. Ugolini

ATA Studio

Via Degli Scipioni, 268A

ROMA, 00192

ITALY

Donald L. Vaccari

Allison Gas Turbines

P.O. Box 420, Speed Code S49

Indianapolis IN 46206-0420

Carl F. Van Conant

Boride Products, Inc.

2879 Aero Park Drive

Traverse City MI 49684

John F. Vander Louw

3M Company

3M Center, Bldg. 60-1N-01

Saint Paul MN 55144

Marcel H. Van De Voorde

Commission of the European Community

P.O. Box 2

1755 ZG Petten

THE NETHERLANDS 
O. Van Der Biest

Katholieke Universiteit Leuven

Dept. Metaalkunde en Toegepaste

de Croylaan 2

B-3030 Leuven

BELGIUM

Michael Vannier

Washington University,

St. Louis

510 S. Kings Highway

St. Louis MO 63110

Stan Venkatesan

Southern Coke \& Coal Corp.

P.O. Box 52383

Knoxville TN 37950

V. Venkateswaran

Carborundum Company

Niagara Falls R\&D Center

P.O. Box 832

Niagara Falls NY 14302

Theodore Vojnovich

U.S. Department of Energy

Laboratory Technology Applications

ER-32, Forrestal Bldg.

Washington DC 20585

John B. Wachtman

Rutgers University

P.O. Box 909

Piscataway NJ 08855

Shigetaka Wada

Toyota Central Rescarch Labs

Nagakute Aichi, 480-11

JAPAN

Janet Wade

AlliedSignal Engines

P.O. Box 52180, MS:1303-2

Phoenix AZ 85072-2180
Richard L. Wagner

Ceramic Technologies, Inc.

537 Turtle Creek South Dr.

Indianapolis IN 46227

J. Bruce Wagner, Jr.

Arizona State University

Center for Solid State Science

Tempe AZ 85287-1704

Daniel J. Wahlen

Kohler, Co.

444 Highland Drive

Kohler WI 53044

Ingrid Wahlgren

Royal Institute of Technology

Studsvik Library

S-611 82 Nykoping

SWEDEN

Ronald H. Walecki

AlliedSignal, Inc.

Ceramic Components

P.O. Box 2960, MS:T21

Torrance CA 90509-2960

Michael S. Walsh

Vapor Technologies Inc.

6300 Gunpark Drive

Boulder CO 80301

Chien-Min Wang

Industrial Technology Research Institute

195 Chung-Hsing Road, Sec. 4

Chutung Hsinchu 31015 R.O.C.

TAIWAN

Robert M. Washburn

ASMT

11203 Colima Road

Whittier CA 90604

Kevin Webber

Toyota Technical Center, U.S.A.

1410 Woodridge, RR7

Ann Arbor MI 48105 
James K. Weddell

Du Pont Lanxide Composites Inc.

P.O. Box 6100

Newark DE 19714-6100

R. W. Weeks

Argonne National Laboratory

MCT-212

9700 S. Cass Avenue

Argonne IL 60439

Ludwig Weiler

ASEA Brown Boveri AG

Eppelheimer Str. 82

D-6900 Heidelberg

GERMANY

James Wessel

127 Westview Lane

Oak Ridge TN 37830

Robert D. West

Therm Advanced Ceramics

P.O. Box 220

Ithaca NY 14851

Thomas J. Whalen

1845 Cypress Pointe Court

Ann Arbor MI 48108

Ian A. White

Hoeganaes Corporation

River Road

Riverton NJ 08077

Sheldon M. Wiederhorn

NIST

Building 223, Room A329

Gaithersburg MD 20899

John F. Wight

Alfred University

McMahon Building

Alfred NY 14802
D. S. Wilkinson

McMaster University

1280 Main Street, West

Hamilton Ontario L8S 4L7

CANADA

James C. Williams

General Electric Company

Engineering Materials Tech.

One Neumann Way, Mail Drop:H85

Cincinnati $\mathrm{OH} 45215-6301$

Steve J. Williams

RCG Hagler Báilly, Inc.

1530 Wilson Blvd., Suite 900

Arlington VA 22209-2406

Thomas A. Williams

National Renewable Energy Lab

1617 Cole Boulevard

Golden CO 80401

Craig A. Willkens

Norton Company

SGNICC/NRDC

Goddard Road

Northboro MA 01532-1545

Roger R. Wills

Ohio Aerospace Institute (OAI)

22800 Cedar Point Road

Brook Park OH 44142

David Gordon Wilson

Massachusetts Institute of Technology

77 Massachusetts Ave., Rm 3-455

Cambridge MA 02139

J. M. Wimmer

AlliedSignal, Inc.

Ceramic Components

2525 West 190th Street

P. O. Box 2960, MS:T21

Torrance, CA 90509-2960 
Matthew F. Winkler

Seaworthy Systems, Inc.

P.O. Box 965

Essex CT 06426

Gerhard Winter

Hermann C. Starck Berlin GmbH

P.O. Box 2540

D-3380 Goslar 3380

GERMANY

Thomas J. Wissing

Eaton Corporation

Engineering and Research Center

P.O. Box 766

Southfield MI 48037

James C. Withers

MER Corporation

7960 S. Kolb Road

Building $\mathrm{F}$

Tucson AZ 85706

Dale E. Wittmer

Southern Illinois University

Mechanical Engineering Dept.

Carbondale IL 62901

Warren W. Wolf

Owens Corning Fiberglass

2790 Columbus Road, Route 16

Granville OH 43023

Egon E. Wolff

Caterpillar Inc.

Technical Center

P.O. Box 1875

Peoria IL 61656-1875

George W. Wolter

Howmet Turbine Components Corp.

Technical Center

699 Benston Road

Whitehall MI 49461
Wayne L. Worrell

University of Pennsylvania

3231 Walnut Street

Philadelphia PA 19104

John F. Wosinski

Corning Inc.

ME-2 E-5 H8

Corning NY 14830

Ruth Wroe

ERDC

Capenhurst Chester $\mathrm{CH} 1$ 6ES

ENGLAND

Bernard J. Wrona

Advanced Composite Materials

$1525 \mathrm{~S}$. Buncombe Road

Greer SC 29651

Carl C. M. Wu

Naval Research Laboratory

Ceramic Branch, Code 6373

Washington DC 20375

David C. Wu

AlliedSignal Engines

P.O. Box 52181, MS:301-227

Phoenix AZ 85072-2181

John C. Wurst

U. of Dayton Research Institute

300 College Park

Dayton OH 45469-0101

Neil Wyant

ARCH Development Corp.

9700 S. Cass Avenue, Bldg. 202

Argonne IL 60439

Roy Yamamoto

Texaco Inc.

P.O. Box 509

Beacon NY 12508-0509 
John Yamanis

AlliedSignal Aerospace Company

P.O. Box 1021

Morristown NJ 07962-1021

Harry C. Yeh

AlliedSignal, Inc.

Ceramic Components

P.O. Box 2960, MS:T21

Torrance CA 90509-2960

Hiroshi Yokoyama

Hitachi Research Lab :

4026 Kuji-Cho

Hitachi-shi Ibaraki 319-12

JAPAN

Thomas M. Yonushonis

Cummins Engine Company, Inc.

P.O. Box 3005, Mail Code 50183

Columbus IN 47202-3005

Jong Yung

Sundstrand Aviation Operations 4747 Harrison Avenue

Rockford IL 61125

\section{A. L. Zadoks}

Caterpillar Inc.

Technical Center, Building L

P.O. Box 1875

Peoria IL 61656-1875

Avi Zangvil

University of Illinois

104 S. Goodwin Avenue

Urbana IL 61801

Charles H. Zenuk

Transtech

6662 E. Paseo San Andres

Tucson AZ 85710-2106

Zhenqi Zhu

University of Connecticut

Precision Manufacturing Center

Storrs, CT 06269-5119
Carl Zweben

General Electric Company

P. O Box 8555, VFSC/V4019

Philadelphia PA 19101

Department of Energy

Oak Ridge Operations Office

Assistant Manager for Energy

Research and Development

P. O. Box 2001

Oak Ridge TN 37831-8600

Department of Energy (2)

Office of Scientific and Technical

Information

Office of Information Services

P. O. Box 62

Oak Ridge TN 37831

For distribution by microfiche as shown in DOE/OSTI-4500, Distribution Categoŕy UC-332 (Ceramics/Advanced Materials). 